- Digitalisierte Fassung im Format PDF -

\title{
Die Entstehung der Kontinente und Ozeane
}

Alfred Wegener

Die Digitalisierung dieses Werkes erfolgte im Rahmen des Projektes BioLib (www.BioLib.de).

Die Bilddateien wurden im Rahmen des Projektes Virtuelle Fachbibliothek Biologie (ViFaBio) durch die Universitätsbibliothek Johann Christian Senckenberg (Frankfurt am Main) in das Format PDF überführt, archiviert und zugänglich gemacht. 


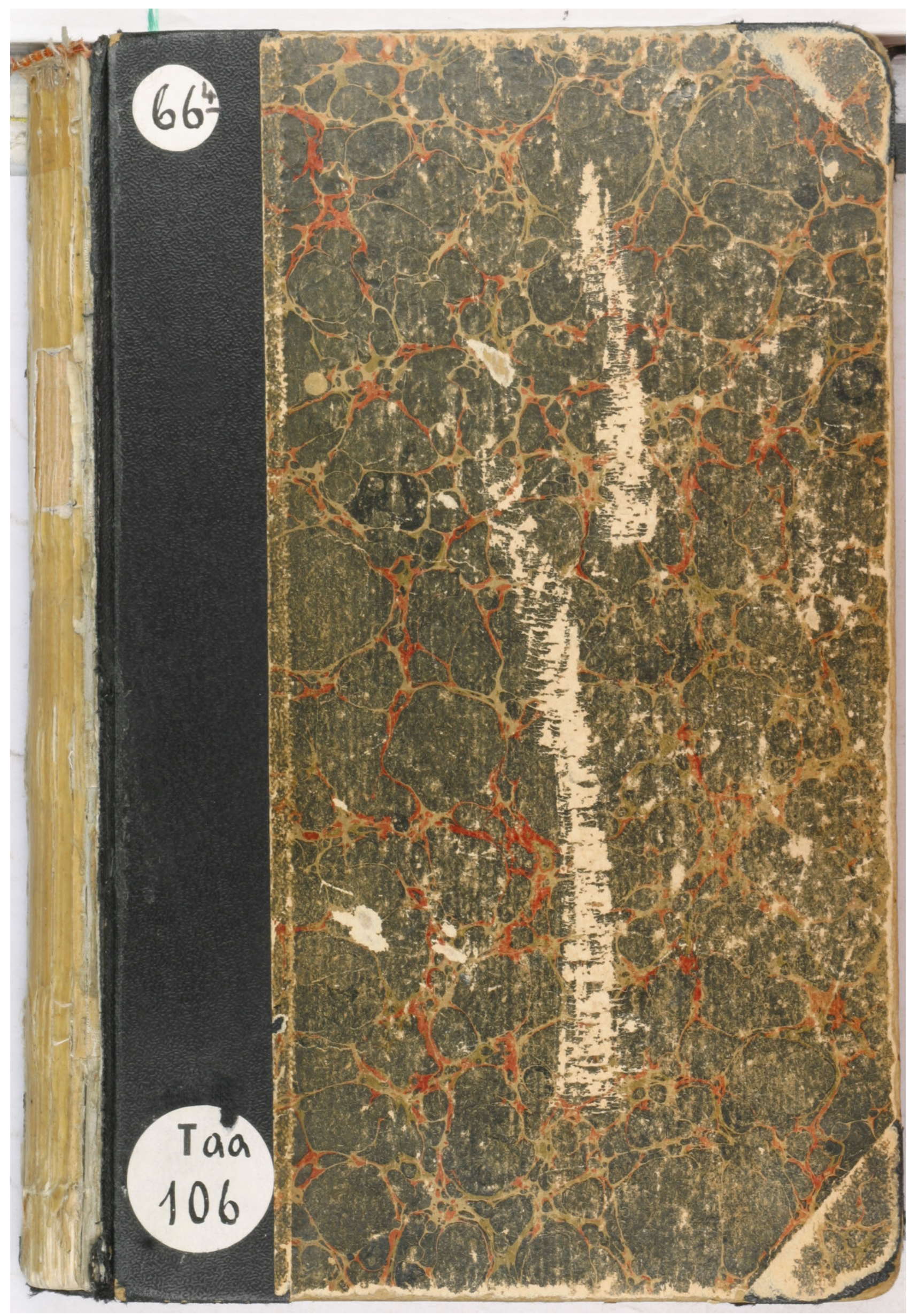




\section{$T$ a a $106-66.1929+4$}

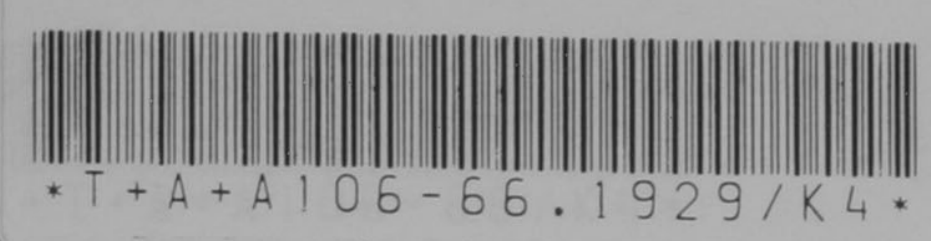




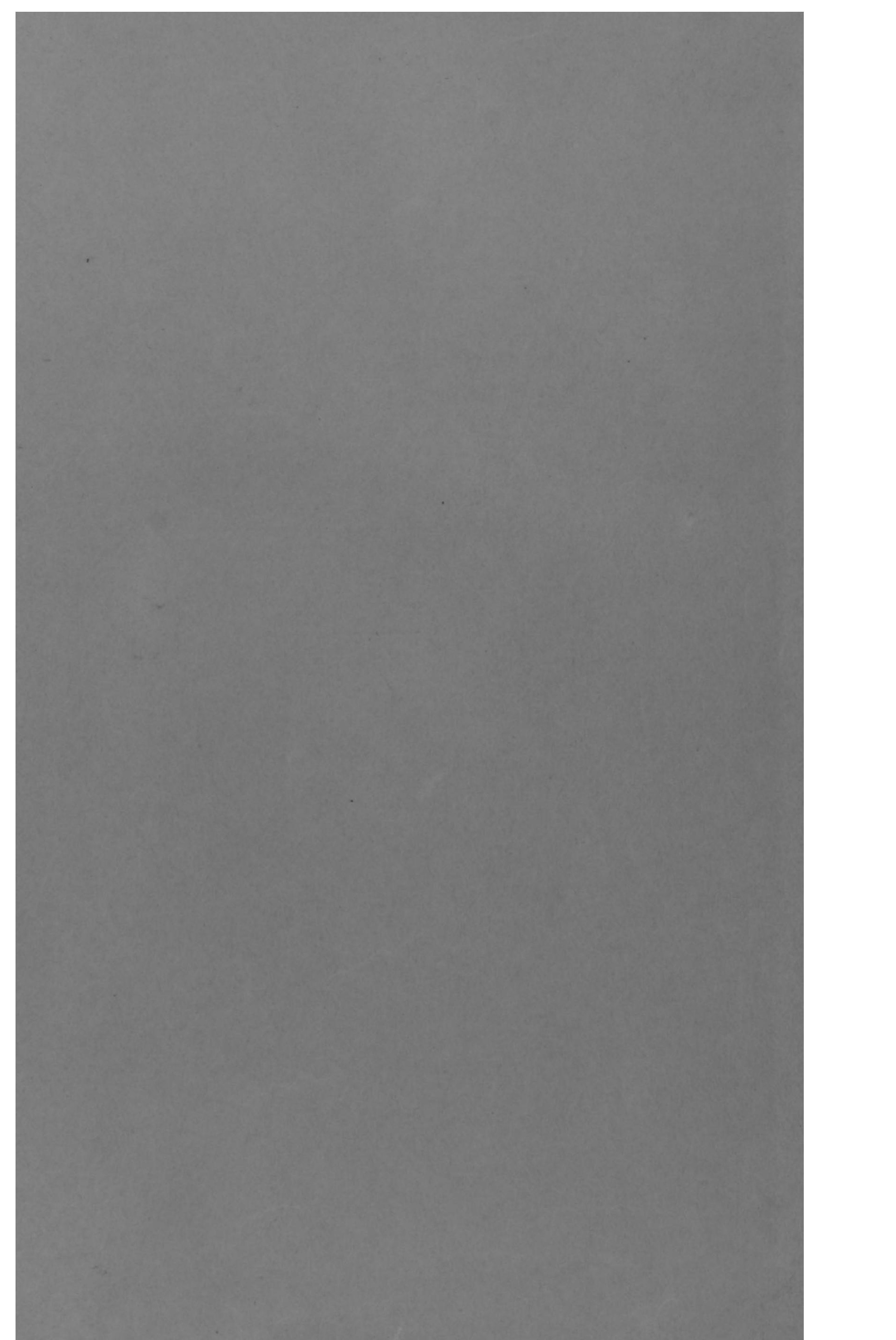




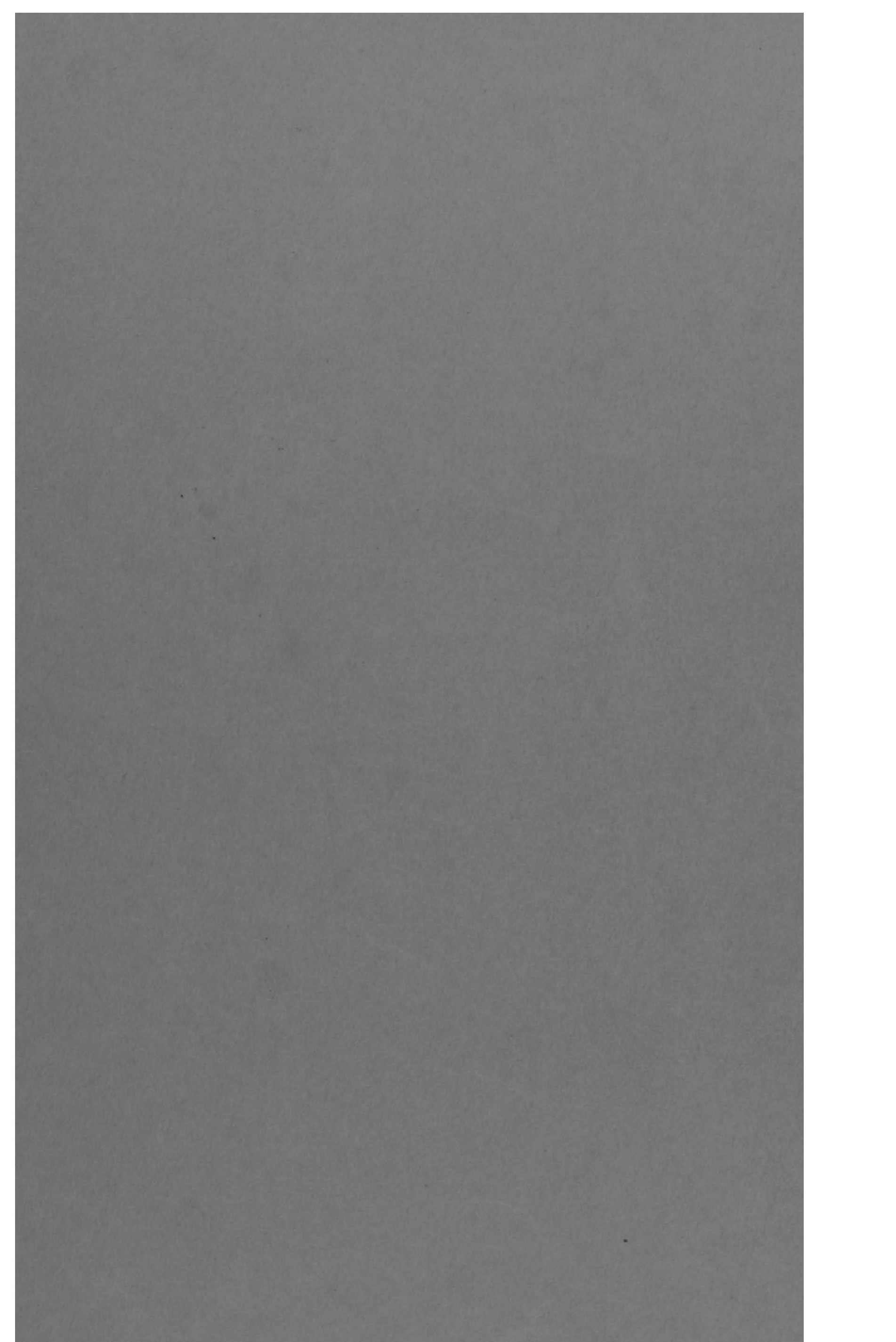


DIE WISSENSCHAFT EINZELDARSTELLUNGEN AUS DER NATURWISSENSCHAFT UND DER TECHNIK. BD.66 HERAUSGEGEBEN VON PROF. DR. WILHELM WESTPHAL

\title{
Die Entstehung der
}

Kontinente und Ozeane

\author{
Von
}

Alfred Wegener

\section{Vierte Auflage}

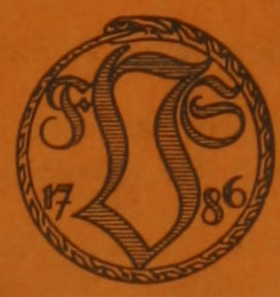

FRIEDR. VIEWEG \& SOHN AKT.-GES. BRAUNSCHWEIG 


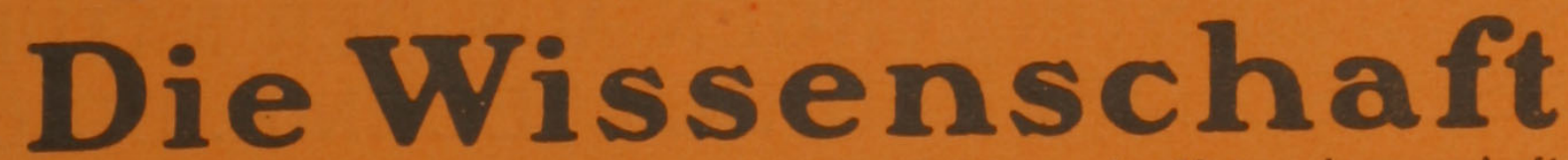

Sammlung von Einzeldarstellungen aus den Gebieten der Naturwissenschaft und der Technik, herausgegeben von Prof. Dr. Eilhard Wiedemann

1. Curie, Mme. S., Untersuchungen über die radioaktiven Substanzen. Vergriffen.

2. Schmidt, Prof. Dr. G. C., Die Kathodenstrahlen. 2. verb. und verm. Auflage. Mit 50 Abbildungen.

Geh. 3,- RM

3. Thomson, Prof. Dr. J. J., Elektrizität und Materie. Vergriffen.
4. Freiherr von und zu Aufsess, Dr. O t to, Die physikalischen Eigenschaften

4. Freiherr von und zu Aufsess, Dr. O t to, Die physikalischen Eigenschaften
der Seen. Mit 36 Abbildungen.

5. Frölich, Dr. O., Die Entwickelung der elektrischen Messungen. Mit 124 Abbildungen.

Geh. 6,- RM

6. Ritter von Geitler, Prof. Dr. Josef, Elektromagnetische Schwingungen und Wellen. 2. verm. Aufl. Mit 113 Abbild. Geh. 7,50 RM, geb. 9,- RM

7. Baumhauer, Prof. Dr. H., Die neuere Entwickelung der Kristallographie. Mit 46 Abbildungen.

Geh. 4,50 RM

8. Werner, Prof. Dr. A., Neuere Anschauungen auf dem Gebiete der an= organischen Chemie. 5. durchgesehene Aufl. Geh. 14,- RM, geb. 16,-RM

9. Faust, Dr. Edw. St., Die tierischen Gifte.

Geh. 6,- RM

10. Lipps, Dr. G. F.. Die psychischen Maßmethoden. Mit 6 Abbildungen.

Geh, 3,50 RM

11. Kobold, Prof. Dr. Hermann, Der Bau des Fixsternsystems mit be= sonderer Berücksichtigung der photometrischen Resultate. Mit $19 \mathrm{Ab}$ bildungen und 3 Tafeln.

Geh. 6,50 RM

12. Jäger, Prof. Dr. G., Die Fortschritte der kinetischen Gastheorie. 2. verb. und verm. Auflage. Mit 11 Abbildungen. Geh. 5,- RM, geb. 6,50 RM

13. Doelter, Prof. Dr. C., Petrogenesis. Mit 1 Lichtdrucktafel und 5 Ab= bildungen.

Geh. 7,- RM

14. Donath, Dr. B., Die Grundlagen der Farbenphotographie. Vergriffen.

15. v. Knebel, Dr. phil. Walther, Höhlenkunde, mit Berücksichtigung der Karstphänomene. Mit 42 Abbildungen.

16. Geinitz, Prof. Dr. F. E., Die Eiszeit. Mit 25 Abbildungen im Text, 3 farbigen Tafeln und einer Tabelle.

17. Gehrcke, Dr. E., Die Anwendung der Interferenzen in der Spektroskopie und Metrologie. Mit 73 Abbildungen. Geh. 5,50 RM

18. Fischer, Prof. Dr. Otto, Kinematik organischer Gelenke. Mit $77 \mathrm{Ab}=$ bildungen.

19. Wangerin, Prof. Dr. A., Franz Neumann und sein Wirken als Forscher und Lehrer. Mit einer Textfigur und dem Bildnis. Neumanns in Heliogravüre. $\quad$ Geh. 5,50 RM, geb. 7,- RM

20. Kuenen, Prof. Dr. J. P., Die Zustandsgleichung der Gase und Flüssig= keiten und die Kontinuitätstheorie. Mit 9 Abbildungen. Geh. 6,50 RM

21. Rutherford, Prof. E., Radioaktive Umwandlungen. Vergriffen.

22. König, Prof. Dr. E., Kant und die Naturwissenschaft. Geh.6,- RM

23. Schmidt, Prof. Dr. Julius, Synthetisch=organische Chemie der Neuzeit. 2. Auflage.

24. Sackur, Dr. Otto, Die Geh. 18,- RM, geb. 20,- RM 5 Abbildungen im Die chemische Affinität und ihre Messung. Mit

25. Thomson, Prof. Dr. J. J., Die Korpuskulartheorie der Materi. V. - RM

26. Vageler, Dr. P. Die B., Die Korpuskulartheorie der Materie. Vergriffen. Vickstoffs in Natur und Technik. Mit 16 Abbildungen. $\quad$ Geh. 4,50 RM

27. Messerschmitt, Prof. Dr. Joh. Bapt., Die Schwerebestimmung an der Erdoberfläche. Mit 25 Abbildungen. Geh. 5,- RM

28. Bjerknes, Prof. V., Die Kraftfelder. Mit 29 Abbildungen. Geh. 7,- - RM 


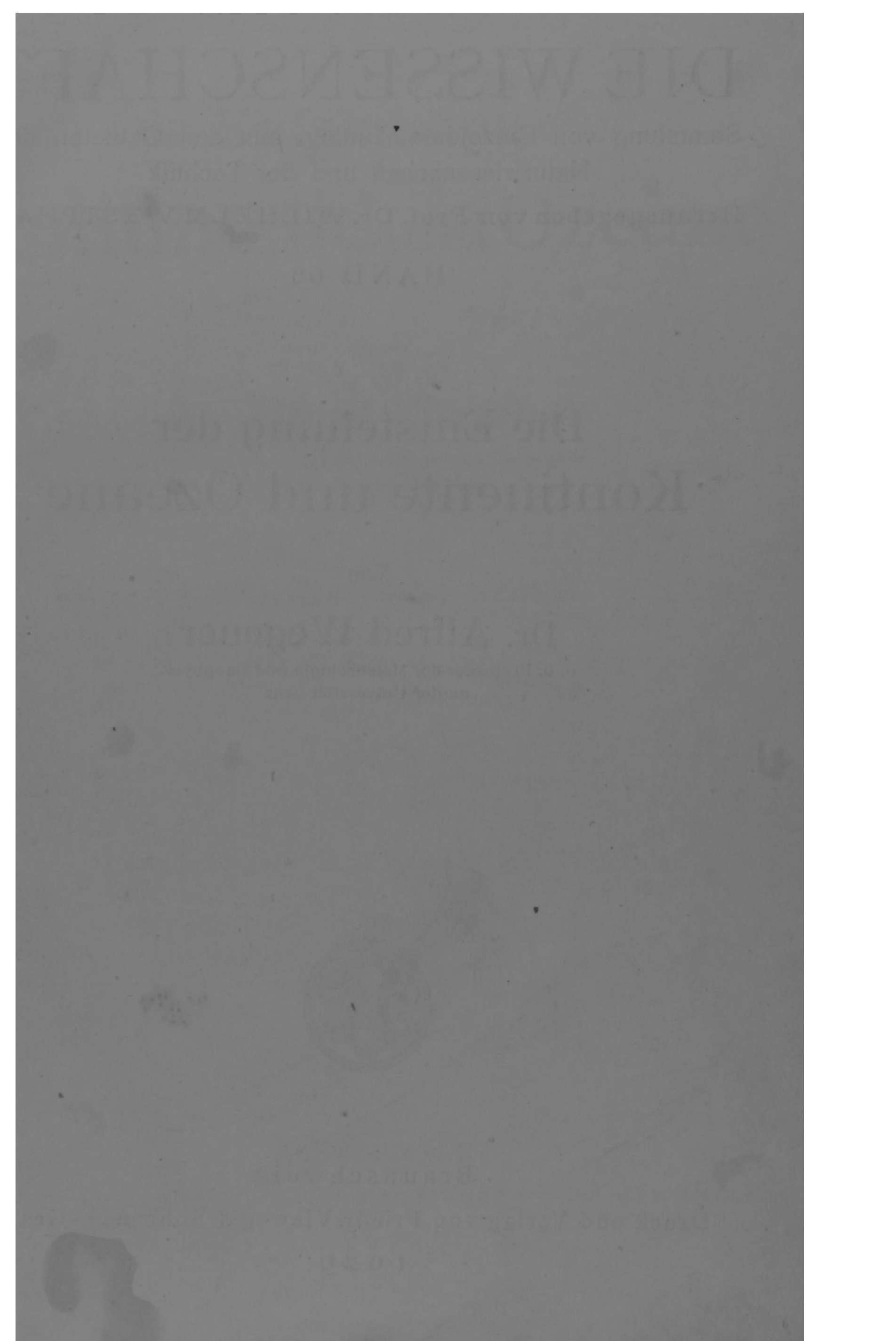




\title{
DIE WIS SSEN $\mathrm{NS}$ SCHAFT
}

Sammlung von Einzeldarstellungen aus den Gebieten der Naturwissenschaft und der Technik

Herausgegeben von Prof. Dr. WILHELM WESTPHAL

$$
\text { BAND } 66
$$

\section{Die Entstehung der}

\section{Kontinente und Ozeane}

\author{
Von
}

\section{Dr. Alfred Wegener}

o. ö. Professor der Meteorologie und Geophysik

an der Universităt Graz

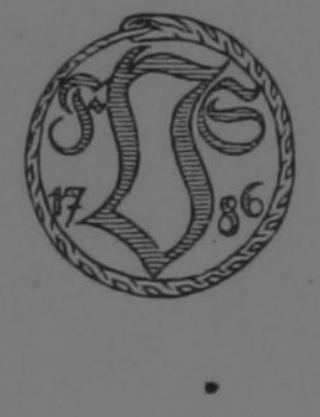

Braunschweig

Druck und Verlag von Friedr. Vieweg \& Sohn Akt.-Ges. 


\subsection{1}

\section{Die Entstehung der}

Kontinente und Ozeane

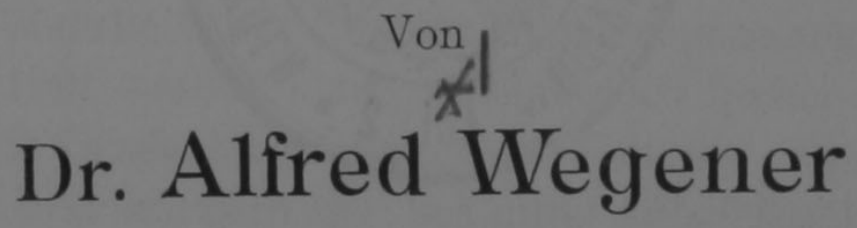

o. o. Professor der Meteorologie und Geophysik an der Universităt Graz

Vierte umgearbeitete Auflage

Mit 63 Abbildungen

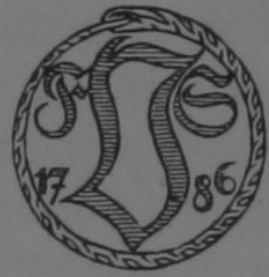

Braunschweig

Druck und Verlag von Friedr. Vieweg \& Sohn Akt.-Ges. 


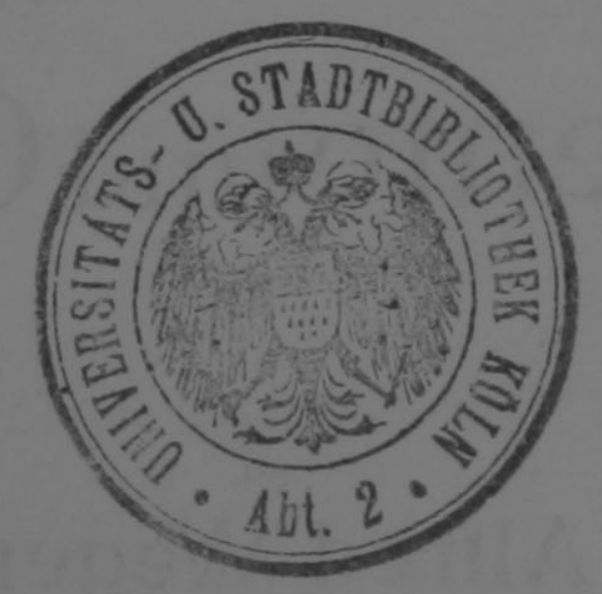

Alle Rechte vorbehalten

Printed in Germany 


\section{Vorwort.}

Die Erkenntnis, daß zur Entschleierung der früheren Zustände unserer Erde alle Geo-Wissenschaften Indizien beizusteuern haben, und daß die Wahrheit nur durch Zusammenfassung aller dieser Anzeichen ermittelt werden kann, scheint noch immer nicht in dem wünschenswerten Grade Allgemeingut der Forscher geworden zu sein.

So schrieb erst kürzlich der bekannte südafrikanische Geologe du Toit [78]: „Indessen muß, wie schon gesagt, dem geologischen Nachweis so gut wie vollständig die Entscheidung über die Wahrscheinlichkeit dieser Hypothese (der Kontinentverschiebungen) zufallen, denn solche Argumente, die auf der Verbreitung der Tiere beruhen, sind unfähig hierzu, da sie in der Regel in gleicher Weise, wenn auch weniger glatt, nach der orthodoxen Anschauung erklärbar sind, die ausgedehnte, später im Ozean versunkene Landverbindungen annimmt."

Der Paläontologe v. Ihering [122] dagegen meint kurz und bündig: „Es ist nicht meine Aufgabe, um geophysische Vorgänge mich zu kümmern.“ Er hat die „Überzeugung, daß nur die Geschichte des Lebens auf Erden die Erfassung der verflossenen geographischen Wandlungen gestattet“.

Ja auch ich selber habe einmal in einer schwachen Stunde von der Verschiebungstheorie geschrieben [121]: „Dennoch glaube ich, daß die endgültige Entscheidung über sie nur durch die Geophysik gefällt werden kann, da nur sie über genügend exakte Methoden verfügt. Käme die Geophysik zu dem Ergebnis, daß die Verschiebungstheorie falsch ist, so müßte diese auch in den systematischen GeoWissenschaften trotz aller Bestätigungen aufgegeben werden, und es müßte für deren Tatsachen eine andere Erklärung gesucht werden."

Solche Urteile, nach denen jeder Forscher gerade sein eigenes Fachgebiet für das am meisten oder gar allein kompetente hält, ließen sich wohl noch leicht vermehren.

Aber die Dinge liegen doch offenbar anders. Die Erde kann zu einer bestimmten Zeit durchaus nur ein Aussehen gehabt haben. Direkte Auskunft hierüber gibt sie nicht. Wir stehen ihr gegenüber 
wie der Richter gegenüber einem Angeklagten, der jede Auskunft verweigert, und haben die Aufgabe, die Wahrheit auf dem Wege des Indizienbeweises zu ermitteln. Alle Belege, die wir beibringen können, tragen den trügerischen Charakter von Indizien. Wie würden wir den Richter beurteilen, der sein Urteil nur auf Grund eines Teiles der verfügbaren Indizien fällt?

Nur durch Zusammenfassung aller Geo-Wissenschaften dürfen wir hoffen, die „Wahrheit“ zu ermitteln, d. h. dasjenige Bild zu finden, das die Gesamtheit der bekannten Tatsachen in der besten Ordnung darstellt und deshalb den Anspruch auf größte Wahrscheinlichkeit hat; und auch dann müssen wir ständig darauf gefaßt sein, daß jede neue Entdeckung, aus welcher Wissenschaft immer sie hervorgehen möge, das Ergebnis modifizieren kann.

Diese Überzeugung diente mir als Ansporn, wenn mir bei der Neubearbeitung dieses Buches bisweilen der Mut sinken wollte. Denn es übersteigt die Arbeitskraft des einzelnen, die lawinenartig wachsende Literatur über die Verschiebungstheorie in den verschiedenen Wissenschaften lückenlos zu verfolgen, und es werden sich daher in dem vorliegenden Buche trotz aller darauf verwendeten Mühe zahlreiche und auch empfindliche Lücken in der Berichterstattung aufweisen lassen. Daß mir dieselbe überhaupt in dem erreichten Umfańg möglich war, verdanke ich lediglich der außerordentlich großen Zahl von Zusendungen aus allen in Frage kommenden Fachgebieten, deren Spendern herzlich gedankt sei.

Das Buch wendet sich in gleicher Weise an Geodäten, Geophysiker, Geologen, Paläontologen, Tiergeographen, Pflanzengeographen und Paläoklimatologen. Es bezweckt nicht nur, den Forschern auf diesen Gebieten eine skizzenhafte Darstellung der Bedeutung und Leistungsfähigkeit der Verschiebungstheorie auf ihrem eigenen Gebiet zu geben, sondern vor allem auch sie zu orientieren über die Anwendungen und Bestätigungen, die diese Theorie auf den übrigen Gebieten gefunden hat.

Über die Geschichte dieses Buches, die zugleich die Geschichte der Verschiebungstheorie ist, findet der Leser alles Wissenswerte im ersten Kapitel.

Erst während der Korrektur erschien der im Anhang mitgeteilte Nachweis der Verschiebung Nordamerikas durch die 1927 ausgeführte neue Längenbestimmung, auf die der Leser hingewiesen sei.

Graz, im November 1928. 


\section{Inhaltsverzeichnis.}

Vorwort ................ Seite

Erstes Kapitel: Geschichtliche Vorbemerkungen . . . . . 1

Entstehung der Verschiebungstheorie 1. - Charakter der vorliegenden Auflage 2. - Vorläufer 2.

Zweites Kapitel: Das Wesen der Verschiebungstheorie und ihr Verhältnis zu den bisher herrschenden Vorstellungen über die Änderungen der Erdoberfläche in geologischen Zeiten . . . .

Ehemalige Landverbindungen 4. - Hypothese versunkener Zwischenkontinente 8. - Die Kontraktionstheorie 9 . - Beträge des Gebirgszusammenschubs 10. - Radioaktive Wärmeerzeugung 11. - Flachseenatur der marinen Sedimente 12. Wasserverdrängung der Zwischenkontinente 12. - Isostasie 13. - Postglaziale Hebung Fennoskandiens 14. - Permanenztheorie 16. - Theorie der Kontinentverschiebungen 17.

Drittes Kapitel: Geodätische Argumente ... . . . . .

Zeitdauer der geologischen Perioden 22. - Zu erwartende heutige Verschiebungen 25. - Anzeichen für Längenänderung Grönlands nach Mondbeobachtungen 25. - Nachweis der Verschiebung Grönlands durch funkentelegraphische Längenbestimmung 28. - Die Längendifferenz NordamerikaEuropa $30^{1}$ ). - Änderung der Länge von Madagaskar 31. Breitenänderungen 33.

Viertes Kapitel: Geophysikalische Argumente . . . . . . .

Die beiden Häufigkeitsmaxima der Höhenverteilung 34. Deutung derselben 36. - Andere Deutungsversuche 37. Komplikationen beim Tiefseeboden 38. - Schweremessungen 39. - Deutung derselben nach Pratt und Airy 40. - Heutiges Aufsteigen Skandinaviens und die Schwereverteilung 43. - Geschwindigkeitssprung der Erdbebenwellen in $60 \mathrm{~km}$ Tiefe 45 . Fehlen der Schichtgrenze im Pazifik 46. - Geschwindigkeit seismischer Oberflächenwellen auf ozeanischem und kontinentalem Gebiet 46. - Andere seismische Verschiedenheiten

1) Vergleiche hierzu den Anhang S. 220. 
zwischen Kontinent und Ozean 49. - Erdmagnetische Belege für größeren Eisengehalt des Ozeanbodens 50. - Vulkanische Dredschproben aus der Tiefsee 52. - Sima und Sial 52. Material der Hauptschichten des Erdkörpers 53. - Schichtenfolge Granit, Basalt, Dunit 53. - Der Zähigkeitskoeffizient der Erde 55. - Schätzungen von Schweydar, Jeffreys, Meyermann 56. - Optimale Schicht für Schmelzung 58. - Granitaufschmelzungen 59. - Übermäßige radioaktive Wärmeerzeugung unter Kontinenten 60. - Geothermische Tiefenstufe in Europa und Amerika 60. - Unterströmungen 60. - Konvektionsströmungen 60 .

Fünftes Kapitel: Geologische Argumente

Breiten des Atlantischen Ozeans 62. - Kapgebirge und Sierren von Buenos Aires 62. - Gleichheit der Eruptivserien in Südamerika und Afrika 63. - Gleichheit der Sedimente 65. Streichrichtungen in Brasilien und Afrika 66. - Geologische Vergleichung durch du Toit 68. - Beweis ehemaliger Nachbarschaft aus den Faziesunterschieden 72. - Weitere Zeugnisse 74. - Das Atlasgebirge 74. - Atlantische Inseln 75. - Die Großen Antillen 75. - Die karbonische Faltung in Europa 76. - Ihre Fortsetzung in Nordamerika 76. - Die kaledonische Faltung 77. - Die algonkische Faltung 77. - Grenzen des quartären Inlandeises 78. - Bedeutung der gehäuften Übereinstimmungen 79. Grönland 79. - Neufundland 81. - Island 81. - Mittelatlantische Bodenschwelle 82. - Madagaskar 83. - Vorderindien 84. - Himalaja 84. - Nebenerscheinung bei dessen Zusammenschub 86. - Argands Auffassung 87. - Gesamtbau Südamerikas und Afrikas nach Argand 88. - Argumente aus der Faltungstonnage nach Argand 88. - Vorderindiens Zusammenhang mit Australien 90. — Faltung in Ostaustralien und auf Neuseeland 90. - Tiefenkarte um Neuguinea 91. Verteilung des Vulkanismus 92. - Prüfung der Verschiebungstheorie im Sunda-Archipel durch Smit Sibinga 94. Australiens Zusammenhang mit Antarktika 96. - Feuerland und Grahamland als Musterbeispiel für Kontinentverschiebung 97. - Argands Résumé 98.

Sechstes Kapitel: Paläontologische und biologische Argumente

Berichtigung der Fragestellung 100. - Anzeichen früherer Landverbindung zwischen Brasilien und Afrika 101. - Desgleichen zwischen Nordamerika und Europa 103. - Beispiele 104. - v. Ubischs Urteil 105. - Aal-Laichplätze 107. - Flora Grönlands und Grinnell-Lands 108. - Floren der atlantischen Inseln 109. - Lemurien und Gondwanaland 110. - Tierwelt 
Australiens 111. - Neuseeland 114. - Pazifik 115. - Pazifische Inseln 116. - Gesamtverbreitung der Blütenpflanzen nach Irmscher 117. - Verbreitung der Koniferen nach Koch und Studt 119. - Verbreitung der Regenwürmer nach Michaelsen 121 .

Siebentes Kapitel: Paläoklimatische Argumente

Untersuchung von Köppen und Wegener 125. - Heutiges Klimasystem 126. - Höhe der Schneegrenze 127. - Moränen als Klimazeugen 128. - Kohlen 128. - Salz, Gips, Wüstensandstein 129. - Marine Kalke 129. - Pflanzenwelt 130. - Tierwelt 130. - Klimaänderung Europas seit dem Tertiär 131. Klimaänderung Spitzbergens 131. - Entgegengesetzte Klimaänderung Südafrikas 132. - Polwanderungen 133. - Bisheriges Mißlingen der Erklärung durch solche 133. - Beseitigung der Schwierigkeiten durch die Verschiebungstheorie 134. - Die permokarbone Vereisung der Südkohtinente 135. - Unmöglichkeit der Erklärung bei heutiger Lage der Kontinente 136. Pseudoglaziale Bildungen 138. - Squantum-Tillit 140. - Lage der Eisspuren nach der Verschiebungstheorie 141. - Der Hauptsteinkohlengürtel des Karbons 143. - Potoniés Gründe für tropische Herkunft 144. - Einwände 146. - Notwendigkeit der Verschiebungstheorie beim Kohlengürtel 148. - Permkohlen auf den Moränen des Gondwanalandes 148. - Trockengebiete im Karbon und Perm 150. - Die folgenden Zeiten 151.

Achtes Kapitel: Grundsätzliches über Kontinentverschiebungen und Polwanderungen.

Definition der Kontinentverschiebung 152. - Ausgeglichene Kontinentverschiebung 152. - Definition der Polwanderung 153. - Absolute Polwanderung 154. - Der Nachweis einer gegenwärtigen Polwanderung 155. - Definition der Krustenwanderung 157. - Anzeichen einer Gesamtkrustendrehung nach Westen 157. - Anzeichen partieller Krustenwanderung zum Äquator 158. - Anzeichen für Krustenwanderung aus der Schwereverteilung 158. - Interne Achsenverlagerung, Stimmen dazu 161. - Theoretische Betrachtungen 163. - Kriterium aus der Schwereverteilung 164. - Anzeichen für interne Achsenverlagerungen aus dem Transgressionswechsel $165 .-$ Prüfung für die ganze Erde für die Zeit Devon bis Perm 166. - Prüfung für Europa für die Zeit seit dem Karbon 168. Astronomische Achsenverlagerungen 169. - 40000 jährige Periode der Ekliptikschiefe 169. - Änderungen des Polarklimas im Laufe der Erdgeschichte 170. - Deutung derselben durch Änderungen der Ekliptikschiefe 171. 
Neuntes Kapitel: Die verschiebenden Kräfte. . . . . . . 172

Der induktive und deduktive Weg 172. - Die Polflucht 173. - Die Polfluchtkraft 173. - Lelys Versuch zur Demonstration der Polfluchtkraft 178. - Unzulänglichkeit der Polfluchtkraft zur Erklärung der Gebirge 179. - Gezeitenreibung 180. Schweydars Westverschiebungskraft 181. - Kräfte aus Abweichungen vom Rotationsellipsoid 182. - Massenströmungen bei internen Achsenverlagerungen 183. - Mitschleppende Konvektionsströmungen im Sima 184. - Identität der Verschiebungskräfte mit den gebirgsbildenden Kräften 185.

Zehntes Kapitel: Ergänzende Bemerkungen über die Sialsphäre 185

Die Grenzen der Sialschollen 185. - Rolle der Sedimente 187. - Transgressionen 187. - Mögliche Ursachen derselben 188. Faltung 190. - Staffelfalten und normale Falten 192. Spaltung 193. - Ostafrikanische Brüche 193. - Fließbewegungen der unteren Schollenteile 196. - Fjordbildung 197. - Untermeerische Flußmündungen 197. - Girlanden von Ostasien 198. - Entstehung 201. - Gleiten von Randketten 202. - Erdbebenverwerfung bei San Franzisko 203. - Hinterindien 204. - Atlantischer und pazifischer Küstenbau 205. Vulkanismus 206. - Urzustand der Sialdecke 207.

Elftes Kapitel: Ergänzende Bemerkungen über die Tiefseeböden 210

Mitteltiefen der Ozeane 210. - Entstehung der Unterschiede durch Temperatur 211. - Ebene Flächen am Tiefseeboden 212. - Material der mittelatlantischen Bodenschwelle 213. - Basalt und Dunit 214. - Strömungserscheinungen am Tiefseeboden 216. - Tiefseerinnen 218.

Anhang zum dritten Kapitel: Nachweis der Verschiebung Nordamerikas durch neue Längenmessungen . . . . . . . 220 Literatur. . . . . . . . . . . . . . . . . . . 221 
Erstes Kapitel.

\section{Geschichtliche Vorbemerkungen.}

Die Vorgeschichte dieses Buches ist nicht ganz ohne Interesse. Die erste Idee der Kontinentverschiebungen kam mir bereits im Jahre 1910 bei der Betrachtung der Weltkarte unter dem, unmittelbaren Eindruck von der Kongruenz der atlantischen Küsten, ich ließ sie aber zunächst unbeachtet, weil ich sie für unwahrscheinlich hielt. Im Herbst 1911 wurde ich mit den mir bis dahin unbekannten paläontologischen Ergebnissen über die frühere Landverbindung zwischen Brasilien und Afrika durch ein Sammelreferat bekannt, das mir durch Zufall in die Hände fiel. Dies veranlaßte mich, eine zunächst flüchtige Durchmusterung der für die Frage in Betracht kommenden Forschungsergebnisse auf geologischem und paläontologischem Gebiet vorzunehmen, wobei sich sogleich so wichtige Bestätigungen ergaben, daß die Überzeugung von der grundsätzlichen Richtigkeit bei mir Wurzel schlug. Am 6. Januar 1912 trat ich zum erstenmal mit der Idee in einem Vortrag in der Geologischen Vereinigung in Frankfurt a. M. hervor, der betitelt war: „Die Herausbildung der Großformen der Erdrinde (Kontinente und Ozeane) auf geophysikalischer Grundlage". Diesem Vortrag folgte am 10. Januar ein zweiter über „Horizontalverschiebungen der Kontinente“ in der Ges. z. Beförd. d. gesamten Naturwiss. zu Marburg. Im gleichen Jahre 1912 folgten auch die beiden ersten Veröffentlichungen [1, 2]. Zunächst verhinderte mich die Teilnahme an der Grönlanddurchquerung unter J.P. Koch 1912/13 und später der Kriegsdienst an der weiteren Ausarbeitung der Theorie. 1915 konnte ich jedoch einen längeren Krankenurlaub dazu benutzen, eine etwas ausführlichere Darstellung unter dem Titel dieses Buches in der Sammlung Vieweg zu geben [3]. Als nach Schluß des Krieges hiervon eine zweite Auflage (1920) nötig wurde, willigte der Verlag dankenswerterweise ein, dieselbe aus der Sammlung Vieweg in die Sammlung Wissenschaft hinüberzunehmen, wodurch die Möglichkeit zu einer 
erheblich weitergehenden Durcharbeitung gegeben war. 1922 erschien bereits die 3. Auflage, wiederum wesentlich verbessert. Diese Auflage wurde in einer ungewöhnlich hohen Zahl gedruckt, um mir die Möglichkeit zu schaffen, mich einige Jahre mit anderen Aufgaben zu beschäftigen. Sie ist seit einiger Zeit wieder völlig vergriffen. Von dieser Auflage entstand auch eine Reihe von Übersetzungen, und zwar zwei in das Russische, und je eine ins Englische, Französische, Spanische und Schwedische. Für die letztere, die 1926 erschien, habe ich bereits einige Änderungen des deutschen Textes vorgenommen.

Die gegenwärtige 4. Auflage des deutschen Originals ist wiederum wesentlich umgearbeitet, ja sie ist nahe daran, einen anderen Charakter anzunehmen als ihre Vorgänger. Als nämlich die vorige Auflage geschrieben wurde, war zwar auch schon eine umfangreiche Literatur über die Frage der Kontinentverschiebungen entstanden und $\mathrm{zu}$ berücksichtigen. Aber diese Literatur beschränkte sich in der Hauptsache auf zustimmende oder ablehnende Äußerungen und auf Anführung von Einzelbeobachtungen, die entweder für oder gegen die Richtigkeit sprachen oder zu sprechen schienen. Seit 1922 hat aber die Diskussion dieser Fragen in den verschiedenen GeoWissenschaften nicht nur außerordentlich zugenommen, sondern teilweise auch ihren Charakter geändert, indem die Theorie in zunehmendem Maße als Grundlage für weitergehende Untersuchungen benutzt wird. Dazu kommt noch der soeben erfolgte exakte Nachweis für die gegenwärtige Verschiebung Grönlands, durch den die Diskussion der ganzen Frage wohl für viele auf eine ganz andere Basis gestellt wird. Während daher die früheren Auflagen im wesentlichen nur eine Darstellung der Theorie selber und eine Zusammenstellung der für ihre Richtigkeit sprechenden Einzeltatsachen enthielten, stellt die gegenwärtige bereits eine Übergangsform zu einem Sammelreferat über diese neuen Forschungszweige dar.

Schon bei der ersten Beschäftigung mit dieser Frage und von Zeit zu Zeit auch bei der späteren Entwicklung stieß ich mehrfach auf Anklänge an meine eigenen Vorstellungen bei älteren Autoren. Schon 1857 sprach Green von ,Segmenten der Erdkruste, die auf dem flüssigen Kern schwimmen“ [63]. Eine Drehung der gesamten Erdkruste - deren Teile aber dabei ihre gegenseitige Lage nicht ändern sollten - ist bereits von mehreren Autoren, wie Löffelholz von Colberg [4], Kreichgauer [5], Evans u.a. angenommen worden. $\mathrm{H}$. Wettstein hat ein Buch geschrieben [6], in welchem neben vielen Ungereimtheiten doch auch Ahnungen 
von großen horizontalen Relativverschiebungen der Kontinente vorkommen. Die Kontinente - deren Schelfe er allerdings nicht mit berücksichtigt - erleiden nach ihm nicht nur Verschiebungen, sondern auch Deformationen; sie wandern sämtlich nach Westen, gezogen durch die Flutkräfte der Sonne im zähflüssigen Erdkörper (was auch E. H. L. Schwarz [7] annimmt). Aber die Ozeane sind auch bei ihm versunkene Kontinente, und über die sogenannten geographischen Homologien und andere Probleme des Erdantlitzes äußert er phantastische Vorstellungen, die wir übergehen. Ebenso wie der Verfasser ist auch Pickering von der Kongruenz der südatlantischen Küsten ausgegangen in einer Arbeit [8], in der er die Vermutung ausspricht, Amerika sei von Europa-Afrika abgerissen und um die Breite des Atlantik fortgezogen worden. Er hat aber nicht beachtet, daß man in der geologischen Geschichte dieser beiden Kontinente tatsächlich einen früheren Zusammenhang bis zur Kreidezeit anzunehmen genötigt ist, und so verlegte er diesen Zusammenhang in eine graue Vorzeit und dachte sich das Abreißen verbunden mit der von G. H. Darwin angenommenen einstmaligen Abschleuderung der Mondmasse von der Erde, deren Spur er noch im pazifischen Becken zu sehen meinte.

Mantovani [86] hat 1909 in einem kurzen Artikel Ideen über Kontinentverschiebungen geäußert und durch Kärtchen erläutert, die zwar zum Teil von den meinigen abweichen, an einigen Stellen aber, wie z. B. in bezug auf die ehemalige Gruppierung der Südkontinente um Südafrika, erstaunlich damit übereinstimmen. Brieflich wurde ich darauf aufmerksam gemacht, daß Coxworthy in einem nach 1890 erschienenen Buch die Hypothese ausgesprochen haben soll, die heutigen Kontinente seien die zerrissenen Teile einer ehemals zusammenhängenden Masse [9]. Selbst hatte ich keine Gelegenheit, dies Buch einzusehen.

Große Ähnlichkeit mit meinen eigenen Ideen fand ich auch in einer 1910 erschienenen Arbeit von F. B. Taylor [10], in welcher dieser für die Tertiärzeit nicht unbedeutende horizontale Verschiebungen einzelner Kontinente annimmt, die er dann mit den großen tertiären Faltensystemen in Zusammenhang bringt. Für die ${ }^{\circ}$ ostrennung Grönlands von Nordamerika kommt er z. B. zu praktisch den gleichen Vorstellungen wie ich. Beim Atlantik nimmt er an, daß nur ein Teil seiner Breite durch Fortziehen der amerikanischen Schollen entstanden sei, während der Rest abgesunken sei und die mittelatlantische Bodenschwelle darstelle. Auch diese 
Vorstellung unterscheidet sich nur quantitativ, aber nicht in dem Entscheidenden, Neuen, von der meinigen. Aus diesem Grunde wird die Verschiebungstheorie von den Amerikanern bisweilen die Taylor-Wegenersche Theorie genannt. Allerdings habe ich selbst beim Lesen von Taylors Schrift den Eindruck, daß er vor allem ein gestaltendes Prinzip für die Anordnung der großen Gebirgsketten suchte und dieses in einer Polflucht des Landes zu finden glaubte, und daß bei diesem Gedankengange die Verschiebung einiger Kontinente in unserem Sinne nur eine untergeordnete Rolle spielte und auch nur sehr kurz begründet wurde.

Ich selbst habe alle diese Arbeiten - auch die von Taylor erst zu einer Zeit kennengelernt, zu der die Verschiebungstheorie in ihren Hauptzügen von mir bereits ausgearbeitet war, einige sogar noch wesentlich später. Es ist wohl nicht ausgeschlossen, daß im Laufe der Zeit noch weitere Arbeiten entdeckt werden, die Anklänge an die Verschiebungstheorie enthalten oder diesen oder jenen Punkt vorwegnehmen. Eine historische Untersuchung hierüber ist noch nicht angestellt und im gegenwärtigen Buche nicht beabsichtigt.

\section{Zweites Kapitel.}

\section{Das Wesen der Verschiebungstheorie und ihr Verhältnis zu den bisher herrschenden Vorstellungen über die Änderungen der Erdoberfläche in geologischen Zeiten.}

Es ist eine seltsame und für den gegenwärtigen unfertigen Stand unserer Kenntnisse bezeichnende Tatsache, daß man hinsichtlich der vorzeitlichen Zustände unserer Erde zu ganz entgegengesetzten Resultaten kommt, je nachdem man von der biologischen oder der geophysikalischen Seite an das Problem herantritt.

Die Paläontologen und ebenso die Tier- und Pflanzengeographen kommen immer wieder zu dem Ergebnis, daß die Mehrzahl der heute durch eine breite Tiefsee getrennten Kontinente in der Vorzeit eine Landverbindung gehabt haben müssen, über welche hinweg sich ein ungestörter Austausch der Landfauna und Landflora vollzog. Die Paläontologen schließen dies aus dem Vorkommen zahlreicher identischer Arten, die in der Vorzeit hüben und drüben nachweislich gelebt haben und deren gleichzeitige getrennte Entstehung an ver- 
schiedenen Orten undenkbar erscheint. Und wenn immer nur ein beschränkter Prozentșatz von Identitäten in den gleichzeitigen fossilen Faunen oder Floren gefunden wird, so erklärt sich dies natürlich leicht aus dem Umstand, daß nur ein Bruchteil der gesamten damals lebenden Organismenwelt in fossilem Zustande erhalten ist und bisher gefunden wurde. Denn selbst wenn die ganze Organismenwelt auf zwei solchen Kontinenten einst restlos identisch war, wird die Unvollständigkeit unserer Kenntnis zur Folge haben müssen, daß die beiderseits gemachten Funde nur teilweise identisch ausfallen, zum anderen, meist größeren Teile aber Unterschiede vortäuschen; und dazu kommt natürlich noch der Umstand, daß die Organismenwelt auch bei vollkommener Austauschmöglichkeit doch nicht vollkommen identisch gewesen sein wird, wie ja auch heute z. B. Europa und Asien keineswegs identische Fauna und Flora haben.

Und zu dem gleichen Ergebnis gelangt auch die vergleichende Untersuchung der heutigen Tier- und Pflanzenwelt. Die heutigen Arten auf zwei solchen Kontinenten sind zwar verschieden, aber die Gattungen und Familien sind noch die gleichen; und was heute Gattung oder Familie ist, war in der Vorzeit einmal Art. So führt auch die Verwandtschaft der heutigen Landfaunen und Landfloren zu dem Schluß, daß diese Faunen und Floren in der Vorzeit einmal identisch waren und daher im Austausch gestanden haben müssen, der nur über eine breite Landverbindung gedacht werden kann. Erst nach Abbruch dieser Landverbindung kam es zur Aufsplitterung in die heute verschiedenen Arten. Es ist wohl nicht zuviel gesagt, daß die ganze Entwicklung des Lebens auf der Erde und die Verwandtschaft der heutigen Organismen auch auf weit getrennten Kontinenten uns ein unlösbares Rätsel bleiben muß, wenn wir nicht solche ehemaligen Landverbindungen annehmen.

Nur ein Zeugnis für viele: de Beaufort schreibt [123]: „Es könnten noch viele andereł Beispiele genannt werden, aus denen hervorgeht, daß es in der Zoogeographie unmöglich ist, zu einer annehmbaren Erklärung der Verbreitung der Tiere zu kommen, wenn man nicht Verbindungen annimmt zwischen heute getrennten Kontinenten, und zwar nicht nur Landbrücken, von denen, wie Matthew es ausdrückt, nur ein paar Planken weggenommen sind, sondern auch solche Verbindungen, wo jetzt der tiefe Ozean trennt“"1).

1) ,Allerdings gibt es heute auch noch einige Gegner der Landbrïcken. Unter ihnen ist besonders G. Pfeffer hervorzuheben. Er geht davon aus, daß verschiedene jetzt auf die Süderdteile beschränkte Formen 
Selbstverständlich sind viele Einzelfragen hierbei noch ungenügend geklärt. In manchen Fällen sind ẹhemalige Landbrücken auf Grund sehr dürftiger Anzeichen konstruiert worden und haben beim Fortschritt der Forschung keine Bestätigung erfahren. In anderen Fällen herrscht wenigstens noch keine völlige Einigkeit über den Zeitpunkt, zu dem die Verbindung erlosch und die heutige Trennung einsetzte. Aber bei den wichtigsten dieser alten Landverbindungen herìscht doch heute schon unter den Spezialisten eine erfreuliche Übereinstimmung, ob sie nun ihre Schlüsse auf die geographische Verbreitung der Säugetiere oder der Regenwürmer, der Pflanzen oder eines anderen Teiles der Organismenwelt gründen. Arldt [11] hat aus den Äußerungen bzw. Karten von 20 Forschern $^{1}$ ) eine Art Abstimmungstabelle über die Existenz oder Nichtexistenz der verschiedenen Landverbindungen für die verschiedenen geologischen Zeiten entworfen. Für die vier wichtigsten dieser ehemaligen Landverbindungen habe ich das Ergebnis dieser Auszählung graphisch in Abb. 1 dargestellt. Hierin sind für jede Landverbindung drei Kurven gezeichnet, nämlich die Zahl der bejahenden, die Zahl der verneinenden Stimmen und deren Differenz, also die Stärke der Majorität, letztere durch Schraffur der zugehörigen Fläche hervorgehoben. So zeigt die oberste Darstellung, daß die Verbindung Australiens mit Vorderindien, Madagaskar und Afrika (das alte „Gondwanaland") nach der Mehrzahl der Forscher seit kambrischen Zeiten bis zum Beginn der Jurazeit andauerte, zu diesem Zeitpunkt aber erlosch; die zweite Darstellung zeigt, daß die alte Landverbindung

auf der Nordhalbkugel fossil nachgewiesen sind. Für diese ist es nach ihm unzweifelhaft, daß sie einst mehr oder weniger universal verbreitet waren. Ist nun schon dieser Schluß nicht unbedingt zwingend, so noch viel weniger der weitere, daß wir eine universale Ausbreitung auch in allen den Fällen diskontinuierlicher Verbreitung im Süden annehmen dürfen, in denen ein fossiler Nachweis im Norden noch nicht stattgefunden hat. Wenn er so alle Verbreitungseigentümlichkeiten ausschließlich durch Wanderungen zwischen den Nordkontinenten und ihren mediterranen Brücken erklären will, so steht diese Annahme durchaus auf ganz unsicherem Boden." (Árldt [135].) Daß sich die Verwandtschaften der Südkontinente einfacher und volls tändiger durch unmittelbare Landzusammenhänge erklären lassen, als durch parallele Abwanderung vom gemeinsamen Nordgebiet, bedarf wohl keiner Erläuterung, wenn auch in einzelnen Fällen der Vorgang sich so abgespielt haben kann, wie Pfeffer annimmt.

$\left.{ }^{1}\right)$ Arldt, Burckhardt, Diener, Frech, Fritz, Handlirsch, Haug, v. Ihering, Karpinsky, Koken, Kossmat, Katzer, Lapparent, Matthew, Neumayr, Ortmann, Osborn, Schuchert, Uhlig, Willis. 
zwischen Südamerika und Afrika („Archhelenis“) nach der Mehrzahl der Forscher in der Unter- bis Mittelkreide erlosch. Noch später, nämlich an der Wende zwischen Kreide und Tertiär, erlosch nach der dritten graphischen Darstellung die alte Landverbindung zwischen Madagaskar und Dekan (,Lemurien“). Erheblich unregelmäßiger war die Landverbindung zwischen Nordamerika und Europa, wie die vierte graphische Darstellung zeigt. Aber auch hier herrscht trotz des häufigen Wechsels der Verhältnisse doch eine recht weit-

Abb. 1.

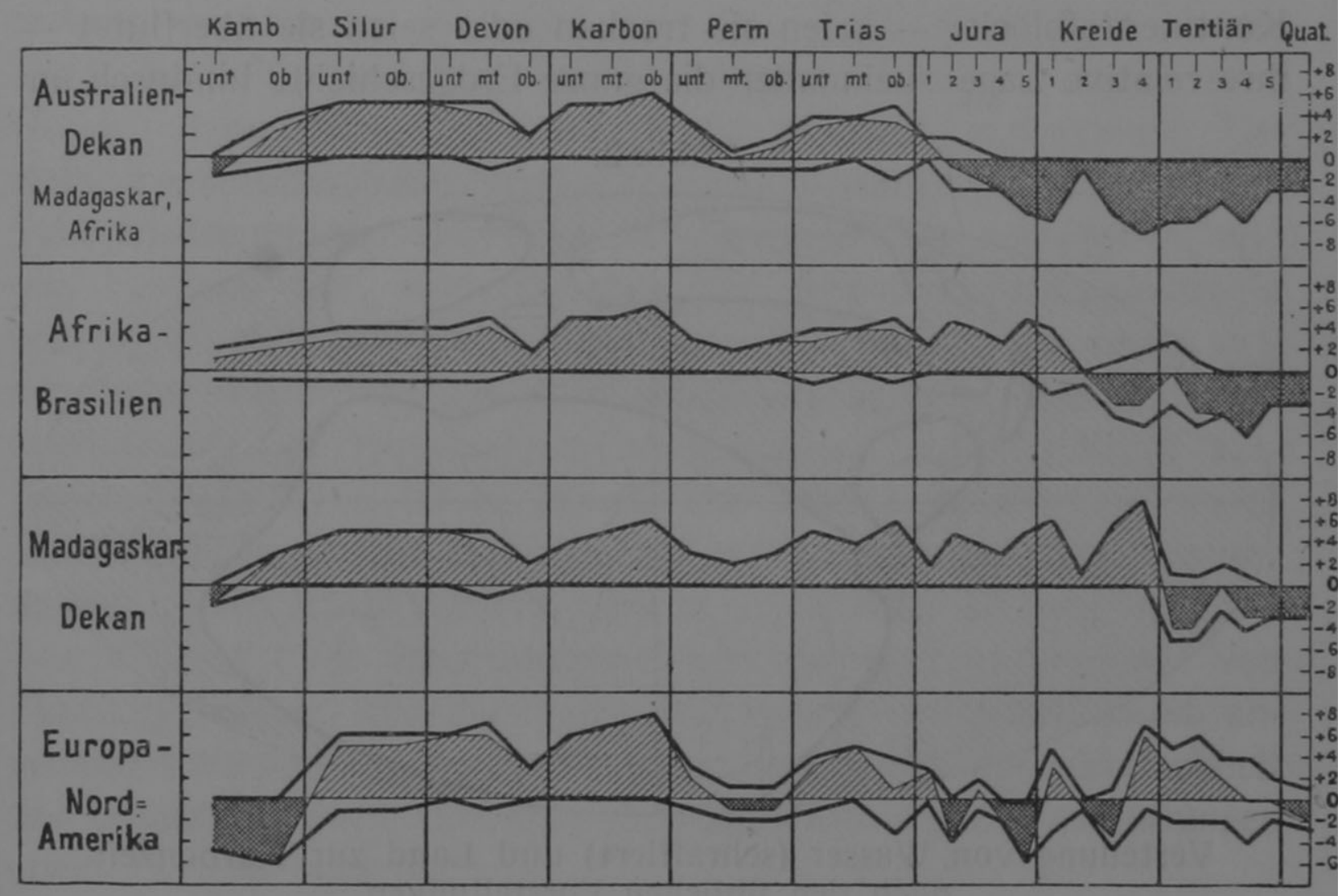

Zahl der bejahenden (obere starke Kurve) und Zahl der verneinenden Stimmen (untere starke Kurve)

zur Frage der Existenz von vier Landbrücken seit dem Kambrium. Die Differenz (Majorität) ist schraffiert. Doppelt, wenn verneinend.

gehende Übereinstimmung der Ansichten: Die Verbindung war in der älteren Zeit wiederholt, namentlich im Kambrium, im Perm, sowie in der Jura- und Kreidezeit, gestört, offenbar aber nur durch seichte „Transgressionen“, die eine spätere Wiederherstellung der Verbindung zuließen. Der endgültige Abbruch der Beziehungen, wie er der heutigen Trennung durch eine breite Tiefsee entspricht, kann aber, wenigstens im Norden bei Grönland, erst im Quartär vor sich gegangen sein.

Auf manche Einzelheiten wird später eingegangen werden. Hier sei nur ein Punkt hervorgehoben, der von den Vertretern dieser 
Landbrückentheorie bisher unbeachtet gelassen wurde, aber von größter Wichtigkeit ist: Diese ehemaligen Landverbindungen werden nicht nur für solche Stellen, wie z. B. die Beringstraße, gefordert, wo heute ein seichtes Schelfmeer oder Transgressionsmeer die Kontinente trennt, sondern auch für heutige Tiefseegebiete. Alle vier Beispiele unserer Abb. 1 betreffen solche Fälle. Sie sind mit Absicht ausgewählt, weil gerade bei ihnen die neuen Gedankengänge der Verschiebungstheorie einsetzen, wie noch zu zeigen ist.

Da man bisher als selbstverständlich voraussetzte, daß die Kontinentalblöcke - seien sie trocken oder seien sie überflutet ihre relative Lage zueinander die ganze Erdgeschichte hindurch- un-

Abb. 2.

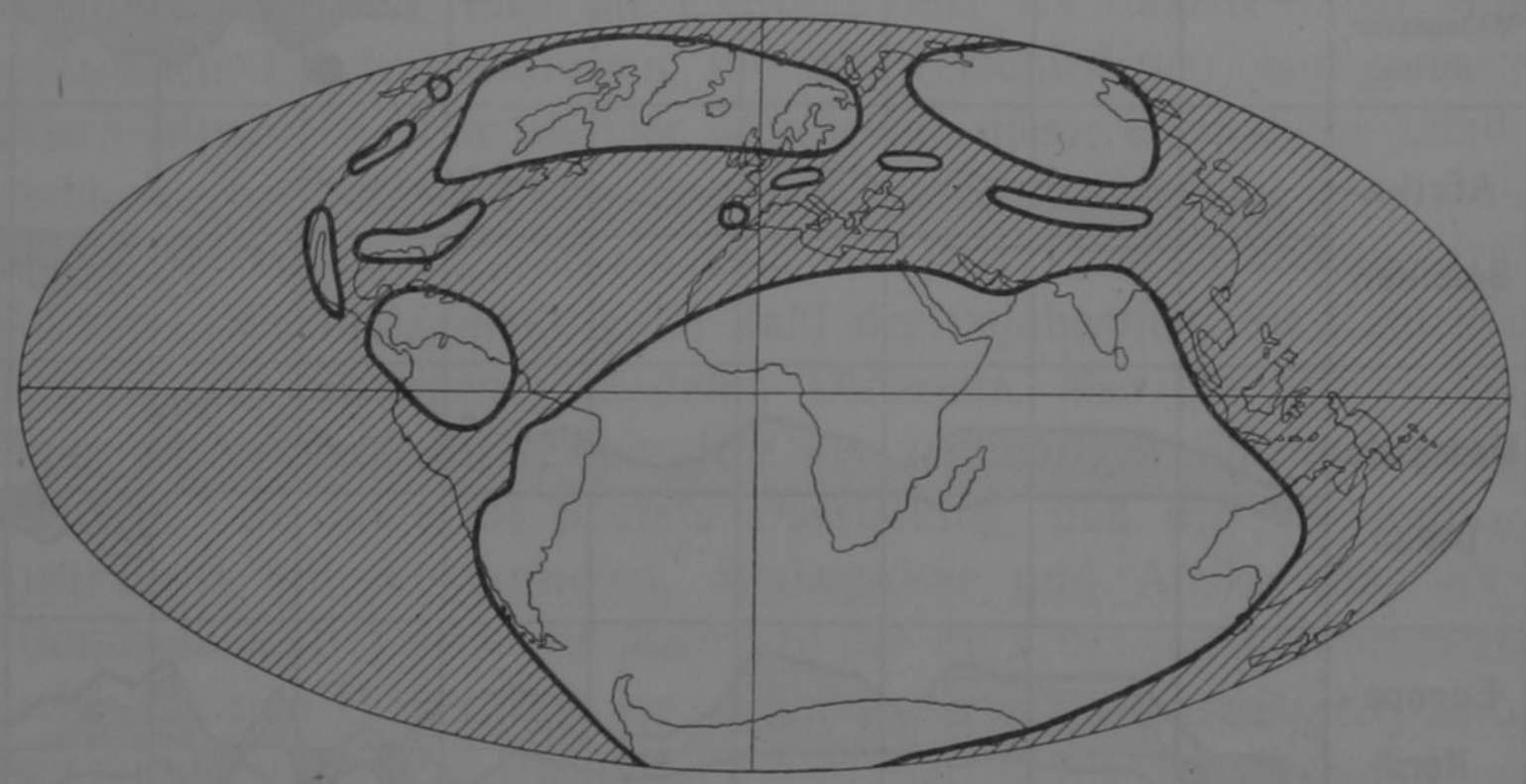

Verteilung von Wasser (schraffiert) und Land zur Karbonzeit nach den üblichen Vorstellungen.

verändert beibehalten hätten, so blieb natürlich nichts weiter übrig, als anzunehmen, daß die geforderten Landverbindungen in Gestalt von Zwischenkontinenten vorhanden gewesen waren, die später, als der Austausch der Landfauna und Landflora aufhörte, unter den Meeresspiegel versanken und heute den Boden der zwischenliegenden Tiefsee bildeten. So entstanden die bekannten paläogeographischen Rekonstruktionen, von denen Abb. 2 ein Beispiel für die Karbonzeit gibt.

Diese Annahme versunkener Zwischenkontinente war in der Tat die nächstliegende, solange man auf dem Boden der Lehre von der Kontraktion oder der Schrumpfung der Erde stand, auf die wir im folgenden etwas näher eingehen müssen. Diese Lehre entstand in Europa; sie wurde namentlich von Dana, Albert Heim und 
Eduard Suess begründet und ausgebaut und beherrscht noch bis in die Gegenwart die Grundvorstellungen in den meisten europäischen Lehrbüchern der Geologie. Suess prägte den kürzesten Ausdruck für den Inhalt dieser Theorie: „,Der Zusammenbruch des Erdballs ist es, dem wir beiwohnen" [12, Bd. 1, S. 778]. Wie ein trocknender Apfel durch den Wasserverlust des Innern faltige Runzeln an der Oberfläche bekommt, so sollen sich durch die Abkühlung und damit verbundene Schrumpfung des Erdinnern die Gebirgsfalten an der Oberfläche bilden. Infolge dieses Zusammensinkens der Kruste soll ein allgemeiner "Gewölbedruck“ in der Rinde herrschen und bewirken, daß einzelne Teile als Stufen oder Horste stehenbleiben, gewissermaßen getragen von diesem Gewölbedruck. Im weiteren Verlauf können dann diese zurückgebliebenen Teile wiederum den anderen in der Sinkbewegung vorauseilen, und was Festland war, kann Meeresboden werden und umgekehrt in beliebig oft wiederholtem Wechsel, eine Vorstellung, die von Lyell begründet wurde und auf die Tatsache zurückgeht, daß man fast überall auf den Kontinenten Ablagerungen früherer Meere vorfindet. Man kann dieser Theorie das historische Verdienst nicht absprechen, lange Zeit hindurch eine ausreichende Zusammenfassung unseres geologischen Wissens gebildet zu haben. Und wegen dieser langen Zeit ist die Kontraktionstheorie auf eine große Menge von Einzelergebnissen der Forschung mit solcher Folgerichtigkeit angewendet worden, daß sie noch heute in ihrer großzügigen Einfachheit des Grundgedankens und der Vielgliedrigkeit seiner Anwendungen etwas Bestechendes hat.

Seit der großartigen Zusammenfassung, die das geologische Wissen von der Erde durch das vierbändige Werk von Eduard Suess „Das Antlitz der Erde“ vom Gesichtspunkt der Kontraktionstheorie erfuhr, haben sich indessen die Zweifel an der Richtigkeit der Grundvorstellung immer mehr gehäuft. Die Vorstellung, daß alle Hebungen nur scheinbar seien, nämlich nur in einem Zurückbleiben hinter dem allgemeinen Hinstreben der Kruste zum Erdmittelpunkt beständen,' wurde durch den Nachweis absoluter Hebungen widerlegt [71]. Die Vorstellung von einem ständig und überall wirkenden Gewölbedruck, schon theoretisch von Hergesell [124] für die oberste Rindenschicht widerlegt, erwies sich als unhaltbar, da der Bau von Ostasien und die ostafrikanischen Grabenbrüche umgekehrt auf Zugkräfte in großen Teilen der Erdrinde schließen ließen. Die Auffassung der Gebirgsfaltungen als Rinden- 
runzelung bei der Schrumpfung des Erdinnern führte zu der unannehmbaren Konsequenz einer Druckübertragung innerhalb der Erdrinde über eine Strecke von 180 Großkreisgraden. Zahlreiche Autoren, wie Ampferer [13], Reyer [14], Rudzki [15], Andrée [16] u. a. haben mit Recht dagegen Stellung genommen und gefordert, es müßte die ganze Erdoberfläche gleichmäßig von der Runzelung betroffen werden, was ja auch der trocknende Apfel zeigt. Besonders war es aber die Entdeckung des schuppenartigen „Deckfaltenbaues“ oder der Überschiebungen in den Alpen, welche die ohnehin schwierige Erklärung der Gebirge durch Schrumpfung immer unzulänglicher erscheinen ließ. Diese durch die Arbeiten von Bertrand, Schardt, Lugeon u. a. eingeführte neue Auffassung vom Bau der Alpen und zahlreicher anderer Gebirge führt zu weit größeren Beträgen des Zusammenschubs als die früheren Vorstellungen. Während Heim nach der letzteren noch für die Alpen eine Verkürzung auf 1/2 berechnete, findet er unter Zugrundelegung des heute allgemein anerkannten Deckfaltenbaues eine Verkürzung auf $1 / 4$ bis $1 / 8$ [17]. Da die heutige Breite etwa $150 \mathrm{~km}$ beträgt, so wäre also hier ein Rindenstück von 600 bis $1200 \mathrm{~km}$ Breite ( 5 bis 10 Breitengraden) zusammengeschoben. Aber in der jüngsten großen Synthese über den Deckfaltenbau der Alpen kommt R. Staub [18] in Übereinstimmung mit Argand sogar zu noch größeren Beträgen des Zusammenschubs. Er kommt auf S. 257 zu dem Schluß:

„,Die alpine Orogenese ist der Effekt der Nordwanderung der afrikanischen Scholle. Glätten wir nur die alpinen Falten und Decken auf dem Querschnitt zwischen Schwarzwald und Afrika wieder aus, so ergibt sich gegenüber der jetzigen Distanz von rund $1800 \mathrm{~km}$ schon ein ursprünglicher Abstand von rund 3000 bis $3500 \mathrm{~km}$, also ein Zusammenschub der alpinen Region, alpin in weiterem Sinne gemeint, um rund $1500 \mathrm{~km}$. . Um diesen Betrag muß sich Afrika gegenüber Europa verschoben haben. Wir kommen damit also auf eine wahre Kontinentalverschiebung der afrikanischen Scholle um große Beträge“"1).

In ähnlichem Sinne haben sich auch andere Geologen geäußert, wie z. B. F. Hermann [106], Edw. Hennig [19] oder Kossmat [21],

1) Wie es scheint, sind die Schätzungen der Größe des Zusammenschubs der Alpen noch immer im Wachsen. So schreibt Staub neuerdings [214, ähnlich in 215]: „,Denken wir uns nun aber diesen alpinen, wohl dutzendfach übereinandergeschobenen Deckenhaufen wieder aus- 
der betont, „daß eine Erklärung der Gebirgsbildung mit großartigen tangentialen Rindenbewegungen rechnen muß, die sich nicht in den Vorstellungskreis der einfachen Kontraktionstheorie einfügen lassen". Für Asien hat insbesondere Argand [20] in einer umfangreichen Untersuchung, auf die wir noch weiter unten zurückkommen werden, ganz entsprechende Vorstellungen entwickelt, wie er selbst und Staub für die Alpen. Jeder Versuch, diese gewaltigen Zusammenschübe der Rinde auf eine Temperaturerniedrigung des Erdinnern zurückzuführen, muß scheitern.

Aber sogar die scheinbar selbstverständliche Grundannahme der Kontraktionstheorie, nämlich daß die Erde sich ständig abkühle, ist durch die Entdeckung des Radiums völlig ins Wanken geraten. Dieses Element, durch dessen Zerfall fortwährend Wärme entsteht, ist nämlich in den uns zugänglichen Gesteinen der Erdrinde überall in meßbaren Mengen enthalten, und die zahlreichen Messungen führen zu dem Schluß, daß, wenn auch das Innere der Erde den gleichen Radiumgehalt hätte, die Produktion von Wärme unvergleichlich viel größer sein müßte als ihre Abfuhr nach außen, die wir durch die Temperaturzunahme mit der Tiefe in Bergwerken bei Berücksichtigung der Leitfähigkeit der Gesteine kontrollieren können. Das hieße aber so viel, daß die Temperatur der Erde dauernd im Steigen sein müßte. Allerdings legt die sehr geringe Radioaktivität der Eisenmeteoriten nahe, daß auch der eiserne Kern der Erde vermutlich viel weniger Radium enthält als die Rinde, so daß dieser paradoxe Schluß vielleicht vermeidbar ist; aber jedenfalls kann man heute den thermischen Zustand der Erde nicht mehr wie früher als die augenblickliche Phase im Abkühlungsprozeß einer früher viel heißeren Kugel betrachten, sondern viel eher als einen Gleichgewichtszustand zwischen der radioaktiven Wärmeproduktion des Erdinnern und der Wärmeabgabe an den Weltraum. Ja die neuesten Untersuchungen über diese Frage, die später eingehender zu besprechen

geglättet...., so kommen wir notgedrungen mit dem starren Rückland der Alpen viel weiter nach Süden, und die ursprüngliche Distanz zwischen Vorland und Rückland der Alpen ist eine wohl zehn- bis zwölfmal größere gewesen als der heutige Abstand zwischen den beiden." Er fügt hinzu: „,Die Schaffung eines Gebirges geht also hier ganz deutlich und zweifelsfrei . auf selbständige Wanderungen größerer, nach ihrem Bau und ihrer Zusammensetzung sicher kontinentalen Schollen zurück, und damit gelangen wir, von der Geologie der Alpen, von der Deckentheorie Hans Schardts, ganz selbstverständlich und ungezwungen zu der Anerkennung des Grundprinzips der großen Wegenerschen Theorie von den Verschiebungen der kontinentalen Schollen." 
sein werden, kommen zu dem Ergebnis, daß wenigstens unter den Kontinentalschollen tatsächlich mehr Wärme erzeugt als abgeführt wird, die Temperatur also hier ansteigen muß, während allerdings im Gebiet der Tiefseebecken umgekehrt die Abgabe gegenüber der Produktion überwiegt, und es so für die ganze Erde zu einem Gleichgewicht zwischen Produktion und Abgabe kommt. Jedenfalls sieht man hieraus, daß durch diese neuen Anschauungen der Kontraktionstheorie ihre Grundlage völlig entzogen wird.

Aber auch noch manche anderen Schwierigkeiten erheben sich gegen die Kontraktionstheorie und ihre Gedankengänge. Die Vorstellung eines schrankenlosen zeitlichen Wechsels zwischen Kontinent und Meeresboden, die durch die marinen Sedimente auf den heutigen Kontinenten nahegelegt war, mußte stark eingeschränkt werden. Denn bei der genaueren Untersuchung dieser Sedimente zeigte sich immer deutlicher, daß es sich fast ohne Ausnahme um Flachseesedimente handelte. Manche früher für Tiefseeablagerungen angesprochenen Sedimente erwiesen sich als der Flachsee entstammend, wie es z. B. für die Schreibkreide vion Cayaux nachgewiesen wurde. Dacqué [22] hat eine gute Übersicht über diese Frage gegeben. Nur bei ganz wenigen Sedimenten, wie den kalkarmen Radiolariten der Alpen und gewissen roten Tonen, die an den roten Tiefseeton erinnern, nimmt man auch heute noch große Entstehungstiefen (4 bis $5 \mathrm{~km}$ ) an, vor allem, weil das Seewasser erst in großer Tiefe auflösend auf den Kalk wirkt. Aber die räumliche Erstreckung dieser echten Tiefseeablagerungen auf den heutigen Kontinenten ist, verglichen mit der Größe dieser letzteren und der auf ihnen liegenden Flachseesedimente, so verschwindend, daß der Satz von der grundsätzlichen Flachseenatur der fossilen Meeresablagerungen auf den heutigen Kontinenten dadurch nicht beeinträchtigt wird. Hierdurch entsteht aber für die Kontraktionstheorie eine große Schwierigkeit. Denn da wir die Flachsee geophysikalisch mit zur Kontinentalscholle rechnen müssen, so besagt dieser Satz, daß die Kontinentalschollen als solche in der Erdgeschichte „permanent" geblieben sind und niemals den Boden der Tiefsee gebildet haben. Dürfen wir dann noch annehmen, daß der heutige Tiefseeboden jemals Kontinent war? Die Berechtigung dieses Schlusses ist offenbar mit der Feststellung der Flachseenatur der marinen Ablagerungen auf den Kontinenten verloren gegangen. Aber mehr als das, dieser Schluß führt jetzt auf einen offenen Widerspruch. Wenn wir nämlich jene Zwischenkontinente nach Art der Abb. 2 rekonstruieren, also 
einen großen Teil der heutigen Tiefseebecken ausfüllen, ohne die Möglichkeit einer Kompensation durch Hinabdrücken heutiger Kontinentalgebiete zum Niveau des Tiefseebodens zu haben, so haben die Wassermassen des Weltmeeres keinen Platz mehr in den nunmehr stark verkleinerten Tiefseebecken. Die Wasserverdrängung der Zwischenkontinente wäre eine so gewaltige, daß der Spiegel des Weltmeeres über das gesamte Kontinentalgebiet der Erde ansteigen und alles überfluten würde, die heutigen Kontinente wie die Zwischenkontinente, und die Rekonstruktion führt also gar nicht zu dem gewünschten Ziel, das doch in trockenen Landverbindungen zwischen trockenen Kontinenten besteht. Abb. 2 stellt also eine unmögliche Rekonstruktion dar, sofern wir nicht Zusatzhypothesen einführen, die als Hypothesen ,ad hoc" unwahrscheinlich sind, wie z. B., daß die Wassermenge des Weltmeeres damals gerade um so viel kleiner war als heute, oder daß die übrigbleibenden Tiefseebecken damals gerade um so viel tiefer waren als heute. Willis, A. Penck u. a. haben auf diese eigentümliche Schwierigkeit hingewiesen.

Von den vielen Einwürfen gegen die Kontraktionstheorie sei nur noch einer hervorgehoben, der ein ganz besonderes Gewicht hat. Die Geophysik ist, hauptsächlich durch Schweremessungen, zu der Vorstellung gekommen, daß die Erdrinde im Tauchgleichgewicht auf einer etwas schwereren, zähflüssigen Unterlage schwimmt. Man nennt diesen Zustand Isostasie. Isostasie ist nichts anderes als Tauchgleichgewicht nach dem archimedischen Prinzip, wobei das Gewicht des eintauchenden Körpers gleich dem Gewicht der verdrängten Flüssigkeit ist. Die Einführung eines besonderen Wortes für diesen Zustand bei der Erdrinde ist jedoch deshalb zweckmäßig, weil die Flüssigkeit, in welche die Erdrinde eintaucht, wahrscheinlich von einer sehr großen, nur schwer vorstellbaren Zähigkeit ist, so daß Schwingungen um die Gleichgewichtslage ausgeschlossen sind, und das Hinstreben zur Gleichgewichtslage nach Eintritt einer Störung derselben ein-Prozeß ist, der nur mit äußerster Langsamkeit fortschreitet und viele Jahrtausende zur Vollendung braucht. Im Laboratorium würde sich diese „Flüssigkeit" vielleicht kaum von einem „festen“ Körper unterșcheiden. Doch sei daran erinnert, daß auch bei Stahl, den wir doch gewiß als festen Körper betrachten, z. B. kurz vor dem Zerreißen typische Fließerscheinungen eintreten.

Ein Beispiel für eine Störung der Isostasie der Erdrinde bildet ihre Belastung mit einer Inlandeiskappe. Sie hat zur Folge, daß die Erdrinde unter dieser sich langsam senkt und einer neuen, der 
Belastung entsprechenden Gleichgewichtslage zustrebt, um nach dem Abschmelzen des Inlandeises wieder nach und nach die alte Gleichgewichtslage anzunehmen, wobei die während der Depression gebildeten Strandlinien mit emporgetragen werden. So zeigen die aus den Strandlinien abgeleiteten "Isobasenkarten" de Geers [23] für die letzte Vereisung Skandinaviens eine Depression des zentralen Teiles um mindestens $250 \mathrm{~m}$, die nach außen allmählich

Abb. 3.

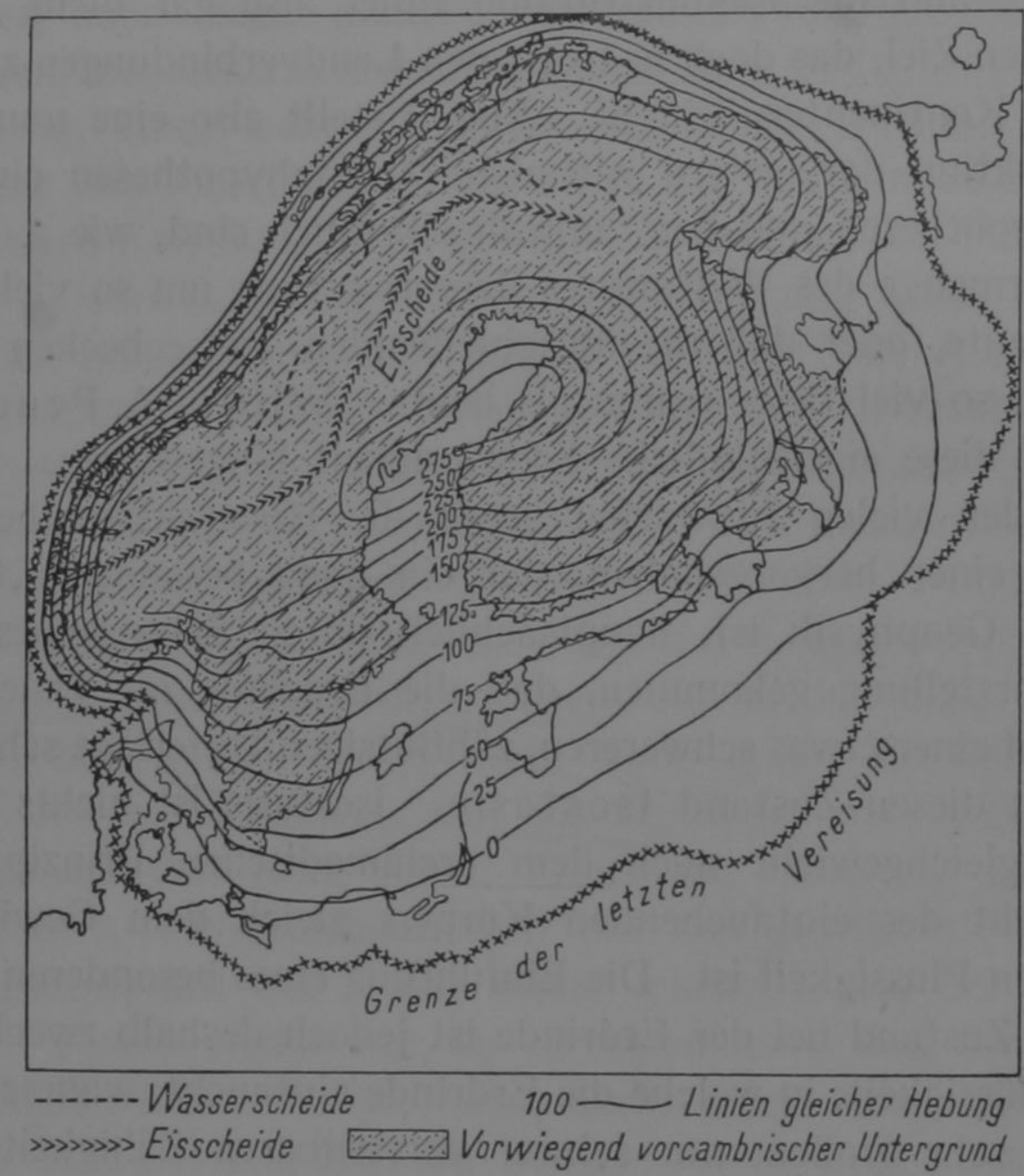

Betrag der postglazialen Hebung Fennoskandiens nach Högbom, in Metern.

geringer wird, und für die größte der quartären Vereisungen sind noch höhere Werte anzunehmen. In Abb. 3 geben wir eine Karte dieser postglazialen Hebung Fennoskandias nach Högbom (aus Born [43]) wieder. Dieselbe Erscheinung hat de Geer auch für das nordamerikanische Vereisungsgebiet nachgewiesen. Rudzki [15] hat gezeigt, daß man unter Annahme der Isostasie hieraus plausible Werte für die Dicke der Inlandeisschicht berechnen kann, nämlich 930 m für Skandinavien und 1670 m für Nordamerika, wo die Senkung 
$500 \mathrm{~m}$ betrug. Infolge der Zähigkeit der Unterlage hinken diese Ausgleichsbewegungen natürlich stark nach: Die Strandlinien haben sich meist erst nach Abschmelzen des Eises, aber vor der Hebung des Landes gebildet, und auch heute steigt Skandinavien, wie die Pegelmessungen zeigen, noch um etwa $1 \mathrm{~m}$ in 100 Jahren.

Auch sedimentäre Ablagerungen haben, wie wohl Osmond Fisher zuerst erkannte, eine Senkung der Scholle zur Folge: Jede Aufschüttung von oben führt zu einer freilich etwas nachhinkenden Senkung der Scholle, so daß die neue Oberfläche wieder fast in der alten Höhe liegt. Auf diese Weise können viele Kilometer mächtige Ablagerungen entstehen, die alle gleichwohl in flachem Wasser gebildet sind.

Wir werden später noch näher auf die Isostasielehre eingehen. Hier sei nur so viel gesagt, daß sie durch geophysikalische Beobachtungen in solchem Umfang bestätigt worden ist, daß sie heute zum festen Bestand der Geophysik gehört und an ihrer grundsätzlichen Richtigkeit nicht mehr gezweifelt werden kann¹).

Man sieht ohne weiteres, daß dies Ergebnis dem Vorstellungskreis der Kontraktionstheorie ganz zuwiderläuft und sich sehr schwer mit ihr vereinigen läßt. Insbesondere erscheint es hiernach unmöglich, daß sich eine Kontinentalscholle von der Größe der geforderten Zwischenkontinente unbelastet bis zum Boden der Tiefsee senkt oder das umgekehrte eintritt. Die Isostasielehre ist also nicht nur mit der Kontraktionslehre im Widerspruch, sondern insbesondere

1) Von amerikanischer Seite, z. B. von Taylor [101] wird bisweilen unter der Bezeichnung Isostasielehre Bowies Hypothese über die Entstehung der Geosynklinalen und der Gebirge verstanden. Nach Bowies Annahme [224] tritt die erste Hebung der mit Sedimenten angefüllten Mulde, der Geosynklinale, durch ein Ansteigen der Isothermen in ihr und die damit verbundene Volumenvergrößerung ein. Sobald diese zu einer Erhebung des Landes geführt hat, setzt die Erosion ein, es entsteht ein zerschnittenes Gebirge, dessen Unterlage infolge der Entlastung immer weiter steigt. Schließlich sind durch dieses Steigen die Isothermen in übernormale Höhen hinauf verschleppt, sie beginnen abwärts zu wandern, der Block kühlt sich also ab, es findet Kontraktion und Senkung der Oberfläche statt, und aus dem Gebirge wird wieder ein Senkungsgebiet, in dem nun neue Sedimentation einsetzt. Durch diese wird die Senkung weiter fortgesetzt, bis die Isothermen eine abnorm tiefe Lage haben, wieder ansteigen usf. in mehrfachem Wechsel. Diese Vorstellung, deren Unanwendbarkeit bei den großen Faltengebirgen mit ihren Überschiebungen von Taylor $u$. a. hervorgehoben ist, bedient sich zwar des isostatischen Prinzips, sollte aber nicht als Isostasielehre schlechthin bezeichnet werden. 
auch mit der aus der Verbreitung der Organismen abgeleiteten Lehre von den versunkenen Landbrücken ${ }^{1}$ ).

Wir haben mit Absicht im vorangehenden die Einwände gegen die Kontraktionstheorie etwas ausführlicher besprochen. Denn in einem Teile der hier vorgebrachten Gedankengänge wurzelt eine andere, heute namentlich unter den amerikanischen Geologen verbreitete Theorie, welche man als Permanenztheorie bezeichnet. Willis [27] faßte sie in die Formel: „Die großen Tiefseebecken bilden permanente Erscheinungen der Erdoberfläche und haben mit geringen Änderungen ihrer Umrisse schon seit der ersten Sammlung des Wassers an derselben Stelle gelegen, an der sie jetzt liegen." In der Tat waren wir schon oben durch die Flachseenatur der marinen Sedimente auf den heutigen Kontinenten zu dem Schluß gekommen, daß die Kontinentalschollen als solche in der Erdgeschichte permanent gewesen sind. Die aus der Isostasielehre folgende Unmöglichkeit, die heutigen Tiefseeböden als versunkene Zwischenkontinente aufzufassen, ergänzt dies Resultat zu einer. allgemeinen Permanenz der Tiefseebecken und der Kontinentalschollen. Und da man auch hier von der selbstverständlich erscheinenden Annahme ausging, daß die Lage der Kontinentalschollen relativ zueinander keine Änderung erfahren habe, so erscheint die Formulierung, die Willis der Permanenzlehre gab, als logischer Schluß aus unseren geophysikalischen Erfahrungen, freilich unter Nichtachtung der aus der Verbreitung der Organismen abgeleiteten Forderung nach ehemaligen Landverbindungen. Und so haben wir das seltsame Schauspiel, daß über das vorzeitliche Antlitz unserer Erde zwei ganz gegensätzliche Lehren gleichzeitig bestehen, nämlich in Europa

$\left.{ }^{1}\right)$ Die hier aufgezählten Einwände gegen die Kontraktionstheorie richten sich in erster Linie gegen deren typische ältere Form. In neuester Zeit sind von verschiedenen Seiten, wie Kober [24], Stille [25], Nölcke [26], Jeffreys [102] u. a. Versuche gemacht worden, die Kontraktionstheorie zu modernisieren und teils durch Einschränkungen, teils durch Zusatzhypothesen den gegen sie erhobenen Einwänden auszuweichen. Ähnliches gilt für die von R. T. Chamberlin propagierte Kontraktion, die durch ,rearrangement" des Materials im Erdinnern verursacht sein soll als Folge der von diesem Autor angenommenen planetesimalen Entstehung [160]. Wenn auch diesen Versuchen ein gewisses Geschick bei der Verfolgung ihres Zieles nicht abgesprochen werden kann, so kann andererseits doch nicht die Rede davon sein, daß die Einwände wirklich widerlegt und die Theorie in befriedigende Übereinstimmung mit den Erfahrungen, namentlich auf geophysikalischem Gebiet, gebracht worden wäre. Eine eingehende Besprechung dieser Neokontraktionstheorie würde indessen den Rahmen unserer Darstellung
überschreiten. 
fast überall die Lehre von ehemaligen Landbrücken, in Amerika fast überall die Lehre von der Permanenz der Ozeanbecken und Kontinentalschollen.

Es ist wohl kein Zufall, daß die Permanenzlehre gerade in Amerika ihre zahlreichsten Vertreter zählt; die Geologie hat sich dort erst spät und darum gleichzeitig mit der Geophysik entwickelt, und dies mußte zur Folge haben, daß sie die Ergebnisse dieser Schwesterwissenschaft schneller und vollständiger aufnahm als in Europa. Sie kam gar nicht in Versuchung, die der Geophysik widersprechende Kontraktionslehre zu ihrer Grundannahme zu machen. Anders in Europa, wo die Geologie bereits eine lange Entwicklung hinter sich hatte, bevor die Geophysik zu ihren ersten Ergebnissen kam, ja wo sie ohne diese bereits zu einem großartigen Entwicklungsbild in Gestalt der Kontraktionstheorie gelangt war. Es ist durchaus verständlich, daß es vielen europäischen Forschern schwer fällt, sich von dieser Tradition völlig frei zu machen, und daß sie den Ergebnissen der Geophysik mit einem nie ganz versiegenden Mißtrauen gegenüberstehen.

Aber was ist nun die Wahrheit? Die Erde kann zu einer Zeit nur ein Antlitz gehabt haben. Gab es damals Landbrücken oder lagen die Kontinente wie heute durch breite Tiefseebecken getrennt? Es ist unmöglich, die Forderung nach den alten Landverbindungen abzulehnen, wenn wir nicht gänzlich darauf verzichten wollen, die Entwicklung des Lebens auf der Erde zu verstehen. . Aber es ist ebenso unmöglich, sich den Gründen zu entziehen, mit denen die Vertreter der Permanenzlehre die versunkenen Zwischenkontinente ablehnen. Da bleibt offenbar nur eine Möglichkeit: es muß ein versteckter Fehler in den als selbstverständlich gemachten Voraussetzungen liegen.

Hier setzt die Verschiebungstheorie ein. Die sowohl bei den versunkenen Landbrücken wie bei der Permanenz zugrunde gelegte selbstverständliche Annahme, daß die relative Lage der Kontinentalschollen (von ihrer wechselnden Flachseebedeckung wird abgesehen) zueinander sich nie geändert habe, muß falsch sein. Die Kontinentalschollen müssen sich verschoben haben. Südamerika muß neben Afrika gelegen und mit diesem eine einheitliche Kontinentalscholle gebildet haben, die sich in der Kreidezeit in zwei Teile spaltete, die dann wie die Stücke einer geborstenen Eisscholle im Wasser im Laufe der Jahrmillionen immer weiter voneinander wichen. Die Ränder dieser beiden Schollen sind noch heute auffallend kon- 
Abb. 4.
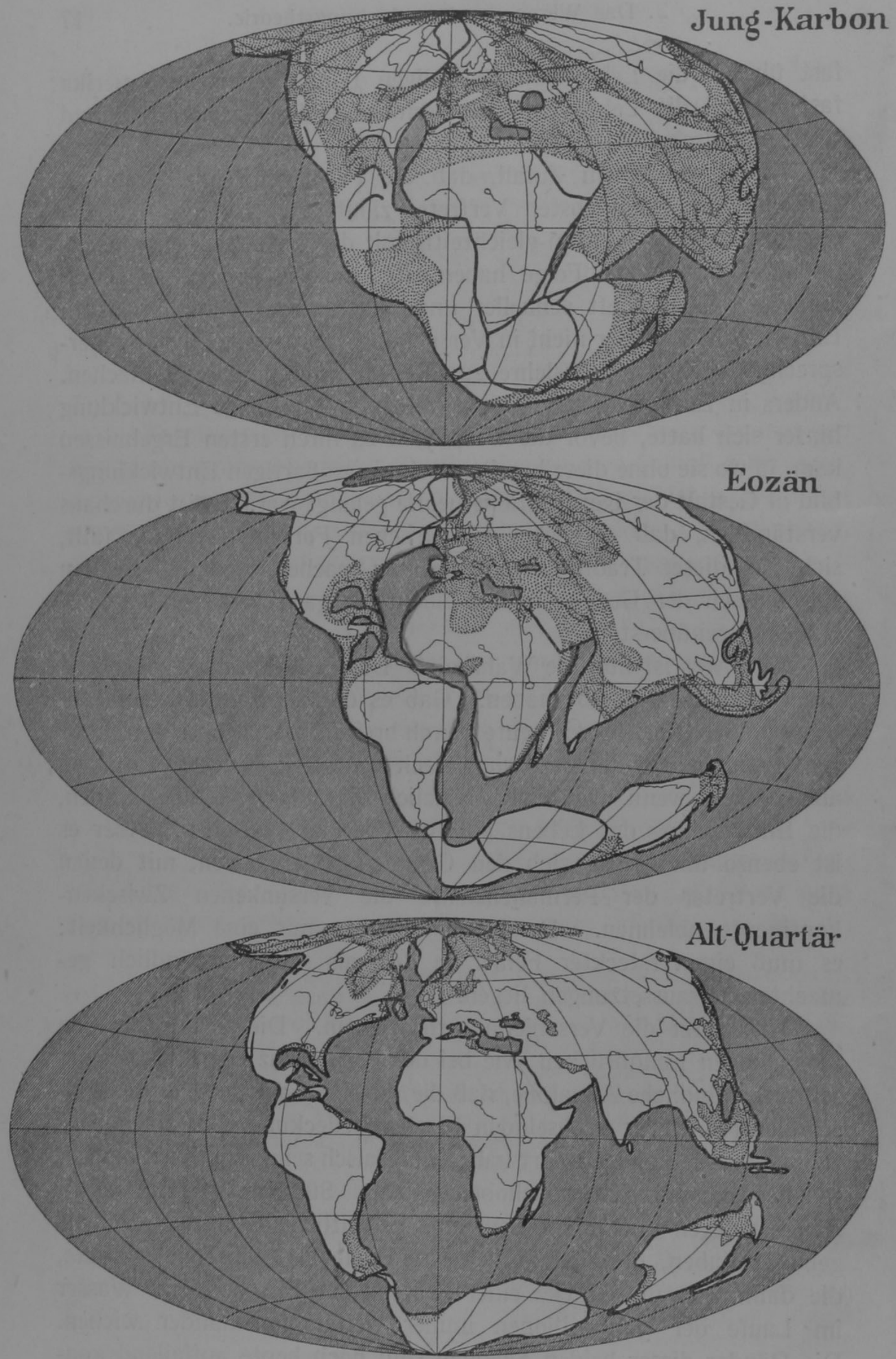

Rekonstruktionen der Erdkarte nach der Verschiebungstheorie für drei Zeiten.

Schraffiert: Tiefsee ; punktiert: Flachsee; heutige Konturen und Flüsse nur zum Erkennen. Gradnetz willkürlich (das heutige von Afrika). 
Abb. 5.
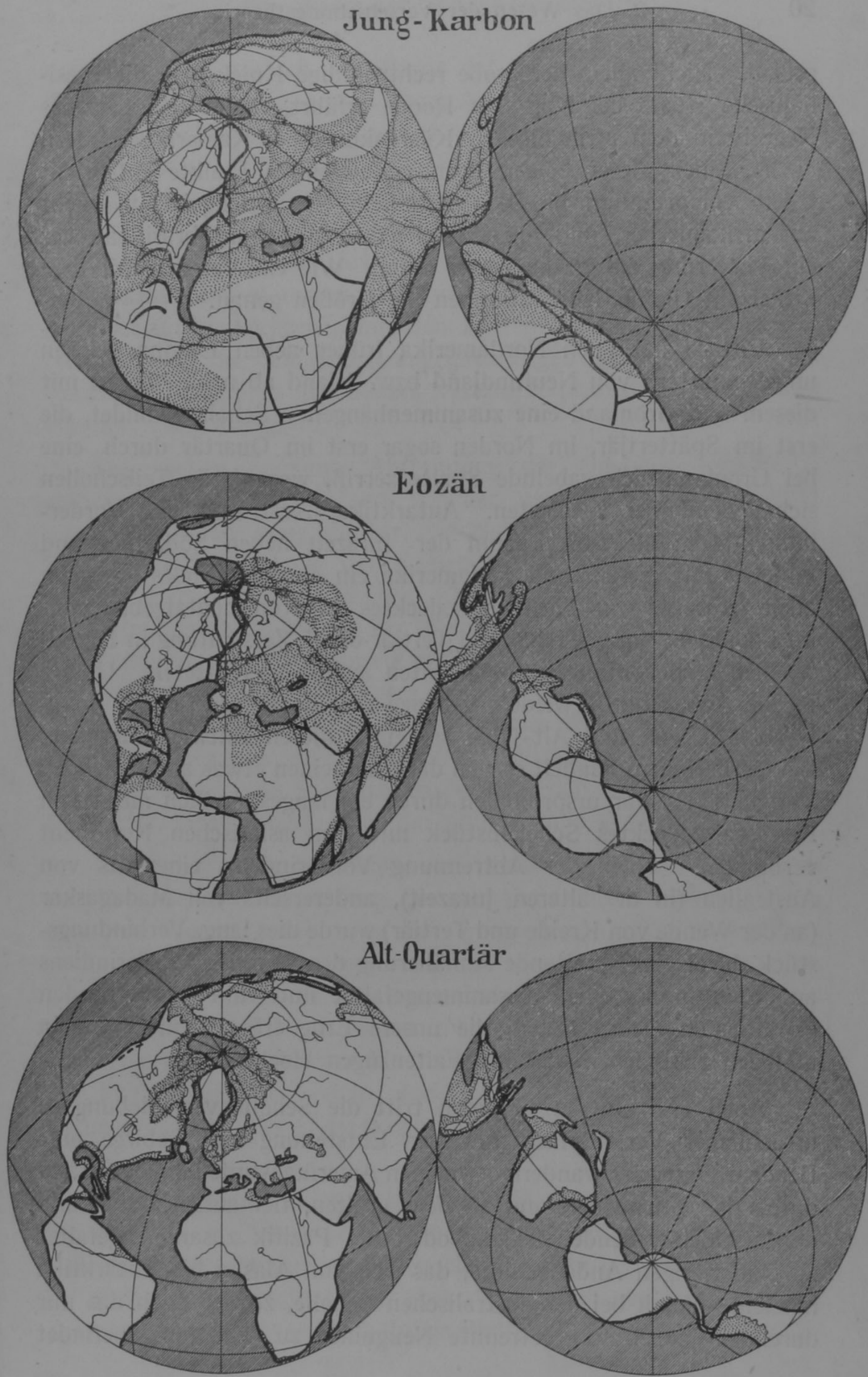

Dieselben Rekonstruktionen wie in Abb. 1, in anderer Projektion. 
gruent. Nicht allein der große rechtwinklige Knick, den die brasilianische Küste bei Kap San Roque erfährt, findet sein getreues Negativ in dem afrikanischen Küstenknick bei Kamerun, sondern auch südlich dieser beiden korrespondierenden Punkte entspricht jedem Vorsprung auf brasilianischer Seite eine gleichgeformte Bucht auf afrikanischer, und umgekehrt jeder Bucht auf brasilianischer ein Vorsprung auf afrikanischer Seite. Wie ein Versuch mit dem Zirkel am Globus lehrt, stimmen die Größen genau.

Ebenso hat auch Nordamerika früher neben Europa gelegen und wenigstens von Neufundland bzw. Irland ab nach Norden mit diesem und Grönland eine zusammenhängende Scholle gebildet, die erst im Spättertiär, im Norden sogar erst im Quartär durch eine bei Grönland sich gabelnde Spalte zerriß, worauf die Teilschollen sich voneinander entfernten. Antarktika, Australien und Vorderindien lagen bis zum Beginn der Jurazeit neben Südafrika und bildeten mit diesem und Südamerika ein einziges großes - wenn auch teilweise von Flachsee bedecktes - Kontinentalgebiet, das im Laufe von Jura, Kreide und Tertiär durch Zerspaltung in Einzelschollen zerfiel, die nach allen Seiten auseinandertrifteten. Unsere in den Abb. 4 und 5 wiedergegebenen drei Erdkarten für das JungKarbon, Eozän und Alt-Quartär zeigen diesen Entwicklungsgang. Bei Vorderindien handelt es sich dabei um einen etwas abweichenden Vorgang: Es war ursprünglich durch ein langes, freilich meist von Flachsee bedecktes Schollenstück mit dem asiatischen Kontinent verbunden. Nach der Abtrennung Vorderindiens einerseits von Australien (in der älteren Jurazeit), andererseits von Madagaskar (an der Wende von Kreide und Tertiär) wurde dies lange Verbindungsstück durch fortschreitende Annäherung des heutigen Vorderindiens an Asien immer mehr zusammengefaltet und ruht heute in den gewaltigsten Gebirgsfalten, die unsere Erde trägt, dem Himalaja und den zahlreichen weiteren Faltenzügen Hochasiens.

Auch auf anderen Gebieten tritt die Schollenverschiebung in ursächlicher Verknüpfung mit der Entstehung der Gebirge auf: Bei dem Westwärtswandern der beiden Amerika wurde ihr Vorderrand durch den Stirnwiderstand an dem uralten, tief ausgekühlten und daher widerstrebenden Tiefseeboden des Pazifik zusammengefaltet zu dem riesigen Andengebirge, das sich von Alaska bis Antarktika hinzieht. Auch bei der australischen Scholle, zu der auch das nur durch ein Schelfmeer getrennte Neuguinea zu zählen ist, befindet 
sich auf der Vorderseite im Sinne der Bewegung das hohe junge Gebirge von Neuguinea; vor ihrem Abriß von Antarktika war ihre Bewegungsrichtung, wie unsere Karten zeigen, eine andere: die heutige Ostküste war damals die Vorderseite. Damals wurden die Gebirge Neuseelands aufgefaltet, das dieser Küste unmittelbar vorgelagert war und sich in der Folgezeit bei veränderter Verschiebungsrichtung als Girlande ablöste und zurückblieb. Aus noch älteref Zeit stammen die heutigen Kordilleren Ostaustraliens; sie entstanden gleichzeitig mit den älteren Faltungen in Süd- und Nordamerika, die den Anden zugrunde liegen (Präkordilleren), am Vorderrand der sich als Ganzes verschiebenden Kontinentalmasse vor der Aufspaltung.

Die soeben erwähnte Abtrennung der einstigen Randkette, späteren Girlande Neuseeland von der australischen Scholle leitet uns zu der Erscheinung hinüber, daß kleinere Schollenteile besonders bei der Westwanderung der großen Schollen zurückbleiben. So trennen sich am ostasiatischen Kontinentalrand die Randketten als Girlanden ab, so bleiben die Kleinen und Großen Antillen hinter der Bewegung der mittelamerikanischen Scholle zurück und ebenso der sogenannte Südantillenbogen zwischen Feuerland und der Westantarktis, ja sogar alle sich in meridionaler Richtung zuspitzenden Schollen zeigen eine Verbiegung dieser Spitzen durch Zurückbleiben nach Osten, wie die Südspitze Grönlands, der Schelf von Florida, Feuerland, Grahamland oder das abbrechende Ceylon.

Man wird leicht bemerken, daß dieser ganze Vorstellungskreis der Verschiebungstheorie von der Annahme ausgeht, daß Tiefseeboden und Kontinentalscholle aus verschiedenem Material bestehen, gewissermaßen verschiedene Schichten des Erdkörpers darstellen. Die äußerste, durch die Kontinentalschollen repräsentierte Schicht bedeckt nicht (vielleicht nicht mehr) die ganze Erdoberfläche; die Tiefseeböden aber stellen die freie Oberfläche der nächsten Schicht des Erdkörpers dar, welche auch unter den Kontinentalschollen anżunehmen ist. Dies ist die geophysikalische Seite der Verschiebungstheorie.

Legen wir diese Verschiebungstheorie zugrunde, so befriedigen wir alle berechtigten Forderungen sowohl der Lehre von den ehemaligen Landverbindungen, wie auch der Lehre von der Permanenz. Es heißt jetzt: Landbrücken, aber nicht durch später versinkende Zwischenkontinente, sondern durch Berührung der heute getrennten 
Schollen. Permanenz nicht der einzelnen Ozeane oder Kontinente als solche, sondern des Tiefseeareals und des kontinentalen Areals im ganzen.

Die ausführliche Begründung dieser neuen Vorstellungen wird den Hauptinhalt dieses Buches bilden.

\section{Drittes Kapitel. \\ Geodätische Argumente.}

Wir beginnen die Beweisführung mit dem Nachweis heutiger Kontinentverschiebungen durch wiederholte astronomische Ortsbestimmung, und zwar aus dem Grunde, weil vor kurzem auf diesem Wege der erste wirkliche Nachweis für die von der Verschiebungstheorie vorausgesagte heutige Verschiebung Grönlands erbracht worden ist, und weil diese auch zahlenmäßig gute Bestätigung der Verschiebungstheorie von der Mehrzahl der Forscher vermutlich als ihr exaktester und einwandfreiester Beweis gewertet werden wird.

Es ist ein großer Vorzug, den die Verschiebungstheorie vor allen anderen Theorien mit ähnlich weitreichenden Aufgaben voraus hat, daß sie sich durch exakte astronomische Ortsbestimmungen prüfen läßt. Wenn die Kontinentverschiebungen so lange Zeiträume hindurch tätig waren, so ist es auch wahrscheinlich, daß sie auch heute noch fortdauern, und es ist nur die Frage, ob die Bewegungen schnell genug sind, um sich unseren astronomischen Messungen innerhalb nicht allzu langer Zeiträume zu verraten.

Um hierüber ein Urteil zu gewinnen, müssen wir auf die absolute Zeitdauer der geologischen Abschnitte etwas eingehen. Die Bewertung derselben ist bekanntlich unsicher, aber doch nicht in dem Maße, daß es eine Beantwortung unserer Frage unmöglich macht.

Der seit der letzten Eiszeit verflossene Zeitraum wird von A. Penck auf Grund seiner alpinen Glazialstudien auf 50000 Jahre, von Steinmann auf mindestens 20000, höchstens 50000 Jahre, von Heim nach Berechnungen aus der Schweiz und ebenso von den Glazialgeologen der Vereinigten Staaten nur auf etwa 10000 Jahre geschätzt. Milankovitch kommt durch astronomische Untersuchungen auf einen klimatischen Höhepunkt der letzten Eiszeit etwa vor 25000 Jahren (die Hauptphase derselben Eiszeit allerdings 
schon vor 75000 Jahren) und ein unmittelbar folgendes Klimaoptimum (das in Nordeuropa geologisch bestätigt ist) vor 10000 Jahren. De Geer schließt aus seinen Auszählungen von Lehmhorizonten, daß. der zurückgehende Eisrand vor 14000 Jahren Schonen (Südschweden) passiert hat, vor 16000 Jahren aber noch in Mecklenburg lag. Die Gesamtlänge des Quartärs ergibt sich nach Milankovitchs Rechnungen zu etwa 0,6 bis 1 Million Jahre. Für unsere Zwecke reicht die Übereinstimmung dieser Zahlen bereits völlig aus.

Für die älteren Zeiten hat man aus der Mächtigkeit der Sedimente ein Urteil über die Zeitdauer ihrer Ablagerungen zu gewinnen versucht und ist dabei nach Dacqué [171] und Rudzki [170] z. B. für die Länge der Tertiärperiode auf eine Größenordnung von 1 bis 10 Millionen Jahre gekommen. Für das Mesozoikum findet man etwa die dreifache, für das Paläozoikum etwa die zwölffache Länge.

Sehr viel größere Zeiten, zumal für die älteren Perioden, liefern die Altersbestimmungen auf Grund der radioaktiven Vorgänge, die heute das größte Ansehen genießen [207]. Sie beruhen auf dem allmählichen Zerfall der Uran- und Thoratome, wobei $\alpha$-Strahlen (das sind Heliumatome) ausgesendet werden und die Substanz sich schließlich nach Durchlaufung mehrerer Zwischenstadien in Blei verwandelt.

Man unterscheidet drei Methoden der Altersbestimmung auf dieser Grundlage. Die erste ist die Heliummethode, bei welcher die relative Menge des entwickelten und im Mineral sich allmählich anreichernden Heliums gemessen wird. Diese Methode liefert kleinere Zahlen als die folgenden, wie man meint, weil das Helium teilweise allmählich entweicht, so daß diese Methode für weniger gut gehalten wird. Zweitens kann man die relative Menge des Endproduktes Blei feststellen und daraus auf die Zeit schließen. Und die dritte Methode ist die der ,pleochroitischen Höfe“, die dadurch entstehen, daß die ausgeschleuderten Heliumatome einen farbigen Hof von sehr geringer Ausdehnung um die radioaktive Substanz herum im Gestein erzeugen, der im Laufe der Zeit größer wird, und aus dessen Größe man daher die Zeitdauer ermitteln kann.

Auf diesem Wege hat man nach Born (in Gutenberg [45]) für ein miozänes Gestein ein Alter von 6 Millionen Jahren, für ein miozän-eozänes Gestein ein solches von 25 Millionen Jahren und für ein spätkarbonisches ein Alter von 137 Millionen Jahren gefunden. Diese drei Werte beruhen auf der Heliummethode. Nach der Bleimethode ergibt sich wesentlich mehr, nämlich für Spätkarbon bereits 
320 Millionen Jahre, und für das Algonkium, wo die Heliummethode nur 350 Millionen Jahre liefert, sogar 1200 Millionen Jahre. Diese Werte sind ganz erheblich größer als die Schätzungen nach der Mächtigkeit der Sedimente ${ }^{1}$ ).

Da wir es aber hier hauptsächlich nur mit den Zeiten seit dem Tertiär zu tun haben, wo die verschiedenen Methoden noch leidlich gleichartige Ergebnisse liefern, so genügen diese Angaben für unsere Zwecke. Wir dürfen daher etwa die folgenden Zahlen zugrunde legen:

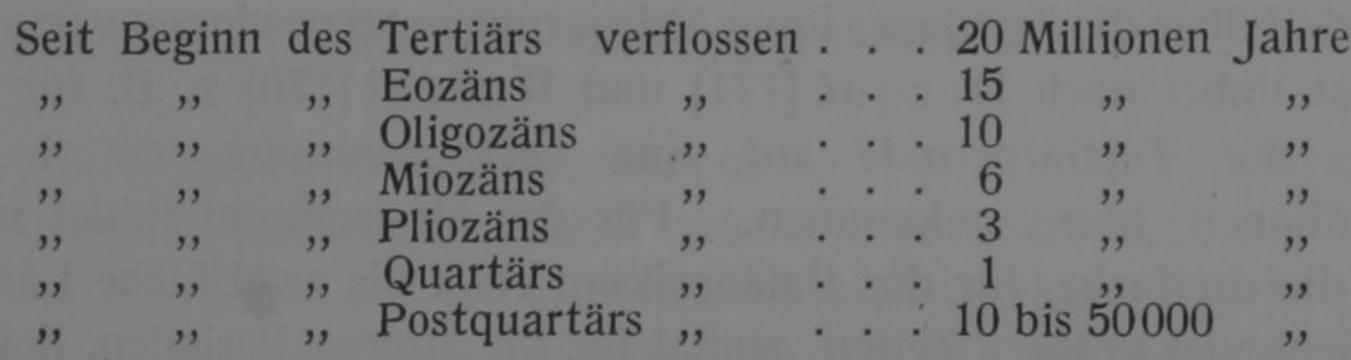

Mit Hilfe dieser Zahlen und der von den Kontinenten zurückgelegten Wege können wir uns ein ungefähres Bild von dem Betrag der jährlichen Verschiebung machen, wenn wir annehmen, daß diese Verschiebung mit gleichförmiger Geschwindigkeit vor sich ging und noch weiter geht. Diese beiden Annahmen sind allerdings ziemlich unkontrollierbar; nimmt man dazu die Unsicherheit der Altersbestimmung, die leicht um 50, vielleicht $100 \%$ falsch sein kann, und weiter die Unsicherheit der Zeitsetzung des Abrisses, so ist ohne weiteres klar, daß die folgenden Zahlen nur als eine ungefähre Orientierung dienen können, und daß man sich nicht wundern darf, wenn sich bei der Nachmessung etwa wesentlich andere Ziffern ergeben. Trotzdem ist diese Überschlagsrechnung sehr nützlich, da sie das Augenmerk auf solche Stellen lenkt, wo Aussicht besteht, die Verschiebung in kürzerer Zeit messen zu können.

Die Tabelle auf S. 25 gibt die zu erwartende jährliche Abstandsvergrößerung für eine Reihe besonders interessanter Stellen.

Die größte Änderung ist also bei dem Abstand Grönlands von Europa zu erwarten, dann auch bei demjenigen Islands von Europa

1) Wenngleich nicht daran zu zweifeln ist, daß die geologischen Perioden im allgemeinen um so längere Zeiträume umfassen, je älter sie sind, so kommt mir Dacqués Standpunkt [171] doch nicht ganz unberechtigt vor, wenn er meint, daß eine so gewaltige Streckung der älteren Perioden mit der Mächtigkeit der Ablagerungen im Widerspruch steht, und er deswegen der radioaktiven Altersbestimmung Mißtrauen entgegenbringt. Für die hier allein betrachteten jüngeren geologischen Zeiten spielt diese Frage indessen keine Rolle. 
Kap Farvel-Schottland

1780

Island-Norwegen .

920

Neufundland-Irland

2410

Buenos Aires-Kapstadt

6220

Madagaskar-Afrika .

890

Vorderindien-Südafrika

5550

Tasmania-Wilkesland .

2890

\section{Trennung vor Millionen Jahren \\ etwa}

Jährliche

Bewegung

m

und Madagaskars von Afrika. Bei Grönland und Island ist die Bewegung eine ostwestliche, die astronomischen Ortsbestimmungen können also nur eine Vergrößerung der Längendifferenz, nicht der Breitenunterschiede, ergeben.

Man ist nun in der Tat bereits seit einiger Zeit auf diese Vergrößerung der Längendifferenz Grönland-Europa aufmerksam geworden. Der historische Hergang dieser Entdeckung ist nicht ganz ohne Interesse. Als ich die Verschiebungstheorie in ihrer ersten, skizzenhaften Form ausgearbeitet hatte, waren die Längenbestimmungen der Danmarkexpedition nach Nordostgrönland (1906 bis 1908 unter Leitung von Mylius-Erichsen), an denen ich selbst als Assistent teilgenommen hatte, noch nicht ausgerechnet. Es war mir aber bekannt, daß aus dem Arbeitsgebiet unserer Expedition schon ältere Längenbestimmungen vorhanden waren, und daß durch ein Dreiecksnetz die Verbindung dieser älteren, auf der Sabineinsel gelegenen Längenstationen mit der unserigen, am Danmarkshavn gelegenen, erreicht war. Ich schrieb deshalb an den Kartographen der Expedition, J. P. Koch, teilte ihm meine Hypothese der Kontinentverschiebungen kurz mit und fragte, ab unsere Längenbestimmungen in der erwarteten Weise von den älteren abwichen. Koch machte darauf einen provisorischen Abschluß der Rechnungen und teilte mir mit, daß tatsächlich ein Unterschied von der erwarteten Größenordnung vorhanden sei, daß er aber nicht glauben könne, daß derselbe auf einer Verschiebung Grönlands beruhe. Bei der definitiven Berechnung hat Koch dann die Fehlerquellen mit besonderer Rücksicht auf diese Frage untersucht und kam nun zu dem Schluß, daß die Verschiebungstheorie tatsächlich die plausibelste Erklärung sei [172]: „Aus dem Vorangehenden geht 
hervor, daß die Fehlerquellen weder einzeln noch vereinigt genügen, um den Unterschied von $1190 \mathrm{~m}$ zu erklären, der zwischen der Lage von Haystack nach den Bestimmungen der Danmarkexpedition und der Germaniaexpedition_(1869 bis 1870) besteht. Die einzige Fehlerquelle, die in dieser Verbindung überhaupt in Betracht kommt, ist die astronomische Längenbestimmung. Aber um die Abweichung durch die fehlerhafte Lage des Observatoriums zu erklären, müßten wir den wirklichen Fehler der astronomischen Längenbestimmung vier- bis fünfmal größer annehmen als dessen mittleren Fehler ..."

Da auch schon Sabine im Jahre 1823 die Länge in Nordostgrönland bestimmt hat, so lagen dort im ganzen sogar drei Bestimmungen vor. Freilich sind diese ältesten Messungen nicht ganz an derselben Stelle ausgeführt; Sabine beobachtete am Südufer der nach ihm benannten Insel, und leider bestehen hier auch noch gewisse, freilich nicht sehr wichtige Unsicherheiten über den genauen Beobachtungsort, der nicht markiert wurde. Börgen und Copeland beobachteten auf der Germaniaexpedition 1870 ebendort, aber einige $100 \mathrm{~m}$ östlicher, Kochs Beobachtungen dagegen sind weit nördlicher, am Danmarkshavn auf Germanialand angestellt, wurden aber durch ein Dreiecksnetz mit der Sabineinsel verbunden. Die aus dieser Übertragung entspringende Ungenauigkeit wurde von Koch genau untersucht mit dem Ergebnis, daß sie gegenüber der viel größeren Ungenauigkeit der Längenbestimmung selber vernachlässigt werden darf. Die Beobachtungen liefern folgende Vergrößerungen des Abstandes zwischen Nordostgrönland und Europa:

im Zeitraum von 1823 bis $1870 \ldots 420 \mathrm{~m}$ oder $9 \mathrm{~m}$ pro Jahr

" " " $1870,1907 . .1190 \mathrm{~m} \quad, 32 \mathrm{~m}$, ,

Und die mittleren Fehler der drei Beobachtungsreihen betragen:

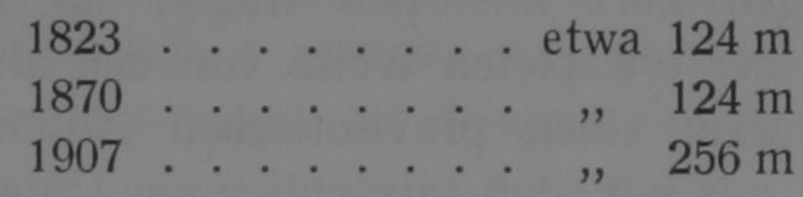

Nun hat allerdings Burmeister [173] mit Recht eingewendet, daß im vorliegenden Falle, wo es sich um Mondbeobachtungen handelt, der mittlere Fehler nicht wie in anderen Fällen die Realität verbürgen kann, vor allem, weil bei Mondbeobachtungen auch systematische Fehler auftreten können, die im mittleren Fehler nicht zum Ausdruck kommen, und die im ungünstigsten Falle ihrer 
Größe nach das Ergebnis erreichen oder vielleicht sogar überschreiten können. Man konnte daher nur so viel aus diesen Beobachtungen schließen, daß sie ausgezeichnet zu den Annahmen der Verschiebungstheorie passen und sich am besten durch sie erklären lassen, daß sie aber noch nicht den Charakter eines exakten Nachweises tragen.

Seitdem hat sich dankenswerterweise die dänische Gradmessung (jetzt Geodätisches Institut in Kopenhagen) der Frage angenommen. P. F. Jensen [174] hat im Sommer 1922 aus diesem Anlaß in Westgrönland neue Längenbestimmungen ausgeführt, und zwar nunmehr mit der viel genaueren Methode der funkentelegraphischen Zeitübermittlung. Berichte über seine Ergebnisse sind in deutscher Sprache von A. Wegener [175] und Stück [176] veröffentlicht worden. Jensen hat dort zwei Arbeiten durchgeführt. Einmal hat er nämlich die frühere Längenmessung bei der Kolonie Godthaab wiederholt, um auch hier einen Vergleich mit älteren Beobachtungen zu erhalten. Die früheren Messungen stammen teils aus dem Jahre 1863 (von Falbe und Bluhme) und teils aus dem internationalen Polarjahr 1882/83 (von Ryder) und sind natürlich auch mit dem Mond erhalten und mit entsprechender Ungenauigkeit behaftet. Jensen schlägt sie daher zu einer mittleren, dem Jahre 1873 entsprechenden Messung zusammen, der er nun seine eigene, viel genauere und vor allem von der Möglichkeit größerer systematischer Fehler freie Messung gegenüberstellt. Das Ergebnis ist auch hier eine Verschiebung Grönlands in der Zwischenzeit um $980 \mathrm{~m}$ oder um $20 \mathrm{~m}$ pro Jahr nach Westen.

Das Ergebnis dieser Messungen habe ich [175] zusammen mit demjenigen der ostgrönländischen Beobachtungen zur Veranschaulichung in Abb. 6 dargestellt, wobei der Radius der einzelnen Kreise nach Maßgabe der Skala auf der Abszissenachse gleich dem mittleren Fehler der Messungsreihe in Metern gewählt ist, wodurch sogleich die viel größere Genauigkeit der Jensenschen Beobachtungen in die Augen springt. Die Beobachtungen unter I beziehen sich auf die Sabineinsel in Nordostgrönland, die unter II auf Godthaab in Westgrönland. Hier sind neben dem oben genannten Mittel der älteren Beobachtungen auch noch die Werte von 1863 und von 1882/83 selbst eingetragen; ihr Unterschied würde allerdings in entgegengesetzter Richtung gehen, allein bei der Kürze der Zwischenzeit darf man hierin wohl nur den Einfluß ihrer Ungenauigkeit sehen. Jede von ihnen gibt aber, mit Jensens viel späteren Beobachtungen verglichen, eine mit der Zeit wachsende geographische 
Länge. Im ganzen lagen also nunmehr bereits folgende vier voneinander unabhängige Vergleiche vor:

$$
\begin{aligned}
& \text { Koch - Börgen und Copeland, } \\
& \text { Koch - Sabine, } \\
& \text { Jensen - Falbe und Bluhme, } \\
& \text { Jensen - Ryder, }
\end{aligned}
$$

welche sämtlich im Sinne der Verschiebungstheorie ausfielen. Wenngleich also alle diese Vergleichungen ganz oder teilweise an dem Umstand kranken, daß sie auf Mondbeobachtungen beruhen, die mit unkontrollierbaren systematischen Fehlern behaftet sein können, so wurde doch durch diese Häufung gleichartiger Ergebnisse, denen

Abb. 6.

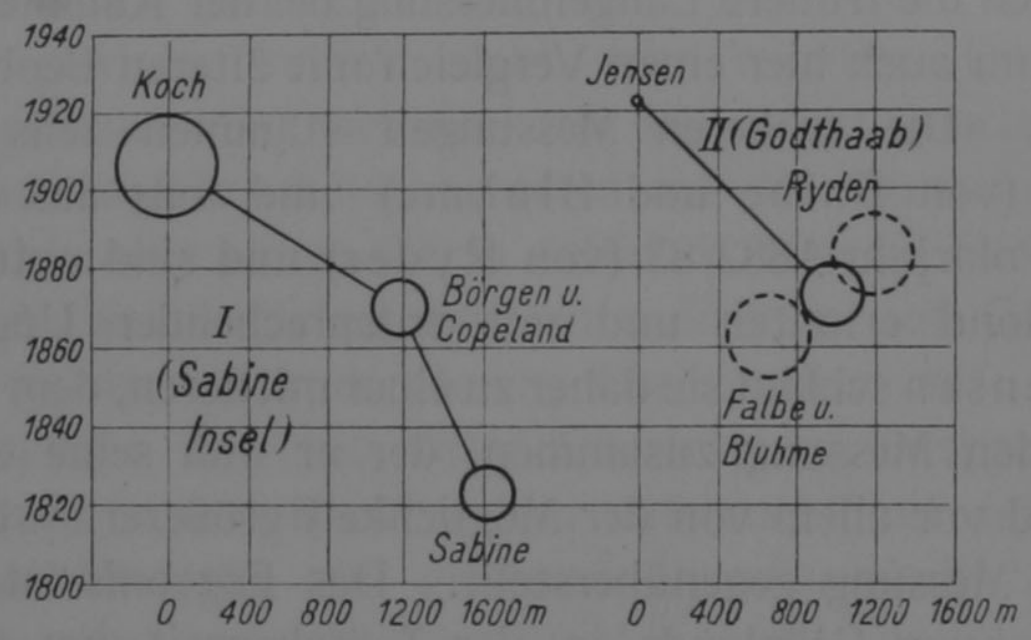

Verschiebung Grönlands nach den älteren Längenbestimmungen.

anders geartete nicht gegenüberstehen, bereits die Annahme, daß es sich überall nur um unglückliche Anhäufung extremer Beobachtungsfehler handele, in hohem Maße unwahrscheinlich.

Die dänische Gradmessung hatte aber glücklicherweise eine Wiederholung dieser Längenbestimmungen in regelmäßigen Zeitabständen in ihr Arbeitsprogramm aufgenommen; und dementsprechend bestand die zweite Arbeit Jensens in der Anlage einer für solche Zwecke geeigneten Station bei Kornok in dem klimatisch begünstigten inneren Teil des Godthaabfjords und der Ausführung der ersten grundlegenden Bestimmung von deren geographischer Länge mit Hilfe der genauen funkentelegraphischen Zeitübertragung. Er fand für die Länge von Kornok im Jahre 1922 den Wert: 
Diese Längenbestimmung in Kornok ist nun im Sommer 1927 durch Premierleutnant Sabel -Jörgensen wiederholt worden [209], und zwar unter Anwendung des modernen unpersönlichen Mikrometers, also unter Ausschaltung des persönlichen Fehlers, wodurch die Genauigkeit noch wesentlich weiter getrieben werden konnte als bei Jensens Messung.

Das mit Spannung erwartete Ergebnis lautet $\left.{ }^{1}\right)$ : Länge von Kornok 1927: $3^{\text {h }} 24^{\mathrm{m}} 23,405^{\mathrm{s}} \pm 0,008^{\mathrm{s}}$.

Der Vergleich mit Jensens Messung ergibt eine Vergrößerung der Längendifferenz gegen Greenwich, das ist des Abstandes Grönlands von Europa um 0,9 Zeitsekunden in fünf Jahren oder um etwa $36 \mathrm{~m}$ pro Jahr.

Da der Betrag neunmal größer als der mittlere Fehler der Beobachtungen ist, und größere systematische Fehlerquellen bei der Methode der funkentelegraphischen Zeitübertragung nicht in Betracht kommen, so ist hiermit der Nachweis der noch im Gange befindlichen Verschiebung Grönlands nunmehr erbracht, es sei denn, daß man die sehr unwahrscheinliche Hypothese aufstellt, Jensens persönlicher Fehler habe $9 / 10$ Zeitsekunden betragen.

Die Messungen in Kornok sollen auch weiterhin von fünf zu fünf Jahren nach der unpersönlichen Methode fortgesetzt werden. Es wird von Interesse sein, den Betrag der jährlichen Verschiebung quantitativ noch genauer zu bestimmen und festzustellen, ob die Verschiebung mit gleichförmiger Geschwindigkeit vor sich geht oder Schwankungen unterliegt.

Durch diesen ersten exakten astronomischen Nachweis einer Kontinentverschiebung, der auch quantitativ die Voraussage der Verschiebungstheorie vollauf bestätigt, wird die ganze Diskussion über diese Theorie meines Erachtens auf eine neue Basis gestellt, indem das Interesse jetzt von der Frage nach ihrer grundsätzlichen Richtigkeit sich auf diejenige nach der Richtigkeit bzw. dem weiteren Ausbau ihrer Einzelaussagen verlagert.

Weniger günstig als in Grönland liegen die Dinge für die Messung der Abstandsänderung Nordamerikas für Europa, wie unsere Tabelle lehrt. Allerdings hat man hier insofern günstigere Bedingungen, als man nicht auf Mondbeobachtungen angewiesen ist, da auch die

1) Dem Direktor des Geodätischen Instituts in Kopenhagen, Herrn Professor Nörlund, sei für seine Erlaubnis, dies noch nicht veröffentlichte Ergebnis hier mitzuteilen, herzlich gedankt. 
älteren Längenbestimmungen in Nordamerika bereits auf telegraphischem Wege mit dem Kabel gewonnen wurden. Zum Entgelt ist aber die zu erwartende Änderung hier sehr klein. Unsere Tabelle gibt dafür etwa $1 \mathrm{~m}$ pro Jahr, aber diese Zahl gilt als Mittel seit dem Abriß Neufundlands von Irland. Seitdem dürfte aber eine Bewegungsänderung Nordamerikas durch den Abriß von Grönland (der noch im Gange ist) eingetreten sein, vermutlich in dem Sinne, daß Nordamerika seitdem relativ zur Unterlage mehr nach Süden gleitet. Dies scheint aus der heutigen relativen Lage der korrespondierenden Küstenpunkte von Labrador und Südwestgrönland hervorzugehen und wird auch bestätigt durch die Sprungrichtung bei der Erdbebenspalte von San Franzisko sowie die beginnende Stauchung der kalifornischen Halbinsel. Es läßt sich deshalb schwer sagen, wie groß der zu erwartende heutige Längenzuwachs ist; jedenfalls dürfte er noch etwas kleiner sein als der berechnete Wert von $1 \mathrm{~m}$ pro Jahr.

Aus den älteren, mit dem Kabel gewonnenen transatlantischen Längenbestimmungen von 1866, 1870 und 1892 hatte ich seinerzeit auf eine tatsächliche Vergrößerung des Abstands um sogar $4 \mathrm{~m}$ im Jahre geschlossen. Nach Galle [177] soll dies Ergebnis aber auf einer ungünstigen Kombination der Messungen beruhen. Diese Kombination ist aus dem Grunde schwierig, weil diese älteren Messungen sich nicht auf die gleichen Orte in Europa und Nordamerika beziehen, so daß noch die Längenunterschiede innerhalb der Kontinente zu berücksichtigen sind, für die man auf verschiedenen Wegen etwas verschiedene Ergebnisse erhält, was das Resultat beeinflußt. Kurz vor dem Weltkrieg war mit Rücksicht auf unsere Frage eine neue Längenbestimmung mit Amerika im Gange, die auch durch eine funkentelegraphische Messung kontrolliert wurde. Obwohl die Messung durch Zerschneiden des Kabels bei Kriegsbeginn vorzeitig abgebrochen wurde und infolgedessen das Resultat nicht die wünschenswerte Genauigkeit besitzt, scheint doch daraus hervorzugehen, daß die Veränderung noch zu klein ist, um sich schon jetzt mit Sicherheit nachweisen zu lassen. Es wurde nämlich für den Längenunterschied Cambridge-Greenwich gefunden [178]:

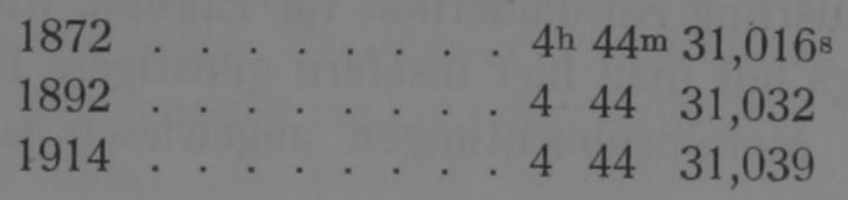

Die älteste Bestimmung, für welche ich $4^{\mathrm{h}} 44^{\mathrm{m}} 30,89^{\mathrm{s}}$ gefunden hatte, ist hier als angeblich zu ungenau fortgelassen worden. 
Seit 1921 werden nun mit Hilfe der funkentelegraphischen Zeitsignale fortlaufende Bestimmungen der Längendifferenz zwischen Europa und Nordamerika ausgeführt, die Wanach [179] bis zum Jahre 1925 diskutiert hat. Da es sich hier nur um 4 Jahre handelt, ist es nicht verwunderlich, daß in diesen Beobachtungen eine Vergrößerung des Abstands noch nicht deutlich erkennbar ist. Doch sprechen auch diese Beobachtungen keineswegs gegen eine solche; im Gegenteil, wenn man sie vereinigt, so ergeben sie eine jährliche Bewegung Amerikas nach Westen im Betrage von 0,6 m, allerdings $\pm 2,4 \mathrm{~m}$. Wanach schließt: „Einstweilen läßt sich also nichts weiter sagen, als daß eine etwaige Verschiebung Amerikas gegen Europa im Betrage von wesentlich mehr als $1 \mathrm{~m}$ jährlich sehr unwahrscheinlich ist." Und ebenso urteilt Brennecke [229]: „Das so gewonnene Material spricht zwar nicht zugunsten einer Verschiebung der Kontinente in den oben genannten Beträgen, es spricht aber auch keineswegs dagegen. Die Entscheidung muß also noch abgewartet werden." $\mathrm{Zu}$ beachten ist, daß bei diesen neuen funkentelegraphischen Bestimmungen die älteren, mit dem Kabel gewonnenen ganz außer acht gelassen sind. Dies ist zwar insofern berechtigt, als die Kabelbeobachtungen merklich ungenauer sind als die funkentelegraphischen. Es könnte aber doch sein, daß dieser Mangel durch die viel größere Zeitspanne, die dann zur Verfügung stände, ausgeglichen wird und es sich daher dennoch lohnen würde, die alten Beobachtungen mit den neuen zu verbinden. Dies muß den Geodäten überlassen bleiben. Ich zweifle aber nicht daran, daß es in nicht allzu ferner Zeit auch glücken wird, die Verschiebung Nordamerikas relativ zu Europa exakt zu messen.

Auch bei Madagaskar ist man neuerdings auf die Änderung der geographischen Koordinaten aufmerksam geworden. Die geographische Länge des Observatoriums in Tananariva ist 1890 mit Hilfe von Mondkulminationen und nach der Zerstörung und dem Wiederaufbau an gleicher Stelle in den Jahren 1922 und 1925 auf funkentelegraphischem Wege bestimmt worden [180]. Nach einer dankenswerten brieflichen Mitteilung von Professor Ch. Maurain in Paris sind die drei Positionen folgende:

Jahr

Beobachter

Methode

Länge ö. v. Gr.

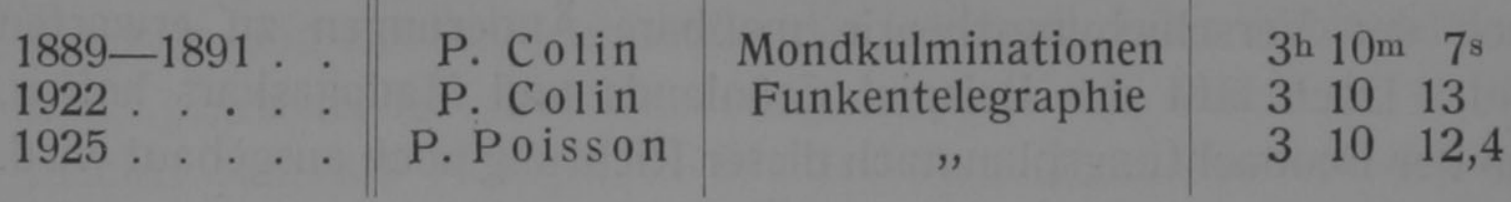


Diese Werte weisen auf eine Verschiebung Madagaskars relativ zum Meridian von Greenwich um den großen Betrag von 60 bis $70 \mathrm{~m}$ pro Jahr hin. In unserer Tabelle S. 25 ist ein wesentlich kleinerer Betrag für die Verschiebung relativ zu Afrika genannt. Es scheint also, als ob auch Südafrika sich relativ zu Greenwich nach Osten bewegt, worüber die Verschiebungstheorie wegen der großen Entfernung dieser Gebiete voneinander keine brauchbaren Aussagen mehr machen kann. Es ist zu hoffen, daß auch die Längen von Südafrika künftig überwacht werden, um auf diese Weise auch die Längendifferenz Madagaskars gegen Südafrika, auf die es in der Verschiebungstheorie am meisten ankommt, kontrollieren zu können. Auch wären wiederholte genaue Breitenbestimmungen an beiden Stellen notwendig, um auch die andere Komponente der relativen Bewegung Madagaskars zu Afrika messend verfolgen zu können. Jedenfalls aber geht die beobachtete Längenänderung Madagaskars im Sinne der Verschiebungstheorie vor sich. Zu beachten ist natürlich auch hier, daß die älteste Messung mit dem Monde ausgeführt ist, woraus sich ähnliche Einwände ergeben wir für die oben besprochenen Messungen in Nordostgrönland. Aber die Gesamtverschiebung, die hier fast $2 \frac{1}{2} \mathrm{~km}$ beträgt, ist doch so groß, daß die Annahme, sie beruhe vollständig auf Beobachtungsfehlern, sehr wenig Wahrscheinlichkeit beanspruchen darf. Auch auf Madagaskar ist aber Vorsorge für weitere Wiederholungen der Messungen getroffen, so daß voraussichtlich in kurzem auch von dort einwandfreie Ergebnisse vorliegen werden.

Auf dem Geodätenkongreß im Jahre 1924 in Madrid und weiter auf der Tagung der internationalen astronomischen Union im Jahre 1925 ist ein umfangreicher Plan zur Verfolgung der Kontinentverschiebungen mittels funkentelegraphischer Längenbestimmungen aufgestellt worden, wonach solche Messungen nicht nur zwischen Europa und Nordamerika stattfinden sollen, sondern auch auf Honolulu, in Ostasien, Australien und Hinterindien. Die erste Vermessungsserie gemäß diesem Programm ist im Herbst 1926 zur Durchführung gelangt; über die von französischer Seite erhaltenen Ergebnisse hat soeben G. Ferrié berichtet [213]. Etwaige Änderungen werden sich natürlich erst bei späteren Wiederholungen zeigen können. Wie es scheint, ist übrigens bei diesem Plane nur wenig Rücksicht auf die Frage genommen, an welchen Stellen der Erde nach der Verschiebungstheorie meßbare Änderungen zu erwarten sind. Doch läßt das Beispiel Grönlands und Madagaskars hoffen, daß der Beobachtungsplan nach dieser Richtung noch ausgebaut wird. 
Man sieht jedenfalls, daß die exakte Nachprüfung der Verschiebungstheorie durch wiederholte astronomische Ortsbestimmungen bereits in großem Ausmaß im Gange ist, und daß die ersten Nachweise für ihre Richtigkeit bereits erbracht sind.

Zum Schlusse sei noch an die seit langem an den europäischen und nordamerikanischen Sternwarten beobachteten Breitenänderungen erinnert.

Wie Günther [181] berichtet, betrachtete A. Hall folgende Breitenabnahmen als gesichert:

Bei Paris in 28 Jahren um $1,3^{\prime \prime}$; bei Mailand in 60 Jahren um $1,51^{\prime \prime}$; bei Rom in 56 Jahren um $0,17^{\prime \prime}$; bei Neapel in 51 Jahren um $1,21^{\prime \prime}$; bei Königsberg i. Pr. in 23 Jahren um $0,15^{\prime \prime}$; bei Greenwich in 18 Jahren um 0,51". Auch für Pulkowa ergab sich nach Kostinsky und Sokolow eine säkulare Breitenabnahme. Dazu kommt in Nordamerika bei Washington eine Abnahme in 18 Jahren um 0,47".

Da man die Entdeckung machte, daß durch die sogenannte „Saalrefraktion“ in der Kuppel systematische Fehler ähnlicher Größe entstehen konnten, war man lange Zeit geneigt, alle solche Abweichungen auf diese Fehlerquelle zu schieben.

Indessen mehren sich neuerdings die Stimmen, nach denen solche Änderungen dennoch als reell zu betrachten sind, insbesondere seitdem Lambert [182] gezeigt hat, daß die Breite von Ukiah in Kalifornien und anderer nordamerikanischer Stationen sich gegenwärtig offensichtlich ändert. In einer neueren Arbeit [221] sagt Lambert: „Die internationalen Stationen (des Breitendienstes) sind nicht die einzigen, an denen überraschende Änderungen der Breite aufgetreten sind. Rom hat anscheinend seine Breite seit 1855 um 1,45" geändert. Ein systematisches Studium solcher Anomalien wäre höchst wünschenswert."

Auffallenderweise geht diese gegenwärtige Änderung aber im umgekehrten Sinne vor sich als die oben angeführten älteren, denn die Breite von Ukiah wächst.

Die Deutung dieser Breitenänderungen ist aus dem Grunde schwierig, weil sie sowohl auf Kontinentverschiebung als auch auf Polwanderung beruhen können, welche letztere nicht mit relativer Lagenänderung der Kontinente zueinander verbunden zu sein braucht. Wie später eingehender gezeigt werden wird, hat man in jüngster Zeit aus den Messungen des internationalen Breitendienstes eine gegenwärtige Polwanderung nachweisen können, vermöge welcher sich der Nordpol in Richtung auf Nordamerika verlagert, 
wodurch für die nordamerikanischen Stationen eine Erhöhung der Breite folgt. Aber der Betrag dieser Polwanderung ist nach den bisherigen Ergebnissen kleiner als die in Nordamerika beobachtete Breitenzunahme. Wenn sich also nicht etwa künftig die Polwanderung doch noch als größer herausstellen sollte, so käme man zu dem Schluß, daß sich Nordamerika relativ zur übrigen Erdoberfläche nordwärts verschiebt, was sehr auffallend wäre, da mancherlei Anzeichen dafür sprechen, daß es sich relativ zur Unterlage nach Süden bewegt. Die vollständige Deutung dieser Dinge wird wohl erst auf Grund längerer Beobachtungsreihen möglich sein. Und ob man zu einer klaren Deutung der älteren Veränderungen überhaupt je kommen wird, erscheint unter diesen Umständen zweifelhaft.

\section{Viertes Kapitel. \\ Geophysikalische Argumente.}

Die Statistik der Höhenstufen der Erdrinde führt zu dem merkwürdigen Ergebnis, daß es zwei Höhen gibt, die am häufigsten vorkommen, während die dazwischen liegenden Stufen recht selten sind. Die höhere Stufe entspricht den Kontinentaltafeln, die tiefere den Tiefseeböden. Denkt man sich die ganze Erdoberfläche in Quadratkilometer eingeteilt und ordnet diese in einer Reihe nach ihrer Seehöhe, so erhält man das bekannte Bild der sogenannten hypsometrischen Kurve der Erdoberfläche (Abb. 7), welches deutlich zwei Treppenstufen zeigt. Zahlenmäßig stellt sich die Häufigkeit der verschiedenen Stufen nach den Berechnungen von H. Wagner [28] folgendermaßen ${ }^{1}$ ):

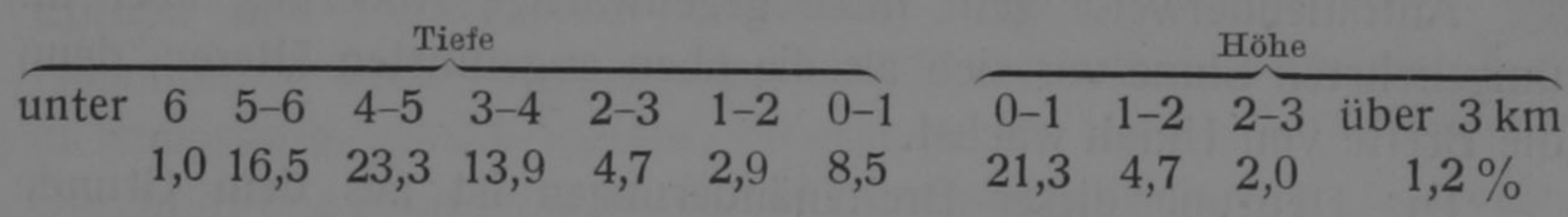

Diese Reihe wird am besten veranschaulicht durch eine andere Darstellung, die von Trabert [31] auf Grund etwas älterer, aber nur unwesentlich abweichender Zahlen entworfen und in Abb. 8

1) Bei diesen Zahlen ist die Ausmessung der Ozeane durch Kossinna [29] zugrunde gelegt. Unsere Figuren sind noch nach den älteren wenig abweichenden Werten bei Krümmel [30] und Trabert [31]
entworfen. 
wiedergegeben ist. Sie bezieht sich auf $100 \mathrm{~m}$-Stufen, infolgedessen sind die Prozentzahlen natürlich nur etwa $1 / 10$ derjenigen der obenstehenden Reihe. Die beiden Maxima liegen hiernach bei einer Tiefe von etwa $4700 \mathrm{~m}$ und einer Erhebung von etwa $100 \mathrm{~m}$.

Bei diesen Zahlen ist noch zu beachten, daß mit der Zunahme der Lotungen der Steilabfall vom Kontinental- oder Schelfrand zur Tiefsee sich immer schroffer zeigt, wie jeder Vergleich älterer Tiefseekarten mit den neueren von Groll [32] entworfenen zeigt. Während z. B. Trabert noch 1911 für die Stufen 1 bis $2 \mathrm{~km} \mathrm{4,0 \%}$ und für 2 bis $3 \mathrm{~km} 6,5 \%$ angibt, finden wir bei Wagner, dessen Zahlen

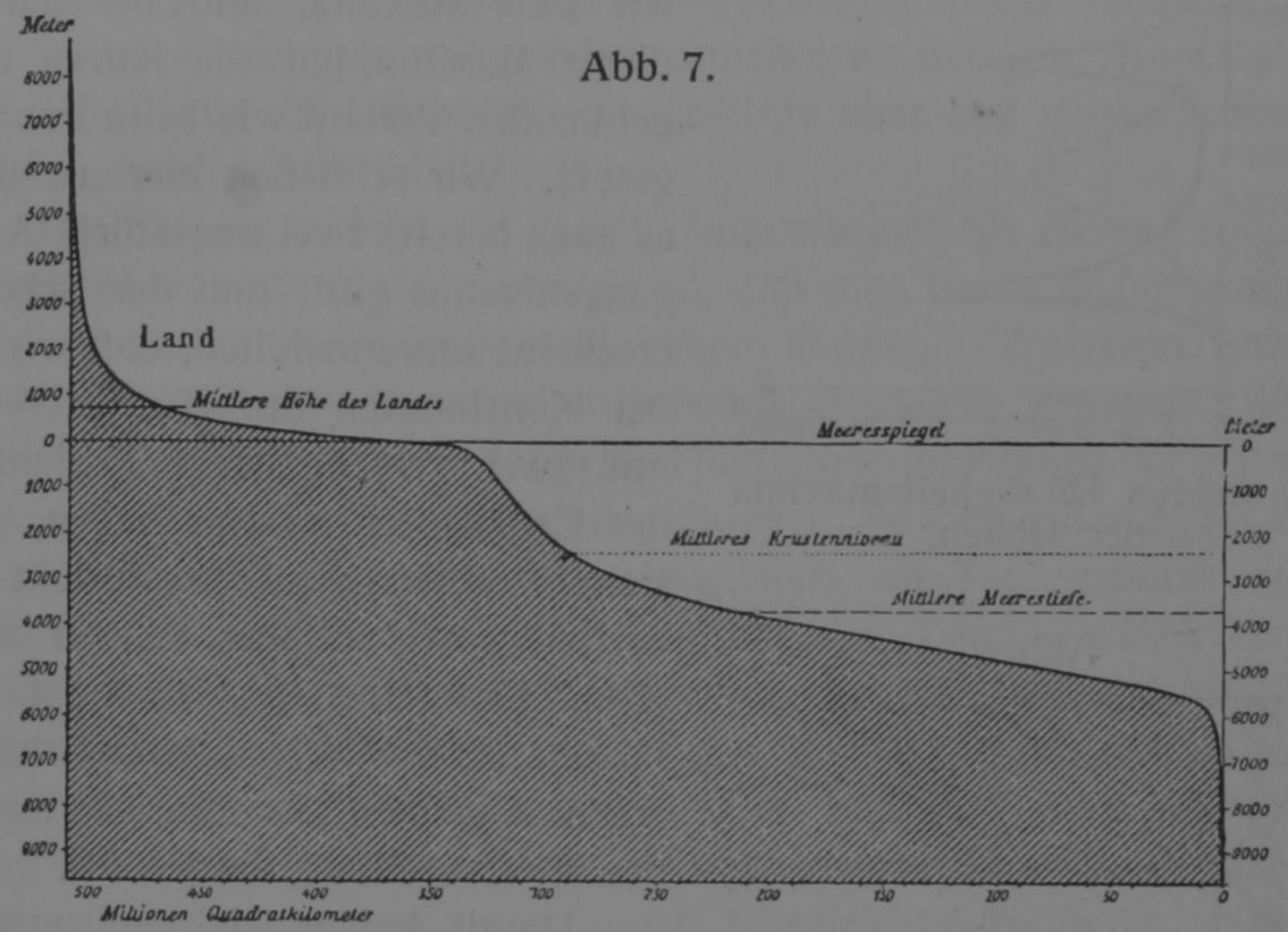

Hypsometrische Kurve der Erdoberfläche, nach Krümmel.

letzten Endes auf den Grollschen Tiefseekarten basieren, für die gleichen Stufen nur 2,9 bzw. 4,7\%. Es ist also wohl zu erwarten, daß in Zukunft die beiden Häufigkeitsmaxima sich noch schärfer getrennt zeigen werden als nach den bisherigen Beobachtungen.

Es gibt wohl in der ganzen Geophysik kaum ein zweites Gesetz von solcher Klarheit und Sicherheit wie dieses, daß es zwei bevorzugte Niveaus auf der Erde gibt, die abwechselnd nebeneinander vorkommen und in den Kontinenten und Tiefseeböden in Erscheinung treten. Es ist deshalb sehr merkwürdig, daß man für dies Gesetz, das doch seit langem gut bekannt ist, noch kaum nach einer Erklärung gesucht hat. Wenn nämlich, gemäß der üblichen geologischen 
Deutung, die Höhen durch Hebungen, die Tiefen durch Senkungen von nur einem einheitlichen Ausgangsniveau entstanden wären, und dabei, was selbstverständlich erscheint, um so seltener sind, je größer ihr Ausmaß ist, so müßte sich die resultierende Häufigkeitsverteilung ungefähr nach dem Gaußschen Fehlergesetz regeln (etwa wie in Abb. 8 durch die gestrichelte Kurve angegeben). Es

Abb. 8.

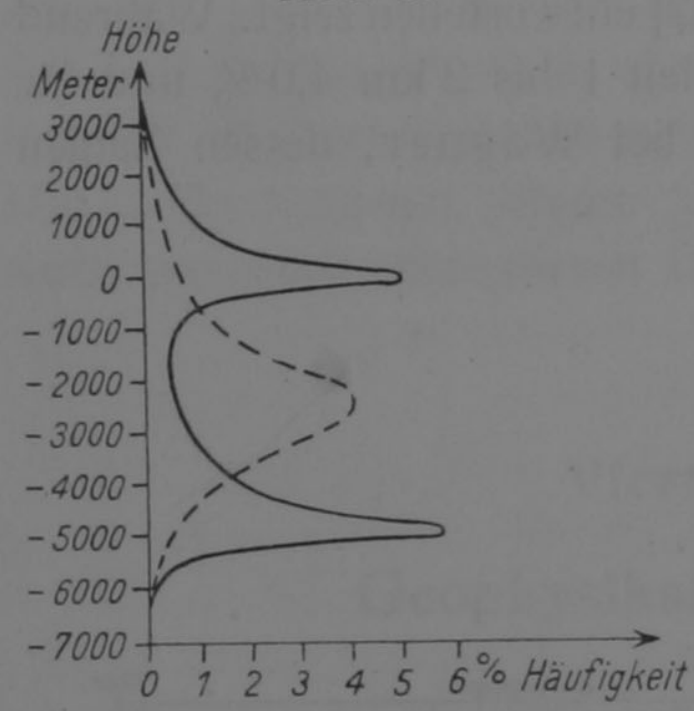

Die beiden Häufigkeitsmaxima der Höhen.

Abb. 9.

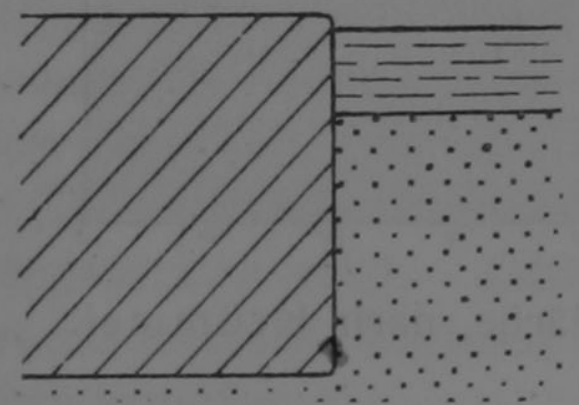

Schematischer Querschnitt durch einen Kontinentalrand. Horizontale Strichelung = Wasser. müßte also nur ein einziges Häufigkeitsniveau etwa in der Gegend des mittleren Krustenniveaus (-2450 m) vorhanden sein. Statt dessen sehen wir zwei Maxima, und bei jedem dieser Maxima hat die Kurve ungefähr den Verlauf wie beim Fehlergesetz. Wir schließen hioraus, daß es auch bereits zwei ungestörte Ausgangsniveaus gibt, und der Schritt erscheint unvermeidlich, daß wir es bei Kontinenten und Tiefseeböden mit zwei verschiedenen Schichten des Erdkörpers zu tun haben, die sich - übertrieben ausgedrückt verhalten wie offenes Wasser und große Eistafeln. In Abb. 9 ist ein schematischer Vertikalschnitt durch einen Kontinentalrand nach dieser neuen Vorstellung dargestellt.

Damit haben wir zum ersten Male eine plausible Lösung für die alte Frage nach dem Verhältnis der großen Tiefseebecken zu den Kontinentalschollen gewonnen. Schon 1878 warf A. Heim [33] einen Seitenblick auf dieses Problem mit der Feststellung, „daß, bevor genauere Beobachtungen über die kontinentalen Schwankungen der Vorzeit gemacht sind, ... und bevor wir vollständigere Messungen über die Beträge des ausgeglichenen Zusammenschubs der meisten Gebirge haben, kaum ein wesentlich sicherer Fortschritt in der Erkenntnis des ursächlichen Zusammenhangs von Gebirgen und Kontinenten und der Form der letzteren untereinander zu erwarten sein wird". 
Das Problem meldete sich aber immer dringender, je zahlreicher die Lotungen auf den Weltmeeren wurden und je schärfer hierdurch der Gegensatz zwischen den weiten, ebenen Tiefseeflächen und den gleichfalls ebenen, aber etwa $5 \mathrm{~km}$ höher liegenden Kontinentalflächen herausgearbeitet wurde. 1918 schrieb E. Kayser [34]: „Gegenüber dem Rauminhalt dieser Steinkolosse (der Kontinentalblöcke) erscheinen alle festländischen Erhebungen unbedeutend und geringfügig. Selbst Hochgebirge wie der Himalaja sind nur verschwindende Runzeln auf der Oberfläche jener Sockel. Schon diese Tatsache läßt die alte Ansicht, nach der die Gebirge das maßgebende Gebälk der Kontinente darstellen sollen, heute unhaltbar erscheinen ... Wir müssen vielmehr umgekehrt annehmen, daß die Kontinente das Ältere und Bestimmende, die Gebirge aber nur nebensächliche jüngere Gebilde darstellen."

Die Lösung, welche die Verschiebungstheorie für dieses Problem liefert, ist so einfach und naheliegend, daß man kaum meinen sollte, daß sie Anlaß zu Widerspruch geben könnte. Trotzdem haben einige Gegner der Verschiebungstheorie Versuche gemacht, eine andere Erklärung für das doppelte Häufigkeitsmaximum der Höhen zu geben. Aber diese Versuche sind mißlungen. So meinte Soe rgel [35], wenn von einem Ausgangsniveau einerseits ein Teil gehoben und andererseits ein Teil gesenkt wird, und das Zwischenstück dann durch Steilerstellung sehr verkleinert wird, so müßten zwei Häufigkeitsmaxima entstehen, den gehobenen und den gesenkten Teilen entsprechend. Und ähnlich meinten G. V. und A. V. Douglas [36], wenn das Ausgangsniveau durch Faltung in eine Sinus-Wellenfläche verwandelt wird, so müßten sich zwei Häufigkeitsmaxima einstellen, die dem Wellenberg und Wellental entsprechen. Beide Überlegungen beruhen auf demselben Grundirrtum, denn sie verwechseln den Einzelvorgang mit dem statistischen Ergebnis. Bei letzterem ist die geometrische Form des Einzelvorgangs ganz gleichgültig. Es handelt sich eben nur darum, ob bei der unendlich großen Zahl von Hebungen und Senkungen, um mit Soergel, oder von Faltungen, um mit Douglas zu reden, zwei Häufigkeitsmaxima vorkommen können, wo doch das Höhenausmaß der Einzelfälle beliebig variiert. Offenbar könnte dies nur dann der Fall sein, wenn irgend eine Tendenz zur Bevorzugung bestimmter Höhenausmaße wirksam wäre. Dies ist aber nicht der Fall. Für Hebungen und Senkungen sowohl wie für Faltungshöhen kennen wir nur die eine Regel: sie sind um so seltener, je größer sie sind. Daher muß bei 
ihnen stets auf das Ausgangsniveau die größte Häufigkeit entfallen, und von da ab muß die Häufigkeit sowohl nach oben wie nach unten etwa gemäß dem Gaußschen Fehlergesetz abnehmen.

Es sei auch noch daran erinnert, daß einige Autoren, wie namentlich Trabert [31], die Ansicht vertreten haben, die Tiefseebecken seien durch die größere Auskühlung des Untergrundes durch das kalte Tiefseewasser gebildet worden. Aber gerade aus Traberts Rechnungen geht hervor, daß man hierzu eine bis zum Erdmittelpunkt reichende Abkühlung der Tiefseesektoren annehmen müßte, und da dies unannehmbar erscheint, so sind Traberts Rechnungen eher geeignet, diese Vorstellung zu widerlegen, als ihre Richtigkeit zu beweisen. Außerdem ist aber leicht einzusehen, daß wir auf diese Weise nur eine allgemeine Tendenz erhalten können, schon bestehende Vertiefungen der Erdoberfläche weiter zu vertiefen, aber kein Mittel, die Existenz einer in allen Ozeanen in fast gleicher Tiefe gelegenen Bodenfläche, des zweiten Häufigkeitsmaximums der Erdrinde, zu erklären, wie auch kürzlich von Nansen [222] hervorgehoben wurde. In der Tat wird auch auf diese schon von Faye herrührende Erklärung heute nur mehr selten zurückgegriffen, zumal durch die Entdeckung des Radiums in der Erdkruste sich die Grundlage für die Beurteilung des Wärmehaushalts der Erde völlig verschoben hat.

Natürlich wird es nötig sein, sogleich vor einer Übertreibung dieser neuen Auffassung von der Natur der Tiefseeböden zu warnen. Schon bei unserem Vergleich mit den tafelförmigen Eisbergen ist zu bedenken, daß ja auch die Meeresoberfläche zwischen ihnen sich wieder mit Jungeis bedecken kann, und daß weiter auch kleinere Brocken des Eisberges, die von seinem oberen Rande abgesprengt wurden oder von seinem tief unter Wasser befindlichen Fuß aufstiegen, die Wasseroberfläche bedecken können. Ähnliches wird natürlich auch an manchen Stellen der Tiefseeböden stattfinden. Inseln sind meist bereits größere Kontinentalbrocken, die mit ihrem Unterbau, wie die Schweremessungen wahrscheinlich machen, bis etwa $50 \mathrm{~km}$ tief unter den Tiefseeboden hinabreichen. Und weiter ist zu berücksichtigen, daß die Kontinentalschollen, so spröde sie an der Oberfläche sein mögen, in der Tiefe plastisch werden und sich hier teigartig ziehen können, so daß bei der Trennung von Schollen auch auf diese Weise kontinentales Material von entsprechend geringerer Mächtigkeit sich über kleinere oder größere Teile des Tiefseebodens ausbreiten kann. Als besonders unrein in diesem Sinne muß der Boden des Atlantischen Ozeans gelten, welcher der 
Länge nach von der mittelatlantischen Bodenschwelle durchzogen wird. Aber auch die anderen Tiefseebecken zeigen mit ihren Inselketten und unterseeischen Erhebungen Ähnliches. Auf Einzelheiten wird später im Abschnitt über den Tiefseeboden näher eingegangen werden.

Es ist nicht undenkbar, daß das hier erörterte Schema im weiteren Verlauf der Forschung sich nur als Haupterscheinung herausstellen wird, und daß zu einer genauen Darstellung der wirklichen Verhältnisse noch Komplikationen eingeführt werden müssen. So fand ich selber [37] bei einer statistischen Untersuchung der ersten, von amerikanischer Seite gewonnenen Echolotungen quer über den Nordatlantik, daß das Hauptmaximum der Häufigkeit hier wesentlich tiefer, bei etwa $5000 \mathrm{~m}$ Tiefe, lag, und daß anderseits ein sekundäres Häufigkeitsmaximum bei 4400 m Tiefe zu erkennen war. Über die Realität dieses letzteren Maximums, das auf eine mehrfache Schichtung hinweisen würde, wird man allerdings erst auf Grund der viel zahlreicheren Echolotungen der deutschen „Meteor“-Expedition ein Urteil gewinnen, die gegenwärtig noch nicht daraufhin untersucht sind.

Es entsteht natürlich die Frage, ob die Anschauung von der grundsätzlichen Verschiedenheit der Kontinentalschollen und der Tiefseebecken und von den horizontalen Verschiebungen der ersteren sich mit den übrigen Ergebnissen der Geophysik verträgt bzw. ob sich von dieser Seite her Bestätigungen für ihre Richtigkeit erbringen lassen.

Was zunächst die schon früher erwähnte Isostasielehre betrifft, so steht sie mit dem ganzen Vorstellungskreis der Verschiebungstheorie natürlich in bester Übereinstimmung, aber ein direkter Nachweis der Richtigkeit ist auf diesem Wege kaum zu erbringen. Wir wollen im folgenden etwas näher auf diese Untersuchungen eingehen.

Ihre physikalische Begründung fand diese von Pratt herrührende Lehre von der Isostasie (das Wort wurde erst 1892 von Dutton geprägt) durch die Schweremessungen. Schon 1855 hatte Pratt festgestellt, daß der Himalaja nicht die erwartete Anziehung auf das Lot ausübt; nach Kossmat beträgt z. B. in Kaliana in der Gangesebene, 56 englische Meilen vom Gebirgsfuß entfernt, die Nordkomponente der Lotablenkung nur eine Bogensekunde, während die Anziehung des Gebirges eine solche von 58 Bogensekunden verursachen sollte, und ähnlich zeigt Jalpaiguri nur eine Bogensekunde 
statt 77. Und dem entspricht auch die überall bestätigte Tatsache, daß die Schwerkraft bei großen Gebirgen nicht in dem zu erwartenden Maße von ihrem normalen Werte abweicht, so daß die Gebirgsmassive durch unterirdische Massendefekte irgendwelcher Art kompensiert erscheinen, wie die Arbeiten von Airy, Faye, Helmert u. a. zeigten, und wie es von Kossmat in einem sehr lichtvollen Referat [38] ausgeführt wurde. Und auch auf den Ozeanen hat es sich gezeigt, daß die Schwerkraft ungefähr ihren Normalwert besitzt, trotz des sichtbaren großen Massendefekts, den die Ozeanbecken darstellen. Die früheren Messungen auf Inseln ließen zwar noch verschiedenartige Deutungen zu. Aber die Zweifel wurden beseitigt, als Hecker, einem Vorschlag von Mohn folgend, auch an Bord des fahrenden Schiffes Schweremessungen durch gleichzeitige Ablesungen am Quecksilberbarometer und am Siedethermometer ausführte; vor kurzem ist es dem holländischen Geodäten Vening Meinesz sogar gelungen [39], die viel genauere Pendelmethode für Messungen im Unterseeboot brauchbar zu machen, und die Ergebnisse der ersten auf diese Weise ausgeführten Fahrten bestätigen vollauf Heckers Ergebnis, daß in großen Zügen auch auf den Ozeanen Isostasie herrscht, also der in den Tiefseebecken in Erscheinung tretende Massendefekt durch einen unterirdischen Massenüberschuß irgendwelcher Art kompensiert wird.

Über die Art, wie man sich diese unterirdischen Massenüberschüsse und Defizite zu denken hat, sind im Laufe der Zeit verschiedene Vermutungen angestellt.

Pratt dachte sich die Erdrinde etwa wie eine Teigmasse, die ursprünglich überall gleich dick, in den Kontinenten durch irgend eine Art der Auflockerung emporgewachsen und in den ozeanischen Gebieten zusammengepreßt ist. Je größer die Seehöhe der Oberfläche, um so geringer sei die Dichte oder das spezifische Gewicht der Erdrinde. Unterhalb der sogenannten Ausgleichstiefe (in etwa $120 \mathrm{~km}$ Tiefe) seien aber alle horizontalen Dichteunterschiede verschwunden (vgl. Abb. 10). Diese Vorstellung wurde von Helmert und Hayford weiter ausgebaut und allgemein zur Beurteilung der Schwerkraftbeobachtungen verwendet. Sie wird gegenwärtig insbesondere von W. Bowie [224] vertreten, der sich folgenden Experiments zur Erläuterung bedient: Er läßt auf Quecksilber eine Anzahl Prismen schwimmen, die aus verschiedenen Materialien, Kupfer, Eisen, Zink, Pyrit u. a., mit verschiedenem spezifischen Gewicht bestehen. Die Prismen müssen gerade solche Höhen be- 
sitzen, daß sie alle gleich tief in das Quecksilber eintauchen. Ihre gemeinsame Unterfläche entspricht dann der Ausgleichsfläche des Druckes. Wegen ihres verschiedenen spezifischen Gewichts ragen sie dann verschieden hoch über den Quecksilberspiegel empor, das schwerste Material am wenigsten, das leichteste am meisten. Diese Deutung der Schweremessungen findet eine gewisse Stütze in der Beobachtungstatsache, daß im allgemeinen das Material der Erdrinde um so leichter ist, aus je größerer Seehöhe es stammt. Aber die Vorstellung, daß die Dichteunterschiede überall nur bis zu einer ganz bestimmten Tiefe, der Ausgleichsfläche reichen, enthält eine physikalische Unwahrscheinlichkeit, die man sich am leichtesten an Hand des Versuchs von Bowie klarmachen kann. Damit nämlich diese verschiedenen Prismen mit ihrer Unterseite alle gleich tief

Abb. 10.
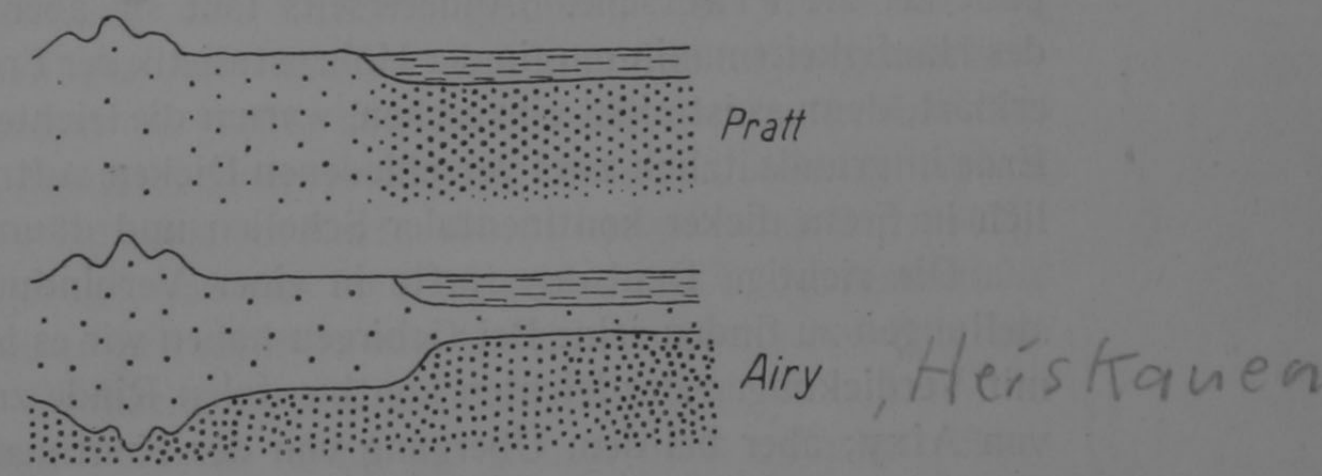

Isostasie nach Pratt und Airy.

eintauchen sollen, müssen ihre Höhen in einem ganz bestimmten, durch das spezifische Gewicht gegebenen Verhältnis zueinander stehen. Teilen wir also die Erdrinde in Prismen von verschiedenem Material ein, so müßte ein und dasselbe Material, wo immer auf der Erde es vorkommt, stets eine ganz bestimmte Mächtigkeit haben, die zu der Mächtigkeit der anderen Materialien in einem ein für allemal festgelegten, nämlich dem spezifischen Gewicht genau entsprechenden Verhältnis steht. Für eine solche Bindung zwischen Material (oder spezifischem Gewicht) und Mächtigkeit, die zu der willkürlichen Bedingung einer Konstanz der Unterfläche aller Prismen führt, ist aber kein natürlicher Grund erkennbar.

Neuerdings wird von manchen Geodäten, wie Schweydar [40] und namentlich Heiskanen [41, 42], eine andere, schon 1859 von Airy ausgesprochene Vorstellung zur Deutung der Schweremessungen verwendet, die auch in Abb. 10 dargestellt ist. Heim war wohl der 
erste, der annahm, daß unter den Gebirgen die leichte Rinde verdickt ist und das schwere Magma, auf dem sie schwimmt, hier in größere Tiefen drängt. Umgekehrt mußte dann die leichte Rinde unter tiefgelegenen Teilen der Erdoberfläche, wie den Ozeanbecken, besonders dünn sein. Hier werden also nur zwei Materialien angenommen, eine leichte Rinde und ein schweres Magma. Bowie veranschaulicht diese Vorstellung durch einen dem vorigen entsprechenden Versuch, indem er eine Anzahl verschieden hoher, aber alle aus dem gleichen Material (Kupfer) hergestellter Prismen auf Quecksilber schwimmen läßt, die dann natürlich verschieden tief eintauchen; das längste Prisma taucht am tiefsten ein, hat aber gleichzeitig auch die höchste Oberfläche. Es ist vielfach hervorgehoben worden, daß diese Airysche Vorstellung viel besser zu dem geologischen Bilde der Erdrinde, namentlich bei den großen Zusammenschüben in Faltengebirgen, paßt als die Prattsche. Andererseits läßt sie aber die Duplizität des Häufigkeitsmaximums in der Höhenstatistik der Erdoberfläche unerklärt, denn es ist nicht einzusehen, warum die leichte Kruste auf der Erde in grundsätzlich zwei verschiedenen Dicken auftreten soll, nämlich in Form dicker kontinentaler Schollen und dünner ozeanischer.

Die richtige Deutung dürfte in einer Verbindung beider Vorstellungen zu finden sein: Bei Gebirgen haben wir es im wesentlichen mit Verdickungen der leichten kontinentalen Rinde zu tun im Sinne von Airy; aber bei dem Übergang von der Kontinentalscholle zum Tiefseeboden mit Materialverschiedenheit im Sinne von Pratt.

Die neuere Entwicklung dieser Isostasielehre betrifft vor allem die Frage ihres Gültigkeitsbereiches. Für größere Schollen, wie z. B. einen ganzen Kontinent oder einen ganzen Tiefseeboden, muß ohne weiteres Isostasie angenommen werden. Aber im Kleinen, bei einzelnen Bergen, verliert dieses Gesetz seine Gültigkeit. Solche kleineren Teile können durch die Elastizität der ganzen Scholle getragen werden, genau wie ein Stein, den man auf eine schwimmende Eisscholle legt. Die Isostasie vollzieht sich dann zwischen Scholle und Stein als Ganzem und dem Wasser. So zeigen die Schweremessungen auf den Kontinenten bei Gebilden, deren Durchmesser nach Hunderten von Kilometern mißt, sehr selten eine Abweichung von der Isostasie; beträgt der Durchmesser nur Zehner des Kilometers, so herrscht meist nur eine teilweise Kompensation, und beträgt er nur einige Kilometer, so fehlt die Kompensation meist ganz.

Ob man nun die ältere Prattsche Vorstellung oder die von Airy und Heiskanen zugrunde legt, in jedem Falle führt die 
Diskussion der Schweremessungen auf den Ozeanen, die nichts von dem großen sichtbaren Massendefizit der Tiefseebecken erkennen lassen, zu dem Ergebnis, daß der Boden der Tiefsee aus dichterem, schwererem Material besteht als die Kontinentalschollen. Daß diese größere Dichte nicht nur auf den Unterschieden der physikalischen Zustände, sondern auch auf solchen des Stoffes besteht, läßt sich auf diesem Wege allerdings nicht exakt beweisen, wohl aber durch Überschlagsrechnungen unter plausiblen Annahmen sehr wahrscheinlich machen.

Die Isostasielehre liefert aber auch ein direktes Kriterium für die Frage nach der horizontalen Verschiebbarkeit der Kontinente. Es war schon oben auf die isostatischen Ausgleichsbewegungen hingewiesen worden, deren schönstes Beispiel die noch jetzt andauernde Hebung Skandinaviens um etwa $1 \mathrm{~m}$ im Jahrhundert ist, die als Nachwirkung der Entlastung durch das vor mehr als 10000 Jahren erfolgte Abschmelzen der Inlandeiskappe betrachtet werden kann, zumal die größte heutige Hebung dort zu beobachten ist, wo das Eis zuletzt verschwunden ist. Dies geht sehr schön aus der von Witting entworfenen Karte Abb. 11 hervor (nach Born [43]). Born [43] hat gezeigt, daß dies Hebungsgebiet eine Schwereanomalie im Sinne zu kleiner Schwerkraft hat, soweit es sich nach den bisher noch dürftigen Beobachtungen beurteilen läßt (vgl. Abb. 12), und so muß es in der Tat sein, wenn die Kruste noch unterhalb ihrer Gleichgewichtslage ist. Eine besonders eingehende Beschreibung aller auf diese Hebung Skandinaviens bezüglichen Erscheinungen hat Nansen [222] gegeben; die größte Depression betrug $284 \mathrm{~m}$ nach den Strandmarken an der Küste von Ångermanland und wahrscheinlich $300 \mathrm{~m}$ im Innern. Diese Hebung begann langsam vor etwa 15000 Jahren, erreichte vor 7000 Jahren ihre größte Geschwindigkeit von etwa $1 \mathrm{~m}$ in 10 Jahren und ist heute im Abklingen. Die zentrale Eisdicke wird auf etwa 2300 m geschätzt. Diese Vertikalbewegungen großer Krustenteile setzen natürlich Fließbewegungen in der Unterlage voraus, durch welche das verdrängte Material nach außen geschafft wird. Dies wird auch bestätigt durch die ungefähr gleichzeitig von Born, Nansen, A. Penck und Köppen (Literatur in [43]) gemachte Entdeckung, daß das Depressionsgebiet der Inlandeiskappe ringförmig von einem Gebiet schwacher Hebung umgeben ist, die eben auf das nach außen gepreßte Material des Untergrundes zurückzuführen ist. Jedenfalls beruht die ganze Isostasielehre auf der Vorstellung, daß die Unterlage der Kruste einen gewissen Grad 
von Fluidität oder Flüssigkeit besitzt. Ist dies aber der Fall, schwimmen also die Kontinentalschollen wirklich in einer, wenn auch sehr zähen Flüssigkeit, so ist offenbar kein Grund einzusehen, warum sich ihre Beweglichkeit nur in der Vertikalen äußern solle, und nicht auch horizontale Bewegungen vorkommen sollten, sofern nur Kräfte existieren und geologische Zeiten hindurch andauern,

Abb. 11.

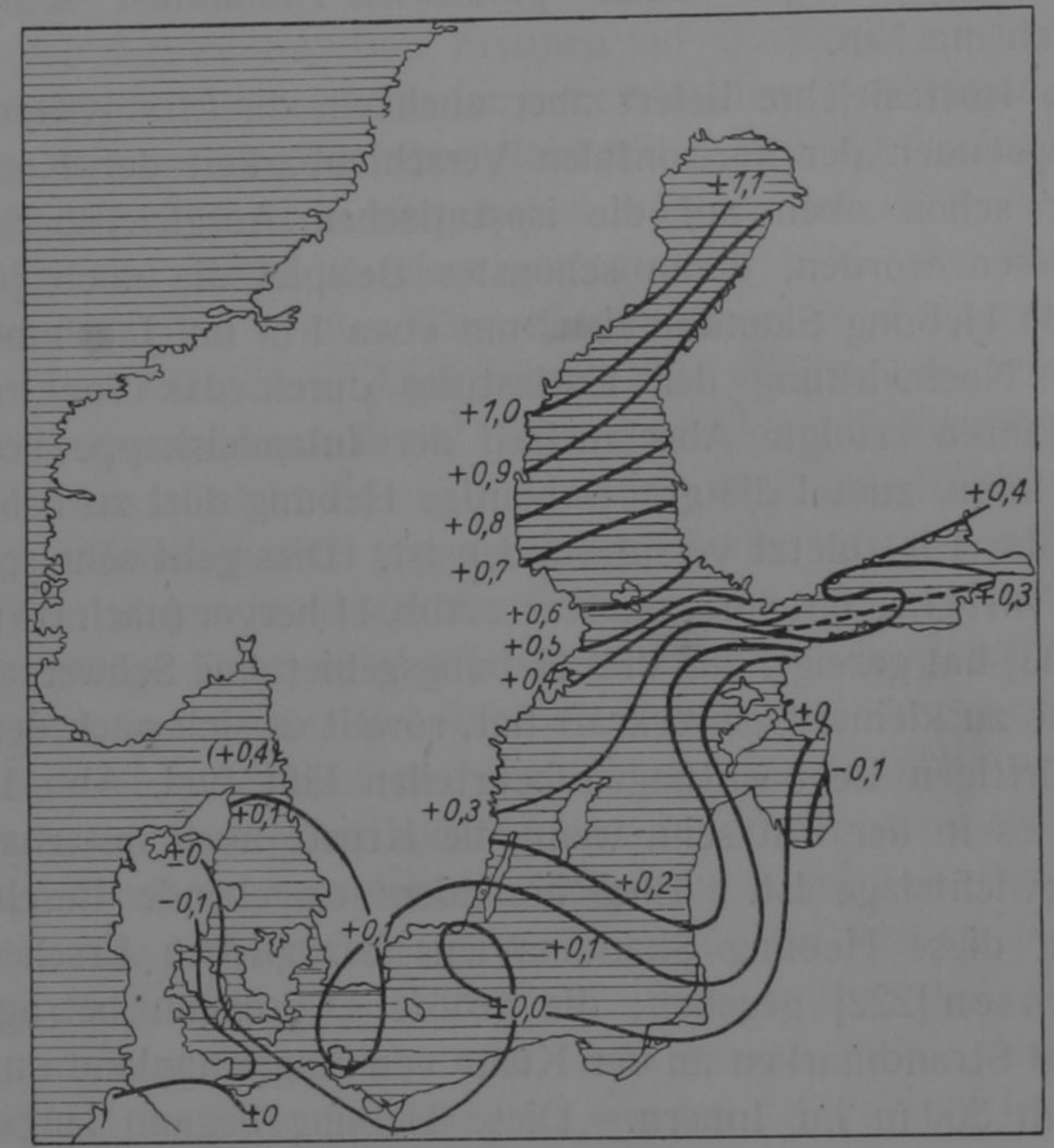

Gegenwärtige Hebung im Ostseegebiet nach Pegelmessungen $(\mathrm{cm} / \mathrm{Jahr})$, nach Witting.

die die Kontinentalschollen zu verschieben streben. Daß aber solche Kräfte wirklich existieren, beweisen ja die Gebirgszusammenschübe.

Von größter Wichtigkeit für unsere Fragen sind die neueren Ergebnisse der Erdbebenforschung, die von Gutenberg [44, 45] an verschiedenen Stellen übersichtlich zusammengefaßt worden sind.

Von den Erdbebenwellen nehmen bekanntlich die longitudinalen „ersten“ und die transversalen „zweiten Vorläufer“ ihren Weg durch das Erdinnere, während die „Hauptwellen“ an der Oberfläche entlang rollen. Je weiter die registrierende Station vom Herd ent- 
fernt ist, um so größere Tiefen haben die Vorläuferwellen durchdrungen. Aus der Zeitdifferenz zwischen Beben und Eintreffen an der Station, der „Laufzeit“, läßt sich die Geschwindigkeit der Wellen für die verschiedenen Tiefen ermitteln. Diese Geschwindigkeit ist aber eine Materialkonstante und kann uns also Auskunft geben über Materialschichtung im Innern der Erde.

\section{Abb. 12.}

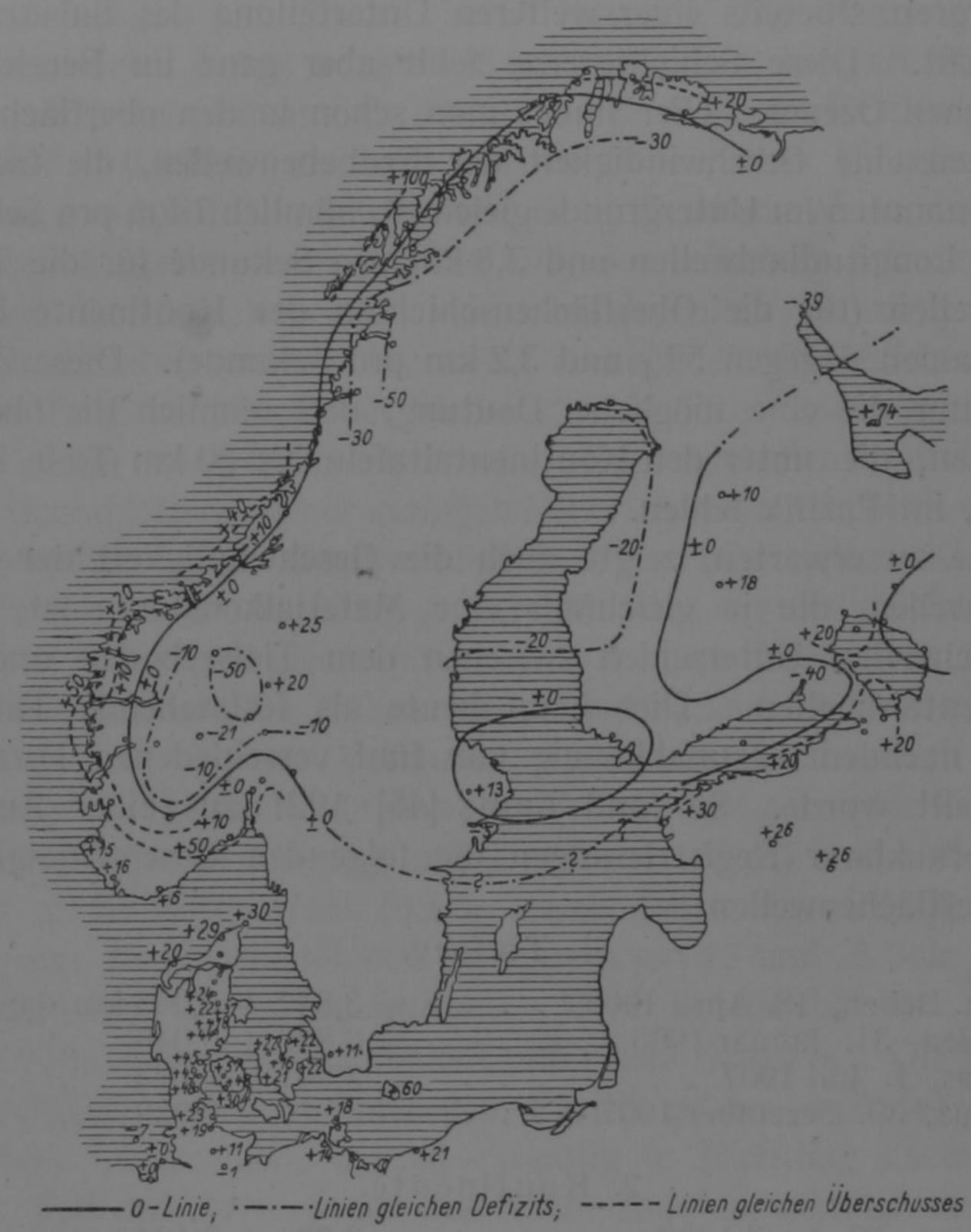

Schwereanomalie in Skandinavien, nach Born.

Es hat sich dabei gezeigt, daß unter Eurasien und auch unter der nordamerikanischen Kontinentalscholle in 50 bis $60 \mathrm{~km}$ Tiefe eine sehr auffallende Schichtgrenze nachweisbar ist, an welcher die Geschwindigkeit der Longitudinalwellen von $53 / 4 \mathrm{~km}$ pro Sekunde (oberhalb) auf $8,0 \mathrm{~km}$ pro Sekunde (unterhalb), und die der Transversalwellen von $31 / 3 \mathrm{~km}$ pro Sekunde (oberhalb) auf $4,4 \mathrm{~km}$ pro 
Sekunde (unterhalb) springt. Diese Schichtgrenze hat man bisher meist mit der Unterseite der Kontinentalschollen identifiziert, wie schon die Übereinstimmung der Tiefe mit dem von Heiskanen aus den Schweremessungen abgeleiteten Wert der Schollendicke nahelegt ${ }^{\mathbf{1}}$ ). Es scheint allerdings, als ob diese Auffassung heute nicht mehr aufrechtgehalten werden kann, sondern als Schollendicke nur etwa der halbe Wert in Betracht kommt, während die genannte Schichtgrenze bereits einer weiteren Unterteilung des Substratums entspricht. Diese Schichtgrenze fehlt aber ganz im Bereich des Pazifischen Ozeans. Hier findet man schon in den oberflächlichen Schichten eine Geschwindigkeit der Erdbebenwellen, die fast der oben genannten im Untergrunde gleich ist, nämlich $7 \mathrm{~km}$ pro Sekunde für die Longitudinalwellen und $3,8 \mathrm{~km}$ pro Sekunde für die Transversalwellen (für die Oberflächenschichten der Kontinente lauten diese Zahlen dagegen $5 \frac{3}{4}$ und 3,2 km pro Sekunde). Diese Zahlen haben nur die eine mögliche Deutung, daß nämlich die obersten Schichten, die unter den Kontinentaltafeln bis $60 \mathrm{~km}$ Tiefe herabreichen, im Pazifik fehlen.

Wie zu erwarten, zeigte auch die Geschwindigkeit der Oberflächenwellen, die ja gleichfalls eine Materialkonstante ist, einen entsprechenden Unterschied zwischen dem Tiefseeboden und den Kontinentalschollen. Dies kann heute als feststehende Tatsache gelten, nachdem es unabhängig von fünf verschiedenen Forschern festgestellt wurde. So fand Tams [46] 1921 aus einer Auswahl besonders klarer Registrierungen die folgenden Geschwindigkeiten der Oberflächenwellen:

\section{Tiefsee.}

Anzahl

Kaliforn. Beben, 18. April $1906 \ldots v=3,847 \pm 0,045 \mathrm{~km} / \mathrm{sec} \quad 9$

Kolumbien, 31. Januar 1906 . . . . . $\quad 3,806 \pm 0,046 \quad, \quad 18$

Honduras, 1. Juli 1907 . . . . . . . . $\quad 3,941 \pm 0,022 \quad$ ", 20

Nicaragua, 30. Dezember 1907 . . . . $\quad 3,916 \pm 0,029 \quad$ ", 22

2. Kontinente.

Kalifornien, 18. April $1906 \ldots . . v=3,770 \pm 0,104 \mathrm{~km} / \mathrm{sec}$

Philippinen I, 18. April 1907 . . . . $3,765 \pm 0,045 \quad, \quad 30$

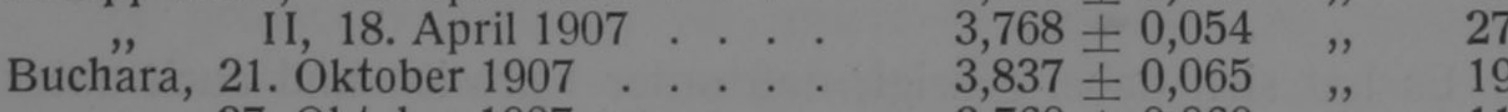

, 27. Oktober 1907

$3,760 \pm 0,069 \quad$,

1) Unter Zugrundelegung der Prattschen Theorie war man zu größeren Werten der Schollendicke (100 bis $120 \mathrm{~km})$ gekommen, während die Airysche Theorie praktisch das gleiche Ergebnis liefert wie die Erdbebenforschung. Dies spricht für den auch sonst anerkannten Vorzug der Airyschen Theorie. 
Es ist also, wenn auch die Einzelwerte bisweilen einander überschneiden, doch im Mittel ein deutlicher Unterschied in dem Sinne zu erkennen, daß die Fortpflanzungsgeschwindigkeit der Oberflächenwellen am Boden der Tiefsee um etwa 0,1 km pro Sekunde größer ist als auf den Kontinenten, was mit dem nach den physikalischen Eigenschaften vulkanischer Tiefengesteine $\mathrm{zu}$ erwartenden theoretischen Wert übereinstimmt.

Andererseits hat Tams auch versucht, die Beobachtungen möglichst vieler Beben zu Mitteln zu vereinigen, und erhält so als Mittel aus den Geschwindigkeitswerten bei 38 Beben für den Pazifik $v=3,897 \pm 0,028 \mathrm{~km} / \mathrm{sec}$ und bei 45 Beben über Eurasien oder Amerika $v=3,801 \pm 0,029 \mathrm{~km} / \mathrm{sec}$, d. h. dieselben Werte wie oben.

Auch Angenheister [47] hat 1921 den seismischen Unterschied zwischen Tiefseebecken und Kontinentalschollen bei einer Reihe pazifischer Beben untersucht, wobei er auch die Oberflächenwellen behandelt. Er unterscheidet hierbei die bei Tams nicht getrennten beiden Arten von „,Querwellen“ und „Rayleighwellen“, und findet so ạf Grund allerdings nur geringen Materials sogar erheblich größere Unterschiede: „Die Geschwindigkeit der Hauptwellen ist unter dem Pazifik um 21 bis $26 \%$ größer als unter dem asiatischen Kontinent." Wir fügen gleich hinzu, daß er auch für andere Wellenarten charakteristische Unterschiede fand: „Die Laufzeiten für $P$ (undae primae = erste Vorläufer, Longitudinalwellen mit Fortpflanzung durch das Erdinnere) und $S$ (undae secundae $=$ zweite Vorläufer, Transversalwellen mit ähnlichem Wege) sind unter dem Pazifik bei $6^{0}$ Herddistanz (bei so kurzer Distanz durchlaufen diese Wellen nur die oberflächlichen Schichten) um 13 und 25 Sek. kleiner als unter dem Kontinent Europa. Dem entspricht für $S$ eine um $18 \%$ größere Geschwindigkeit unter dem Ozean ... Die Periode der Nachläuferwellen ist unter dem Pazifik größer als unter Asien." Alle diese Unterschiede deuten einmütig in Richtung unserer Annahme, daß der Tiefseeboden aus einem anderen, nämlich dichteren Material besteht.

Desgleichen ist Visser hinsichtlich der Oberflächenwellen zu dem gleichen Ergebnis gekommen [48]. Er fand nämlich:

über kontinentalem Gebiet . . . . . $v=3,70 \mathrm{~km} / \mathrm{sec}$

, ozeanischem Gebiet .

$$
v=3,78 \quad,
$$

Einen Geschwindigkeitsunterschied der Oberflächenwellen in gleichem Sinne fand auch Byerly bei dem Beben von Montana vom 28. Juni 1925 [223]. 
Und endlich hat Gutenberg auf anderem Wege dies Resultat bestätigt [44, 45]. Er benutzt dazu die Querwellen, also Oberflächenwellen, die den gleichfalls oberflächlichen Rayleighwellen unmittelbar vorausgehen (und oft von ihnen nicht zu trennen sind). Die Geschwindigkeit dieser Wellen hängt einmal ab von ihrer Wellenlänge oder Periode, zweitens aber auch von der Dicke der obersten Rinden-

Abb. 13.

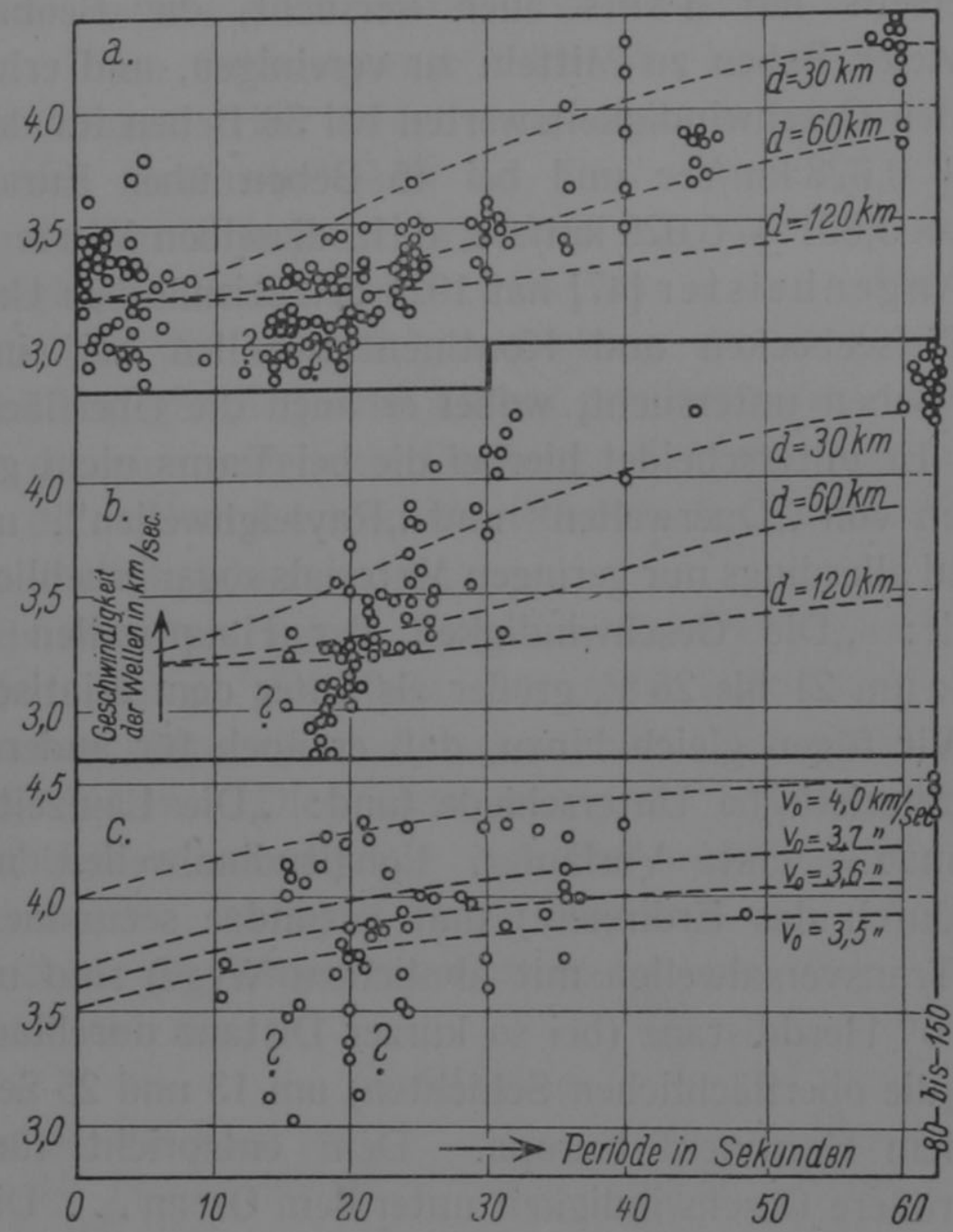

Geschwindigkeit der Quer-(Oberflächen-) Wellen nach Gu te nberg. Siehe Text.

schicht, in der sie sich abspielen. Da man aus den Registrierungen nicht nur die Laufzeiten (Geschwindigkeiten), sondern auch die Periode entnehmen kann, so kann man die Dicke der Rindenschicht bestimmen. Freilich ist die Ausmessung immer ziemlich ungenau, und man braucht für dasselbe Gebiet eine größere Zahl von Fällen mit verschiedener Periode, um einen Schluß auf die Schichtdicke ziehen zu können. In Abb. 13 ist Gutenbergs Ergebnis für die drei Gebiete a) Eurasien, b) bei vorwiegendem Verlauf im Boden 
des Atlantik, c) im Pazifik wiedergegeben. Nach rechts ist die Periode, nach oben die Geschwindigkeit der Wellen abgetragen. Wären die Messungen fehlerfrei, so müßten alle Punkte auf einer Kurve liegen, deren Lage im Diagramm von der Schichtdicke abhängt. In a) und b) sind drei solche theoretischen Kurven für die Schichtdicke 30, 60 und $120 \mathrm{~km}$ eingetragen, in c) mehrere für die Schichtdicke Null. Gutenberg schließt, daß sich für Eurasien die Punkte am besten der Kurve für die Schichtdicke $60 \mathrm{~km}$, für die vorwiegend atlantischen Strecken besser der für die Schichtdicke $30 \mathrm{~km}$, für den Pazifik aber derjenigen für Schichtdicke Null anschmiegen. Die Streuung ist groß, das Verfahren also kein sehr genaues. Das Ergebnis ist aber später von Gutenberg noch weiter gestützt worden. Das wichtigste ist, daß im Pazifik die oberste Schicht auch nach dieser Untersuchung zu fehlen scheint, und daß sich für Strecken, die vorwiegend im Atlantik verlaufen, also teils über Tiefsee, teils über kontinentales Gebiet, ein zwischen Null und $60 \mathrm{~km}$ liegender mittlerer Wert der Schichtdicke ergibt ${ }^{1}$ ).

Wie oben erwähnt, fand schon Angenheister, daß auch die Periode der Nachläuferwellen im Bereich des Pazifik größer ist als auf dem asiatischen Kontinent. Dies ist von Wellmann [49] genauer untersucht und bestätigt worden. Er faßt seine Ergebnisse anschaulich in Abb. 14 zusammen, in der die Herde der von ihm untersuchten Beben gekennzeichnet sind, und zwar durch Kreuze oder ausgefüllte Kreise, je nachdem sie Nachläufer mit langer oder kurzer Periode auf den Registrierungen in Hamburg lieferten. Berücksichtigt man, daß der Weg der Wellen vom Herde bis nach Hamburg stets senkrecht zu den in der Abbildung gestrichelten Linien gleichen Abstandes von Hamburg verlaufen muß, so zeigt die Abbildung in anschaulicher Weise, daß die von den Kreuzen gekommenen Wellen vorzugsweise über Tiefseegebiete (Pazifik, Nordmeer, Nordatlantik) gelaufen sind, während die von den schwarzen Kreisen herrührenden vorzugsweise über Kontinentalgebiet (Asien) gelaufen sein müssen.

Man sieht also, daß die Erdbebenforschung in ihrer neueren Entwicklung auf den verschiedensten, voneinander unabhängigen Wegen zu einer Bestätigung der Vorstellung gekommen ist, daß die Tiefseeböden grundsätzlich aus anderem Material bestehen als

1) Gutenberg will, meines Erachtens mit Unrecht, in dem Ergebnis für den Atlantik einen Widerspruch gegen die Verschiebungstheorie sehen, worauf in Kap. 11 zurückgekommen werden wird.

Wegener, Kontinente und Ozeane. 4. Aufl. 
die Kontinentalschollen, und zwar aus einem Material, das einer tieferen Schicht des Erdkörpers entspricht.

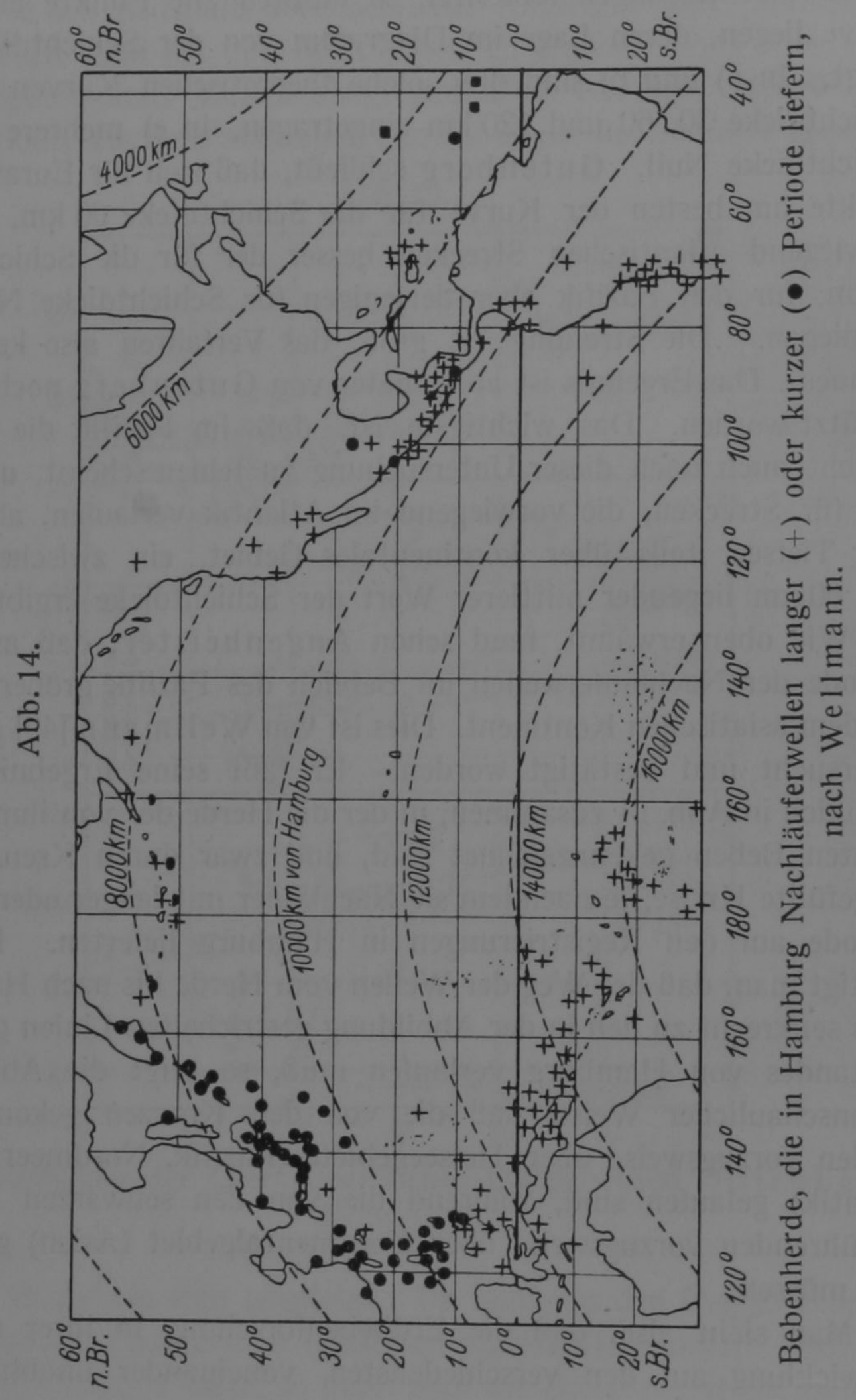

In der erdmagnetischen Forschung wird, worauf A. Nippoldt mich aufmerksam machte, allgemein die Ansicht vertreten, daß die Tiefseeböden aus stärker magnetisierbarem, also vermutlich eisenhaltigerem Material bestehen als die Kontinentalschollen. Besonders 
tritt dies in der Diskussion über das magnetische Modell der Erde von Henry Wilde [50] hervor, bei dem die Ozeanflächen mit Eisenblech belegt werden mußten, um eine dem Erdmagnetismus entsprechende Verteilung der magnetischen Kraft $\mathrm{zu}$ erhalten. A. W. Rücker [51] beschreibt diesen Versuch mit den Worten: „Herr Wilde hat ein gutes magnetisches Modell der Erde mit einer Versuchsanordnung vorgeführt, die aus der Wirkung eines primären Feldes einer gleichförmig magnetisierten Kugel und eines sekundären Feldes von Eisenmassen bestand, die nahe der Oberfläche lagen und durch Induktion magnetisiert wurden. Die Hauptmasse des Eisens ist unter den Ozeanen angebracht... Herr Wilde legt das Hauptgewicht auf die Bedeckung der Ozeane mit Eisen." Auch Raclot [52] hat neuerdings bestätigt, daß dieser Versuch von Wilde in rohen Zügen das Verteilungsbild des Erdmagnetismus gut darstellt. Allerdings ist es bisher noch nicht geglückt, diesen Unterschied zwischen Kontinenten und Tiefsee rechnerisch aus den erdmagnetischen Beobachtungen abzuleiten, anscheinend aus dem Grunde, weil er von einem anderen, viel größeren Störungsfeld noch unbekannter Herkunft überlagert wird, welches keine Beziehung zur Kontinentalverteilung zeigt und wohl auch nicht zeigen kann, wie aus seinen großen, in der Säkularvariation zum Ausdruck kommenden Veränderungen hervorzugehen scheint. Jedenfalls aber sprechen die Ergebnisse des Erdmagnetismus auch nach Ansicht solcher Fachleute (wie Ad. Schmidt), welche die Beweiskraft von Wildes Versuch noch nicht ohne Einschränkung anerkennen wollen, keineswegs gegen die Annahme, daß die Tiefseeböden aus eisenhaltigerem Gestein bestehen. Da bekanntlich allgemein angenommen wird, daß bereits in dem Silikatmantel der Erde der Eisengehalt mit der Tiefe wächst und das Erdinnere weiterhin überhaupt vorwiegend aus Eisen besteht, so besagt dies, daß wir es hier mit einer tieferen Schicht zu tun haben. Nun erlischt der Magnetismus im allgemeinen bei der Temperatur der Rotglut, welche unter Zugrundelegung der gewöhnlichen geothermischen Tiefenstufe bereits in etwa 15 bis $20 \mathrm{~km}$ Tiefe erreicht wird. Der starke Magnetismus der Tiefseeböden müßte also gerade in den obersten Schichten vorhanden sein, was mit unserer Annahme, daß hier die schwächer magnetischen Massen fehlen, gut zu stimmen scheint.

Es liegt sehr nahe, zu fragen, ob man nicht irgendwelche Proben dieses Tiefengesteins unmittelbar vom Tiefseeboden beschaffen kann. Allein es wird wohl noch lange unmöglich sein, mit dem Schleppnetz 
oder auf andere Weise Proben des anstehenden Gesteins aus diesen Tiefen hochzubringen. Immerhin verdient aber Beachtung, daß bei den Dredschzügen die Hauptmasse der heraufgebrachten losen Proben nach Krümmel [30] vulkanisch ist; ,namentlich überwiegen Bimssteine..., sodann begegnen die Trümmer von Sanidin, Plagioklas, Hornblende, Magnetit, vulkanischem Glas und deren Zersetzungsprodukt Palagonit, auch Lavabrocken von Basalten, Augitandesiten usw.“. Vulkanische Gesteine zeichnen sich nun in der Tat durch größeres spezifisches Gewicht und größeren Eisengehalt aus und werden allgemein als aus größeren Tiefen stammend betrachtet. Suess nannte diese ganze basische Gesteinsgruppe, deren Hauptvertreter Basalt ist, „Sima“ nach den Anfangsbuchstaben der Hauptbestandteile Silicium und Magnesium, im Gegensatz zu der anderen, kieselsäurereichen Gruppe des „Sal“ (Silicium-Aluminium), dessen Hauptvertreter Gneis und Granit den Untergrund unserer Kontinente bildet ${ }^{1}$ ). Einer brieflichen Anregung von Pfeffer folgend, möchte ich statt „Sal“, um die Identität mit dem lateinischen Worte für Salz zu vermeiden, „Sial“" schreiben. Der Leser wird nach dem Vorangegangenen wahrscheinlich schon selbst den Schluß ziehen, daß die Gesteine der Simagruppe, die wir freilich nur als Eruptivgesteine auf den sialischen Kontinentalschollen kennen, wo sie als Fremdkörper erscheinen, ihren eigentlichen Platz unter diesen Schollen haben und wahrscheinlich auch den Boden der Tiefsee bilden. Basalt hat, wie es scheint, die Eigenschaften, welche wir für das Material der Tiefseeböden brauchen.

Indessen hat sich über diese Frage, aus welchen Materialien die verschiedenen Erdschichten bestehen, in den letzten Jahren eine große Zahl von Untersuchungen entsponnen, teils auf petrographischer und geochemischer Grundlage, teils auf Grundlage der Erdbebenwellen, und die Frage ist gegenwärtig noch so im Fluß, daß es zu einer einigermaßen übereinstimmenden Ansicht zwischen den verschiedenen Forschern heute noch nicht gekommen ist. Wir wollen uns deshalb hier, ohne selbst Stellung zu nehmen, mit einem kurzen Überblick über die teilweise noch recht auseinandergehenden Ergebnisse begnügen.

Anfangs ging man allgemein davon aus, daß es genüge, unterhalb der kontinentalen Sialschicht, die sicher aus gneis- oder granit-

$\left.{ }^{1}\right)$ Diese Einteilung geht schon auf Robert Bunsen zurück, der die nichtsedimentären Gesteine in "normal trachytische" (kieselsäurereiche) und "normal pyroxenitische" (basische) einteilte. Suess erfand jedoch die bequemen Namen. 
artigem Material besteht, eine Simaschicht anzunehmen, die bis etwa $1200 \mathrm{~km}$ Tiefe reicht. Dies ist der Mantel. Unterhalb desselben liegt, bis zur Tiefe von $2900 \mathrm{~km}$, die Zwischenschicht, und dann kommt der wesentlich aus Nickeleisen bestehende Kern. Die Zwischenschicht besteht entweder nach Analogie der Materialfolge der Meteoriten aus Mesosiderit (Pallasit) oder, in Anlehnung an Hüttenerfahrungen, aus Schwefeleisen und anderen Erzen (Schlacke). $\mathrm{Da}$ dies in der Tat die wichtigsten Schichten des Erdkörpers sind, steht wohl ein für allemal fest. Die Frage aber, ob die Simaschicht einheitlich ist oder einer weiteren Unterteilung bedarf, wird verschieden beantwortet. Als typischen Vertreter des Simas erklärte V. M. Goldschmidt Eklogit, Williamson und Adams Peridotit oder Pyroxenit, andere Dunit. Jedenfalls muß die Hauptmasse des Simas ein sehr basisches oder ,ultrabasisches“ Gestein sein, noch basischer als Basalt, so daß dies letztere Material höchstens als oberster Teil des Simas in Frage kommt. Zahlreiche Arbeiten und teilweise Bücher von Jeffreys [53], Daly [54], S. Mohorovičić [55], Joly [56], Holmes [57], Poole [58], Gutenberg [59], Nansen [222] u. a. haben sich mit den hier auftauchenden Fragen beschäftigt, wobei besonders bemerkenswert ist, daß das Buch von Daly (Our mobile Earth, London 1926) ganz auf dem Standpunkt der Verschiebungstheorie steht; das von Joly (The surface history of the earth, Oxford 1925) spricht sich zwar gegen die Verschiebungstheorie aus, bringt aber in Wirklichkeit wichtige neue Stützen für sie durch die Berücksichtigung der radioaktiven Wärme.

Einigkeit scheint bei allen Autoren darüber $\mathrm{zu}$ herrschen, daß unter dem Granit der Kontinentalschollen zunächst Basalt kommt. Aber die Grenze zwischen diesen beiden Materialien wird heute von der Mehrzahl der Forscher nicht mehr mit der aus den Erdbeben abgeleiteten großen Schichtgrenze bei $60 \mathrm{~km}$ identifiziert, sondern schon etwa bei 30 bis $40 \mathrm{~km}$ Tiefe angenommen, wo die Erdbeben gleichfalls eine, wenn auch weniger bedeutende Schichtgrenze erkennen lassen. Einer der Hauptgründe dafür, daß man den Granit nicht bis $60 \mathrm{~km}$ Tiefe reichen lassen will, besteht darin, daß eine so dicke Schicht zu viel Radium enthalten und daher $\mathrm{zu}$ viel Wärme produzieren würde. Bei $60 \mathrm{~km}$ Tiefe würde dann also das ultrabasische Material (Dunit und anderes) beginnen. Ferner hat namentlich Mohorovičć betont, daß die 60-km-Schichtgrenze keine Variationen ihrer Tiefenlagen unter Gebirgen und Flachland aufweist, wohl aber die höher liegende Grenze zwischen Granit 
und Basalt. Es entsteht deshalb die Frage, ob man unter diesen Umständen als Untergrenze der Kontinentalschollen nicht lieber die Granitgrenze bei etwa 30 bis $40 \mathrm{~km}$ Tiefe betrachten soll, statt wie bisher die große Schichtgrenze bei $60 \mathrm{~km}$ Tiefe. Andererseits ist noch ungeklärt, wie sich die letztere Schichtgrenze unter den Ozeanen verhält. Gutenberg nimmt an, daß diese bei $60 \mathrm{~km}$ Tiefe liegende große Schichtgrenze unter dem Pazifik die Oberfläche bildet, so daß hier gleich das ultrabasische Material (Dunit) zutage läge. Mohorovičić glaubt dagegen, daß der Ozeanboden von Basalt gebildet wird.

Man wird die weitere Entwicklung dieser Untersuchungen abwarten müssen, ehe es möglich ist, ein abgeschlossenes Bild zu gewinnen. Es ist aber sehr wohl möglich, daß durch diese Schichtenvermehrung auch hinsichtlich der Natur der Tiefseeböden größere Komplikationen sich ergeben werden, wofür schon oben (S. 39) in anderem Zusammenhang sich Anzeichen ergaben.

Aber wie auch die weitere Entwicklung dieser Ansichten sein mag, so viel ist schon ersichtlich, daß sie im Sinne der Verschiebungstheorie fortschreiten, denn an dem grundlegenden Gegensatz zwischen Tiefseeboden und Kontinenten wird nicht mehr gerüttelt, und für die Verschiebungstheorie ist es zunächst gleichgültig, ob ersterer aus Basalt oder vielleicht stellenweise bereits ultrabasischem Material besteht. Jedenfalls fehlt hier (von Resten abgesehen) die Granitdecke der Kontinentalschollen.

Nicht selten wird gegen die Verschiebungstheorie eingewendet: Die Erde ist so starr wie Stahl, also können sich die Kontinente nicht verschieben. In der Tat hat die Beobachtung der Erdbeben, der Polschwankungen und der Gezeiten der festen Erde zu dem übereinstimmenden Ergebnis geführt, daß der Koeffizient der Form-Elastizität oder die Riegheit der Erde im Mittel $2.10^{12} \mathrm{~g} / \mathrm{cm} \cdot \mathrm{sec}^{2}$ beträgt, oder bei Unterscheidung eines bis $1200 \mathrm{~km}$ Tiefe reichenden Gesteinsmantels und eines Erz- und Metallkerns für ersteren $7 \cdot 10^{11}$ und für letzteren $3 \cdot 10^{12}$. Da dieser Koeffizient für kalten Stahl $8.10^{11}$ beträgt, so ist also wirklich die Erde so rieg wie Stahl. Aber was folgt daraus? Für unsere Frage zunächst gar nichts. Denn die Geschwindigkeit, mit der sich ein Kontinent unter der Wirkung einer gegebenen Kraft bewegen kann, hängt überhaupt nicht von der Riegheit des Simas ab, sondern von einer anderen, von dieser unabhängigen Materialkonstante, der „,inneren Reibung“ oder „Zähigkeit“, oder der zu 
ihr reziproken „Fluidität“. Diese Zähigkeit hat die Dimension $\mathrm{g} / \mathrm{cm}$. sec. Leider kann man nicht mit Sicherheit von der Riegheit auf die Zähigkeit schließen, sondern diese muß durch besondere Untersuchungen bestimmt werden. Nun sind diese Zähigkeitsmessungen an sogenannten festen Körpern äußerst schwierig. Auch im Laboratorium, wo man dazu die Dämpfung elastischer Schwingungen oder die Deformationsgeschwindigkeit bei Biegung oder Torsion oder auch die Messung der sogenannten Relaxationszeit benutzt, sind sie erst an sehr wenigen Stoffen durchgeführt worden. Und über den Zähigkeitskoeffizienten der Erde sind wir leider einstweilen in einer fast hoffnungslosen Weise im unklaren. Es sind zwar in neuerer Zeit verschiedene Versuche gemacht worden, diesen Zähigkeitskoeffizienten teils als Mittel für die ganze Erde, teils für gewisse Schichten abzuschätzen, aber die Ergebnisse gehen in dem Maße auseinander, daß wir nur unsere völlige Unkenntnis feststellen können.

Mit Sicherheit läßt sich nur sagen, daß sich die Erde kurzperiodischen Kräften wie den Erdbebenwellen gegenüber wie ein fester, elastischer Körper verhält; hier tritt die Fließfähigkeit nicht in Erscheinung. Dagegen muß sich die Erde Kräften gegenüber, die geologische Zeiten hindurch andauern, wie eine Flüssigkeit verhalten, wie z. B. daraus hervorgeht, daß ihre Abplattung gerade ihrer Rotationsdauer angepaßt ist. Aber wo die Zeitgrenze zu suchen ist, bei der die elastischen Deformationen durch fließende abgelöst werden, hängt eben vom Zähigkeitskoeffizienten ab.

G. H. Darwin nahm bei seiner Untersuchung über die Mondablösung an, daß schon die 12- und 24stündigen Gezeitenkräfte zu Fließbewegungen Anlaß geben, und von zahlreichen anderen Autoren ist diese Hypothese angewendet worden. In einer neueren Untersuchung kommt Prey [60] allerdings zu dem Ergebnis, daß die Darwinschen Annahmen nicht zu der Konsequenz führen, daß etwa heute noch die Erdrinde durch die Flutreibung merkliche Verschiebungen nach Westen erfährt. Vor 50 bis 60 Millionen Jahren mag der Zähigkeitskoeffizient noch den verhältnismäßig geringen Betrag von etwa $10^{13}$ (etwa die gleiche Zähigkeit hat Gletschereis) gehabt haben, und damals, meint Prey, seien daher große Verschiebungen der Rinde vorgekommen. Aber seitdem müsse der Zähigkeitskoeffizient so zugenommen haben, daß heute solche Verschiebungen ausgeschlossen seien. Dazu ist freilich $\mathrm{zu}$ bemerken, daß D arwin noch nicht den Radiumgehalt der Erdrinde in Betracht 
ziehen konnte. Prey nimmt trotz des Radiums eine fortschreitende Abkühlung an. Aber es erscheint doch nach unserer heutigen Kenntnis der vorhandenen Radiummengen und auch nach den geologischen Tatsachen sehr fraglich, ob im Laufe der geologischen Zeiten, die auf erheblich größere Länge geschätzt werden, sich der Zähigkeitskoeffizient der Erde, von Schwankungen abgesehen, überhaupt systematisch in merkbarer Weise geändert hat.

Von geologischer Seite ist oft eine Magmaschicht unter der festen Erdrinde angenommen worden, und ähnlich glaubte Wiechert gewisse Eigentümlichkeiten bei den Erdbebenregistrierungen durch eine solche ziemlich leichtflüssige Schicht erklären $\mathrm{zu}$ können. Hiergegen wendet sich Schweydar [61] auf Grund der meßbaren Gezeiten der festen Erde. Wäre nämlich die Fluidität merklich an diesen beteiligt, so müßten sie hinter Sonne und Mond nachhinken. Da die Beobachtungen aber kein solches Zurückbleiben zeigen, muß der beobachtete Betrag der Gezeiten ganz durch Elastizität, und gar nicht durch Fluidität verursacht sein. Die Fehlergrenze der Beobachtungen liefert so wenigstens einen Grenzwert des Zähigkeitskoeffizienten, der allerdings je nach der Dicke der Schicht, für die er angenommen wird, verschieden ausfällt. Denn eine leichtflüssige dünne Schicht leistet die gleichen Verschiebungen wie eine zähflüssige Schicht von entsprechend größerer Dicke. So findet Schweydar, daß der Zähigkeitskoeffizient größer als $10^{9}$ sein muß, wenn es sich nur um eine $100 \mathrm{~km}$ dicke Schicht handelt, dagegen größer als $10^{13}$ oder $10^{14}$, wenn diese Schicht $600 \mathrm{~km}$ dick ist. Allerdings ist dabei noch die Voraussetzung wesentlich, daß es sich um eine zusammenhängende, die ganze Erde umkleidende Schicht handelt. Abgeschlossene kleinere Partien des Erdkörpers könnten erheblich flüssiger sein.

Einen weiteren Versuch, die Zähigkeit der Erde zu ermitteln, hat Schweydar 1919 in seiner Untersuchung über die Polbewegung [62] gemacht. Er berechnete nämlich rückwärts, wie die Polschwankungen ausfallen müßten, wenn der halbe Zähigkeitskoeffizient der Erde die Werte $10^{11}, 10^{14}, 10^{16}, 10^{18}$ hätte, und fand, daß bei den ersten beiden Werten überhaupt nur eine etwa 80 jährige Periode der Polbewegung auftreten kann. Erst bei den größeren Werten tritt an deren Stelle eine kurze Periode von 470 bis 370 Tagen, also von der Art der wirklich vorhandenen. Natürlich kommt es auch hier wieder darauf an, wie dick man die zähflüssige Schicht annimmt. Betrachtet man die ganze Erde als gleichmäßig 
zähflüssig, so tritt die kleine Periode erst bei dem Wert $10^{18}$ auf, dagegen bei $10^{13}$, wenn nur die Schicht zwischen 120 und $600 \mathrm{~km}$ Tiefe als zähflüssig vorausgesetzt wird. Da die Rechnung nur für konstante Dichte im Erdkörper ausgeführt werden konnte, kann das Resultat nur als eine erste Orientierung betrachtet werden. Bei späterer Gelegenheit hat Schweydar einmal den Wert $10^{19}$ benutzt unter der Annalime, daß nur die Schicht zwischen 100 und $1600 \mathrm{~km}$ Tiefe fluid ist.

Schweydar ist ein Verfechter der hohen Werte für die Zähigkeit. Dennoch kommt er selbst zu dem Ergebnis: „Immerhin muß es als möglich bezeichnet werden, daß die Kontinente unter der Einwirkung der Polfluchtkraft eine nach dem Äquator gerichtete Verschiebung erleiden" [40]. Über diese Polfluchtkraft und die Rechnung, die zu diesem Ergebnis führt, wird später das Nötige gesagt werden.

Noch höhere Werte des Zähigkeitskoeffizienten, nämlich $10^{21}$ in der Schicht, wo er am kleinsten ist, hat Jeffreys [53] angenommen. Soweit mir bekannt, ist dies die extremste Annahme.

Andererseits erheben sich aber in neuester Zeit Stimmen, die gerade erstaunlich kleine Zähigkeitskoeffizienten, wenn auch nur in einer relativ dünnen Schicht, annehmen. So geht Meyermann $[64,65]$ von der auf astronomischem Wege neuerdings nachgewiesenen Tatsache einer Ungleichförmigkeit der Erdrotation aus: „1700 z. B. befand sich jeder Punkt der Erdoberfläche etwa 15 Sekunden östlich, 1800 etwa ebensoviel westlich, 1900 etwa 10 Sekunden östlich und 1924 über 20 Sekunden westlich des ihm auf einer gleichmäßig rotierenden Erde zukommenden Ortes. Da es ausgeschlossen ist, daß die Erde als ganze derartige Schwankungen ausführt, sehe ich in diesen einen Beweis dafür, daß die Erdkruste gegenüber dem Kern eine Westdrift besitzt... Wächst die Reibung, so wird die Westdrift geringer ... Nimmt die Reibung ab, so bewegt sich umgekehrt die Erdoberfläche gegenüber der hypothetischen Erde nach Westen." Sowohl in den Elementen des Erdmagnetismus wie auch in der Schwankung der Tageslänge trete eine Periode von 270 Jahren auf; hieraus schließt Meyermann auf einen vollen Umlauf der Kruste in der erstaunlich kurzen Zeit von 270 Jahren und kommt demgemäß, wenn die Fluidität auf eine Zone von $10 \mathrm{~km}$ Dicke beschränkt ist, auf einen Reibungskoeffizienten in dieser Schicht von nur etwa $10^{3}$ (21 mal dickflüssiger als Glycerin bei $\left.0^{0}\right)$. Es muß aber vorläufig dahingestellt bleiben, ob seine Deutung 
der Erscheinungen überhaupt zutrifft. In dieser Hinsicht ist eine Arbeit von Schuler [66] beachtenswert, in der gezeigt wird, daß bei Verstärkung der polaren Inlandeiskappen durch die hierbei erzeugte Annäherung der Massen an die Rotationsachse nach dem Satze von der Erhaltung des Rotationsmoments eine merkliche Beschleunigung der Erddrehung bewirkt werden muß, und umgekehrt eine Verlangsamung bei Abschmelzung der Eismassen, wobei wieder ein Massentransport zum Äquator, also von der Achse fort, vor sich geht.

Die Frage nach der Zähigkeit der unter den Kontinentalschollen gelegenen Schichten hängt eng zusammen mit derjenigen, ob die Temperatur dieser Schichten den Schmelzpunkt überschreitet oder nicht. Obwohl es wahrscheinlich ist, daß das geschmolzene Magma bei sehr hohem Druck auch sehr hohe Zähigkeit haben kann und sich daher wie festes Material verhält - die Erscheinungen bei so hohen Drucken sind ja unbekannt - , so neigen doch alle Autoren, die für eine schmelzflüssige Schicht eintreten, zu der Annahme, daß die Zähigkeit in dieser Schicht hinreichend klein ist, um große Verschiebungen, ja Strömungen, zu gestatten. Und gerade für diese Frage haben sich durch die Berücksichtigung des Radiums ganz neue Gesichtspunkte ergeben.

In Abb. 15 ist eine von v. Wolff herrührende Darstellung des Temperaturverlaufs in den obersten $120 \mathrm{~km}$ der Erdrinde gegeben, wie er sich unter verschiedenen Annahmen über den Radiumgehalt der Kruste berechnen läßt (Kurven a bis e). Außerdem sind aber noch zwei Schmelzkurven $S$ und $A$ eingetragen. Je nach dem Material, das man annimmt, bekommt man auch hier verschiedene Kurven. $S$ gibt die niedrigsten denkbaren Schmelztemperaturen für die verschiedenen Tiefen. Wie aus der Krümmung der Temperaturkurven und der Neigung der Schmelzkurven hervorgeht, gibt es in etwa 60 bis $100 \mathrm{~km}$ Tiefe eine optimale Region für Schmelzung, und es ist also möglich, daß hier eine geschmolzene Schicht zwischen zwei kristallinischen eingebettet ist.

Es liegt nahe, zu fragen, ob nicht die Erdbebenforschung über diese Frage Aufschluß geben kann. Leider ist dies nicht der Fall; sie könnte es dann, wenn geschmolzen soviel wie leichtflüssig bedeutete, denn in einem leichtflüssigen Medium können sich keine Transversalwellen, wie es die zweiten Vorläufer sind, fortpflanzen. Man nimmt aber heute meist an, daß dasjenige Material, was über den Schmelzpunkt temperiert und also geschmolzen ist, sich 
in einem amorphen, glasartigen, also festen Zustand befindet. Einen kleinen Fingerzeig liefert aber die Erdbebenforschung doch. Es läßt sich nämlich zeigen, daß unter den wahrscheinlichsten Annahmen über die Dichte des Materials sein elastischer Widerstand gegen Formveränderungen, der sonst allgemein mit der Tiefe wächst, bei etwa $70 \mathrm{~km}$ Tiefe eine Unterbrechung dieses Wachstums, vielleicht sogar eine vorübergehende Schwächung erfährt. Und dies wird, z. B. von Gutenberg [104], so ausgelegt, daß wahrscheinlich in dieser Tiefe der kristalline Zustand von dem amorphen glasartigen abgelöst wird. Und wenn letzterer auch für die kurzdauernden

Abb. 15.

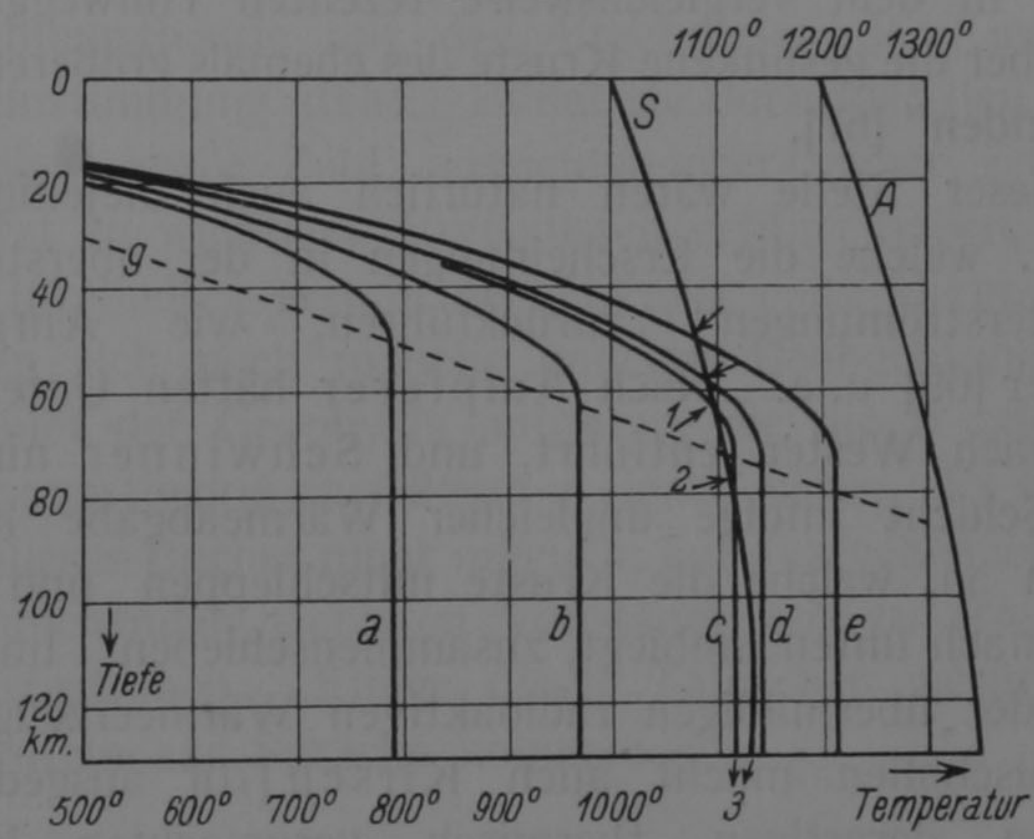

Temperaturverlauf ( $a$ bis $e$ ) und Schmelztemperaturen $(S$ und $A$ ) bis $120 \mathrm{~km}$ Tiefe, nach v. Wolff.

Kräfte der Erdbebenwellen als fest zu betrachten ist, so ist es doch nicht unwahrscheinlich, daß er Kräften gegenüber, die durch geologische Zeiten wirken, einen beträchtlichen Grad von Fluidität aufweist.

Auch gewisse geologische Tatsachen erfordern in diesem $\mathrm{Zu}$ sammenhang Beachtung. Die seltsamen großen „Granitaufschmelzungen“, wie sie z. B. von Cloos [103] aus Südafrika beschrieben sind, zeigen, daß die Schmelzisotherme des Granits in gewissen erdgeschichtlichen Perioden stellenweise bis dicht unter die Erdoberfläche vorgedrungen ist. Um so mehr müssen also damals die Tiefen von 60 bis $100 \mathrm{~km}$ geschmolzen gewesen sein. Die Isothermenflächen haben eben in der Erde keine feste Lage, sondern variieren sowohl 
zeitlich wie räumlich. Joly [56] sieht die Erklärung hierfür in dem Umstand, daß unter den Kontinentalschollen infolge der übermäßigen radioaktiven Wärmeproduktion die Temperatur beständig im Steigen ist, bis diese Schollen infolge der Schmelzung flott werden und sich über kühlere Teile der Erdkugel, vormalige Tiefseegebiete, hinüberschieben. In der Tat spricht für diese Deutung sehr die Tatsache, daß die geothermische Tiefenstufe in Europa im Mittel $31,7 \mathrm{~m}$, in Nordamerika aber im Mittel $41,8 \mathrm{~m}$ beträgt. Dieser neuerdings viel diskutierte merkwürdige Unterschied besagt ja, daß das Erdinnere unter Nordamerika kühler ist als unter Europa. Daly meint wohl mit Recht: „Eine ausreichende Erklärung hierfür kann man in dem vergleichsweise rezenten Hinweggleiten Nordamerikas über die gesunkene Kruste des ehemals größeren pazifischen Beckens finden" [67].

An dieser Stelle wären natürlich auch diejenigen Autoren zu nennen, welche die Erscheinungen in der obersten Erdrinde auf „Unterströmungen“ zurückführen, wie Ampferer [68], Schwininer [69] u. a. Nach Ampferer hätten Unterströmungen Amerika nach Westen entführt, und Schwinner nimmt in der flüssigen Schicht infolge ungleicher Wärmeabgabe Konvektionsströmungen an, welche die Kruste mitschleppen und da, wo die Bewegung nach unten umbiegt, zusammenschieben. Im Zusammenhang mit der übermäßigen radioaktiven Wärmeerzeugung in den Kontinentalschollen macht auch Kirsch [70] ausgedehnten Gebrauch von derartigen thermisch verursachten Konvektionsströmungen in der flüssigen Schicht. Er nimmt an, daß unter der ehemals zusammenhängenden Kontinentalscholle eine übermäßige Wärmeproduktion stattfand (Granitaufschmelzungen in Südafrika!) und $\mathrm{zu}$ einer Zirkulationsbewegung der flüssigen Unterlage führte, indem diese überall nach außen gegen die Tiefseebecken abströmte, hier infolge stärkeren Wärmeentzuges sich abwärts bewegte und mitten unter dem Kontinentalgebiet aufstieg. Durch die Reibung wurde dabei schließlich die Kontinentaldecke zerrissen und vom Strome nach allen Seiten auseinandergeführt. Kirsch kommt hier zu erstaunlich großen Strömungsgeschwindigkeiten und entsprechend kleinen Werten der Zähigkeit in der Schmelzschicht.

Alle diese Arbeiten zeigen jedenfalls das eine, daß wir heute in bezug auf den Zähigkeitskoeffizienten des Erdinnern und namentlich der einzelnen Erdschichten nicht dogmatisch sein dürfen; wir wissen noch gar nichts über ihn. Schweydars Ergebnisse sind aus dem 
Grunde nicht ausschlaggebend, weil sie nicht die Möglichkeit einer unzusammenhängenden, relativ leichtflüssigen Schicht ausschließen, und natürlich auch nichts darüber aussagen, ob es in gewissen Perioden der Vorzeit eine solche relativ leichtflüssige, zusammenhängende Schicht gegeben haben kann. Sie sind aber von großem Werte deshalb, weil sie auch bei Ablehnung einer leichtflüssigen Schicht doch auf Zähigkeitswerte führen, die Kontinentverschiebungen zulassen. Die Möglichkeit der letzteren hängt also nicht davon ab, ob diejenigen Autoren Recht behalten, die neuerdings für die wenigstens regionale und zeitweise Existenz einer leichtflüssigen Unterlage der Kontinentalschollen eingetreten sind.

Nach dem Vorangehenden erübrigt es sich, festzustellen, daß die Verschiebungstheorie mit den Ergebnissen der Geophysik in bester Übereinstimmung steht. Bildet sie doch hier den Ausgangspunkt für eine große Zahl aussichtsreicher neuer Forschungen, die schon jetzt zu wichtigen Ergebnissen geführt haben, wenn sich auch viele Einzelheiten erst in der Zukunft ganz klären werden.

Es ließen sich noch manche anderen Beobachtungstatsachen auf dem Gebiet der Geophysik anführen, die direkt oder indirekt die Verschiebungstheorie zu stützen geeignet wären. Es ist indessen im Rahmen dieses Buches nicht möglich, auf den verschiedenartigen, hier $\mathrm{zu}$ besprechenden Gebieten Vollständigkeit $\mathrm{zu}$ erreichen oder auch nur anzustreben. Einige dieser Tatsachen werden noch in späteren Kapiteln zur Sprache kommen.

Fünftes Kapitel.

\section{Geologische Argumente.}

Für unsere Auffassung, daß der Atlantik eine ungeheuer erweiterte Spalte darstellt, deren Ränder früher unmittelbar oder doch so gut wie unmittelbar zusammengehangen haben, ergibt sich eine scharfe Kontrolle durch einen Vergleich des geologischen Baues der beiden Seiten. Denn man wird erwarten dürfen, daß manche Faltungen und andere Strukturen, die vor dem Abriß entstanden sind, von der einen Seite zur anderen hinüberführen, und zwar müssen ihre Enden beiderseits des Ozeans gerade so gelegen sein, daß sie in der Rekonstruktion als unmittelbare Verlängerungen erscheinen. Da die Rekonstruktion selber infolge der markanten 
Linienführung der Schollenränder eine durchaus zwangsläufige ist und keinen Spielraum für eine Anpassung an diese Forderung zuläßt, haben wir es hier mit einem ganz unabhängigen Kriterium zu tun, das für die Beurteilung der Richtigkeit der Verschiebungstheorie von größter Bedeutung ist.

Die atlantische Spalte ist am breitesten im Süden, wo sie zuerst aufriß. Ihre Breite beträgt hier 6220 km. Zwischen Kap San Roque und Kamerun liegen nur noch 4880, zwischen der Neufundlandsbank und dem britischen Schelf nur noch 2410, zwischen Scoresbysund und Hammerfest 1300, und zwischen den Schelfrändern von Nordostgrönland und Spitzbergen wohl nur noch etwa 200 bis $300 \mathrm{~km}$. Hier scheint der Abriß erst in allerjüngster Zeit erfolgt zu sein.

Beginnen wir mit der Vergleichung im Süden. Ganz im Süden Afrikas findet sich ein von Ost nach West streichendes permisches Faltengebirge (die Zwarten Berge). In der Rekonstruktion trifft die Verlängerung dieser Kette nach Westen auf die nach der Karte zunächst durch nichts hervorgehobene Partie südlich von Buenos Aires. Es ist nun hochinteressant, daß Keidel $[72,73]$ in den hier befindlichen Sierren, namentlich der stärker gefalteten südlichen, alte Faltungen erkannt hat, die nach ihrem Bau, der Gesteinsfolge und dem Fossilinhalt nicht allein der nordwestlich davon sich der Andenfaltung anschmiegenden Vorkordillere der Provinzen San Juan und Mendoza, sondern vor allem auch dem südafrikanischen Kapgebirge völlig gleichen. ,,In den Sierren der Provinz Buenos Aires, besonders in dem südlichen Zuge, finden wir eine Schichtenfolge, die der in den Kapgebirgen Südafrikas sehr ähnlich ist. Große Übereinstimmung scheint wenigstens bei drei Gliedern vorhanden zu sein: bei dem unteren Sandstein der unterdevonischen Transgression, den fossilführenden Schiefern, die den Höhepunkt ihrer Ausbreitung bezeichnen, und bei einem jüngeren, sehr kennzeichnenden Gebilde, dem glazialen Konglomerat des oberen Paläozoikums... Sowohl die Sedimente der devonischen Transgression als auch das glaziale Konglomerat sind, wie in den Kapgebirgen, stark gefaltet; und die Bewegung ist hier wie dort in der Hauptsache gegen Norden gerichtet." Damit ist der Nachweis geführt, daß hier eine langgestreckte alte Faltung vorhanden ist, welche die Südspitze Afrikas durchzieht und sodann Südamerika südlich von Buenos Aires durchquert, um schließlich, nach Norden abbiegend, sich dem Verlauf der Anden anzugliedern. Heute sind die Bruchstücke dieser Faltung durch eine Tiefsee von mehr als $6000 \mathrm{~km}$ Breite voneinander getrennt. 
In unserer Rekonstruktion, die doch gerade hier kein Zurechtschieben zuläßt, werden die Teilstücke gerade zur Berührung aneinandergefügt; ihre Abstände von Kap San Roque bzw. Kamerun sind gleich. Dieser Beweis für die Richtigkeit unserer Zusammensetzung ist sehr auffallend und erinnert an die durchgerissene Visitenkarte als Erkennungszeichen. Es beeinträchtigt diese Übereinstimmung nur wenig, daß sich von dem südafrikanischen Zuge bei Erreichung der Küste die Kette der Cedarberge nach Norden abzweigt. Denn dieser bald erlöschende Zweig trägt den Charakter einer lokalen Ablenkung, die durch irgend eine Diskontinuität an der späteren Spaltungsstelle verursacht sein mag. Solche Abzweigungen sehen wir in noch viel größerem Maße bei den europäischen Faltengebirgen, sowohl bei den karbonischen, als bei den tertiären, und sie hindern uns auch hier nicht, diese Faltungen zu einem System zusammenzufassen und auf einheitliche Ursachen zurückzuführen. Auch wenn, wie es nach neueren Untersuchungen scheint, die afrikanische Faltung noch in jüngeren Zeiten fortgedauert hat, so läßt sich doch hieraus kein Altersunterschied konstruieren, denn bei Keidel lesen wir: „In den Sierren ist, als die jüngste Bildung, das glaziale Konglomerat gefaltet worden; in den Kapgebirgen zeigen die Eccaschichten an der Basis der Gondwanaserie (Karrooschichten) noch Spuren der Bewegungen... In beiden Gebieten können also die hauptsächlichen Bewegungen in dem Zeitabschnitt vom Perm bis zur unteren Kreide vor sich gegangen sein."

Aber diese Bestätigung unserer Ansichten durch das Kapgebirge und seine Verlängerung in den Sierren von Buenos Aires steht keineswegs allein da, vielmehr finden wir noch zahlreiche weitere Belege dafür längs den Küsten des Atlantik. Schon in großen Zügen zeigt die ungeheure, seit langen Zeiten nicht mehr gefaltete Gneistafel Afrikas eine auffallende Ähnlichkeit mit derjenigen Brasiliens. Und daß diese Ähnlichkeit sich nicht nur auf Allgemeinheiten beschränkt, zeigt einmal die Übereinstimmung der Eruptivgesteine und Sedimente und andererseits die der alten Faltungsrichtungen hüben und drüben.

Die Eruptivgesteine hat H. A. Brouwer verglichen [74]. Er findet nicht weniger als fünf Parallelen, nämlich 1. den älteren Granit, 2. den jüngeren Granit, 3. alkalireiche Gesteine, 4. vulkanische jurassische Gesteine und intrusiven Dolerit, 5. Kimberlit, Alnoit usw.

Der ältere Granit ist in Brasilien enthalten in dem sogenannten „Brasilianischen Komplex“, in Afrika in dem „Fundamental- 
komplex“ von Südwestafrika, ferner auch dem „Malmesburysystem“ der südlichen Kapkolonie und dem „,Swazilandsystem“ von Transvaal und Rhodesia. „Sowohl die Ostküste von Brasilien in der Serra do Mar wie die gegenüberliegende Westküste von Süd- und Mittelafrika bestehen zum größten Teil aus diesen Gesteinen, und sie verleihen in beiden Kontinenten der Landschaft vielfach einen gleichartigen topographischen Charakter."

Der jüngere Granit ist in Brasilien intrusiv in der „Minasserie“ in den Provinzen Minas Geraes und Goyaz, wo er goldführende Gänge bildet, sowie in der Provinz Sao Paulo. In Afrika entspricht ihm der Erongogranit im Hereroland und der Brandberggranit im nordwestlichen Teil von Damaraland, sowie auch die Granite des „Bushveld Igneous Complex" in Transvaal.

Die alkalireichen Gesteine ferner finden sich gerade an den korrespondierenden Küstenstrecken: auf brasilianischer Seite an verschiedenen Stellen der Serra do Mar (Itatiaya, Serra do Gericino bei Rio de Janeiro, Serra de Tingua, Cabo Frio), auf afrikanischer Seite an der Küste von Lüderitzland, bei Kap Cross nördlich von Svakopmund, aber auch noch in Angola. In weiterer Entfernung von der Küste gehören hierher auch die beiden etwa 30 km Durchmesser haltenden Eruptivgebiete von Poços de Caldas im Süden der Provinz Minas Geraes und von Pilandsberg im Rustenburgdistrikt in Transvaal. Gerade diese alkalireichen Gesteine sind in ihrer völlig gleichen Ausbildung des Tiefengesteins, des Ganggesteins und des Effusivgesteins sehr auffallend.

Mit Bezug auf die vierte Gruppe von Gesteinen (jurassische vulkanische Gesteine und intrusiver Dolerit) sagt Brouwer: „Ebenso wie in Südafrika kommt im untersten Horizont des ungefähr mit dem südafrikanischen Karroosystem übereinstimmenden Santa Catharina-Systems eine mächtige Serie vulkanischer Gesteine vor, die als jurassisch betrachtet werden kann und große Flächen in den Provinzen Rio Grande do Sul, Santa Catharina, Parana, Sao Paulo und Matto Grosso und sogar noch von Argentinien, Uruguay und Paraguay bedecken." In Afrika gehört hierher namentlich die Kaokoformation zwischen 18 und $21^{\circ}$ Südbreite, welcher gleichartige Gesteine in den südbrasilianischen Provinzen Santa Catharina und Rio Grande do Sul entsprechen.

Am bekanntesten endlich ist die letzte Gesteinsgruppe (Kimberlit, Alnoit usw.), weil sie in Brasilien wie Südafrika die Lagerstellen der bekannten Diamantenfunde abgibt. In beiden Gebieten kommt 
die eigenartige Lagerungsform der „Pfeifen“ vor. Weiße Diamanten gibt es in Brasilien in der Provinz Minas Geraes und in Südafrika nur nördlich des Oranje. Aber deutlicher als in diesen immerhin seltenen Diamantvorkommen zeigt sich die Übereinstimmung in der Ausbreitung des kimberlitischen Muttergesteins. Dies ist in Gängen auch in der Provinz Rio de Janeiro festgestellt. „Ebenso wie die kimberlitischen Gesteine nahe der Westküste von Südafrika gehören auch die bekannten brasilianischen Gesteine beinahe alle zu den glimmerarmen basaltischen Varietäten $\left.{ }^{1}\right) . "$

Brouwer hebt aber hervor, daß auch die Sedimente eine große Übereinstimmung hüben und drüben zeigen: „Die Gleichheit zwischen einigen Gruppen von Sedimentgesteinen beiderseits des Atlantischen Ozeans ist ebenfalls auffallend. Wir nennen nur das südafrikanische Karroosystem und das brasilianische Santa Catharina-System. Das Orleanskonglomerat in Santa Catharina und Rio Grande do Sul stimmt überein mit dem Dwykakonglomerat von Südafrika, und in beiden Kontinenten werden die obersten Abschnitte durch die schon genannte mächtige Serie vulkanischer Gesteine gebildet, wie die vom Drakenberg in der Kapkolonie und die von der Serra Geral in Rio Grande do Sul.“

Du Toit [75] vermutete sogar, daß das erratische permokarbonische Material in Südamerika teilweise aus Afrika stammt: „Der südbrasilianische Tillit stammt nach Coleman von einer Eiskappe, die wahrscheinlich ihr Zentrum im Südosten ${ }^{2}$ ), außerhalb der heutigen Küstenlinie, hatte. Sowohl er wie Woodworth erwähnen gewisse erratische Geschiebe aus einem eigentümlichen Quarzit oder Sandstein mit Kieseln aus gebändertem Jaspis, der nach ihrer Beschreibung genau demjenigen gleicht, der vom Transvaaleise von den Bergketten der "Matsap beds" in Westgriqualand aufgenommen und mindestens bis zum 18. Meridian nach Westen transportiert ist. Könnte er, wenn wir an die Hypothese der Kontinentverschiebungen denken, nicht möglicherweise noch viel weiter nach Westen geschafft worden sein?" Aber neuerdings hat

1) H. S. Washington [113] gibt diese Übereinstimmungen der vulkanischen Gesteine zwar gleichfalls $\mathrm{zu}$, meint aber trotzdem hauptsächlich wohl infolge zu hoch gespannter Forderungen -, daß ein Vergleich nicht zugunsten der Verschiebungstheorie spreche. Seine schlecht begründete Ablehnung ist leider für die Haltung vieler amerikanischer Geologen ausschlaggebend geworden.

${ }^{2}$ ) Im Original steht (wie die folgenden Worte zeigen, offenbar durch Versehen): south-west. 
L. C. Ferraz (erwähnt in [78]) dies Gestein südlich der Fundstelle bei Blumenau in Santa Catharina, am Nordufer des Itajahýflusses, anstehend gefunden, wodurch die von du Toit vorgeschlagene Deutung ihre Beweiskraft einbüßt. Andererseits ist aber das gleichartige Vorkommen des anstehenden Gesteins in Brasilien und Südafrika wiederum ein sehr beachtenswertes Glied in der langen Kette auffallender Übereinstimmungen zwischen diesen beiden Kontinenten.

Weitere Übereinstimmung finden wir in den Richtungen der uralten Faltungen, welche diese großen Gneistafeln überall durch-

Abb. 16 .

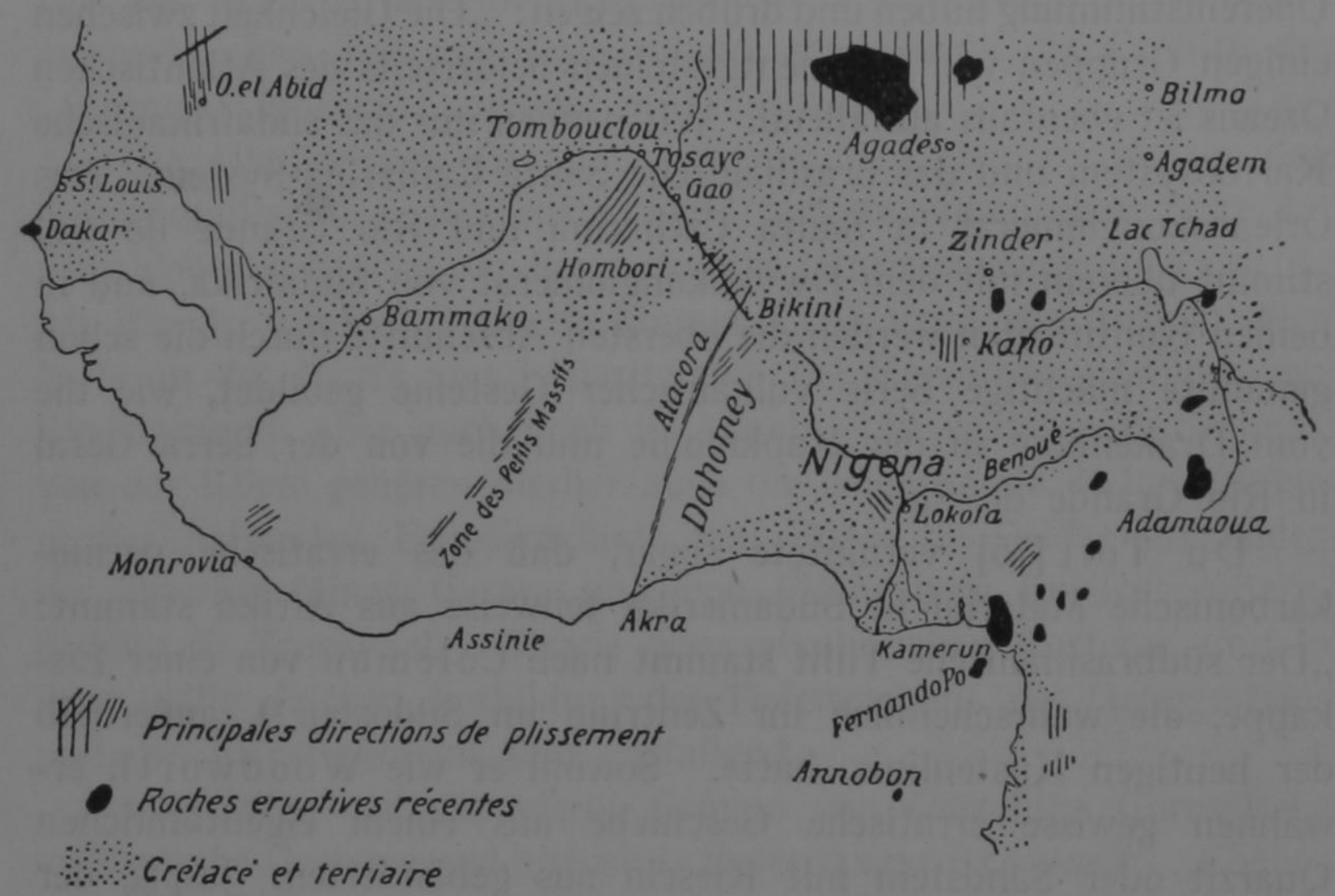

Streichrichtungen in Afrika, nach Lemoine.

ziehen. Für Afrika verweisen wir auf die in Abb. 16 dargestellte, von Lemoine [76] entworfene Karte. Sie ist für andere Zwecke hergestellt und zeigt daher das, was wir brauchen, nicht sehr deutlich, aber sie zeigt es doch. In dem Gneismassiv des afrikanischen Kontinents kommen hauptsächlich zwei etwas verschieden alte Streichrichtungen vor. Im Sudan herrscht die ältere nordöstliche Streichrichtung vor, welche sich schon in dem geradlinigen gleichgerichteten Oberlauf des Niger zeigt und noch bis Kamerun beobachtet wird. Sie schneidet die Küste unter einem Winkel von etwa $45^{\circ}$. Südlich von Kamerun dagegen - auf der Karte gerade noch erkennbar - tritt die andere, jüngere Streich- 
richtung in den Vordergrund, welche etwa von Norden nach Süden weist und der Küste mit ihren Krümmungen parallel verläuft.

In Brasilien finden wir dieselbe Erscheinung. Schon E. Suess schreibt: „Die Karte des östlichen Guayana... zeigt mehr oder minder ostwestliches Streichen der alten Felsarten, aus welchen dieses Gebiet besteht. Auch die eingelagerten paläozoischen Schichten, welche den nördlichen Teil der Mulde des Amazonas ausmachen, verfolgen diese Richtung, und der Verlauf der Küste von Cayenne gegen die Mündung des Amazonas ist daher quer auf das Streichen ... Soweit der Bau Brasiliens heute bekannt ist, muß angenommen werden, daß auch bis Kap San Roque der Umriß des Festlandes das Streichen des Gebirges quert, aber von diesem Vorgebirge an wird allerdings bis nach Uruguay hinab die Lage der Küste durch das Gebirge vorgezeichnet." Auch hier folgen die Flußläufe (Amazonas einerseits, Rio San Francisco und Parana andererseits) in großen Zügen der Streichrichtung. Allerdings haben die neueren Forschungen, wie die von Keidel (a. a. O.) hauptsächlich nach J. W. Evans gegebene, in Abb. 17 reproduzierte tektonische Karte von Südamerika zeigt, die Existenz noch einer dritten, der Nordostküste parallelen Streichrichtung nachgewiesen, wodurch sich die Verhältnisse etwas komplizierter gestalten. Allein die anderen beiden Streichrichtungen treten auch in dieser Karte, wenngleich teilweise etwas von der Küste abgedrängt, sehr deutlich hervor. Bei der beträchtlichen Drehung, welche Südamerika bei der Rekonstruktion erfahren muß, wird die Richtung des Amazonas gerade parallel zum Oberlauf des Niger, so daß die beiden Streichrichtungen mit den afrikanischen zusammenfallen. Hierin dürfen wie eine weitere Bestätigung eines ehemaligen unmittelbaren Zusammenhangs sehen.

In neuerer Zeit ist der gleichartige Bau Brasiliens und Südafrikas immer stärker betont worden. So stellt Maack [77] fest: „Wer Südafrika kennt, für den ist der geologische Bau dieser (brasilianischen) Landschaft überraschend. Auf Schritt und Tritt wurde ich an Landschaftsformen des Namalandes und Transvaals erinnert. Die Schichtfolge mit all ihren Besonderheiten entspricht vollkommen dem Aufbau des südafrikanischen Sockels." Maack fand auf dieser Reise fünf Kimberlitpfeifen bei Patos (etwa $181 / 2^{0}$ Süd, $461 / 2^{0}$ West). Er kommt zu dem Schluß: „Es liegt auf der Hand, daß man bei der heutigen Entfernung der korrespondierenden Formationen das Absinken von Landbrücken in der Breite des Atlantischen Ozeans ablehnen muß. Man kommt auf eine Kontinentverschiebung im 
Sinne A. Wegeners, eine Auffassung, die ihre Stützen in der Beobachtung findet, daß seit ältesten geologischen Zeiten, mit Ausnahme des Permokarbons, im westlichen Südafrika ein Trockenklima geherrscht hat und andererseits die triassischen Ablagerungen in Minas einem trockenen Binnenlandklima entsprechen."

Besonders eingehende vergleichende Studien hat der bekannte südafrikanische Geologe du Toit auf einer zu diesem Zwecke ausgeführten Forschungsreise in Südamerika durchgeführt. Die Ergebnisse dieser Untersuchung, bei der auch die Literatur sehr vollständig berücksichtigt ist, sind 1927 in einem 157 Seiten starken Buch als Publikation Nr. 381 der Carnegie Institution of Washington unter dem Titel „A geological Comparison of South America with South Africa“ [78] veröffentlicht. Das ganze Buch ist eine einzige geologische Beweisführung für die Richtigkeit der Verschiebungstheorie auf diesem Teile der Erde. Wollten wir alle Einzelheiten anführen, die sich in ihm zugunsten dieser Theorie ergeben, so müßten wir es von Anfang bis zu Ende übersetzen. Recht häufig finden sich Äußerungen wie die folgende: „In der Tat hatte ich auch bei genauer Untersuchung große Schwierigkeiten, mir vorzustellen, daß ich mich hier auf einem anderen Kontinent befand und nicht in einem Teile des südlichen Kaplands" (S. 26). Auf S. 97 sagt der Verfasser: „Als ich diesen Überblick vorbereitete, habe ich zuerst versucht, den historischen Bericht zu schreiben ohne Rücksicht auf irgend eine Hypothese über die Art und Weise eines solchen ehemaligen Zusammenhangs oder über die Art der schließlichen Trennung der Landmassen; aber als die Daten gesammelt waren, zeigte sich klar, daß sie sehr bestimmt in Richtung der Verschiebungstheorie weisen." Übereinstimmungen beiderseits des Ozeans seien jetzt in so großer Zahl bekannt, daß der Zufall dafür nicht mehr in Betracht komme, zumal sie sich auf enorme Landstrecken und Zeiten vom Vordevon bis zum Tertiär erstrecken. „Außerdem sind diese sogenannten Koinzidenzen sowohl von stratigraphischer als lithologischer, paläontologischer, tektonischer, vulkanischer und klimatischer Natur."

Wir können hier nicht einmal die kurzgefaßte Aufzählung der Übereinstimmungen wiedergeben, die in Kapitel VII (Bearing on the displacement hypothesis) 7 Seiten füllt. Dagegen sei im folgenden die auf S. 15 bis 16 zusammengestellte Vergleichung der geologischen Hauptzüge mitgeteilt:

„Wir wollen nun die beiden Strecken, nämlich die von Sierra Leone bis zum Kap auf der einen und die von Pará bis Bahia Blanca 
Abb. 17.

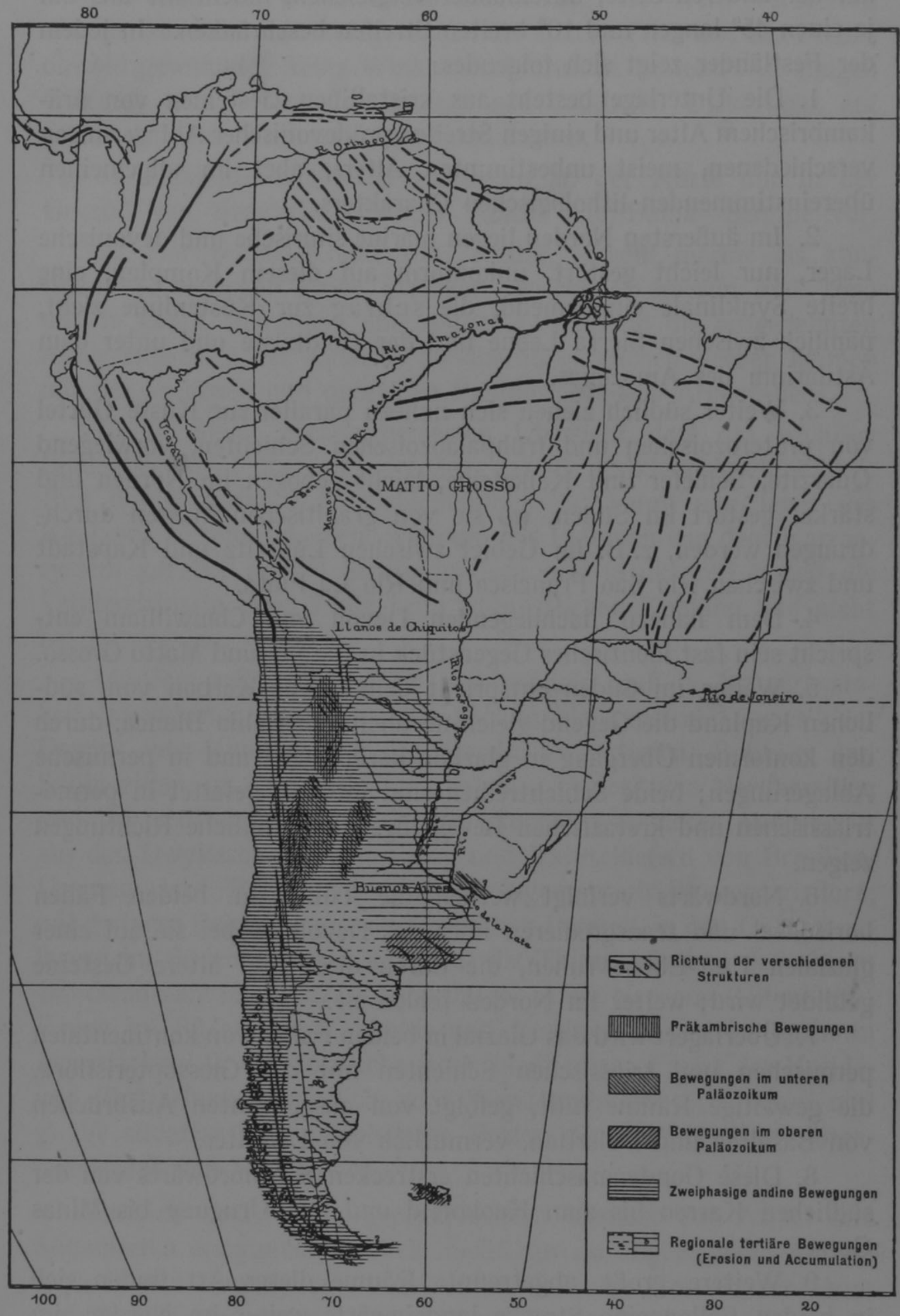

Schematische tektonische Karte von Südamerika, nach Keidel und J. W. Evans. 
auf der anderen Seite, miteinander vergleichen, indem wir uns auf je einen $45^{\circ}$ langen und $10^{\circ}$ breiten Streifen beschränken. In jedem der Festländer zeigt sich folgendes:

1. Die Unterlage besteht aus kristallinen Gesteinen von präkambrischem Alter und einigen Streifen prädevonischer Ablagerungen verschiedenen, meist unbestimmten Alters, aber im allgemeinen übereinstimmenden lithologischen Charakters.

2. Im äußersten Norden liegen marine silurische und devonische Lager, nur leicht gestört, unkonform auf diesem Komplex, eine breite Synklinale einnehmend, die schräg zur Küstenlinie zieht, nämlich zwischen Sierra Leone und der Goldküste und unter dem Ästuarium des Amazonas.

3. Weiter südlich ziehen sich nahezu parallel zur Küste Gürtel von proterozoischen und frühpaläozoischen Schichten, vorwiegend Quarzite, Schiefer und Kalksteine, leicht gebogen im Norden und stärker gestört im Süden, wo sie von granitischen Massen durchdrungen werden, z. B. im Gebiet zwischen Lüderitz und Kapstadt und zwischen Rio São Francisco und Rio La Plata.

4. Dem nahezu flachliegenden Devon von Clanwilliam entspricht sein fast identisches Gegenstück in Paraná und Matto Grosso.

5. Weiter im Süden entspricht dem Devon-Karbon vom südlichen Kapland die Gegend gleich nördlich von Bahia Blanca, durch den konformen Übergang in glaziale karbonische und in permische Ablagerungen; beide Schichtreihen sind intensiv gefaltet in permotriassischen und kretazischen Bewegungen, die ähnliche Richtungen zeigen.

6. Nordwärts verfolgt werden die Tillite in beiden Fällen horizontal und transgredieren über das Devon, wobei sie auf einer glazialen Fast-Ebene ruhen, die durch diese und ältere Gesteine gébildet wird; weiter im Norden fehlen sie.

7. Überlagert wird das Glazial in beiden Fällen von kontinentalen permischen und triassischen Schichten mit der Glossopterisflora, die gewaltige Räume füllt, gefolgt von ausgedehnten Ausbrüchen von Basalten und Doleriten, vermutlich von Liasalter.

8. Diese Gondwanaschichten erstrecken sich nordwärts von der südlichen Karroo bis zum Kaokofeld und von Uruguay bis Minas Geraes.

9. Weitere große abgetrennte Räume dieser Art finden sich in beiden Fällen eine Strecke landeinwärts weiter im Norden, im Angola-Kongo und im Piauhý-Maranhãogebiet. 
10. Eine Intraformationsunterbrechung ist weit verbreitet, nämlich zwischen den Ablagerungen der späten Trias und des Perms, obwohl gewöhnlich keine Winkelunkonformität besteht. In einigen Gebieten aber lagern die ersteren mit deutlicher Diskordanz auf permischen der vorpermischen Formationen.

11. Gekippte Kreidelager kommen an der Küste nur in der Gegend von Benguella-Unterer Kongo und Bahia-Sergipe vor.

12. Horizontale Kreide und Tertiär, sowohl marine als kontinentale, bedecken große Strecken zwischen Kamerun und Togo und in Ceará, Maranhão und südlicher, während die ausgedehnten Ablagerungen in der Kalahari annähernd verglichen werden können mit der neogenen und quartären Pampasformation Argentiniens.

13. In dieser verallgemeinerten Übersicht darf das wichtige Bindeglied nicht übersehen werden, das die Falklandsinseln bilden. Ihre devono-karbonische Schichtenfolge ist kaum von jener des Kaplands zu unterscheiden, während das Lafonian eng dem Karroosystem parallel geht. Stratigraphisch und strukturell haben die Falklandsinseln ihren Platz beim südwestlichen Kapland und nicht bei Patagonien.

14. Vom paläontologischen Gesichtspunkt muß die Aufmerksamkeit besonders gerichtet werden auf: a) die „,australe Fazies“ des Devons von Kapland, Falklandsinseln, Argentinien, Bolivien und Südbrasilien, im Gegensatz zur „borealen Fazies“ von Nordbrasilien und der zentralen Sahara; b) das Reptiliengeschlecht Mesosaurus aus den Dwykaschiefern vom Kap und Iratyschiefern von Brasilien, Uruguay und Paraguay; c) die Gangamopteris-Glossopterisflora, mit geringer Beimischung von nordischen Formen, in den Gondwanalagern im Süden beider Länder; d) die Thinnfeldiaflora des oberen Gondwana am Kap und in Argentinien; e) die Neocom- (Uitenhage-) Fauna im Süden des Kaplands und Nordwesten von Neuquén in Argentinien; f) die nordische oder mediterrane Fazies der Kreideund Tertiärfaunen nördlich vom Wendekreis des Steinbocks und g) die südatlantisch-antarktische Fazies des Eozäns (San Jorgeformation) von Patagonien.

Endlich sind 15. die geographischen Umrisse von Afrika und Südamerika erstaunlich ähnlich, nicht nur im allgemeinen, sondern sogar in den Einzelheiten; überdies ist, außer im Norden, der Saum von Tertiärablagerungen von geringer Breite und die Anwesenheit dieser Lager deshalb wenig wichtig." - 
Von besonderem Interesse ist ein ganz neues Moment in den geologischen Beziehungen der beiden Kontinente, auf welches du Toit zum ersten Male aufmerksam macht. Auf S. 109 sagt er:

„,Von allergrößter Wichtigkeit ist aber der Beweis, den das Studium der Faziesunterschiede innerhalb der einzelnen Formationen liefert, wenn diese innerhalb der Kontinente untersucht werden.

Betrachten wir zur Erläuterung den Fall von zwei äquivalenten Formationen, deren eine in Südamerika an oder nahe bei der atlantischen Küste bei $A$ beginnt und nach Westen bis $A^{\prime}$ reicht, während die andere in Afrika ähnlich nahe der Küste bei $B$ beginnt und nach Osten bis $B^{\prime}$ reicht. Dann läßt sich in mehr als einem solchen Falle nachweisen, daß die Faziesänderung zwischen $A$ und $A^{\prime}$ oder zwischen $B$ und $B^{\prime}$ größer ist als die zwischen $A$ und $B$, obwohl die ganze Breite des Atlantik zwischen $A$ und $B$ liegt. Mit anderen Worten, diese einzelnen Formationen haben an den gegenüberliegenden Küsten die Tendenz, gleichartiger zu sein als innerhalb einer oder auch ihrer beiden heutigen sichtbaren Erstreckungen in den betreffenden Kontinenten. Mit der Vervielfältigung solcher Beispiele, die sich aus mehr als einer geologischen Epoche anführen lassen, kann eine solche eigentümliche Beziehung nicht mehr als rein zufällig betrachtet werden, und folglich muß eine bestimmte Erklärung dafür gesucht werden. Eine genauere Untersuchung zeigt ferner, daß diese unerwartete Tendenz gleich stark hervortritt, ob nun die betreffenden Formationen marine, Delta-, kontinentale, glaziale, äolische oder vulkanische sind."

Du Toit gibt in seinem Buche die in Abb. 18 wiedergegebene Karte, welche die gegenseitige Lage der beiden Kontinente vor der Trennung zeigt. Du Toit hebt hervor, daß man bei der Rekonstruktion immerhin einen Zwischenraum von mindestens 400 bis $800 \mathrm{~km}$ zwischen den heutigen Küsten lassen müsse, wenn man den an ihnen zu beobachtenden Faziesunterschieden Rechnung tragen will. Ich kann ihm in diesem Punkte nur völlig zustimmen. Denn zwischen beiden Küsten muß ja nicht nur Platz für den vorgelagerten Schelf, sondern außerdem vielleicht auch noch für das Material der mittelatlantischen Bodenschwelle bleiben. Eine genauere Angabe der gegenseitigen Lage der Schollen wird vielleicht möglich werden, wenn die zahlreichen Echolotungen der „Meteor"-Expedition ausgewertet und bearbeitet sein werden. Ich vermute, daß sich auf solchem Wege ein ähnliches Bild ergeben wird, wie das von du Toit auf Grund der geologischen Vergleichung gefundene. 
$\mathrm{Da}$ B die Falklandsinseln, obwohl sie sich vom patagonischen Küstenschelf erheben, keine geologische Verwandtschaft mit Patagonien, wohl aber mit Südafrika zeigen, betrachtet du Toit mit Recht als eine besondere Stütze der Verschiebungstheorie ${ }^{1}$ ).

Abb. 18.

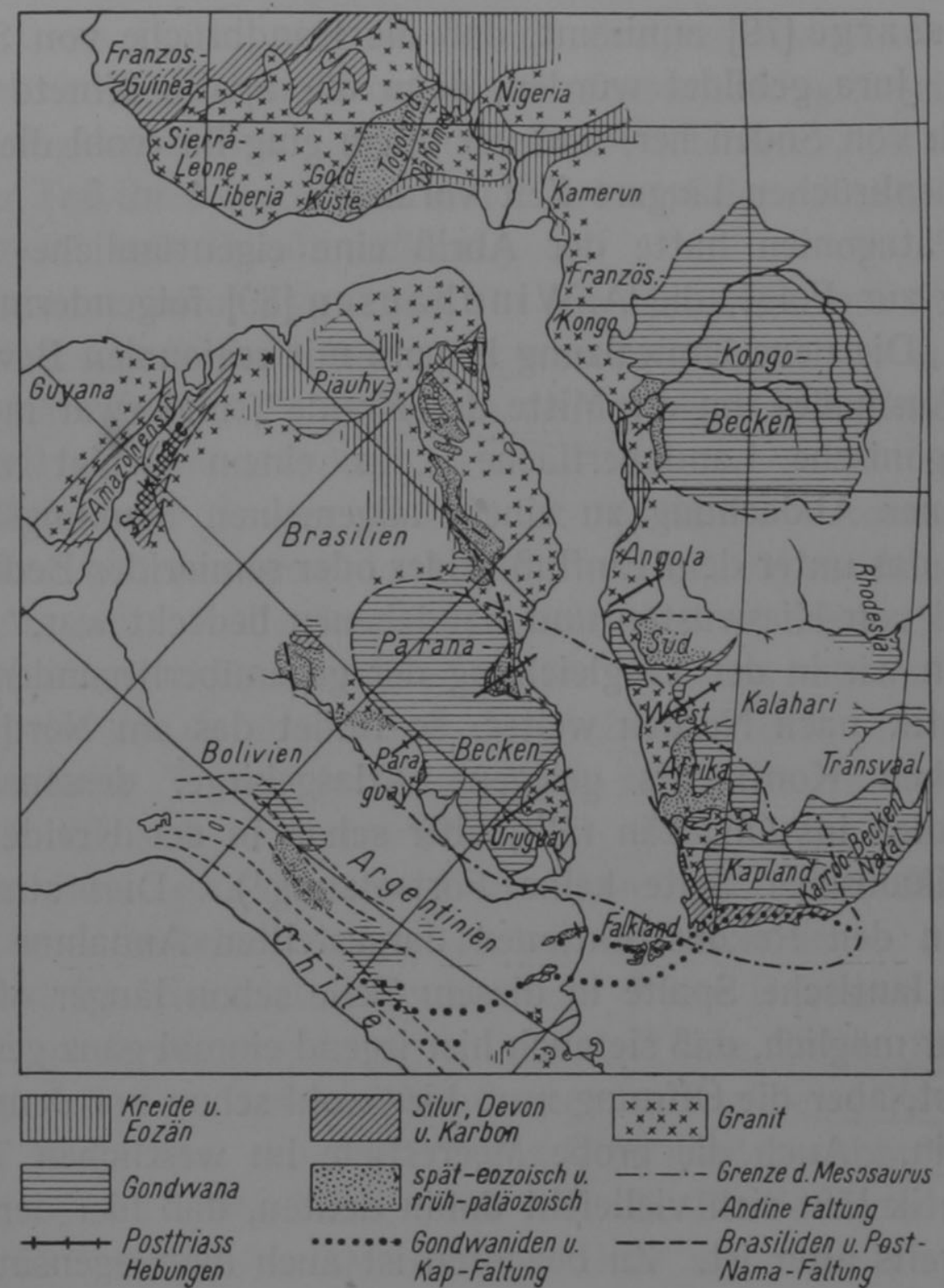

Frühere relative Lage Südamerikas und Afrikas nach du Toit.

Ich muß gestehen, daß die Lektüre von du Toits Buch einen außerordentlichen Eindruck auf mich gemacht hat, da ich eine so

1) Ich gestehe, daß mir die von du Toit in Abb. 18 angenommene Position der Falklandsinseln in der Rekonstruktion mit Hinblick auf ihre heutige Lage und die Tiefenkarte des Südatlantik doch bedenklich erscheint. Ich würde sie in der Rekonstruktion eher südlich als westlich vom Kap der Guten Hoffnung setzen; doch ist dies eine Nebenfrage, die gewiß einmal durch die weitere Forschung geklärt werden wird. 
vollkommene geologische Übereinstimmung der beiden Kontinente bisher kaum zu erwarten gewagt hatte.

Wie schon früher gezeigt wurde, muß aus paläontologischen und biologischen Gründen geschlossen werden, daß der Formenaustausch zwischen den Landgebieten Südamerikas und Afrikas in der unteren bis mittleren Kreide erlosch. Damit steht nicht im Widerspruch, wenn Passarge [79] annimmt, daß die Randbrüche von Südafrika schon im Jura gebildet wurden, denn die Spalte öffnete sich nur allmählich von Süden her, und vor allem ging ihr wohl die Bildung von Grabenbrüchen längere Zeit voraus.

In Patagonien hatte der Abriß eine eigentümliche Schollenbewegung zur Folge, die A. Windhausen [80] folgendermaßen beschreibt: „Die neue Umwälzung begann mit regionalen Bewegungen größten Ausmaßes um die Mitte der Kreide“, und zwar indem sich die patagonische Landoberfläche ,aus einem Gebiet mit ausgesprochener Abdachung zu einem allgemeinen Senkungsfeld umwandelte, das unter dem Einfluß arider oder semiarider Bedingungen stand und von Kieswüsten und Sandebenen bedeckt war."

Gehen wir in der Vergleichung der gegenüberliegenden Küsten des Atlantik nach Norden weiter, so findet das am Nordrand des afrikanischen Kontinents gelegene Atlasgebirge, dessen Faltung hauptsächlich ins Oligozän fällt, aber schon in der Kreide begann, auf amerikanischer Seite keine Fortsetzung ${ }^{1}$ ). Dies stimmt mit unserer, in den Rekonstruktionen dargestellten Annahme überein, $\mathrm{daß}$ die atlantische Spalte in diesem Teile schon länger offen war. Es ist zwar möglich, daß sie auch hier irgend einmal ganz geschlossen gewesen ist, aber die Öffnung muß hier wohl schon vor dem Karbon erfolgt sein. Auch die große Meerestiefe im westlichen Teile des Nordatlantik läßt sich vielleicht dahin deuten, daß hier der Meeresboden bereits älter ist. $\mathrm{Zu}$ beachten ist auch die Gegensätzlichkeit der spanischen Halbinsel mit der gegenüberliegenden amerikanischen Küste, die einen ehemaligen unmittelbaren Zusammenschluß der Küsten sehr unwahrscheinlich macht. Aber ein solcher darf auch nach der Verschiebungstheorie nicht angenommen werden. Denn

1) Gentil (neuerdings auch Staub in [214]) möchte zwar in den gleichaltrigen mittelamerikanischen Gebirgen, speziell den Antillen, eine solche Fortsetzung sehen, doch hat Jaworski dem entgegengehalten, daß dies mit der allgemein angenommenen Auffassung von E. Sues's unvereinbar ist, welcher den östlichen Kordillerenbogen Südamerikas in die Kleinen Antillen übergehen und also wieder nach Westen umbiegen läßt, ohne daß dabei Ausläufer nach Osten entsendet werden. 
zwischen Spanien und Amerika liegt das breite untermeerische Massiv der Azoren. Wie ich aus dem ersten transatlantischen Echolotprofil abzuleiten versuchte [37], stellt dies Massiv wahrscheinlich einen niedergebrochenen Trümmerstreifen aus kontinentalem Material dar, dessen ursprüngliche Breite möglicherweise auf über 1000 km geschätzt werden darf.

Daß diese Inseln, ebenso wie die übrigen atlantischen Inseln, in der Tat als Kontinentalbrocken aufzufassen sind, entspricht völlig ihrem geologischen Bau. (Fraglich bleibt allerdings, ob sich nicht ein großer Teil ihres Unterbaus und überhaupt der mittelatlantischen Bodenschwelle aus Basalt aufbaut.)

So kommt auch Gagel [81] für die Kanarien und Madeira zu dem Schluß, „daß diese Inseln abgesprengte Reste des europäischafrikanischen Kontinents sind, von dem sie erst in verhältnismäßig junger Zeit getrennt wurden“"

Im Gebiet der Großen Antillen ist Matley vor kurzem bei der geologischen Untersuchung der Caymaninseln [105] zu dem Ergebnis gekommen, daß sich die dortigen Verhältnisse am besten auf Grund der Verschiebungstheorie erklären lassen: „Erstens haben alle Großen Antillen, obwohl sie manchmal durch beträchtliche Entfernungen und ozeanische Tiefen getrennt sind, eine bemerkenswert enge Familienähnlichkeit in ihrem Charakter, ihrer Fazies und den Beziehungen ihrer geologischen Formationen und der Folge ihrer vulkanischen Gesteine. Ihre geologische Geschichte ist, soweit sie bekannt ist, gleichfalls sehr ähnlich. Diese Faktoren sind nicht nur nicht ungünstig, sondern im Gegenteil eine Stütze für die Anschauung, daß diese Inseln früher näher beieinander gelegen haben, als sie es heute tun. Und weiter sind die großen submarinen Senkungen des Karibischen Meeres, wie z. B. die Bartlettrinne (zwischen Jamaika und Kuba), welche schon Taber als einen Grabenbruch angesprochen hat, so tief, daß es schwierig zu verstehen ist, wie abgesunkene Teile der Antillenlandmasse so tief in die Erdkruste einsinken sollten." Gewiß nur ein unbedeutendes Detail. Aber aus solchen Mosaiksteinchen setzt sich schließlich das großartige Bild der ganzen Erdoberfläche zusammen.

Weiter im Norden finden wir in unmittelbarer Folge drei alte Faltungszonen, welche sich von der einen Seite des Atlantik auf die andere hinüberziehen und wieder sehr auffallende Bestätigungen für die Annahme eines einstigen unmittelbaren Zusammenhangs liefern. 
Am meisten in die Augen fallend sind die karbonischen Faltungen, welche E. Suess das armorikanische Gebirge nennt, und welche die Kohlenlager Nordamerikas als die unmittelbare Fortsetzung der europäischen erscheinen lassen. Dieses heute stark eingeebnete Gebirge zieht sich in Europa, aus dem Innern des Kontinents kommend, in bogenförmigem Verlauf zuerst gegen WNW, dann gegen W, um in Südwestirland und der Bretagne eine wild zerrissene Küste (sogenannte Riasküste) zu bilden. Die südlichsten, Frankreich durchsetzenden Faltenzüge dieses Systems scheinen in dem vorgelagerten Schelf ganz nach Süden umzubiegen und jenseits der buchförmig sich öffnenden Tiefseespalte der Biscaya auf der spanischen Halbinsel ihre Fortsetzung $\mathrm{zu}$ finden. Suess nannte diese Abzweigung den ,,asturischen Wirbel“. Die Hauptketten aber setzen offenbar durch die nördlicheren Teile des Schelfes nach Westen fort, wenngleich durch die Abrasion der Brandungswoge abgehobelt, und weisen hier, eine Fortsetzung heischend, in den Atlantischen Ozean hinaus ${ }^{1}$ ).

Diese Fortsetzung auf amerikanischer Seite bilden, wie Bertrand zuerst 1887 entdeckte, die Ausläufer der Appalachen auf Neuschottland und dem südöstlichen Neufundland. Hier endigt gleichfalls ein karbonisches Faltengebirge, ebenso wie das europäische nach Norden gefaltet, indem es eine Riasküste erzeugt und davor wohl noch den Schelf der Neufundlandbank durchzieht. Seine Richtung, sonst nordöstlich, geht nahe der Abrißstelle in die rein östliche über. Schon nach den bisherigen Vorstellungen nahm man an, daß es sich um ein einziges großes Faltensystem handele, wofür E. Suess die Bezeichnung ,transatlantische Altaiden“ gebrauchte. Die Verschiebungstheorie bringt hier schon dadurch eine große Vereinfachung, daß die beiden Teilstücke in der Rekonstruktion fast zur gegenseitigen Berührung gebracht werden, während man bisher ein versunkenes Mittelstück annehmen mußte, das länger als die uns bekannten Enden wäre, was Penck schon als Schwierigkeit empfand. Auf der Verbindungslinie der Abrißstellen liegen einige vereinzelte Erhöhungen des Meeresbodens, die man bisher als Gipfel der versunkenen Kette betrachtet hat. Nach unseren Vorstellungen sind

1) Die von E. Suess abweichende Ansicht Kossmats [82], daß sämtliche europäischen Falten im ozeanischen Gebiet herumbiegen und nach der spanischen Halbinsel zurückkehren, dürfte schwer aufrechtzuhalten sein, da sich ein so großer Faltenbogen nicht mehr im Schelf unterbringen läßt. 
es Brocken vom Rande der sich trennenden Schollen, deren Loslösung gerade in solchen tektonischen Störungszonen leicht verständlich ist.

In Europa folgen weiter, unmittelbar nördlich sich anschließend, die Faltenzüge eines noch älteren, zwischen Silur und Devon aufgeworfenen Gebirges, welches sich durch Norwegen und Nordengland hindurchzieht. E. Suess nennt es das kaledonische Gebirge. Mit der Frage der Fortsetzung dieser Gebirgsfaltung in den „,Kanadischen Kaledoniden" (Termier), nämlich den schon kaledonisch gefalteten kanadischen Appalachen, haben sich Andrée [83] und Tilmann [84] beschäftigt. Es beeinträchtigt natürlich nicht die Übereinstimmung, daß diese kaledonische Faltung in Amerika von der soeben besprochenen armorikanischen Faltung noch einmal überaibeitet wurde, was hüben nur im mittleren Europa (Hohes Venn und Ardennen), aber nicht im nördlichen Europa der Fall war. Die Berührungsstücke dieser kaledonischen Faltungen dürften in den schottischen Hochlanden und Nordirland einerseits und Neufundland andererseits zu suchen sein.

Wiederum dicht nördlich der kaledonischen Faltung liegt in Europa das noch ältere (algonkische) Gneisgebirge der Hebriden und Nordschottlands. Diesem entsprechen auf amerikanischer Seite die gleichaltrigen Gneisgebirge von Labrador, welche bis an die Belle-Islestraße nach Süden reichen und sich weit nach Kanada hineinziehen. Die Streichrichtung ist in Europa Nordost-Südwest, in Amerika wechselnd von derselben Richtung bis Ost-West. Dacqué [22] bemerkt hierzu: „Daraus kann man folgern, daß die Kette über den Nordatlantischen Ozean hinüberreichte." Das angeblich versunkene Verbindungsglied müßte allerdings nach den bisherigen Vorstellungen eine Länge von $3000 \mathrm{~km}$ gehabt haben, auch weist die gerade Verlängerung des europäischen Teiles bei der jetzigen Lage der Kontinente mehrere tausend Kilometer an dem amerikanischen vorbei nach Südamerika. Nach der Verschiebungstheorie erfährt auch hier wieder das amerikanische Stück gerade eine solche Querversetzung und zugleich Drehung, daß es unmittelbar an das europäische anschließt und als seine Verlängerung erscheint.

In das soeben betrachtete Gebiet fallen weiter auch die Endmoränen der großen diluvialen Inlandeiskappen Nordamerikas und Europas. Ihre Ablagerung fällt in eine Zeit, zu der Neufundland bereits von Europa abgerissen war, während im Norden bei Grönland die Schollen noch verbunden waren. Jedenfalls muß Nord- 
amerika damals noch wesentlich näher an Europa gelegen haben als heute. Trägt man die Moränen in unsere für die Zeit vor der Trennung gültige Rekonstruktion ein, so fügen sie sich, wie Abb. 19 zeigt, ohne Lücke oder Knick zusammen, was doch sehr unwahrscheinlich wäre, wenn die Küsten zur Zeit der Ablagerung schon

Abb. 19.

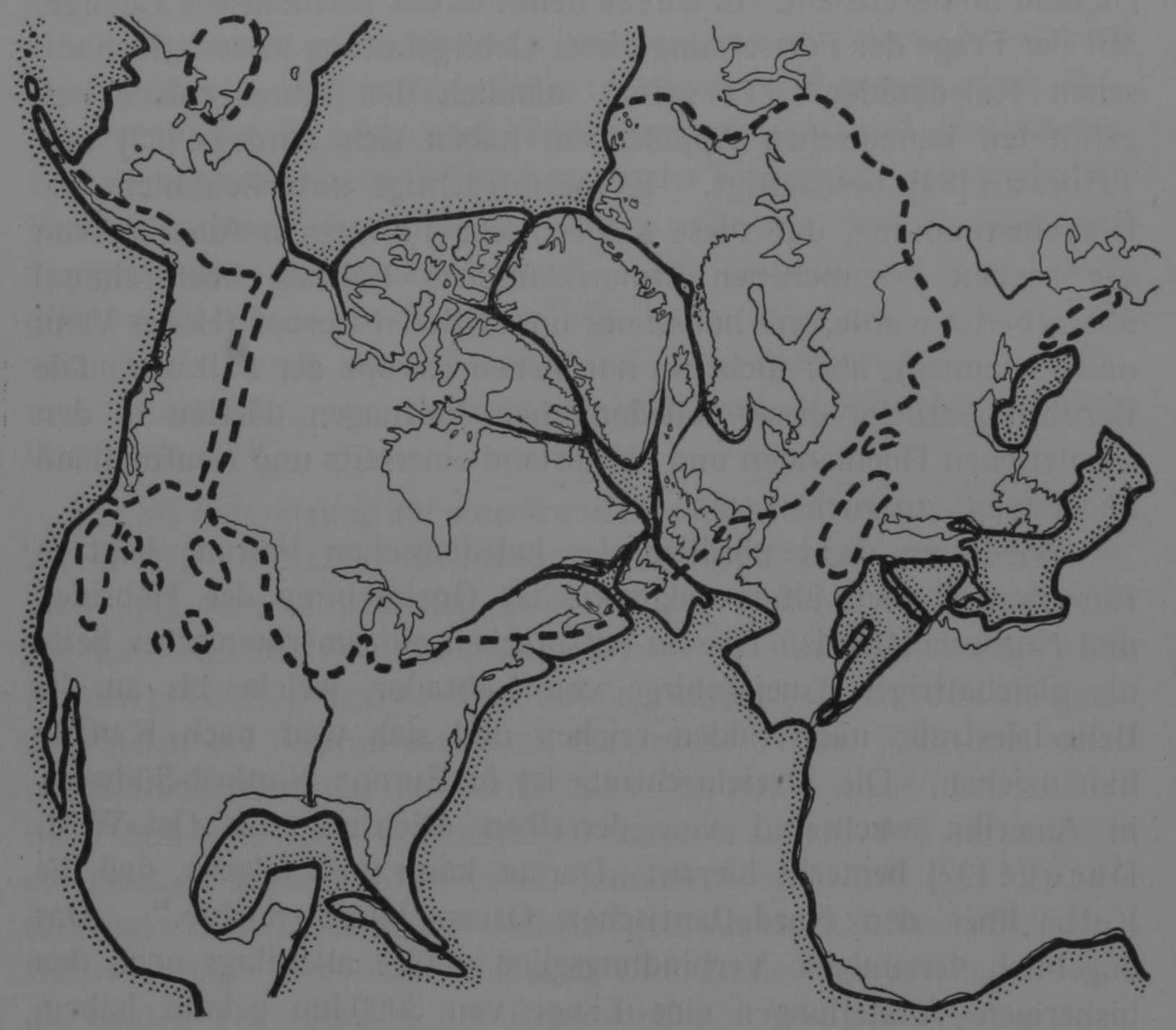

Grenzen des quartären Inlandeises, eingetragen in die Rekonstruktion für die Zeit vor dem Abriß Nordamerikas.

ihren heutigen Abstand von $2500 \mathrm{~km}$ gehabt hätten, zumal das amerikanische Ende heute $4 \frac{1}{2}$ Breitengrade südlicher liegt als das europäische.

Die bisher angeführten Übereinstimmungen der atlantischen Küsten, nämlich die Faltung des Kapgebirges und der Sierren von Buenos Aires, ferner die Übereinstimmung der Eruptivgesteine, Sedimente, Streichrichtungen und zahlloser anderer Einzelheiten in den großen Gneistafeln von Brasilien und Afrika, die armorikanische, 
kaledonische und algonkische Faltung und die diluviale Endmoräne bilden, wenn auch die Auffassung in gewissen Einzelfragen noch unsicher sein mag, in ihrer Gesamtheit einen schwer zu erschütternden Beweis für die Richtigkeit unserer Auffassung, daß der Atlantik als eine erweiterte Spalte $\mathrm{zu}$ betrachten ist. Von entscheidender Bedeutung dabei ist der Umstand, daß, obwohl die Zusammenfügung der Schollen auf Grund anderer Erscheinungen, nämlich ihrer Konturen, vorgenommen werden muß, dennoch durch diese Zusammenfügung die jenseitige Fortsetzung einer jeden Struktur gerade mit dem diesseitigen Ende zur Berührung gebracht wird. Es ist so, als wenn wir die Stücke einer zerrissenen Zeitung nach ihren Konturen zusammensetzen und dann die Probe machen, ob die Druckzeilen glatt hinüberlaufen. Tun sie dieses, so bleibt offenbar nichts weiter übrig, als anzunehmen, daß die Stücke einst wirklich in dieser Weise zusammenhingen. Wenn nur eine einzige Zeile eine solche Kontrolle ermöglichte, so hätten wir schon eine hohe Wahrscheinlichkeit für die Richtigkeit der Zusammensetzung. Haben wir aber $n$ Zeilen, so potenziert sich diese Wahrscheinlichkeit noch mit $n$. Es ist gewiß nicht unnütz, sich klar zu machen, was dies bedeutet. Nehmen wir an, daß wir allein auf Grund unserer ersten "Zeile“, der Faltung des Kapgebirges und der Sierren von Buenos Aires, zehn gegen eins wetten können, daß die Verschiebungstheorie richtig ist. Dann können wir, da im ganzen mindestens sechs solche unabhängigen Kontrollen vorliegen, in Kenntnis dieser letzteren bereits $10^{6}$, d. i. eine Million gegen eins wetten, daß unsere Annahmen zutreffen. Diese Zahlen mag man gern für übertrieben halten. Sie sollen nur dazu dienen, zu zeigen, was es $\mathrm{zu}$ bedeuten hat, wenn sich die unabhängigen Kontrollen mehren.

Nördlich des bisher betrachteten Gebietes gabelt sich die atlantische Spalte beiderseits von Grönland und wird zunehmend schmaler. Die beiderseitigen Übereinstimmungen verlieren dadurch an Beweiskraft, weil ihre Entstehung auch bei der jetzigen Lage der Schollen immer leichter erklärbar wird. Dennoch ist es nicht ohne Interesse, die Vergleichung bis zu Ende durchzuführen. Wir finden die Bruchstücke einer ausgedehnten Basaltdecke am Nordrande von Irland und Schottland, auf den Hebriden und auf den Färöern; sodann wechselt sie über Island hinüber zur grönländischen Seite, wo sie namentlich die große, den Scoresbysund im Süden begrenzende Halbinsel zusammensetzt und sich weiter bis $75^{\circ}$ Nord die Küste entlangzieht. Auch an der westgrönländischen Küste finden sich 
ausgedehnte Basaltdecken. An allen diesen Orten kommen in gleicher Weise Landpflanzen führende Kohlen zwischen zwei basaltischen Lavadecken vor, woraus man auf ehemaligen Landzusammenhang geschlossen hat. Der gleiche Schluß ergibt sich aus der Verteilung der terrestrischen devonischen „Old Red“-Ablagerungen in Amerika von Neufundland bis New York, in England, Südnorwegen und dem Baltikum, in Grönland und Spitzbergen. Diese Funde geben in ihrer Gesamtheit das Bild eines zur Entstehungszeit zusammenhängenden, einheitlichen Verbreitungsgebietes, welches heute zer-

Abb. 20.

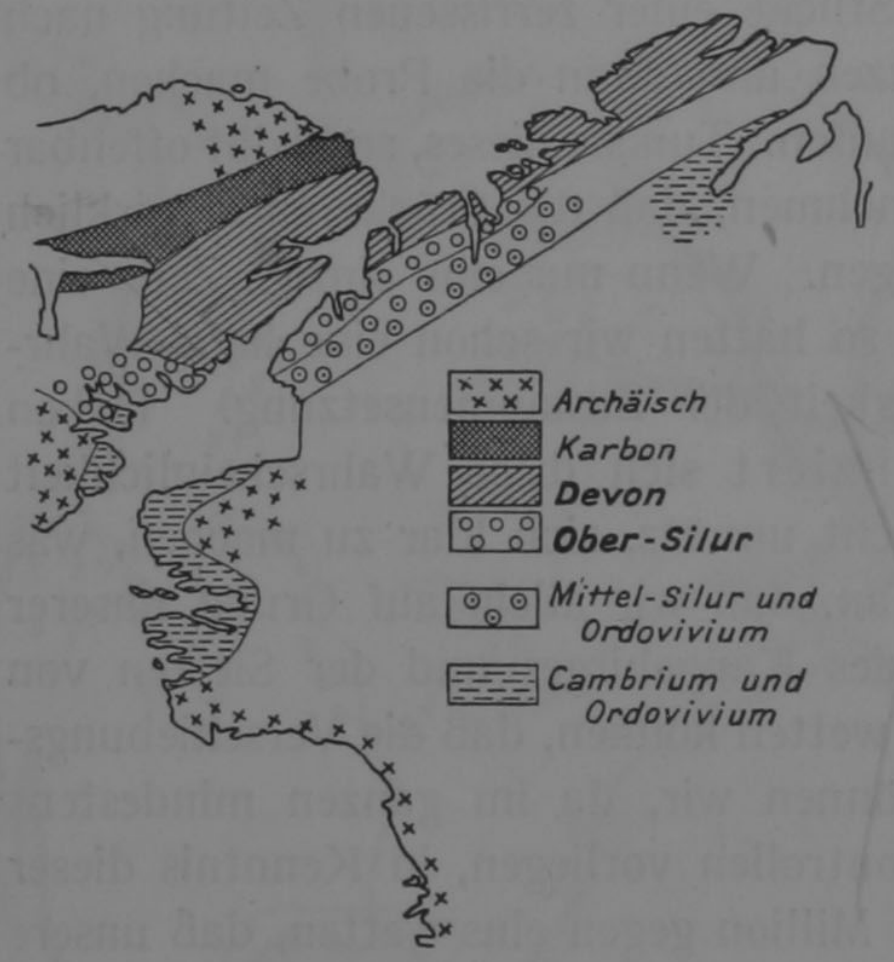
stückelt ist, - nach den bisherigen Vorstellungen durch Versinken der Zwischenglieder, nach der Verschiebungstheorie durch Zerbrechen und Auseinandertreiben.

Erwähnenswert ist in diesem Zusammenhang auch das gleichartige Vorkommen ungefalteter karbonischer Ablagerungen einerseits in Nordostgrönland auf $81^{0}$ Nordbreite und andererseits gegenüber auf Spitzbergen.

Auch zwischen Grön-

Geologische Karte von Nordwestgrönland, land und Nordamerika nach Lauge-Koch.

herrscht die $\mathrm{zu}$ erwartende Übereinstimmung im Bau.

Bei Kap Farvel und nordwestlich davon treten nach der „Geologic Map of North America“ der U. S. Geol. Survey vielfach präkambrische Intrusivgesteine im Gneis auf, welche man amerikanischerseits gerade an der entsprechenden Stelle, nämlich auf der Nordseite der Belle-Islestraße, wiederfindet. Beim Smithsund und Robesonkanal im Nordwesten Grönlands besteht die Verschiebung nicht in einem Auseinanderziehen der Spaitenränder, sondern in einer horizontalen Verwerfung von großen Dimensionen, einer sogenannten Blattverschiebung. Grinnell-Land gleitet an Grönland entlang, wodurch wohl auch die auffallend geradlinige Begrenzung der beiden Schollen erzeugt wird. Diese Verschiebung läßt sich in dem in Abb. 20 dargestellten Ausschnitt aus der geologischen 
Karte von Nordwestgrönland von Lauge-Koch [85] erkennen, wenn man die Grenze zwischen Devon und Silur sucht, welche in Grinnell-Land auf $80^{\circ} 10^{\prime}$, in Grönland auf $81^{\circ} 30^{\prime}$ liegt. Auch die von diesem Autor entdeckte kaledonische Faltung, die sich von Grönland nach Grinnell-Land hinüberzieht, läßt dieselbe Verschiebung erkennen.

In aller Kürze seien hier noch einige Andeutungen gemacht, in welcher Weise bei der Rekonstruktion der präatlantischen Kontinentalverbindungen vorgegangen wurde. Eine ausführlichere Besprechung der hierbei berücksichtigten Erscheinungen, wie Plastizität der Sialschollen, Schmelzung von unten u. a., wird zwar später noch gegeben werden. Allein es ist auch schon bei der geologischen Vergleichung der Spaltenränder notwendig, einiges hiervon zu erwähnen, um Mißverständnissen vorzubeugen.

In Nordamerika zeigt unsere Rekonstruktion eine Abweichung von der heutigen Karte insofern, als Labrador stark nach Nordwesten gedrückt erscheint. Es wurde angenommen, daß der starke Zug, der schließlich zum Abreißen Neufundlands von Irland führte, vor dem Abriß eine Dehnung und oberflächliche Zerreißung der beiderseitigen Schollenteile bewirkte. Auf der amerikanischen Seite wurde nicht nur die neufundländische Scholle (einschließlich der Neufundlandbank) herausgebrochen und um etwa $30^{\circ}$ gedreht, sondern ganz Labrador sackte bei dieser Gelegenheit nach Südosten, so daß der vorher geradlinige Grabenbruch St. Lorenzstrom-BelleIslestraße seine jetzige S-förmige Biegung erhielt. Auch die Flachmeere der Hudsonbai und der Nordsee dürften bei dieser Zerrung entstanden oder vergrößert sein. Der Neufundlandschelf erfährt also eine zweifache Korrektion der Lage, nämlich eine Drehung und eine Verschiebung nach Nordwest, und paßt sich dadurch der Schelflinie bei Neu-Schottland besser an, über die er gegenwärtig weít hinausragt.

Island wird zwischen einer Doppelspalte gelegen angenommen, worauf die heutige Tiefenkarte seiner Umgebung hinzudeuten scheint. Vielleicht entstand hier zuerst zwischen dem grönländischen und dem norwegischen Gneismassiv eine Spalte (Grabenbruch), die sich dann teilweise mit geschmolzenen Sialmassen von der Unterseite der Schollen anfüllte. Da die Spalte aber im übrigen, wie heute das Rote Meer, mit Sima gefüllt war, so konnte eine erneute Zusammenpressung der Schollen die Wirkung haben, daß diese Simafüllung 
unten von ihrer Verbindung mit den tieferen Regionen abgeschnitten und nach oben heraufgepreßt wurde und so die großen Basaltüberschwemmungen schuf. Daß dies gerade im Tertiär stattfand, erscheint besonders plausibel; denn durch die tertiäre Westwanderung Südamerikas mußte auch auf Nordamerika ein Drehungsmoment übertragen werden, welches sich, solange die Verankerung durch die von Irland nach Neufundland hinüberreichenden Ketten hielt, nördlich davon in einer Zusammenpressung äußern mußte.

Es sei in diesem Zusammenhang auch ganz kurz der mittelatlantischen Bodenschwelle gedacht ${ }^{1}$ ). Die Auffassung von Haug, welcher den ganzen Atlantik als eine riesige "Geosynklinale“ und die mittelatlantische Schwelle als den Beginn der Faltung dieser Geosynklinale betrachten will, ist heute wohl allgemein als unzureichend erkannt. Wir verweisen hier nur auf Andrées Kritik [16]. Nach meinem Dafürhalten handelt es sich bei dieser Schwelle jedenfalls um Abfallprodukte bei der Trennung der Schollen. Man kann hierbei annehmen, daß statt einer einheitlichen Spalte ein netzartiges Geflecht von Spalten entstand, also ein Trümmerstreifen, dessen Teile, weil ihre Unterlage sich auszog und verflachte, größtenteils unter den Meeresspiegel versanken. Da, wo die heutigen Ränder nicht mehr gut zueinander passen, mag diese Zertrümmerungszone von beträchtlicher Breite gewesen sein.

So wurde oben erwähnt, daß das Gebiet der Azoren einem Zertrümmerungsstreifen entspricht, der ursprünglich schätzungsweise über $1000 \mathrm{~km}$ breit gewesen sein mag. Dies ist freilich ein Ausnahmefall, an den meisten Stellen ist die mittelatlantische Schwelle viel schmaler. Aus der von du Toit gegebenen Abb. 18 würde man, bei Berücksichtigung der heutigen Randschelfe, nur auf einen Zertrümmerungsstreifen von einigen hundert Kilometern schließen, stellenweise mag er noch schmaler gewesen sein; damit stimmt der Umstand, daß die Schollenränder hier noch heute auffallend kongruent sind, wenn man von einigen Störungen, wie die Abrolhosbank oder den Vorsprung an der Nigermündung, absieht. Unsere Rekonstruktionskarten Abb. 4 und 5 sind insofern schematisch, als sie auf diesen schwer abzuschätzenden Zertrümmerungsstreifen vielleicht nicht genügend Rücksicht nehmen. Aber ob es jemals gelingen wird, die Rekonstruktion in solchen Details exakt durchzuführen, muß wohl einstdes Atlantischen Ozeans. 2. Aufl. Hamburg 1926. 
weilen dahingestellt bleiben; denn wenn man auch das Profil des atlantischen Meeresbodens völlig genau kennte, so bliebe doch unklar, ein wie großer Teil dieser Massen aus Basalt besteht und ursprünglich unter den beiden heutigen Kontinentalschollen ihren Platz gehabt hat und erst beim Trennungsprozeß durch „Ziehen“ des Materials unter diesen herausgezerrt wurde oder herausgeflossen ist. Dieser Teil dürfte aber bei der Rekonstruktion nicht berücksichtigt werden.

Weniger als über die atlantische Spalte ist in geologischer Hinsicht über die anderen von uns angenommenen Kontinentalzusammenhänge zu sagen.

Madagaskar besteht wie das benachbarte Afrika aus einer Tafel gefalteten Gneises mit nordöstlicher Streichrichtung. An der Abrißlinie sind beiderseits identische marine Sedimente abgelagert, welche andeuten, daß seit der Trias beide Länder durch einen überschwemmten Grabenbruch getrennt waren, was auch die madagassische Landfauna verlangt. Aber noch in der Mitte der Tertiärzeit, als Indien bereits abgerückt war, sind nach Lemoine [87] zwei Tiere, der Potamochoerus und der Hippopotamus, von Afrika eingewandert, die, wie Lemoine meint, höchstens einen Meeresarm von $30 \mathrm{~km}$ Breite durchschwimmen konnten, während jetzt der Kanal von Mozambique gut $400 \mathrm{~km}$ breit ist. Erst nach dieser Zeit kann sich also die madagassische Scholle auch untermeerisch von Afrika losgerissen haben, wodurch sich der weite Vorsprung erklärt, den Vorderindien in der Verschiebung nach Nordosten gegenüber Madagaskar bekommen hat.

Ein nicht unwesentliches Moment im Bau von Afrika sind die meist nordsüdlich verlaufenden und besonders in Ostafrika ausgebildeten Brüche. Evans hat in einer interessanten Untersuchung über Erdgebiete mit Zug [107] unter manchem anderen, was für die Verschiebungstheorie spricht, besonders diesen Punkt betont: „,Vieles von der Struktur des afrikanischen Kontinents muß noch bestimmt werden; aber soweit sie bekannt ist, scheint sie die Ansicht zu stützen, daß überall das Vorwalten eines Zuges zu erkennen ist, der vom Zentrum nach außen gerichtet ist. Dies ist in Übereinstimmung mit Wegeners Auffassung, daß es zu Beginn der mesozoischen Zeit einen großen ,Urkontinent' gab, dessen Zentrum Afrika war, und daß er seitdem aufgebrochen ist durch eine relative Bewegung Südamerikas nach Westen, Westantarktikas nach Südwest, Indiens 
nach Nordost, Australiens nach Ost und Ostantarktikas nach Südost"1).

Auch Vorderindien ist eine flache Tafel aus gefaltetem Gneis. Die Faltung wirkt noch heute formengebend in dem uralten Arvalligebirge im äußersten Nordwesten (am Rande der Wüste Tharr) und in den gleichfalls sehr alten Koranabergen. Nach Suess weist sie im ersteren nach N $36^{\circ} \mathrm{O}$, in letzteren nach Nordost. Beide Richtungen stimmen also hinreichend mit der afrikanischen und madagassischen Streichrichtung überein, zumal nach der geringen, bei der Rekonstruktion nötigen Drehung Indiens. Übrigens tritt auch hier daneben eine etwas jüngere, aber immer noch alte Faltung in den Ghats von Nellore oder dem Vellakondagebirge auf, welche von Nord nach Süd streicht und wohl mit der gleichfalls jüngeren nordsüdlichen Streichrichtung in Afrika gleichzusetzen ist. Die Diamantvorkommen in Indien schließen sich an die von Südafrika an. In unseren Rekonstruktionen ist angenommen, daß die indische Westküste mit der Ostküste Madagaskars zusammengehangen hat. Beide Küsten bestehen aus einem auffällig geradlinigen Abbruch eines Gneisplateaus, der den Gedanken nahelegt, sie könnten nach der Spaltenbildung aneinander entlang geglitten sein, ähnlich wie GrinnellLand und Grönland. Am nördlichen Ende dieses an beiden Küsten etwa 10 Breitengrade langen Abbruches treten beiderseits Basalte auf. In Indien ist es die bei $16^{0}$ Nordbreite beginnende Basaltdecke des Dekans, die aus dem Beginn des Tertiärs stammt und deshalb vielleicht in ursächlichen Zusammenhang mit der Ablösung gebracht werden darf. Und auf Madagaskar ist der nördlichste Teil der Insel ganz aus zwei verschieden alten Basalten aufgebaut, deren Entstehungszeit anscheinend noch nicht ermittelt·ist.

Die riesigen, wesentlich im Tertiär gebildeten Falten des Himalajagebirges bedeuten den Zusammenschub eines erheblichen Stückes der Erdrinde, durch dessen Rekonstruktion die Umrisse des asiatischen Kontinents ganz andere werden. Wahrscheinlich nahm das ganze östliche Asien über Tibet und die Mongolei hinweg bis zum Baikalsee und vielleicht sogar bis zur Beringstraße an dem Zusammenschub teil. Die neueren Untersuchungen haben gezeigt, daß die jungen Faltungsvorgänge keineswegs nur auf den Himalaja selbst beschränkt sind, sondern z. B. noch im Gebirge Peters des

1) Zur Zeit des Beginns dieser Bewegungen waren die Himmelsrichtungen wegen der geänderten Pollage teilweise wesentlich andere. 
Großen eozäne Schichten bis 5600 m Seehöhe emporgefaltet und im Tienschansystem große Überschiebungen erzeugt haben [88]. Aber auch da, wo solche Faltungserscheinungen fehlen; steht die junge Erhebung ungefalteten Landes gleichfalls in enger Verbindung mit diesem Faltungsprozeß. Die gewaltigen Massen sialischen Materials, welche bei der Faltung in die Tiefe gesenkt werden, müssen dort Abb. 21.

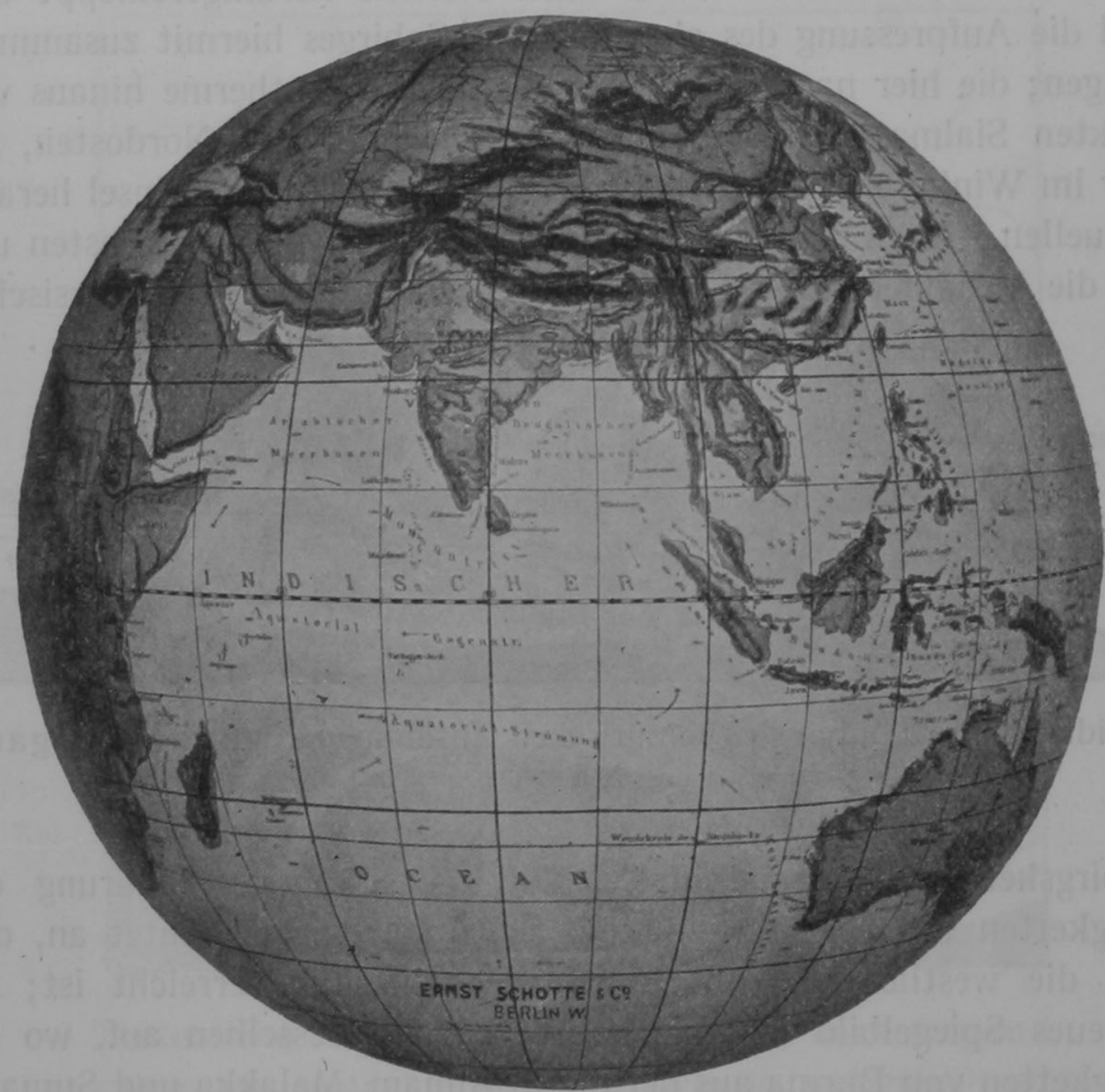

Der lemurische Zusammenschub.

schmelzen und sich ausbreitend die angrenzenden Schollenteile unterlagern, wodurch diese gehoben werden müssen. Beschränken wir uns in unserer Betrachtung auf die höchste, im Mittel etwa $4000 \mathrm{~m}$ über dem Meere liegende Region der asiatischen Scholle, die in der Schubrichtung $1000 \mathrm{~km}$ mißt, und nehmen wir (trotz der größeren Höhe!) nur eine gleiche Verkürzung wie bei den Alpen, nämlich auf den vierten Teil ihrer ursprünglichen Erstreckung an, so erhalten wir eine Verschiebung Vorderindiens um $3000 \mathrm{~km}$, so 
daß es vor dem Zusammenschub neben Madagaskar gelegen haben muß. Für eine versunkene Lemuria im alten Sinne bleibt kein Platz.

Die Spuren dieses riesigen Zusammenschubs sind auch rechts und links von der ziemlich schmalen Schubzone noch zu erkennen. Die Loslösung Madagaskars von Afrika, das ganze System junger Grabenbrüche in Ostafrika, zu dem auch das Rote Meer und das Jordantal gehört, bilden Teilerscheinungen in diesem Bilde. Die Somalihalbinsel dürfte etwas nach Norden herumgeschleppt sein und die Aufpressung des abessinischen Gebirges hiermit zusammenhängen; die hier nach unten über die Schmelzisotherme hinaus versenkten Sialmassen flossen unter der Scholle nach Nordosten, um hier im Winkel zwischen Abessinien und der Somalihalbinsel herauszuquellen. Auch Arabien spürte noch den Zug nach Nordosten und hat die Ausläufer des Akdargebirges wie einen Sporn in die persischen

Abb. 22.

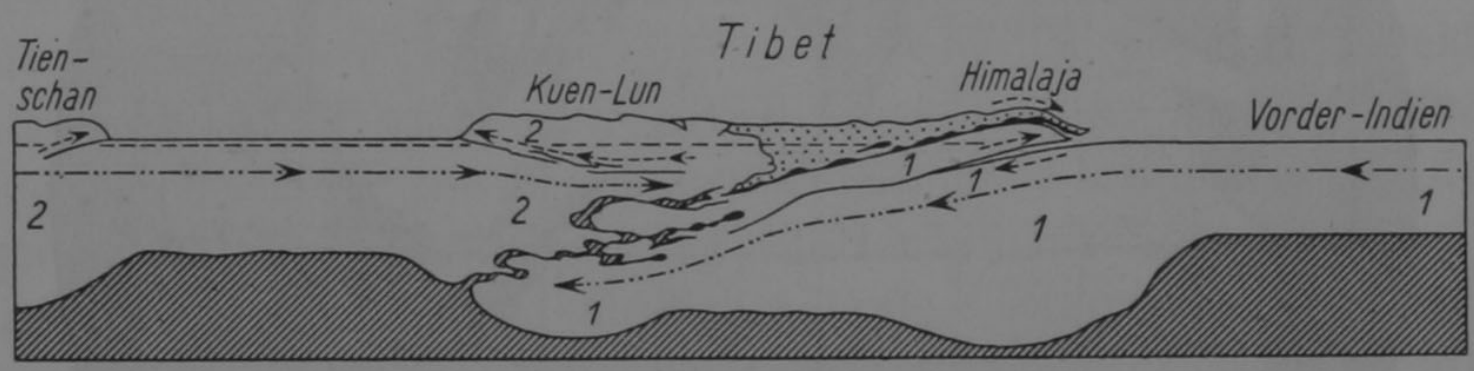

Meridianschnitt durch den lemurischen Zusammenschub, nach Argand. $1=$ Lemurien (Indien) ; $2=$ Asien.

Gebirgsketten hineingedrängt. Die fächerförmige Scharung der Bergketten des Hindukusch- und Soleimangebirges deutet an, daß hier die westliche Grenze des Zusammenschubs erreicht ist; ihr getreues Spiegelbild tritt auch am Ostrand desselben auf, wo die Bergketten von Burma aus der durch Annam, Malakka und Sumatra vorgezeichneten Richtung heraus bis zur Nordsüdrichtung herumgeschleppt werden. Das ganze östliche Asien ist wohl noch von diesem Zusammenschub betroffen worden, der seine westliche Begrenzung in dem gestaffelten Faltensystem zwischen Hindukusch und Baikalsee und dessen Fortsetzung bis zur Beringstraße findet, während die Ostgrenze durch die bauchigen Küstenformen mit den Inselgirlanden Ostasiens gebildet wird.

Auf den ersten Blick könnten diese Ansichten vielleicht phantastisch erscheinen, aber sie werden durch die neueren Untersuchungen der Gebirgstektoniker durchaus bestätigt. Insbesondere gilt dies 
für die 1924 erschienene großzügige Untersuchung Argands über die Tektonik Asiens [20].

Wir geben in Abb. 22 eine seiner Darstellungen wieder, welche seine Auffassung von dem großartigen Zusammenschub Hochasiens erläutert. Sie stellt einen Meridionalschnitt von Indien bis zum Tien-schan dar, gedacht für den Schluß der Tertiärzeit; schraffiert

Abb. 23.

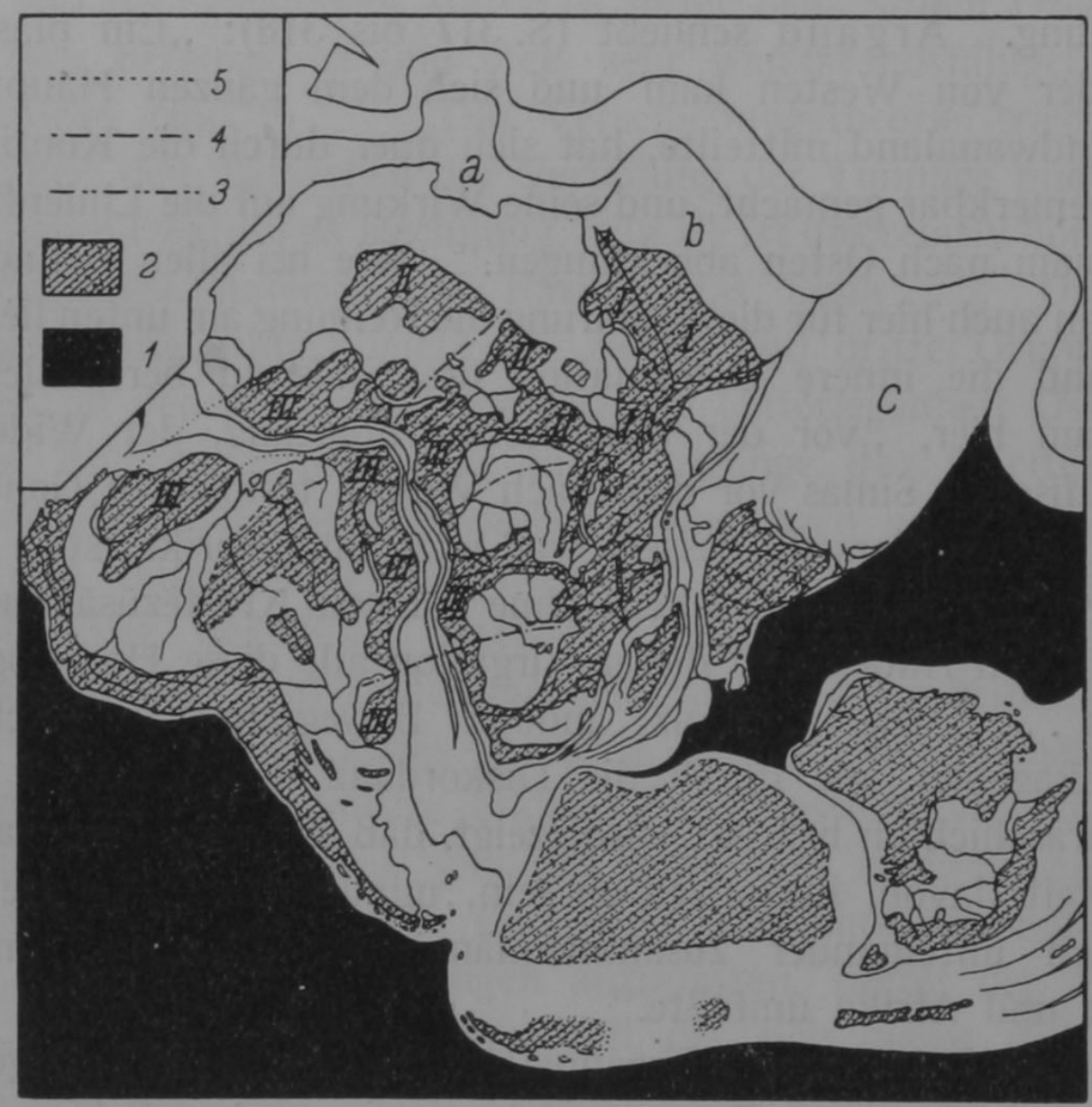

Tektonische Karte des Gondwanalandes, nach Argand.

$1=$ vorherrschend Sima $; 2=$ Gebiete, in denen die antiklinale Grundfaltung überwiegt; I, II, III = die drei Zweige der inneren Virgation der Gondwanascholle; $3=$ Kulminationsachsen der Grundfalten; $4=$ Senkungsachsen der Grundfalten; $5=$ Verbindungen, a, b, c = afrikanisches, arabisches, indisches Vorgebirge des Gondwanalandes.

bedeutet das tragende Sima, weiß die Sialschollen, punktiert die aus der Tethys hervorgegangenen Produkte. Die vom Sial mitgerissenen basischen (Sima-) Gesteine sind angedeutet. Die Pfeile geben die relative Bewegung. In der Hauptsache hätten wir es also hier mit einer riesigen Überschiebung $\mathrm{zu}$ tun, bei welcher die Sialscholle Lemuriens unter die asiatische Scholle hinuntergeschoben ist. 
Von den weiteren Darstellungen, die sich in dem wichtigen Werke befinden, geben wir nur noch Abb. 23 wieder, welche anschaulich zeigt, wie vollständig die Ergebnisse dieses hervorragenden Tektonikers mit denen der Verschiebungstheorie übereinstimmen. Argand macht u. a. auf folgende Eigentümlichkeit aufmerksam. Betrachtet man die drei Züge der Grundfaltengebiete I, II, III, die Argand als eine große Virgation auffaßt, so zeigen die einzelnen Züge eine den Anden Südamerikas ähnliche, aber nach Osten abnehmende Krümmung. Argand schließt (S. 317 bis 318): „Ein plastischer Stoß, der von Westen kam und sich dem ganzen Hauptgefüge von Gondwanaland mitteilte, hat sich quer durch die Kontinentalmasse bemerkbar gemacht, und seine Wirkung auf die Linienführung ist langsam nach Osten abgeklungen." Wie bei allen Grundfalten, habe man auch hier für die Erklärung die Reibung am unten liegenden Sima und die innere Deformation des Sials zu berücksichtigen; dazu kam hier, „,vor der atlantischen Spaltung, der Widerstand des pazifischen Simas vor dem nach Westen treibenden Gondwana, d. i. an der Vorderseite dessen, was jetzt Südamerika ist... Vergeblich würde man versuchen, ohne solchen Kräftezusammenhang zwischen den Anden und dieser Virgation alle diese Homologien zu erklären ... Die Existenz andiner Bewegungen nördlich vom Tanganikagebiet, die durch die Diskordanz der mittleren Kreide über Juraschichten bezeugt wird, zeigt, daß dieser Kräftezusammenhang, weit davon, illusorisch zu sein, mindestens die ganze Breite der noch miteinander zusammenhängenden Schollen von Südamerika und Afrika umfaßte."

Noch auf ein anderes Ergebnis Argands muß hier hingewiesen werden. Er hat für die Hauptfaltungszonen den Faltungsbetrag der Grundfalten bestimmt; auf die Methode einzugehen, ist hier nicht der Ort. Das Ergebnis drückt er in Tonnage pro Längeneinheit aus. Er unterscheidet ferner die Tonnage der Grundfalten (im Sial) und die der „,neuen Ketten“, die für Energiebetrachtungen von geringerer Bedeutung sind. So findet er auf statistischem Wege, daß im mediterranen Faltenzug (Alpen-Himalaja) die "Tonnage“" stark schwankt, im Gegensatz zum zirkumpazifischen Faltenzug. Insbesondere hat der enorme zentralasiatische Zusammenschub keine Parallele am pazifischen Ufer. Weiter ist die „Tonnage“ an der nordamerikanischen Westküste sehr viel größer als an der Ostküste Asiens. Und drittens ist die Tonnage der neuen Ketten in Ostasien absolut und relativ größer als in Nordamerika, wo sie fast 
ganz fehlt, wodurch die Unterlegenheit Ostasiens hinsichtlich des Faltungsbetrages noch unterstrichen wird.

Das erste Resultat, die große Variabilität im Ausmaß der Faltung in der mediterranen Faltungszone, erklärt Argand durch die Heterogenität der Sialschollen, die sich hier begegnen. „Umgekehrt zeugen die schwachen Schwankungen der Tonnage im zirkumpazifischen Gebiet von der Anwesenheit oder dem Vorherrschen eines homogeneren und nachgiebigeren Materials unter dem Stillen Ozeąn, als es die stark heterogenen und stets sehr widerstandsfähigen Kontinentalblöcke sind.“... „Die Verschiebungstheorie trägt ohne Schwierigkeit den Tatsachen der Verteilung der Tonnage und deren unmittelbaren Deutungen Rechnung. Für sie ist das relativ homogene und nachgiebige Material des Pazifik das Sima ... Die Verschiebungstheorie erklärt leicht die zweite und dritte Gruppe von Tatsachen, in denen sich die energetische Unterlegenheit Ostasiens gegenüber Amerika äußert. Sie läßt Vorgänge der Vorderseite zu, welche das Sial unter gewissen Bedingungen gegen das Sima pressen und falten, und Vorgänge der Rückseite, die aus einem Rückzug des Sials bestehen, wodurch eine mehr oder minder vollständige Unterbrechung der Faltenbildung bedingt wird, mit den Wirkungen des Zuges: gezerrte Brüche, knopflochähnliche Zerreißungen, die Randmeere bilden, Zurücklassung von Gebirgszügen, die von da ab in der Spur des Kontinents nachschleppen als mehr oder weniger abgelöste Girlanden, während das Sima, gezwungen, sich neuen Bedingungen anzupassen, hinter der Scholle aufsteigt. Durch die Verspätung, mit der sich dieses Aufsteigen vollzieht, entstehen die tiefen Furchen, aus denen die klassische Auffassung Vortiefen macht. Da die Verschiebungstheorie verlangt, daß die Vorgänge der Vorderseite überwiegend am Westrand von Amerika und die der Rückseite lange Zeit in Ostasien stattgefunden haben, so erklärt sich das Übergewicht des ersteren über das letztere an Tonnage von selbst."

„Die Eleganz, mit der die Verschiebungstheorie diese bedeutsamen Tatsachen erklärt, die zur Zeit ihrer Aufstellung nicht bekannt waren, ist gewiß ein starkes Zeugnis zu ihren Gunsten. Strenggenommen beweist zwar keine dieser Tatsachen die Verschiebungstheorie oder auch nur das Vorhandensein des Simas, aber sie alle stimmen vorzüglich zu beiden, bis zu einem Grade, der sie sehr wahrscheinlich macht." 
Soweit Argand, der, wie man sieht, in dieser Arbeit über die Tektonik Asiens auch die Hauptzüge des ganzen Erdantlitzes in Betracht zieht.

Eine genaue geologische Vergleichung würde sich auch für die Ostküste Vorderindiens und die Westküste Australiens verlohnen, denn diese Küsten oder besser Schelfränder haben nach unserer Annahme bis etwa zur Jurazeit unmittelbar zusammengehangen. Aber bisher ist ein solcher Vergleich von geologischer Seite anscheinend noch nicht durchgeführt worden. Die Ostküste Vorderindiens stellt einen jähen Abbruch des Gneisplateaus dar. Eine Unterbrechung erfährt dies nur durch das grabenartig schmale Kohlengebiet des Godavari, welches aus den unteren Gondwanaschichten besteht. Die oberen Gondwanaschichten liegen, der Küste folgend, diskordant quer über seinem Ende. Auch Westaustralien bildet eine ähnliche Gneistafel mit welliger Oberfläche wie Vorderindien und Afrika. Sie fällt längs der Küste mit einem langen Steilrande, der „Darling Range“ und ihrer nördlichen Fortsetzung zum Meere ab. Vor dem Steilrand liegt ein abgesunkener Streifen flachen Landes, der aus paläozoischen und mesozoischen Schichten aufgebaut und an wenigen Stellen von Basalten durchbrochen ist, und vor diesem wieder ein schmaler, bisweilen ganz verschwindender Gneiszug an der Küste. Die genannten Sedimente enthalten am Irvinflusse auch ein Kohlengebiet. Die Streichrichtung der Gneisfaltung ist in Australien überall meridional gerichtet und würde also bei Angliederung an Vorderindien in Nordost-Südwest verwandelt und somit parallel zur dortigen Hauptrichtung werden.

Im Osten Australiens verlaufen die wesentlich im Karbon gefalteten australischen Kordilleren längs der Küste von Süden nach Norden, um hier in einem staffelförmig nach Westen zurückweichenden Faltensystem, dessen einzelne Falten immer genau nordsüdlich verlaufen, zu endigen. Ebenso wie bei den staffelförmigen Falten zwischen Hindukusch und Baikalsee zeigt dies die seitliche Grenze des $\mathrm{Zu}$ sammenschubs an; die riesenhafte Andenfaltung, welche in Alaska beginnend durch vier Erdteile hindurchstreicht, erreicht hier ihr Ende. Die westlichsten Ketten der australischen Kordilleren sind die ältesten, die östlichsten die jüngsten. Tasmanien bildet eine Fortsetzung dieses Faltensystems. Interessant ist im Bau des Gebirges die spiegelbildliche Ähnlichkeit mit den südamerikanischen Anden, wo wegen der Lage jenseits des Poles die östlichsten Ketten die ältesten sind. Indessen fehlen in Australien die jüngsten Ketten. 
Suess findet sie in Neuseeland wieder [12]. Die Faltung reicht freilich auch hier nicht bis ins Tertiär: „Nach Ansicht der meisten neuseeländischen Geologen fällt die Hauptfaltung der maorischen Gebirgskette in die Zeit zwischen Jura und Kreide.“ Vorher war fast alles vom Meere bedeckt, erst die Faltung „,verwandelte die neuseeländische Region in eine Landmasse“. Oberkreide und Tertiär liegen meist randlich und ungefaltet. Und zwar gibt es Kreideablagerungen auf der Südinsel nur an ihrer Ostküste, nicht an der Westküste. Im Tertiär erfolgte der "Abbruch der Westküste“, "denn die tertiären Meeresablagerungen finden sich auch an dieser". Im Jungtertiär endlich entstanden noch weitere, freilich geringere Faltungen, Verwerfungen und Überschiebungen, die dem Gebirge seine heutigen Formen gaben (Wilckens [89]). Nach der Verschiebungstheorie erklärt sich dies alles dadurch, daß Neuseeland früher den Ostrand der australischen Scholle bildete, so daß seine Hauptfaltung sich an die australischen Kordilleren anschließt. Als die neuseeländischen Ketten sich aber als Girlande ablösten, erlosch auch der Faltungsvorgang. Die jungtertiäre Störung kann wohl mit dem Vorbeiziehen und Abwandern der australischen Scholle im $\mathrm{Zu}$ Abb. 24.

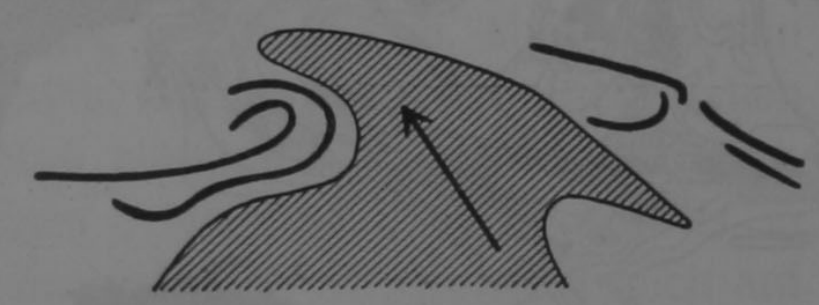

Sprengung der Inselketten durch Neuguinea, schematisch. sammenhang stehen.

Von diesen letzten Bewegungen Australiens erzählt uns namentlich die Tiefenkarte der Umgebung von Neuguinea mancherlei Einzelheiten. Die große australische Scholle drängt sich, wie Abb. 24 schematisch erläutert, mit ihrem amboßartig verdickten vorderen Ende, dem zu einem hohen jugendlichen Gebirge aufgefalteten Neuguinea nebst Schelf, von Südosten kommend, zwischen die Ketten der südlichsten Sunda-Inseln und des Bismarck-Archipels. Betrachten wir auf der Tiefenkarte Abb. $25^{1}$ ) die beiden südlichsten Reihen der Sunda-Inseln; die westöstlich streichende Kette Java -Wetter biegt sich am Ende spiralig über die Banda-Inseln zur Siboga-Bank nach Nordost, Nord, Nordwest, West, Südwest. Die

1) Am anschaulichsten wirkt die vorzügliche Karte der Sunda-Inseln in G. A. Molengraaff, Modern Deep-Sea Research in the East Indian Archipelago, The Geograph. Journal, Febr. 1921, S. 95-121, welche Landhöhen und Meerestiefen in gleichen Intervallen gibt. 
ihr vorgelagerte Timorkette bezeugt schon durch ihre gestörte, wechselnde Richtung die Kollision mit dem australischen Schelf, für die H.A. Brouwer auch die geologische Beweisführung im einzelnen gegeben hat [90]. Diese Kette wird weiterhin in einer ähnlichen energischen Spirale bis Buru zurückgebogen. Eine interessante Einzelheit, der Brouwer eine Sonderpublikation widmet [112], sei hier angeführt: Die innere Kette ist im allgemeinen mit noch heute tätigen Vulkanen besetzt; nur auf der Strecke zwischen den beiden Inseln Pantar und Dammer (exklusive) ist der früher auch hier tätige Vulkanismus jetzt erloschen. Das ist aber gerade die

Abb. 25.

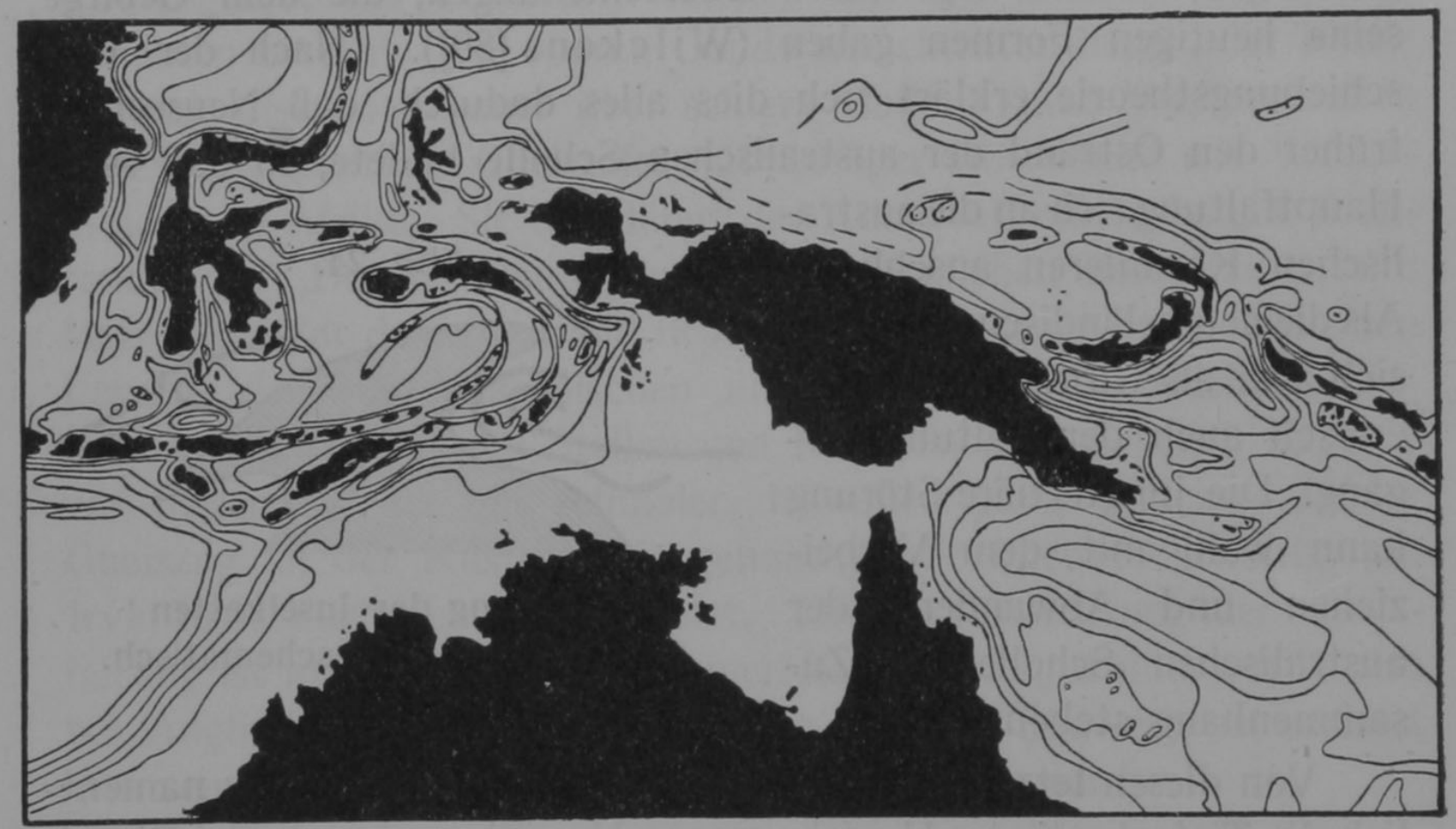

Tiefenkarte der Umgebung von Neuguinea.

Partie, gegen welche die äußere Kette am Nordrand von Timor durch den australischen Schelf gepreßt wird, so daß hier der sonst überall wohl noch weitergehende Biegungsvorgang aufgehoben wird. Diese Verhältnisse passen ausgezeichnet $\mathrm{zu}$ der Vorstellung einer Kollision mit der australischen Scholle und sind zugleich sehr lehrreich für die Frage nach der Entstehung des Vulkanismus durch den bei der Biegung der Ketten auftretenden Druck.

Eine sehr interessante Ergänzung zu diesem Kollisionsvorgang sieht man auf der Ostseite Neuguineas: Von Südosten kommend, hat dies die Inseln des Bismarck-Archipels gestreift, dabei die Insel Neupommern an ihrem früheren Südostende erfaßt und mit sich 
geschleppt, die lange Insel um mehr als $90^{\circ}$ herumdrehend und halbkreisförmig biegend. Eine tiefe Rinne blieb hinter ihr zurück und bezeugt die Gewaltsamkeit dieses Vorganges, da das Sima sie noch nicht wieder auszufüllen vermocht hat.

Es wird manchem kühn erscheinen, solche Schlüsse allein aus der Tiefenkarte zu ziehen. Aber diese erweist sich fast überall als zuverlässiger Wegweiser für die Schollenbewegungen namentlich der letzten Zeiten.

Auch im Sunda-Archipel weisen zahlreiche Einzelergebnisse auf die Richtigkeit unserer Anschauungen hin. So erklärte z. B. Wanner [96] die tektonisch unerwartete Tiefsee zwischen Buru und Sula Besi dadurch, daß ersteres sich um $10 \mathrm{~km}$ horizontal verschoben habe, was sich gut in unsere Vorstellungen einfügen läßt. G. A. F. Molengraaff [97] gibt eine Karte der Sunda-Inseln, in welcher das Gebiet mit um mehr als $5 \mathrm{~m}$ gehobenen Korallenriffen eingetragen ist. Dies Gebiet deckt sich überraschend mit dem, in welchem nach der Verschiebungstheorie die Sialmassen durch Zusammenschub sich verdicken müssen, es ist nämlich, abgesehen von der Südwestküste Sumatras und Javas, das ganze vor der australischen Scholle liegende Gebiet bis Celebes einschließlich, sowie die Nordund Nordwestküste von Neuguinea. Nach Gagel [98] gibt es in Neuguinea am Kap König Wilhelm und nach Sapper [99] auch auf Neu-Pommern ganz junge Terrassen, die 1000, 1250, ja vielleicht fast $1700 \mathrm{~m}$ gehoben sind. Diese sehr auffallende Erscheinung deutet jedenfalls auch darauf hin, daß hier in jüngster Zeit ganz gewaltige Kräfte zur Äußerung kamen, und paßt somit gut zu unserer Vorstellung von der Kollision dieser Teile.

Da gerade bei den Sunda-Inseln die Folgerungen aus der Verschiebungstheorie auf den ersten Blick so phantastisch anmuten, ist es gewiß beachtenswert, daß die holländischen Geologen, die im Sunda-Archipel arbeiten, mit die ersten waren, die sich auf den Boden der Verschiebungstheorie gestellt haben, allen voran Molengraaff, der schon 1916 für sie eintrat [91], später auch van Vuuren [92], Wing Easton [93], Escher [95] und neuerdings ganz besonders Smit Sibinga [94], der eine vollständige Darstellung der geologischen Entwicklung des Sunda-Archipels vom Standpunkt der Verschiebungstheorie aus gegeben hat, wobei er auch zu einer Lösung der alten Frage nach der Entstehung der eigenartigen Formen von Celebes und Halmahera gelangt. Er kommt zu dem Schluß: „,Die kleinen Sunda-Inseln, Celebes und die Molukken 
stellen ursprünglich vom Sunda-Land abgetrennte Randketten dar, die zuerst eine normale doppelte Randkette bildeten und danach infolge eines Zusammenstoßes mit dem australischen Kontinent ihre heutige Form erhielten." Wir geben hier den Schlußabschnitt seiner Untersuchung in der Übersetzung wieder:

, In einem letzten Abschnitt wollen wir punktweise auf einige geologische Tatsachen und Eigentümlichkeiten im MolukkenArchipel hinweisen, welche erklärt oder besser erklärt werden können durch die oben entwickelte, auf Taylors und Wegeners Grundgedanken basierte Arbeitshypothese als auf andere Weise."

„1. Sie erheischt nicht das Absinken früherer Landmassen zu ozeanischen Tiefen, um das heutige Relief, den Prozeß der Gebirgsbildung und das Verschwinden früherer Landverbindungen zu erklären, mit anderen Worten, sie ist in Übereinstimmung mit der Isostasielehre."

„2. Sie erklärt die heutige Konfiguration auf eindeutige und mechanisch logische Weise durch den Zusammenstoß einer ursprünglichen doppelten Molukkenkette mit dem australischen Kontinent."

„3. Sie gibt eine Erklärung für die eigenartige, für eine Geantiklinale sehr ungewöhnliche und unerklärliche S-Form des Nordarmes von Celebes. Auch diese wird durch den vom australischen Kontinent ausgehenden Druck verursacht, der die Timor-Ceramkette bis nach Celebes herübergeschoben hat, wobei die Kette zwischen Buru und den Sula-Inseln zerbrochen (eingedrückt) wurde.“

„4. Sie gibt eine ungezwungene Lösung für die merkwürdige Form der das Bandabecken kreisförmig umschließenden Inselketten als „eingedrückte Kette“. Wir setzten oben schon ausführlich die unhaltbaren Folgerungen auseinander, zu denen die Kontraktionstheorie hier führt."

„5. Sie erklärt die Divergenz der Transversalbrüche in der TimorCeramkette von dem Bandabecken aus als Folge davon, daß diese Kette in den Angriff des australischen Kontinents einbezogen wurde, eine Erscheinung, die vom Standpunkt der Kontraktionstheorie aus unerklärlich ist."

„6. Sie macht die abnormen tertiären Streichrichtungen in der Außenkette begreiflich, weil sie entstanden, als die Kette noch ihre ursprüngliche Form hatte, also vor ihrer Eindrückung."

„7. Sie läßt die gebirgsbildende Kraft vom australischen ${ }^{1}$ ) Kontinent ausgehen und erklärt dadurch, warum gerade die Außenkette,

1) Im Original steht, wohl durch Druckfehler: asiatischen. 
welche mit diesem Kontinent in unmittelbare Berührung kam, so viel intensiver gefaltet und überfaltet wurde als die Innenkette, Celebes und die Halmaheragruppe. Die Innenkette kam eben niemals in Berühr'ing mit Australien; nach Celebes wurden diese gebirgsbildenden Kräfte erst über die Außenkette als Mittelglied übertragen und mußten demgemäß an Intensität einbüßen; die Halmaheragruppe erreichte noch fast den gleichen innigen Kontakt, der zwischen Australien und der Außenkette bestanden hat. Nimmt man dagegen einen aus dem Bandabecken hervorgehenden Tangentialdruck an, so sollte man die intensivste Gebirgsbildung in der Innenkette und auf Ost-Celebes erwarten."

„8. Bei der Erklärung der Gebirgsbildung vermeidet sie die Konstruktion eines Vorlandes mit geologisch wie zoologisch heterogenen Elementen."

„9. In dem Zerreißen der Außenkette zwischen den Tukang Besiund Banggai-Inseln und der dadurch verursachten Aufhebung der Spannung läßt sich eine Erklärung finden für die Unterbrechung der Gebirgsbildung im Unterpliozän, die dann aufs neue, wẹnn auch weniger intensiv, einsetzte, als im Oberpliozän der Kontakt mit Celebes erreicht wurde."

„10. Sie gibt eine annehmbare Erklärung für den auffallenden geologischen Unterschied zwischen Celebes westlich und Celebes östlich der Boni-Posso-Depression. Das Erlöschen des aktiven Vulkanismus in Zentral-Celebes und sein Wiedereinsetzen in dessen Nordarm lassen sich auf die gleiche Weise erklären wie die Unterbrechung des aktiven Vulkanismus zwischen Panter und Dammer (Brouwer), nämlich durch Hineindrängen der Außenkette (Ostcelebes) in die Innenkette (Westcelebes)."

„11. Das stratigraphische Bild des östlichen Teiles des ostindischen Archipels wird eindeutiger und übersichtlicher. Seit dem jüngsten Paläozoikum dringt eine intermittierende Transgression bis zu neogenen Zeiten immer weiter in das Sundaland hinein, in naher Verbindung mit einer gleichzeitigen Bildung und Abscheidung von Randketten. Aus einem Geosynklinalstreifen, der vor dem Rande des mesozoischen Sundalandes lag, entwickelte sich die Außenkette, aus einem anderen Streifen, der vor dem Rande des tertiären Sundalandes lag, entstand weiter im Frühmiozän die Innenkette, wobei die Randketten, die aus der in der Hauptsache neogenen Geosynklinale aufgefaltet waren, noch mit dem Sundaland vereinigt blieben." 
„12. Sie ermöglicht eine mehr befriedigende Erklärung der Verbreitung der Fauna in den Molukken. Sie fordert an früheren Landverbindungen eine Brücke zwischen Philippinen, Molukken und Java und eine Verbindung zwischen der Halmaheragruppe und Nordcelebes, welche gerade auch von den Zoogeographen angenommen werden."

Wie man sieht, ist die Verschiebungstheorie auf diesem sehr schwierigen Gebiet der Erde bereits vollkommen zum Handwerkszeug des Fachgeologen geworden.

Zwei unterseeische Rücken verbinden Neuguinea und Nordostaustralien mit den beiden neuseeländischen Inseln und scheinen den Weg der Verschiebung zu weisen, vielleicht als durch Ziehen verflachte und darum abgesunkene ehemalige Landgebiete, teilweise wohl auch als geschmolzene, zurückgebliebene Massen von der Unterseite der Scholle.

Über die Verbindung Australiens mit Antarktika läßt sich wegen unserer Unkenntnis des letzteren Kontinents nur wenig sagen. Ein breiter Streifen tertiärer Sedimente begleitet die ganze Südkante Australiens und zieht sich durch die Baßstraße hindurch, findet sich aber dann erst auf Neuseeland wieder, während die Ostküste Australiens frei von ihnen ist. Vielleicht hat also im Tertiär schon ein überschwemmter Grabenbruch Australien von Antarktika getrennt, vielleicht auch schon, mit Ausnahme des tasmanischen Ankers, Tiefsee. Allgemein wird angenommen, daß sich der tasmanische Bau nach dem antarktischen Viktorialand fortsetzt. Andererseits schreibt Wilckens [89]: „Der südwestliche Bogen des neuseeländischen Faltengebirges (der sogenannte Otagosattel) erscheint an der Ostküste der Südinsel jäh abgeschnitten. Dies Ende ist nicht natürlich, sondern beruht wohl zweifellos auf einem Abbruch. Die Fortsetzung des Gebirges kann nur in einer Richtung gesucht werden, in der auf die Kordillere des Grahamlandes, die ,Antarktanden‘."

Erwähnt sei noch, daß in ähnlicher Weise auch das Ostende des Kapgebirges in Südafrika einen Abbruch darstellt. Nach unserer freilich unsicheren Rekonstruktion der Lage von Antarktika hätten wir die Fortsetzung des Gebirges hier zwischen Gaußberg und Coatsland zu suchen, wo die Küste aber noch ganz unbekannt ist.

Die schon früher erwähnte Verbindung der Westantarktis mit Feuerland bietet in geologischer Hinsicht ein Musterbeispiel zur Veranschaulichung der Verschiebungstheorie (Abb. 26). Noch im Pliozän 
dürfte nach den paläontologischen Beziehungen wenigstens ein beschränkter Formenaustausch zwischen Feuerland und Grahamland geherrscht haben, was nur möglich war, wenn beide Landspitzen noch in der Nähe des Inselbogens der Süd-Sandwichinseln lagen. Seitdem sind sie von da aus nach Westen weitergewandert, ihre schmale Verbindung aber ist im Sima stecken geblieben. In 'der Tiefenkarte ${ }^{1}$ ) erkennt man deutlich, wie die gestaffelten Ketten eine

Abb. 26.

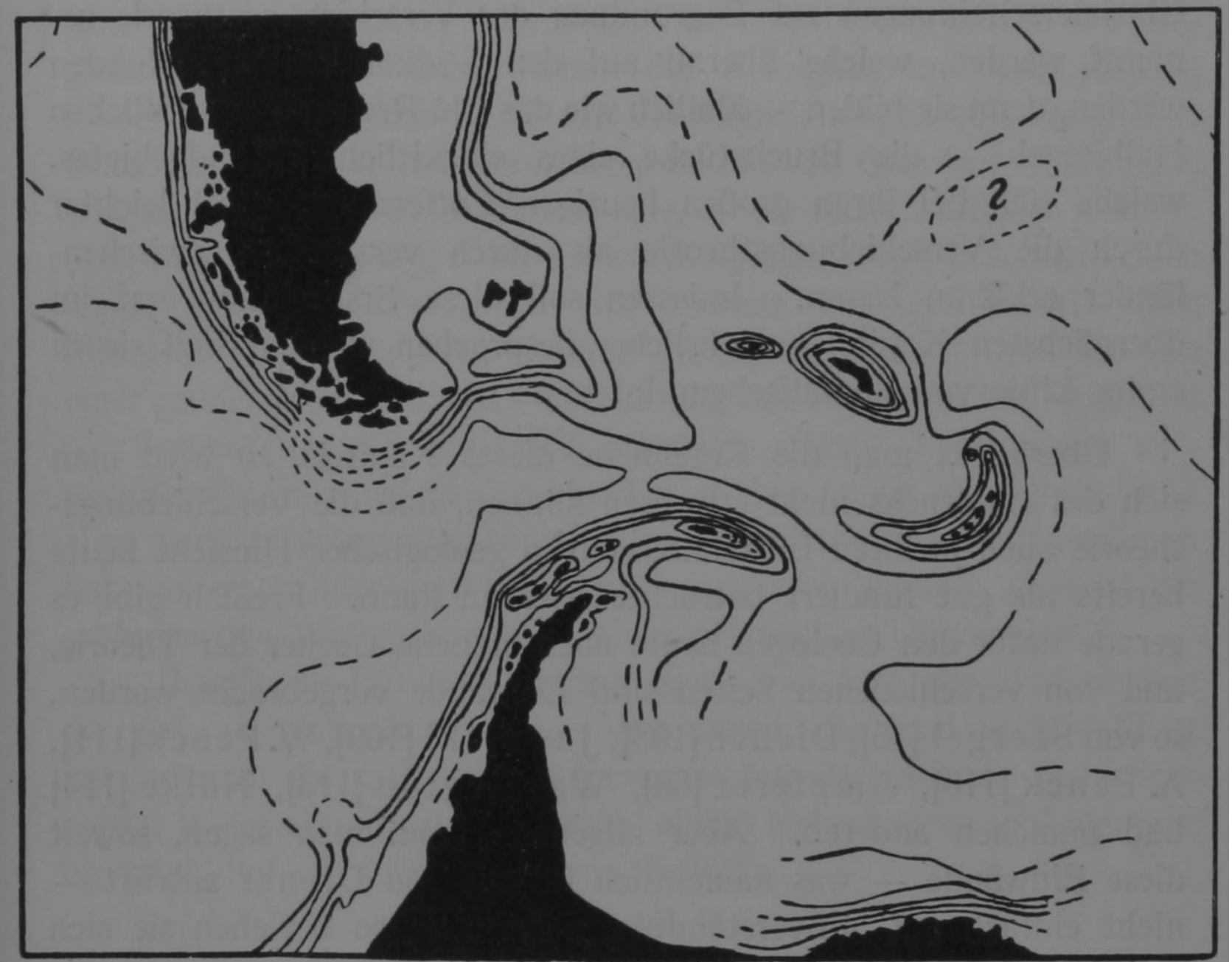

Tiefenkarte der Drakestraße, nach Groll.

nach der anderen von den vorrückenden Schollen abgestreift und zurückgelassen werden. Die gerade mitten in der Abrißstelle gelegene Gruppe der Süd-Sandwichinseln ist durch diese Bewegungsvorgänge am stärksten gebogen worden; dabei wurden die Simaeinschlüsse ausgepreßt. Die Inseln sind basaltisch und eine davon (die Insel Zawadowski) noch heute tätig. Im übrigen fehlen nach F. Kühn [100]

1) Eine gute Tiefenkarte der Drakestraße ist von H. Heyde entworfen und von $\mathrm{F}$. Kühn reproduziert [100]. Indessen sind die $\mathrm{Ab}$ weichungen von unserer Abbildung noch nicht von Belang.

Wegener, Kontinente und Ozeane. 4. Aufl. 
auf der ganzen Kette des „Südantillenbogens“ die jungtertiären Andenfaltungen, während die älteren Faltungen auf Südgeorgien, Südorkney usw. bekannt sind. Gerade diese Eigentümlichkeit wird durch die Verschiebungstheorie erklärt, denn wenn wirklich die Faltung in Südamerika und Grahamland durch die Westwanderung der Schollen erzeugt wurde, so mußte sie auf dem Südantillenbogen in dem Zeitpunkt aufhören, als dieser stecken blieb.

In diesem Zusammenhang könnten auch noch die permokarbonen Glazialerscheinungen zur Begründung der Verschiebungstheorie genannt. werden, welche überall auf den Südkontinenten gefunden werden, denn sie bilden - ähnlich wie das Old Red auf der nördlichen Halbkugel - die Bruchstücke eines einheitlichen Landgebietes, welche sich bei ihren großen heutigen Entfernungen viel leichter durch die Verschiebungstheorie als durch versunkene Zwischenländer erklären lassen. Indessen soll diese Erscheinung erst im übernächsten Kapitel ausführlicher besprochen werden, weil sie in erster Linie von klimatischem Interesse ist.

Überblickt man die Ergebnisse dieses Kapitels, so wird man sich des Eindrucks nicht erwehren können, daß die Verschiebungstheorie auch in ihren Einzelaussagen in geologischer Hinsicht heute bereits als gut fundiert betrachtet werden kann. Freilich gibt es gerade unter den Geologen heute noch manche Gegner der Theorie, und von verschiedenen Seiten sind Einwände vorgebracht worden, so von Soergel [35], Diener [108], Jaworski [109], W. Penck [111], A. Penck [110], Ampferer [68], Washington [113], Nölke [114] und manchen anderen. Aber allgemein kann man sagen, soweit diese Einwände - was namentlich für die von Diener zutrifft nicht einfach auf Mißverständnissen beruhen, so beziehen sie sich meist nur auf nebensächliche Fragen, deren Beantwortung für die Grundgedanken der Verschiebungstheorie nicht von wesentlicher Bedeutung ist. Es sei gestattet, auch hierfür das Zeugnis von Argand [20] anzurufen, der uns versichert:

„Seit 1915 und besonders seit 1918 habe ich lange den Grad der Glaubwürdigkeit der Verschiebungstheorie geprüft, indem ich den ganzen Atlas tektonischer Formen heranzog, über den ich verfügte, und alle Widerspiele von Bewegungen, die ich sehen kann. So daß, wenn mir heute die Zeit fehlt, um einige meiner Schlußfolgerungen $z u$ begründen, man sie doch nicht ohne Übertreibung für übereilt oder unbegründet wird ansehen können." 
Argand schreibt über diese Einwände:

„Die Gesundheit einer Theorie ist nichts anderes als ihre Eignung, die Gesamtheit der Tatsachen darzustellen, die zurzeit bekannt sind. In dieser Hinsicht ist die Theorie der großen Kontinentverschiebungen von einer blühenden Gesundheit. In ihren Anfängen hat sie ins Unbekannte gezielt (ell'a visé à l'absolu); in der Folge hat sie sehr an Kraft und Hilfsmitteln gewonnen, ohne irgend etwas von ihrem logischen Rüstzeug zu opfern, im Gegenteil bereichert und in immer besserer Harmonie mit den Ideen, welche die Allgemeinheit leiten. Diese Arbeit der Reinigung und Verfeinerung ist sehr fühlbar in der Reihe der Veröffentlichungen von Wegener. Stark begründet in den Kreuzungspunkten von Geophysik, Geologie, Biogeographie und Paläoklimatologie, ist sie nicht widerlegt worden. Man muß selbst lange nach Einwürfen gesucht und besonders auch einige gefunden haben, um eine gewisse Unangreifbarkeit nach ihrem Werte schätzen zu können, die sie auszeichnet und die von einer großen Biegsamkeit in Verbindung mit einem großen Reichtum an Verteidigungsmöglichkeiten herrührt. Man glaubt einen entscheidenden Einwurf in der Hand zu haben; noch ein Schlag, und alles muß zusammenbrechen. Aber nichts bricht zusammen; man hat nur einen oder mehrere Punkte vergessen gehabt. Das ist die proteusartige Widerstandskraft eines plastischen Universums. “

„Gewiß, die Einwürfe mehren sich, aber fast alle sind sie von der Art, wie ich eben sagte. Von denen, die man veröffentlicht hat oder an die man denken kann, ist nur der kleinste Teil stichhaltig, er bezieht sich dabei nur auf einige Nebensachen und niemals, bis jetzt, auf die lebenswichtigen Teile."

Sechstes Kapitel.

Paläontologische und biologische Argumente.

Auch die Paläontologie und die Tier- und Pflanzengeographie haben ein wichtiges Wort bei der Entschleierung der vorzeitlichen Zustände der Erde mitzureden, und der Geophysiker wird leicht auf Irrwege geraten, wenn er nicht auch die Ergebnisse dieser Wissenschaften zur Kontrolle der seinigen ständig im Auge behält.

Umgekehrt sollte aber auch der Biologe, wenn er sich überhaupt mit der Verschiebungsfrage beschäftigt, zu seiner eigenen Urteils- 
bildung die Tatsachen der Geologie und der Geophysik mitverwerten, denn sonst droht auch ihm ein nutzloses Irregehen. Es ist nicht unnütz, dies zu betonen. Denn soweit ich sehen kann, steht heute ein großer Teil der Biologen auf dem Standpunkt, daß es gleichgültig sei, ob man versunkene Zwischenkontinente oder Kontinentverschiebungen annimmt. Und dies ist verkehrt. Auch der Biologe kann, ohne fremden Meinungen blind zu glauben, selbst einsehen, daß die Erdrinde aus leichterem Material bestehen muß als das Erdinnere, und daß folglich, wenn die Tiefseeböden abgesunkene Kontinente wären und also das leichte Rindenmaterial in gleicher Mächtigkeit besäßen wie die Kontinente, die Schweremessungen auf den Ozeanen das Fehlen der Anziehung einer 4 bis $5 \mathrm{~km}$ mächtigen Gesteinsschicht anzeigen müßten. Und sie müssen selbst imstande sein, aus der Tatsache, daß dies nicht der Fall ist, vielmehr auf den Ozeanen etwa Normalschwere herrscht, den Schluß zu ziehen: also ist die Annahme versunkener Zwischenkontinente auf Schelfgebiete und überhaupt flache Meeresteile zu beschränken, aber für die großen Tiefseebecken auszuschalten. Nur bei solcher Fühlung mit den Nachbarwissenschaften kann die Lehre von der einstigen und heutigen Verbreitung der Organismen auf der Erde ihr reiches Tatsachenmaterial mit vollem Gewicht zur Ermittlung der Wahrheit in die Waagschale werfen.

Ich habe diese grundsätzlichen Erörterungen vorausgeschickt, weil sie mir in der biologischen Literatur über die Verschiebungstheorie bisher oft nicht genügend berücksichtigt $\mathrm{zu}$ sein scheinen, und zwar auch da, wo die betreffenden Verfasser zu einem günstigen Urteil über die Verschiebungstheorie kommen. v. Ubisch [117, 227], Eckhardt [119], Colosi [118], de Beaufort [123] u. a. haben zusammenfassende Referate über die Stellung der Biologie zur Verschiebungstheorie geschrieben, wobei sie dieser im allgemeinen zustimmen, aber fast immer ohne den angeführten Gesichtspunkten genügend Rechnung zu tragen. Und so ist es nicht verwunderlich, daß auch Fälle vorkommen, wie der von Ökland [116] oder v. Ihering [122], wo der erstere für den Nordatlantik, der zweite für den Südatlantik bei einer Prüfung der Verschiebungstheorie zu dem Schluß kommen, daß sie jedenfalls nicht besser sei als die der versunkenen Zwischenkontinente, oder letztere sogar vorzuziehen sei. Die Fragestellung ist eben verkehrt. Es handelt sich im Bereich der Tiefseebecken nicht darum, ob die Verschiebungstheorie oder die Theorie der versunkenen Zwischenkontinente vorzuziehen ist, 
denn letztere kommt hier gar nicht in Betracht, sondern nur um die Wahl zwischen Verschiebungstheorie und der Theorie der Permanenz der Tiefseebecken.

Aus den angeführten Gründen sind wir berechtigt, alle diejenigen Tatsachen der Biologie zugunsten der Verschiebungstheorie zu buchen, welche auf ehemalige ungehinderte Landverbindungen über heutige Tiefseebecken hinweg deuten. Ihre Zahl ist Legion. Es wäre für den Nichtfachmann ein hoffnungsloses Unternehmen, und im Rahmen dieses Buches schon aus Platzgründen unmöglich, hier alle in Betracht kommenden Tatsachen anzuführen. Aber es ist dies auch unnötig aus dem Grunde, weil darüber eine reiche fachmännische Literatur besteht, über die z. B. Arldt [11] einen Überblick gegeben hat, und die Ergebnisse in großen Zügen bereits feststehen und so gut wie allgemein anerkannt sind.

Für die ehemalige Landverbindung Südamerikas und Afrikas liegen die Dinge besonders klar. Wie unter anderem Stromer betont, nötigt die Verbreitung der Glossopterisflora, der Reptilfamilie der Mesosauridae und vieles andere zu der Annahme eines großen, die Südkontinente vereinigenden ehemaligen Festlandes [115]. So kommt auch Jaworski [109] bei einer Prüfung aller Einwände, die natürlich auch hier nicht fehlen, zu dem Resultat: „Alles, was an geologischen Tatsachen in Westafrika und Südamerika bekannt ist, steht in voller Übereinstimmung mit der Annahme, zu der wir auf Grund tier- und pflanzengeographischer Tatsachen der Gegenwart und der Vorzeit gekommen sind, daß nämlich in früheren Erdperioden zwischen Afrika und Südamerika eine Landverbindung an Stelle des heutigen südatlantischen Ozeans bestanden hat." Aus pflanzengeographischen Gründen hat Engler [126] den Schluß gezogen: „Unter Berücksichtigung aller dieser Verhältnisse würden die angeführten Vorkommnisse von Amerika und Afrika gemeinsamen Pflanzentypen am besten ihre Erklärung finden, wenn erwiesen werden könnte, daß zwischen dem nördlichen Brasilien, südöstlich vom Mündungsgebiet des Amazonenstromes, und der Bai von Biafra im Westen Afrikas größere Inseln oder eine kontinentale Verbindungsmasse und ferner zwischen Natal und Madagaskar eine Verbindung bestanden hätte, deren Fortsetzung in nordöstlicher Richtung nach dem vom sino-australischen Kontinent getrennten Vorderindien schon längst behauptet wurde. Die vielen verwandtschaftlichen Beziehungen der Kapflora zur australischen machen außerdem eine Verbindung mit Australien durch Vermittlung des antarktischen 
Kontinents wünschenswert." Die letzten Verbindungen scheinen zwischen dem nördlichen Brasilien und der Guineaküste geherrscht zu haben: „Westafrika hat ferner mit dem tropischen Süd- und Mittelamerika die Seekuh Manatus gemeinsam, die in Strömen und seichtem, warmem Meerwasser lebt, die atlantische Tiefsee aber unmöglich überqueren kann. Man schließt daraus, daß in naher Vergangenheit eine Seichtwasserverbindung, wohl entlang der Nordküste des Südatlantiks, zwischen Westafrika und Südamerika bestanden habe." (Stromer.)

Namentlich ist es aber v. Ihering, der in seinem Buche: „Die Geschichte des Atlantischen Ozeans" ein überreiches Beweismaterial für diesen ehemaligen Landzusammenhang gebracht hat [122]. Auf Einzelheiten gehen wir nicht ein; stellt doch das ganze Buch eine Beweisführung für diese Verbindung dar, wenn auch unter der unhaltbaren Deutung, daß dieselbe durch einen Zwischenkontinent „Archhelenis“ gebildet wurde, bei unveränderter Lage der heutigen Kontinentalschollen ${ }^{1}$ ). Der Abbruch der Verbindung scheint, wie unsere Abb. 1 (S. 7) zeigt, kurz vor Mitte der Kreidezeit erfolgt zu $\left.\operatorname{sein}^{2}\right)$.

Die ehemalige Landverbindung zwischen Europa und Nordamerika liefert, wie schon dieselbe Abbildung zeigt, ein weniger

1) Soweit ich sehen kann, findet sich in v. Iherings Buch trotz seiner temperamentvollen Ablehnung der Verschiebungstheorie nicht ein einziger positiver Grund gegen dieselbe. Insbesondere habe ich das Kap. 20 (,,Zwei Weltanschauungen: v. Ihering und TaylorWegener") mehrmals mit der besten Absicht durchgelesen, mich über seine Einwände zu orientieren. Aber ich fand nur fortwährende Verwechslungen von Kontinent und Kontinentalscholle, und von Flachsee und Tiefsee. Es scheint daher, daß v. Iherings Ablehnung der Verschiebungstheorie nicht auf den Beobachtungstatsachen beruht, die im Gegenteil, wie auch Köppen [127] hervorgehoben hat, ausgezeichnet zu dieser passen, sondern auf nicht ausreichender Bekanntschaft mit dem Wesen dieser Theorie (vgl. hierzu meine Entgegnung auf v. Iherings Kritik in [128]).

$\left.{ }^{2}\right)$ Die Angaben hierüber wie auch über die Schlußzeiten der anderen Verbindungen sind naturgemäß nicht bei allen Forschern ganz gleichlautend. So glaubte ich noch bei der zweiten Auflage dieses Buches aus der mir damals zugänglichen Literatur entnehmen zu sollen, daß die Verbindung zwischen Südamerika und Afrika noch bis in den ältesten Abschnitt des Tertiärs hinein angedauert habe, während ich mich später überzeugen konnte, daß sie nach der Mehrzahl der Forscher schon in der Kreidezeit erlosch. Einzelne Gegner der Verschiebungstheorie, die nicht bemerkt haben, daß diese unbedeutende Korrektur schon in der dritten Auflage dieses Buches berücksichtigt wurde, klammern sich noch heute an diese Ungenauigkeit und glauben dadurch seltsamerweise die Verschiebungstheorie widerlegen zu können. In Wirklichkeit hat die 
einfaches Bild; sie war offenbar wiederholt durch Transgressionen aufgehoben oder doch behindert. Lehrreich ist die folgende, von Arldt [11] gegebene Tabelle, welche die Prozentzahlen der identischen Reptilien und Säugetiere hüben und drüben angibt:

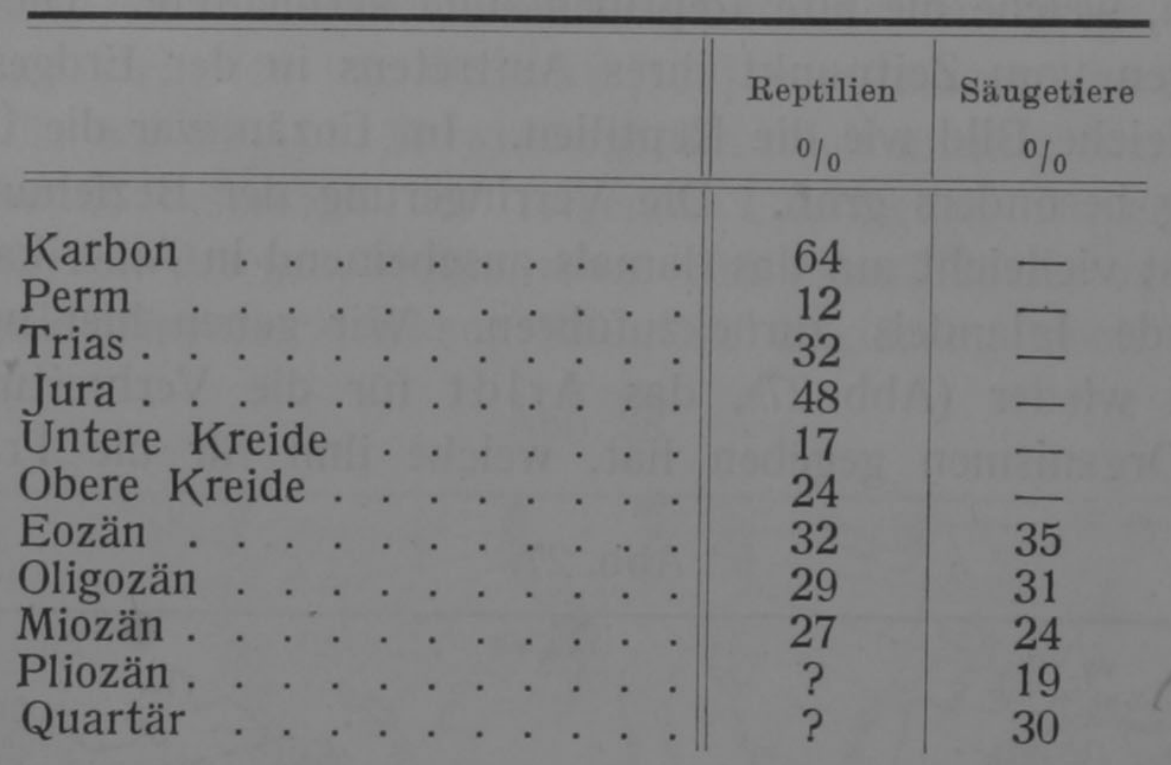

Der Gang dieser Zahlen stimmt gut mit unserem in Abb. 1 dargestellten Abstimmungsresultat überein, nach welchem die Landverbindungen im Karbon, in der Trias, dann allerdings nur für den unteren, nicht mehr den oberen Jura, aber wieder von der Oberkreide ab das ältere Tertiär hindurch von der Mehrzahl der Fachgelehrten angenommen wird. Ganz besonders tritt die Übereinstimmung für das Karbon hervor, vielleicht weil hier die Fauna besonders gut bekannt ist. Sowohl über die Fauna wie die Flora des europäischen und nordamerikanischen Karbons liegen besonders eingehende Untersuchungen in großer Zahl vor von Dawson, Bertrand, Walcott, Ami, Salter, v. Klebelsberg u. a. Letzterer [129] hat besonders auf die faunistische Gemeinsamkeit der marinen Zwischenschichten in den kohlenführenden Schichtenfolgen vom Donez durch Oberschlesien - Ruhrrevier - Belgien England bis nach dem Westen Nordamerikas hingewiesen, welche bei ihrer kurzen Zeitdauer sehr auffallend ist. Dabei sind die Identi-

Frage der Zeitsetzung überhaupt nichts mit der Richtigkeit oder Unrichtigkeit der Verschiebungstheorie zu tun; sie bleibt vollkommen den Spezialwissenschaften überlassen und dient der Verschiebungstheorie nur dazu, ihre Aussagen präziser zu gestalten. Auch wenn künftig was durchaus möglich ist - in diesen Zeitsetzungen noch kleine Korrekturen angebracht werden müßten (große sind nicht mehr zu befürchten), so wäre doch kein Anlaß, von einer Korrektur der Verschiebungstheorie zu sprechen. 
täten keineswegs auf solche Elemente beschränkt, welche eine Verbreitung über die ganze Erde hatten. Wir können auf weitere Einzelheiten hier nicht eingehen. Das Fehlen von Identitäten bei den Reptilien im Pliozän und Quartär ist natürlich eine Wirkung der Kälte, welche die alte Reptilienfauna vernichtete. Die Säugetiere zeigen vom Zeitpunkt ihres Auftretens in der Erdgeschichte ab das gleiche Bild wie die Reptilien. Im Eozän war die Übereinstimmung besonders groß. Die Verringerung der Beziehungen im Pliozän ist vielleicht auf das damals anscheinend in Amerika bereits entstehende Inlandeis zurückzuführen. Wir geben hier noch das Kärtchen wieder (Abb. 27), das Arldt für die Verbreitung derjenigen Organismen gegeben hat, welche ihm für die Frage der

Abb. 27.

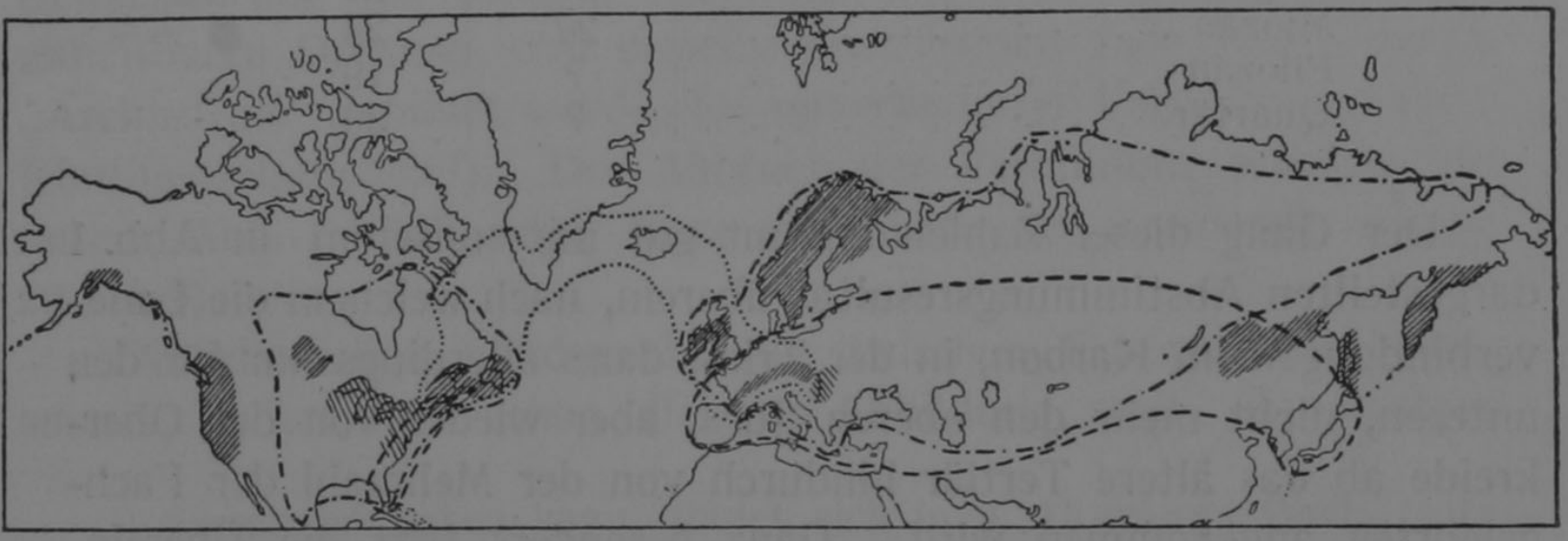

Verbreitung nordatlantischer Organismen, nach Arldt.

Punktiert $=$ Gartenschnecke ; gestrichelt $=$ Lumbricinen (Regenwürmer) $;$ Strichpunktiert = Barsche; schraffiert Nordost-Südwest $=$ Perlmuschel; desgl. Nordwest-Südost $=$ Hundsfische (Umbra).

nordatlantischen Brücke am meisten entscheidend zu sein schienen. Die junge Regenwurmgattung der Lumbriciden ist, wie die Abbildung zeigt, von Japan bis Spanien, jenseits des Ozeans aber nur im Osten der Union verbreitet. Die Perlmuschel kommt an den Abrißstellen der Kontinente, auf Irland und Neufundland und den beiderseits angrenzenden Gebieten vor. Die Familie der Barsche (Perciden) und andere Süßwasserfische finden sich in Europa und Asien, in Nordamerika aber nur im östlichen Teil. Vielleicht wäre auch noch das gemeine Heidekraut (Calluna vulgaris) zu nennen, das sich außer in Europa nur in Neufundland und den daran angrenzenden Gebieten findet, wie denn auch umgekehrt sich besonders viele amerikanische Pflanzen in Europa ganz auf den Westen Irlands beschränken. Wenn für die letzteren vielleicht auch der Golfstrom 
als Erklärung angeführt werden kann, so ist das doch für das Heidekraut gewiß nicht der Fall. Besonders auffallend ist auch die Verbreitung der Gartenschnecke von Süddeutschland über die britischen Inseln, Island und Grönland hinüber zur amerikanischen Seite, wo sie aber nur in Labrador, Neufundland und dem Osten der Union vorkommt. Hierfür hat Ökland [116] vor kurzem eine Karte gegeben, die wir in Abb. 28 wiedergeben. Ich möchte hier die Aufmerksamkeit besonders auf folgende Überlegung lenken: Selbst wenn wir von der geophysikalischen Unhaltbarkeit der versunkenen Zwischenkontinente absehen, ist diese Erklärung doch der VerAbb. 28.

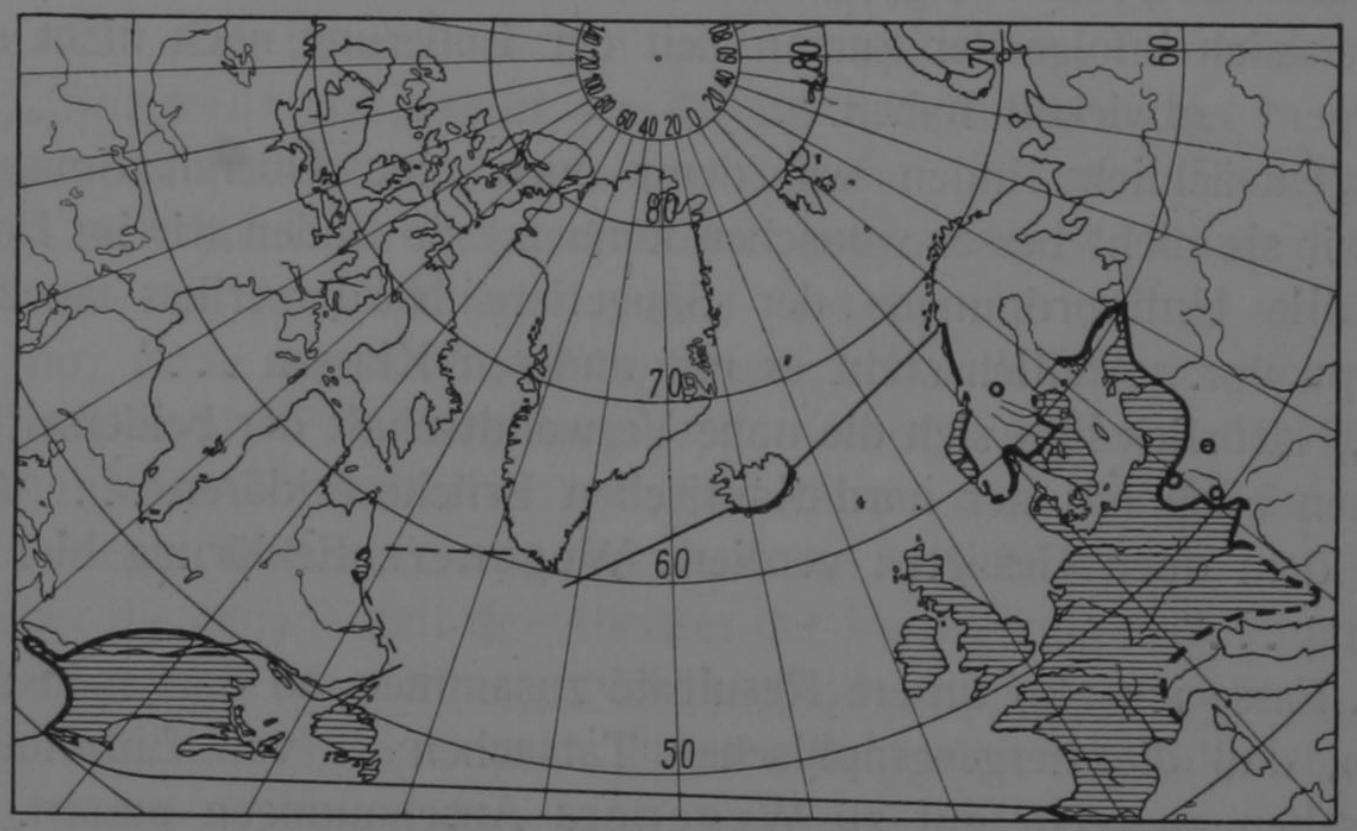

Genauere Verbreitung der Gartenschnecke, nach Ökland.

schiebungstheorie unterlegen, denn sie muß, um die beiden kleinen Verbreitungsgebiete zu verbinden, ein sehr langes hypothetisches Stück einschalten. Und mit der Häufung solcher Fälle wird es immer unwahrscheinlicher, daß die Ost- und Westgrenzen der Verbreitung gerade immer auf die heutigen Kontinente und nicht auf dem breiten Zwischenkontinent, also im heutigen Ozean, lägen.

v. Ubisch [117] sagt mit Recht: „Die hypothetischen Brücken der älteren Theorie erstrecken sich meist über sehr beträchtliche Gebiete... Einige Brücken haben sich sogar durch verschiedene Klimazonen erstreckt. Daher konnten die Brücken sicher nicht von allen Tieren der durch sie verbundenen Kontinente benutzt werden, genau so wenig, wie wir auf heute zusammenhängenden Kontinenten, selbst wenn sie sich durch einheitliche Klimazonen 
erstrecken, eine ganz einheitliche Fauna vorfinden. Am besten läßt sich das für Eurasien demonstrieren, von dessen einheitlicher Tierregion Ostasien meist als besondere Provinz abgetrennt wird." „Anders liegen die Dinge nach Wegeners Theorie. Nach dieser wird durch den erfolgten Abriß ein völlig einheitliches Faunengebiet zerrissen, wenn derselbe nicht zufällig auf eine schon bestehende Faunengrenze trifft ..."

„,Besonders deutlich müßten sich die Folgen der Zerreißung eines einheitlichen Faunengebiets in Nordamerika bzw. Europa zeigen. Denn der Abriß erfolgte relativ spät, die paläontologischen Urkunden sind entsprechend zahlreich. Außerdem sind gerade diese Gebiete besonders gut durchforscht. Auch die lebenden Formen können sich infolge der kurzen Zeit der Isolierung noch nicht sehr divergent entwickelt haben."

„Tatsächlich finden wir denn auch eine Übereinstimmung, wie wir sie nicht besser wünschen können. So finden wir im Eozän fast alle Unterordnungen der Säugetiere Nordamerikas auch in Europa vor. Ähnlich steht es mit anderen Klassen ..."

„Natürlich läßt sich die nahe Verwandtschaft der beiderseitigen Faunen auch mit der nordatlantischen Brücke erklären .... Aber nach dem oben Gesagten verdient Wegeners Erklärung hier den Vorzug ..."

„Fasse ich also unsere Resultate zusammen, so darf man wohl sagen, daß die tiergeographischen Tatsachen - von Einzelheiten abgesehen - recht gut zu Wegeners Anschauungen passen. In vielen Fällen ist die Verschiebungstheorie sogar geeignet, uns einfachere Lösungen der Verhältnisse zu geben als jede andere frühere Theorie ${ }^{1}$ )".

Auch Huus betrachtet es in einer Arbeit über die Ascidien [130] als einen besonderen Vorzug der Verschiebungstheorie, daß sie außer der Landverbindung auch noch eine Annäherung der Fundstellen bietet: „Besonders einfach wird die Deutung der trans-

1) Ökland zieht aus dem gleichen Material den Schluß, daß die Theorie des versunkenen Zwischenkontinents - dessen geophysikalische Unhaltbarkeit er nicht beachtet - vorzuziehen sei, und zwar, weil nach der Verschiebungstheorie noch mehr Identitäten zu erwarten seien als vorhanden sind. Er stellt offenbar die Forderungen in diesem Punkt zu hoch; denn erstens ist auch nach der Verschiebungstheorie keineswegs eine völlige Identität der ehemaligen Faunen und Floren zu erwarten, und zweitens wird die Zahl der Identitäten absolut wie prozentisch stark herabgesetzt durch die Unvollständigkeit der fossilen Funde. 
atlantischen Beziehungen durch die Verschiebungstheorie Wegeners. Nach dieser Theorie kann nicht nur die genannte Strandregion, sondern auch ein in der Tertiärzeit viel kleinerer Abstand als jetzt zwischen den zwei Kontinenten vorausgesetzt werden. Eine damalige Ausbreitung quer über den Ozean wird dadurch denkbar und die transatlantischen Beziehungen in den mittleren und südlichen Teilen dieses Ozeans leicht verständlicher. Auch mögen durch diese Theorie die innigen Beziehungen der Ascidienfauna Westindiens zu der des Indischen Ozeans eine natürliche Erklärung finden."

Auf eine interessante Einzelheit im Gebiet des Nordatlantik haben v. Ubisch [134], Hoffmann [133] und neuerdings Osterwald [120] hingewiesen, nämlich daraú, daß die gemeinsamen Laichplätze des amerikanischen und europäischen Flußaales, wie von J. Schmidt festgestellt wurde, im Sargassomeer liegen, und daß der europäische Aal entsprechend der größeren Entfernung dieser Laichplätze auch eine erheblich längere Entwicklung durchmacht als der amerikanische. Wie Osterwald richtig ausführt (und mir, wenn ich mich recht erinnere, schon 1922 mündlich von J. Schmidt als Erklärung angegeben wurde), erklären sich diese eigentümlichen Verhältnisse zwanglos durch das allmähliche Abrücken dieses Tiefseebeckens mit Amerika von Europa ${ }^{1}$ ).

Über die genaue Zeit des Abrisses der Verbindung Nordamerikas mit Europa auf der Strecke Neufundland-Irland herrschen, wie schon unsere Abb. 1 zeigt, noch beträchtliche Meinungsunterschiede.

1) v. Ubisch und Hoffmann finden beide umgekehrt, daß diese Tatsachen gegen die Verschiebungstheorie und für den versunkenen Zwischenkontinent sprechen, aber infolge des Mißverständnisses: „Man könnte ja zunächst denken, daß die Verlegung der Laichplätze passiv in der Weise erfolgt wäre, daß der Teil des Meeresbodens, an dem die Aale in der Kreide-Eozän laichten, wie eine Waschschüssel von dem amerikanischen Kontinent mit nach Westen gezogen worden sei."

„Diese Vorstellung ist aber nach Wegeners Theorie nicht zulässig. Denn Wegener nimmt an, daß bei der Abwanderung der Kontinente stets frische Simaoberfläche entblößt wird ..." Der Boden des Sargassomeeres dürfte nicht aus frisch entblößtem Sima bestehen, sondern ist wohl identisch mit dem Boden des in meiner Eozänkarte (Abb. 4) erkennbaren Tiefseebeckens zwischen Florida und Spanien. Es wird in Wirklichkeit noch kleiner gewesen sein, da in der Rekonstruktion die Sialmassen der Azoren, die Spanien und Nordafrika anzugliedern wären, nicht genügend berücksichtigt sind. Aber existiert hat es jedenfalls schon damals östlich von Florida. Die kristalline Decke dieses Beckens wird sich dann, an Amerika haftend, mit diesem nach Westen verschoben haben. In einem neuen Sammelreferat [227], das noch erheblich mehr tiergeographische Literatur als die hier angeführte berücksichtigt, erkennt v. Ubisch auch die hier gegebene Lösung als möglich an, die er 
Jedenfalls scheint er sich im Spättertiär vollzogen zu haben. Teilweise mag die Unsicherheit des Ergebnisses damit zusammenhängen, daß, wie Scharff sehr wahrscheinlich gemacht hat [131], weiter im Norden die Brücke über Island und Grönland noch bis ins Quartär hinein bestehen blieb.

Lehrreich sind in dieser Hinsicht die Untersuchungen Warmings und Nathorsts über die grönländische Flora, welche zeigen, daß an der Südostküste Grönlands, also gerade auf der Strecke, die nach der Verschiebungstheorie noch im Quartär Skandinavien und Nordschottland vorgelagert war, die europäischen Elemente überwiegen, während auf der ganzen übrigen grönländischen Küste einschließlich Nordostgrönlands der amerikanische Einfluß vorherrscht.

Nach Semper [125] war die tertiäre Flora von Grinnell-Land interessanterweise enger ( $\mathrm{zu}$ 63\%) mit der von Spitzbergen als mit der von Grönland (30\%) verwandt, während es heute natürlich umgekehrt ist (64 bzw. 96\%). Unsere Rekonstruktion für das Eozän gibt die Lösung dieses Rätsels, indem hier der Abstand GrinnellLand-Spitzbergen kleiner ist, als der zwischen ersterem und den grönländischen Fundorten.

W. A. Jaschnov weist in einer Arbeit über die Crustaceen von Nowaja Semlja [225] darauf hin, daß sich auch die heutige Verbreitung der Süßwasserkrebse am besten durch die Verschiebungstheorie erklärt: ... ,mit großer Wahrscheinlichkeit kann gesagt werden, daß in der Hydrobiologie viele Fragen der Verbreitung der niederen Wasserorganismen, jedenfalls in der nördlichen Halbkugel, auf Grund der Prinzipien der Theorie der Verschiebung der Kontinente gelöst werden können. Als Beispiel erwähnen wir die gegenwärtige zerstreute Verbreitung von Limnocalanus macrurus, für welchen der passive Transport (gemeint ist durch Wind und durch Vögel) infolge des Fehlens der Ruhestadien ausgeschlossen ist. Beim Vorhandensein laut Wegeners Theorie einer Verbindung

aber in die Form kleidet, daß Europa nach Osten, nicht Amerika nach Westen gewandert sei. Wegen der Relativität der Bewegung kommt dies natürlich auf dasselbe hinaus; denn wenn Amerika relativ zu Europa nach Westen wandert, so wandert Europa relativ zu Amerika nach Osten. - Ich benutze die Gelegenheit, hier nochmals zu betonen, daß die Trennung Südamerikas von Afrika schon in der mittleren Kreide eintrat; denn auf S. 162, 163 und 172 des genannten Sammelreferats werden faunistische Unterschiede aus späterer Zeit (Eozän, Miozän!) immer noch als Einwände gegen die Verschiebungstheorie gewertet! Vgl. hierzu S. 102 Anmerkung ? 
beider Kontinente war das Areal der Verbreitung dieser Art gar nicht groß (s. Abb. 29)."

Von weiteren Autoren sei nur noch Handlirsch [136] erwähnt, welcher durch eingehende Untersuchungen zu dem Schluß kommt: „Es müssen unbedingt noch im Tertiär und vielleicht auch Quartär durch mehr oder minder lange Zeiträume oder wiederholt Landverbindungen zwischen dem nördlichen Nordamerika und Europa, bzw. nördlichem Ostasien bestanden haben ... Dagegen finde ich keinen triftigen Grund zu der Annahme direkter oder antarktischer tertiärer Landverbindungen zwischen Südamerika, Afrika und Australien; womit selbstverständlich nicht behauptet sein soll, daß solche Verbindungen auch früher nicht bestanden."

Abb. 29.

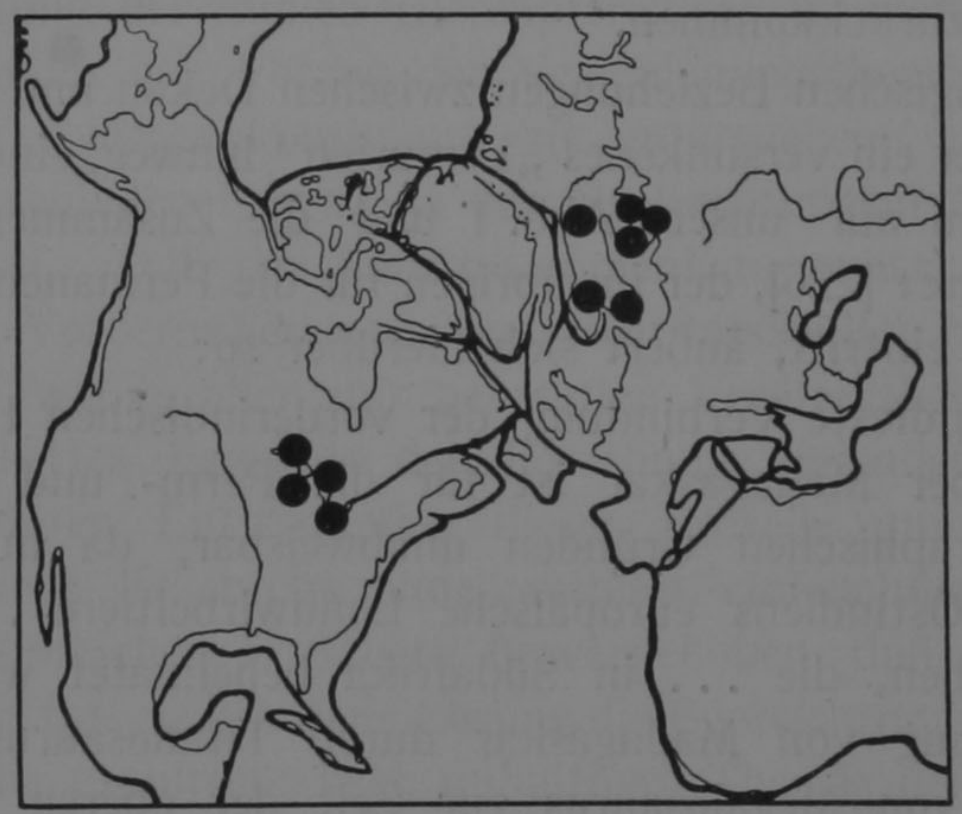

Verbreitung von Limnocalanus macrurus, nach Jaschnov.

Kubart [137] hat in einer interessanten Studie die Flora der Inseln der mittelatlantischen Bodenschwelle, die ja geologisch als Kontinentalbrocken aufgefaßt werden, untersucht und kommt durch eine Statistik der indigenen Typen zu dem auch durch die Fauna bestätigten zahlenmäßig nachweisbaren Ergebnis, daß die Isolierung dieser Inseln von Süden nach Norden fortgeschritten ist. „Allerdings können diese Tatsachen nicht allein für die Verschiebungstheorie, sondern auch für die Existenz eines großen Brückenkontinents ausgewertet werden. Die Inseln werden eben in beiden Fällen als Reste dieser seinerzeitigen Vorgänge aufgefaßt, und auch nach der Landbrückentheorie erfolgte das Absinken des afrikanisch-südamerikanischen Zwischenkontinents in einer geologisch früheren 
Zeit als das der Nordatlantis. Da aber nach der Permanenzlehre das Hochziehen eines großen Atlantiskontinents als ausgeschlossen bezeichnet werden muß, so wird diese floristische Prozentreihe, die durch die zoologischen Verhältnisse vollauf bestätigt wird, und der die Geologie nicht zu widersprechen scheint, tatsächlich zu einem direkten Beweis für eine vom Süden nach Norden fortschreitende Trennung der afrikanisch-europäisch-amerikanischen Scholle. " Das ist genau der Standpunkt der Verschiebungstheorie ${ }^{1}$ ).

Wir könnten noch viele andere Autoren anführen, die die frühere Existenz der angegebenen Landverbindungen quer über den Atlantik bestätigen. Aber da diese Verbindungen heute wohl kaum noch irgendwie in Zweifel gezogen werden, dürfte sich dies erübrigen. Auf die Zeugnisse aus der Regenwurmverbreitung werden wir ohnehin noch später zurückkommen.

Die biologischen Beziehungen zwischen Dekan und Madagaskar, angeblich über ein versunkenes „Lemurien“ hinweg, sind allbekannt. Wir verweisen auf unsere Abb. 1 und die Zusammenstellung bei Arldt. Diener [226], der im übrigen für die Permanenz der großen Ozeanbecken eintritt, äußert sich hierüber so:

„Eine landfeste Verbindung der vorderindischen Halbinsel mit Südafrika über Madagaskar ist für die Perm- und Triasperiode aus tiergeographischen Gründen unabweisbar, da in den Gondwanafaunen Ostindiens europäische Landwirbeltiere ... sich mit solchen mischen, die ... in Südafrika beheimatet waren. Auch die Besiedelung von Madagaskar durch Titanosaurus und einen Verwandten von Megalosaurus zur Zeit der oberen Kreide muß auf dem Wege über Vorderindien stattgefunden haben, da der Kanal von Mozambique bereits im Lias geöffnet war. Erst im jüngeren Abschnitt der Kreideperiode dürfte die schmale, langgestreckte Insel, deren Enden wir im Dekan und auf Madagaskar zu suchen haben; mit ihrem Mittelstück vollends zur Tiefe niedergegangen sein, so daß das Äthiopische Mittelmeer Neumayrs, bis dahin eine Dependenz der Tethys, nunmehr in eine breite, offene Verbindung mit dem Indischen Ozean trat." - Statt des von Diener angenommenen Niedergehens auf mehr als $4000 \mathrm{~m}$ Tiefe, das in solcher

1) Natürlich hat Kubart Recht, wenn er meint, daß man die ältere Vorstellung vom Versinken der Landbrücken nicht gan z ausschalten darf. Der Leser wird im Gegenteil bemerken, daß in diesem Buch an vielen Stellen von ihr Gebrauch gemacht wird, nur nicht im Bereich der großen Ozeanbecken. 
Ausdehnung isostatisch nicht möglich ist, nehmen wir den Zusammenschub dieser Brücke zur Bildung von Hochasien an. Der tiergeographische Unterschied besteht darin, daß dann Dekan vor der Trennung unmittelbar neben Madagaskar gelegen hat. Gerade darin zeigt sich der Vorzug der Verschiebungstheorie, da die beiden Teile in ihrer heutigen Lage einen bedeutenden Breitenunterschied besitzen und nur deshalb ähnliches Klima haben und ähnliche Formen beherbergen können, weil der Äquator zwischen ihnen liegt. Für die Zeiten der Glossopterisflora würde uns dieser große Abstand ein klimatisches Rätsel aufgeben, welches durch die Verschiebungstheorie beseitigt wird. Auf die Gruppe der paläoklimatischen Argumente werden wir indessen erst im nächsten Kapitel näher eingehen.

Sahni [138] hat den (unnötigen) Versuch gemacht, an Hand der Verbreitung der kühlen Glossopterisflora im Bereich des alten Gondwanalandes den Vorzug der Verschiebungstheorie vor der der versunkenen Zwischenkontinente zu untersuchen, muß aber die Frage unentschieden lassen, da das Beobachtungsmaterial noch zu lückenhaft sei. Daß der Landzusammenhang zwischen Südafrika, Madagaskar, Vorderindien und Australien tatsächlich bestanden hat, wird hier - wie in allen mir bekannten Veröffentlichungen - als längst gesichertes Ergebnis der Forschung behandelt. Bei den riesigen heutigen Entfernungen dieser Erdteile untereinander ist es aber meines Erachtens ohne weiteres einleuchtend, und wird auch von zahlreichen Forschern hervorgehoben, daß die durch die Verschiebungstheorie gebotene Lösung die Beobachtungen noch besser erklärt als die geophysikalisch unhaltbare Theorie der versunkenen Zwischenkontinente.

Von einem ganz besonderen Interesse ist in unserem Zusammenhang die Tierwelt Australiens. Schon Wallace [139] erkannte eine deutliche Gliederung in drei verschieden altertümliche Elemente, und an diesem Ergebnis hat sich auch durch die neueren Untersuchungen z. B. von Hedley nichts Wesentliches geändert; das älteste Element, welches hauptsächlich im Südwesten Australiens anzutreffen ist, zeigt Verwandtschaft namentlich mit Vorderindien und Ceylon, weiter auch mit Madagaskar und Südafrika. Hier sind auch wärmeliebende Tiere in der Verwandtschaft vertreten, und auch die Regenwürmer, die gefrorenen Boden scheuen. Diese Verwandtschaft entstammt der Zeit, als Australien noch mit Vorderindien zusammenhing. Nach unserer Abb. 1 wurde diese Verbindung bereits in der älteren Iurazeit aufơehohen 
Das zweite Faunenelement Australiens ist sehr bekannt, denn es gehören hierher die eigenartigen Säugetiere - Beutler und Kloakentiere - , die sich von der Fauna der Sundainseln so scharf unterscheiden (Wallace-Grenze der Säugetiere). Dies Faunenelement zeigt Verwandtschaftsbeziehungen nach Südamerika. Beuteltiere leben jetzt z. B. außer in Australien sowie auf den Molukken und verschiedenen Südseeinseln hauptsächlich in Südamerika (Opossum oder Beutelratte in einer Art auch noch in Nordamerika verbreitet); fossil sind sie auch noch aus Nordamerika und Europa, aber nicht aus Asien bekannt. Sogar die Parasiten der australischen und südamerikanischen Beutler sind die gleichen: E. Bresslau [140] hebt hervor, daß von den Plattwürmern sich die Geoplaniden mit $3 / 4$ ihrer rund 175 Arten in diesen beiden Gebieten finden. „,Die geographische Verbreitung der Trematoden und Cestoden, die natürlich der ihrer Wirte entspricht, ist bis jetzt nur selten Gegenstand besonderer Untersuchungen gewesen. Daß auch hier Tatsachen von hohem zoogeographischen Interesse zu ermitteln sind, lehrt die Cestodengattung Linstowia, die sich ausschließlich in den südamerikanischen Didelphyiden (Beutelratten) und in australischen Beutlern (Perameles) und Monotremen (Echidna) findet." Von dieser Verwandtschaft mit Südamerika sagt Wallace [139]: „Es ist wichtig, hier zu bemerken, daß die hitzeliebenden Reptilien kaum einen Beweis einer nahen Verwandtschaft zwischen den beiden Regionen liefern, während es die kälteaushaltenden Amphibien und Süßwasserfische im Überfluß tun." Die gleiche Eigentümlichkeit zeigt die ganze übrige Fauna, so daß Wallace von der Landverbindung Australien-Südamerikà meint, „daß dieselbe, wenn sie überhaupt vorhanden war, nach ihren kalten südlichen Grenzen zu lag“. Auch die Regenwürmer haben diese Brücke nicht benutzt. Da man hierdurch geradezu auf Antarktika als Verbindung hingewiesen wird, was ja auch auf dem kürzesten Verbindungsweg liegt, so ist nicht zu verwundern, daß die von vereinzelten Autoren statt dessen vorgeschlagene ,südpazifische“ Brücke, die nur auf der Merkatorkarte die kürzeste Verbindung vortäuscht, fast überall abgelehnt wird. Dies zweite australische Faunenelement entstammt also der Zeit, als Australien noch über Antarktika mit Südamerika zusammenhing, also zwischen älterem Jura (dem Abriß von Vorderindien) und dem Eozän (dem Abriß Australiens von Antarktika). Für diese Formen bietet die heutige Lage Australiens keine Isolierung mehr, sie dringen langsam in Sundaarchipel weiter vor, so daß Wallace die Säugetiergrenze 
bereits zwischen den Inseln Bali und Lombok hindurch und weiter durch die Makassarstraße legen mußte.

Die dritte Fauna Australiens ist die jüngste, von den Sundainseln eingewanderte, die in Neuguinea haust und bereits den Nordosten Australiens erobert hat. Der Dingo (wilde Hund), Nagetiere, Fledermäuse und andere Tiere sind postdiluvianisch nach Australien eingewandert. Die junge Regenwurmgattung Pheretima, welche mit großer Lebenskraft auf den Sundainseln, den südostasiatischen Küstengebieten von der Malaiischen Halbinsel bis China und auf Japan die meisten älteren Gattungen verdrängt hat, hat auch Neuguinea vollständig erobert und bereits auf der Nordspitze Australiens festen Fuß gefaßt. Alles dies beweist einen Austausch von Fauna und Flora, der erst in jüngster geologischer Zeit begonnen hat.

Diese Dreigliederung der australischen Fauna steht aufs schönste mit der Verschiebungstheorie in Übereinstimmung. Man braucht nur auf unsere drei Rekonstruktionskarten S. $18 \mathrm{zu}$ blicken, um aus ihnen die Erklärung sofort abzulesen. Gerade diese Verhältnisse zeigen aber auch aufs deutlichste den großen Vorzug, den die Verschiebungstheorie auch rein biologisch vor der der versunkenen Brücken besitzt. Der Abstand der einander nächsten Punkte von Südamerika und Australien, nämlich Feuerland und Tasmanien, beträgt, in Großkreis gerechnet, heute $80^{\circ}$, also ebensoviel wie der zwischen Deutschland und Japan; und das mittlere Argentinien liegt von Mittelaustralien ebenso weit ab wie von Alaska, oder wie Südafrika vom Nordpol. Glaubt man wirklich, daß hier eine bloBe Landverbindung genügt, um den Formenaustausch sicherzustellen? Und wie seltsam, daß Australien mit den so unvergleichlich näher gelegenen Sundainseln gar keinen Formenaustausch hatte, denen es wie ein Fremdkörper aus einer anderen Welt gegenüberliegt! Niemand kann leugnen, daß hier unsere Annahme, die den früheren Abstand Australiens von Südamerika auf einen Bruchteil des heutigen verringert, und es andererseits von den Sundainseln für lange Zeiträume durch ein breites Tiefseebecken trennt, der Eigenart der australischen Tierwelt in ganz anderer Weise gerecht wird, als die ohnehin geophysikalisch unmögliche Theorie der versunkenen Zwischenkontinente. Ich glaube in der Tat, daß die australische Fauna das wichtigste Material liefern wird, das die Biologie zu dem Gesamtproblem der Kontinentverschiebungen wird beisteuern können. Möchte sich bald ein Fach- 
mann finden, der sie zusammenfassend unter diesem Gesichtspunkt bearbeitet!

In der Frage der ehemaligen Landverbindungen Neuseelands scheint noch nicht völlige Klarheit zu herrschen. Es war schon oben (S. 91) darauf hingewiesen, daß ein großer Teil der Inseln erst durch die jurassische Faltung trockengelegt wurde. Damals bildete Neuseeland wohl großenteils noch einen Randschelf Australiens, der, an der Vorderseite der Verschiebung gelegen, der Faltung unterlag. Nach Süden hatte Neuseeland Anschluß an die Westantarktis und über diese an Patagonien. v. Ihering schreibt [122]: „Zur Zeit der oberen Kreide und im Beginn des Alttertiärs stand den Wanderungen mariner Tiere von Chile nach Patagonien und umgekehrt, sowie nach Grahamland und anderen Teilen der Antarktis bis nach Neuseeland hin der Weg offen." Die Landflora der damaligen Zeit war nach Marshall [141] auf Neuseeland kein Vorläufer der heutigen, sondern es fanden sich Eichen und Buchen, die vermutlich auf dem Wege über die Westantarktis, demselben, den die Flachseetiere genommen haben, von Patagonien herübergekommen waren. Damals konnte also wohl keine unmittelbare Landverbindung zwischen Australien und Neuseeland bestehen. Im Laufe der Tertiärzeit muß diese aber offenbar, wenigstens beschränkte Zeit hindurch, bestanden haben, so daß die heutige Flora einwandern konnte. Daß die Inseln in der Vorzeit jedenfalls Flachseeverbindung mit Australien gehabt haben, geht nach Bröndsted [142] auch aus der Untersuchung der Schwämme hervor.

- Von besonderem Interesse für die Frage der neuseeländischen Landverbindungen ist eine Arbeit von Meyrick über die Microlepidopteren [143]. Außer interessanten Beziehungen zwischen Afrika und Südamerika, welche die oben skizzierten Ergebnisse durchaus bestätigen, findet er, daß eine sowohl in Südamerika wie in Australien durch zahlreiche Arten vertretene Gattung (Machimia) in Neuseeland ganz fehlt; und andererseits kommt die Gattung Crambus gerade umgekehrt in Neuseeland (mit 40 endemischen Arten) und in reicher Ausbildung auch in Südamerika vor, während sich in Australien nur zwei Arten davon finden. Mit anderen Worten: Im ersten Falle erscheint Südamerika mit Australien verbunden und Neuseeland ganz ausgeschlossen, und im zweiten Falle erscheint Südamerika mit Neuseeland verbunden und Australien fast ganz ausgeschlossen.

Dies wie auch die oben angeführten Tatsachen zeigen wohl nur so viel, daß es von Südamerika aus zwei getrennte Wander- 
straßen gab: die eine nach Neuseeland, vermutlich über die Westantarktis, und die andere nach Australien, vermutlich über die Ostantarktis. Neuseeland scheint dabei trotz seiner damals viel näheren Lage bei Australien mit diesem, wenn überhaupt, so nur kurze Zeit in eigentlicher Landverbindung gestanden zu haben. Bei der genauen Klärung dieser Vorgänge ist natürlich unsere geringe Kenntnis der Antarktis äußerst hinderlich.

Das Becken des Pazifischen Ozeans muß nach allem, was wir wissen, schon seit sehr alten geologischen Zeiten als solches bestanden haben. Eine Reihe von Autoren hat zwar das Gegenteil angenommen, wie Haug, der die Inseln als Reste eines großen „abgesunkenen“ Kontinents deuten will, oder Arldt, der die Beziehungen zwischen Südamerika und Australien durch eine dem Breitenparallel folgende Landbrücke quer durch den Südpazifik erklären zu sollen glaubte während doch der Blick auf den Globus sofort zeigt, daß der Weg von Südamerika nach Australien über Antarktika geht. Auch v. Ihering hat einen pazifischen Kontinent angenommen, aber die Gründe hierfür sind, wie schon früher unter anderem von Simroth [144] gezeigt und neuerdings wieder von v. Ubisch [149] betont wurde, durchaus unhaltbar. Auch Burckhardt hat einen südpazifischen Kontinent, der sich von der Westküste Südamerikas nach Westen erstreckte, angenommen, aber der Grund hierfür besteht nur in einer einzelnen geologischen Beobachtung, die sich wohl auch anders erklären läßt. Jedenfalls ist auch diese Hypothese von Simroth [144], Andrée [145], Diener, Sörgel u. a. abgelehnt, und selbst Arldt, einer der wenigen Anhänger, muß zugeben, daß diese Landbrücke sich am wenigsten von allen stützen läßt [146]. Wir befinden uns also mit unserer Annahme einer Permanenz der pazifischen Tiefsee mindestens seit der Karbonzeit in Übereinstimmung mit der weit überwiegenden Mehrzahl der Forscher.

Biologisch ist dies größere Alter des Pazifik gegenüber dem Atlantik gut ausgeprägt. So schreibt v. Ubisch [117]: „Im Stillen Ozean finden wir zahlreiche altertümliche Formen, wie Nautilus, Trigonia, Ohrenrobbe. Derartige Formen fehlen im Atlantischen Ozean." Und Colosi [118] hebt hervor, daß die Fauna des Atlantik ebenso wie die des Roten Meeres dadurch ausgezeichnet ist, daß sie stets nur Verwandtschaftsbeziehungen $\mathrm{zu}$ den angrenzenden Gebieten zeigen, während für den Pazifik vereinzelte Verwandtschaftsbeziehungen zu weit entfernten Gebieten charakteristisch sind; 
letzteres ist aber das Kennzeichen alter, ersteres das jung besiedelter Gebiete.

Svedelius [155] hat kürzlich in einer Studie über die diskontinuierliche geographische Verbreitung einiger tropischer und subtropischer mariner Algen darauf hingewiesen, daß das Material zwar für eine Prüfung der Verschiebungstheorie nicht ausreicht; ,doch ist zu beachten, daß meine Untersuchung zeigt, daß die Mehrzahl der älteren Genera der Algen offensichtlich ihre Hauptverbreitung im Indisch-Pazifischen Ozean haben, von wo aus sie in den Atlantik eingewandert sind. Nur in ein oder zwei Fällen scheint die Wanderung in umgekehrter Richtung vor sich gegangen zu sein. So darf die Algenflora des Atlantik vielleicht für jünger angesehen werden als die des Indisch-Pazifischen Ozeans. Dies widerspricht nicht Wegeners Theorie, nach welcher der Atlantik viel jüngeren Alters ist als der Indisch-Pazifische Ozean."

Die pazifischen Inseln (mitsamt ihrem submarinen Unterbau) werden in der Verschiebungstheorie als von den Kontinentalschollen abgelöste Randketten betrachtet, die bei der allgemeinen, vorwiegend westlich gerichteten Bewegung der Erdkruste über den Kern allmählich nach Osten zurückgeblieben sind (vgl. Kap. 8). Ihre Heimat wäre hiernach, ohne auf Einzelheiten einzugehen, auf der asiatischen Seite des Ozeans zu suchen, der sie jedenfalls in den hier betrachteten geologischen Zeiten erheblich näher als heute gelegen haben müssen.

Die biologischen Verhältnisse scheinen dies zu bestätigen. So haben nach Griesebach [147] und Drude [148] die Hawaiinseln eine Flora, die am nächsten verwandt nicht mit Nordamerika ist, das ihnen doch am nächsten liegt, und von dem heute Luft- und Meeresströmung herkommen, sondern mit der alten Welt. Die Insel Juan Fernandez zeigt nach Skottsberg botanisch gar keine Verwandtschaft mit der doch so nahen Küste von Chile, sondern mit Feuerland, Antarktika, Neuseeland und den anderen pazifischen Inseln. Doch sei hervorgehoben, daß die biologischen Verhältnisse auf Inseln allgemein schwerer zu deuten sind als diejenigen auf größeren Landräumen.

Zum Schluß seien noch einige neuere Arbeiten besprochen, die als die ersten eingehenderen Spezialarbeiten unter Berücksichtigung der Verschiebungstheorie von besonderer Wichtigkeit sind. Den Anfang machte Irmschers 1922 erschienene große Untersuchung „Pflanzenverbreitung und Entwicklung der Kontinente“ [150]. Es 
wird darin die heutige und ehemalige Verbreitung der Blütenpflanzen bis zurück zur Kreidezeit in bisher unerreichter Vollständigkeit untersucht und durch zahlreiche Karten veranschaulicht. Einzelheiten aus diesem ungemein reichhaltigen Material hier vorzubringen, ist unmöglich ${ }^{1}$ ). Die Arbeit schließt mit den Worten:

„Die Ergebnisse berechtigen uns zu der Auffassung, daß drei Faktorenkomplexe in engem Zusammenwirken dies heutige Verbreitungsbild der Blütenpflanzen geschaffen haben:"

„1. Polverlagerungen als Ursache der Pflanzenwanderung und Florendurchmischung."

„2. Großschollenverschiebung und damit im Gefolge Veränderung des Großformenbildes."

„3. Aktive Ausbreitung und Weiterentwicklung des Pflanzenbestandes."

Es ist kein Zufall, daß hier die Polwanderungen an erster und die Kontinentverschiebungen erst an zweiter Stelle genannt werden; denn es wird ja nur die Zeit von der Kreide ab behandelt, und je mehr wir uns der Gegenwart nähern, um so ähnlicher wird auch das Erdbild dem heutigen, und um so weniger werden die Kontinentverschiebungen in der Pflanzenverbreitung nachweisbar. Daher ist es sehr natürlich, daß die große tertiäre und quartäre Polwanderung in erster Linie der Pflanzenverteilung ihren Stempel aufgedrückt hat. Um so wichtiger aber ist es, daß trotzdem auch die Verschiebungstheorie bestätigt wird: „Wir sind zu dem Ergebnis gelangt, daß die Permanenztheorie aus mehrfachen Gründen zur Erklärung der Verbreitungstatsachen der Blütenpflanzen und ihrer Forderungen unzulänglich ist. Dagegen zeigte sich bei Gegenüberstellung unserer Befunde und der Wegenerschen Verschiebungstheorie, daß die einzelnen Züge der Arealstruktur und die Forderungen der Pflanzenverbreitung mit den von Wegener postulierten Schicksalen der

1) v. Ihering [122] polemisiert gegen Irmscher, weil dieser eine Reihe von fossilen Pflanzenfunden aus Südamerika und Antarktika teilweise etwas anders datiert als die Bearbeiter. Abgesehen davon, daß Irmschers Ansicht nicht, wie v. Ihering meint, einfach einer vorgefaßten Theorie zuliebe ausgesprochen, sondern fachmännisch begründet ist, handelt es sich in fast allen diesen Fällen um so geringe Änderungen in der Zeitsetzung, daß man eher von einer Präzisierung als von einer Berichtigung sprechen sollte. Übrigens haben Köppen und Wegener[151] inzwischen gezeigt, daß man in der Mehrzahl dieser Fälle auch bei Beibehaltung der ursprünglichen Datierung zu einer völligen Übereinstimmung mit der Verschiebungstheorie und den mit ihrer Hilfe abgeleiteten Polwanderungen kommt. 
Großformen in überraschender Weise übereinstimmen und jene in diesen geradezu ihr Spiegelbild finden." .

„Was die Permanenztheorie nie zu erklären vermag, das Rätsel der australischen Flora, findet jetzt zum erstenmal eine völlig befriedigende Lösung. Die von Wegener angenommene abweichende Kontinentallage im Mesozoikum liefert allein den Schlüssel für die sonst unverständliche Tatsache, daß die extratropischen Formen Australiens keine näheren Beziehungen $\mathrm{zu}$ den asiatischen erkennen lassen, die nach der heutigen geographischen Lage eigentlich zu fordern wären, zumal sich in dieser Zone keine Polverschiebung mit ihren schädigenden Einflüssen ausgewirkt hat. Diese frühere Lage Australiens bietet auch den Schlüssel dafür, daß diese alte Flora sich gerade in diesem Gebiet bis heute so ungestört und formenreich erhalten und weiterentwickeln konnte. Die Nordwanderung Australiens nach seiner Loslösung von Antarktika war ja eine Periode weitgehender Isolierung für diesen Kontinent." - Man sieht, daß die Pflanzenwelt Australiens ganz dasselbe Bild liefert wie die Tierwelt!

„Im Verlauf unserer Untersuchung trat nie die Notwendigkeit auf, das Bestehen eines einstigen pazifischen Kontinents fordern zu müssen."

Irmscher geht, wie man sieht, den richtigen Weg, indem er die Verschiebungstheorie nicht mit der ohnehin geophysikalisch unhaltbaren Theorie der versunkenen Brückenkontinente, sondern mit der Permanenztheorie vergleicht. Trotzdem hat er auch der ersteren Beachtung geschenkt, muß sie aber auch rein vom botanischen Standpunkt aus ablehnen:

„Die ... erwähnte fossile nordamerikanische Wilcoxflora, die im Bereich der südöstlichen Staaten der Union (Texas bis Florida) aufgefunden wurde, ist nach Berrys grundlegenden Bearbeitungen an nächsten mit der gleichfalls ins Eozän gesetzten Alum-Bayflora von Südengland verwandt. Legen wir nun den Äquator, wie wir ihn nach der von Wegener für das Eozän geforderten Pollage anzunehmen haben, um die Erde, so läuft er in Europa etwa durch das Mittelmeergebiet, so daß England kaum $15^{\circ}$ vom Äquator entfernt ist, und in Asien etwa durch Hinterindien. Es ergibt sich daraus für Amerika - unter Annahme der Permanenz der heutigen Kontinentallagen - ein durch Kolumbien-Ekuador streichender Äquator, von dem das Gebiet der Wilcoxflora 30 und mehr Grad entfernt ist. Es entstehen also Schwierigkeiten, die beiden fossilen 
Floren, die ein ähnliches Klima fordern, auch nur annähernd unter dieselbe Breite zu bringen, da die Wilcoxflora viel nördlicher zu liegen kommt als die südenglische. Schieben wir dagegen entsprechend Wegeners Auffassung Amerika an Europa-Afrika heran, so kommen mit einem Schlage beide Floren in dieselbe Breite zu liegen, und den von ihnen gestellten relativ gleichen Klimaansprüchen ist ohne weiteres Genüge getan. Hier ist tatsächlich ein Fall vorhanden, wo nur die Verschiebungstheorie bestehende Widersprüche restlos zu lösen vermag, während die Brückentheorie wohl das Vorhandensein ähnlicher Floren auf heute getrennten Großschollen erklären, aber nicht die erforderliche Klimagleichheit herstellen kann. Die Permanenztheorie muß für diese Frage überhaupt als unzulänglich abgelehnt werden."

„Was wir hier für zwei Floren nachwiesen, gilt ebenso auch für die Areale vieler Gattungen, die in die Tropenzone zu liegen kommen. Auch hier ist die Rekonstruktion derselben auf einem größten Kreis nur möglich, wenn Amerika an Zone 2 (Europa-Afrika) herangeschoben wird, da bei heutiger Kontinentallage der Äquator in Zone 1 (Amerika) zu weit südlich verlaufen würde. Schon oben machten wir auf diese Schwierigkeit aufmerksam, um jetzt erst in der Verschiebung ein Mittel zu ihrer Beseitigung zu erkennen. Somit ist hier zum erstenmal gezeigt worden, wie auch vom biogeographischen Standpunkt aus der Verschiebungstheorie gegenüber der Brückentheorie der Vorzug zu geben ist."

Diese letzten Betrachtungen Irmschers leiten bereits auf das Gebiet der Paläoklimatologie hinüber, das wir erst im nächsten Kapitel behandeln wollen.

Eine Fortsetzung dieser wichtigen Arbeit von Irmscher bildet die Dissertationsschrift von Studt über ,,die heutige und frühere Verbreitung der Koniferen und die Geschichte ihrer Arealgestaltung" [152], der eine kürzere von Koch über den gleichen Gegenstand [153] vorausgegangen war. Obwohl diese beiden Autoren in verschiedenen botanischen Fragen nicht übereinstimmen, kommen sie doch hinsichtlich der Verschiebungstheorie beide zu dem gleichen Ergebnis. So sagt Koch: „Das rezente und fossile Vorkommen der Koniferen steht mit der Polwanderungs- und Verschiebungstheorie völlig im Einklang und ist nur durch sie befriedigend $\mathrm{zu}$ erklären." Und weiter: ..., ,Denn wir verstehen jetzt unter anderem, warum nahverwandte Araucarienarten in zwei verschiedenen, durch weite Weltmeere getrennten Erdteilen vorkommen, warum Podo- 
carpusarten nicht nur in. Neuseeland, Australien und Tasmanien, sondern auch in Südafrika, Südbrasilien und Chile heimisch sind, und warum einerseits Microcachrys und Fitzroya Archeri in Tasmanien, die entsprechenden Formen Saxogothaea und Fitzroya patagonica sich auch in Chile vorfinden."

y Und ebenso schreibt Studt: „Das rezente und fossile Verbreitungsbild der Koniferen kann am einfachsten und widerspruchlosesten durch die Wegenersche Verschiebungstheorie erklärt werden. Die große Übereinstimmung zwischen der nordamerikanischen

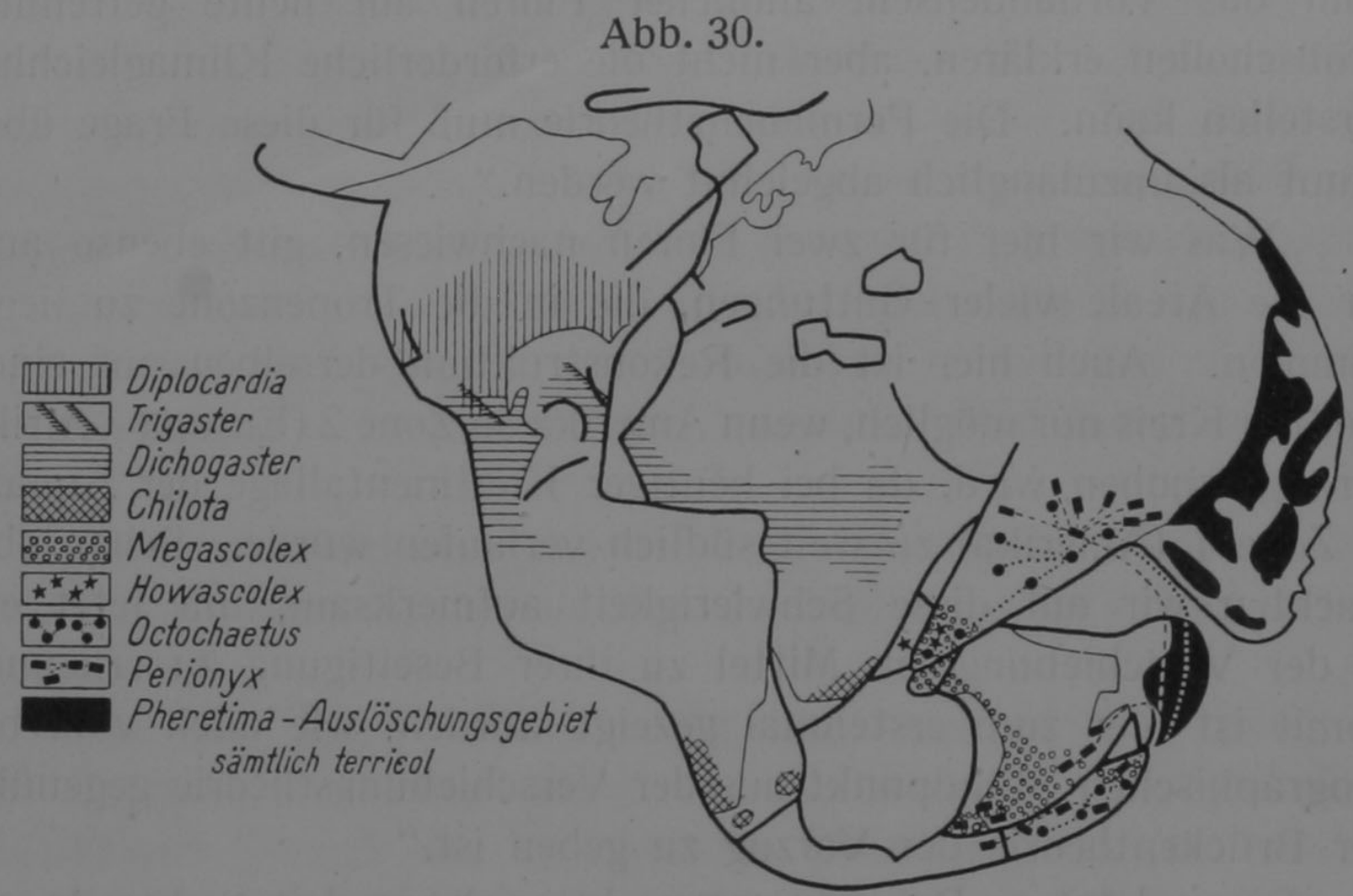

Heutige Verbreitung einiger Regenwurmgattungen der Familienreihe Megascolecina, eingetragen in die vorjurassische Rekonstruktion gemäß der Verschiebungstheorie, nach $\mathrm{Mich}$ a elsen.

und europäischen Kreideflora und die häufig bis auf die Arten hinab sich erstreckende Gleichförmigkeit in der Zusammensetzung der jurassischen Flora in heute weit voneinander entfernten Gebieten trotz beschränkter Verbreitungsmöglichkeiten der Samen verlangt einen kontinuierlichen Landzusammenhang und Verkürzung der Entfernungen zwischen den Kontinenten. Diesen beiden Forderungen kann nur die Verschiebungstheorie gerecht werden." Auch Studt weist wieder darauf hin, daß sich unter der Annahme der Verschiebungstheorie die zonale Verteilung der Koniferen weit besser den Klimazonen anschmiegt und also verständlicher wird, als wenn man die heutige Lage der Kontinente auch für die Vorzeit voraussetzt. 
Zum Schluß wollen wir noch kurz die wichtige Arbeit von Michaelsen über die geographische Verbreitung der Regenwürmer [154] besprechen, die mir besonders gute Bestätigungen der Verschiebungstheorie zu enthalten scheint, da die Regenwürmer weder Seewasser noch Eisboden vertragen und (außer durch den Menschen) auch schwer verschleppt werden können.

Michaelsen zeigt, daß die Permanenztheorie bei der Erklärung der Verbreitung der Regenwürmer auf große Schwierigkeiten führt,

Abb. 31.

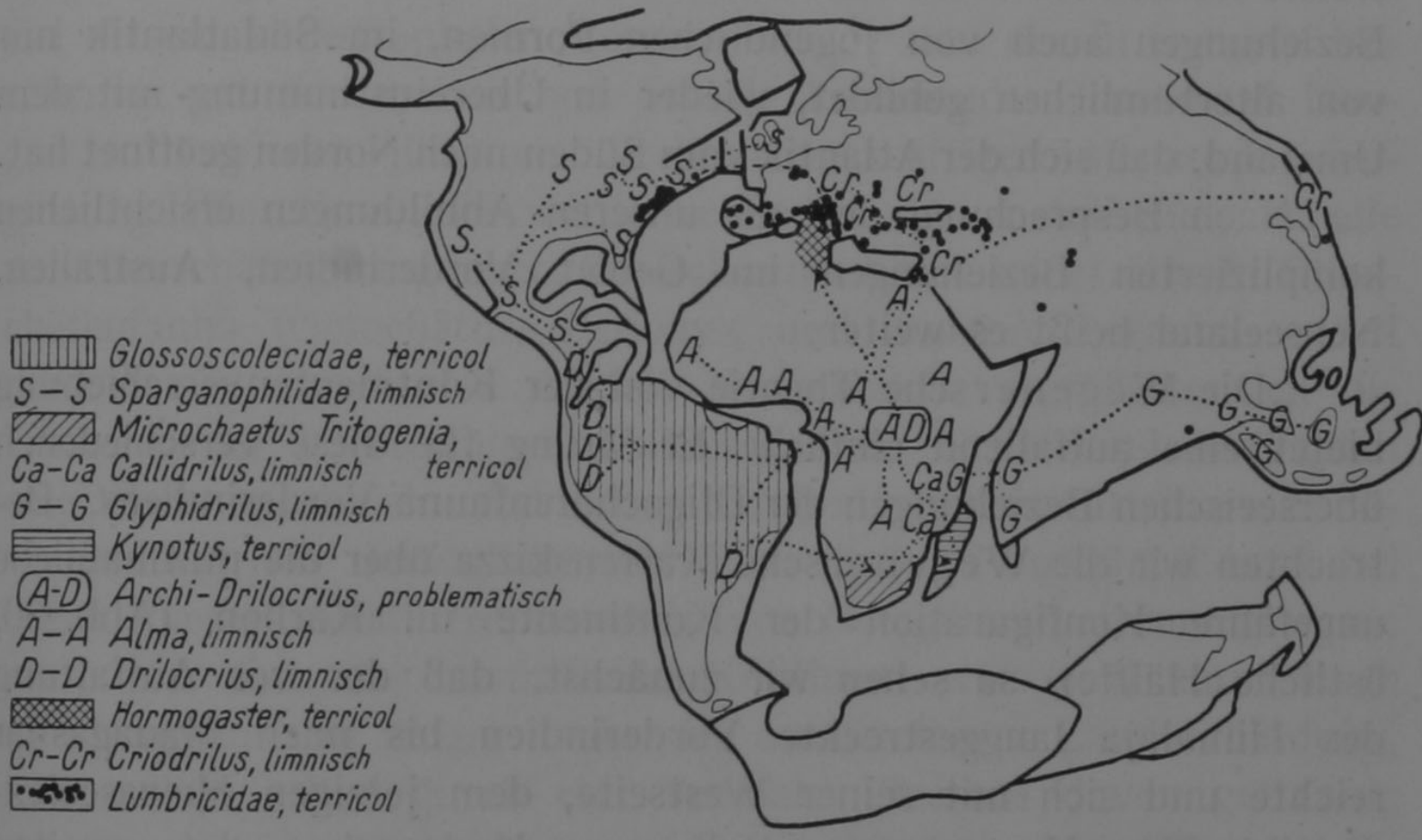

Heutige Verbreitung der Regenwurm-Familienreihe Lumbricina, eingetragen in die nach der Verschiebungstheorie rekonstruierte Eozänkarte, nach Michaelsen.

während die Verschiebungstheorie ,in geradezu überraschender Weise" diese Verbreitung erklärt. Um dies zu veranschaulichen, bedient er sich zweier Kartenskizzen, die wir in den Abb. 30 und 31 wiedergeben. Als Kartengrundlage ist dabei die frühere Anordnung der Kontinentalschollen benutzt, worin nun die heutigen Regenwurmgattungen (fossile sind nicht bekannt) eingetragen sind. Bezüglich der transatlantischen Beziehungen sagt er: „Ich habe oben eingehend dargelegt und durch eine tabellarische Zusammenstellung veranschaulicht, wie sich eine große Anzahl von Beziehungslinien, nämlich fünf terrikole und drei limnische Formengruppen betreffend, quer über den Atlantischen Ozean spannen, eine Häufung regelmäßiger, annähernd paralleler Beziehungen, die es höchst wahrschein- 
lich macht, daß man es hier mit unmittelbaren, d. h. transatlantischen Beziehungen zu tun habe. Diese transatlantischen Beziehungen sind durch die Wegenersche Theorie ohne weiteres zu erklären. Denkt man sich den nach dieser Theorie von Europa-Afrika abgebrochenen und westwärts abgeschobenen amerikanischen Kontinent wieder zurückgeschoben und an Europa-Afrika angeschmiegt, so würden die jetzt weit getrennten Sondergebiete rechts und links vom Atlantischen Ozean meist zu einem einheitlichen Gebiet zusammenfließen. Es würde dadurch ein höchst einfaches Verbreitungssystem erzielt werden ..." Im Nordatlantik werden diese transatlantischen Beziehungen auch von jugendlichen Formen, im Südatlantik nur von altertümlichen gebildet, wieder in Übereinstimmung mit dem Umstand, daß sich der Atlantik vom Süden nach Norden geöffnet hat.

Nach Besprechung der aus unseren Abbildungen ersichtlichen komplizierten Beziehungen im Gebiet Vorderindien, Australien, Neuseeland heißt es weiter:

„Die Wegenersche Theorie von der Kontinentenverschiebung bietet eine auffallend einfache Erklärung für diese verschiedenen überseeischen Beziehungen der Oligochätenfauna Vorderindiens. Betrachten wir die Wegenersche Kartenskizze über die mutmaßliche ungefähre Konfiguration der Kontinente im Karbon (Abb. 30, östliche Hälfte), so sehen wir zunächst, daß das vor Auffaltung des Himalaja langgestreckte Vorderindien bis nach Madagaskar reichte und sich mit seiner Westseite, dem jetzigen Howascolexdistrikt (Curg-Mysore), unmittelbar an Madagaskar, dem zweiten Fundort von Howascolex, anschmiegte: Einfache Erklärung für die transozeanische Beziehung des Westdistriktes von Vorderindien. Ferner sehen wir, daß die australisch-neuseeländisch-neuguineensische Scholle, südlich mit der antarktischen Scholle im Zusammenhang stehend, mit ihrem nördlichen Kopfende (Neuguinea) in den Meereswinkelraum (den späteren Golf von Bengalen) zwischen Vorderindien und Hinterindien samt der malaiischen Scholle hineinragt. Es ist anzunehmen, daß diese australische Scholle in noch früherer Zeit mit ihrer Westseite an die Ostseite Vorderindiens angelagert gewesen sei $^{1}$ ). Es konnten sich in diesem Zusammenhang

$\left.{ }^{1}\right)$ Es hindert gewiß nichts, diesen Zusammenhang auch noch für die Karbonzeit und vielleicht noch erheblich länger anzunehmen. Die Lücke in meiner Karbonkarte bedeutet nur, daß mir bisher jeder Anhalt für einen Landzusammenhang hier fehlte, da eben dieser Teil der Ostküste des verlängerten Vorderindiens in Hochasien zusammengefaltet liegt und auf Kongruenz mit dem australischen Schollenrand nicht geprüft werden kann. 
die einfachen und ununterbrochenen Verbreitungslinien vom südlichen Vorderindien über Ceylon nach dem südlichsten Westaustralien usw. (Megascolex) und vom nördlichen Vorderindien über Neuguinea nach Neuseeland (Octochätus, Pseudisolabis) bzw. nach Nordqueensland, Neuseeland, Südostaustralien (Perionyx) bilden. Zu beachten ist, daß Neuguinea ein vollwertiges Glied dieser nördlichen Verbreitungslinie darstellt. Nachdem sich dann die australische Scholle von der antarktischen losgelöst hatte, wurde sie nordostwärts abgedrängt und mit ihrem nordostwärts vorragenden Kopfe Neuguinea in die malaiische Scholle hineingeschoben ... Bei diesem katastrophalen Vorgang wurde nun der in innigste $\mathrm{Be}$ rührung mit der malaiischen Scholle kommende Rammkopf Neuguinea von der jüngsten, verbreitungskräftigen Megascolecidengattung Pheretima, die mittlerweile auf der malaiischen Scholle zur Herrschaft gelangt war, überschwemmt und seiner älteren Oligochätenfauna (Octochätus, Perionyx und andere) beraubt. Auf diese Weise, durch den Ausfall Neuguineas, vergrößerte sich die Lücke in der Verbreitungslinie Nordindien-Neuseeland und nahm eine Weite an, die eine Erklärung durch einstige unmittelbare Landverbindung fast unmöglich erscheinen ließ. Neuseeland muß bei dieser Pheretimakatastrophe schon von Neuguinea getrennt gewesen sein, und auch der australische Kontinent war wohl kaum noch mit Neuguinea in länger dauernder unmittelbarer Landverbindung, mutmaßlich schon durch eine schmale Flachsee davon getrennt; denn es konnte höchstens eine einzige Pheretimaart (Ph. queenslandica, anscheinend in Nordqueensland endemisch) nach dem australischen Kontinent gelangen. Auch die Trennung Neuseelands von Australien, wenigstens durch eine Flachsee, muß schon ziemlich früh stattgefunden haben, denn Neuseeland zeigt nur geringe $\mathrm{Be}-$ ziehungen zum australischen Kontinent ... Wahrscheinlich lösten sich zuerst die mittleren Teile Neuseelands bogenförmig vom australischen Kontinent los, während das Südende mit Tasmania, das Nordende mit Neuguinea zunächst noch im Zusammenhang blieb. Dann sonderte sich das Südende von Tasmania und erst eine beträchtliche Zeit später das Nordende von Neuguinea ab ... Eine etwas länger dauernde, vielleicht isthmusartige Landverbindung hat wahrscheinlich noch durch Vermittlung Neukaledoniens und die Norfolkinsel zwischen Südqueensland und der Nordinsel vón Neuseeland stattgefunden und die Überwanderung von Megascolex ermöglicht. Der Weg über Neuguinea scheint mir für Megascolex 
nicht annehmbar, weil Megascolex eine typisch südaustralische Form ist ..."

\section{Im Schlußwort sagt Michaelsen:}

„Ich glaube die Ergebnisse meiner Untersuchungen dahin formulieren zu sollen, daß die Verbreitung der Oligochäten keinesfalls gegen die Wegenersche Theorie der Kontinentenverschiebung spricht, daß sie im Gegenteil als eine gute Stütze derselben anzusehen ist und, falls von anderer Seite der endgültige Beweis für diese Theorie erbracht würde, in manchen Einzelheiten zu einem weiteren Ausbau der Theorie benutzt werden könnte ${ }^{1}$ ) ..."

„Es mag zum Schluß noch gesagt werden, daß die zu den oben abgedruckten Verbreitungskarten benutzten und diesen Ausführungen zugrunde gelegten Wegenerschen Kartenskizzen ohne Berücksichtigung der Oligochätenverbreitung entstanden sind. Erst nachdem ich ihn auf den bemerkenswerten Einklang der Oligochätenverbreitung mit den seiner Theorie entsprechenden früheren Landverbindungen hinwies, nahm Wegener bei der zweiten, umgearbeiteten Auflage seines Werkes über die Kontinentenverschiebung einzelne Tatsachen der Oligochätenverbreitung in die Begründung seiner Theorie auf. Ich erwähne diese Tatsache, weil sie mir geeignet scheint, die Stützkraft der Oligochätenverbreitung für die Wegener sche Theorie zu stärken."

1) Michaelsen hebt mehrfach hervor, daß die Regenwurmverbreitung auf das zeitweise Bestehen einer Landbrücke über die Beringstraße hinweist, von der er irrtümlich glaubt, daß ich sie ablehnte. Dies ist nie der Fall gewesen. Vielleicht geht das Mißverständnis zurück auf Dieners unrichtige Behauptung [108]: ,Wer Nordamerika an Europa heranschiebt, zerreißt seinen Zusammenhang mit der asiatischen Kontinentalscholle an der Beringstraße" - eine offenbar von der Merkatorkarte abgelesene Täuschung, deren Unhaltbarkeit sofort in die Augen springt, wenn man den Globus zur Hand nimmt und berücksichtigt, daß die Bewegung Nordamerikas relativ zu Europa im wesentlichen in einer Drehung etwa um Alaska bestand (Abstand der Schelfränder Neufundland-Irland $2400 \mathrm{~km}$, Abstand Nordostgrönland -Spitzbergen wenige hundert Kilometer, wenn nicht Null!). Dieselbe Behauptung ist neuerdings wieder von Schuchert [163] wiederholt worden; aber auch er rekonstruiert falsch, indem er Nordamerika nicht um Alaska, sondern um den Nordpol dreht, wozu doch jeder Grund fehlt. - Die früher erwähnte Abstimmungstabelle von Arldt über die Existenz der Landbrücken, die auch die Brücke über die Beringstraße berücksichtigt, zeigt, daß hier Landverbindung vermutlich schon im Perm und im Jura, mit Sicherheit aber vom Eozän bis ins Quartär hinein bestanden hat. Die heutige Trennung durch den flachen Schelf des Beringmeeres ist also sehr jungen Alters. 


\section{Siebentes Kapitel.}

\section{Paläoklimatische Argumente.}

Seit der letzten Auflage dieses Buches ist das Problem der Klimate der geologischen Vorzeit von W. Köppen und mir [151] einer systematischen Untersuchung unterzogen worden, eine Arbeit, die an Umfang der vorliegenden kaum nachstand. Obwohl es sich hierbei im wesentlichen um die Sammlung geologischen und paläontologischen Materials handelte, wobei der Klimatologe und Geophysiker natürlich Schwierigkeiten und Irrtümern ausgesetzt ist, die der Fachmann vermeiden kann, hielten wir uns für einen solchen Versuch für berechtigt, denn die Paläoklimatologie kann nur als Vereinigung dieser Wissenschaften gedeihen, und aus ihrer bisherigen Literatur geht nur allzu deutlich hervor, daß die von ihr bisher verwendeten meteorologischen und klimatologischen Grundlagen unzulänglich sind. Im vorliegenden Kapitel wird weitgehend auf diese ausführliche Darstellung Bezug genommen werden.

Doch handelt es sich hier nicht um ein Referat über den Gesamtinhalt unseres Buches. Die Aufgabe des letzteren war die Entwirrung der geologischen Klimate; die Kontinentverschiebungen bilden hierbei nur eine unter mehreren Ursachen für Klimaänderungen, und für die jüngeren Zeiten nicht einmal die wichtigste. Hier haben wir dagegen nur die Frage zu behandeln, wieweit die Vorzeitklimate Kriterien für die Richtigkeit der Verschiebungstheorie liefern, und nur so weit brauchen wir also die fossilen Klimazeugnisse heranzuziehen. Damit scheidet z. B. die Frage nach den Ursachen der quartären Vergletscherung so gut wie völlig aus; denn im Quartär war die Lage der Kontinente zueinander der heutigen bereits so ähnlich, daß sich aus dieser Zeit nur wenig paläoklimatische Kriterien für die Verschiebungstheorie mehr ergeben.

Um so mehr ist dies aber für die älteren geologischen Zeiten der Fall, ja hier finden sich gerade ganz außerordentlich schlagende Beweise für die Unabweisbarkeit der Verschiebungstheorie, und die Zahl derjenigen Autoren, die sich gerade aus diesen Gründen der Theorie angeschlossen haben, ist nicht gering.

Zur Bildung eines richtigen Urteils sind hier zwei Dinge nötig: eine Kenntnis des heutigen Klimasystems und seiner Auswirkung auf die anorganische und organische Welt, und eine Kenntnis und 
richtige Deutung der fossilen Klimazeugnisse. Beide Forschungszweige stehen noch in ihren Anfängen und lassen zahlreiche Fragen heute noch offen. Um so wichtiger ist aber die Beachtung des bisher in ihnen Erreichten.

Das heutige Klimasystem ist bekanntlich von Köppen bearbeitet und in einer Karte der Klimate der Erde dargestellt [156]. Diese Karte, für viele andere Zwecke noch nicht detailliert genug, ist doch für unsere Zwecke schon allzu inhaltsreich, da die fossilen Klimazeugen nur eine sehr ungefähre Schätzung des Klimas zuAbb. 32 .

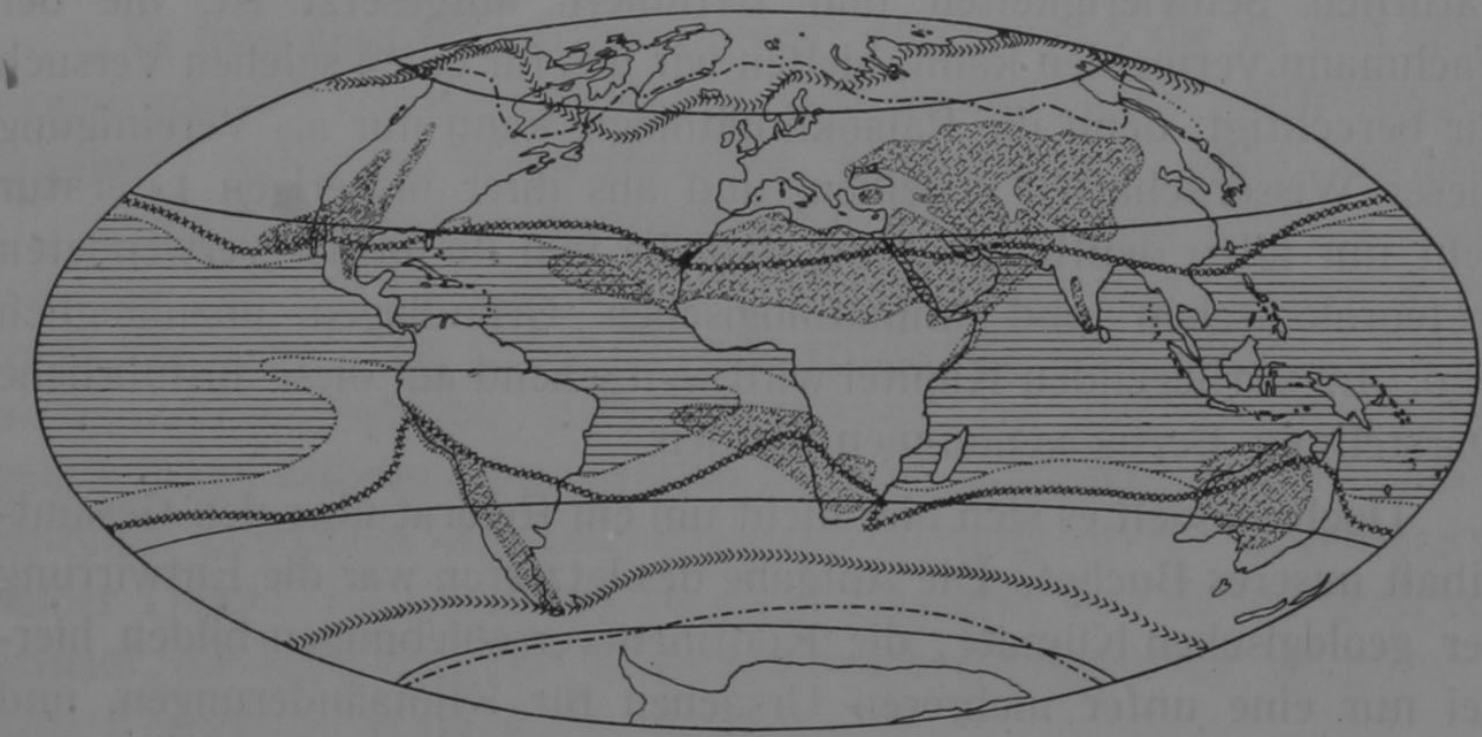

-...-... Mitteltemperatur des Jahres $-2^{0}$ (Grenze des gefrorenen Bodens)

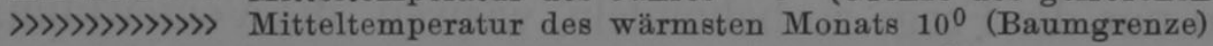
$x \times \times \times \times \times \times \times \times x$ Mitteltemperatur des kältesten Monats $18^{0}$

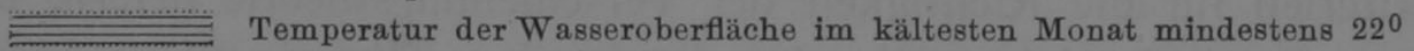

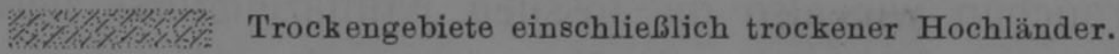

Heutige Hauptisothermen (im Meeresniveau) und Trockengebiete.

lassen. Wir haben sie daher in unserem Buche durch die vereinfachte, in Abb. 32 wiedergegebene Karte der heutigen Hauptisothermen und Trockengebiete ersetzt, die alles für unsere Zwecke Wesentliche enthält. Wir erkennen eine äquatoriale Regenzone mit Gewitterregen, die die ganze Erde lückenlos umspannt; anschließend daran in den Hochdruckgürteln der Roßbreiten mit absteigender Luft die Trockengebiete, die regelmäßig am Ostrand der Kontinente durch die Monsunregengebiete unterbrochen sind, dagegen an den Westküsten weit aufs Meer hinausreichen und im Innern großer Kontinente polwärts vorstoßen. X Darauf folgen die nördliche und südliche Regenzone der gemäßigten Breiten mit Zyklonenregen, und jenseits dieser 
die mehr oder minder vereisten Polarkappen. Die Zone warmen Meereswassers ist ganz zwischen den beiden Breitenparallelen von etwa 28 oder $30^{\circ} \mathrm{N}$ und $\mathrm{S}$ eingeschlossen. Alle Isothermen zeigen das Vorherrschen einer zonalen Anordnung der Klimate, doch bestehen charakteristische, durch die Verteilung von Land und Wasser erzeugte Abweichungen: Die 100-Isotherme des wärmsten Monats, die bekanntlich mit der Baumgrenze erstaunlich eng zusammenfällt, liegt auf Landgebieten in höherer Breite als auf dem Meere, weil das Land größere Jahresschwankung besitzt als letzteres. Die Jahresmitteltemperatur von $-2^{0}$, die ungefähr der Grenze ewig gefrorenen Bodens entspricht, hat einen anderen Verlauf. Wo sie in höherer Breite liegt als die Baumgrenze, repräsentiert sie zugleich

Abb. 33.

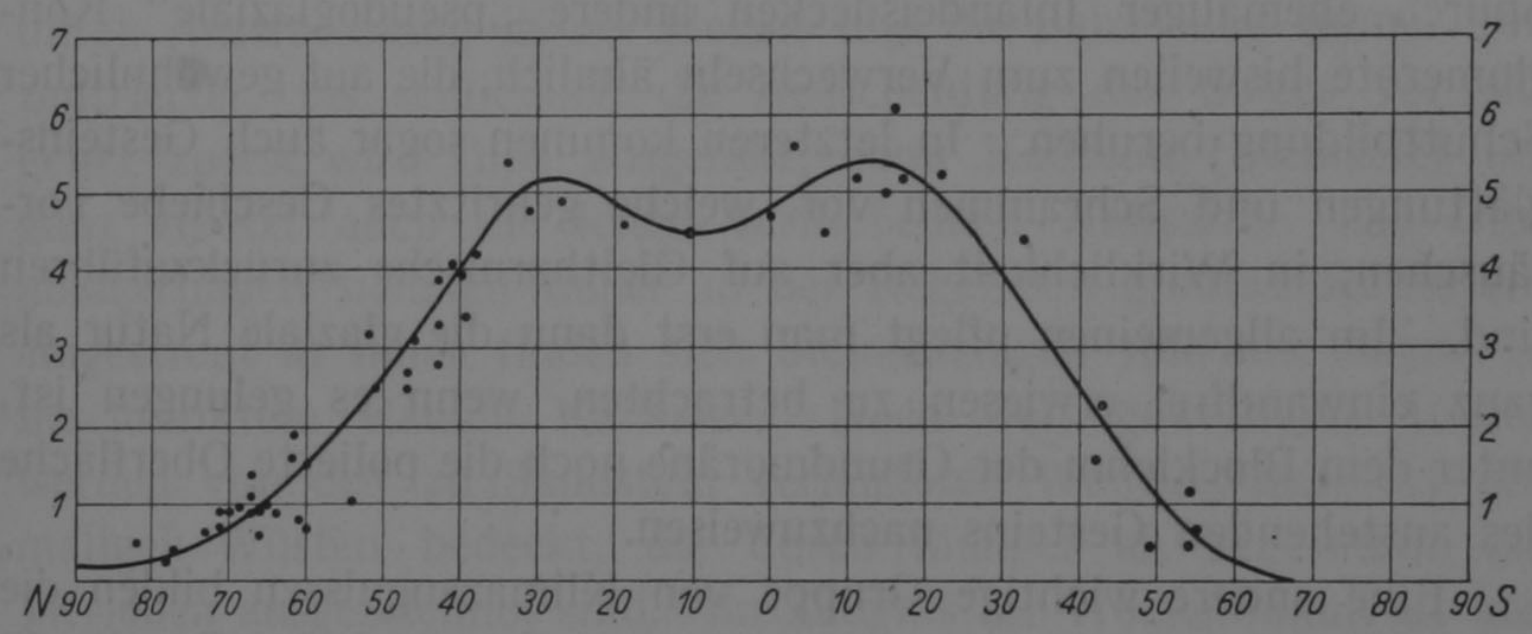

Heutige Höhe der Schneegrenze in den verschiedenen Breiten.

das Klima, welches Inlandeis erzeugt (Grönland, Antarktika); wo sie in niedrigerer Breite liegt, wie in Sibirien, haben wir Wald auf gefrorenem Boden. Alles Inlandeis ist auf Breiten von mehr als $60^{\circ}$ beschränkt.

Als Ergänzung geben wir noch in Abb. 33 eine Darstellung der Höhenlage der Schneegrenze in den verschiedenen Breiten nach Paschinger [157] und Köppen [158]. Sie erreicht ihre größte Höhe von über $5000 \mathrm{~m}$ in den Roßbreiten. Die Darstellung gilt für Einzelberge oder Bergketten. Bei ausgedehnten Hochländern liegt die Schneegrenze erheblich höher.

Die geologischen und biologischen Wirkungen dieses Klimasystems sind sehr mannigfaltige. Wir wollen sie gleich zusammen mit den bisher verfügbaren fossilen Klimazeugnissen besprechen.

Vielleicht die wichtigsten Klimazeugnisse, wenn auch etwas gefährlicher Art, sind die Spuren, welche frühere Inlandeisdecken 
zurückgelassen haben. Weil zur Entwicklung von Inlandeis niedrige Sommertemperaturen das entscheidende Erfordernis sind, die im Innern großer Kontinente wegen der dort großen Jahresschwankung der Temperatur fehlen, braucht sich das Polarklima nicht immer durch Inlandeisspuren $\mathrm{zu}$ erkennen $\mathrm{zu}$ geben. Umgekehrt haben wir es aber, wo wir solche Spuren finden, zweifellos mit Produkten des Polarklimas zu tun. Am häufigsten findet man die Blocklehme, mit deren Namen treffend das unsortierte Durcheinander von feinstem und gröbstem Material gekennzeichnet wird, das die Moränen auszeichnet. Die Blocklehme der älteren Zeiten sind meist zu festen Gesteinen, Tilliten, verhärtet. Man kennt oder glaubt solche zu kennen aus dem Algonkium, Kambrium, Devon, Karbon, Perm, Miozän, Pliozän und Quartär. Leider sind gerade diesen häufigsten Spuren ehemaliger Inlandeisdecken andere „pseudoglaziale“ Konglomerate bisweilen zum Verwechseln ähnlich, die auf gewöhnlicher Schuttbildung beruhen. In letzteren kommen sogar auch Gesteinsglättungen und Schrammen vor, welche gekritztes Geschiebe vortäuschen, in Wirklichkeit aber auf Gleitharnische zurückzuführen sind. Im allgemeinen pflegt man erst dann die glaziale Natur als ganz einwandfrei erwiesen zu betrachten, wenn es gelungen ist, unter dem Blocklehm der Grundmoräne noch die polierte Oberfläche des anstehenden Gesteins nachzuweisen.

Eine andere wichtige Gruppe von Klimazeugnissen bilden die Kohlen, die als fossile Torfschichten aufzufassen sind. Damit ein Wasserbecken vermooren kann, muß es jedenfalls mit Süßwasser gefüllt sein, und dies kann nur in den Regenzonen der Erde, nicht in den Trockengebieten geschehen. Kohle bezeugt also Regenklima, wobei es sich sowohl um die äquatoriale Regenzone als auch um die Regenzone der gemäßigten Breiten, wie auch um das subtropische Regenklima der Monsungebiete an den Osträndern der Kontinente handeln kann. So bildet sich heute Torf in zahlreichen Mooren am Äquator, aber auch in den Subtropen, wo diese feucht sind, und ebenso in den gemäßigten Breiten, wo unter anderem die quartären und postquartären Torfmoore Nordeuropas am längsten bekannt sind. Über die Temperatur erhält man also aus der bloßen Anwesenheit von Kohlenschichten keinen Anhaltspunkt; dazu muß vielmehr der Charakter der Flora herangezogen werden, deren Reste sich in den Kohlenschichten und ihren Nachbarschichten finden. Einen kleinen Fingerzeig, dessen Wert man aber nicht überschätzen darf, gibt auch die Mächtigkeit der Kohlenschichten insofern, als 
der üppigere und unterbrechungslose Pflanzenwuchs der Tropen ceteris paribus Torfschichten von größerer Mächtigkeit erzeugen kann als der langsamere in den gemäßigten Breiten.

Eine besonders wichtige Gruppe von Klimazeugnissen bilden die Produkte der Trockengebiete, insbesondere Salz, Gips und Wüstensandsteine. Steinsalz entsteht durch Verdunsten von Seewasser. In den meisten Fällen handelt es sich dabei um größere Überschwemmungen (Transgressionen) des Festlandes, die durch Bodenbewegungen ganz oder doch in ausreichendem Maße vom offenen Meere abgesperrt werden. In den Regenklimaten werden sie zunehmend ausgesüßt, wie die Ostsee. Im Trockenklima aber, wo die Verdunstung gegenüber dem Niederschlag überwiegt, wird bei völliger Absperrung zunächst das Areal der Überschwemmung durch Austrocknung immer kleiner und die Salzlösung immer konzentrierter, bis schließlich die Ausscheidung des Salzes vor sich geht: zuerst wird Gips ausgefällt, dann Kochsalz (Steinsalz) und ganz zuletzt auch die leicht zerfließenden Kalisalze. Die Gipsablagerungen nehmen daher in der Regel den größten Raum ein; eingestreut in ihnen finden sich Steinsalzlagen und nur selten auf beschränktem Raume Kalisalze. Noch weit gewaltigere Räume werden von den zu Sandstein verhärteten Wanderdünen der ehemaligen Wüsten bedeckt, die durch Mangel an Vegetation und Tierleben ausgezeichnet sind. Ihr Zeugnis für Trockenklima ist aber kein so sicheres wie das von Salz und Gips, da Sande und Dünen, wenn auch in geringerer Ausdehnung, auch in regenreichen Klimaten als Strandbildungen auftreten, wie heute in Norddeutschland, und sogar vor dem Rande des Inlandeises, wie die Sandr auf Island. Einen, wenn auch schwachen, Anhalt über die Temperaturverhältnisse liefert die Farbe dieser Sandsteine, weil in den Tropen und Subtropen bei der Bodenbildung die rote Farbe, in den gemäßigten und hohen Breiten braune und gelbe Farbe vorherrscht. Strandsande sind freilich auch in den Tropen weiß.

Für die Ablagerungen des Meeres gilt das Gesetz, daß mächtige Kalkschichten nur in den warmen Gewässern der Tropen und Subtropen abgesetzt werden können. Die Ursache ist, wenn auch Bakterientätigkeit eine Rolle dabei zu spielen scheint, sehr wahrscheinlich einfach die Tatsache, daß das kalte Polarwasser viel größere Kalkmengen lösen kann und daher ungesättigt ist, während das warme Wasser der Tropen, das viel weniger Kalk in Lösung haben kann, gesättigt oder übersättigt ist (vgl. die Ausscheidung 
von Kesselstein). Damit hängt offenbar auch die in den Tropen allgemein viel größere Kalkausscheidung der Organismen zusammen, vor allem der Korallen und Kalkalgen, aber auch der Muscheln und Schnecken. Im Polarklima scheint die Ablagerung von massiven Kalkschichten überhaupt unmöglich zu sein, ebenso wie der Kalk auch bei den eigentlichen Tiefseesedimenten wegen der niedrigen Temperatur des Tiefenwassers verschwindet.

$\mathrm{Zu}$ diesen anorganischen Klimazeugnissen kommen nun noch diejenigen der Pflanzen- und Tierwelt, bei denen allerdings größere Vorsicht nötig ist, weil die Organismen über große Anpassungsfähigkeit verfügen. Aus einem Einzelfund läßt sich deshalb nur selten ein Schluß ziehen, dagegen erhält man stets brauchbare Ergebnisse, wenn man die gesamte geographische Verbreitung der Pflanzen- bzw. Tierwelt einer bestimmten Periode ins Auge faßt. Durch Vergleichung gleichzeitiger Floren aus verschiedenen Erdteilen kann man meist mit großer Sicherheit entscheiden, welche von beiden die wärmere und welche die kühlere war, wenn auch der Absolutwert der Temperatur sich nur in den jüngeren geologischen Formationen, wo die Pflanzen schon den heutigen ähnlich sind, abschätzen läßt, während er bei den älteren Floren meist unbestimmt bleibt. Fehlen von Jahresringen in Holzgewächsen deutet auf tropisches, starkes Hervortreten derselben auf gemäßigtes Klima hin, trotz der Ausnahmen, die von dieser Regel gar nicht selten vorkommen. Wo hochstämmige Bäume wuchsen, dürfen wir auch wohl für die Vorzeit eine Temperatur des wärmsten Monats von mehr als $10^{\circ} \mathrm{C}$ voraussetzen.

Auch die Tierwelt liefert zahlreiche Klimakriterien. Reptilien, die keine Eigenwärme produzieren, verfallen in winterkalten Klimaten der Winterstarre, die sie wehrlos macht. Sie können daher in solchen Klimaten nur leben, wenn sie, wie unsere Eidechsen und Ringelnattern, klein genug sind, um sich leicht verbergen zu können. Fehlt, wie im Polargebiet, auch noch die Sommerwärme, so können auch ihre Eier nicht mehr von der Sonne ausgebrütet werden, so daß sie hier überhaupt keine erträglichen Lebensbedingungen finden. Wo also dieser Stamm in besonders großen Vertretern reich entwickelt ist, kann man auf tropisches oder wenigstens subtropisches Klima schließen. Allgemein liefern Pflanzenfresser ein Kriterium über die Vegetation und danit über die Regenmenge; Schnellläufer, wie Pferde, Antilopen, Laufvögel, zeugen von Steppenklima, da ihr Körperbau auf Beherrschung großer Räume ein- 
gerichtet ist. Kletterer, wie Affe oder Faultier, sind im Walde zu Hause.

Es ist hier nicht möglich, auf alle derartigen Klimazeugnisse einzugehen; das Gesagte wird aber genügen, um ein ungefähres Bild davon zu geben, auf welche Weise man überhaupt zu Schlüssen über das vorzeitliche Klima gelangt.

Die ungeheure Menge von Tatsachen, die sich in dieser Weise als fossile Klimazeugen verwerten lassen, zeigt nun überraschenderweise, $\mathrm{da} \beta$ in den meisten Gegenden der Erde in der Vorzeit ein ganz anderes Klima geherrscht hat als heute. So ist bekannt, daß Europa den größten Teil der Erdgeschichte hindurch subtropisches bis tropisches Klima gehabt hat. Noch zu Beginn der Tertiärperiode hatte Mitteleuropa das Klima der äquatorialen Regenzone; dann folgt in der Mitte dieser Periode die Bildung großer Salzlager, also Trockenklima, sodann gegen Ende der Tertiärperiode ein etwa dem heutigen Klima entsprechendes, und darauf folgt dann die quartäre Inlandeisüberschwemmung, also Polarklima wenigstens für Nordeuropa.

Ein besonders in die Augen fallendes Beispiel für große Klimaänderungen bilden auch die Nordpolargebiete, namentlich das am besten bekannte Spitzbergen, das nur durch ein Flachseegebiet von Europa getrennt ist und also einen Teil der großen eurasiatischen Kontinentalscholle bildet. Heute liegt Spitzbergen bei strengem Polarklima unter Inlandeis; aber im Frühtertiär (als Mitteleuropa in der äquatorialen Regenzone lag) standen dort Wälder von größerem Artenreichtum, als er heute in Mitteleuropa gefunden wird. Nicht nur Kiefern, Fichten und Eiben fanden sich dort, sondern auch Linden, Buchen, Pappeln, Ulmen, Eichen, Ahorn, Efeu, Schlehe, Hasel, Weißdorn, Schneeball, Esche, ja sogar so wärmeliebende Gewächse wie Wasserlilien, Walnuß, Sumpfzypresse (Taxodium), gewaltige Sequoien, Platanen, Kastanien, Ginkgo, Magnolie, die Weinrebe! Es muß damals offenbar auf Spitzbergen ein Klima geherrscht haben wie heute etwa in Frankreich, d. h. die Jahresmitteltemperatur muß etwa $20^{\circ}$ höher gewesen sein als heute. Und gehen wir noch weiter in der Erdgeschichte zurück, so finden wir Anzeichen für noch größere Wärme: im Jura und der älteren Kreide wuchsen dort Sagopalmen, die heute nur in den Tropen vorkommen, Ginkgo (heute in einer einzigen Art in China und Südjapan), Baumfarne und anderes. Und auch schon im Karbon finden wir auf Spitzbergen teils mächtige Gipslager, die von subtropischem Trocken- 
klima zeugen, teils eine Flora, die gleichfalls subtropischen Charakter hat.

Dieser enorme Klimawechsel - in Europa vom tropischen zum Klima der gemäßigten Breiten, in Spitzbergen vom subtropischen zum Polarklima - legt sofort den Gedanken einer Verschiebung der Pole und des Äquators und damit des ganzen zonalen Systems der Klimate nahe. Und diese Annahme findet eine unabweisbare Bestätigung darin, daß Südafrika - $80^{\circ}$ südlich von Europa, $110^{\circ}$ südlich von Spitzbergen - in demselben Zeitraum eine ebenso gewaltige, aber gerade umgekehrte Klimaänderung erlitt: Im Karbon unter Inlandeis begraben, also im Polarklima, heute in subtropischem Klima!

Diese völlig sichergestellten Tatsachen lassen keine andere Erklärung zu als die durch Polwanderungen ${ }^{1}$ ). Wir können hierauf auch noch eine Probe machen. Wenn der Meridian Spitzbergen-Südafrika die größte Klimaänderung durchgemacht hat, so muß die gleichzeitige Klimaänderung in den zwei Meridianen, die $90^{\circ}$ östlich und westlich davon liegen, Null oder jedenfalls sehr unbedeutend gewesen sein. Und dies ist in der Tat der Fall; denn der Sundaarchipel, $90^{\circ}$ östlich von Afrika, hatte mit Bestimmtheit schon im Frühtertiär das gleiche tropische Klima wie heute, wie sich schon in der unveränderten Erhaltung zahlreicher altertümlicher Pflanzen und Tiere, wie z. B. der Sagopalme oder des Tapirs, zeigt, und neuerdings hat man dort auch Karbonpflanzen von der gleichen Art gefunden, wie sie aus Europa bekannt sind und von den besten Kennern für tropisch gehalten werden. Und in ähnlicher Lage war auch der nördliche Teil von Südamerika, wo unter anderem gleichfalls der Tapir erhalten blieb, während er in Nordamerika, Europa und Asien nur fossil, in Afrika gar nicht zu finden ist. Allerdings erweist sich für das nördliche Südamerika die Klimakonstanz als nicht so vollkommen wie für die Sundainseln; dies ist, wie wir sehen werden, eine Folge der Verschiebung der Kontinente; Südamerika lag eben früher nicht $90^{\circ}$ westlich vom Meridian Spitzbergen-Südafrika, sondern diesem viel näher.

Es ist nach dem Gesagten nicht zu verwundern, daß man bei den Versuchen, das System der vorzeitlichen Klimaänderungen zu ergründen, schon frühzeitig und immer wieder auf Polwanderungen zurückgegriffen hat. Bereits Herder hat in seinen Ideen zur Philo-

1) Über den Begriff der Polwanderungen siehe Kan 8 
sophie der Geschichte der Menschheit auf eine solche Erklärung der Vorzeitklimate hingewiesen. Sodann wurde sie mehr oder weniger ausführlich von zahlreichen Autoren vertreten, nämlich Evans (1876), Taylor (1885), Löffelholz von Colberg (1886), Oldham (1886), Ne umayr (1887), Nathorst (1888), Hansen (1890), Semper (1896), Davis (1896), Reibisch (1901), Kreichgauer (1902), Golfier (1903), Simroth (1907), Walther (1908), Yokoyama (1911), Dacqué (1915), E. Kayser (1918), Eckardt (1921), Kossmat (1921), Stephan Richarz (1926) und vielen anderen. Arldt [159] hat diese Literatur bis 1918 zusammengestellt, aber seitdem ist die Zahl der Autoren, die für Polwanderungen eingetreten sind, immer schneller angewachsen.

Früher stieß diese Lehre innerhalb des engeren geologischen Fachkreises auf recht allgemeinen Widerspruch, und bis $\mathrm{zu}$ den Arbeiten von Neumayr und Nathorst hat die große Mehrzahl der Geologen Polwanderungen ganz abgelehnt. Nach den genannten Arbeiten ändert sich das Bild, indem nun unter den Geologen die Anhänger der Polwanderungen, wenn auch langsam, zahlreicher wurden, und heute steht wohl die weit überwiegende Mehrzahl der Geologen auf dem in E. Kaysers Lehrbuch der Geologie formulierten Standpunkt, daß jedenfalls die Annahme einer großen tertiären Polverschiebung ,,schwer zu umgehen“ ist, wenn auch einige Gegner sich noch vor wenigen Jahren mit schwer verständlicher Schärfe gegen diese Vorstellungen gewendet haben.

So zwingend indessen die Gründe für Polwanderungen in der Erdgeschichte sind, so ist es doch andererseits unleugbar, daß alle früheren Versuche, die Lage der Pole und des Äquators kontinuierlich durch die ganze Zeitenfolge zu bestimmen, stets auf Ungereimtheiten geführt haben, und zwar von so grotesker Art, daß es gar nicht zu verwundern ist, wenn hieraus der Verdacht entstand, man befinde sich mit der Annahme von Polwanderungen überhaupt auf einem Irrwege. Solche systematischen Versuche, die meist nur von Außenseitern unternommen wurden, sind daher auch nie zur Anerkennung durchgedrungen. Es stammen solche von Löffelholz von Colberg [4], Reibisch [161] und Simroth [162], Kreichgauer [5] und Jacobitti [164]. Von ihnen hat Reibisch leider seine von der Kreide ab ganz zutreffenden Vorstellungen in die wunderliche Zwangsjacke einer strengen „Pendulation“ der Pole auf einem "Schwingungskreis" eingekleidet, die als physikalisches Kreiselgesetz wahrscheinlich falsch, jedenfalls unbegründet ist und oben- 
drein zu zahlreichen Widersprüchen mit den Beobachtungen führt. Simroth hat, um die Pendulationstheorie zu beweisen, ein umfangreiches biologisches Tatsachenmaterial gesammelt, welches zwar gute Belege für Polwanderungen enthält, aber von der behaupteten strengen Gesetzmäßigkeit des Hin- und Herpendelns nicht überzeugen kann. Richtiger natürlich ist der rein induktive Weg, nämlich ohne vorgefaßte Meinung über das Ergebnis die Lage der Pole aus den fossilen Klimazeugen einfach abzuleiten. Diesen Weg ist namentlich Kreichgauer in seinem klar geschriebenen Buche gegangen, wenn er sich auch neben den eigentlichen Klimazeugen noch auf ein unzureichend begründetes Dogma über die Anordnung der Gebirge stützt. Fast alle diese Versuche ergeben für die jüngeren Zeiten ungefähr das gleiche Resultat, zu dem auch Köppen und der Verfasser gekommen sind, nämlich eine Lage des Nordpols zu Beginn des Tertiärs in der Nachbarschaft der Aleuten und von da eine Wanderung nach Grönland, wo er zu Beginn des Quartärs anzutreffen ist ${ }^{\mathbf{1}}$ ). Für diese Zeiten ergeben sich auch keine größeren inneren Unstimmigkeiten. Anders wird es jedoch für die Zeiten vor der Kreide. Hier gehen nicht nur die Ansichten der genannten Autoren weit auseinander, sondern es führen alle diese Rekonstruktionen, weil sie die Unveränderlichkeit der Lage der Kontinente zueinander als selbstverständlich voraussetzen, auf hoffnungslose Widersprüche, und zwar charakteristischerweise auf Widersprüche solcher Art, daß sie für jede überhaupt denkbare Pollage ein absolutes Hindernis bilden.

Legt man dagegen die Verschiebungstheorie zugrunde, trägt man also die fossilen Klimazeugnisse in eine nach dieser Theorie entworfene Kartengrundlage für die betreffende Zeit ein, so verschwinden diese Widersprüche vollständig, und alle Klimazeugnisse ordnen sich von selbst zu dem uns aus der Gegenwart vertrauten Bilde der Klimazonen: zwei Trockenstreifen, zwischen denen ein feuchter Streifen längs eines Großkreises die Erdkugel umzieht und die mit letzterem zusammen alle Zeugnisse für tropische Wärme

1) Diese Pollage im Frühquartär hat erst neuerdings wieder durch eine Reihe biologischer Tatsachen, die v. Ihering [122] aus Südamerika beigebracht hat, eine auffallende Bestätigung erfahren, worauf Köppen [127] hingewiesen hat. v. Ihering selbst will diese Tatsachen freilich durch Wechsel der Meeresströmungen bei der heutigen Pollage erklären, meines Erachtens in unzulässiger Weise, worauf indessen hier nicht eingegangen werden kann, da die Frage außerhalb unseres Themas liegt. 
enthalten; nach außen beiderseits anschließend wieder zwei feuchte Gürtel; und wo sich Zeugnisse von Polarklima finden, liegt ihre Mitte 90 Großkreisgrade vom mittelsten feuchten Streifen und etwa 60 Großkreisgrade vom nächsten trockenen entfernt.

Betrachten wir zunächst die Karbonzeit als die älteste, für welche bisher Erdkarten nach der Verschiebungstheorie gezeichnet sind. Hier begegnen wir gleich der größten Schwierigkeit der bisherigen Paläoklimatologie, nämlich in Gestalt der permokarbonischen Eisspuren.

Alle heutigen Südkontinente (und Dekan) trugen am Ende der Karbon- und am Anfang der Permzeit Inlandeis; dagegen ist, von Dekan abgesehen, kein Kontinent der heutigen Nordhalbkugel in dieser Zeit vereist gewesen.

Am genauesten sind diese Inlandeisspuren in Südafrika studiert, wo Molengraaff 1898 zuerst unter der-alten Moräne den vom Eise geglätteten Felsboden auffand und damit die letzten Zweifel an der Moränennatur des dortigen „Dwykakonglomerats“ beseitigte [165]. Die späteren Untersuchungen, von denen besonders diejenigen von du Toit hervorzuheben sind [166], geben ein sehr eingehendes Bild von dieser Eisbedeckung. An vielen Stellen kann man aus den Schrammen auf dem geglätteten Felsen die Bewegungsrichtung des Eises ablesen; man kann so eine Reihe von Vereisungszentren feststellen, von denen das Eis ausstrahlte, und man wird auch schon aufmerksam auf geringfügige Zeitdifferenzen in der Haupttätigkeit dieser Zentren, die im ganzen einer Verlagerung der größten Eismächtigkeit vom (heutigen) Westen nach Osten entsprechen. Vom 33. Breitengrad südwärts liegt in Südafrika der Blocklehm konkordant auf Meeresablagerungen und erscheint als deren unmittelbare Fortsetzung; man kann dies nur so deuten, daß das Inlandeis hier als schwimmende „Barriere“ geendet hat wie heute in der Antarktis, wobei die am Unterrand ausschmelzende Grundmoräne als natürliche Fortsetzung der früheren Meeressedimentation sich auf diese legte. Die Schneegrenze muß hier also im Meeresniveau gelegen haben. Auch schon die Ausdehnung dieser südafrikanischen Vereisung, die fast der heutigen von Grönland gleichkommt, beweist, daß es sich um echtes Inlandeis und nicht etwa um eine bloße Gebirgsvergletscherung handelt.

Aber ganz dieselben Moränenablagerungen finden sich auch auf den Falklandsinseln, in Argentinien und Südbrasilien, in Vorderindien und in West-, Mittel- und Ostaustralien. In allen diesen 
Gebieten ist durch die völlige Gleichartigkeit der ganzen Schichtenfolge auch die glaziale Deutung der dortigen verhärteten Blocklehme völlig gesichert. Sie alle lagen, wie Südafrika, unter Inlandeis. In Südamerika und Australien hat man - ganz entsprechend den quartären Eis- und Interglazialzeiten Nordeuropas - mehrere übereinanderliegende Blocklehmschichten mit eingeschalteten interglazialen Ablagerungen gefunden. So gibt es im mittleren Teil Ostaustraliens (Neusüdwales) zwei Moränen, getrennt durch kohlenführende Interglazialschichten; das Land wurde hier also zweimal vom Inlandeis überschwemmt, in der Zwischenzeit aber gab es auf der Moränenlandschaft Süßwasserseen, die vermoorten. Südlich davon, in Victoria, hat man aber nur einen Glazialhorizont und nördlich davon, in Queensland, gar keinen. Der südlichste Teil Ostaustraliens war also in diesem Zeitraum ständig unter Eis begraben, über den mittleren stieß das Eis nur zweimal vor, und der nördliche blieb ganz frei. So beginnt sich hier ganz das gleiche Bild zu enthüllen, wie wir es seit langem für das quartäre Eiszeitalter Europas und Nordamerikas kennen. Bei letzterem kann die Wechselfolge von Eiszeiten und Interglazialzeiten auf periodische Änderungen der Erdbewegung und damit des Strahlungsempfangs zurückgeführt werden; daß solche Schwankungen die ganze Erdgeschichte hindurch stattgefunden haben, muß als sicher angenommen werden. Auffallende Erscheinungen konnten sie aber nur hinterlassen zu Zeiten, in denen Inlandeis in den Polarkappen lag. Alle diese Einzelheiten zeigen klar, daß es sich bei der permokarbonischen Vereisung der Südkontinente um echtes Inlandeis handelt.

Aber diese Spuren des permokarbonischen Eiszeitalters sind heute weit voneinander getrennt und nehmen fast die Hälfte der ganzen Erdoberfläche ein!

Betrachten wir Abb. 34. Selbst wenn wir den Südpol an die denkbar günstigste Stelle in die Mitte dieser Spuren legen, das ist auf etwa $50^{\circ}$ südlicher Breite und $45^{\circ}$ östlicher Länge, so bekommen, wie der zu dieser Pollage gehörige Äquator ausweist, die polfernsten Inlandeisspuren in Brasilien, Vorderindien und Ostaustralien eine geographische Breite von nicht ganz $10^{\circ}$, es hätte also Polarklima bis fast zum Äquator geherrscht. Und von der anderen Erdhälfte hätten wir, wie wir vorwegnehmen, nur Spuren tropischer und subtropischer Hitze bis nach Spitzbergen hinauf. Daß dies Ergebnis sinnlos ist, braucht nicht gesagt zu werden. Der Versuch, 
diese Eisspuren klimatisch zu erklären, wurde schon 1907, als die südamerikanischen Funde noch für unsicher gehalten werden durften, von Koken [167] praktisch ad absurdum geführt; denn sein Schluß, daß anscheinend nichts übrigbleibe als die Annahme, alle diese Eisspuren seien in großer Seehöhe gebildet, kommt aus dem Grunde nicht in Betracht, weil auch Hochländer dieser Ausdehnung kein Inlandeis in den Tropen erzeugen, und zudem die Beobachtungen gerade umgekehrt beweisen, $\mathrm{da}$ die Schneegrenze hier bis zum

Abb. 34 .

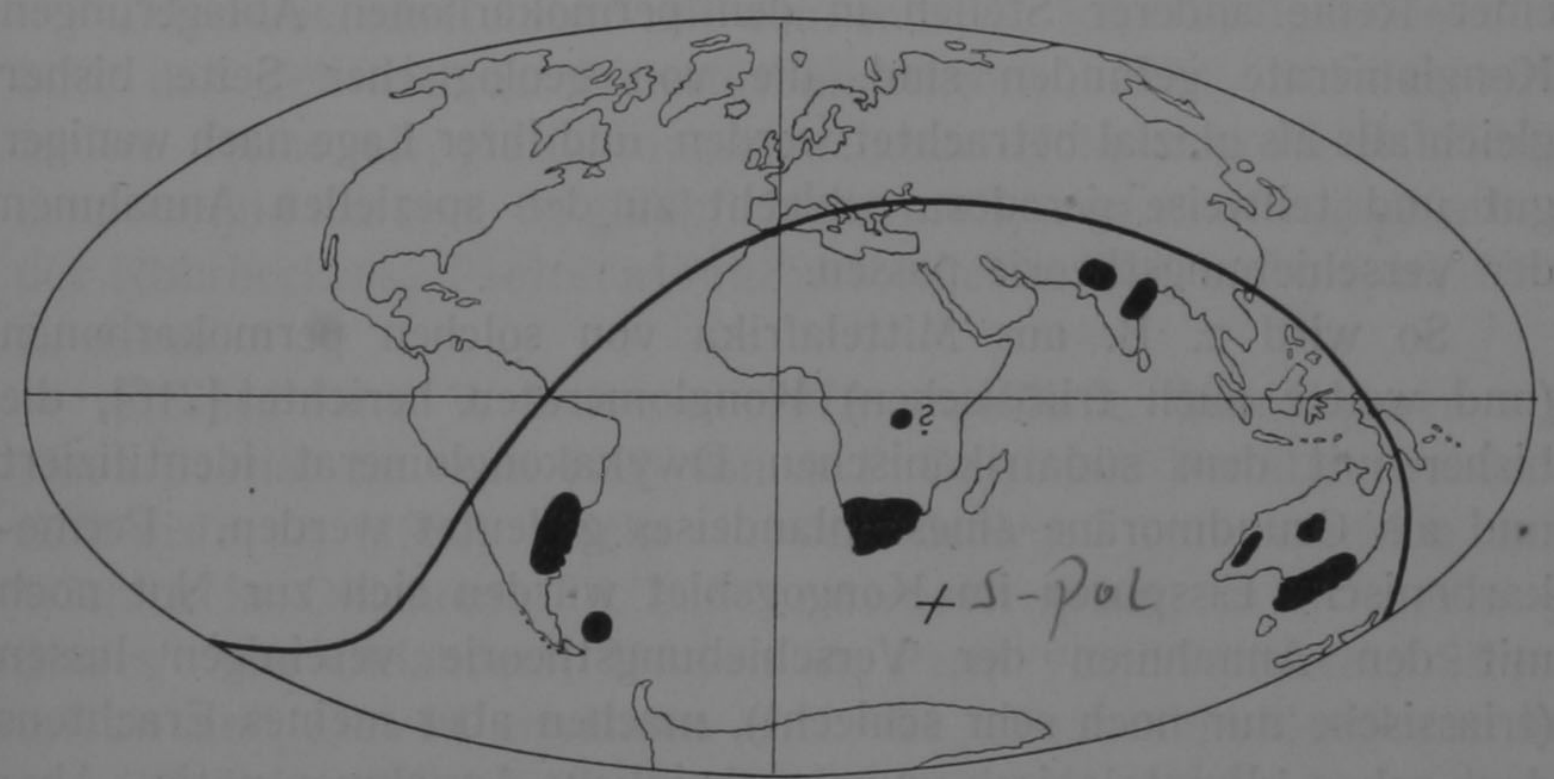

Die permokarbonen Inlandeisspuren auf den heutigen Kontinenten, Das Kreuz bezeichnet die für die Erklärung günstigste Lage des Südpols; die stark ausgezogene Kurve ist der zugehörige Äquator.

Meeresspiegel herabgesenkt war. Und in der Tat ist seitdem auch kein Versuch einer klimatischen Erklärung der Erscheinungen mehr unternommen worden.

So bilden diese Eisspuren eine eklatante Widerlegung der Hypothese der Immobilität der Kontinente. Was würden wir zu der Verschiebungstheorie sagen, wenn sie an irgend einer Stelle des großen, von ihr zusammengefaßten Materials auf einen solchen Widersinn führte? Die Unveränderlichkeit der Lage der Kontinentalschollen ist bisher wie eine aprioristische Wahrheit behandelt worden, die keines Beweises bedarf. Aber sie ist doch in Wirklichkeit auch nur eine Hypothese, die an den Beobachtungen geprüft werden muß. Und ich zweifle stark, ob die Geologie imstande ist, für irgend eines ihrer Ergebnisse je einen strengeren Beweis $\mathrm{zu}$ erbringen als den für die Unrichtigkeit der Immobilitätshypothese auf Grund der permokarbonen Glazialspuren. 
Wir verzichten hier darauf, das Gesagte durch Zitate aus der Literatur zu belegen. Was jeder sehen kann, bedarf keiner Stützung durch fremde Meinungen; und wer nicht sehen will, dem ist ohnehin auf keine Weise $\mathrm{zu}$ helfen.

Für uns lautet die Frage jetzt nicht mehr: Haben sich die Kontinentalschollen verschoben? - denn daran ist ein Zweifel nicht möglich -, sondern: Haben sie sich so verschoben, wie es die spezielle Formulierung der Verschiebungstheorie annimmt?

Dabei darf zunächst nicht übergangen werden, daß noch an einer Reihe anderer Stellen in den permokarbonen Ablagerungen Konglomerate gefunden sind, die von geologischer Seite bisher gleichfalls als glazial betrachtet werden und ihrer Lage nach weniger gut und teilweise geradezu schlecht zu den speziellen Annahmen der Verschiebungstheorie passen.

So wird z. B. aus Mittelafrika von solchen permokarbonen (und weiter auch triassischen) Konglomeraten berichtet [216], die bisher mit dem südafrikanischen Dwykakonglomerat identifiziert und als Grundmoräne eines Inlandeises gedeutet werden. Permokarbonische Eisspuren im Kongogebiet würden sich zur Not noch mit den Annahmen der Verschiebungstheorie vereinigen lassen (triassische nur noch sehr schlecht), machen aber meines Erachtens doch schon klimatologisch unwahrscheinliche Annahmen nötig. Aber wie steht es hier mit der Sicherheit der glazialen Deutung? Es war schon oben darauf hingewiesen, daß täuschend ähnliche ,pseudoglaziale“ Konglomerate mit angeschliffenen Stücken auch in ganz anderen Klimaten (insbesondere im Trockenklima) entstehen können und nachweislich entstanden sind. Der geglättete Fels unter der angeblichen Moräne ist im Kongogebiet bisher nirgends gefunden, man hat also bisher nur solche Kennzeichen, die auch für das Pseudoglazial typisch sind. Außerdem ist die Schichtenfolge dort erst in kleinen Bruchstücken bekannt - selbst die Einordnung in das Permokarbon ist noch unsicher - , so daß man auch nicht sagen kann, daß die glaziale Deutung durch die Identität der ganzen Schichtenfolge gestützt wird. Das wenige, was wir von diesen Schichten wissen, scheint im Gegenteil auf eine bereits wesentlich andere Ausbildung und also auf Entstehung unter anderem Klima hinzudeuten. Keinesfalls kann also die glaziale Deutung hier schon als gesichert gelten. Und dazu kommt der direkte Einwand, daß man in Südafrika die Nordgrenze des Inlandeises bestimmen $\mathrm{zu}$ können glaubt. Es ist schwer glaublich, daß eine andere, getrennte 
Eiskappe gleichzeitig in Zentralafrika lag. Es ist deshalb berechtigt, die Konglomerate von Zentralafrika einstweilen als Klimazeugnisse außer acht zu lassen. Ich halte es für wahrscheinlich, daß sich später ihre pseudoglaziale Natur herausstellen wird.

Noch wahrscheinlicher ist dies bei den von Koert in Togo gefundenen permokarbonen Konglomeraten, die nach der bisherigen, noch wenig eingehenden Untersuchung gleichfalls als glazial angesprochen wurden, aber meines Erachtens höchst wahrscheinlich im Trockenklima gebildet sind.

Durchaus unvereinbar mit dem sonst so folgerichtigen Gesamtbild, das sich aus der Verschiebungstheorie ergibt, ist aber eine andere Reihe als glazial angesprochener Konglomerate in Nordamerika und Europa. So glaubte Hobson Spuren von Eis im Karbon des Ruhrbeckens, Tschernischew solche im Oberkarbon des Ural zu sehen.

Ebenso fand W. Dawson 1872 angebliche Glazialspuren auf Nova Scotia, die noch 1925 von A. P. Coleman bestätigt wurden; S. Weidman (1923) solche in den Gebirgen von Arbuckle und Wichita in Oklahoma; J. B. Woodworth (1921) in den „Caney Shales" von Oklahoma; Udden im Perm von Westtexas; Süssmilch und David erwähnen auch die „Fountain“-Konglomerate von Colorado. Diese Fälle werden heute bereits von der überwiegenden Mehrzahl der Geologen für pseudoglazial gehalten, sicherlich mit Recht, denn die glaziale Deutung würde allen übrigen, so zahlreichen Klimazeugen gerade aus diesen Gebieten widersprechen. Van Waterschoot van der Gracht [210] schreibt über sie:

„Wir müssen sehr vorsichtig mit ,Tilliten' sein. Ich halte es nicht für nachgewiesen, daß irgend eines der permokarbonen Konglomerate von Texas, Kansas, Oklahoma und namentlich Colorado als glazialen Ursprungs betrachtet werden kann. Wer mit Wolkenbrüchen, namentlich solchen, die in Wüsten oder am Rande arider Zonen vorkommen, vertraut ist, für den hat es nichts Überraschendes, daß unsortiertes, meist klastisches und teilweise kantiges Material in großer Mächtigkeit durch die Fluten abgelagert wird, die durch solche Regengüsse erzeugt werden. Diese Fluten sind äußerst heftig, obwohl von kurzer Dauer. Die Ströme bestehen meist mehr aus Schlamm als aus Wasser, und die Mischung hat ein so großes spezifisches Gewicht, daß sie nicht nur unglaublich große Blöcke transportieren kann, sondern auch jede Sichtung des Materials verhindert. Man benötigt kein Eis, um das zu erklären. 
Wir sehen die gleichen Vorgänge gegenwärtig in allen Wüsten, auch in denen des amerikanischen Westens."

„Vereinzelte große Blöcke in sonst feinen marinen Ablagerungen brauchen nicht durch schwimmendes Eis transportiert zu sein. Große Bäume können das gleiche verursachen, wenn sie große Steine, die von ihren Wurzeln umfaßt werden, mit auf die See hinausführen."

„Selbst angeschliffene und gekritzte Steine brauchen nicht glazial zu sein, außer wenn die Schrammen sehr häufig sind und die Steine aus sehr dichtem und hartem Felsen bestehen. Solche Steine, die glazialen Blöcken und Erratikum in erstaunlicher Weise gleichen, aus den permischen Konglomeraten von Nordwesteuropa, mit klaren Anzeichen von ,glazialem' Charakter, werden jetzt als bloße durch Rutschung geschrammte Fragmente betrachtet. 1909 habe ich selber einmal den Irrtum begangen, eines dieser europäischen Konglomerate als einen Tillit zu beschreiben."

$\mathrm{Zu}$ den oben angeführten Fällen kommt aber als besonders auffallende Erscheinung noch ein bei Boston in Nordamerika entdecktes permokarbones Konglomerat, das den Namen „Squantum Tillit" erhalten hat und bisher von allen Besuchern, insbesondere von Sayles [168], der die genaueste Beschreibung geliefert hat, als verhärtete Moräne gedeutet wurde. Diese Ablagerungen bedecken etwa ein Areal fast so groß wie der Vatna-Jökull auf Island. Das Konglomerat enthält geglättete Steine, die.als vom Eise gekritzte Geschiebe angesehen werden, und in der Ungebung dieses Gebiets werden verhärtete Tonschichten gefunden, die den von de Geer studierten quartären und postquartären Warven in Schweden ähnlich sind. Doch sind alles dies Erscheinungen, die auch pseudoglazial sein können. Der geschliffene Felsen unter dieser angeblichen Moräne ist bisher nirgends gefunden worden.

Gegen die glaziale Deutung dieses Squantum-Tillits bestehen, wie von mir kürzlich hervorgehoben wurde [217], die schwersten Bedenken vom klimatologischen Standpunkt aus, und zwar ganz unabhängig von der Verschiebungstheorie. Alle übrigen Klimazeugen von Nordamerika aus permokarboner Zeit, die ungemein zahlreich sind, beweisen in völlig eindeutiger Weise, daß das Gebiet der Vereinigten Staaten im Westen während dieser ganzen Zeit das Klima der heißen Wüste hatte, während der Osten im Karbon noch in der äquatorialen Regenzone, im Perm aber gleichfalls im Gebiet der heißen Wüste lag. Einzelheiten über diese Klimazeugen, unter denen Salz- und Gipsablagerungen und Korallenriffe eine Hauptrolle 
spielen, werden weiter unten genannt werden. Nun geht aber aus unserer Abb. 33 hervor, daß in den Klimaten, die solche Ablagerungen erzeugen, die Schneegrenze gerade ihre höchste Lage auf der ganzen Erde hat. Sie wird auch damals in Gebiet der Vereinigten Staaten über $5000 \mathrm{~m}$ hoch gelegen haben. Da erscheint es völlig ausgeschlossen, daß inmitten dieser Ablagerungen eine Eismasse von der Größe des Vatna-Jökull gelegen haben kann oder gar, wie manche annehmen, in demselben Meere, in dem sich die Korallenriffe bildeten, Eisberge schwammen. Dies ist physikalisch unmöglich, denn das Klima kann nicht gleichzeitig heiß und kalt gewesen sein. Auch mit der Annahme, daß diese Glazialbildungen in großer Höhe entstanden wären, kommt man auf keine Weise aus. Ich halte es deshalb für sehr wahrscheinlich, daß sich auch der Squantum-Tillit als pseudoglazial herausstellen wird, wie bereits so manche andere Konglomerate.

$\mathrm{Zu}$ beachten ist dabei, daß diese klimatologischen Bedenken gegen die glaziale Natur des Squantum-Tillits auf derr zeitlich und räumlich benachbarten Ablagerungen der nordamerikanischen Scholle selbst beruhen, also überhaupt nichts mit der Verschiebungstheorie zu tun haben und ohne Rücksicht auf sie eine Klärung erheischen.

Aus diesem Grunde ist es unlogisch, in dem Squantum-Tillit einen Einwand zu sehen. Denn wie es sich auch mit dem SquantumTillit verhalten möge, es ist ja selbstverständlich, daß wir der großen Zahl sicherer und untereinander übereinstimmender Zeugnisse folgen müssen und nicht dem einen abweichenden, das sich schon in so vielen Fällen als trügerisch erwiesen hat.

Ich bin auf die pseudoglazialen Erscheinungen des Permokarbons hier etwas näher eingegangen, weil ich bisher mit meinem Protest gegen die glaziale Deutung des Squantum-Tillits noch allein zu stehen scheine ${ }^{1}$ ) und ihn deshalb eingehender begründen mußte. Gehen wir nun zu der Prüfung über, wie sich die verläßlichen Klimazeugen aus dem Karbon und Perm bei Annahme der Verschiebungstheorie ordnen!

Die wichtigsten von ihnen sind in die beiden Karten der Abb. 35 und 36 eingetragen. Die echten Eisspuren sind durch den Buchstaben $E$ bezeichnet. Wie man sieht, haben sich jetzt alle damals vereisten Gebiete um Südafrika zusammengeschlossen und nehmen

1) Nur van Waterschoot van der Gracht [210] scheint sich meinen Zweifeln anzuschließen. 
eine Kappe von etwa $30^{\circ}$ Radius auf der Erdoberfläche ein. Die gleichzeitigen Zeugnisse für Polarklima sind also jetzt auf das gleiche Areal beschränkt wie im heutigen Klimasystem. Das ist eine Bestätigung unserer Annahmen, wie sie besser nicht gewünscht werden $\operatorname{kann}^{1}$ ).

Wie kommt es nun, daß den vielen Zeugnissen vom Inlandeis am Südpol keine solchen aus der nördlichen Polarkappe gegenüberstehen? Die Erklärung liegt darin, daß der Nordpol im Stillen Ozean lag an einer Stelle, die von allen Kontinenten weit entfernt war.

Abb. 35.

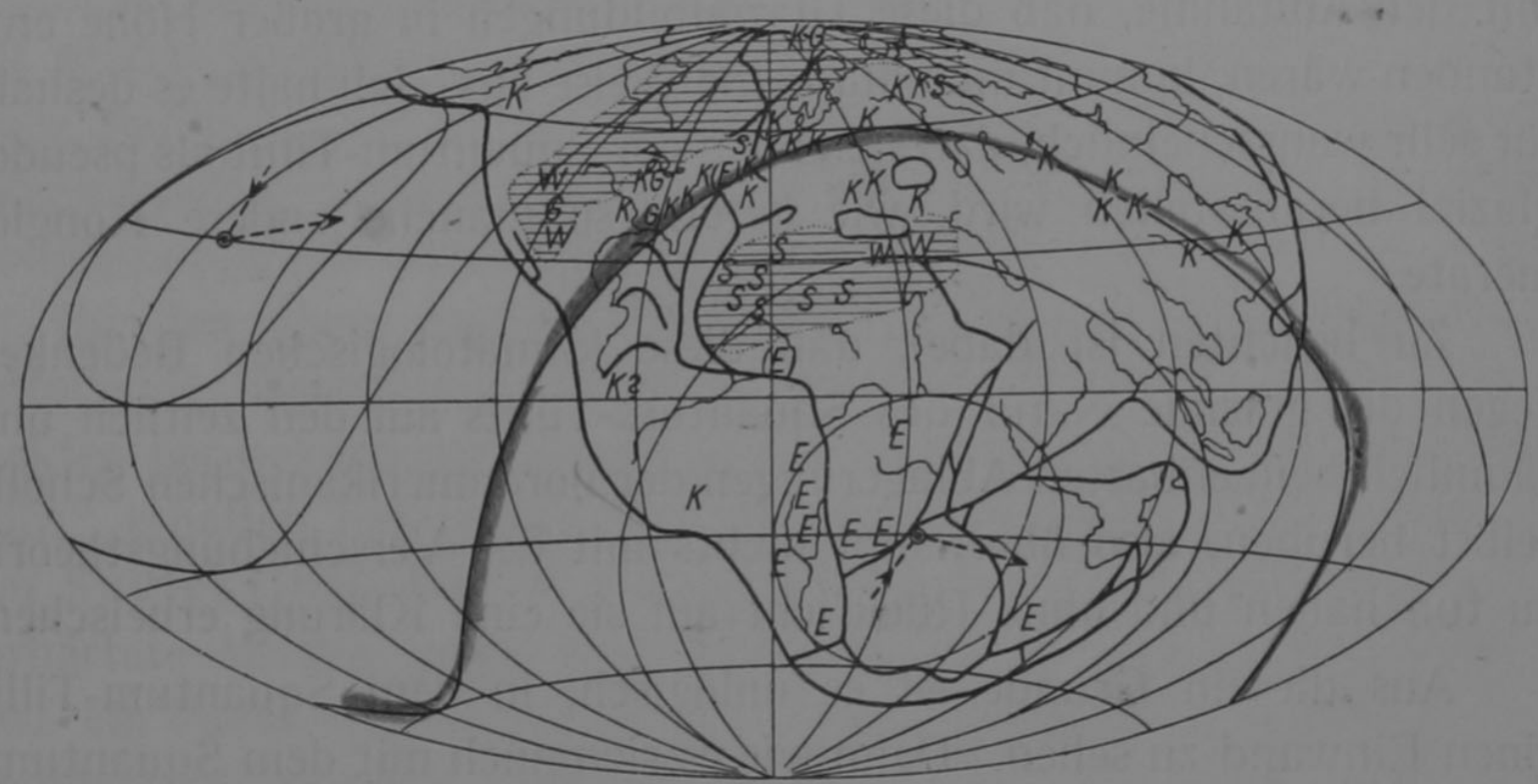

Eis, Moore und Wüsten im Karbon.

$E=$ Eisspuren ; $K=$ Kohlen $S=$ Salz $; G=$ Gips $; W=$ Wüstensandstein schraffiert $=$ Trockengebiete. Nach Köppen-Wegener.

Von der Mitte des Vereisungsgebietes aus als Südpol ist in den Abbildungen auch der zugehörige Äquator, die Breitenparallele von 30 und $60^{\circ}$ nördlicher und südlicher Breite und der Nordpol eingetragen. Diese Kurven erscheinen natürlich in der Projektion der Abbildung außerordentlich verzerrt; der Äquator, in Wirklichkeit ein Großkreis auf der Kugel, ist durch die gebogene, etwas stärkere Linie dargestellt. Wie liegen nun hierzu die übrigen Klimazeugnisse?

1) Mit Unrecht wird eingewendet: Da die Vereisungen der Südkontinente nicht ganz gleichzeitig waren, käme man auch mit der heutigen Lage der Kontinente aus, wenn man nur eine (allerdings sehr große und rasche!) Polwanderung dazunimmt. Aber die erste Vereisung Australiens fand schon im Karbon, gleichzeitig mit der von Südamerika und Südafrika, statt, und bei der Riesenwanderung des Südpols müßte der Nordpol Mexiko gequert haben, wo doch heißes Wüstenklima herrschte. Und alle übrigen, über die Erdoberfläche verteilten Klima- 
Der große karbonische Steinkohlengürtel, der sich durch Nordamerika, Europa, Kleinasien und China hindurchzieht, bildet in unserer Rekonstruktion (nicht auf der heutigen Erde!) einen Großkreis, und zwar denjenigen, dessen Pol mitten im Vereisungsgebiet liegt; er fällt mit unserem Äquator zusammen.

Kohlen bedeuten, wie erwähnt, Regenklima. Ein Regengürtel, der wie hier die Erde in Gestalt eines GroBkreises umgibt, kann natürlich durchaus nur der äquatoriale sein. Läßt sich dann obendrein feststellen, wie hier, daß er $90^{\circ}$ von der Mitte Abb. 36 .

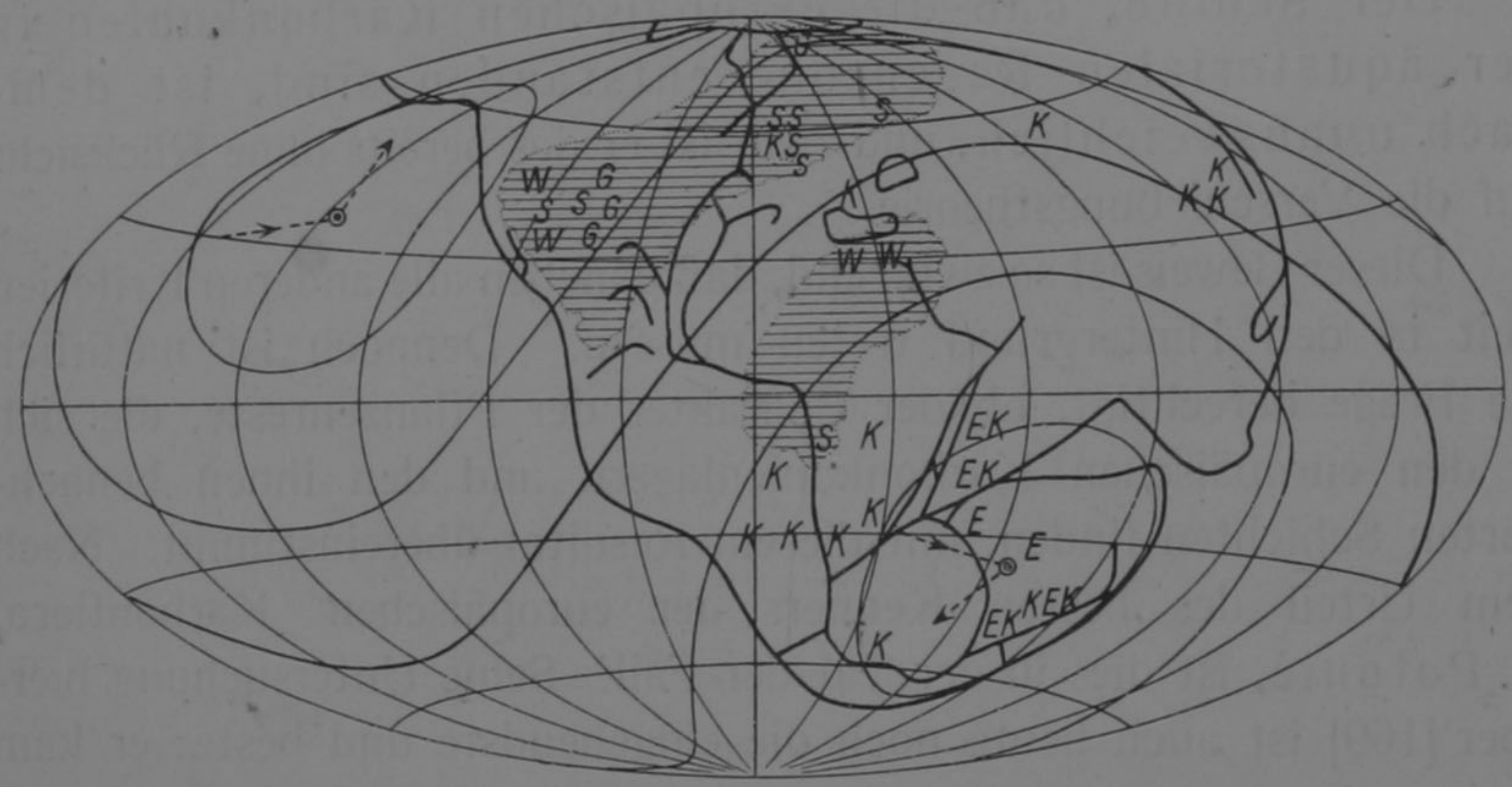

Eis, Moore und Wüsten im Perm.

$E=$ Eisspuren $; K=$ Kohlen $; S=\mathrm{Salz} ; G=$ Gips $; W=$ Wüstensandstein schraffiert $=$ Trockengebiete. Nach Köppen-Wegener.

eines großen Inlandeisgebietes entfernt ist, so sind wir um so mehr berechtigt, auf seine äquatoriale Lage zu schließen.

Es ist wichtig, sich klarzumachen, daß dieser Schluß durchaus unvermeidlich ist, gleichgültig, ob wir dabei von der Verschiebungstheorie ausgehen oder nicht. Die europäischen Kohlenfelder des Karbons liegen heute genau $80^{\circ}$ nördlich der so eingehend untersuchten, sicheren Inlandeisspuren aus gleicher Zeit in Südafrika, wo wir Belege dafür haben, daß die Schneegrenze, wie heute nur in der Antarktis, den Meeresspiegel erreichte. Wegen des alpinen Zusammenschubes im Tertiär wird der Abstand zur Karbonzeit 10 bis $15^{0}$ größer gewesen sein als heute, im übrigen aber kann die Lage Europas zu Südafrika keine wesentlichen Veränderungen durchoemacht hahen $F_{0}$ lannn dohom nicht du 
Bildung gerade um einen Erdquadranten von der Mitte eines großen Inlandeisgebiets entfernt waren, gleichgültig, welche Annahmen man über die Lage der anderen Kontinente zur damaligen Zeit macht. In $90^{\circ}$ Abstand vom Pol kann man sich aber durchaus nur auf dem Äquator befinden. Auch Spitzbergen liegt noch auf der europäischen Kontinentalscholle und muß also auch im Karbon wesentlich die gleiche Lage zu Europa gehabt haben wie heute. Seine großen karbonischen Gipslager bezeugen subtropisches Trockenklima und zeigen also an, daß die nördliche Zone subtropischen Klimas damals noch $30^{\circ}$ nördlich der europäischen Kohlenlager lag.

Der Schlu'ß, daß die europäischen Karbonkohlen in der äquatorialen Regenzone entstanden sind, ist demnach unausweichlich, und zwar ist er das bereits ohne Rücksicht auf die Verschiebungstheorie.

Dieser Beweis ist so zwingend, daß daneben alle anderen Kriterien weit in den Hintergrund treten müssen. Dennoch ist natürlich die Frage berechtigt, ob der Charakter der Pflanzenreste, die sich in den europäischen Karbonkohlenlagern und den ihnen benachbarten Schichten finden, mit diesem Resultat übereinstimmt. Nach dem Urteil des besten Kenners der europäischen Karbonflora, H. Potonié, ist dies in der Tat der Fall. Seine Untersuchung hierüber [169] ist auch heute noch die eingehendste und beste; er kam darin, rein aus botanischen Gründen, zu dem Schluß, daß die europäischen Kohlenlager des Karbons fossile Torfmoore vom Charakter tropischer Flachmoore seien.

Die Gründe, die Potonié für diese Auffassung vorbringt, sind natürlich nicht von zwingender Natur; denn es ist sehr schwer, den Klimacharakter einer so alten Flora zu beurteilen. Diese Unsicherheit ist von seinen Gegnern, deren es unter den heutigen Phytopaläontologen nicht wenige gibt, sehr betont worden; aber es ist doch auffallend, daß diese - soweit mir bekannt - nicht in der Lage sind, Potoniés Gründe dadurch zu entkräften, daß sie für die von ihm angeführten Charakterzüge der Flora eine wahrscheinlichere, andere klimatische Deutung gefunden hätten, oder daß sie andere Charakterzüge dieser Flora nennen könnten, die Potonié nicht anführt, und die dabei auf ein anderes Klima hinwiesen. Es sind vielmehr stets Einwände allgemeiner Art, die von Potoniés Gegnern vorgebracht werden. Gerade aus diesem Grunde, weil Potoniés botanische Beweisführung, wie es scheint, noch immer 
kennenzulernen. Er gibt hauptsächlich séchs Charakterzüge der Flora an, die für tropischen Ursprung sprechen:

1. Soweit die Fruchtorgane der fossilen Farne ein Urteil zuließen, ergab sich ihre Verwandtschaft mit Familien, die heute in den Tropen zu Hause sind. Unter anderem ist die Verwandtschaft vieler karbonischer.Farne mit den heutigen Marattiaceen erwähnenswert.

2. In der Karbonflora treten stark in den Vordergrund Baumfarne und kletternde bzw. windende Farne. Überhaupt überwiegen baumförmige Gewächse auch in Gruppen, die heute meist krautig sind.

3. Manche karbonischen Farne, z. B. das Baumfarn Pecopteris, haben Aphlebien, d. h. unregelmäßig zerschlitzte Fiedern an den Ansatzstellen der Nebenspindeln, die sich von der übrigen regelmäßigen Fiederung der Wedel auffallend unterscheiden. Sie sind schon ausgewachsen, wenn die jungen Normalfiedern noch eingerollt sind. Solche Aphlebien werden heute nur an tropischen Farnen beobachtet.

4. Eine bedeutende Zahl von Karbonfarnen hat so große Wedel, wie sie nur in den Tropen vorkommen. Es gibt Wedel, die mehrere Quadratmeter groß sind.

5. Zuwachszonen (Jahresringe) fehlen vollständig in den Stämmen der europäischen Karbonbäume. Das Wachstum ist also wohl weder durch periodische Trockenzeiten noch durch periodische Kälte unterbrochen worden. Wir können jetzt linzufügen: Dagegen hat man sowohl auf den Falklandsinseln wie in Australien die beide, wie Abb. 35 und 36 zeigen, in hoher Südbreite lagen permokarbone Hölzer mit deutlichen Jahresringen gefunden.

6. Man hat Stammbürtigkeit der Blüten (Cauliflorie) festgestellt „,bei Calamariaceen und Lepidophyten, und zwar bei diesen letzteren bei gewissen Lepidodendraceen (der ,Gattung‘ Ulodendron, die sich sogar ausschließlich auf jene großen Male an den Stammresten gründet, welche stammbürtigen Blüten entsprechen) und Sigillariaceen ... Heutzutage sind Gehölze, deren Blüten aus altem Holze (aus Stämmen und Zweigen) seitlich hervorbrechen, fast ganz auf den tropischen Regenwald beschränkt ... Es ist vielleicht der durch die dichte, tropische Vegetationsdecke bedingte mächtige Kampf ums Licht, der sich darin ausspricht, daß die lichtbedürftigen 
Laubblätter oft ganz ausschließlich den Gipfel einnehmen, während die Fortpflanzungsorgane an den Teilen der Pflanzen auftreten, die dem Lichte weniger zugänglich sind, wo sie jedenfalls die ausgiebige Lebensverrichtung der Laubblätter in keiner Weise behindern."

Mag man solche botanischen Schlüsse, wie erwähnt, für unsicher halten, zweierlei kann man mit Bestimmtheit aussagen: Diese Flora hat weder im kalten Polarklima noch in dem gemäßigten Klima, das heute an ihren Fundorten herrscht, gelebt, sondern es kann sich nur um tropisches oder subtropisches Klima bei ihr handeln. Und zweitens passen alle Anzeichen vorzüglich zu unserem auf ganz anderem und viel sichererem Wege gefundenen Ergebnis, daß diese Kohlenlager in der äquatorialen Regenzone entstanden sind.

Die Gegner von Potonié vertreten meist den Standpunkt, es handele sich nicht um tropisches, sondern subtropisches Klima. Als Grund hierfür führte man früher (ich weiß nicht, ob es heute noch jemand tut) die Behauptung ins Feld, daß es in der heutigen äquatorialen Regenzone keine Torfmoore geben solle und auch nicht könne, da sich oberhalb einer bestimmten Temperaturgrenze wegen der in der Wärme schnelleren Zersetzung der Pflanzenteile Torf angeblich nicht mehr bilde. Dieser Gedankengang läßt sich am einfachsten dadurch widerlegen, daß man in neuerer Zeit fast überall in der heutigen äquatorialen Regenzone Torfmoore gefunden hat, insbesondere auf Sumatra, Ceylon, am Tanganjikasee und in Britisch-Guayana. Viele andere sind wohl noch in den Sumpfgebieten des Kongo und Amazonas vorhanden, die man noch nicht kennt, deren Existenz aber durch die teefarbenen „Schwarzwässer“" vieler der dortigen Flüsse sehr wahrscheinlich wird. Es handelt sich also bei diesem Einwand um weiter nichts als einen Irrtum, verursacht durch die Unzugänglichkeit der tropischen Sümpfe und unseren daraus entspringenden bisherigen Mangel an ihrer Kenntnis. Am Karbonäquator wurde freilich die Bildung von Torfmooren besonders begünstigt durch die gleichzeitig einsetzenden Bodenbewegungen der großen karbonischen Faltungen, durch die der natürliche Wasserablauf gestört und Sümpfe in besonders großer Ausdehnung geschaffen wurden.

Als weiteren Grund für die Annahme subtropischen Klimas hat man angeführt, daß Baumfarne, wie sie in den Karbonkohlen häufig sind, heute weniger in den Tropen als in den Subtropen, 
und zwar hier an feuchten Berghängen, vorkommen. Aber einerseits ist dies kein zwingender Grund, denn Baumfarne kommen tatsächlich auch heute, wenn auch relativ selten, in den Torfmooren der äquatorialen Regenzone vor, und es ist nicht unwahrscheinlich, daß sie hier heute nur durch besser angepaßte neuere Formen teilweise verdrängt sind, die es im Karbon noch nicht gab, und die ihnen daher den Rang nicht streitig machen konnten. Und andererseits paßt der Vergleich mit den heutigen Subtropen insofern schlecht, als diese bis auf die Monsunregengebiete am Ostrand der Kontinente trocken sind, so daß sich ein so langgestreckter Moorgürtel, wie er den karbonischen Hauptkohlen entspricht, in den Subtropen klimatisch nicht unterbringen läßt. Kohlengürtel können eben nur äquatorialem oder kühlgemäßigtem Klima entsprechen. In letzterem sind aber Baumfarne ausgeschlossen.

Wenn endlich von manchen Autoren Potoniés Deutung aus dem Grunde in Zweifel gezogen wird, weil dieser auch bei der klimatischen Deutung der tertiären Braunkohlen geirrt habe ${ }^{1}$ ), so dürfen wir hierüber wohl hinweggehen, denn der Schluß, daß, wer einmal irrt, darum stets irren muß, ist ganz gewiß noch unsicherer als Potoniés Beweisführung für die Tropennatur der europäischen Karbonkohlen.

Dieser ganze Streit um die tropische oder subtropische Natur dieser Kohlen wird mit Gründen geführt, die nicht von zwingendem Charakter sind, was ja bei einer so alten Flora nicht zu verwundern ist. Ich wiederhole aber, daß die Lage dieser Kohlen im Abstand eines Erdquadranten von der Mitte eines zweifellos polaren Inlandeisgebietes ein durchaus zwingender Grund für ihre Entstehung im äquatorialen Regenklima ist, und zwar, wie hervorgehoben, ganz unabhängig vom Problem der Kontinentenverschiebung.

1) Ohne mich in den Streit der Phytopaläontologen einzumischen, möchte ich die Gelegenheit wahrnehmen, darauf hinzuweisen, daß̉ Mitteleuropa nach der Gesamtheit der Klimazeugen im Frühtertiär zweifellos noch in der äquatorialen Regenzone, im Mitteltertiär im subtropischen (teilweise Trocken-) Klima und im Spättertiär etwa im heutigen Klima gelegen hat. Die tertiären Kohlen Mitteleuropas müssen also je nach ihrem Alter unter sehr verschiedenem Klima gebildet sein. Man sollte auch hier beachten, daß sich das Klima unvergleichlich sicherer durch die Gesamtheit der fossilen Klimazeugen aus dem damaligen Europa bestimmen läßt als durch die eine Gruppe von Zeugnissen, die die Kohlenflora liefert. 
Die Verschiebungstheorie vervollständigt diesen Beweis nur noch durch Hinzuziehung der außereuropäischen Glieder dieses großen Kohlengürtels, deren heutige Lage ohne Berücksichtigung der Kontinentverschiebungen zu Widersprüchen führt.

Die Gleichheit der Flora und damit auch der klimatischen Entstehungsbedingungen ist heute für die großen Karbonkohlenlager von Nordamerika, Europa, Kleinasien und China allgemein anerkannt. Da die europäischen notwendigerweise in der äquatorialen Regenzone entstanden sein müssen, so muß also das gleiche auch für die anderen Glieder dieses Gürtels gelten. Ihre heutige Anordnung liefert nun einen direkten Beweis für die Verschiebungstheorie, denn sie entspricht heute nicht der Forderung, daß alle diese Lager auf einem Großkreis liegen müssen. Zur Erläuterung geben wir in Abb. 37 die von Kreichgauer [5] gezeichnete Erdkarte für das Karbon mit dem von ihm angenommenen Äquator; wir sehen hier das Bild, zu dem man ohne die Verschiebungstheorie kommen würde: Für Europa, Afrika und Asien stimmt es mit dem unserigen ungefähr überein. Aber der Äquator geht auf ihm nicht durch den Osten der Vereinigten Staaten, wohin er nach den Klimazeugnissen gehört, sondern durch Südamerika, wo er nicht gelegen haben kann, da hier, kaum $10^{\circ}$ von ihm entfernt, das Inlandeis sich ausbreitete. Natürlich ist auch wieder die Unverträglichkeit der Lage Vorderindiens und Australiens mit ihren Inlandeisspuren hier besonders in die Augen fallend.

Auch die große Mächtigkeit der Kohlenschichten im Hauptkohlengürtel des Karbons, die sie so wertvoll macht, paßt ausgezeichnet zu ihrer Entstehung in der äquatorialen Regenzone. Viel weniger mächtig sind die Kohlenschichten, die sich auf den Südkontinenten im Perm allenthalben auf den Grundmoränen des abgeschmolzenen Inlandeises bildeten (vgl. Abb. 36). Die zugehörige Flora, die nach dem Krautfarn Glossopteris benannt wird, war eine kühle. Hier handelt es sich um Moore der südlichen subpolaren Regenzone ganz gleicher Entstehung wie die der quartären und postquartären Torfmoore Nordeuropas und Nordamerikas. Auch diese Kohlenformation und die Glossopterisflora erfordern einen Zusammenschluß dieser Gebiete, die heute einen für ihr damaliges Klima viel zu großen Raum einnehmen.

Auch die übrigen Klimazeugen aus dem Karbon und Perm bestätigen unsere in Abb. 35 und 36 dargestellten Ergebnisse, wobei 


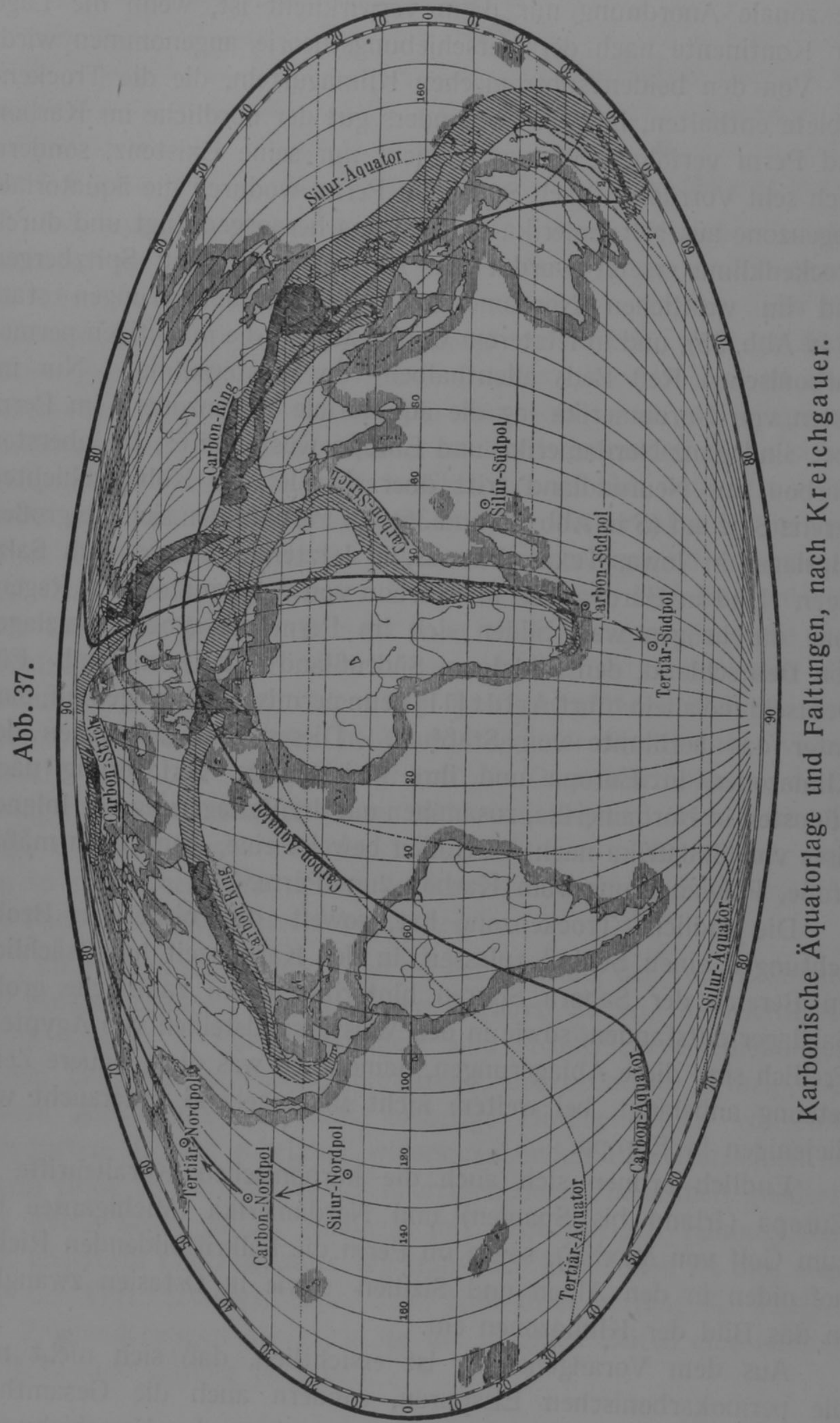


die zonale Anordnung nur dann verwirklicht ist, wenn die Lage der Kontinente nach der Verschieburrgstheorie angenommen wird. Von den beiden subtropischen Klimagürteln, die die Trockengebiete enthalten, läßt sich besonders gut der nördliche im Karbon und Perm verfolgen, und zwar nicht nur seine Existenz, sondern auch sein Vorrücken nach Süden im Perm, wodurch die äquatoriale Regenzone aus Nordamerika und Europa herausgedrängt und durch Trockenklima ersetzt wurde: Im Karbon fanden auf Spitzbergen und im westlichen Nordamerika große Gipsablagerungen statt ( $G$ in Abb, 35), und in letzterem Gebiet zeugen die mächtigen permokarbonischen Red Beds allenthalben von Wüstenklima. Nur im Osten von Nordamerika lag die äquatoriale Regenzone. Im Perm aber sind ganz Nordamerika und Europa wüstenhaft: Im obersten Karbon auf Neufundland tritt über den letzten Kohlenschichten bereits Salz auf ( $S$ in Abb: 35 und 36), im Perm bilden sich die großen Gipslager in Iowa, Texas, Kansas, in letzterem Staate auch Salzlager. Und in Europa, das im Karbon von der äquatorialen Regenzone durchzogen war, bilden sich im Perm die großen Salzlager von Deutschland, den Südalpen, Südrußland und Ostrußland. Für Deutschland allein führt Arldt [11] neun permische Salzlager auf, darunter das berühmte von Staßfurt. Dieses Südwärtsrücken der Klimazonen in Europa und ihre gleichzeitige Verlagerung nach Südosten in Nordamerika, zusammen mit der Verlagerung des Inlandeises von Südafrika nach Australien beweist eine, wenn auch mäßig große, Polwanderung vom Karbon zum Perm.

Die südliche Trockenzone hat, soweit die bisherigen Beobachtungen einen Schluß zulassen, in der Karbonzeit hauptsächlich im Bereich der Sahara Spuren hinterlassen, wo zahlreiche große Salzlager entstanden, sowie in den Wüstensandsteinen von Ägypten. Freilich sind diese Ablagerungen, namentlich was die genauere Zeitsetzung anbelangt, bei weitem nicht so eingehend untersucht wie diejenigen in Europa.

Endlich ordnen sich auch die karbonischen Korallenriffe in Europa (Irland bis Spanien) und Nordamerika (Michigansee bis zum Golf von Mexiko), sowie im Perm die kalkriffbildenden Richthofeniden in den Alpen und Sizilien sowie in Ostasien zwanglos in das Bild der Klimazonen ein.

Aus dem Vorangehenden ist ersichtlich, daß sich nicht nur die permokarbonischen Eisspuren, sondern auch die Gesamtheit der damaligen Klimazeugnisse bei Anwendung der Verschiebungs- 
theorie in ein System ordnen, das vollkommen dem heutigen Klimasystem entspricht, wenn man den Südpol in die Gegend von Südafrika verlegt. Bei der heutigen Lage der Kontinente dagegen ist es überhaupt unmöglich, sie zu einem verständlichen Klimasystem zusammenzufassen. Dadurch werden diese Beobachtungen zu einem der stärksten Beweise für die Richtigkeit der Verschiebungstheorie.

Der paläoklimatische Beweis für die Verschiebungstheorie wäre allerdings unvollständig, wenn er nur für die Karbon- und Permzeit zu führen wäre und für die folgenden Zeiten versagte. (Für die vorangehenden ist er einstweilen nicht $\mathrm{zu}$ führen, weil für diese Zeiten gegenwärtig noch die Kartengrundlage fehlt.) Dies ist aber keineswegs der Fall. Ich habe in dem gemeinsam mit Köppen verfaßten Buche [151] der Reihe nach alle folgenden geologischen Zeiten in der gleichen Weise behandelt, wie es hier - gekürzt - für das Karbon und Perm geschehen ist. Der beschränkte Raum verbietet es, diese Ausführungen hier zu wiederholen, und wir müssen den Leser deshalb auf unser Buch verweisen. Das Ergebnis ist aber stets das gleiche: Benutzt man als Kartengrundlage die Rekonstruktion nach der Verschiebungstheorie, so ordnen sich die Klimazeugnisse stets zu einem dem heutigen grundsätzlich gleichen System, während bei der heutigen Lage der Kontinente Widersprüche auftreten. Je mehr wir uns der Gegenwart nähern, desto geringer werden natürlich diese Widersprüche, weil eben auch die Lage der Kontinente sich der heutigen immer mehr nähert, und um so schwächer wird daher die Beweiskraft dieser Zeugnisse für die Richtigkeit der Verschiebungstheorie.

Im übrigen sei bemerkt, daß bei der Deutung der Vorzeitklimate die Polwanderungen, zumal in den späteren Zeiten, die wichtigste Rolle spielen. Polwanderungen und Kontinentverschiebungen bilden hier, sich gegenseitig ergänzend, das ordnende Prinzip, bei dessen Anwendung sich das bisherige Durcheinander von ungeordneten, ja sich scheinbar widersprechenden Einzeltatsachen zu einem Bilde von immer wieder überraschender Einfachheit gliedert, das durch seine völlige Analogie mit dem jetzigen Klimasystem von ungemein überzeugender Wirkung ist. $\mathrm{Zu}$ danken ist dies aber erst der Verschiebungstheorie, denn ohne diese vermag die Theorie der Polwanderungen höchstens für die jüngsten Zeiten eine leidlich befriedigende Lösung zu geben. 
Achtes Kapitel.

\section{Grundsätzliches über Kontinentverschiebungen und Polwanderungen.}

Die Worte Kontinentverschiebung und Polwanderung werden in der bisherigen Literatur bisweilen in recht verschiedenem Sinne gebraucht, und es herrscht über ihr Verhältnis zueinander eine Unklarheit, die nur durch eine genaue Definition beseitigt werden kann. Eine solche ist auch notwendig, um die Probleme, die in diesen Worten enthalten sind, überhaupt klar zu erkennen.

Die Aussagen der Verschiebungstheorie beziehen sich durchgängig auf relative Kontinentverschiebungen, d. h. auf Verschiebungen von Teilen der Erdkruste relativ zu einem willkürlich gewählten Teil derselben. Insbesondere sind in den Rekonstruktionen der Abb. 4 (S. 18) die Kontinentverschiebungen relativ zu Afrika angegeben, so daß Afrika in allen Rekonstruktionskarten in gleicher Lage gezeichnet wurde. Die Wahl des Bezugskontinents fiel auf Afrika, weil dies den Kern der ehemaligen Urkontinentalscholle darstellt. Beschränkt man die Betrachtung auf einen Teil der Erdoberfläche, so wird man das Bezugssystem naturgemäß auf ein engeres Gebiet dieses Teiles verlegen und dann dies Bezugsgebiet in unveränderter Lage darstellen. Die Wahl desselben ist eine reine Zweckmäßigkeitsfrage. Wegen der neuerdings eingeleiteten Überwachung der geographischen Längenänderungen wird man vielleicht später dazu übergehen, die Kontinentverschiebungen auf der ganzen Erde relativ zur Greenwicher Sternwarte darzustellen.

Um von der willkürlichen Wahl des Bezugssystems freizukommen, könnte man vielleicht ausgeglichene Kontinentverschiebungen definieren, die relativ zur Gesamtheit der Erdoberfläche an Stelle nur eines Teiles derselben zu bestimmen wären. Deren Bestimmung wäre aber praktisch mit großen Schwierigkeiten verknüpft und kommt einstweilen nicht in Betracht.

Es ist wichtig, sich die völlige Willkürlichkeit des von uns benutzten Bezugssystems Afrika zu vergegenwärtigen. Wenn beispielsweise Molengra aff [in 228] hervorhebt, die mittelatlantische Schwelle zeige, daß Afrika von dort nach Ósten gewandert sei, so kann ich hierin keinen Widerspruch mit der Verschiebungstheorie anerkennen. Bezogen auf Afrika, wanderten Amerika und die mittelatlantische 
Bodenschwelle nach Westen, und zwar ersteres etwa doppelt so schnell wie letztere; bezogen auf die mittelatlantische Bodenschwelle, wanderte Amerika nach Westen und Afrika etwa gleich schnell nach Osten; und bezogen auf Amerika, wanderten sowohl die mittelatlantische Schwelle wie Afrika beide nach Osten, letzteres doppelt so schnell wie erstere. Bei der Relativität der Bewegung sind alle drei Aussagen identisch. Wählen wir aber einmal Afrika als Bezugssystem, so können wir definitionsgemäß diesem Kontinent keine Bewegung zuteilen. Daß diese Wahl nicht für die einzelnen Teile der Erde, sondern höchstens für die Gesamtheit der Erdoberfläche die zweckmäßigste sein kann, wurde schon gesagt.

Die so definierten Kontinentverschiebungen enthalten noch keinerlei Aussage über Lagenänderungen zum Pol oder zur Unterlage. Ich halte es für wichtig, diese Begriffe von dem der Kontinentverschiebung zu trennen.

Polwanderung ist ein geologischer Begriff. Da dem Geologen nur der oberste Teil der Erdrinde zugänglich ist, und die frühere Lage der Pole sich nur an der Hand fossiler Klimazeugnisse beurteilen läßt, die der Erdoberfläche entstammen, so müssen wir die Polwanderungen als oberflächliche definieren, d. h. als Drehung des Systems der Breitenkreise relativ zur gesamten Erdoberfläche oder auch, was wegen der Relativität aller Bewegung auf das gleiche hinausläuft, als Drehung der gesamten Erdoberfläche relativ zum System der Breitenkreise. Um wirksam zu sein, muß diese Drehung natürlich um eine Achse erfolgen, die von der Rotationsachse der Erde abweicht. Die Frage, wie sich das Erdinnere hierbei verhält, ob es in bezug auf das System der Breitenkreise oder in bezug auf die Erdoberfläche ruht, oder drittens, was auch möglich ist, sich in bezug auf beide dreht, bleibt bei dieser Definition ganz aus dem Spiele. Und das ist notwendig, um Klarheit zu schaffen. Oberflächliche Polwanderungen in diesem Sinne lassen sich für die Vorzeit nur durch die fossilen Klimazeugnisse nachweisen. Die Geophysik kann über ihre Existenz oder Möglichkeit kein Urteil abgeben.

Die Bestimmung der Polwanderung nach dieser Definition ist allerdings wegen des gleichzeitigen Auftretens der Kontinentverschiebungen mit Schwierigkeiten verknüpft. Gäbe es keine Kontinentverschiebungen, so würde man die Pollagen, wie sie aus den fossilen Klimazeugnissen hervorgehen, unmittelbar miteinander vergleichen können, und man erhielte ohne weiteres die Polwanderung nach Richtung und Größe. Sind aber in der Zwischenzeit zwischen 
den betrachteten beiden Zeitpunkten Kontinentverschiebungen eingetreten, so können wir zwar auch auf den beiden rekonstruierten Erdkarten, die mit Berücksichtigung der Kontinentverschiebung entworfen sind, auf Grund der Klimazeugen die Pollagen für beide Zeitpunkte finden, aber es entsteht die eigentümliche Schwierigkeit, daß wir nicht wissen, wie zur Zeit 2 die ,unveränderte“, d. h. mit der Zeit 1 übereinstimmende Pollage anzusetzen ist, von der aus wir Betrag und Richtung der Polwanderung zu rechnen hätten.

Man könnte hier etwa folgendermaßen verfahren: Denkt man sich das Gradnetz zur Zeit 1 auf die damalige Erdoberfläche fest

Abb. 38.

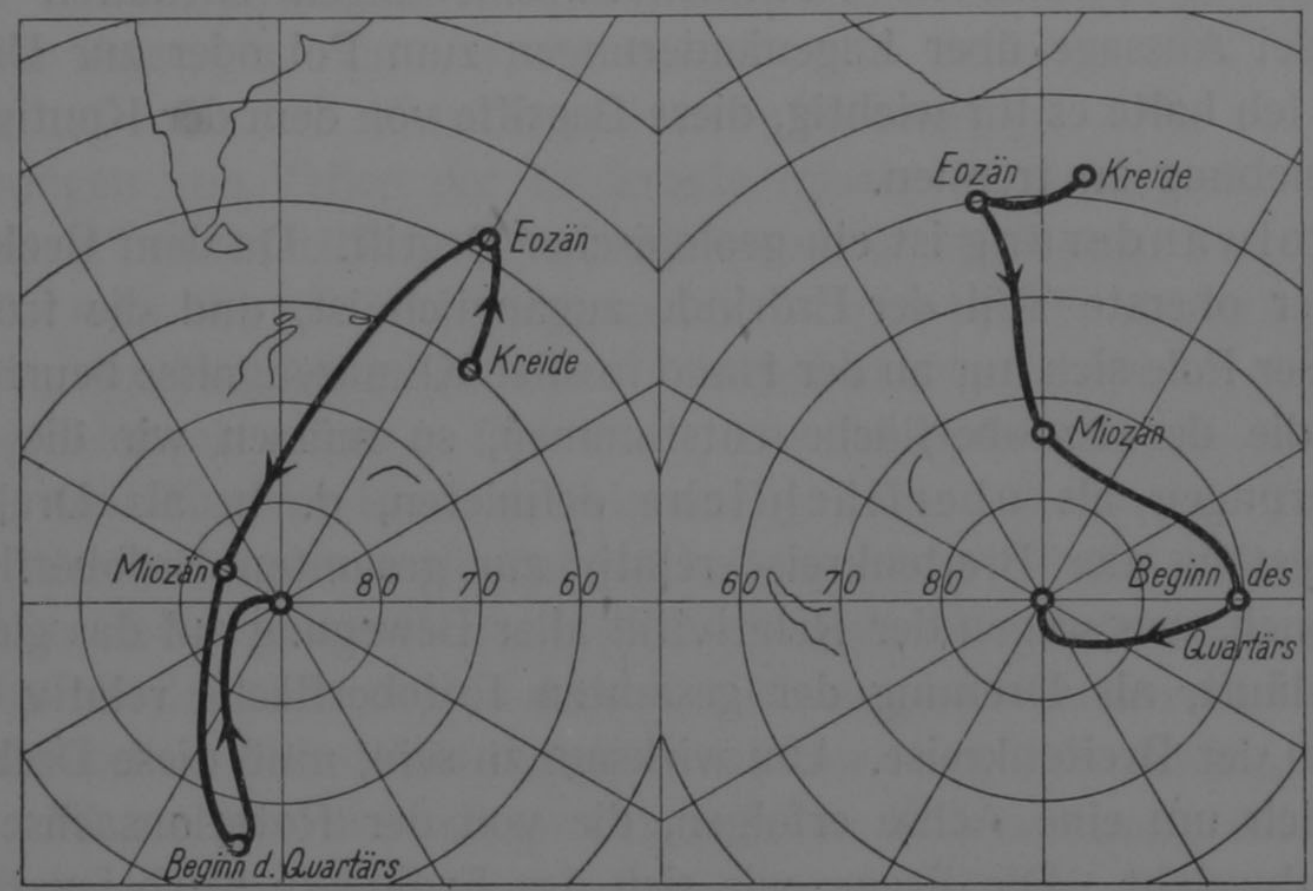

Wanderung des Südpols seit der Kreide; links bezogen auf Südamerika, rechts bezogen auf Afrika.

eingraviert, so wird es zur Zeit 2 infolge der Kontinentverschiebungen deformiert erscheinen. Suchen wir nun dasjenige nicht deformierte Gradnetz, das sich dem deformierten möglichst eng anschmiegt ${ }^{1}$ ), so stellen dessen Pole die ,unveränderten“ Pole für die Zeit 2 dar, und der Vergleich mit den wirklichen, aus den fossilen Klimazeugen abgeleiteten Polen zur Zeit 2 ergibt dann den Betrag der Polwanderung zwischen 1 und 2 .

Dies wäre die absolute oberflächliche Polwanderung. Wegen der genannten Schwierigkeit ist noch kein Versuch zu ihrer Be-

1) Auf die mathematische Bedingung hierfür brauchen wir hier nicht einzugehen. 
stimmung gemacht, man hat sich vielmehr stets begnügt, relative oberflächliche Polwanderungen anzugeben, d. h. diese relativ zu einem beliebig gewählten Kontinent zu bestimmen. Köppen und der Verfasser [151] haben hierzu wieder den Kontinent Afrika benutzt und also die Polwanderung relativ zu Afrika beschrieben. Wählt man einen anderen Kontinent als Bezugskontinent, so wird natürlich die Polwanderung ganz anders. Nur wenn es keine Kontinentverschiebungen gäbe, würde man bei jeder beliebigen Wahl immer die gleiche Polwanderung, nämlich die absolute, finden. Wie verschieden die relative Polwanderung infolge der Kontinentverschiebung je nach der Wahl des Bezugskontinents ausfällt, möge Abb. 38 erläutern, welche dieselbe Polwanderung seit der Kreide, bezogen einmal auf Afrika und andererseits auf Südamerika, darstellt.

Auch die heutige Polwanderung, wie sie neuerdings aus den Beobachtungen des Internationalen Breitendienstes abgeleitet ist, läßt sich nur auf die Erdoberfläche beziehen. Es ist ein Markstein in der Entwicklung unserer Kenntnisse der Polbewegungen der Erde, $\mathrm{daß}$ es vor kurzem gelungen ist, diese heutige fortschreitende Polwanderung abzuleiten, nachdem man bis dahin immer nur periodische Schwankungen um eine unveränderte Mittellage des Pols feststellen konnte. 1915 leitete Wanach zuerst eine Verlagerung dieser Mittellage $a b$, konnte sie aber wegen ihres damals noch sehr geringen Betrages noch nicht für verbürgt halten $\left.{ }^{1}\right)$. Den ersten zahlenmäßig einwandfreien Nachweis brachte Lambert 1922, und vor kurzem hat Wanach [208] eine neue Ableitung der Polwanderung auf Grund der Beobachtungen des Breitendienstes von 1900,0 bis 1925,9 gegeben. Wir geben in Abb. 39 eine der Abbildungen Wanachs wieder, die die Dimensionen gut veranschaulicht. Die totale Polbewegung besteht bekanntlich in einer kreisähnlichen, bald mit größerem, bald mit kleinerem Radius vor sich gehenden Bewegung des Rotationspols um den Trägheitspol. Um die Abbildung nicht unübersichtlich zu machen, hat Wanach von dieser totalen Polbewegung nur drei Bruchstücke eingezeichnet, nämlich das mit besonders kleinem Radius von 1900,0 bis 1901,2, das mit sehr großem Radius von 1909,9 bis 1911,1 und wieder das mit kleinem Radius von 1924,7 bis 1925,9. Der Trägheitspol der Erde, der immer die

1) Schon 1912 habe ich in Petermanns Mitteilungen (S. 309) darauf hingewiesen, daß man mit dem Auge, das ja für Symmetrieformen äußerst empfindlich ist, die systematische Verlagerung des Mittelpunktes der vom Pol beschriebenen Kurven erkennen könne. 
Mitte der Erscheinung bildet und durch eine Ausgleichsrechnung gefunden wird, hat sich dabei längs der in der Mitte gezeichneten schrägen kurzen Linie verschoben. Seine jährliche Bewegung, das ist die heutige jährliche Polwanderung, beträgt $14 \pm 2 \mathrm{~cm}$ oder $140 \mathrm{~km}\left(1,3^{\circ}\right)$ pro Jahrmillion, das ist mehr als die aus den geologischen Zeugnissen abgeleitete Polwanderung im Mesozoikum, aber weniger Abb. 39.

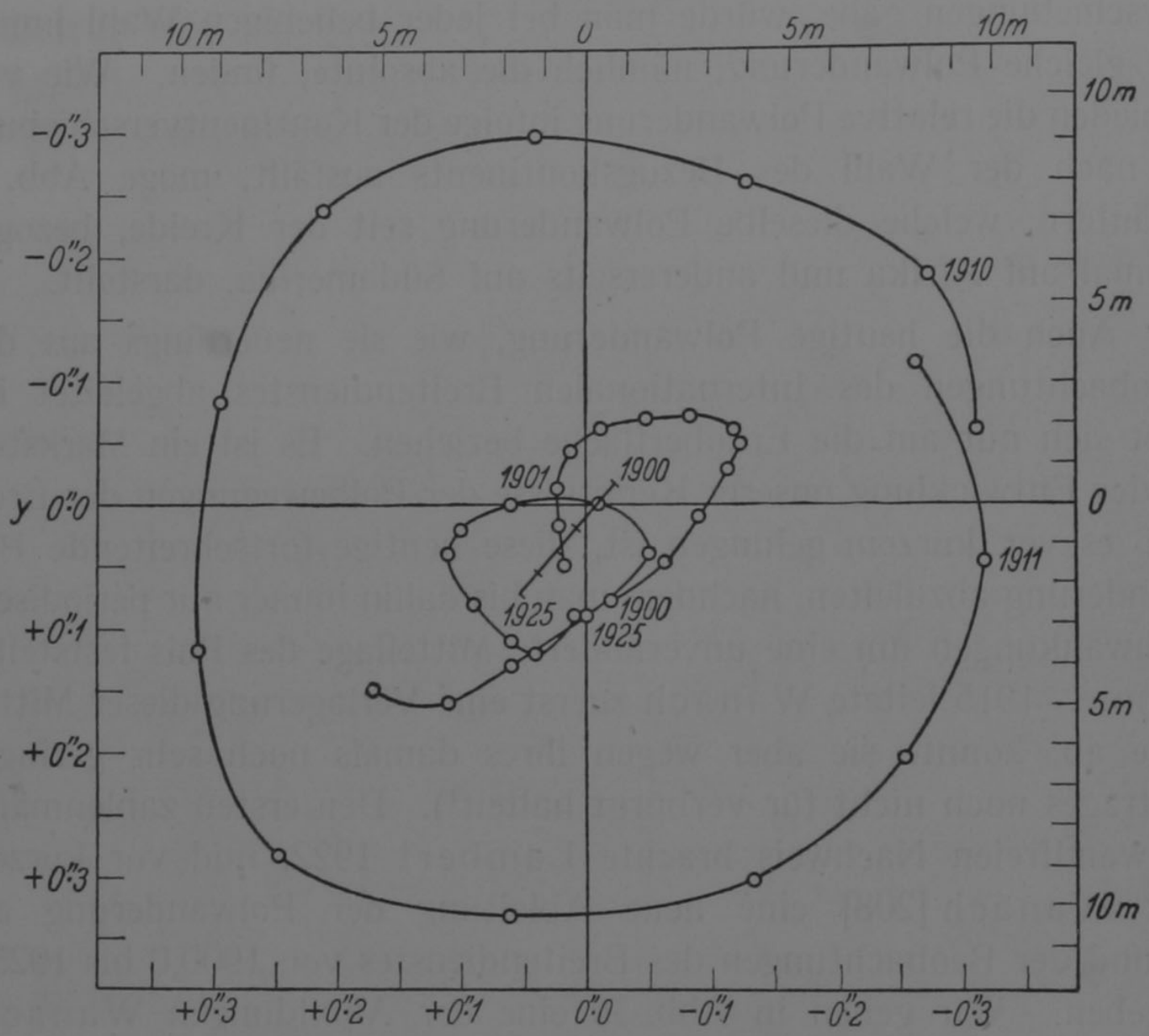

Polwanderung von 1900 bis 1925 nebst ausgewählten Stücken der vollständigen Polbewegung, nach Wanach.

als die im Tertiär. Bei gleichbleibender Geschwindigkeit und Richtung würde der Nordpol in 23 Millionen Jahren die Südspitze von Grönland erreichen.

Diese gegenwärtige Polwanderung entspricht begrifflich nicht der relativen Polwanderung, bezogen auf einen Einzelkontinent, sondern weit eher, wenn auch nicht vollkommen, der absoluten Polwanderung, die auf die ganze Erdoberfläche bezogen ist; denn die Breitenstationen sind um die ganze Erde herum verteilt. Immerhin ist $\mathrm{zu}$ beachten, daß zur Ableitung der absoluten Polwanderung strenggenommen Polhöhenmessungen von allen Punkten der Erd- 
oberfläche aus nötig wären, so daß uns der Internationale Breitendienst doch nur eine Annäherung an die absolute Polwanderung liefern kann. Genau würde sich die letztere nur dann ergeben, wenn die Stationen des Breitendienstes ihre gegenseitige Lage nicht durch Kontinentverschiebung veränderten. Daß sie dies aber tatsächlich tun, scheint aus dem von Schumann [220] hervorgehobenen Umstand hervorzugehen, daß sich bei der Ableitung der Polbahn Restfehler ergeben, die wegen ihres systematischen Charakters nicht als Beobachtungsfehler gedeutet werden können, deren Herkunft aber zunächst nicht ersichtlich ist.

Es ist meines Erachtens von großer Wichtigkeit, die Polwanderungen in der angegebenen Weise als oberflächliche zu definieren und auf diese Weise die Streitfrage, ob sie durch Verschiebung der Kruste über ihre Unterlage oder durch innere Achsenverlagerung entstehen, von der Feststellung ihrer Realität zu trennen. In der bisherigen Literatur ist das nicht geschehen, und die Folge davon sind Unklarheit und Verwirrung. Bisher werden Polwanderungen von den Geologen empirisch nachgewiesen (bzw. die heutige Polwanderung von den Geodäten aus den Breitenbestimmungen abgeleitet), manche Geophysiker bestreiten aus theoretischen Gründen ihre Möglichkeit, und eine dritte Klasse von Autoren macht den Vermittlungsvorschlag, sie bestünden nicht in inneren Achsenverlagerungen, sondern nur in Drehungen der Kruste über ihre Unterlage. Um aus den Unklarheiten herauszukommen, ist eine strengere Begriffsbildung nötig, und der erste Schritt dazu ist der, daß wir Polwanderungen als oberflächliche definieren; solche oberflächlichen Polwanderungen sind sowohl für die geologische Vorzeit wie für die Gegenwart nachgewiesen, und es hat also keinen Sinn, über ihre Möglichkeit zu diskutieren.

Unter Krustenwanderung und Krustendrehung wollen wir Bewegungen der Erdkruste relativ zu ihrer Unterlage verstehen. Das Wort Kruste enthält ja den Gegensatz zum Innern der Erde, so daß diese Definition eine naturgemäße ist. Anzeichen für solche Krustenwanderung über die Unterlage haben wir mannigfacher Art, doch gestatten diese Anzeichen nur eine Beurteilung der Verschiebungsrichtung, aber nicht der Größe.

Zunächst haben wir zahlreiche Anzeichen für eine Gesamtkrustendrehung, die nach Westen gerichtet ist, also um eine mit der Rotationsachse übereinstimmende Achse vor sich geht. Hierher gehört die Erscheinung, daß kleine Schollen relativ zu großen nach 
Osten zurückbleiben, wie die Randketten von Ostasien, die westindischen Inseln, der Südantillenbogen zwischen Kap Horn und Grahamsland, ferner das Umbiegen spitzer Kontinentalenden nach Osten, wie der Schelfgebiete des Sundaarchipels und Floridas, der Südspitze Grönlands und Feuerlands, der Nordspitze Grahamslands, ferner das Abbrechen Ceylons, das östliche Abwandern Madagaskars von Afrika und Neuseelands von Australien; und weiter ist der Zusammenschub der Anden zu nennen. Alle diese Erscheinungen fallen zwar zunächst unter den Begriff der Kontinentverschiebung; aber sie bezeugen eine systematische Verschiebung der Kontinentalschollen relativ $z u$ den neben ihnen liegenden Simamassen der Ozeanböden nach Westen und deuten deshalb an, daß sich die Kontinentalschollen wahrscheinlich auch relativ $\mathrm{zu}$ den unter ihnen liegenden Simamassen nach Westen verschieben, und da diese Anzeichen sich um die ganze Erde herum verfolgen lassen, werden sie zu einem Zeugnis für eine westwärts gerichtete Gesamtkrustendrehung. In der Tat wird von einer solchen Vorstellung ja in der heutigen Geophysik vielfach Gebrauch gemacht.

Andererseits bezeugen gewisse Erscheinungen auch eine partielle Krustenwanderung, namentlich eine solche zum Äquator hin gerichtete. Schon theoretisch ist eine solche zu erwarten wegen der Existenz der an den Kontinentalschollen angreifenden Polfluchtkraft. Das große tertiäre Faltensystem vom Atlas bis zum Himalaja bezeugt einen Zusammenschub in Richtung auf den damaligen Äquator, der nur durch Krustenwanderung über die Unterlage zustande kommen kann.

Alles dies sind indirekte Anzeichen. Ein mehr unmittelbares Zeugnis für Krustenwanderung über die Unterlage liefert die Schwereverteilung. Hierauf müssen wir etwas näher eingehen.

Wir geben in Abb. 40 eine von Kossmat [38] entworfene Karte der Schwerestörungen in Mitteleuropa wieder. Die wirklich beobachteten Schwerewerte sind, wie üblich, so reduziert worden, als wenn das ganze Relief der Erde bis zum Meeresniveau abgehobelt und die Messung in diesem Meeresniveau ausgeführt wäre, d. h. es ist außer der Reduktion auf das Meeresniveau auch noch der Einfluß der Massen oberhalb des letzteren vom Resultat abgezogen. Der so reduzierte Beobachtungswert ist dann mit dem für die betreffende geographische Breite gültigen Normalwert der Schwere verglichen und die Differenz, die Schwereanomalie, in der Abbildung dargestellt worden. Sie zeigt uns unmittelbar das Massendefizit unter dem 
Abb. 40 .

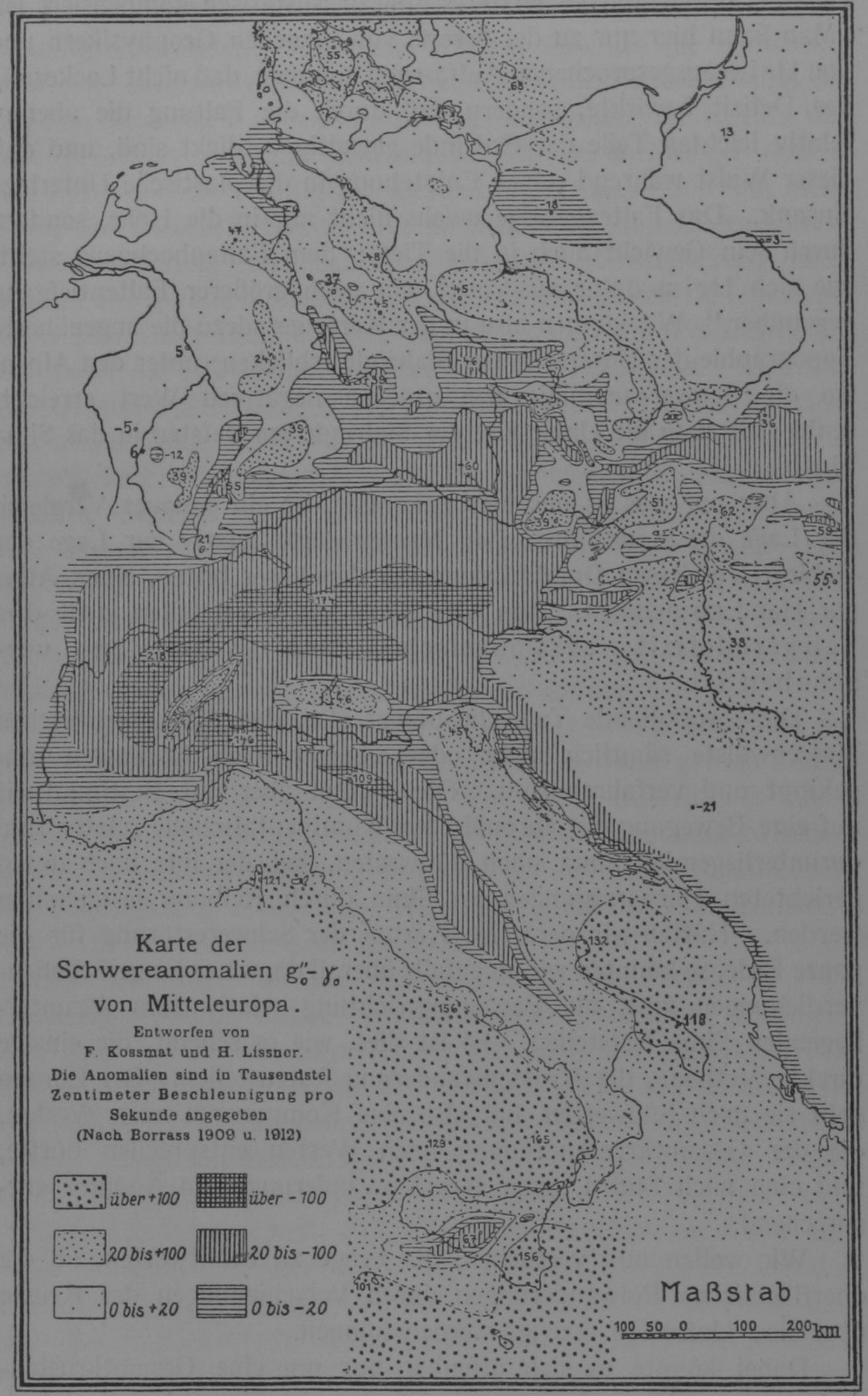


Gebirge, durch welches letzteres nahezu isostatisch kompensiert ist. „Man kann hier nur zu der bereits von manchen Geophysikern und von Heim ausgesprochenen Auffassung kommen, daß nicht Lockerung das Defizit bewirkte, sondern daß durch die Faltung die oberen, relativ leichten Teile der Erdrinde gewaltig verdickt sind, und daß dieser Wulst während seiner Entstehung in die plastische Unterlage einsank. Das Faltengebirge wuchs nicht nur in die Höhe, sondern durch sein Gewicht auch in die Tiefe: dem Faltenhochgang steht, wie sich Heim dafür ausdrückt, ein noch größerer Faltentiefgang gegenüber." Wir können also in der Karte geradezu die angenäherte Topographie der Unterseite der Sialrinde erblicken; unter den Alpen, wo die Schwereanomalie den größten negativen Wert erreicht, senkt sich auch die Unterseite der Sialrinde am tiefsten in das Sima hinab.

Aber auf was es uns hier ankommt, ist ein genauer Vergleich der Lage dieser unterirdischen Massenwülste relativ zur Lage der Gebirge, zu dessen Durchführung wir den Leser bitten, einen Atlas zur Hand zu nehmen. Man wird dabei leicht feststellen, daß das Schweredefizit systematisch nach Nordosten verschoben ist.

Diese auffallende Tatsache besagt also, daß die unterirdischen Massenwülste sämtlich mehr oder weniger nach Nordosten umgekippt und verfahren sind. Dies deutet aber mit Bestimmtheit auf eine Bewegung der europäischen Kontinentalscholle relativ zum darunterliegenden Sima nach Südwesten, bei der ihre nach unten gerichteten Hervorragungen im Sima durch Reibung festgehalten werden. Hätten wir derartige Karten der Schwerestörung für die ganze Erde, so könnten wir jedenfalls überall da, wo es junge Schollenverdickungen gibt, die Bewegungsrichtung relativ zum darunterliegenden Sima feststellen. Es ist dies, wie es scheint, die einzige direkte Methode, die Krustenwanderung festzustellen. Bei Europa geht sie nach Südwesten, hat also eine Komponente nach Westen, die der Gesamtkrustendrehung nach Westen entsprechen dürfte, und eine nach Süden, einer Krustenwanderung zum Äquator entsprechend.

Wir wollen nun versuchen, die Frage zu beantworten, ob die oberflächlichen Polwanderungen durch Verschiebungen der Kruste über ihre Unterlage erzeugt werden können.

Dabei könnte es sich offenbar nur um eine Gesamtkrustendrehung handeln, und zwar um eine von der Rotationsachse stark 
abweichende Achse. Die Beobachtungen deuten aber eine solche Gesamtkrustendrehung nur nach Westen, also um die Rotationsachse, an; man sollte meinen, daß eine Gesamtkrustendrehung, die um eine wesentlich andere Achse vor sich ginge, im Antlitz der Erde gleichfalls erkennbar sein müßte. Die Beobachtungen deuten also nicht auf die Richtigkeit dieser Lösung hin. Und wie steht es mit der Theorie? Sowohl eine partielle, zum Äquator gerichtete Krustenwanderung als auch eine Gesamtkrustenwanderung nach Westen, also gerade die beiden empirisch angedeuteten Bewegungen, lassen sich theoretisch stützen, nämlich durch die Polfluchtkraft und durch die Kräfte der Gezeiten und der Präzession. Aber für eine Gesamtkrustendrehung, die um eine von der Rotationsachse ganz abweichende. Achse vor sich gehen müßte, fehlt offenbar jede theoretische Erklärungsmöglichkeit. Der wohlgemeinte Vermittlungsvorschlag mancher Autoren, man könne die Polwanderungen durch eine Gesamtkrustendrehung erklären, entbehrt also sowohl von empirischer wie theoretischer Seite jeder Stütze. Es erscheint mir deshalb sehr unwahrscheinlich, daß er zutrifft. Wenn diese Lösung aber unbrauchbar ist, so bleibt zur Erklärung der oberflächlichen Polwanderungen nur die innere Achsenverlagerung.

Bei dem Worte Achsenverlagerung ist es nächstliegend, an eine Verlagerung der Achse innerhalb des sie auf ihrer ganzen Länge umgebenden Mediums zu denken. Wir wollen deshalb das Wort auch nur in diesem Sinne verwenden. Wir können dabei noch zwischen der inneren Achsenverlagerung im Erdkörper und der astronomischen Achsenverlagerung relativ zum Weltraum unterscheiden. Zunächst wollen wir nur von ersterer sprechen.

An die Frage, ob die nachgewiesenen oberflächlichen Polwanderungen durch innere Achsenverlagerung zustande kommen, kann man sowohl von theoretischer als auch, wie gezeigt werden wird, von empirischer Seite herantreten. Was die theoretische Seite betrifft, so ist von zahlreichen Autoren immer wieder behauptet worden, innere Achsenverlagerungen von der geforderten Größe seien unmöglich; um dies zu belégen, haben z. B. Lambert und Schweydar ausgerechnet, daß selbst eine Verschiebung Asiens um 45 Breitengrade nur eine Verlegung der Hauptträgheitsachse der Erde um 1 bis $2^{0}$ erzeugen würde. Es ist selbstverständlich, daß diese Behauptungen und Rechnungen so angesehener Geophysiker starken Eindruck bei den Geologen machen, die nicht in der Lage sind, die Voraussetzungen dieser Rechnungen $\mathrm{zu}$ prüfen und $\mathrm{zu}$ 
beurteilen. Und so haben diese Behauptungen zu einem beschämenden Zustand der Verwirrung geführt, dessen Beseitigung mir eine dringende Pflicht der theoretischen Geophysiker zu sein scheint.

Schon die Urteile so hervorragender Theoretiker wie Lord Kelvin, Rudzki, Schiaparelli sollten doch stutzig machen. Lord Kelvin schreibt [212]: „Wir können nicht nur zulassen, sondern sogar als höchst wahrscheinlich behaupten, daß die Achse größter Trägheit und die Rotationsachse, immer nahe beieinander, in alten Zeiten sehr weit von ihrer gegenwärtigen geographischen Position entfernt gewesen sein können, und daß sie nach und nach um 10, 20, 30, 40 oder mehr Grade gewandert sein können, ohne daß dabei jemals eine wahrnehmbare plötzliche Störung, sei es des Wassers oder des Landes, stattgefunden hat.“ Und ganz im gleichen Sinne schreibt Rudzki [15]: „Falls die Paläontologen einmal zu der Überzeugung kämen, daß in einer der vergangenen geologischen Epochen die Verteilung klimatischer Zonen auf eine von der gegenwärtigen ganz verschiedene Rotationsachse hinweist, so bliebe den Geophysikern nichts übrig, als dieses Postulat zu akzeptieren."

Etwas eingehender hat Schiaparelli [211] in einer wenig bekannten Schrift die Frage behandelt. Einen Auszug aus seinem Gedankengang hat W. Köppen [200] gegeben. Er behandelt dabei die drei Fälle einer völlig starren Erde, einer völlig flüssigen Erde und drittens einer solchen, die sich bis zu einem gewissen Grenzwert der Kräfte wie starr verhält, bei Überschreitung derselben aber zu fließen beginnt, und findet im Fall 2 und 3 unbegrenzte Achsenverlagerungen möglich.

Aber wie kommt es, daß andere Autoren zu einer so strikten Ablehnung von inneren Achsenverlagerungen gekommen sind? Die einfache Antwort hierauf lautet: weil sie die unrichtige Voraussetzung machen, daß bei diesen Vorgängen der äquatoriale $\mathrm{Ab}$ plattungswulst der Erde seine Lage unverändert beibehält! Alle Verneinungen der inneren Achsenverlagerung gehen von dieser nicht nur unbegründeten, sondern sicher unzulässigen Voraussetzung aus.

Machen wir diese falsche Voraussetzung, so ist auch ohne Rechnung klar, daß die Hauptträgheitsachse der Erde und damit auch die Rotationsachse ein für allemal festgelegt sind. Der Äquatorradius der Erde ist $21 \mathrm{~km}$ länger als der polare. Der äquatoriale Massenwulst stellt daher eine ungeheure Masse dar die um den Erd- 
äquator herum gelegen ist und dadurch der Erdachse ein Trägheitsmoment verschafft, das ungeheuer viel größer ist als die Trägheitsmomente, die zu den äquatorialen Durchmessern der Erde gehören. Auch die größten geologischen Veränderungen können doch nur zu Änderungen der Massenanordnung führen, die im Vergleich mit diesem Abplattungswulst von ganz verschwindender Größe sind. Bleibt letzterer also unverändert, so sieht man auch ohne Rechnung, daß die Hauptträgheitsachse der Erđe nur um ganz minimale Beträge geändert werden kann. Und die Rotationsachse muß ja stets in der Nähe der Hauptträgheitsachse bleiben.

Ich muß aber gestehen, daß es mir schwer verständlich ist, wie man heute im Ernst die Annahme machen kann, daß der äquatoriale Abplattungswulst seine Lage unverändert beibehalten sollte, als ob die Erde absolut starr wäre. Das Auftreten isostatischer Ausgleichsbewegungen und relativer Kontinentverschiebungen bezeugt zur Genüge, daß die Erde über einen endlichen Grad von Fließfähigkeit verfügt, und wenn dies der Fall ist, so muß auch der äquatoriale Abplattungswulst sich umorientieren können. Wir brauchen die Betrachtung von Lambert und Schweydar nur fortzusetzen: Nehmen wir an, der Trägheitspol sei (ohne Änderung des Abplattungswulstes) um einen geringen Betrag $x$ durch geologische Vorgänge verschoben worden. Der Rotationspol muß folgen. Die Erde rotiert jetzt um eine von der früheren ein wenig abweichende Achse. Die Folge muß sein, daß sich der Äquatorwulst umorientiert. Wegen der Zähigkeit des Erdinnern geschieht diese Umorientierung langsam, auch ist es möglich, daß sie nicht vollständig beendet wird, sondern vorher steckenbleibt; über letzteres wissen wir nichts. Als erste Näherung werden wir zweifellos annehmen müssen, daß eine vollständige Umorientierung erreicht wird, wenn auch erst nach langer Zeit. Ist sie aber erreicht, so haben wir wieder den gleichen Zustand wie nach Eintritt der geologischen Veränderung: die geologische Ursache wirkt wiederum und verschiebt den Hauptträgheitspol wieder um das Stück $x$ in gleicher Richtung, und das Spiel wiederholt sich in beliebig langer Folge. An Stelle einer einmaligen Verlagerung um den Betrag $x$ erhalten wir jetzt eine fortschreitende Verlagerung, deren Geschwindigkeit einerseits durch die Größe der Anfangsverlagerung $x$ und andererseits durch die Zähigkeit des Erdinnern bestimmt ist, und die nicht eher zur Ruhe kommt, als bis die geologische Ursache ihre Wirkung eingebüßt hat; bestand diese Ursache z. B. in dem Hinzufügen einer Masse $m$ 
irgendwo in mittleren Breiten, so kann die Achsenverlagerung erst dann erlöschen, wenn diese Zusatzmasse am Äquator angelangt ist, oder, besser gesagt, wenn der Äquator sie erreicht hat.

Natürlich bedarf das Problem einer eingehenden mathematischen Behandlung. Aber die vorstehende elementare Betrachtung ist meines Erachtens ausreichend, um zu zeigen, daß mit der Annahme eines unveränderlichen Abplattungswulstes ein fundamentaler Fehler gemacht wird, der zu einer völligen Entstellung des vorliegenden Problems führt. Es liegt nach meiner Meinung nicht der geringste theoretische Grund vor, an der Möglichkeit und Realität sehr großer, wenn auch langsamer innerer Achsenverlagerungen im Laufe der geologischen Zeiten zu zweifeln. Es wäre aber sehr zu wünschen, daß das Problem bald von theoretischer Seite mit einem brauchbaren Ansatz in Angriff genommen wird; so einfach wie bei der Annahme eines starren, unveränderlichen Abplattungswulstes wird freilich die Behandlung nicht sein können.

Man kann aber, wie schon erwähnt, auch auf empirischem Wege zu einem Urteil darüber gelangen, ob die oberflächlichen Polwanderungen durch Achsenverlagerungen erzeugt sind. Freilich sind die Wege, die sich hierzu bieten, indirekte und deshalb wenig sichere. Aber bemerkenswerterweise deuten sie, soweit sie bisher ein Urteil zulassen, alle auf eine Realität von inneren Achsenverlagerungen hin.

Zunächst sei an unsere Abb. 40 und die daraus abgeleitete südwestlich gerichtete Krustenwanderung Europas über seine Unterlage erinnert. Da die nach Nordosten verschleppten Sialwülste der europäischen Gebirge hauptsächlich im Laufe des Tertiärs nach unten gedrängt wurden, dürfen wir wohl annehmen, daß auch die nach Südwesten gerichtete Krustenwanderung Europas schon etwa seit Beginn der Tertiärperiode im Gange ist. Im Laufe der Tertiärperiode wuchs aber die geographische Breite Europas um etwa $40^{\circ}$, der Nordpol rückte Europa um diesen Betrag näher, während Europa gleichzeitig relativ zur Unterlage eine Verschiebung zum Äquator erlitt! Dies ist offenbar nur dann möglich, wenn eine innere Achsenverlagerung stattfand, deren Betrag sogar den für die Erdoberfläche berechneten etwas überstieg. Die einzige Möglichkeit, diesen Schluß zu umgehen, würde darin bestehen, daß man annimmt, die Verlagerung der Schweredefizite nach Nordosten in Europa datiere erst seit dem Quartär, und im Tertiär habe das Schweredefizit systematisch südöstlich der Gebirge gelegen. Dies 
ist vielleicht nicht ganz ausgeschlossen, erscheint mir aber doch wenig wahrscheinlich ${ }^{1}$ ).

Dazu kommt nun noch eine anderej empirische Prüfungsmöglichkeit, nämlich mit Hilfe der Transgressionswechsel.

$\mathrm{Da}$ interne Achsenverlagerungen wegen der Ellipsoidgestalt der Erde und der verzögerten Anpassung derselben an die neue Achsenlage, während das Meer sofort folgt, mit systematischen Transgressionswechseln verbunden sein müssen, haben schon zahlreiche Autoren, wie Reibisch, Kreichgauer, Semper, Heil, Köppen u. a., ausgesprochen. Abb. 41 erläutert dies: Da der Ozean bei der Umorientierung des .̈̈quatorwulstes sofort folgt, der Erdkörper aber nicht sofort, muß in dem Quadranten vor dem wandernden Pol zunehmende Regression oder Trockenlegung, in dem Quadranten hinter ihm zunehmende Transgression oder Überschwemmung herrschen. Da

Abb. 41 .

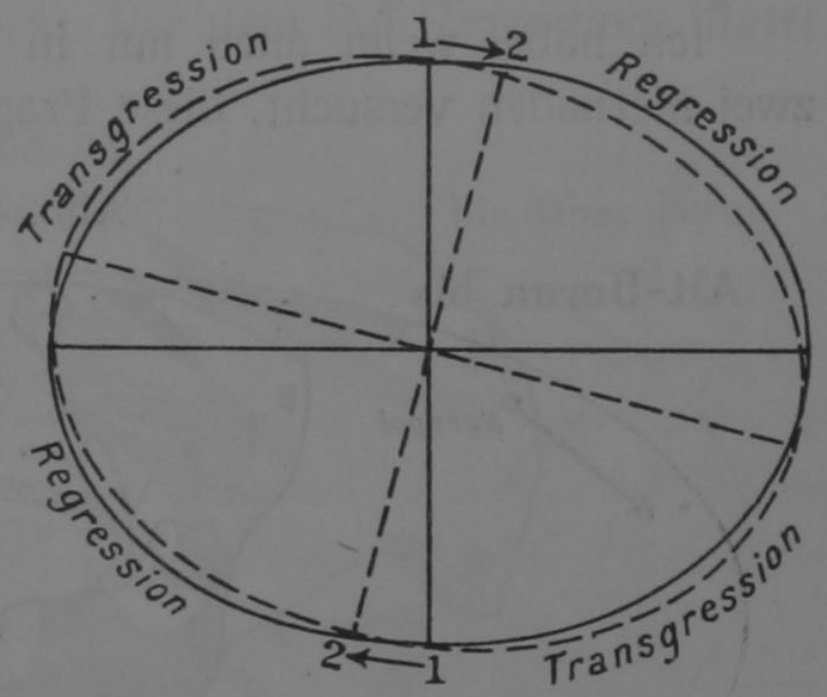

Trans- und Regressionen bei Polwanderung. der Äquatorradius der Erde um 21000 m größer ist als der polare, so müßte bei der etwa $60^{\circ}$ betragenden Polwanderung zwischen

$\left.{ }^{1}\right)$ Staub schreibt in seinem großen Werk über den Bau der Alpen [18; ähnlich auch in 215]: „Europa und Afrika wanderten gemeinsam nach N. Europa flieht von Afrika seit den Tagen des Perms, aber der gewaltige Koloß holt das kleine Europa schließlich im mittleren Tertiär ein, treibt die Böden des einstigen Ozeans zwischen Europa und Afrika als gewaltiges Gebirge über dasselbe hinaus und stößt es weiter nach N. Die Kontinentalverschiebung beträgt ...50 Breitengrade für Afrika und rund 35 bis 40 für Europa." Die Breitenänderung Europa als Kontinentverschiebung zu bezeichnen, ist eine entschiedene Begriffsverwirrung. Die Folge ist ein unbegründetes und höchst wahrscheinlich unrichtiges physikalisches Bild des Vorgangs, welches die beiden Annahmen involviert, daß 1. Europa und Afrika sich um die angegebenen Beträge über ihre Unterlage verschoben haben (Krustenwanderung Europas nach Norden, widerlegt durch die Schwereverteilung), und 2. keine innere Achsenverlagerung der Erde stattgefunden hat (unwahrscheinlich gemacht durch die systematischen Transgressionswechsel). Das Beispiel zeigt - und viele andere ließen sich hinzufügen - , wie wichtig im gegenwärtigen Stadium dieser Probleme eine scharfe Begriffsbestimmung ist. 
Karbon und Quartär, wenn sie von gleich großer interner Achsenverlagerung begleitet war, Spitzbergen um etwa $20 \mathrm{~km}$ aufgetaucht sein und Zentralafrika sich um einen ähnlichen Betrag unter den Meeresspiegel gesenkt haben, falls die Erde dabei ihre Form bewahrt hätte. Natürlich kann sie letzteres nicht getan haben, denn auf ihrer fließenden Umorientierung beruht ja überhaupt die Möglichkeit großer Achsenverlagerungen. Aber sie wird in ihrer Anpassung um einen Betrag in der Größenordnung von 100 m zurückgeblieben sein hinter der sofortigen Anpassung des Meeresspiegels, und dies müßte sich in den Transgressionswechseln zeigen.

Ich habe, wenn auch nur in vorläufiger Untersuchung, nach zwei Methoden versucht, diese Frage an der Hand des empirischen

Abb. 42.

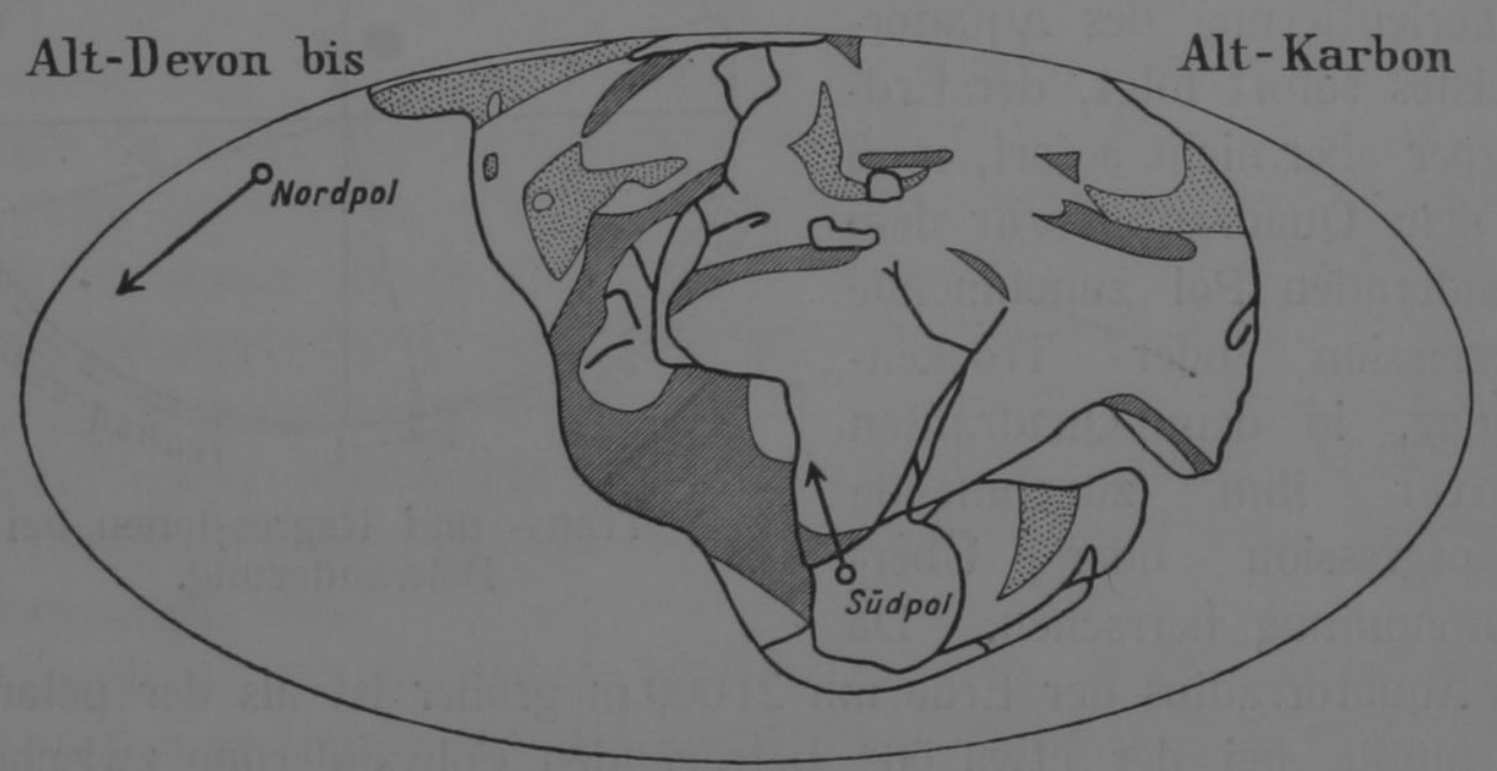

Transgression (punktiert), Regression (schraffiert) und Polwanderung zwischen Früh-Devon und Früh-Karbon.

Materials über die Transgressionswechsel zu beantworten, und es sei vorausgeschickt, daß beide Methoden zu einer Bestätigung interner Achsenverlagerungen in Verbindung mit den Polwanderungen $z u$ führen scheinen.

Die eine Prüfung besteht in einem Vergleich der Transgressionswechsel zwischen Devon und Perm mit der gleichzeitig erfolgten Polwanderung. Strenggenommen müßte man natürlich die wahre Polwanderung benutzen; aber die hier verwendete relative Polwanderung in bezug auf Afrika wird von ihr nicht sehr stark abweichen. Die größte Unsicherheit entsteht jedenfalls dadurch, daß die Lage und Ausdehnung der Transgressionsmeere für die verschiedenen 
Trägt man in die rekonstruierte Karbon-Erdkarte die Küstenlinien der Transgressionsmeere nach den üblichen paläogeographischen Darstellungen, z. B. von Kossmat oder L. Waagen, für die beiden Zeitpunkte des Früh-Devons und Früh-Karbons ein, so ergeben sich die in Abb. 42 dargestellten, in der Zwischenzeit untergetauchten und aufgetauchten Gebiete (nicht zu verwechseln mit den damals trocken liegenden bzw. unter Wasser liegenden Gebieten). In dieser Zeit rückte aber der Südpol von Antarktika nach Südafrika vor ${ }^{1}$ ), so daß Südamerika in den Quadranten ,,vor" dem wandernden Pol fällt. Der Nordpol dagegen entfernte sich von Nordamerika. Wir sehen also die Regel bestätigt: Vor dem Pol Regression, hinter dem Pol Transgression.

Abb. 43.

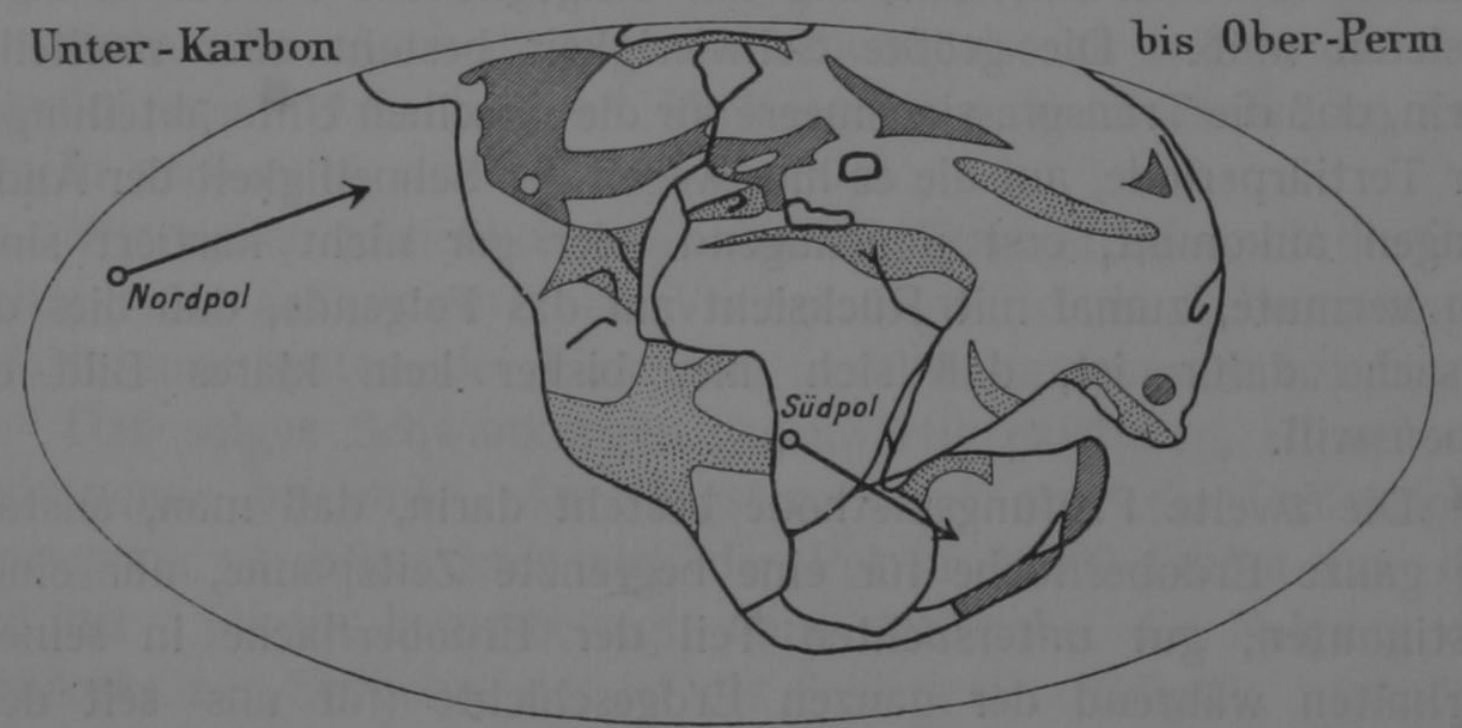

Transgression (punktiert), Regression (schraffiert) und Polwanderung zwischen Früh-Karbon und Spät-Perm.

In der Folgezeit, vom Früh-Karbon bis zum Spät-Perm, haben nun die Pole eine ganz andere Wanderungsrichtung: Der Südpol wandert von Südafrika nach Australien, der Nordpol nähert sich wieder Nordamerika. Die in diesem Zeitraum auftauchenden und untertauchenden Gebiete sind in Abb. 43 eingetragen, und man sieht wieder die Regel bestätigt, was um so wirkungsvoller erscheint, als sich die Verhältnisse sowohl in Nord- wie in Südamerika gerade umgekehrt haben.

1) Die Abbildungen sind auf Grund meiner älteren, vorläufigen Bestimmung der Pollagen entworfen. Die auf Grund vollständigeren Materials in Köppen-Wegener, Die Klimate der geologischen Vorzeit [151], abgeleiteten Pollagen sind etwas andere, doch ist der Unterschied nicht so groß, daß er unsere Schlußfolgerungen beeinträchtigt. Aus diesem Grunde wurde von einer Verbesserung der Abbildungen abgesehen. 
Diese Ergebnisse scheinen also zu zeigen, daß die Polwanderung vom Devon zum Perm tatsächlich mit einer Verlagerung der Erdachse im Erdinnern verbunden war.

Allerdings möchte ich nicht unerwähnt lassen, daß der Versuch einer Fortführung dieser Prüfung für die weiteren erdgeschichtlichen Perioden bisher nicht zu eindeutigen Ergebnissen geführt hat. Die nächsten Perioden der Erdgeschichte haben allerdings so unbedeutende Polwanderungen, daß sie schon aus diesem Grunde für eine solche Prüfung wenig geeignet erscheinen. Aber auch für die Tertiärzeit mit ihrer großen und raschen Polwanderung konnte ich bisher keine klaren Ergebnisse erhalten. Es ist möglich, daß man hier nicht mehr mit den von mir benutzten relativen Polwanderungen auskommt und die Untersuchung auf ausgeglichene Polwanderungen basieren muß. Die größte Schwierigkeit besteht aber zweifellos darin, daß die Transgressionsmeere für die einzelnen Unterabteilungen der Tertiärperiode, auf die es hier wegen der Schnelligkeit der Änderungen ankommt, erst ungenügend oder gar nicht kartiert sind. Ich vermute, zumal mit Rücksicht auf das Folgende, daß dies die Ursache dafür ist, daß sich hier bisher kein klares Bild ergeben will.

* Die zweite Prüfungsmethode besteht darin, daß man, anstatt die ganze Erdoberfläche für eine begrenzte Zeitspanne, nur einen bestimmten, gut untersuchten Teil der Erdoberfläche in seinem Verhalten während der ganzen Erdgeschichte (für uns seit dem Karbon) betrachtet und dabei seine Breitenänderungen mit den Transgressionswechseln vergleicht. Denn wenn die Regel: „Vor dem Pol Regression, hinter ihm Transgression“, gelten soll, so muß jede Breitenzunahme mit Regression, jede Breitenabnahme mit Transgression verbunden sein. Als Probe habe ich den bestbekannten Kontinent Europa benutzt. Für die Breitenänderung können wir die in Köppen-Wegener [151] für Leipzig abgeleiteten Zahlen benutzen (alles Nordbreiten):

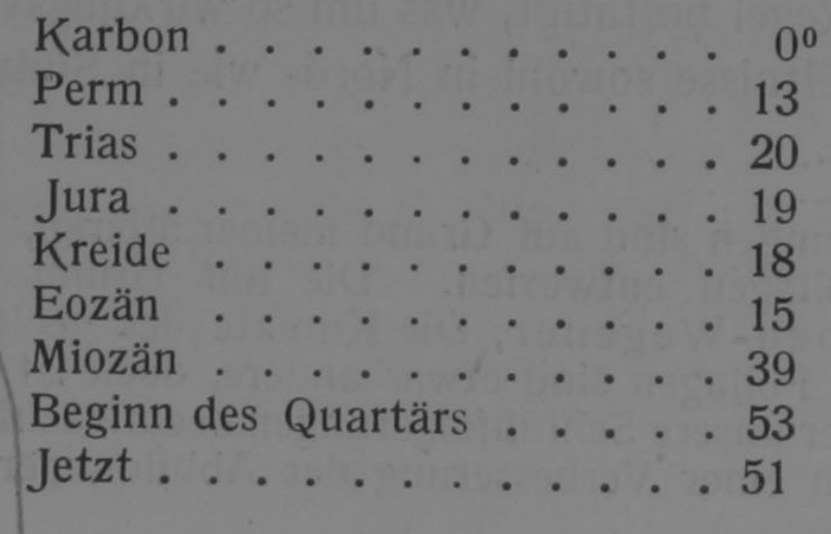


Die Breite nimmt also vom Karbon bis zur Trias zu, dann bis zum Eozän ab und von da bis zum Quartär wieder zu. Die größte Breite erreichte Leipzig wohl erst im mittleren Quartär.

Andererseits lehrt die Geologie, daß vom Karbon bis zum Beginn der Jurazeit im allgemeinen Regression in Europa herrschte; dann aber setzen große Transgressionen ein, die das Jurameer und Kreidemeer schaffen und noch bis zum Eozän einen großen Teil Europas unter Wasser halten. Und von da ab beginnt wieder eine auffallende Regression, die zur gänzlichen Trockenlegung Europas führte. Selbst der schließlichen geringen Breitenabnahme seit dem Quartär scheinen wieder gewisse Transgressionserscheinungen zu entsprechen. Jedenfalls stimmt in großen Zügen die Regel gut, was hier besonders ins Gewicht fällt, weil Europa der bestuntersuchte Kontinent ist. Auch diese Probe scheint also zu zeigen, daß Polwanderungen tatsächlich mit Verlagerungen der Erdachse im Erdinnern verbunden sind. -

Wir wollen schließlich noch kurz die Frage streifen, ob die Erdachse auch astronomische Verlagerungen, d. h. Schwankungen relativ zum System der Fixsterne, ausführt und ausgeführt hat.

$\mathrm{Da}$ B solche Schwankungen gegenwärtig existieren, ist aus der Astronomie bekannt. Am längsten kennt man die Präzessionsbewegung, vermöge deren sich der Pol in 26000 Jahren um den Pol der Ekliptik herumbewegt, ohne daß dabei die Neigung der Erdachse zur Erdbahn, das ist die Schiefe der Ekliptik, verändert wird. Die noch dazutretende kleine Nutationsschwankung kommt in diesem Zusammenhang wegen ihres geringen Betrages nicht in Betracht. Aber außerdem zeigen die Störungsrechnungen, daß auch die Schiefe der Ekliptik nahezu periodische Schwankungen im Ausmaß mehrerer Grade mit einer Periode von etwa 40000 Jahren ausführt, die trotz ihrer Kleinheit im Laufe des Quartärs in Verbindung mit entsprechenden Änderungen der Perihellänge und der Bahnexzentrizität von maßgebendem Einfluß bei der Entstehung der Wechselfolge von Eis- und Interglazialzeiten geworden sind.

Wir dürfen annehmen, daß diese Schwankungen der Ekliptikschiefe die ganze Erdgeschichte hindurch angedauert. haben und dabei auf das Klima von ähnlicher Wirkung gewesen sind wie in der Quartärzeit. Wenn man z. B. neuerdings bei der permokarbonen Vereisung Spuren wiederholter abwechselnder Vorstöße und Rückzüge des Eises gefunden hat, die sich wohl durch weitere Untersuchungen noch vermehren werden, so ist es sehr wahrscheinlich, 
daß bei ihrer Entstehung diese periodische Schwankung der Ekliptikschiefe von ähnlichem maßgebenden Einfluß gewesen sein wird wie bei den entsprechenden Schwankungen im Quartär. Auch hat man bereits die Vermutung ausgesprochen, daß die anscheinend periodischen Schwankungen der Sedimentablagerung mit dieser Schwankung der Ekliptikschiefe zusammenhängen.

Auf die Frage aber, ob etwa auch der Mittelwert, um den die Ekliptikschiefe in dieser Weise periodisch hin und her pendelt, im Laufe der Erdgeschichte größere Änderungen durchgemacht hat, kann uns die astronomische Störungsrechnung in keiner Weise Auskunft geben, und zwar aus zwei Gründen. Denn einerseits gehen in die Störungsrechnung die Massen sämtlicher Planeten des Sonnensystems ein, die nur bis zu einer gewissen Genauigkeitsgrenze bekannt sind, wodurch die Ausdehnung der Rechnung auf geologische Zeiten (mit Ausnahme der jüngsten, des Quartärs) illusorisch wird. Und zweitens ist die Erde nicht starr, wie bei der Störungsrechnung vorausgesetzt, sondern führt fließende Bewegungen aus, unterliegt Kontinentverschiebungen, Krustenwanderungen und wahrscheinlich auch inneren Achsenverlagerungen, alles Eigenschaften, die von großem Einfluß auf das Resultat sein müssen, deren rechnerische Berücksichtigung aber einstweilen ausgeschlossen ist. Von dieser Seite her können wir also keine weitere Auskunft erlangen.

Ich möchte aber aufmerksam machen auf eine Eigentümlichkeit der geologischen Klimate, die in diesem Zusammenhang von großem Interesse ist. Nachdem im Permokarbon im damaligen, auf dem Gondwanaland liegenden Südpolargebiet eine der heutigen mindestens gleiche Entwicklung von Inlandeis geherrscht hatte, finden wir die ganzen folgenden Zeiten, Trias, Jura, Kreide, hindurch bis zum Frühtertiär nirgends auf der Erde sichere Spuren von Inlandeis, obwohl meist wenigstens einer der Pole auf Land oder doch in Landnähe lag, und es somit an Gelegenheit zur Inlandeisbildung kaum gefehlt hätte. Und gleichzeitig finden wir ein erstaunlich weites Vordringen der Pflanzen- und Tierwelt gegen die Pole. Erst im Laufe der Tertiärzeit bildeten sich am Nordpol neue Inlandeismassen, die dann im Quartär ihre größte Ausdehnung erreichten. Diese Schwankungen des Polarklimas würden sich sehr gut durch die Annahme erklären lassen, daß auch der Mittelwert, um den die 40000 jährige Periode der Ekliptikschiefe hin und her geht, im Laufe der Erdgeschichte beträchtlichen Veränderungen unterworfen war, und zwar in der Weise, daß zu den Zeiten mit Inlandeis die Ekliptik- 
schiefe klein, zu den Zeiten ohne Eis und mit weitem Vordringen der Organismen groß gewesen wäre.

Es ist nämlich nicht schwer, sich die Wirkungen solcher Änderungen der Ekliptikschiefe auf das Klimasystem der Erde klarzumachen. Man braucht sich nur zu vergegenwärtigen, daß die Jahresschwankung der Temperatur wesentlich auf der Ekliptikschiefe beruht. Wird diese Null, steht also die Erdachse senkrecht auf der Erdbahn, so fällt bei der Kleinheit der Bahnexzentrizität die Jahresschwankung so gut wie ganz fort, und es herrscht überall auf der Erde das ganze Jahr hindurch zeitlich konstante Temperatur, wie heute nur in den Tropen. Im Polargebiet herrscht dann das ganze Jahr hindurch die dortige, sehr tiefe Mitteltemperatur; der Winter wird zwar wärmer als jetzt, aber die Temperatur bleibt doch dauernd unter dem Gefrierpunkt. Und der Sommer unterscheidet sich nicht von ihm. Pflanzenwuchs ist dann ausgeschlossen, da es im ganzen Jahre überhaupt keine Vegetationsperiode gibt. Die Pflanzenwelt wird also von den Polen weit abgedrängt, und ihr werden die Landtiere folgen müssen. Und weiter kann der Niederschlag, der das ganze Jahr hindurch in Form von Schnee fällt, nicht schmelzen, weil mit der Sommerwärme auch die Schmelzperiode fehlt. Er muß sich anhäufen und alles Land mit Inlandeis überschwemmen.

Wird andererseits die Ekliptikschiefe wesentlich größer als heute, so wächst auch die Jahresschwankung der Temperatur im Polargebiet gewaltig an. Der Sommer wird dort viel wärmer und gestattet daher den Pflanzen und mit ihnen der Tierwelt des Landes, das ganze Gebiet bis einschließlich zum Pol zu besiedeln, selbst hochstämmige Bäume könnten dort wachsen, wenn die Mitteltemperatur des wärmsten Monats über $+10^{\circ} \mathrm{C}$ steigt, denn die strenge Winterkälte können, wie Sibirien zeigt, manche Formen überstehen. Sommerniederschlag fällt als Regen, und der als Schnee fallende Winterniederschlag wird durch die Sommerwärme ohne Schwierigkeit geschmolzen, so daß sich wie in Sibirien auch bei tiefer Jahresmitteltemperatur doch kein Inlandeis bilden kann. Dabei wird aber auch die Jahresmitteltemperatur im Polargebiet, wenn auch nur in geringem Maße, erhöht, weil die stärkere Einstrahlung im Sommer nicht durch größere Ausstrahlung im Winter völlig kompensiert werden kann; denn wenn die Sonne erst einmal unter dem Horizont steht, ist es für die Strahlungsbilanz gleichgültig, wie tief sie unter ihm steht. Man wird also aus den Klimazeugnissen der Pflanzen- und Tierwelt des Landes aus solchen Zeiten 
den Eindruck einer Milderung der Klimaunterschiede zwischen Pol und Äquator bekommen müssen.

Die genannten paläoklimatischen Zeugnisse für derartige Schwankungen des Polarklimas im Laufe der Erdgeschichte bedürfen freilich noch durchaus weiterer Untersuchung. Auch ist zu beachten, daß sich für solche Schwankungen auch noch andere Ursachen finden lassen. Einstweilen erscheint es mir aber nicht unwahrscheinlich, daß sie reell sind, und daß sie sich am besten durch Änderungen der Ekliptikschiefe erklären lassen. Dadurch würden sie zu Anzeichen dafür, daß neben den bisher bekannten astronomischen Achsenänderungen der Erde noch weitere stattgefunden haben, die sich der astronomischen Berechnung entziehen.

\section{Neuntes Kapitel.}

\section{Die verschiebenden Kräfte.}

Die Ermittlung und Begründung der relativen Kontinentverschiebungen ist, wie die vorangehenden Kapitel gezeigt haben, auf rein empirischem Wege erfolgt, nämlich aus der Gesamtheit der geodätischen, geophysikalischen, geologischen, biologischen und paläoklimatischen Anzeichen, aber ohne irgend eine Annahme über die Ursache dieser Vorgänge. Dies ist der induktive Weg, den die Naturforschung in den weitaus meisten Fällen zu gehen genötigt ist. Die Formeln der Fallgesetze, der Planetenbewegung wurden zuerst auf rein induktivem Wege durch Beobachtungen ermittelt, und dann erst kam Newton, der nun diese Gesetze auch deduktiv aus der einen Formel der allgemeinen Gravitation abzuleiten lehrte. Dies ist der sich immer wiederholende normale Gang der Forschung.

Für die Verschiebungstheorie ist der Newton noch nicht gekommen. Man braucht wohl nicht zu besorgen, daß er ganz ausbleiben werde; denn die Theorie ist noch jung und wird heute noch vielfach angezweifelt, und man kann es schließlich dem Theoretiker nicht verübeln, wenn er zögert, Zeit und Mühe an die Aufklärung eines Gesetzes zu wenden, über dessen Richtigkeit noch keine Einigkeit herrscht. Aber es ist allerdings wahrscheinlich, daß die völlige Lösung der Kräftefrage noch lange auf sich warten lassen wird; denn sie bedeutet die Entwirrung eines ganzen Knäuels gegenseitiger Abhängigkeiten, wobei es manchmal schwer fallen wird, 
zu entscheiden, nach welcher Seite der Faden läuft, d. h. was Ursache und was Wirkung ist. Es ist ja von vornherein klar, daß für die Kräftefrage der ganze Komplex von Kontinentverschiebungen, Krustenwanderungen, Polwanderungen, internen und astronomischen Achsenverlagerungen ein zusammenhängendes Problem bildet.

Bisher ist erst eine einzige Teilfrage gelöst und über einige andere sind Vermutungen aufgestellt worden.

Für die Frage nach den Kräften sind zunächst jene Bewegungen von besonderem Interesse, die wir oben als Krustenwanderungen bezeichnet haben, d. h. Verschiebungen der Kontinentalschollen relativ zu ihrer Unterlage, da diese, wenigstens in der Mehrzahl der Fälle, als direkte Wirkung von Verschiebungskräften aufzufassen sind, die an den Kontinentalschollen angreifen, aber in dem darunterliegenden Material entweder gar nicht oder doch schwächer wirken.

Auf eine große Zahl von Einzelheiten, die von diesen beiden Bewegungen zeugen, war schon früher hingewiesen. Am unmittelbarsten fällt die Westwanderung der Kontinentalschollen im heutigen Kartenbild der Erde in die Augen. Die Polflucht ist bei älteren Bewegungen großenteils durch die heutige geänderte Pollage verschleiert und tritt erst nach Rekonstruktion der damaligen Pollage richtig hervor. Aber sie äußert sich schon in ganz großen Zügen durch die Aufspaltung der Kontinentalschollen in den Polargebieten und ihren Zusammenschub am Äquator. So war der permokarbone Vorstoß des Südpols nach Afrika begleitet von der karbonischen Faltung längs des damaligen Äquators und gefolgt von einer Zerspaltung und Auseinanderziehung des Gondwanalandes; und ganz ebenso war der tertiäre Vorstoß des Nordpols, der früher im Pazifik lag, in die Landmassen des heutigen Nordpolargebiets hinein begleitet von der tertiären Faltung längs des damaligen Äquators (Alpen-Himalaja) und wurde und wird noch gefolgt von einer zunehmenden Zerspaltung und Auseinanderziehung der Nordkontinente.

Die einzige Verschiebungskraft, die man gegenwärtig genauer kennt, ist die Polfluchtkraft, die bestrebt ist, die Kontinente relativ zu ihrer Unterlage äquatorwärts zu treiben. Ihre Existenz ist von Eötvös schon 1913 in einer freilich damals unbeachtet gebliebenen Bemerkung [199] ausgesprochen worden. Er machte nämlich in einer Diskussion darauf aufmerksam, „daß die Richtung der Vertikale in der Meridianebene gekrümmt ist, die konkave Seite dem Pol zugewendet, und daß der Schwerpunkt des schwimmen- 
den Körpers (das ist der Kontinentalscholle) höher liegt als der Schwerpunkt der verdrängten Flüssigkeitsmasse. Hieraus geht hervor, daß der schwimmende Körper der Wirkung zweier in verschiedener Richtung wirkender Kräfte unterworfen ist, deren Resultante vom Pol nach dem Äquator gerichtet ist. Bei den Kontinenten würde also eine Neigung vorherrschen, sich nach dem Äquator hin zu bewegen, welche Bewegung eine säkulare Änderung der Breite hervorrufen würde, wie dieselbe für die Sternwarte in Pulkowo vermutet wird."

Ohne diesen kurzen und versteckten Hinweis zu kennen, hat W. Köppen [200] die Natur der Polfluchtkraft und ihre Bedeutung

Abb. 44.

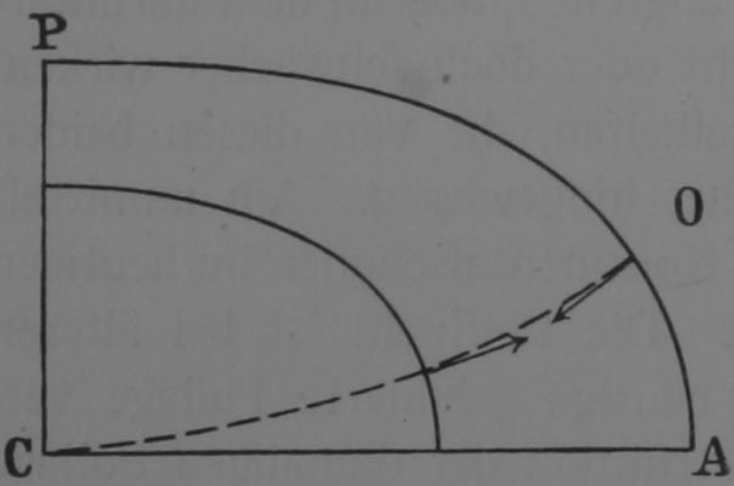

Zwei Niveauflächen und die gebogene Lotlinie. für die. Frage der Kontinentverschiebungen erkannt und, wenn auch ohne Rechnung, eine Beschreibung von ihr gegeben: ... „Die Abplattung der Niveauflächen nimmt also mit der Tiefe ab; sie sind einander nicht parallel, sondern ein wenig gegeneinander geneigt, außer am Äquator und an den Polen, wo sie alle rechtwinklig zum Erdradius sind. Die Abb. 44 zeigt dies an einem Meridianschnitt zwischen $\mathrm{Pol}(P)$ und Äquator $(A)$. Die gestrichelte, nach dem Pol zu konkave Linie ist die Kraftlinie der Schwere bzw. Lotlinie des Ortes O. C ist der Erdmittelpunkt.“

„Nun liegt ja der Angriffspunkt des Auftriebes eines schwimmenden Körpers im Schwerpunkt des verdrängten Mediums, der seines Gewichts dagegen in seinem eigenen Schwerpunkt, und die Richtung beider Kräfte ist rechtwinklig zur Niveaufläche des betreffenden Punktes; ihre Richtungen sind also nicht entgegengesetzt, sondern geben eine kleine Resultierende, die, wenn der Auftriebspunkt unter dem Schwerpunkt liegt, zum Äquator gerichtet ist. Beide Kräfte sind, da auch der Schwerpunkt der Scholle weit unter der Oberfläche der Scholle liegt, nicht senkrecht zum Horizont ihrer Oberfläche, sondern etwas in dieser Richtung geneigt, der Auftrieb aber mehr als das Gewicht der Scholle. Diese Sätze müssen für jeden Schwimmkörper gelten, dessen Schwerpunkt über dem Auftriebspunkt liegt, und ebenso müssen die Kräfte eine Resultierende zum 
punkt liegt; das archimedische Prinzip ist auf der rotierenden Erde nur dann strenge richtig, wenn beide Punkte zusammenfallen."

Die erste Berechnung der Polfluchtkraft hat P. S. Epstein [201] ausgeführt. Er findet dabei für die $\operatorname{Kraft} K_{\varphi}$ in der geographischen Breite $\varphi$ den Ausdruck

$$
K_{\varphi}=-3 / 2 m d \omega^{2} \sin 2 \varphi,
$$

wo $m$ die Masse der Kontinentalscholle, $d$ die halbe Höhendifferenz zwischen Tiefseeboden und Kontinentaloberfläche (oder gleich der Höhendifferenz der Schwerpunkte der Scholle und des verdrängten Simas) und $\omega$ die Winkelgeschwindigkeit der Erde ist.

Diese Gleichung benutzt er, um den Zähigkeitskoeffizienten $\mu$ der Simasphäre aus der Verschiebungsgeschwindigkeit $v$ der Kontinentalschollen zu berechnen (nach der allgemeinen Formel $K=\mu \frac{v}{M}$, wo $M$ die Mächtigkeit der zähflüssigen Schicht ist) und erhält

$$
\mu=\varrho \frac{s d M \omega^{2}}{v}
$$

wo $\varrho$ das spezifische Gewicht der Scholle und $s$ ihre Dicke ist. Indem er nun von folgenden Zahlenwerten ausgeht:

$$
\begin{aligned}
& \varrho=2,9 \\
& s=50 \mathrm{~km} \\
& d=2,5 \mathrm{~km} \\
& M=1600 \mathrm{~km} \\
& \omega=\frac{2 \pi}{86164} \\
& v=33 \mathrm{~m} \text { pro Jahr }
\end{aligned}
$$

findet er den Zähigkeitskoeffizienten des Simas zu

$$
\mu=2,9 \times 10^{16} \mathrm{~g} \mathrm{~cm}^{-1} \mathrm{sec}^{-1}
$$

also dreimal so groß wie den von Stahl bei Zimmertemperatur. Nimmt man, was wohl der Wahrheit näher kommt, $v=1 \mathrm{~m}$ pro Jahr an, so wird $\mu 33$ mal so groß, d. h. etwa gleich $10^{18}$. Epstein schließt hieraus:

„Wir können unsere Ergebnisse dahin zusammenfassen, daß die zentrifugalen Kräfte der Erdrotation eine Polflucht in dem von Wegener angegebenen Betrag erzeugen können und erzeugen 
müssen." Dagegen glaubt Epstein die Frage, ob auch die äquatorialen Faltengebirge auf diese Kraft zurückgeführt werden können, verneinen zu müssen, da diese nur einem Oberflächengefälle von 10 bis $20 \mathrm{~m}$ zwischen $\mathrm{Pol}$ und Äquator entspricht, während die Auftürmung der Gebirge zu Höhen von mehreren Kilometern und die entsprechende Versenkung sialischer Massen in große Tiefen eine bedeutende Arbeit gegen die Schwerkraft darstellt, für welche die Polfluchtkraft nicht reicht. Diese würde nur Berge von 10 bis 20 m Höhe schaffen können.

Fast gleichzeitig mit Epstein hat auch W. D. Lambert [202] die Polfluchtkraft mathematisch abgeleitet, im wesentlichen mit dem gleichen Ergebnis wie Epstein. Er findet die Kraft in $45^{\circ}$ Breite gleich einem Dreimillionstel der Schwere. Da die Kraft in dieser Breite ihren größten Betrag erreicht, so muß sie auf einen länglichen, schräg liegenden Kontinent auch drehend wirken, und zwar wird sie zwischen dem Äquator und $45^{\circ}$ Breite bestrebt sein, seine Längsachse in die Ostwestrichtung zu bringen, zwischen $45^{\circ}$ und dem Pol dagegen in die Meridianrichtung. „Alles dies ist natürlich ganz spekulativ; es basiert auf der Hypothese von schwimmenden Kontinentalschollen und auf der. Annahme eines tragenden Magmas, welches natürlich eine zähe Flüssigkeit sein wird, aber zäh im Sinne der klassischen Zähigkeitstheorie. Nach der klassischen Theorie wird eine Flüssigkeit, gleichviel wie zäh sie sei, ausweichen vor einer Kraft, gleichviel wie klein sie sei, sofern letzterer nur genügend Zeit gegeben ist, zu wirken. Die Eigentümlichkeiten des irdischen Gravitationsfeldes liefern uns sehr kleine Kräfte, wie wir gesehen haben, und die Geologen werden uns zweifellos gestatten, äonenlange Zeiten für die Wirkung dieser Kräfte anzunehmen, aber die Zähigkeit der Flüssigkeit kann von anderer Art sein, als die klassische Theorie fordert, so daß die wirkenden Kräfte erst einen gewissen Grenzbetrag überschreiten müssen, bevor die Flüssigkeit vor ihnen ausweicht, gleichgültig, wie lange die kleine fragliche Kraft wirken möge. Die Frage der Zähigkeit ist eine recht verwickelte, denn die klassische Theorie gibt für manche Beobachtungstatsachen keine angemessene Erklärung, und unsere gegenwärtigen Kenntnisse gestatten es uns nicht, sehr dogmatisch zu sein. Die Polfluchtkraft ist vorhanden, aber ob sie in geologischen Zeiten einen nennenswerten Einfluß auf die Position und Konfiguration unserer Kontinente gehabt hat, diese Frage müssen die Geologen entscheiden.“ 
Weiter hat auch Schweydar [40] die Polfluchtkraft berechnet. Er erhält für die Breite von $45^{0}$ etwa $1 / 2000 \mathrm{~cm} / \mathrm{sec}$, d. h. die Kraft beträgt etwa den zweimillionsten Teil des Gewichts der Schollen. „Ob diese Kraft zu einer Verschiebung ausreicht, ist nicht leicht zu entscheiden. Jedenfalls würde sie nicht eine Westwanderung erklären, da die Geschwindigkeit zu gering ist, um durch die Erdrotation eine merkliche westliche Ablenkung hervorzurufen."

An Epsteins Rechnung setzt Schweydar aus, daß die angenommene Verschiebungsgeschwindigkeit von $33 \mathrm{~m}$ pro Jahr zu groß sei, und daß die hieraus abgeleitete Zähigkeit des Simas erheblich zu klein sei. Aber wenn man die Geschwindigkeit kleiner nimmt, so bekommt man die geforderte größere Zähigkeit: „Nimmt man für den Zähigkeitskoeffizienten die Ordnung $10^{19}$ (statt wie Epstein $10^{16}$ ) an und macht die Voraussetzung, daß die von Epstein benutzte Formel hier anwendbar ist, so erhält man für die Geschwindigkeit einer Scholle in $45^{\circ}$ Breite etwa $20 \mathrm{~cm}$ pro Jahr. Immerhin muß es als möglich bezeichnet werden, daß die Kontinente unter der Einwirkung der Polfluchtkraft eine nach dem Äquator gerichtete Verschiebung erleiden."

Endlich haben Wavre [204] und Berner [203] eine neue Berechnung der Polfluchtkraft ausgeführt, die wohl die genaueste ist. Sie erhalten als Maximalwert der Polfluchtkraft, gültig für $45^{\circ}$ Breite, $1 / 800000$ des Gewichts der Schollen. „Das Verhältnis der verschiebenden Kraft zum Gewicht des Kontinents ist also außerordentlich klein; sie ist nicht imstande, Gebirge zu erzeugen, und erzeugt solche auch gegenwärtig nicht am Äquator."

„Aber die Dinge liegen anders, wenn sich $\mathrm{zu}$ diesem statischen Effekt ein dynamischer addiert."

„Der Widerstand des Simas hindert die Kontinente nicht, sich zu bewegen; und in dem Falle, wo zwei Kontinente sich am Äquator oder in anderen Breiten begegnen, müßte die lebendige Kraft, die ein jeder von ihnen einbüßt, in der einen oder anderen Form zurückgewonnen werden."

Wie es scheint, ist Kreichgauer der erste Entdecker der Polfluchtkraft. In der zweiten Auflage seines Buches „Die Äquatorfrage in der Geologie“ [5] hat er nämlich auf S. 41 eine schon von ihm im Jahre 1900 an anderer Stelle veröffentlichte Überlegung eingeschaltet, welche die Polfluchtkraft ergibt. In der ersten Auflage fehlt diese Ausführung.

Wegener, Kontinente und Ozeane. 4. Aufl. 
Ferner möchte ich erwähnen, daß auch M. Möller [205] im Jahre 1922 eine von ihm schon 1920 gefundene Ableitung der Polfluchtkraft veröffentlicht hat.

Wahrscheinlich läßt sich diese Literaturübersicht noch vermehren; ich habe nur angeführt, was mir zufällig zur Kenntnis gekommen ist.

Nehmen wir also mit Wavre und Berner an, daß die Polfluchtkraft etwa $1 / 800000$ des Gewichts der Kontinentalschollen beträgt, so ist immerhin zu beachten, daß dies etwa 15 mal so viel wie die horizontalen Flutkräfte ausmacht; und während letztere

Abb. 45 .

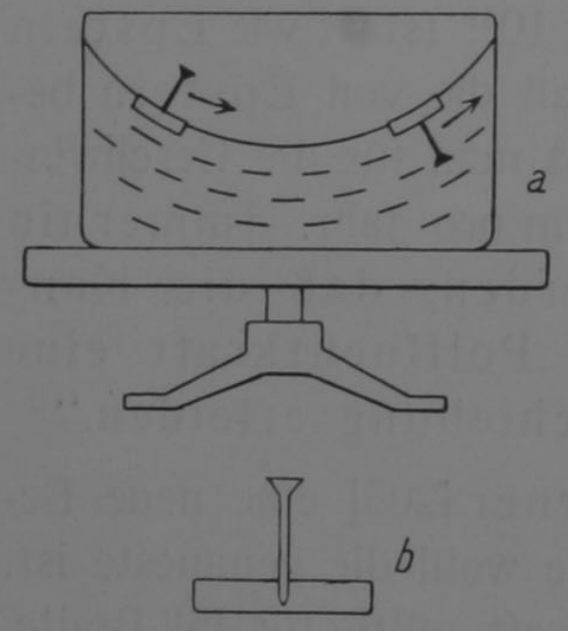

Lelys Versuch zur Erläuterung der Polfluchtkraft. ihre Richtung fortwährend ändern, wirkt die Polfluchtkraft Jahrtausend auf Jahrtausend in unveränderter Richtung und Stärke weiter. Dies ist es, was sie befähigt, die stählerne Zähigkeit des Erdkörpers im Laufe geologischer Zeiten zu überwinden.

Lely hat vor kurzem einen interessanten Versuch zur Demonstration der Polfluchtkraft gemacht [206]. Ich habe ihn gemeinsam mit J. Let z mann wiederholt, und wir fanden, daß er sich ausgezeichnet als Vorlesungsversuch eignet. Auf einen Rotationsschemel wird, recht genau zentriert, ein zylindrisches Wassergefäß gebracht, dessen Spiegel, wenn dasWasser gleichmäßig mitrotiert, eine paraboloidische Krümmung zeigt (Abb. $45 \mathrm{a}$ ). Nun wird ein Schwimmkörper auf diese Wasseroberfläche gesetzt, der aus einem flachen Kork mit in der Mitte eingestecktem Nagel besteht (Abb. 45b). Der Nagel muß möglichst lang sein, doch soll der Kork mit nach oben gerichtetem Nagel, ohne umzufallen, noch schwimmen können. Dieser Schwimmkörper wird nun zuerst mit dem Nagel nach oben und dann mit dem Nagel nach unten auf die Oberfläche des rotierenden Wassers gesetzt. Weist der Nagel nach oben, so sieht man den Schwimmer bald zur Mitte wandern; dagegen wandert er zum Rande, wenn der Nagel nach unten gerichtet ist. Wenn man den Schwimmer mehrmals nacheinander in umgedrehter Stellung auf das Wasser setzt, wobei er jedesmal seine Bewegungsrichtung ändert, so wirkt der Versuch sehr überzeugend. 
Die grundsätzliche Erklärung dieses Versuchs ist sehr einfach, wenn man sich vergegenwärtigt, daß der Schwerpunkt des Schwimmers nicht mit dem Schwerpunkt des von ihm verdrängten Wassers zusammenfällt, sondern bei aufrechtem Nagel oberhalb, bei abwärts gerichtetem unterhalb desselben liegt. Im Wasser herrscht, wie seine gekrümmte Oberfläche zeigt, ein radiales Druckgefälle, das durch die Zentrifugalkraft gerade kompensiert wird. Würde der Schwerpunkt des Schwimmers gerade mit dem des verdrängten Wassers zusammenfallen, so träte keine verschiebende Kraft auf, da sich dann auch für den Schwimmer der Druckunterschied auf der äußeren und inneren Seitenfläche gerade mit der Zentrifugalkraft kompensieren würde. Liegt sein Schwerpunkt aber, bei aufrechtem Nagel, nach oben und zwar senkrecht zum Wasserspiegel verschoben, so wird er dadurch zugleich der Achse genähert, die Zentrifugalkraft wird kleiner, und der Überschuß des Druckgradienten treibt den Schwimmer zur Mitte. Umgekehrt muß der Schwimmer bei abwärts gerichtetem Nagel zum Rande wandern, weil sein Schwerpunkt weiter von der Achse entfernt ist als der des verdrängten Wassers und jetzt also die Zentrifugalkraft über den Druckgradienten überwiegt.

Auf den ersten Blick scheint dieser Versuch gerade das Gegenteil der Polfluchtkraft zu liefern, weil die Kontinente mit ihrem höher gelegenen Schwerpunkt dem Schwimmer mit aufrechtem Nagel entsprechen. Man sieht aber leicht, daß diese Umkehrung des Effektes lediglich eine Folge der entgegengesetzten Krümmung der Flüssigkeitsoberfläche ist. Der Schwerpunkt der Kontinente liegt eben infolge der konvexen Krümmung der Erdoberfläche weiter von der Achse entfernt als der des verdrängten Simas, während im Versuch sein Achsenabstand verringert ist.

Wie aus dem Vorangehenden ersichtlich, ist die Polfluchtkraft ausreichend, um die Kontinentalschollen im Sima zu verschieben, doch nicht ausreichend, um die großen Faltengebirge zu erzeugen, die wir gerade in Verbindung mit der Polflucht der Kontinente entstehen sehen. Allerdings hat Berner mit Recht darauf hingewiesen, daß dies zunächst nur zutrifft, solange man den statischen Druck betrachtet, der durch eine nicht in Bewegung befindliche Kontinentalscholle vermöge der Polfluchtkraft in horizontaler Richtung ausgeübt wird. Anders liegen die Dinge, wenn wir z. B. annehmen, daß ein großer Kontinent sich vermöge der Polfluchtkraft, die dabei die Zähigkeit der Unterlage zu überwinden hat, 
mit gleichförmiger Geschwindigkeit äquatorwärts verschiebt und erst im Laufe dieser Bewegung auf ein Hindernis stößt, das ihn bremst. Dabei muß auch noch die Bewegung der Scholle zur Ruhe kommen, also ihre Bewegungsenergie (lebendige Kraft) vernichtet werden. Freilich darf man diese Wirkung nicht überschätzen. Die Bewegungsenergie ist 1/2 Masse mal dem Quadrat der Geschwindigkeit. Nun ist zwar die in Bewegung befindliche Masse sehr groB, allein die Geschwindigkeit, die quadratisch eingeht, ist sehr klein, so daß in der Regel auch auf diese Weise wohl die Gebirgsbildung nicht zu erklären ist, und es wohl dabei bleiben muß, daß die normale Polfluchtkraft hierfür nicht zur Erklärung ausreicht.

Seltsamerweise scheinen einige Geophysiker diesen Umstand als einen Einwand gegen die Verschiebungstheorie zu betrachten, was doch unlogisch ist. Denn an der Existenz der Faltengebirge kann ja nicht gezweifelt werden. Erfordern sie eine größere Kraft als die Polfluchtkraft, so ist also ihre Existenz ein Beweis dafür, daß im Laufe der Erdgeschichte, mindestens von Zeit zu Zeit, Verschiebungskräfte aufgetreten sind, die noch wesentlich größer waren als die Polfluchtkraft. Wenn aber diese schon ausreicht, um Verschiebungen der Kontinentalschollen zu bewirken, so müssen jene unbekannten gebirgsbildenden Kräfte doch um so mehr dazu imstande gewesen sein!

Weit kürzer können wir uns fassen bei der Besprechung der Kräfte, die für die Westwanderung der Kontinente in Betracht kommen. Verschiedene Autoren, wie E. H. L. Schwarz, Wettstein u. a., haben für eine Drehung der ganzen Erdkruste über den Kern nach Westen die Reibung der Gezeitenwelle in Anspruch genommen, welche durch die Sonnen- und Mondanziehung im festen Erdkörper erzeugt wird. Auch beim Monde wird ja vielfach angenommen, daß er früher eine schnellere Rotation besessen habe, aber durch die von der Erde erzeugte Gezeitenreibung gebremst sei. Es ist auch leicht einzusehen, daß diese Bremsung eines Weltkörpers durch Gezeitenreibung vornehmlich seine obersten Schichten betreffen und zu einem langsamen Gleiten der ganzen Kruste oder auch der einzelnen Kontinentalschollen führen muß. Es ist nur die Frage, ob derartige Gezeiten überhaupt existieren. Die Gezeitendeformation des festen Erdkörpers, die mit dem Horizontalpendel nachweisbar ist, ist nach Schweydar anderer, nämlich elastischer Art und kann also nicht unmittelbar zur Erklärung herangezogen werden. W. D. Lambert [221] meint aber: „Trotzdem können 
wir nicht glauben, daß die freie Schwingung völlig unbeeinflußt vom Reibungswiderstand bleibt, obwohl sich dieser in den Beobachtungen nicht mit Sicherheit nachweisen läßt." Es ist in der Tat ganz fraglos, daß wir die Erde nicht als vollkommen elastisch gegenüber den Flutkräften betrachten können. Es müssen also neben den elastischen, meßbaren Gezeiten auch fließende Gezeiten vorhanden sein, die zwar unmeßbar klein sind, weil die Periode der Gezeiten gegenüber der Zähigkeit des Magmas zu kurz ist, deren Flutreibungswirkung aber im Laufe geologischer Zeiten sich aufsummiert und schließlich beträchtliche Verschiebungen der Erdkruste bewirken kann. Meines Erachtens kann man jedenfalls diese Frage noch nicht damit als erledigt betrachten, daß die elastische Natur der meßbaren täglichen Gezeiten in der festen Erde nachgewiesen ist.

Auf einem anderen Wege, der aber auch auf die Anziehung von Sonne und Mond hinausläuft, nämlich auf Grund der Präzessionstheorie der Erdachse, kommt Schweydar auf eine Kraft, welche eine Westwanderung der Kontinente bewirken kann [40]: „Die Theorie der Präzession der Rotationsachse der Erde unter dem Einfluß der Anziehung von Sonne und Mond ist unter der Voraussetzung bekannt, daß die einzelnen Teile der Erde keine größere Verschiebung gegeneinander ausführen können. Die Berechnung der Bewegung der Erdachse im Raume wird schwieriger, wenn man die Verschiebung der Kontinente zuläßt. In diesem Falle muß man unterscheiden zwischen der Rotationsachse des Kontinents und der ganzen Erde. Ich habe berechnet, daß die Präzession der Umdrehungsachse eines Kontinents, der zwischen den Breitengraden -30 und $+40^{\circ}$ und den Meridianen 0 und $40^{\circ}$ westlicher Länge liegt, etwa $220 \mathrm{mal}$ größer als die der Achse der gesamten Erde ist. Der Kontinent hat das Bestreben, um eine Achse zu rotieren, die von der allgemeinen Rotationsachse abweicht. Hierdurch entstehen Kräfte, die nicht nur in meridionaler Richtung, sondern auch in westlicher Richtung wirken und den Kontinent zu verschieben suchen; die meridionale Kraft wechselt im Laufe des Tages ihre Richtung und kommt bei unserem Problem nicht in Frage. Diese Kräfte sind bedeutend größer als die Polfluchtkraft. Die Kraft ist am stärksten am Äquator, sie ist Null auf den Breitenkreisen $\pm 36^{\circ}$. Eine genauere Beschreibung des Problems hoffe ich später geben zu können. Hierdurch wäre auch eine westliche Verschiebung der Kontinente möglich." - Wenn es sich auch hier 
nur um eine vorläufige Mitteilung handelt (die angekündigte endgültige ist leider noch immer nicht erschienen), so scheint es doch sehr wahrscheinlich zu sein, daß die am deutlichsten erkennbare allgemeine Bewegung der Kontinente, ihre Westwanderung, sich aus den Anziehungswirkungen der Sonne und des Mondes auf die zähflüssige Erde erklären läßt.

Schweydar ist aber der Ansicht, daß auch die aus den Schweremessungen zu schließenden Abweichungen der Erdfigur vom Rotationsellipsoid Anlaß zu Fließbewegungen im Sima und damit auch zu Kontinentverschiebungen geben können: „Man kann aber auch eine Strömung des Simas, wenigstens in früheren Epochen, vermuten. Helmert hat in seiner letzten Arbeit aus der Schwerkraftverteilung auf der Erdoberfläche gefolgert, daß die Erde ein dreiachsiges Ellipsoid ist; der Äquator bildet eine Ellipse. Die Differenz der Achsen dieser Ellipse beträgt nur $230 \mathrm{~m}$; die große Achse schneidet die Erdoberfläche in $17^{\circ}$ westl. Länge (Atlantischer Ozean), die kleine Achse in $73^{\circ}$ östl. Länge (Indischer Ozean). Nach den Theorien von Laplace und Clairaut, über die wir in der Geodäsie nicht hinausgekommen sind, wird die Erde wie eine Flüssigkeit gebaut betrachtet, d. h. der Druck in der festen Erde (abgesehen von der Erdrinde) wird von der Natur des hydrostatischen Druckes angenommen. Von diesem Gesichtspunkt aus ist das Helmertsche Ergebnis unverständlich. Die hydrostatisch gebaute Erde kann bei ihrer Abplattung und Rotationsgeschwindigkeit kein dreiachsiges Ellipsoid sein. Man könnte nun annehmen, daß die Abweichung von einem Rotationsellipsoid durch die Kontinente hervorgerufen wird. Dies ist aber nicht der Fall. Ich habe die Rechnung unter der Voraussetzung, daß die Kontinente schwimmend gelagert sind und die oben angeführte Dicke [200 km; Dichtedifferenz zwischen Sial und Sima 0,034 (Wasser =1)] haben, durchgeführt und gefunden, daß die Verteilung der Kontinente und Meere eine Abweichung der mathematischen Erdgestalt von einem Rotationsellipsoid hervorruft, die bedeutend kleiner ist als die von Helmert gefundene. Außerdem liegen die Achsen der äquatorialen Ellipse völlig anders als bei Helmert; die große Achse fällt in den Indischen Ozean. Es müssen also größere Teile der Erde Abweichungen von dem hydrostatischen Bau haben.“

„Nach meiner Rechnung kann das Helmert sche Ergebnis erklärt werden, wenn eine $200 \mathrm{~km}$ dicke Simaschicht unter dem Atlantischen Ozean um 0,01 dichter ist als unter dem Indischen Ozean. Ein solcher 
Zustand kann sich auf die Dauer nicht halten, und das Sima wird das Bestreben haben, zu strömen, um den Gleichgewichtszustand des Rotationsellipsoids herzustellen. Bei dem geringen Dichteunterschied wird wohl kaum eine Strömung möglich sein, aber die Elliptizität des Äquators und die Dichteunterschiede im Sima und somit die Strömung können in früheren Epochen bedeutender gewesen sein."

Es ist ohne weiteres klar, daß die aus Helmerts Ergebnis abzuleitenden Kräfte dazu dienen können, die Öffnung des Atlantischen Ozeans verständlich zu machen, da gerade hier die Erde aufgewölbt erscheint und die Massen bestrebt sein werden, nach beiden Seiten auseinanderzufließen ${ }^{\mathbf{1}}$ ).

Es sei aber hier noch eine Überlegung angeführt, die man vielleicht als Weiterführung des bisherigen Gedankenganges betrachten darf. Solche Aufwölbungen der Erdoberfläche über ihre Gleichgewichtslage hinaus brauchen natürlich nicht nur auf den Äquator beschränkt zu sein, sondern können an jeder Stelle der Erde auftreten. Es war früher bei Besprechung der Transgressionen und ihres Zusammenhangs mit den Polwanderungen (in Kap. 8) gezeigt worden, daß wir vor dem wandernden Pol eine zu hohe, hinter ihm eine zu tiefe Lage der Erdoberfläche zu erwarten haben, und daß die geologischen Tatsachen das Vorhandensein dieser Abweichungen zu bestätigen scheinen. Auch hier handelt es sich um ähnliche Beträge, wie sie Helmert für den Überschuß der großen über die kleine Äquatorialachse gefunden hat, oder vielleicht um den doppelten Betrag. Bei schnelleren Polwanderungen scheint jedenfalls die Erdoberfläche vor dem Pol einige hundert Meter über, hinter ihm einige hundert Meter unter ihrer Gleichgewichtslage zu liegen. Das größte Gefälle (Größenordnung $1 \mathrm{~km}$ pro Erdquảdrant) würde im Meridian der Polverschiebung an dessen Schnittpunkt mit dem Äquator herrschen, ein fast ebenso großes auch an den beiden Polen. Hierdurch werden Kräfte frei, welche die Massen von den zu hohen nach den zu tiefen Gebieten hinziehen, und diese Kräfte sind ein Vielfaches der normalen Polfluchtkraft, die bei Kontinentalschollen ja nur einem Gefälle von 10 bis 20 m pro Erdquadrant entspricht. Diese Kräfte greifen nicht, wie die Polfluchtkraft, nur an den Kon-

1) Es sei aber darauf hingewiesen, daß neuerdings Zweifel daran laut geworden sind, daß die Erde wirklich ein dreiachsiges Ellipsoid ist. Heiskanen fand nämlich, daß dies Ergebnis nur durch ungünstige Kombination der Schweremessungen vorgetäuscht wird [219]. 
tinentalschollen, sondern auch an dem darunterliegenden Sima an, welches flüssiger ist und vielleicht den Ausgleich unter der starreren Kruste hinweg vollzieht. Allein solange das Gefälle besteht - und die Trans- und Regressionen scheinen von seiner Existenz Zeugnis abzulegen - , muß auch auf die Kontinentalschollen diese Kraft wirken, und sie muß daher auch Verschiebungen und Faltungen derselben bewirken können, wenn auch diese Bewegungen möglicherweise geringer sind als die entsprechenden Bewegungen des flüssigeren Materials unter ihnen. Ich möchte glauben, daß wir in dieser Deformation der Erdfigur durch Polwanderungen eine Kraftquelle haben, die völlig ausreicht, um die Faltungsarbeit zu leisten.

Besonders wahrscheinlich wird diese Deutung durch den schon oben erwähnten Umstand, daß die beiden größten hier in Betracht kommenden Faltensysteme, nämlich die äquatorialen Faltungen des Karbons und des Tertiärs, gerade in solchen Zeiten entstanden sind, in denen wir aus anderen Gründen besonders schnelle und ausgiebige Polwanderungen annehmen müssen.

Neuerdings wird von mehreren Autoren, wie Schwinner [69] und besonders Kirsch [70], Gebrauch gemacht von der Vorstellung von Konvektionsströmungen im Sima. Im Anschluß an Jolys Ansicht, daß unter den Kontinentalschollen infolge ihres großen Radiumgehalts eine Erwärmung des Simas, im ozeanischen Bereich eine Abkühlung eintritt, wird von dem letzteren Autor eine Zirkulation des Simas unter der Kruste angenommen: Es steigt unterhalb der Kontinente bis zu deren Untergrenze auf, fließt dann unter. ihnen zum ozeanischen Gebiet ab, um hier abzusinken und in größerer Tiefe wieder zum Kontinent zurückzukehren. Dabei soll es durch Reibung bestrebt sein, die Kontinentaldecke zu zerreißen und die Bruchstücke auseinanderzutreiben. Wir erwähnten schon früher, daß die relativ große Leichtflüssigkeit des Simas, die hier vorausgesetzt wird, von der Mehrzahl der Autoren bisher für unwahrscheinlich gehalten wird. Bei der Betrachtung der Erdoberfläche läßt sich aber nicht verkennen, daß die Aufspaltung von Gondwanaland und auch die der ehemaligen nordamerikanisch-europäisch-asiatischen Kontinentalscholle sich als Wirkung einer solchen Zirkulation des Simas auffassen läßt. Auch bietet diese anscheinend eine gute Erklärung für die Öffnung des Atlantischen Ozeans. Sie kann also nicht aus dem Grunde abgelehnt werden, weil die Erscheinungen der Erdoberfläche ihr widersprächen. Wenn sich die theoretische Grundlage dieser Vorstellungen als tragfähig erweist, was sich gegen- 
wärtig noch nicht überblicken läßt, so werden sie jedenfalls als mitwirkend bei der Gestaltung der Erdoberfläche in Betracht kommen.

Unsere Ausführungen werden dem Leser gezeigt haben, daß die Frage nach den Kräften, welche die Kontinentverschiebungen verursacht haben und verursachen, mit Ausnahme der bereits gut untersuchten Polfluchtkraft noch völlig in den Anfängen steckt.

Das eine darf aber als sicher angenommen werden: Die Kräfte, welche die Kontinente verschieben, sind dieselben, welche die großen Faltengebirge erzeugen. Kontinentverschiebungen, Spaltung und Zusammenschub, Erdbeben, Vulkanismus, Transgressionswechsel und Polwanderungen stehen untereinander zweifellos in einem großartigen ursächlichen Zusammenhang. Das zeigt schon ihre gemeinsame Steigerung in gewissen Perioden der Erdgeschichte. Was aber Ursache und was Wirkung ist, muß erst die Zukunft enthüllen.

\section{Zehntes Kapitel.}

\section{Ergänzende Bemerkungen über die Sialsphäre.}

Nachdem in den früheren Kapiteln die Hauptbeweisgründe für die Verschiebungstheorie besprochen sind, wollen wir diese nun als richtig voraussetzen und in diesem und dem folgenden Kapitel gewissermaßen als Anhang eine Reihe von Erscheinungen und Problemen besprechen, die immerhin so eng mit unserer Theorie verknüpft sind, daß eine Auseinandersetzung mit ihnen wünschenswert erscheint. Ich möchte betonen, daß diese Ausführungen mehr bezwecken, Fragen aufzuwerfen und Anregungen zu geben, als endgültige Lösungen.

Betrachten wir zunächst die Sialsphäre, die heute nur noch in Bruchstücken in Gestalt der Kontinentalschollen die Erde bedeckt.

In Abb. 46 ist zunächst eine Erdkarte der Kontinentalschollen gegeben. Da die Schelfe zu ihnen gehören, weichen diese Konturen an manchen Stellen erheblich von den bekannten Küstenlinien ab. Es ist für unsere Betrachtungen wichtig, sich von dem gewohnten Bilde der Erdkarte frei zu machen und eine gewisse Vertrautheit mit diesen Konturen der vollständigen Kontinentalschollen zu gewinnen. In der Regel gibt die 200-m-Tiefenlinie am besten den Rand dieser Tafeln wieder, doch erreichen einige Teile, die noch sicher zu den Kontinentaltafeln gehören, auch 500 m Tiefe. 
Es war schon früher gesagt, daß das Material dieser Kontinentalschollen hauptsächlich Granit sei. Es ist aber bekannt, daß die Kontinente an ihrer Oberfläche vielfach nicht aus Granit, sondern Sedi-

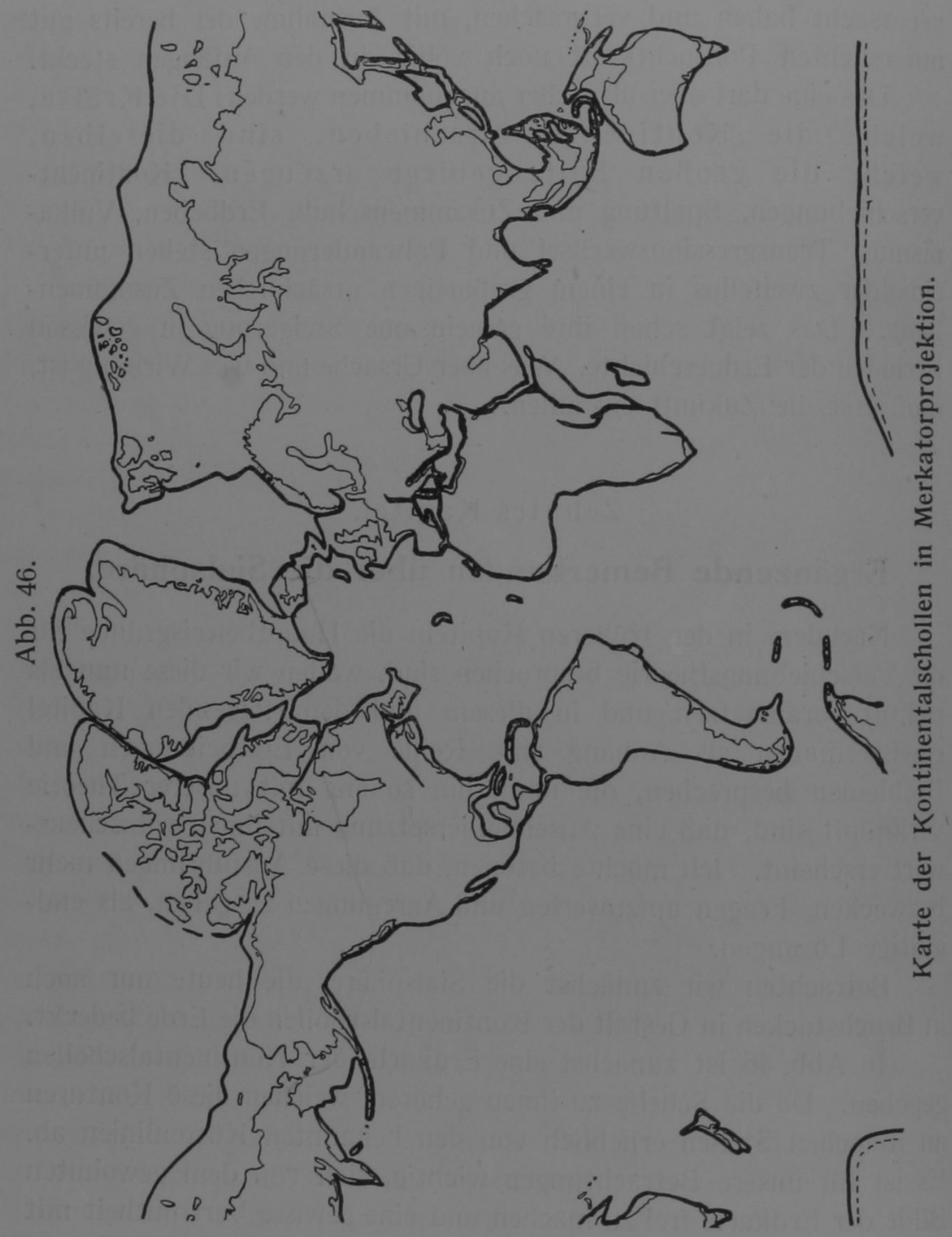

menten bestehen, und wir müssen uns deshalb darüber klar werden, welche Rolle diese im Aufbau der Kontinentalschollen spielen. Als größte Mächtigkeit der Sedimente kann man etwa $10 \mathrm{~km}$ betrachten, 
ein Wert, den die amerikanischen Geologen für die paläozoischen Sedimente der Appalachen berechnet haben; die andere Grenze ist Null, da an vielen Stellen das Urgebirge jeder Sedimentdecke bar ist. Clarke schätzt die mittlere Mächtigkeit auf den Kontinentalschollen zu 2400 m. Da aber heute die Gesamtdicke der Kontinentalschollen auf etwa $60 \mathrm{~km}$, die der Granitschicht auf etwa $30 \mathrm{~km}$ veranschlagt wird, so ist klar, daß diese Sedimentdecke doch nur eine oberflächliche Verwitterungsschicht bedeutet, bei deren völliger Entfernung überdies die Schollen zur Wiederherstellung der Isostasie fast bis zur früheren Höhe ansteigen würden, so daß am Relief der Erdoberfläche wenig geändert würde.

Die Karte darf nicht so verstanden werden, daß durch die mit der starken Linie bezeichneten Schollenränder bereits die Grenze zwischen Sial und Sima gegeben wäre. Wie im nächsten Kapitel gezeigt werden wird, sind auch die Meeresböden wahrscheinlich noch vielfach mit Sialresten bedeckt. Unter Kontinentalscholle ist hier die noch intakte, wesentlich unzertrümmerte Sialdecke verstanden, im Gegensatz zu jenen ozeanischen Sialmassen, die durch oberflächliche Zertrümmerung und in tieferen Schichten durch Auseinanderziehen oder -fließen des Materials der Form nach zerstörte Schollenteile darstellen. Man muß also unterscheiden zwischen dem allgemeineren Begriff der Sialbedeckung und dem spezielleren der Sialschollen. Nur die letzteren sind in unserer Karte zur Darstellung gebracht.

Die eingreifendsten Veränderungen, die auf diesen Sialschollen im Laufe der geologischen Zeiten vor sich gegangen sind, sind zweifellos die wechselnden Transgressionen (Überschwemmungen) und Regressionen (Trockenlegungen), deren Spiel wesentlich an den zufälligen Umstand geknüpft ist, daß die Wassermenge des Weltmeeres gerade etwas größer ist als die vorhandenen Tiefseebecken, so daß die niedriger gelegenen Teile der Kontinentalschollen noch unter Wasser liegen. Stände der Spiegel des Weltmeeres $500 \mathrm{~m}$ tiefer, so würden diese Erscheinungen, die in der Geologie eine so hervorragende Rolle spielen, auf schmale Randstreifen beschränkt sein. Die heutigen Transgressionen gehen aus unserer Karte unmittelbar hervor. Geringe Niveauänderungen der Schollenoberflächen bewirken unter diesen Umständen große Verlagerungen dieser Überschwemmungsgebiete.

Im allgemeinen handelt es sich hierbei um Niveauänderungen, die den Betrag von einigen hundert Metern nicht überschreiten. 
Die Transgressionsmeere der Vorzeit waren ebenso flach, wie die heutigen. Die Frage, wie sich diese nachweisbaren Niveauänderungen mit dem Prinzip der Isostasie oder dem Tauchgleichgewicht der Erdrinde vertragen, ist wahrscheinlich so zu beantworten: Natürlich entsteht, wenn eine Kontinentalscholle durch irgend einen Einfluß unter ihre Tauchgleichgewichtslage hinabgedrückt wird, hier ein Schweredefizit, welches Kräfte ins Leben ruft, die die Wiederherstellung der Gleichgewichtslage anstreben. Solange sich die Niveauänderung innerhalb der angegebenen Grenzen hält, bleibt übrigens auch die Schwereanomalie innerhalb der Grenzen, die tatsächlich in den verschiedenen Erdräumen als geringe regionale Abweichungen von der Isostasie beobachtet werden. Bei der großen Zähigkeit des Materials bedarf es offenbar der Überschreitung eines bestimmten Grenzwertes der Niveauänderung, damit die Kräfte so stark werden, daß merkliche isostatische Ausgleichsbewegungen einsetzen. Es ist deshalb möglich, daß dieser Betrag von einigen hundert Metern diesen Grenzwert - der natürlich nicht als absolut konstant betrachtet werden kann - ungefähr repräsentiert.

Die Klärung der Ursache der Transgressionswechsel in der Erdgeschichte wird eine der wichtigsten, aber auch eine der schwierigsten Aufgaben der künftigen geologischen und geophysikalischen Forschung darstellen. Gegenwärtig kann die Frage noch nicht als gelöst gelten, obwohl bereits beachtenswerte Anfänge wenigstens für Teillösungen vorliegen. Die Hauptschwierigkeit bildet dabei einstweilen der Umstand, daß die geologischen Aufnahmen - trotz der vielen paläogeographischen Erdkarten - noch lange nicht sicher und vollständig genug sind, um eine empirische Verfolgung dieser Transgressionswechsel nach Ort und Zeit zu gestatten, so daß das vorhandene Material meist nicht ausreicht, um die zur Erklärung herangezogenen Hypothesen zu prüfen. Außerdem läßt sich aber schon jetzt sagen, daß sich die Gesamtheit der Transgressionswechsel sicher nicht auf eine einzige Ursache zurückführen läßt, denn es lassen sich verschiedene Ursachen nennen, die mindestens als mitwirkend in Betracht kommen, so daß das Problem an sich zweifellos ein komplexes ist. Das schließt natürlich nicht aus, daß vielleicht künftig eine Ursache als Hauptfaktor erkannt werden kann.

Bisher lassen sich, soweit mir bekannt, folgende Ursachen anführen:

1. Ein merklicher Wechsel der Wassermenge des Weltmeeres, wie er durch Bildung und Abschmelzung großer Inlandeismassen 
bewirkt wird, muß natürlich zu einem Wechsel in der Ausdehnung der Transgressionen führen. Diese Transgressionswechsel müssen dadurch charakterisiert sein, daß sie gleichsinnig auf der ganzen Erde und ohne Störung der Isostasie vor sich gehen. Es läßt sich leicht berechnen, daß durch Bildung einer Eiskappe von der Ausdehnung der quartären oder permokarbonen eine Senkung des Meeresspiegels um etwa 50 bis $100 \mathrm{~m}$ bewirkt wird ${ }^{\mathbf{1}}$ ).

2. Hebungen und Senkungen der Sialoberfläche können auch ohne Störung der Isostasie durch horizontalen Zusammenschub (Gebirgsbildung) bzw. horizontale Streckung der Sialdecke (Bruchbildung an der Oberfläche, Ausziehen der tieferen Schichten) bewirkt werden. Dabei wird die Mächtigkeit der Sialdecke im ersten Falle vergrößert, im zweiten verringert. So sind die Alpen durch Faltung aus

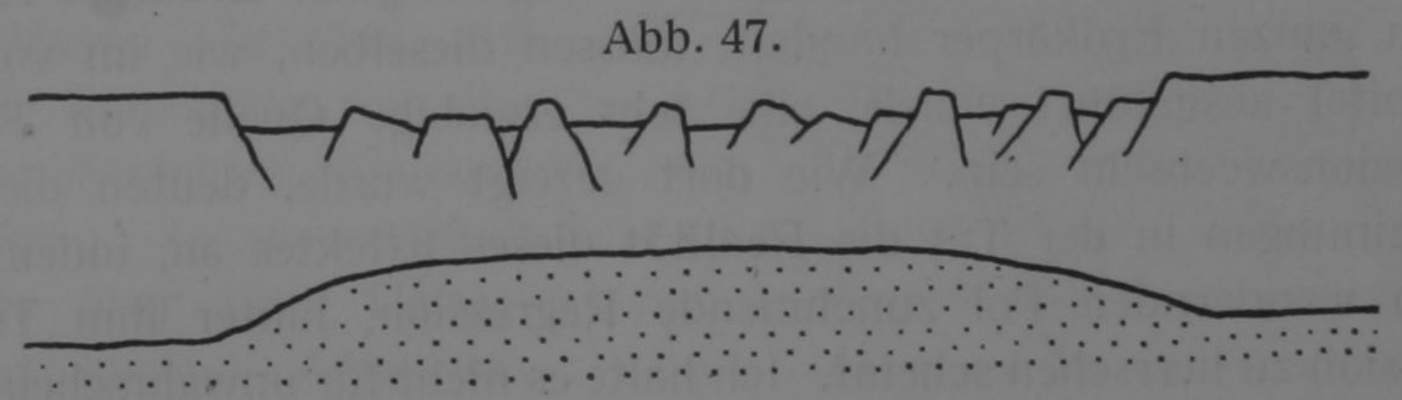

Größerer Einbruch durch Dehnung der Unterlage (schematisch).

dem Meere emporgewachsen, während das Gebiet des Ägäischen Meeres unter Bildung zahlreicher Brüche bis auf die Inselreste versunken ist (vgl. die schematische Abb. 47). Diese Vorgänge gehen - wenn auch lokal dabei mitunter recht erhebliche Schwerestörungen auftreten - doch grundsätzlich ohne Störung der Isostasie vor sich, wenigstens ohne eine solche, die dem Betrag der Hebung oder Senkung entspricht, sie sind ferner mit erheblichen Änderungen der horizontalen Dimensionen der betroffenen Gebiete verbunden und tragen für die großzügige Betrachtung mehr lokalen als regionalen Charakter.

3. Als weitere Ursachen kommen auch astronomische Änderungen der Erdbewegung in Frage, insbesondere solche, welche eine Änderung der Gleichgewichtsabplattung der Erde bewirken. Denn dieser letzteren Änderung wird der Ozean ohne Verzögerung, der sehr zähflüssige Erdkörper aber mit Verzögerung folgen, wodurch bei zunehmender Abplattung Transgressionen am Äquator und $\mathrm{Re}$ gressionen an den Polen, bei abnehmender umgekehrt Regressionen 
am Äquator und Transgressionen an den Polen entstehen müssen. Als Ursache solcher Abplattungsänderungen kämen unter anderem in Betracht Schwankungen der Rotationsgeschwindigkeit der Erde, wie sie neuerdings durch Beobachtungen festgestellt sind (aber ihre Deutung als solche ist noch ungewiß!), und weiter auch die Änderungen der Ekliptikschiefe; denn bei großer Ekliptikschiefe müssen die Gezeitenkräfte eine, wenn auch geringe Verlängerung der Erdfigur in Richtung ihrer Achse erzeugen, die bei kleiner Ekliptikschiefe in ihr Gegenteil, nämlich in eine Vergrößerung des Äquator-Radius übergeht, so daß bei wachsender Schiefe an den Polen Transgression, bei abnehmender Schiefe Regression zu erwarten ist, am Äquator umgekehrt.

4. Sofern die geologisch feststellbaren Polwanderungen so zu deuten sind, daß es sich um eine Verlagerung der Erdachse relativ zum ganzen Erdkörper handelt, müssen dieselben, wie im vorigen Kapitel ausgeführt wurde, eine sehr ergiebige Quelle von Transgressionswechseln sein. Wie dort gezeigt wurde, deuten die Erscheinungen in der Tat die Realität dieses Effektes an, indem vor dem wandernden Pol zunehmende Regression, hinter ihm Transgression zu herrschen scheint. Ich halte es nicht für unwahrscheinlich, daß sich diese Ursache als Hauptursache der Transgressionen erweisen wird, doch zeigt das Gesagte, daß daneben auch noch andere Ursachen in Betracht kommen, deren Zahl sich wohl sogar noch vermehren ließe.

Die unter 2. angegebenen Erscheinungen der Bruchdehnung und des Faltenzusammenschubs bilden neben den Transgressionswechseln die zweite Haupterscheinung bei den Kontinentalschollen. Sie bilden seit langem Gegenstand der Tektonik. Wir wollen hier nur einiges hervorheben, was in diesem Zusammenhang von Interesse ist. Am längsten bekannt ist, daß sich die Entstehung der Faltengebirge unter beträchtlichem horizontalen Zusammenschub vollzieht, wenngleich auch dies von einigen Autoren noch heute bestritten wird, die die Entstehung der Faltengebirge auf grundsätzlich andere Weise erklären wollen, aber mit ihrer Auffassung so allein stehen, daß wir hier nicht darauf einzugehen brauchen. Wichtig ist, daß wir sowohl bei alten wie bei jungen Faltengebirgen keine Schwerestörung von derjenigen Größe finden, die vorhanden sein müßte, wenn diese Bergketten einfach der Erdrinde aufgesetzt wären. Zwar findet man vielfach in solchen Gebirgen gut meBbare Abweichungen von der vollkommenen Isostasie, und deren Diskussion ist von 
großem Interesse in anderer Hinsicht, aber diese sind doch so klein, daß wir in erster Annäherung sagen können: Die Auffaltung der Kettengebirge vollzieht sich unter grundsätzlicher Wahrung der Isostasie. Was dies bedeutet, mag Abb. 48 schematisch erläutern. Beim Zusammenschub einer im Sima schwimmenden Kontinentalscholle muß das Verhältnis von oberhalb zu unterhalb der Simaoberfläche immer das gleiche bleiben. Je nachdem wir die Dicke der um $5 \mathrm{~km}$ aus dem Sima herausragenden Sialdecke zu 30 oder $60 \mathrm{~km}$ annehmen, können wir dies Verhältnis zu 1:6 oder $1: 12$ angeben. Es muß also der nach unten gerichtete Teil des Zusammenschubs 6 - bzw. 12 mal so groß sein wie der nach oben gerichtete. Was wir also in den Gebirgen sehen, ist nur ein kleiner Teil der ganzen zusammengeschobenen Masse. Es sind, bei idealer Stauchung, nur diejenigen Schichten, die auch vor dem Zusammenschub bereits über dem Tiefseeniveau lagen. Alles was unter diesem Niveau lag, bleibt auch bei dem $\mathrm{Zu}$ sammenschub unter ihm, Abb. 48.

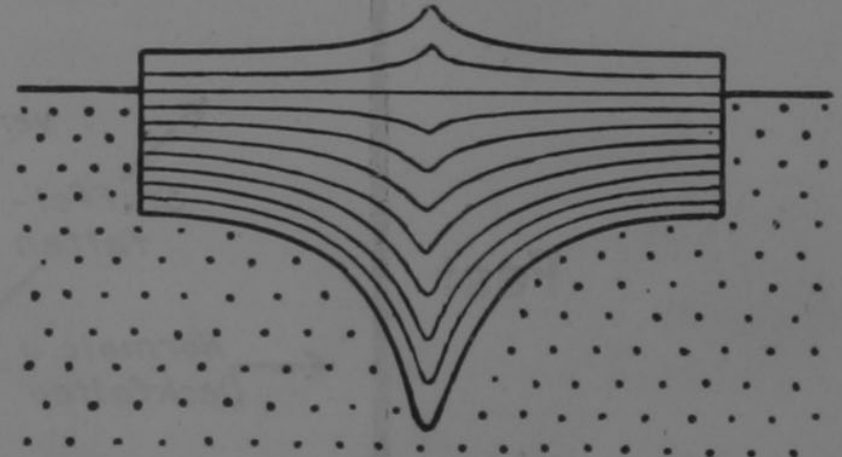

Zusammenschub unter Wahrung der Isostasie.

wenn man von Störungen absieht. Bestand also der Oberbau der Scholle aus einer $5 \mathrm{~km}$ mächtigen Sedimentschale, so wird auch das ganze Gebirge anfangs nur aus Sediment bestehen. Erst wenn dies durch Erosion abgetragen wird, steigt zum isostatischen Ausgleich eine Zentralkette aus Urgestein empor, bis schließlich nach gänzlicher Abfegung der Sedimentdecke ein breites Urgebirge von fast gleicher mittlerer Höhe emporgewachsen ist. Als Beispiel für das erste Stadium können der Himalaja und seine Nachbargebirge gelten. Die Erosion in diesen Sedimentfalten ist eine gewaltige, so daß die Gletscher unter dem Schutt fast vergraben sind, wie z. B. der Baltorogletscher, der größte im KaraKorum-Gebirge, der bei nur 11/2 bis $4 \mathrm{~km}$ Breite (Länge $56 \mathrm{~km}$ ) nicht weniger als 15 Mittelmoränen trägt. Im zweiten Stadium, bei dem die Zentralkette bereits aus Urgestein besteht, beiderseits aber noch von Sedimentzonen flankiert wird, befinden sich die Alpen. Da die Erosion im Urgestein viel geringer ist, sind die Alpengletscher moränenarm, eine Hauptursache ihrer Schönheit. Das norwegische 
Gebirge endlich repräsentiert das dritte Stadium. Die Sedimentdecke ist hier zum allergrößten Teile ganz beseitigt, und der Aufstieg des Urgebirges ist vollendet. Auch die Abtragung der Sedimenthaube eines Gebirges vollzieht sich also unter Wahrung der Isostasie.

Sehr häufig kann man erkennen, daß die parallelen Faltenzüge eines Gebirges gestaffelt liegen. Verfolgt man einen solchen Faltenzug, so findet man, daß er früher oder später an den Rand des Gebirges heraustritt und schließlich erlischt, worauf die nächst innere Kette den Rand bildet, um in einiger Entfernung gleichfalls zu erlöschen usw. Dies ist dann der Fall, wenn die beiden Schollen sich nicht gerade

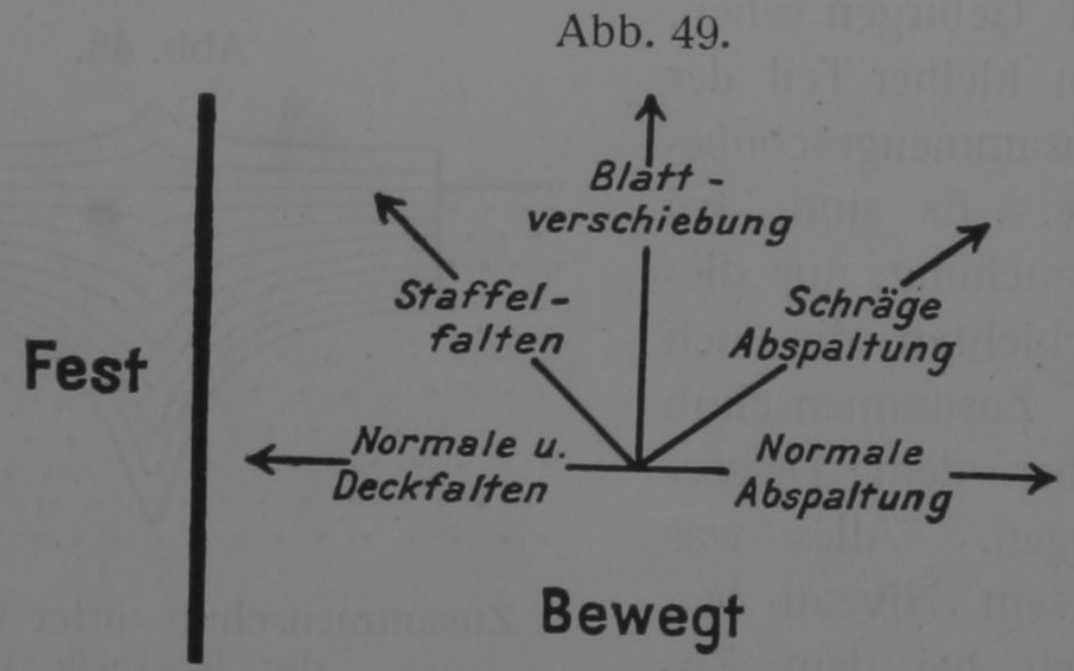

Faltung oder Spaltung als Resultat verschieden gerichteter Schollenbewegung.

aufeinander zu bewegen, sondern eine scherende Bewegung, wenn auch mit einer Komponente gegeneinander, haben. Allgemein läßt sich die Wirkung der verschiedenen Bewegungen der Schollen relativ zueinander durch Abb. 49 veranschaulichen: Die linke Scholle sei fest, die rechte bewegt. Ist ihre Bewegung normal zur Schollengrenze hin gerichtet, so entstehen keine Staffelfalten, aber besonders große Falten (Überschiebungen); ist sie schräg zur Schollengrenze hin gerichtet, so entstehen Staffelfalten, die um so enger und niedriger werden, je mehr die Bewegungsrichtung parallel zum Schollenrande wird. Bei genauer Parallelität entsteht eine Gleitfläche mit Blattverschiebung; besitzt endlich die Bewegung eine Komponente, die von der Schollengrenze fort gerichtet ist, so haben wir schräge bzw. normale Abspaltung, die zunächst als Grabenbruch in Erscheinung tritt. Das Verhältnis der normalen zu den gestaffelten Falten können wir sehr gut mit einem Tischtuch veranschaulichen, wenn wir den- 
jenigen Teil desselben, der die feste Scholle darstellen soll, durch Gewichte beschweren und den anderen Teil gegen ihn verschieben.

Schon aus diesen allgemeinen Betrachtungen geht hervor, daß Staffelfalten häufiger vorkommen müssen als normale Faltungen, denn erstere stellen den allgemeinen, letztere den speziellen Fall dar. Die Anordnung der Faltenzüge in der Natur scheint dem zu entsprechen. Ich möchte dies hervorheben, weil auf geologischer Seite vielfach das Bestreben erkennbar ist, nur solche Faltenzüge als eigentlich zusammengehörig anzuerkennen, die sich unmittelbar ineinander fortsetzen, was nach dem Gesagten nicht der Fall zu sein braucht.

Wie schon Abb. 49 zeigt, sind Faltung und Spaltung nur zwei verschiedene Wirkungen derselben Ursache, nämlich der Verschiebung der Schollenteile relativ zueinander, und sie gehen über die Staffelfalten und die Blattverschiebung kontinuierlich ineinander über. Es ist deshalb berechtigt, hier auch gleich den Spaltungsvorgang ins Auge zu fassen.

Das schönste Beispiel solcher Spaltungen bilden die ostafrikanischen Gräben. Sie gehören einem großen Bruchsystem an, welches sich nach Norden noch durch das Rote Meer, den Golf von Akaba und das Jordantal bis an den Rand der taurischen Faltungen verfolgen läßt (Abb. 50). Nach neueren Untersuchungen setzen Abb. 50.

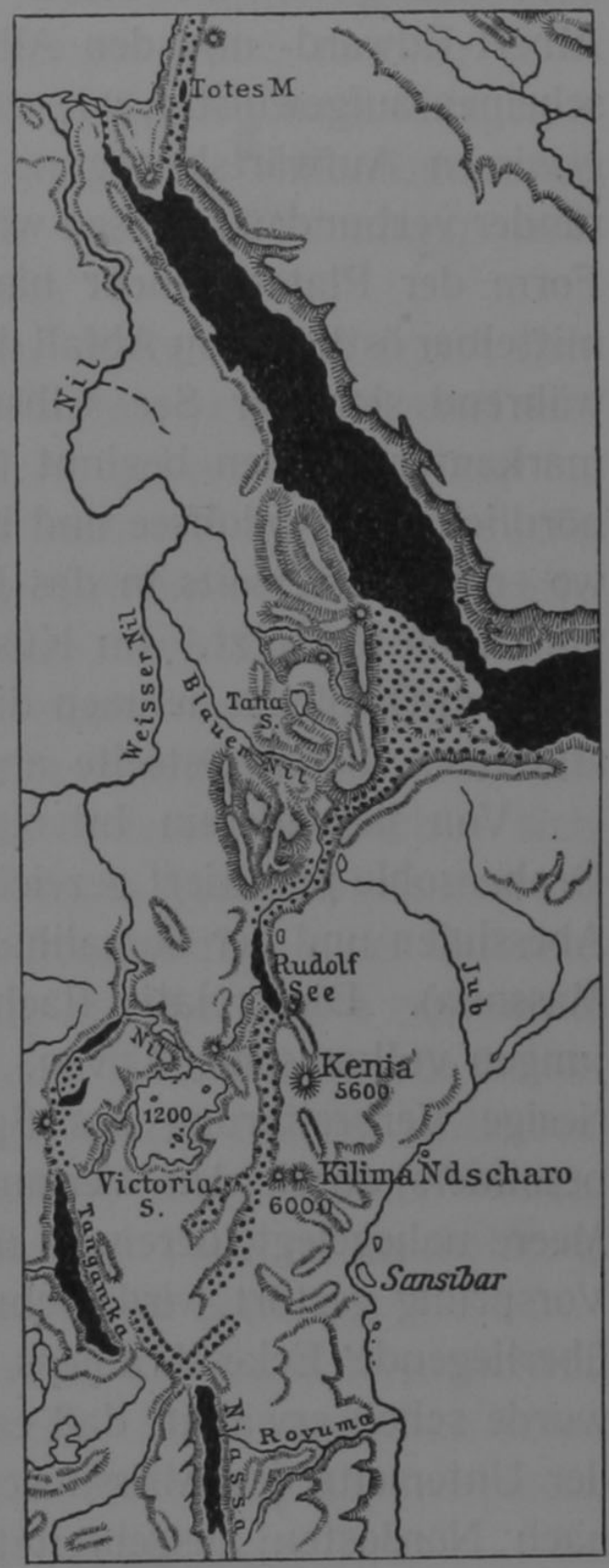

Die ostafrikanischen Gräben, nach Supan.

$\therefore$ Gräben, mit Wasser bedeckte Grabenteile. sich diese Brüche auch nach Süden noch bis zum Kaplande fort, doch sind sie am schönsten in Ostafrika ausgebildet. Neumayr-Uhlig [183] beschreibt sie etwa wie folgt:

Von der Sambesimündung aus zieht sich ein solcher 50 bis $80 \mathrm{~km}$ breiter Graben nach Norden, den Shirefluß und Njassasee enthaltend, 
um dann nach Nordwesten zu drehen und sich zu verlieren. Dafür beginnt dicht neben ihm und parallel zu ihm der Graben des Tanganikasees, von dessen Großartigkeit der Umstand zeugt, daß die Tiefe des Sees 1700 bis 2700 m, die Höhe des mauerförmigen Steilabfalles aber 2000 bis 2400, ja selbst $3000 \mathrm{~m}$ beträgt. In seiner nördlichen Fortsetzung enthält dieser Graben den Russisifluß, den Kiwu-, Albert-Edward- und den Albertsee. „Die Ränder der Senkung erscheinen aufgewulstet, wie wenn hier das Bersten der Erde mit einer gewissen Aufwärtsbewegung der plötzlich frei gewordenen Bruchränder verbunden gewesen wäre. Mit dieser eigentümlichen wulstigen Form der Plateauränder hängt es wohl auch zusammen, daß unmittelbar östlich vom Abfall des Tanganika die Nilquellen entspringen, während sich der See selbst zum Kongo entleert." Ein dritter markanter Graben beginnt östlich des Viktoriasees, enthält weiter nördlich den Rudolfsee und biegt bei Abessinien nach Nordosten ab, wo er sich einerseits in das Rote Meer und andererseits in den.Golf von Aden fortsetzt. Im Küstengebiet und im Innern von ehemals Deutsch-Ostafrika nehmen diese Brüche meist die Form von Bruchstufen an, deren Ostseite abgesunken ist.

Von besonderem Interesse ist das in Abb. 50 ebenso wie die Grabensohle punktiert gezeichnete große Dreieck im Winkel zwischen Abessinien und der Somalihalbinsel (zwischen Ankober, Berbera und Massaua). Dies relativ flache und niedrige Land besteht ganz aus jungen vulkanischen Laven. Die meisten Autoren halten es für eine riesige Verbreiterung des Spaltenbodens. Diese Auffassung wird besonders durch den Verlauf der beiderseitigen Küsten im Roten Meere nahegelegt, deren im übrigen genaue Parallelität durch diesen Vorsprung gestört wird; schneidet man ihn fort, so paßt die gegenüberliegende Ecke Arabiens genau in den Ausschnitt hinein. Es wurde schon erwähnt, daß es sich hier offenbar um Sialmassen von der Unterseite des Abessinischen Gebirges handelt, die sich einseitig nach Nordosten ausgebreitet haben und dabei am Schollenrande aufgetaucht sind. Vielleicht war die Spalte schon mit Basalt erfüllt, so daß die emporsteigenden Sialmassen eine Haube aus diesem Material mit hochtrugen. Die große Erhebung über das Tiefseeniveau deutet jedenfalls auf die Anwesenheit sialischer Massen unter der Lavadecke, falls das Gebiet nicht etwa einen bedeutenden Schwereüberschuß aufweist.

Die Entstehung dieser in Ostafrika selbst maschenförmig angeordneten Brüche ist in geologisch junge Zeiten $\mathrm{zu}$ setzen. An 
mehreren Stellen durchschneiden sie junge basaltische Laven, einmal auch pliozäne Süßwasserbildungen. Jedenfalls können sie also nicht vor Schluß der Tertiärzeit entstanden sein. Andererseits scheinen sie zur Diluvialzeit schon vorhanden gewesen zu sein, wie man aus den Strandterrassen als Marken höheren Wasserstandes bei den abflußlosen, auf der Grabensohle liegenden Seen geschlossen hat. Beim Tanganikasee deutet auch seine offenbar früher marine, dann aber dem Süßwasser angepaßte sogenannte Reliktenfauna auf längeren Bestand. Die häufigen Erdbeben und der starke Vulkanismus der Bruchzone deuten aber wohl darauf hin, daß der Trennungsprozeß jedenfalls auch heute noch im Gange ist.

Für die mechanische Deutung solcher Grabenbrüche ergibt sich nur insofern etwas Neues, als diese die Vorstufe einer völligen Trennung der beiden Schollenteile darstellen, wobei es sich um rezente, noch nicht beendete Abspaltungen oder auch um frühere Versuche einer solchen handeln kann, die infolge Erlahmens der Zugkräfte wieder zur Ruhe gekommen sind. Eine vollständige Trennung würde sich nach unseren Vorstellungen etwa folgendermaßen vollziehen. Zunächst wird nur in den oberen, spröderen Schichten ein klaffender Riß entstehen, während die unteren plastischen sich ziehen. Da vertikale Steilwände von der hier in Betracht kommenden Höhe viel zu große Anforderungen an die Druckfestigkeit der Gesteine stellen würden, so bilden sich gleichzeitig mit der Spalte oder auch an Stelle von ihr schräge Rutschflächen aus, längs welchen die Randpartien der beiden Schollenteile unter zahlreichen lokalen Erdbeben in demselben Tempo in die Spalte absinken, wie diese sich öffnet, so daß immer nur ein Grabenbruch mäßiger Tiefe in Erscheinung tritt, dessen Boden aus verworfenen Schollen derselben Gesteinsserien besteht, die auch seitwärts des Grabens auf der Höhe anstehen. In diesem Stadium ist der Grabenbruch noch nicht isostatisch kompensiert, wie es denn auch nach E. Kohlschütter [184] bei einem großen Teile der jungen ostafrikanischen Gräben der Fall ist. Es ist ja ein unkompensiertes Massendefizit vorhanden; daher wird eine entsprechende Schwerestörung beobachtet, und außerdem steigen beide Spaltenränder zum isostatischen Ausgleich empor, so daß der Eindruck entsteht, als gehe der Graben in der Längsrichtung durch eine Aufwölbung hindurch. Schwarzwald und Vogesen beiderseits des oberrheinischen Grabenbruchs sind bekannte Beispiele für diesen Randwulst. Reißt endlich die Spalte so tief, daß unter ihr nur noch die plastischeren unteren Schichten des Sials liegen, so 
steigen diese und das unter ihnen liegende zähflüssige Sima an, so daß das bisherige Massendefizit ersetzt wird und der Graben sich nunmehr als Ganzes isostatisch kompensiert erweist. Bei der weiteren Öffnung der Spalte wird deren Boden zunächst vollständig mit den auseinandergezogenen Massen der plastischen unteren Schichten der Sialschollen bedeckt sein, die von Bruchstücken der spröderen Oberschichten bedeckt sind, bis schließlich bei sehr weiter Trennung auch Simafenster erscheinen. Bei dem großen Graben des Roten Meeres ist die Entwicklung so weit vorgeschritten, daß, wie Triulzi und Hecker fanden, bereits isostatische Kompensation herrscht.

Der Umstand, daß die obersten Schichten des Sials wesentlich spröder sind als die tieferen, gibt auch die Erklärung für die auffallende Tatsache, daß ehemals zusammengehörige Schollenränder auch dann noch kongruent geblieben sind, wenn zwischen ihnen Sialmassen liegen, die eine glatte Zusammenfügung der Schollen zu verbieten scheinen. Z. B. zeigt die Ostküste von Madagaskar ebenso wie die Westküste von Vorderindien einen auffallend geradlinigen Abbruch der beiderseitigen Gneisplateaus, was kaum einen anderen Schluß zuläßt, als daß beide Teile einst unmittelbar zusammenhingen. Dennoch liegt zwischen ihnen der bogenförmige Schelf der Seychellen, der offenbar gleichfalls aus Sial besteht (die Inseln bestehen aus Granit) und bei der Rekonstruktion dazwischengeschoben werden müßte. Wahrscheinlicher erscheint mir aber, daß wir es hier nur mit dem plastischeren Material der tieferen Sialschichten zu tun haben, das bei dem Trennungsprozeß herausgezogen worden ist und daher bei der Rekonstruktion unter den beiden Schollenteilen anzubringen wäre, was natürlich nicht ausschließt, daß es auch mit kleineren Oberflächenbrocken gekrönt sein kann. Ähnliches gilt für die mittelatlantische Bodenschwelle und manche anderen Gebiete. Es ist wichtig, dies zu berücksichtigen, da es sonst an manchen Stellen rätselhaft erscheinen könnte, warum die Konturen der getrennten Schollen fast genau kongruent sein können, während doch zwischen ihnen noch unregelmäßige Sialmassen liegen.

Auf dieses seitliche Herausziehen der unteren plastischen Schichten des Sials ist es wohl auch zurückzuführen, daß die Ränder gespaltener Kontinentalschollen oft in einer Reihe von Bruchstufen, die dem Rande parallel verlaufen, zum Tiefseeboden abfallen, ja oft in ihrem oberen, allein zu untersuchenden Teile eine „Flexur" vortäuschen, d. h. daß ihre Oberfläche nach außen herabhängt. Doch können wir auf diese Einzelheiten hier nicht weiter eingehen. 
Eine besondere Art von Kräften muß am Rande der plastischen Kontinentalschollen auftreten, wenn diese durch eine Inlandeisdecke belastet sind. Wenn man einen plastischen Kuchen belastet, so wird er in dem Bestreben, seine Mächtigkeit zu verringern und sich horizontal auszudehnen, randliche radiale Risse bekommen. Dies ist die Erklärung für die Fjordbildung, welche in überraschender Gleichförmigkeit an allen ehemals vereisten Küsten (Skandinavien, Grönland, Labrador, pazifische Küste von Nordamerika nördlich $48^{\circ}$ und von Südamerika südlich $42^{\circ}$, sowie Neuseeland-Südinsel) vorhanden ist und bereits von Gregory [185] in einer umfangreichen, noch viel zu wenig gewürdigten Untersuchung auf Bruchbildung zurückgeführt ist. Die heute noch immer viel vertretene Deutung als Erosionstäler halte ich, auch nach eigenen Beobachtungen in Grönland und Norwegen, für unrichtig. :

An den atlantischen Kontinentalrändern ist man durch gehäufte Lotungen auf eine eigenartige Erscheinung aufmerksam geworden, welche sich als untermeerische Fortsetzung von Flußtälern zu erkennen gibt. So setzt sich das Tal des Lorenzstromes noch im vorgelagerten Schelf bis zur Tiefsee fort, desgleichen das des Hudson (bis $1450 \mathrm{~m}$ Tiefe verfolgbar), und auf europäischer Seite ist Ähnliches der Fall vor der Mündung des Tajo und namentlich bei der „Fosse de Cap Breton“, 17 km nördlich der Mündung des Adour. Die schönste derartige Erscheinung ist aber wohl die Kongorinne im Südatlantik (bis $2000 \mathrm{~m}$ verfolgbar). Nach der üblichen Deutung sollen diese Rinnen ertrunkene Erosionstäler sein, die über Wasser entstanden. Dies erscheint mir jedoch in hohem Maße unwahrscheinlich, einmal wegen des großen Betrages der Senkung, zweitens wegen der allgemeinen Verbreitung (bei genügend zahlreichen Lotungen wird man sie vermutlich an allen Kontinentalrändern finden) und drittens, weil nur eine bestimmte Auswahl von Flußmündungen die Erscheinung zeigt, während dazwischenliegende Mündungen sie nicht zeigen. Ich halte es für wahrscheinlicher, daß es sich auch hịer um Spalten im Kontinentalrand handelt, die von den Flüssen benutzt werden. Beim Lorenzstrom ist diese Spaltennatur seines Bettes ohnehin geologisch erwiesen, bei der Fosse de Cap Breton, welche das innerste Ende der buchförmig sich öffnenden Tiefseespalte der Biskaya darstellt, nach ihrer ganzen Lage plausibel.

Die interessanteste Erscheinung des Kontinentalrandes bilden aber die Inselgirlanden, die namentlich an der ostasiatischen Küste ausgebildet sind (Abb. 51). Betrachten wir ihre Verteilung im Pazifik, 
so sehen wir ein großzügiges System. Namentlich wenn wir Neuseeland als einstige Girlande Australiens auffassen, so ist die ganzeWest-

Abb. 51.

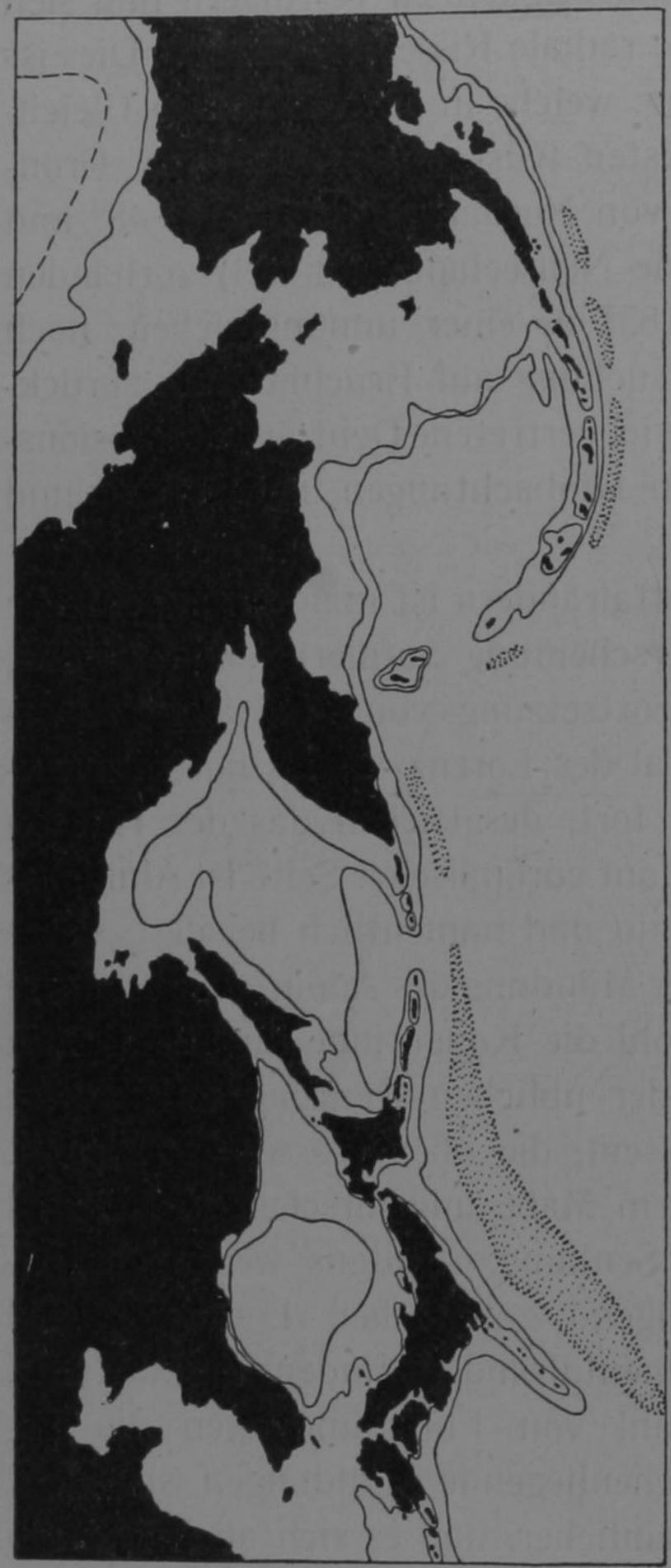

Girlanden von Nordost-Asien.

(Tiefenlinien 200 und $2000 \mathrm{~m}$; Tiefseerinnen punktiert.) küste des Pazifik mit Girlanden bedeckt, während die Ostküste frei davon ist. Bei Nordamerika könnte man vielleicht in der Abtrennung von Inseln zwischen 50 und $55^{\circ}$ Breite, der Küstenausbauchung bei San Franzisko und der Abtrennung der kalifornischen Randkette noch unentwickelte Anfänge von Girlandenbildung erkennen. Im Süden läßt sich möglicherweise die Westantarktis als Girlande (dann vermutlich Doppelgirlande) ansprechen. Im ganzen deutet aber das Girlandenphänomen auf eine Verschiebung der westpazifischen Kontinentalmassen, die etwa nach Westnordwest, also für die diluviale Pollage etwa nach Westen gerichtet war, die ferner mit der Längsachse des Pazifik (SüdamerikaJapan) und mit der Hauptrichtung der alten pazifischen Inselreihen (Hawai - Inseln, Marshall-Inseln, GesellschaftsInseln usw.) zusammenfällt. Die Tiefseerinnen, einschließlich der Tongarinne, sind als Spalten senkrecht zu dieser Verschiebungsrichtung, also

parallel zu den Girlanden, angeordnet. Es ist wohl keine Frage, daß alle diese Dinge ursächlich miteinander verknüpft sind. Ganz ähnliche Girlanden sind auch in Westindien vorhanden, 
land kann, wenn auch in etwas anderem Sinne, als freie Girlande angesprochen werden.

Sehr auffällig ist die gleichartige Staffelung der Girlanden. Die Aleuten bilden eine Kette, welche weiter östlich in Alaska nicht mehr Randkette ist, sondern aus dem Innern kommt. Sie endigen bei Kamtschatka, von wo ab nun die bisher innere Kamtschatka-Kette mit den Kurilen als äußerste Kette die Girlande bildet. Diese endigt wiederum bei Japan, um der bisher inneren Kette Sachalin-Japan den Platz zu räumen. Auch südlich von Japan läßt sich diese Anordnung noch weiter verfolgen, bis bei den Sunda-Inseln die Verhältnisse verworrener werden. Und auch die Antillen zeigen genau dieselbe Staffelung. Es liegt auf der Hand, daß diese Staffelung der Girlanden eine unmittelbare Folge der Staffelung der einstigen Randgebirge der Kontinente ist und also auf das früher besprochene allgemeine Gesetz der Staffelfalten zurückgeht. Die auffällig gleiche Länge der Girlanden [Aleuten 2900, Kamtschatka-Kurilen 2600, Sachalin-Japan 3000, Korea-Riu-Kiu 2500, Formosa-Borneo 2500, Neuguinea-Neuseeland ehemals 2700 km] ${ }^{1}$ ) könnte vielleicht auf diese Weise bereits tektonisch in der Anlage der Randgebirge vorgezeichnet sein.

Fujiwhara [195] hat sich eingehender mit dieser gestaffelten Lage, speziell der japanischen Vulkanketten, beschäftigt und sucht sie durch eine Rotation des nordpazifischen Meeresbodens gegen den Uhrzeiger zu erklären (relativ zu der fest gedachten asiatischen Scholle). Da alle Bewegung relativ ist, könnte man auch umgekehrt an eine Rotation der umgebenden Landmassen um den fest gedachten Boden des Pazifik im Sinne des Uhrzeigers denken. Dies ist deswegen von Interesse, weil der Nordpol bis vor geologisch kurzer Zeit im Pazifischen Ozean lag, so daß eine solche Rotation der Landmassen in der Vorzeit einer Westwanderung derselben entspräche. Ich halte es in der Tat für sehr wahrscheinlich, daß die gestaffelten Randketten von Ostasien durch eine solche ehemalige Westwanderung der Kontinentalschollen zu der Zeit, als der Pol noch im Pazifischen Ozean lag, angelegt wurden.

Die auffallende Übereinstimmung der Girlanden in ihrem geologischen Bau war bereits früher erwähnt worden: ihre konkave

$\left.{ }^{1}\right)$ Die westindischen Girlanden zeigen dagegen eine Abstufung: Kleine Antillen-Südhaiti-Jamaika-Mosquitobank 2600, Haiti-Südcuba-Misteriosabank 1900, Cuba 1100 km. 
Seite trägt stets eine Reihe von Vulkanen, offenbar eine Folge des bei ihrer Biegung hier entstehenden Druckes, der die Simaeinschlüsse herauspreßt. Die konvexe Seite dagegen trägt tertiäre Sedimente, während diese am entsprechenden Festlandsufer meist fehlen. Dies deutet an, daß die Ablösung erst in jüngster ģeologischer Zeit vor sich gegangen ist, und daß die Girlande zur Zeit der Ablagerung dieser Sedimente noch den Rand des Festlandes bildete. Diese tertiären Sedimente zeigen überall starke Lagerungsstörungen, eine Folge des bei der Biegung hier auftretenden Zuges, der zur Zerklüftung und vertikalen Verwerfung führt. Nipon ist durch die zu starke Biegung in der Fossa Magna aufgebrochen. Daß dieser Außenrand der Girlande trotz der mit der Dehnung sonst überall verbundenen Senkung gehoben erscheint, deutet eine Kippbewegung der Girlande an, die man sich dadurch verursacht denken kann, daß sie gemäß der allgemeinen Westwanderung der Kontinentalscholle an ihren Endpunkten mitgeschleppt, in der Tiefe aber durch das Sima zurückgehalten wird. Mit demselben Vorgang scheint auch die meist ihren Außenrand begleitende Tiefseerinne zusammenzuhängen. Es war schon früher darauf aufmerksam gemacht worden, daß sich diese Rinne niemals auf der frisch entblößten Simafläche zwischen Kontinent und Girlande, sondern stets nur an deren Außenrande, also an der Grenze des alten Tiefseebodens bildet. Sie erscheint hier als eine Spalte, deren eine Seite von dem stark ausgekühlten und bis in große Tiefen bereits erstarrten alten Tiefseeboden, und deren andere Seite von dem sialischen Material der Girlande gebildet wird. Gerade in Verbindung mit der genannten Kippbewegung der Girlande wäre die Bildung einer solchen Randspalte zwischen Sial und Sinıa sehr verständlich.

Weiter ist in unserer Abb. 51 die bauchige Form des Kontinentalrandes hinter den Girlanden auffallend. Namentlich wenn wir außer der Küstenlinie selber auch die 200-m-Tiefenlinie betrachten, so zeigt sich, daß der Kontinentalrand stets das Spiegelbild einer S-Form aufweist, während die davorliegende Girlande einen einfachen konvexen Bogen bildet. Diese Verhältnisse sind schematisch in Abb. 52 B dargestellt. Die Erscheinung ist bei allen drei in Abb. 51 enthaltenen Girlanden in gleicher Weise ausgebildet und trifft z. B. auch beim ostaustralischen Kontinentalrand und seiner einstigen, durch den Südost-Ausläufer Neuguineas und Neuseeland gebildeten Girlande zu. Diese bauchigen Küstenlinien kennzeichnen einen Zusammenschub parallel zur Küste und also auch zur Streichrichtung 
der Küstengebirge. Sie sind als horizontale Großfalten zu betrachten. Es handelt sich hierbei um eine Teilerscheinung in dem gewaltigen Zusammenschub, den das ganze östliche Asien in der Richtung Nordost-Südwest erfahren hat. Macht man den Versuch, diese Schlangenlinie der ostasiatischen Festlandsküste zu glätten, so wächst die Entfernung zwischen Hinterindien und der Beringstraße, die jetzt $9100 \mathrm{~km}$ beträgt, auf $11100 \mathrm{~km}$.

Nach unserer Auffassung handelt es sich also bei den Girlanden und insbesondere den ostasiatischen um Randketten, die sich infolge der Westwanderung der Kontinentalmassen von diesen ablösen, indem sie an dem tief erstarrten alten Meeresboden haftenbleiben. Zwischen ihnen und dem Kontinentalrand tritt junger, noch leichtflüssigerer Tiefseeboden fensterartig zutage.

Diese Vorstellung ist eine andere als die, welche F. v. Richthofen, freilich von ganz anderen Voraussetzungen ausgehend, vertreten hat [186]. Er dachte sich die Girlanden entstanden durch einen vom Pazifik kommenden Zug in der Erdrinde. Zusammen mit

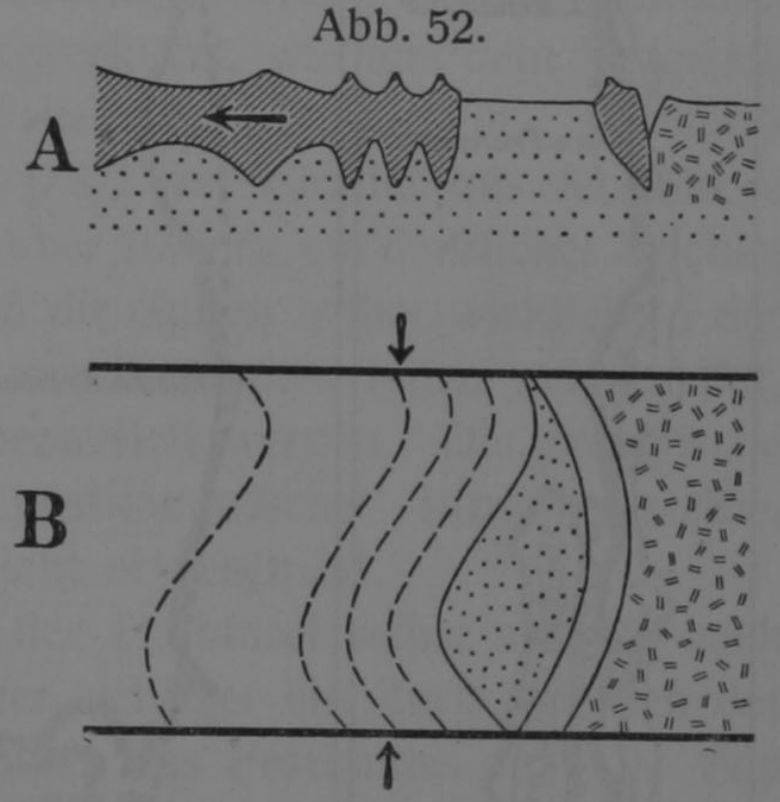

Schema der Entstehung von Inselgirlanden.

A Querschnitt; B Aufsicht. (Der stark ausgekühlte Teil des Simas ist durch Strichelung bezeichnet.)

einer breiten Zone des benachbarten Festlandes, die auch durch bogenförmigen Verlauf der Küste und der Erhebungen ausgezeichnet ist, sollten die Inselbögen ein großes Bruchsystem bilden. Das Gebiet zwischen Inselkette und Festlandsküste sei die erste „Landstaffel“, welche infolge einer Kippbewegung im Westen unter den Meeresspiegel getaucht sei, während der Ostrand als Inselgirlande herausrage. Auf dem Festlande glaubte v. Richt h of en noch zwei weitere derartige Landstaffeln zu sehen, deren Senkung jedoch geringer war. Die regelmäßige Bogenform dieser Brüche bildete zwar eine Schwierigkeit; doch glaubte man, diesen Einwand mit dem Hinweis auf bogenförmige Sprünge im Ásphalt und anderen Stoffen entkräften zu können.

So sehr man auch anerkennen muß, daß diese Theorie das historische Verdienst besitzt, zum ersten Male mit dem Dogma von 
einem überall wirksamen „Gewölbedruck“ bewußt gebrochen und Zugkräfte zur Erklärung herangezogen zu haben, so braucht man doch nicht viel Worte zu verlieren, um zu zeigen, daß sie unseren heutigen Erfahrungen nicht gerecht wird. Namentlich spricht die Tiefenkarte, so unvollkommen sie infolge mangelnder Lotungen hier

Abb. 53.

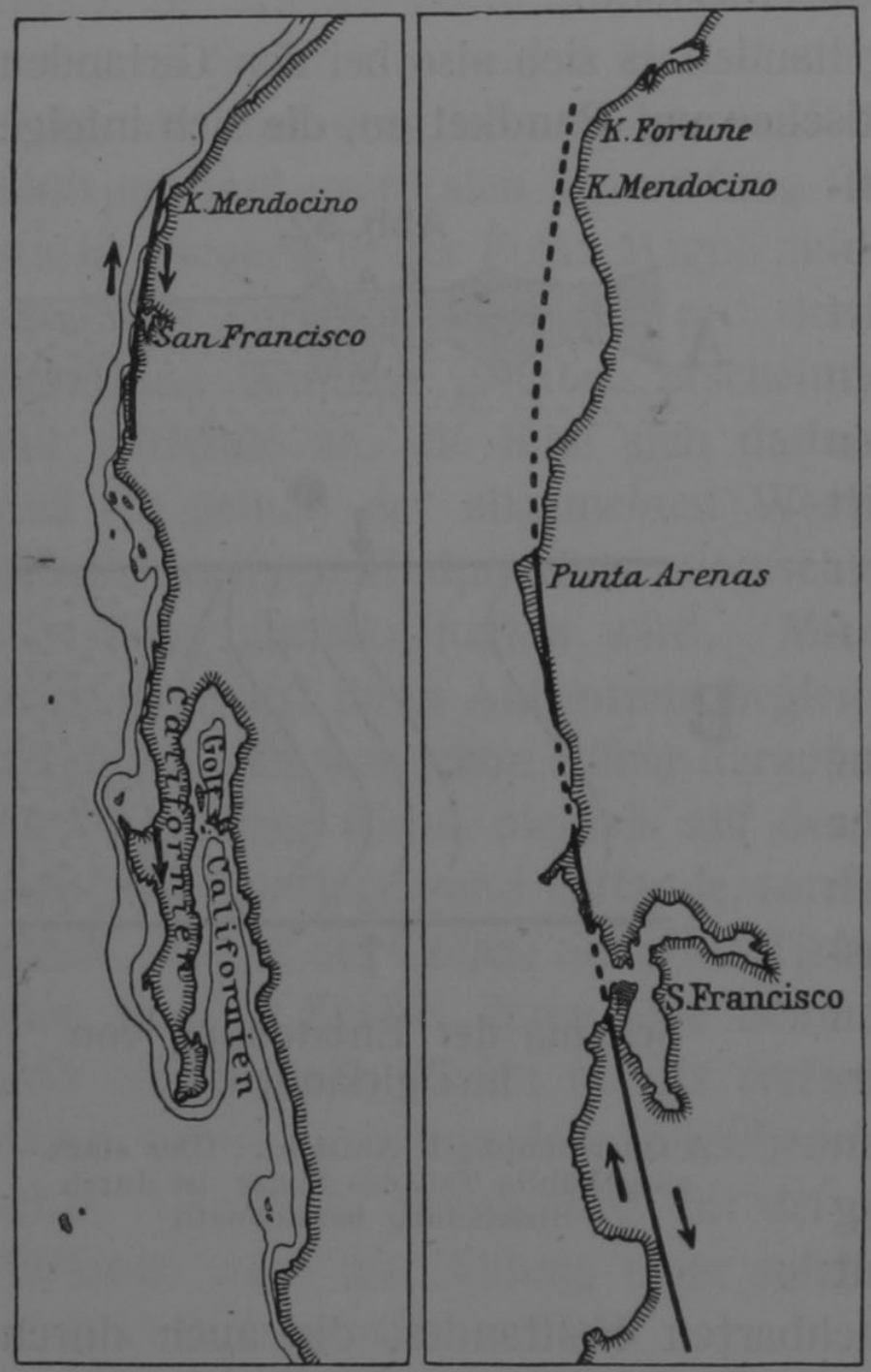

Kalifornien und die Erdbebenverwerfung von San Franzisko. noch ist, entschieden dafür, daß zwischen Girlande und Hauptscholle der Zusammenhang unterbrochen ist.

Wenn die Bewegung der Kontinentalscholle nicht wie in Ostasien senkrecht zu ihrem Rande geschieht, sondern parallel zum Rande, so können die Randketten durch Blattverschiebung abgestreift werden, ohne daß ein Simafenster zwischen ihnen und der Hauptscholle auftritt. Im Grunde genommen handelt es sich hier um die gleichen Erscheinungen, wie sie für das Innere der Kontinentalscholle an der Hand unserer Abb. 49 (S. 192) erläutert waren, nur sinngemäß

übertragen auf den Kontinentalrand: Bewegt sich die Scholle gegen das Sima, so tritt Randfaltung auf, und zwar entweder Überschiebungen oder Staffelfalten, je nach der Richtung der Bewegung. Bewegt sie sich vom Tiefseeboden fort, so spalten sich die Randketten ab. Ist aber die Bewegung eine scherende, so haben wir Blattverschiebung: die Randkette gleitet. Auch in diesem Falle haftet die Randkette an dem erstarrten Tiefseeboden. In unserer Tiefenkarte der Drakestraße Abb. 26 auf S. 97 kann man diesen Prozeß am Nordende von Grahamland besonders schön sehen. 
Desgleichen ist die südlichste Kette der Sunda-Inseln Sumba-Timor -Ceram-Buru, die früher wohl die südöstliche Fortsetzung der Sumatra vorgelagerten Inselreihe gebildet hat, an Java vorbeigeglitten, bis sie von der heranrückenden Scholle Australien-Neuguinea ergriffen wurde.

Ein anderes Beispiel ist Kalifornien. Die Kalifornische Halbinsel zeigt an ihren seitlichen Vorsprüngen Schleppungserscheinungen (Abb. 53), die ein Vorwärtsdrängen der Landmassen nach Südsüdost zu beweisen scheinen. Die Spitze der Halbinsel ist durch den Stirnwiderstand des Simas bereits amboßartig verdickt, und die Halbinsel erscheint im ganzen bereits stark verkürzt, wie aus dem Vergleich mit dem Ausschnitt des kalifornischen Golfs hervorgeht. Ihr nördlicher Teil hat sich nach Wittich [187] erst kürzlich aus dem Meere gehoben, und zwar um Beträge bis über 1000 m, ein deutliches Zeichen für starken Zusammenschub. Daß die Spitze früher wirklich in der vor ihr liegenden Einkerbung der mexikanischen Küste gelegen hat, kann nach den Konturen kaum bezweifelt werden. Die geologische Karte zeigt hüben wie drüben ,postkambrische“ Intrusivgesteine, deren Identität allerdings noch nicht erwiesen ist.

Aber außer der Verkürzung der Halbinsel selbst scheint auch noch ein Gleiten nach Norden oder richtiger ein Zurückbleiben der Halbinsel bei einem Südwärtsdrängen des Festlandes relativ zur Unterlage vorzuliegen, an dem wohl auch die nördlich sich anschließenden Küstenketten teilnehmen. Hierdurch erklärt sich die große Ausbauchung der Küstenlinie bei San Franzisko durch Stauung. Diese Auffassung wird in auffallender Weise bestätigt durch die berühmte Erdbebenverwerfung von San Franzisko vom 18. April 1906, die nach Rudzki [15] und Tams [188] in unsere Abb. 53 eingezeichnet ist. Denn der östliche Teil schnellte hierbei nach Süden, der westliche nach Norden. Wie zu erwarten, zeigten die Vermessungen, daß der Betrag dieser plötzlichen Verschiebung mit zunehmender Entfernung von der Spalte immer geringer wurde und in größerer Entfernung nicht mehr nachweisbar war. Natürlich war die Erdkruste auch schon vor dem Sprung in langsamer kontinuierlicher Bewegung. Andrew C. Lawson [189] hat diese Bewegung zwischen 1891 und 1906 mit der Sprungrichtung verglichen und kommt zu dem in Abb. 54 gezeigten, für die „Point Arenagruppe“ der Beobachtungen gültigen Resultat, daß ein Oberflächenelement auf der späteren Spalte sich in den genannten 15 Jahren um $0,7 \mathrm{~m}$ von A nach B bewegte, dann durch die Spaltenbildung geteilt wurde, wobei die 
westliche Hälfte um 2,43 m nach C und die östliche um 2,23 m nach D schnellte. In der kontinuierlichen Bewegung zwischen $\mathrm{A}$ und $\mathrm{B}$, die relativ zur Hauptmasse des nordamerikanischen Kontinents gedacht werden muß, zeigt sich, daß der westliche Kontinentalrand durch Anhaften am pazifischen Sima beständig nach Norden zurückgehalten wird. Der Sprung bedeutet nur einen ruckweisen Ausgleich der Spannung, bewegt aber nicht die Kontinentalscholle als Ganzes.

Abb. 54 .

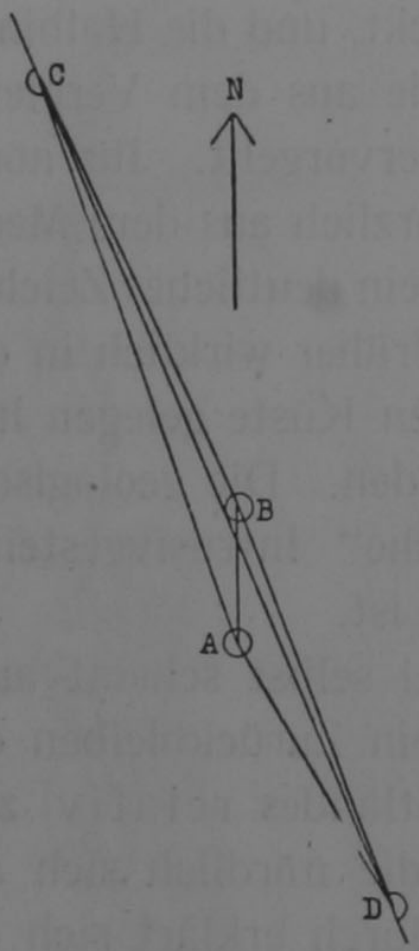

Bewegung eines von der Spalte durchschnittenen Oberflächenelements, nach Lawson.
Abb. 55 .

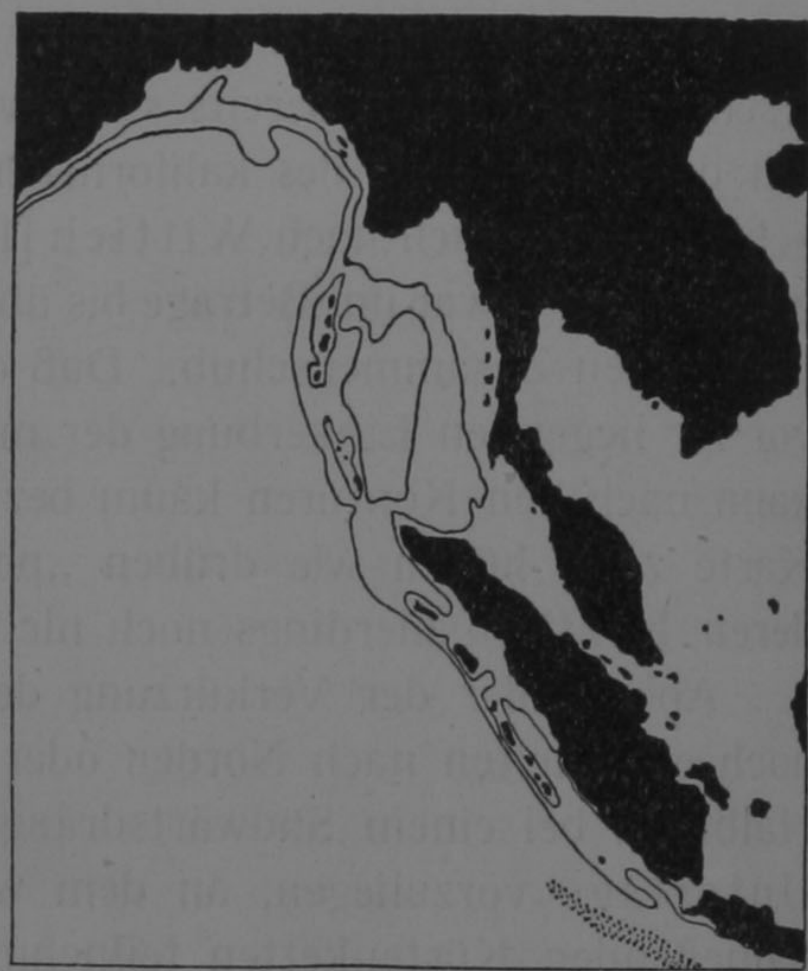

Tiefenkarte von Hinterindien.

(Tiefenlinien 200 u. $2000 \mathrm{~m}$; Tiefseerinne punktiert.)

Es sei in diesem Zusammenhang noch auf einen anderen, gleichfalls sehr interessanten Teil der Erdrinde hingewiesen, der freilich noch wenig untersucht ist, nämlich den Kontinentalrand von Hinterindien (Abb. 55). Es ist namentlich das tiefe Meeresbecken nördlich von Sumatra, welches hier interessiert. Der Knick der Halbinsel Malakka entspricht dem Nordabbruch von Sumatra; aber es ist nicht möglich, die nördlich dieser Insel erkennbare fensterartige Entblößung der tieferen Schichten dadurch wieder zuzudecken, daß wir die Halbinsel Malakka wieder ausrichten. Das zeigt schon die vor dem Fenster liegende Inselkette der Andamanen. Wir dürfen hier vielleicht annehmen, daß der große Zusammenschub des Himalaja einen Zug auf die hinterindischen Ketten in ihrer Längsrichtung 
ausgeübt hat, daß unter diesem Zuge die Sumatrakette am Nordende dieser Insel gerissen ist, und daß der nördliche Teil der Kette (Arakan) wie ein Tauende nach Norden in den großen Zusammenschub hineingezogen worden ist und noch wird. Zu beiden Seiten dieser grandiosen Blattverschiebung müssen sich dabei Gleitflächen ausgebildet haben. Interessanterweise blieb die äußerste Randkette, die Andamanen und Nikobaren, am Sima haften, und es war erst die zweite Kette, die diese merkwürdige Verschiebung erfuhr.

Endlich sei noch kurz des bekannten Unterschiedes zwischen „pazifischem" und „,atlantischem" Küstentypus gedacht. Die „,atlantischen“ Küsten stellen Brüche eines Tafellandes dar, während die „pazifischen“ durch Randketten und vorgelagerte Tiefseerinnen gekennzeichnet sind. $\mathrm{Zu}$ den Küsten mit atlantischem Bau zählt man auch diejenigen von Ostafrika mit Madagaskar, Vorderindien, Westund Südaustralien, sowie die Ostantarktis, zu den pazifischen auch die Westküste Hinterindiens und des Sunda-Archipels, die Ostküste Australiens mit Neuguinea und Neuseeland und die Westantarktis. Auch Westindien mit den Antillen hat pazifischen Bau. Den tektonischen Unterschieden dieser beiden Typen entspricht auch ein verschiedenes Verhalten der Schwerkraft, wie Meissner [190] gezeigt hat. Die atlantischen Küsten sind isostatisch kompensiert, d. h. die schwimmenden Kontinentalschollen sind hier im Gleichgewicht. Dagegen herrschen bei den pazifischen Küsten Abweichungen von der Isostasie. Bekannt ist ferner, daß atlantische Küsten relativ frei von Erdbeben und auch von Vulkanen sind, während pazifische an beiden reich sind. Wo einmal an einer Küste atlantischen Typs ein Vulkan auftritt, zeigen seine Laven, worauf Becke hingewieșen hat, systematische mineralogische Unterschiede gegenüber den pazifischen Laven, sie sind nämlich schwerer und eisenreicher, scheinen also aus größerer Tiefe zu stammen.

Nach unseren Vorstellungen sind die ,atlantischen“ Küsten stets solche, welche sich erst seit dem Mesozoikum, zum Teil noch erheblich später, durch Spaltung der Schollen gebildet haben. Der vor ihnen liegende Meeresboden stellt also eine relativ frisch entblößte Tiefenschicht dar und muß daher als relativ flüssig betrachtet werden. Es kann aus diesem Grunde nicht überraschen, daß diese Küsten isostatisch kompensiert sind. Bei Verschiebungen ferner erfahren die Kontinentalränder wegen dieser größeren Flüssigkeit des Simas nur wenig Widerstand und werden daher weder gefaltet noch gepreßt, so daß weder Randgebirge noch Vulkane entstehen. Auch Erdbeben 
sind hier nicht zu erwarten, da das Sima flüssig genug ist, um alle erforderlichen Bewegungen ohne Diskontinuität, durch reines Fließen, zu ermöglichen. Die Kontinente verhalten sich hier, übertrieben ausgedrückt, wie starre Eisschollen in flüssigem Wasser.

Die Erdoberfläche bietet zahlreiche Anzeichen dafür, daß das Wesen des Vulkanismus in einem passiven Herauspressen der Simaeinschlüsse aus der Sialrinde zu suchen ist. Am schönsten żeigen dies die gebogenen Inselgirlanden. Hier muß durch die Biegung auf der konkaven Inrienseite Pressung, auf der konvexen Außenseite Zerrung eintreten. Tatsächlich ist ihr geologischer Bau, wie schon früher erwähnt, von einer auffallenden Gleichförmigkeit: die Innenseite trägt stets eine Reihe von Vulkanen, die Außenseite zeigt keinen Vulkanismus, aber starke Zerklüftung und Verwerfungen. Diese überall wiederkehrende Anordnung der Vulkane ist so auffallend, daß sie mir von der größten Bedeutung für die Frage nach dem Wesen der Vulkane zu sein scheint. v. Lozinski schreibt [191]: , In den Antillen kann man eine vulkanische Innenzone und zwei Außenzonen unterscheiden, von denen die äußerste aus jüngeren Ablagerungen aufgebaut ist und an Höhe zurücktritt (Suess). Der Gegensatz einer hochvulkanischen Innenzone und einer Außenzone mit zurücktretendem Vulkanismus kommt auch in den Molukken (Brouwer) und in Ozeanien (Arldt) zur Geltung. Die Analogie mit der Anordnung von Vulkanzonen auf der Innenseite von Schubzonen, wie im karpathischen oder varistischen Hinterlande, springt in die Augen." Die Lage des Vesuv, Ätna, Stromboli entspricht diesem Schema; von den Inseln des Südantillenbogens zwischen Feuerland und Grahamland ist gerade der stark gebogene mittelste Rücken der Süd-Sandwich-Inseln basaltisch, und einer seiner Vulkane ist noch tätig. Auf eine besonders interessante Einzelheit von den Sunda-Inseln haben wir schon früher hingewiesen: von den beiden südlichsten Inselketten trägt nur die einheitlich gebogene nördliche Vulkane, nicht die südliche (mit Timor), die, weil Außenkette, unter Zug steht und außerdem durch Kollision mit dem australischen Schelf bereits in umgekehrter Richtung gebogen wird. An einer Stelle aber, bei Wetter, ist auch die nördliche Kette bereits ein wenig eingebeult, weil die südliche (Nordostende von Timor) hier gegen sie drängt; und gerade an dieser Stelle ist auf der nördlichen Kette der Vulkanismus, der früher auch hier tätig war, erloschen, offenbar, weil hier die Biegung zurückgeht. Brouwer macht auch darauf aufmerksam, daß auch die gehobenen Korallen- 
riffe nur da vorkommen, wo der Vulkanismus fehlt oder erloschen ist, was gleichfalls darauf hindeutet, daß gerade diese Gebiete sich zusammenschieben. Das zunächst paradoxe Ergebnis, daß der Vulkanismus dort aufhört, wo Zusammenschub beginnt, findet im Rahmen unserer Vorstellungen eine ungezwungene Erklärung.

Es ist nicht undenkbar, daß in den ältesten vorgeologischen Zeiten die Sialhaut noch die ganze Erde umkleidete. Sie kann dann in jener Zeit nur etwa ein Drittel ihrer heutigen Mächtigkeit gehabt haben und muß mit einer „Panthalassa“ bedeckt gewesen sein, deren durchschnittliche Tiefe A. Penck zu 2,64 km berechnet, und die wohl nur wenige oder gar keine Teile der Erdoberfläche frei ließ.

Für die Richtigkeit dieser Vorstellung sprechen jedenfalls zwei Gründe, nämlich die Entwicklung des Lebens auf der Erde und der tektonische Bau der Kontinentalschollen.

Steinmann sagt [192]: ,,Es zweifelt wohl kaum jemand ernstlich daran, daß das Leben des Süßwassers sowie des festen Landes und der Luft aus dem des Meeres hervorgegangen ist." Vor dem Silur kennen wir keine luftatmenden Tiere; der älteste Landpflanzenrest stammt aus dem Obersilur von Gotland. Nach Gothan [193] sind noch aus dem älteren Devon hauptsächlich nur moosartige Pflanzen ohne eigentliches Laub bekannt. „,Spuren eigentlicher, spreitiger Blätter sind im älteren Devon selten. Fast alle Gewächse waren klein, krautig und von geringer Standfestigkeit." Dagegen wird die Flora im Oberdevon bereits der karbonischen ähnlich „durch das Auftreten großer, entwickelter, geaderter Blattspreiten, durch die durchgeführte Arbeitsteilung der Pflanze in bezug auf Ausbildung der tragenden und assimilierenden Organe... Der Charakter der Flora des älteren Devons, ihre niedrige Organisation, ihre geringe Größe usw. legt den Gedanken nahe, daß die Landflora dem Wasser entstammt, wofür sich schon Potonié, Lignier, Arber u. a. ausgesprochen haben. Die im Oberdevon beobachteten Fortschritte sind aufzufassen als Anpassung an die neue Lebensweise auf dem Lande, in der Luft."

Andererseits scheint es, als ob bei Ausglättung aller Falten in den Kontinentalschollen die Sialrinde tatsächlich genügend vergrößert wird, um sich um die ganze Erde herumzuschließen. Heute nehmen die Kontinentalschollen mit ihren Schelfen allerdings nur noch ein Drittel der Erdoberfläche ein, aber schon für das Karbon erhalten wir eine bedeutende Vergrößerung (auf etwa die Hälfte der Erdoberfläche). Je weiter wir aber in der Erdgeschichte zurück- 
gehen; um so umfangreicher sind die Faltungsvorgänge. E. Kayser [34] schreibt: „Es ist von großer Bedeutung, daß die ältesten archäischen Gesteine überall auf der Erde stark gestört und gefaltet sind. Erst vom Algonkium an finden sich neben gefalteten hier und da ungefaltete oder nur schwach gefaltete Ablagerungen. Gehen wir zur nachalgonkischen Zeit über, so sehen wir, wie die Ausdehnung und Zahl der starren unnachgiebigen Massen hier immer größer und dementsprechend der Umfang der faltbaren Krustenteile immer beschränkter wird. Dies gilt besonders für die karbonisch-permischen Stauungen. In nachpaläozoischer Zeit schwächten sich die faltenden Kräfte allmählich mehr und mehr ab, um indes in der jüngeren Jura- und der Kreidezeit wieder zu erwachen und in der jüngeren Tertiärzeit einen neuen Höhepunkt zu erreichen. Es ist aber sehr bezeichnend, daß das Verbreitungsgebiet dieser jüngsten großen Gebirgsstauung selbst hinter der karbonischen Faltung ganz beträchtlich zurückblieb."

Hiernach steht die Annahme, daß die Sialsphäre einstmals die ganze Erde umgab, jedenfalls nicht mit den sonstigen Anschauungen im Widerspruch. Diese verschiebbare und selber plastische Erdhaut wurde nun durch Kräfte, deren Natur im 9. Kapitel erörtert wurde, auf der einen Seite aufgerissen, auf der anderen zusammengeschoben. Die Entstehung und Erweiterung der Tiefsee stellt also nur die eine Seite dieses Prozesses dar, deren andere Seite in der Faltung besteht. Auch biologische Gründe scheinen dafür zu sprechen, daß die Tiefsee erst im Laufe der Erdgeschichte sich herausgebildet hat. So schreibt Walther [194]: „Allgemeine biologische Gründe, die stratigraphische Stellung der heutigen Tiefseefauna, ebenso wie tektonische Untersuchungen drängen uns die Überzeugung auf, daß die Tiefsee als Lebensbezirk keine primitive Eigenschaft der Erde aus den ältesten Perioden ist, und daß ihre erste Anlage in dieselbe Zeit fällt, wo in allen Teilen der jetzigen Kontinente tektonische Faltungsbewegungen einsetzen und das Relief der Erdoberfläche so wesentlich umgestalten." Die ersten Risse der Sialsphäre, in denen die Simasphäre zum ersten Male zutage trat, mögen denen ähnlich gewesen sein, welche heute die ostafrikanischen Gräben bilden. Sie öffneten sich um so weiter, je größere Fortschritte die Faltung des Sials machte. Es war ein Vorgang, den wir etwa mit dem Zusammenfalten eines runden Papierlampions vergleichen können. Auf der einen Seite Öffnung, auf der anderen Zusammenschub. Höchstwahrscheinlich ist es die Fläche des allgemein für sehr alt gehaltenen Pazifischen 
Ozeans, die auf diese Weise zuerst ihres Sialmantels beraubt wurde. Es wäre nicht undenkbar, daß die alten Faltungen in den Gneismassiven Brasiliens, Afrikas, Vorderindiens und Australiens das Äquivalent dieser Öffnung des Pazifik darstellen.

Diese Zusammenschübe der Sialsphäre mußten natürlich eine Verdickung und damit ein Herauswachsen zur Folge haben, während gleichzeitig die Tiefseebecken geräumiger wurden. Die Überflutungen der Kontinentalschollen mußten daher - abgesehen von ihrem Ortswechsel - im Laufe der Erdgeschichte im ganzen immer mehr abnehmen. Dies Gesetz ist allgemein anerkannt. Es geht auch aus der Betrachtung unserer drei Rekonstruktionskarten (S. 18) sehr deutlich hervor.

Es ist wichtig, $\mathrm{zu}$ beachten, daß der Entwicklungsprozeß der Sialrinde ein einseitiger sein mußte, auch wenn die Kräfte wechselten. Denn Zugkräfte können die Falten einer Kontinentalscholle nicht wieder glätten, sondern sie

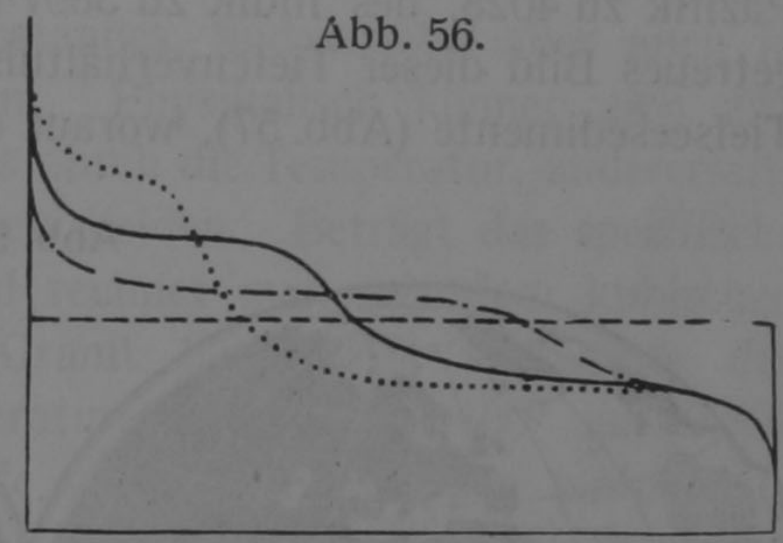

Ehemalige und künftige hypsometrische Kurve der Erdoberfläche. … für die Zukunft, — für die Gegenwart, - - - für die Vorzeit, - - im Urzustand (zugleich mittleres Krustenniveau). höchstens zerreißen. Ein wechselndes Spiel der Druck- und Zugkräfte ist also nicht imstande, seine Wirkungen selbst wieder aufzuheben, sondern erzeugt einseitig fortschreitende Wirkungen: Zusammenschub und Zerteilung. Die Sialdecke wird im Laufe der Erdgeschichte immer kleiner (an Oberfläche) und dicker, aber sie wird auch immer mehr zerteilt. Diese Dinge ergänzen einander und sind Wirkungen derselben Ursachen. In Abb. 56 sind die hypsometrischen Kurven dargestellt, welche hiernach für die Vorzeit, Gegenwart und Zukunft anzunehmen wären. Das mittlere Krustenniveau stellt zugleich die ursprüngliche Oberfläche der noch ungespaltenen Sialsphäre dar.

Andererseits besteht die Möglichkeit, das Becken des Pazifischen Ozeans als die Spur der Mondablösung nach Darwins Ideen zu betrachten. Dann wäre bei diesem Vorgang ein Teil der Sialkruste der Erde verlorengegangen. Der einzige Weg, zu einem Urteil hierüber zu kommen, scheint mir der zu sein, daß man den Grad der Zusammenfaltung der Sialschollen abzuschätzen sucht. Dazu liegt aber bisher wohl noch keine Möglichkeit vor.

Wegener, Kontinente und Ozeane. 4. Aufl. 


\section{Elftes Kapitel.}

\section{Ergänzende Bemerkungen über die Tiefseeböden.}

Morphologisch tritt das Tiefseegebiet als einheitliches Ganzes den Kontinentalschollen gegenüber. Die Tiefen der drei großen Ozeane sind aber doch nicht genau dieselben. Kosisinna [29] berechnet nach den Grollschen Tiefenkarten die mittlere Tiefe des Pazifik zu 4028, des Indik zu 3897 und des Atlantik zu 3332 m. Ein getreues Bild dieser Tiefenverhältnisse gibt auch die Verteilung der Tiefseesedimente (Abb. 57), worauf einst Krümmel mich persönlich

\section{Abb. 57.}

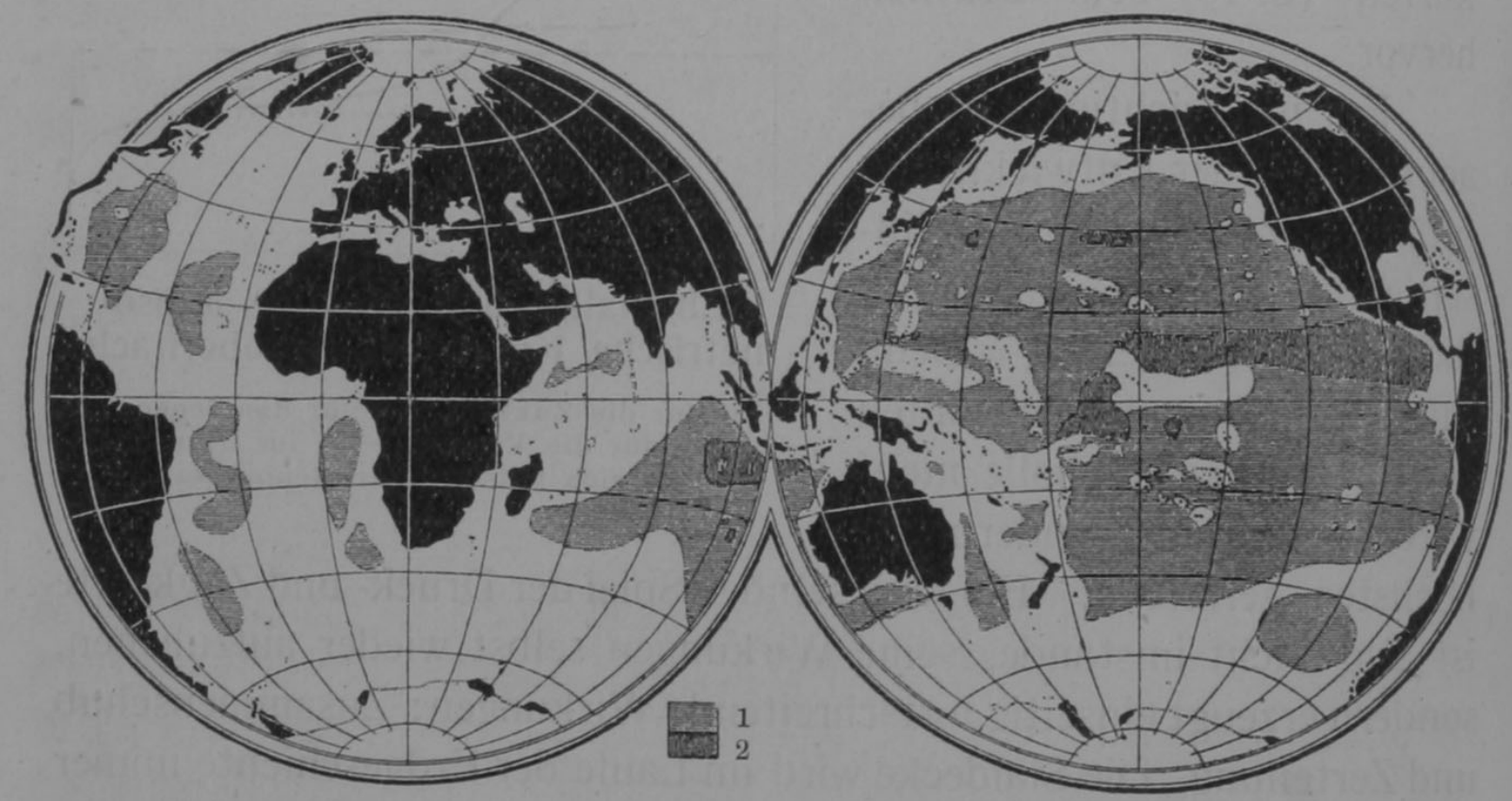

Karte der Tiefseesedimente, nach Krümmel [30].

1 roter Tiefseeton, 2 Radiolarienschlamm.

hinwies. Der rote Tiefseeton und der Radiolarienschlamm, die beiden echt „abyssischen“ (Tiefsee-) Sedimente, sind wesentlich auf den Pazifik und östlichen Indik beschränkt, während Atlantik und westlicher Indik von „epilophischen“ Sedimenten bedeckt sind, deren größerer Kalkgehalt mit der geringeren Meerestiefe ursächlich verknüpft ist. Daß diese Tiefenunterschiede keine zufälligen sind, sondern von systematischer Art, und daß sie mit dem Unterschied zwischen ,atlantischem" und ,pazifischem" Küstentyp zusammenhängen, zeigt am besten der Indik, dessen Westhälfte atlantischen und dessen Osthälfte pazifischen Charakter trägt. Denn hier ist 
wiederum die Osthälfte erheblich tiefer als die Westhälfte. Diese Dinge haben für die Verschiebungstheorie deshalb ein besonderes Interesse, weil ein Blick auf die Karte zeigt, daß es gerade die ältesten Tiefseeböden sind, welche die größte Tiefe haben, während diejenigen, welche erst vor relativ kurzer Zeit entblößt sind, die geringste Tiefe zeigen. So sieht man in Abb. 57 in überraschender Weise sozusagen die Spur der Verschiebungen.

Über die Ursache dieses Tiefenunterschiedes haben wir heute noch keine gefestigten Vorstellungen. Sie kann einerseits in Unterschieden des physikalischen Zustandes, andererseits aber auch in Materialverschiedenheit bestehen. Physikalisch können sich alte und junge Tiefseeböden einerseits durch die Temperatur, andererseits durch den Aggregatzustand unterscheiden. Beträgt das spezifische Gewicht des Materials 2,9, und rechnet man mit dem kubischen Ausdehnungskoeffizienten für Granit 0,0000269, so würde das spezifische Gewicht bei Temperaturerhöhung um $100^{\circ}$ auf 2,892 verändert. Zwei bis $60 \mathrm{~km}$ Tiefe um $100^{\circ}$ verschieden temperierte Tiefseeböden, die untereinander im isostatischen Gleichgewicht stehen, müßten dann einen Tiefenunterschied von $160 \mathrm{~m}$ aufweisen, um welche der wärmere Boden höher liegt.

Andererseits ist es auch nicht unwahrscheinlich, daß bei relativ frisch entblößten Tiefseeböden die kristalline Erstarrungsdecke wesentlich dünner ist als bei alten, wodurch ebenfalls. Unterschiede des spezifischen Gewichts und also der Tiefe erzeugt werden können. Drittens besteht auch dann, wenn man die Ozeanbeckén alle auf gleiche Weise entstanden denkt, die Möglichkeit, bei den großen Zeitunterschieden ihrer Entstehung auch Materialverschiedenheiten anzunehmen, da sich im Laufe langer geologischer Zeiten das Magma - etwa durch fortschreitende Kristallisationsprozesse oder auf anderem Wege - verändern kann und vermutlich auch verändert hat. Und schließlich können die Simaflächen in verschiedenem Grade mit Fließresten der unteren Partien der Kontinentalschollen, sowie randlichen Abfallprodukten derselben bedeckt sein.

Unsere Vorstellungen von dem Material oder den Materialien, mit denen wir es beim Tiefseeboden zu tun haben, sind gegenwärtig, wie schon früher erwähnt, sehr im Fluß, so daß es sich nicht verlohnt, hier alle dazu geäußerten Meinungen anzuführen. Ich möchte mich deshalb darauf beschränken, nur die am besten untersuchten Verhältnisse beim Atlantischen Ozean zu besprechen, wo ohnehin die breite 
mittelatlantische Bodenschwelle eine Erscheinung darstellt, mit der sich auch die Verschiebungstheorie auseinandersetzen muß.

Schon vor langer Zeit ist man darauf aufmerksam geworden, daß der Tiefseeboden über weite Strecken oft erstaunlich geringe Höhenunterschiede zeigt. Solche auffallend ebenen Tiefseegebiete sind bisher hauptsächlich durch die engen Lotungsreihen bei Kabellegungen gefunden worden. So erwähnt Krümmel [30], daß im Pazifischen Ozean auf der $1540 \mathrm{~km}$ langen Strecke zwischen den Midway-Inseln und Guam alle 100 Lotungen zwischen 5510 und $6277 \mathrm{~m}$ Tiefe lagen. Auf einer $180 \mathrm{~km}$ langen Teilstrecke waren bei einer mittleren Tiefe von $5938 \mathrm{~m}$ die größten Abweichungen der

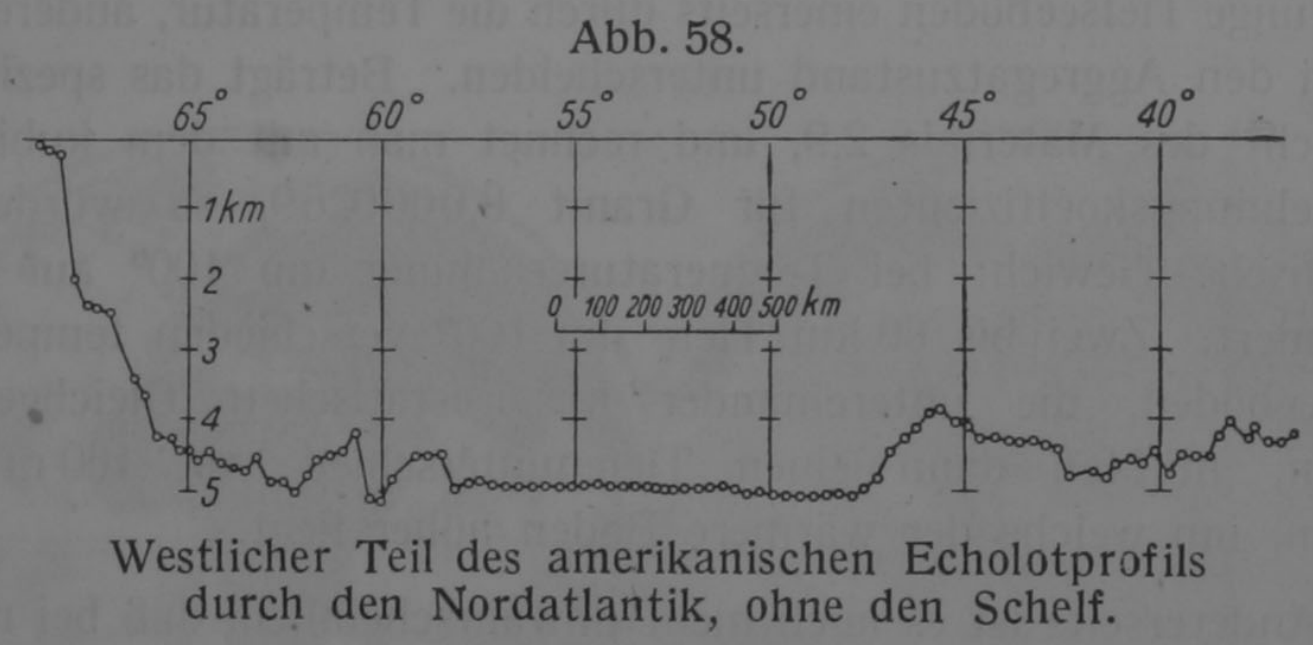

14 Lotungen nur +36 und $-38 \mathrm{~m}$. Auf einem anderen Stücke von $550 \mathrm{~m}$ Länge waren bei $5790 \mathrm{~m}$ Mitteltiefe die größten Abweichungen der 37 Lotungen +103 und $-112 \mathrm{~m}$. Solche engen Lotungsreihen können neuerdings in bequemer Weise vom fahrenden Schiffe aus mittels des Echolotes gewonnen werden. Aus dem Bereich des Atlantik werden in kurzem die zahlreichen Profile, die die deutsche „Meteor“-Expedition gewonnen hat, weitere Beiträge hierzu liefern. Nach dem ersten, von amerikanischer Seite erhaltenen Echolotprofil durch den Nordatlantik habe ich [197] den westlichen Teil, der das Tiefseebecken der Sargassosee noch gerade in deren nördlichstem Teile schneidet, in Abb. 58 dargestellt, welche zwischen 58 und $4712^{0}$ Länge (auf $930 \mathrm{~km}$ ) bei einer Mitteltiefe von $5132 \mathrm{~m}$ als größte Abweichungen -121 und +108 m zeigt. In Teilstrecken ist die Tiefenkonstanz noch viel auffallender, z, B. liegen acht aufeinanderfolgende Messungen (mit je $28 \mathrm{~km}$ Zwischenraum) zwischen 2780 und 2790 Faden (10 Faden war die Genauigkeitsgrenze der Messungen). 
Im Gegensatz zu dieser Gleichförmigkeit zeigen die übrigen, immer noch der Tiefsee angehörigen, wenngleich weniger tiefen Teile der Route ein unruhiges Profil.

Ich habe hieraus geschlossen, daß im Bereich der Sargassosee, wo die Tiefe so auffallend konstant ist, die Simaoberfläche entblößt ist, während den anderen Partien mit unruhigem Bodenrelief vermutlich eine Sialbedeckung von wechselnder, im allgemeinen erheblich geringerer Mächtigkeit als bei den Kontinentalschollen entspricht. Wenn man hiernach die Annahme macht, daß alle unter $5000 \mathrm{~m}$ Tiefe gelegenen Teile des Ozeanbodens ungefähr den freien Simaflächen entsprechen, so würde Abb. 59 die oberflächliche Verteilung des Sials und Simas am Boden des Atlantik zeigen ${ }^{1}$ ).

Dabei entsteht nun aber eine gewisse Schwierigkeit. Wenn wir nämlich annehmen, daß diese Sialmassen die Reste eines bei der Trennung in Trümmer gegangenen Streifens darstellen, so wird dieser Streifen auffallend breit. Auf der in Abb. 59 eingezeichneten Route des ersten transatlantischen Echolotprofils z. B. würden wir es mit den auseinandergezogenen Trümmern eines $1300 \mathrm{~km}$ breiten Streifens zu tun haben. Im Südatlantik würden wir allerdings kleinere Werte erhalten, da die mittelatlantische Bodenschwelle hier schmaler ist und beiderseits, nicht wie auf der genannten Route nur im Westen, an Tiefseebecken grenzt. Genauere Angaben werden sich erst auf Grund der Echolotungen der „Meteor"-Expedition machen lassen, aber immerhin würde man wohl auch hier auf ein in Trümmer gegangenes Zwischengebiet von etwa 500 bis $800 \mathrm{~km}$ kommen. Dies ist zwar nicht gerade widersinnig, erscheint mir aber doch schon

1) Gutenberg hat unter der gleichen Annahme, daß nur die zwei Materialien Sial und Sima in Betracht kommen, eine andere Ansicht geäußert und sie als „Fließtheorie“ der Verschiebungstheorie gegenübergestellt [196]. Er glaubt, ,daß eine einzige Sialscholle auf dem Sima schwimmt, das nur im Pazifischen Ozean zutage tritt". Er rechnet also den Boden des Atlantik und Indik mit zur Kontinentalscholle und nimmt an, daß sich diese hier durch Fließen auf die Hälfte verflacht habe. Dies kann aber nicht richtig sein. Schon wenn wir die Wasserlast außer Betracht lassen, müßte die Tiefe des Atlantik (und Indik) dann nur halb so groß sein wie die des Pazifik, und durch das Wasser müßte sich der Unterschied aus isostatischen Gründen noch vergrößern. Gutenbergs Ansicht wird also durch die morphologische Gleichartigkeit des Gesamtozeanbodens und seinen Gegensatz zu den Kontinentalschollen widerlegt; auch genügt eine Annäherung der Kontinente in den $\mathrm{Re}$ konstruktionen bis auf die Hälfte ihres heutigen Abstandes nicht den Forderungen der Geologie, Biologie und Paläoklimatologie, und schließlich bliebe die auffallende Kongruenz der heutigen Schollenränder rätselhaft. 
reichlich viel, denn die hier so auffallende Kongruenz der heutigen Schollenränder von Südamerika und Afrika scheint doch anzudeuten, daß diese Ränder ziemlich unmittelbar zusammengehangen haben. Und auf ähnliche, wenn auch nicht sehr bedeutende Schwierigkeiten dieser Art stößt man noch an verschiedenen anderen Stellen

Abb. 59 .

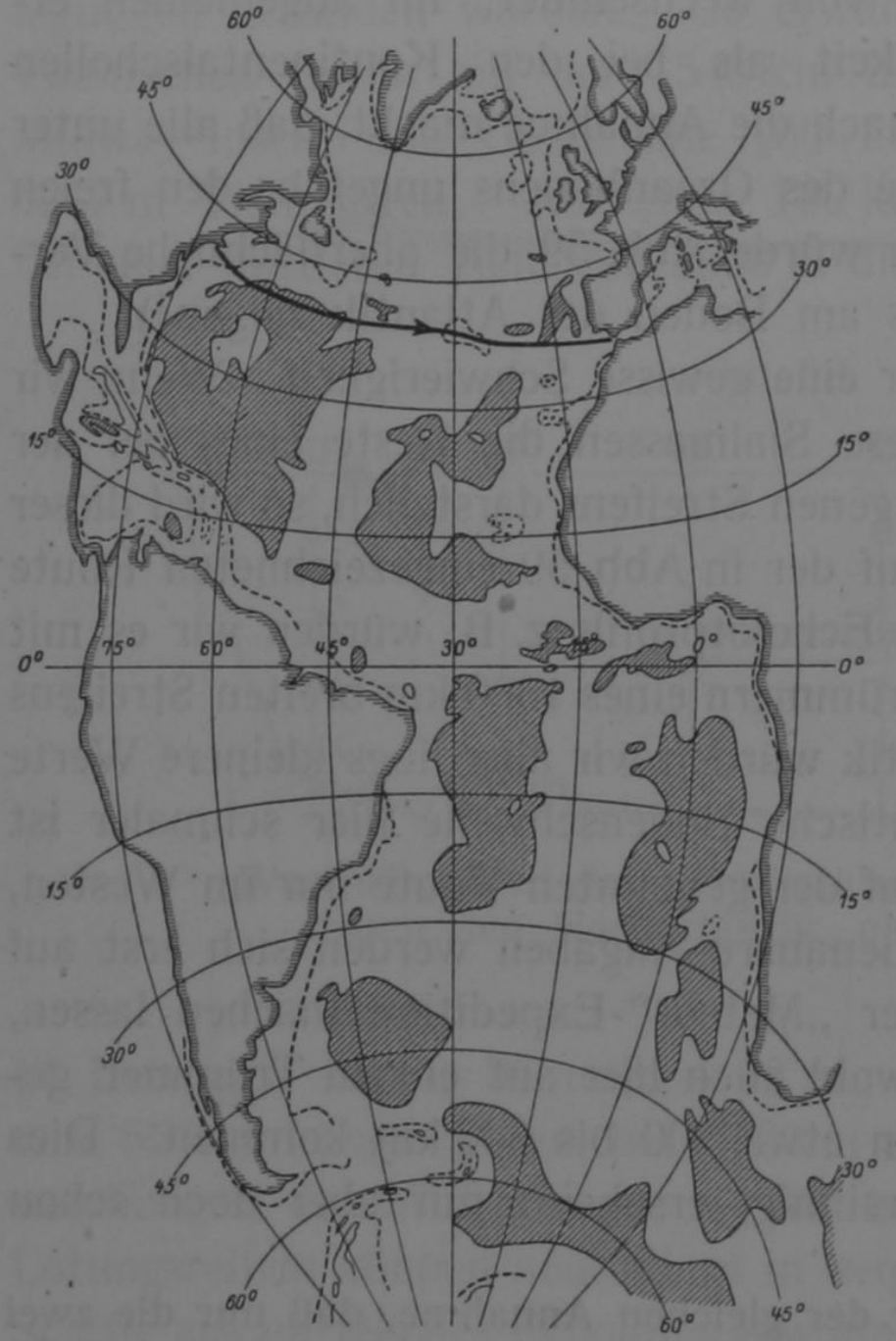

Die unter $5000 \mathrm{~m}$ Tiefe liegenden Flächen des atlantischen Meeresbodens.

in unseren Rekonstruktionen.

Es erscheint mir gegenwärtig als das Wahrscheinlichste, daß diese kleine Unstimmigkeit dadurch verursacht wird, daß wir nur mit den zwei Schichten Sial und Sima gerechnet haben, während in Wirklichkeit die Verhältnisse komplizierter liegen. Nehmen wir in Übereinstimmung mit dem, was aus den neuesten geophysikalischen Untersuchungen immer deutlicher hervorzutreten scheint, statt dessen an, daß wir normalerweise bis $30 \mathrm{~km}$ Tiefe die aus Granit bestehenden Kontinentalschollen und darunter bis $60 \mathrm{~km}$ Tiefe Basalt haben, und unter letzterer Tiefe ein ultrabasisches Gestein (Dunit), so kommt man zu einer Erklärung, die allen heute bekannten Tatsachen völlig befriedigend entspricht. Die Granittafeln der Kontinente sind wirklich zerrissen, wie es in der Verschiebungstheorie angenommen wird, abgesehen von gewissen in der Tiefe geschmolzenen Teilen und von den bei der Trennung erzeugten Randbrocken, die heute als Inseln die mittelatlantische Bodenschwelle krönen. War die basaltische Schicht unter dem Granit wirklich, wie es angenommen ist, besondérs fluid, so mußte sie bei der immer weiter fortschreitenden 
Öffnung der atlantischen Spalte in dieser emporquellen und im weiteren Verlauf ständig von beiden Seiten her nachfließen; sie wird also zunächst überall den Boden des Ozeans gebildet haben und noch heute den größten Teil desselben bilden. Bei immer weiter gehender Öffnung mußte aber schließlich die Fließfähigkeit auch dieses Materials unzureichend werden und der darunterliegende Dunit fensterartig zutage treten (vgl. Abb. 60). Im Nordmeer, wo die Trennung der Schollen noch nicht weit fortgeschritten ist, wird der Boden - abgesehen von Granitresten - ganz aus Basalt bestehen, der hier noch von bedeutender Mächtigkeit sein wird. In den großen Räumen des Pazifik dagegen werden entsprechend große Dunitflächen entblößt sein, während die flacheren Teile auch hier noch die Basaltdecke tragen, die stellenweise sogar von Granitresten gekrönt sein dürfte.

Abb. 60.

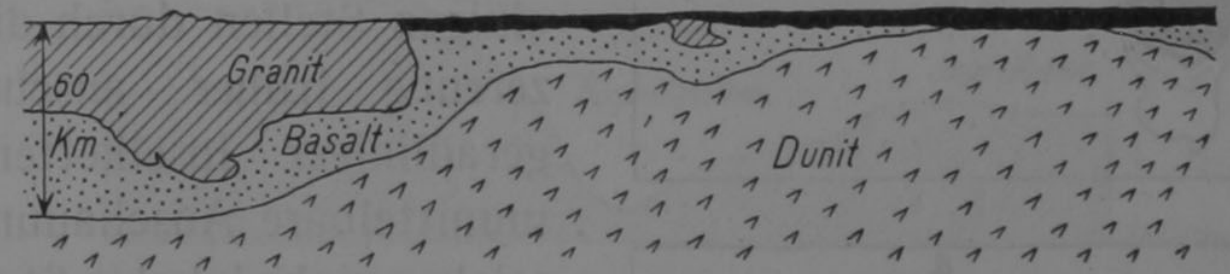

Idealer Schnitt durch Kontinentalscholle und Tiefseeboden.

Natürlich ist dies Bild noch ganz hypothetisch. Ich glaube aber an meiner ursprünglichen Annahme eines ziemlich unmittelbaren ehemaligen Zusammenhanges der Kontinentalschollen nach der Gesamtheit der geologischen, biologischen und paläoklimatischen Argumente festhalten zu müssen; die neuen geophysikalischen Untersuchungen widersprechen dem, wie gezeigt wurde, keineswegs, sondern sind umgekehrt, wie es scheint, geeignet, die Schwierigkeit zu beseitigen, die in dem Umstand liegt, daß zwischen solchen, früher offenbar nach ihren Kanten unmittelbar zusammenhängenden Schollen heute unregelmäßige Bodenerhebungen von der Art der mittelatlantischen Schwelle liegen. Daß daneben gelegentlich auch noch die Kontinentalschollen selbst, wie Gutenberg will, sich durch Fließbewegungen ,,ausgezogen“ haben können, soll keineswegs bestritten werden; wir haben an verschiedenen Stellen, wie namentlich beim Ägäischen Meer, von dieser Vorstellung Gebrauch gemacht. Doch dürfte das eigentliche Fließen auch hier auf die tieferen Schichten beschränkt sein, während die Oberflächenschichten durch Brüche zerstückelt werden. 
Da gegenwärtig über die Frage, wieweit Basalt oder Dunit als Material der Tiefseeböden in Frage kommt, noch keine Einigkeit unter den Geophysikern erzielt ist, wollen wir im folgenden der Kürze

Abb. 61 .
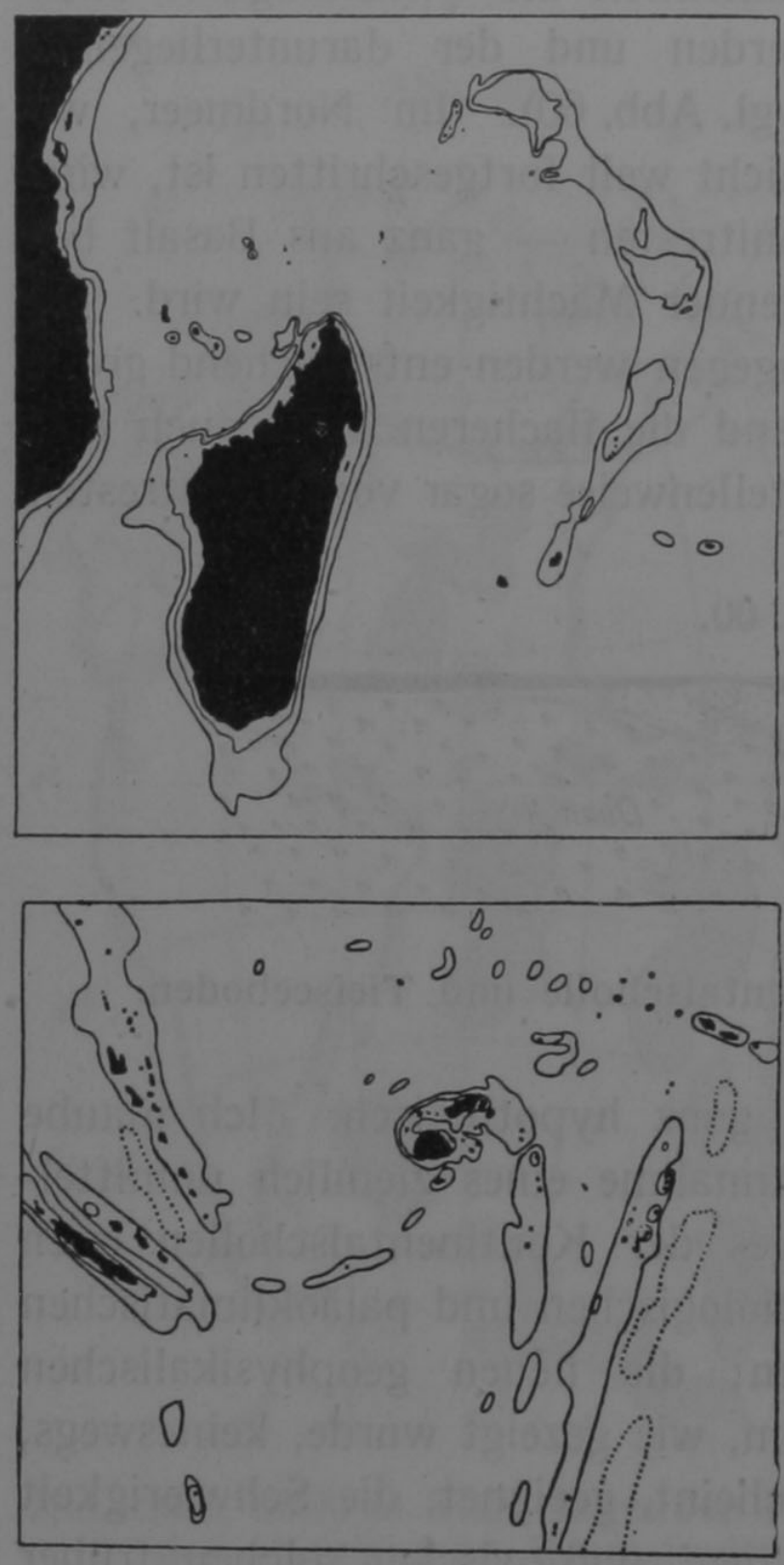

Oben: Madagaskar und SeychellenBank.

Unten: Die Fidschi-Inseln.

(Tiefenlinien 200 und $2000 \mathrm{~m}$; Tiefseerinnen punktiert.) halber wieder zu der bloßen Unterscheidung zwischen Sial und Sima zurückkehren.

Wenn das Sima wirklich ein zähflüssiger Körper ist, so wäre es merkwürdig, wenn sich seine Fähigkeit zu strömen nur im Ausweichen vor den triftenden Sialschollen äußerte, und nicht auch Strömungen selbständigeren Charakters aufträten. Die Karte gibt an einigen Stellen durch die Verzerrung früher anscheinend geradliniger Inselketten eine unmittelbare Anschauung von solchen mehr lokalen Strömungen des Simas. In Abb. 61 sind zwei Beispiele dafür gegeben, nämlich das der Seychellen und das der FidschiInseln. Der halbmondförmige Seychellenschelf, der die einzelnen, aus Granit bestehenden Inseln trägt, läßt sich weder Madagaskar noch Vorderindien anpassen, deren geradlinige Konturen vielmehr auf einstigen unmittelbaren $\mathrm{Zu}-$ sammenhang deuten. So liegt die Deutung nahe, daß es sich um geschmolzene, von der Unterseite der Scholle aufgestiegene Sialmassen handelt, die dann von dem Simastrom entführt wurden und in der Richtung auf Vorderindien bereits ein gut Stück Weges zurückgelegt haben. Dieser Simastrom, dem auch Madagaskar schon folgt, "läuft" genau in der Spur Vorderindiens, vielleicht durch dessen Ver- 
schiebung erzeugt, vielleicht auch umgekehrt letztere erzeugend, worauf das Abbrechen Ceylons hindeutet. Die Bewegungen in Flüssigkeiten, auch in zähen, sind nur selten so einfacher Art, daß man Ursache und Wirkung klar auseinanderhalten kann, und unsere Kenntnis dieser Dinge ist noch allzu lückenhaft. Es ist deshalb töricht, von der Verschiebungstheorie zu verlangen, daß sie jede in Erscheinung tretende relative Bewegung in ihr System eingliedern und erklären könne. Wir betrachten diese Dinge nur zur Erläuterung von Fließerscheinungen im Sima, und diese letzteren gehen besonders aus den zurückgebogenen Enden des Schelfs hervor, welche zeigen, daß die Bewegung des Simastroms von der Mittellinie Madagaskar-Vorderindien beiderseits abnimmt. Wir können auch

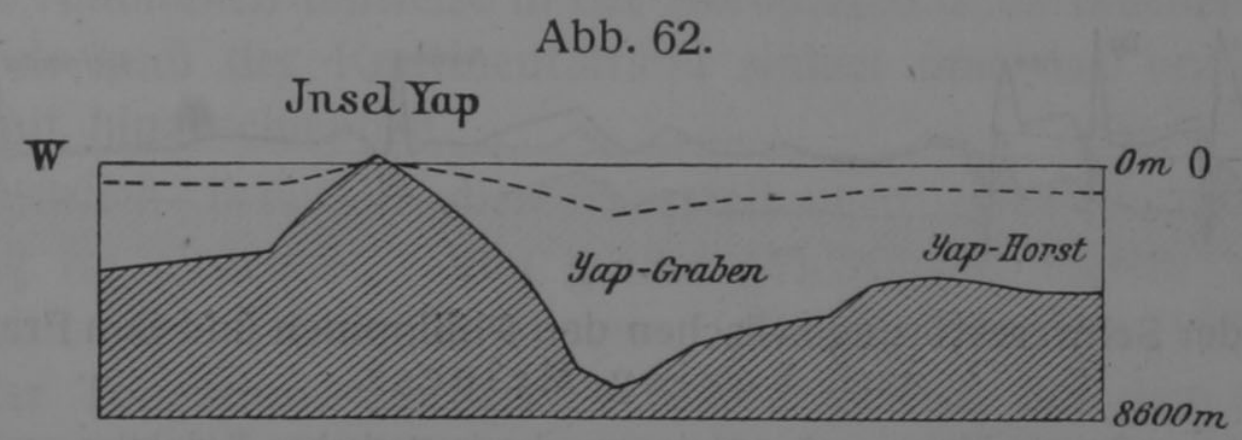

Fünffach übertiefter Querschnitt durch die Yap-Rinne, nach G. Schott und P. Perlewitz.

(Oben gestrichelt die natürlichen Maßverhältnisse.)

sagen: der Strom läuft am stärksten im frisch entblößten Sima, während die älteren Tiefseeböden nordwestlich und südöstlich davon sich langsamer bewegen. Die zweite Figur zeigt in der Gruppe der Fidschi-Inseln eine Form, die an einen zweiarmigen Spiralnebel erinnert und auf eine spiralige Fließbewegung schließen läßt. Ihre Entstehung scheint mit der Bewegungsänderung zusammenzuhängen, welche Australien erfuhr, als es seine letzte Verbindung mit Antartika zerriß und unter Zurücklassung der Girlande Neuseeland seine noch heute erkennbare Bewegung nach Nordwesten begann. Vermutlich bildeten die Fidschi-Inseln vor diesem Zusammenrollen eine parallel neben dem Tongarücken liegende Kette, und beide zusammen eine äußere Girlande der Scholle Australien-Neuguinea, die, wie alle ostasiatischen Girlanden, außen an dem alten Tiefseeboden hafteten und sich daher innen von der Kontinentalscholle lösten; die innere Kette wurde beim Abzug der Scholle wirbelartig zusammengestreift. Die neuen Hebriden und Salomoninseln dürften zwei weitere, gestaffelte Girlanden sein, die unterwegs liegengeblieben 
sind ${ }^{1}$ ). Vom Bismarckarchipel ist dabei Neupommern, wie früher erwähnt, an Neuguinea haftengeblieben und herumgeschleppt worden, während auf der anderen Seite der großen australischen Scholle das spiralige Umbiegen der beiden südlichsten Ketten der Sundainseln eine ähnliche Wirbelströmung im Sima andeutet wie bei den Fidschi-Inseln.

Über die Natur der Tiefseerinnen²) läßt sich wohl auf Grund der bisherigen Beobachtungen noch kein abschließendes Bild gewinnen. Sie sind, mit wenigen Ausnahmen von vielleicht anderer Entstehung, stets den Außen-(konvexen) Seiten der Girlanden vorgelagert, wo diese an alten Tiefseeboden stoßen, während auf

Abb. 63.

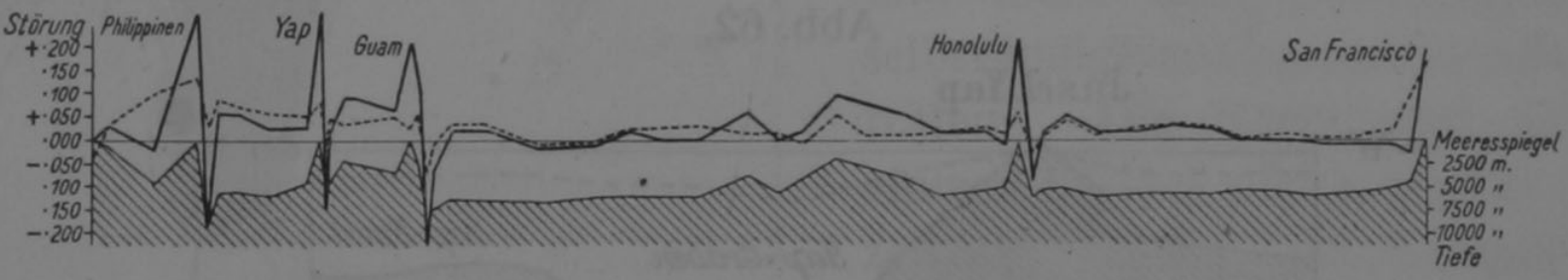

Verlauf der Schwerestörung zwischen den Philippinen und San Franzisko, nach Vening-Meinesz.

Skala links; punktierte Linie: nach Anbringung der isostatischen Reduktion, schraffiert: Meeresboden, Tiefenskala rechts.

der Innenseite der Girlande, wo der neu entblößte Tiefseeboden fensterartig zutage liegt, niemals eine Rinne zu treffen ist. Es scheint also, als sei der alte Tiefseeboden infolge seiner tiefer gehenden Abkühlung und Erhärtung allein dazu befähigt, Rinnen zu bilden. Vielleicht darf man sie als Randspalten auffassen, deren eine Seite vom Sial der Girlande, und deren andere vom Sima des Tiefseebodens gebildet wird. Daran darf das in Abb. 62 dargestellte, in Wirklichkeit sehr flache Profil nicht irremachen, denn es ist natürlich durch die Schwere stark eingeebnet.

Bei der tiefen, rechtwinklig gebogenen Rinne südlich und südöstlich der Insel Neupommern beruht die Entstehung offensichtlich auf dem gewaltsamen Fortzerren der Insel nach Nordwesten infolge Anhaftens an Neuguinea; die tief hinabreichende Inselscholle pflügt das

1) Hedley kommt auch auf biologischem Wege zu dem Resultat, daß Neuguinea mit Neukaledonien, den Neuen Hebriden und den Salomoninseln eine Einheit bildet.

$\left.{ }^{2}\right)$ Die Bezeichnung ,Tiefseegraben“ ist weniger glücklich, da sie die Behauptung einschließt, daß es sich um Grabenbrüche ähnlich denen der Kontinentalschollen handelt. 
Sima, welches nachstıömend das Loch noch nicht ganz gefüllt hat. Es ist dies vielleicht derjenige Fall, wo wir uns am genauesten Rechenschaft über die Entstehung einer Tiefseerinne ablegen können.

Für die Atakamarinne westlich von Chile scheint sich die Möglichkeit noch einer anderen Erklärung zu ergeben. Berücksichtigen wir nämlich, daß sich bei der Aufstauung dieses Gebirges alle Schichten unterhalb des Tiefseeniveaus nach unten stauchen, so muß hierdurch auch der benachbarte Tiefseeboden mit hinabgezogen werden ${ }^{1}$ ). Dazu kommt noch ein weiterer Grund für das Sinken des Kontinentalrandes, nämlich die Abschmelzung der nach unten gerichteten Gebirgsfaltung und die durch die Westwanderung der Scholle bewirkte Entführung der geschmolzenen Massen nach Osten, wo sie nach unseren Annahmen teilweise in der Abrolhosbank, auftauchen. Auch hierdurch muß der Kontinentalrand sinken und das benachbarte Sima mit hinabschleppen.

Natürlich bedürfen diese Vorstellungen noch durchaus der Prüfung im einzelnen. Von großer Wichtigkeit hierfür sind die Ergebnisse der Schweremessungen. Bereits Hecker [198] hatte über der Tongarinne ein starkes Schweredefizit, auf dem benachbarten Tongaplateau dagegen einen Schwereüberschuß gefunden. Dies wurde neuerdings von Vening Meinesz [39] an einer großen Zahl von Tiefseerinnen bestätigt. Wir geben hier aus seinen Veröffentlichungen das in Abb. 63 dargestellte Schwereprofil zwischen den Philippinen und San Franzisko wieder, in dem auch das Bodenprofil eingezeichnet ist. Hier wurden vier Rinnen gekreuzt, und der Schwereverlauf war überall der gleiche: über der Rinne selbst ein Defizit, über der daneben gelegenen Erhebung ein Überschuß. Diese Gesetzmäßigkeit scheint zu zeigen, daß in der Rinne der isostatische Ausgleich durch Nachströmen des Simas noch nicht erfolgt ist; die Anordnung läßt sich vielleicht dadurch erklären, daß die die Erhebung darstellende Scholle eine schiefe Lage besitzt (vgl. Abb. 52, S. 201). Doch sind weitere Forschungen nötig, ehe man zu einem abschließenden Urteil gelangen kann.

1) Der von Ampferer, A. Penck u. a. gemachte Einwand, bei der Bewegung Amerikas nach Westen müßte sich vor dem Schollenrand ein Simagebirge auftürmen, ist unzutreffend, wenn, wie wir annehmen müssen, alle Faltung sich unter Wahrung der Isostasie vollzieht. Die ausweichende Bewegung des Simas kann wegen seiner Schwere nicht nach oben gehen, sondern nur nach unten, und unterhalb der Kontinentalscholle nach rückwärts, genau wie die Bewegung des Wassers, wenn ein schwimmender Körper langsam durch dasselbe fortgezogen wird. 


\section{Anhang.}

Während des Druckes ist eine Bestätigung der im 3. Kapitel geforderten Abstandsvergrößerung zwischen Nordamerika und Europa erbracht worden, die wir dem Leser nicht vorenthalten wollen. F. B. Littell und J. C. Hammond haben nämlich die Ergebnisse der im Oktober und November 1927 zwischen Nordamerika und Europa ausgeführten Längendifferenzenbestimmungen mitgeteilt, und dieselben mit den 1913/14 erhaltenen Messungen verglichen ${ }^{1}$ ).

Der Längenunterschied Washington-Paris ergab sich 1927 zu

$$
5^{\mathrm{h}} 17^{\mathrm{m}} 36,665^{\mathrm{s}} \pm 0,0019^{\mathrm{s}}
$$

dagegen $1913 / 14$

$$
\begin{aligned}
& 5^{\mathrm{h}} 17^{\mathrm{m}} 36,653^{\mathrm{s}} \pm 0,0031^{\mathrm{s}} \\
& 5^{\mathrm{h}} 17^{\mathrm{m}} 36,651^{\mathrm{s}} \pm 0,003^{\mathrm{s}}
\end{aligned}
$$

Von den beiden Angaben für 1913/14 bezieht sich die erste auf die Messungen der amerikanischen, die zweite auf die der französischen Beobachter.

Aus dem Vergleich dieser Zahlen ergibt sich, daß der Längenunterschied Washington-Paris im Laufe von 13 bis 14 Jahren um den Betrag von

$$
0,013^{\mathrm{s}} \pm \text { etwa } 0,003^{\mathrm{s}}
$$

das ist in linearem Maß etwa um

$$
4,35 \mathrm{~m} \text { 土etwa } 1,0 \mathrm{~m}
$$

gewachsen ist. Dies entspricht einer jährlichen Vergrößerung des Abstandes um etwa

$$
0,32 \mathrm{~m} \pm \text { etwa } 0,08 \mathrm{~m}
$$

Sinn wie Betrag dieser Änderung stehen in bester Übereinstimmung mit den im 3. Kapitel erläuterten Folgerungen aus der Verschiebungstheorie.

1) F. B. Littell and J. C. Hammond, World Longitude Operation. The Astronomical Journal 38, No. 908, S. 185, 14. Aug. 1928. 


\section{Literatur.}

[1] A. Wegener, Die Entstehung der Kontinente. Peterm. Mitt. 1912 , S. $185-195,253-256$, 305-309.

[2] A. Wegener, Die Entstehung der Kontinente. Geol. Rundsch. 3, Heft 4, S. 276-292, 1912.

[3] A. Wegener, Die Entstehung der Kontinente und Ozeane. Samml. Vieweg, Nr. 23, 94 S., Braunschweig 1915; 2. Aufl., Die Wissenschaft, Nr. 66, 135 S., Braunschweig 1920; 3. Aufl. 1922.

[4] Carl Freiherr Löffelholz von Colberg, Die Drehung der Erdkruste in geologischen Zeiträumen. 62 S. München 1886. (2., sehr vermehrte Aufl., 247 S. München 1895.)

[5] D. Kreichgauer, Die Äquatorfrage in der Geologie, 304 S., Steyl 1902; 2. Aufl. 1926.

[6] H. Wettstein, Die Strömungen der,Festen, Flüssigen und Gasförmigen und ihre Bedeutung für Geologie, Astronomie, Klimatologie und Meteorologie. $406 \mathrm{~S}$. Zürich 1880.

[7] E. H. L. Schwarz, Geol. Journ. 1912, S. 294-299.

[8] Pickering, The Journ. of Geol. 15, Nr. 1, 1907; auch Gaea 43, $385,1907$.

[9] W. Franklin Coxworthy, Electrical Condition or How and Where our Earth was created. London, W. J. S. Phillips, 1890 (?).

[10] F. B. Taylor, Bearing of the tertiary mountain belt on the origin of the earth's plan. B. Geol. S. Am. 21 (2), 179-226, Juni 1910.

[11] Th. Arldt, Handb. d. Paläogeographie. Leipzig 1917.

[12] E. Suess, Das Antlitz der Erde 1, 1885.

[13] Ampferer, Über das Bewegungsbild von Faltengebirgen. Jahrb. d. k. k. Geol. Reichsanstalt 56, 539-622. Wien 1906.

[14] Reyer, Geologische Prinzipienfragen. Leipzig 1907.

[15] M. P. Rudzki, Physik der Erde. Leipzig 1911.

[16] K. Andrée, Über die Bedingungen der Gebirgsbildung. Berlin 1914.

[17] A. Heim, Bau der Schweizer Alpen. Neujahrsblatt d. Naturf. Ges. Zürich 1908, 110. Stück.

[18] R. Staub, Der Bau der Alpen. Beitr. z. geolog. Karte der Schweiz, N. F. Heft 52. Bern 1924.

[19] Edw. Hennig, Fragen zur Mechanik der Erdkrusten-Struktur. Die Naturwissenschaften 1926, S. 452.

[20] E. Argand, La tectonique de l'Asie. Extrait du Compte-rendu du XIIIe Congrès géologique international 1922. Liège 1924.

[21] F. Kossmat, Erörterungen zu A. Wegeners Theorie der Kontinentalverschiebungen. Zeitschr. d. Ges. f. Erdkunde zu Berlin 1921.

[22] E. Dacqué, Grundlagen und Methoden der Paläogeographie. Jena 1915. 
[23] G. de Geer, Om Skandinaviens geografiska Utvekling efter Istiden. Stockholm 1896.

[24] L. Kober, Der Bau der Erde. Berlin 1921; Gestaltungsgeschichte der Erde. Berlin 1925.

[25] H. Stille, Die Schrumpfung der Erde. Berlin 1922.

[26] F. Nölcke, Geotektonische Hypothesen. Berlin 1924.

[27] B. Willis, Principles of palaeogeography. Sc. 31, N. S., Nr. 790, S. $241-260,1910$.

[28] H. Wagner, Lehrb. d. Geographie 1. Hannover 1922.

[29] Koss in na, Die Tiefen des Weltmeeres. Veröff. d. Inst. f. Meereskde., N. F. A, Heft 9. Berlin 1921.

[30] Krümmel, Handbuch der Ozeanographie. Stuttgart 1907.

[31] W. Trabert, Lehrb. d. kosmischen Physik. Leipzig und Berlin 1911.

[32] M. Groll, Tiefenkarten der Ozeane. Veröff. d. Inst. f. Meereskunde, N. F. A, Heft 2. Berlin 1912.

[33] A. Heim, Untersuchungen über den Mechanismus der Gebirgsbildung, 2. Teil. Basel 1878.

[34] E. Kayser, Lehrb. d. allgem. Geologie, 5. Aufl. Stuttgart 1918.

[35] W. Soergel, Die atlantische „Spalte“. Kritische Bemerkungen zu A. Wegeners Theorie von der Kontinentalverschiebung. Monatsber. d. D. Geol. Ges. 68, 200-239, 1916.

[36] G. V. and A. V. Douglas, Note on the Interpretation of the Wegener Frequence Curve. Geolog. Magazine 60, Nr. 705, 1923.

[37] A. Wegener, Der Boden des Atlantischen Ozeans. Gerlands Beitr. z. Geophys. 17, Heft 3, 1927, S. 311-321.

[38] F. Kossmat, Die Beziehungen zwischen Schwereanomalien und Bau der Erdrinde. Geol. Rundsch. 12, 165-189, 1921.

[39] F. A. Vening-Meinesz, Provisional Results of Determinations of Gravity, made during the Voyage of Her Majesty's Submarine K XIII from Holland via Panama to Java. Kon. Ak. van Wetensch. te Amsterdam Proceed. Vol. XXX, Nr. 7, 1927; Gravity survey by Submarine via Panama to Java. The Geograph. Journ. London LXXI, Nr. 2, Febr. 1928. Über die geologische Deutung siehe A. Born, Die Schwereverhältnisse auf dem Meere auf Grund der Pendelmessungen von Prof. Vening-Meinesz 1926. Zeitschr. f. Geophys. 3, Heft 8, S. 400, 1927.

[40] W. Schweydar, Bemerkungen zu Wegeners Hypothese der Verschiebung der Kontinente. Zeitschr. d. Ges. f. Erdkde. zu Berlin 1921 , S. $120-125$.

[41] W. Heiskanen, Untersuchungen über Schwerkraft und Isostasie. Veröff. d. Finn. Geodät. Instituts Nr. 4. Helsinki 1924.

[42] W. Heiskanen, Die Airysche isostatische Hypothese und Schweremessung. Zeitschr. f. Geophys. 1, 225, 1924/25.

[43] A. Born, Isostasie und Schweremessung. Berlin 1923.

[44] B. Gutenberg, Der Aufbau der Erde. Berlin 1925.

[45] B. Gutenberg, Lehrbuch d. Geophys. Berlin 1927/28, im Erscheinen.

[46] E. Tams, Über die Fortpflanzungsgeschwindigkeit der seismischen Oberflächenwellen längs kontinentaler und ozeanischer Wege. Centralbl. f. Min., Geol. u. Paläont. 1921, S. 44-52, 75-83.

[47] G. Angenheister, Beobachtungen an pazifischen Beben. Nachr. d. Kgl. Ges. d. Wiss. zu Göttingen, Math.-Phys. Klasse 1921, 34 S.

[48] S. W. Visser, On the distribution of earthquakes in the Nederlands East Indian archipelago 1909/19. Batavia 1921. 
[49] H. Wellmann, Über die Untersuchung der Perioden der Nachläuferwellen in Fernbebenregistrierungen auf Grund Hamburger und geeigneter Beobachtungen. Diss. Hamburg 1922.

[50] H. Wilde, Roy. Soc. Proc. June 19, 1890 und January 22, 1891.

[51] A. W. Rücker, The secondary magnetic field of the earth. Terrestrial Magnetism and atmospheric Electricity 4, 113-129, March/December 1899.

[52] Raclot, C. R. 164, 150, 1917.

[53] H. Jeffreys, On the Earth's Thermal History and some related Geological Phenomena. Gerlands Beitr. z. Geophys. 18, 1-29, 1927.

[54] R. A. Daly, Our Mobile Earth. London 1926.

[55] S. Mohorovičić, Über Nahbeben und über die Konstitution des Erd- und Mondinnern. Gerlands Beitr. z. Geophys. 17, 180-231, 1927.

[56] J. Joly, The Surface History of the Earth, Oxford 1925 und unter gleichem Titel in Gerlands Beitr. z. Geophys. 15, 189-200, 1926.

[57] A. Holmes, Contributions to the Theory of Magmatic Cycles. Geol. Mag. 63, 306-329, 1926. - Ferner: Journ. of Geol. June/July 1926. - Oceanic Deeps and the Thickness of the Continents. Nature, 3. Dez. 1927.

[58] J. Joly and J.H. J. Poole, On the Nature and Origin of the Earth's Surface Structure. Phil. Mag. 1927, S. 1233-1246.

[59] B. Gutenberg; Der Aufbau der Erdkruste. Zeitschr. f. Geophys. 3, Heft 7, S. 371, 1927.

[60] A. Prey, UUber Flutreibung und Kontinentalverschiebung. Gerlands Beitr. z. Geophys. 15, Heft 4, S. 401-411, 1926.

[61] W. Schweydar, Untersuchungen über die Gezeiten der festen Erde. Veröff. d. Preuß. Geodät. Inst., N. F. Nr. 54. Berlin 1912.

[62] W. Schweydar, Die Polbewegung in Beziehung zur Zähigkeit und zu einer hypothetischen Magmaschicht der Erde. Veröff. d. Preuß. Geodät. Inst., N. F. Nr. 79. Berlin 1919.

[63] W. L. Green, The Causes of the Pyramidal Form of the Outline of the Southern Extremities of the Great Continents and Peninsulas of the Globe. Edinburgh New Philosophical Journ. Vol. 6, n. s., 1857 sowie Vestiges of the Molten Globe, 1875.

[64] B. Meyermann, Die Westdrift der Erdoberfläche. Zeitschr. f. Geophys. 2, Heft 5, S. 204, 1926.

[65] B. Meyermann, Die Zähigkeit des Magmas. Zeitschr. f. Geophys. 3, Heft 4, S. 135-136, 1927.

[66] M. Schuler, Schwankungen in der Länge des Tages. Zeitschr. f. Geophys. 3, Heft 2/3, S. 71, 1927.

[67] R. A. Daly, The Earth's Crust and its Stability, Decrease of the Earth's Rotational Velocity and its Geological Effects. The Amer. Journ. of Science, Vol. V, May 1923, p. 349-377.

[68] O. Ampferer, Über Kontinentverschiebungen. Die Naturwissenschaften 13, 669, 1925.

[69] R. Schwinner, Vulkanismus und Gebirgsbildung. Ein Versuch. Zeitschr. f. Vulkanologie 5, 175-230, 1919.

[70] G. Kirsch, Geologie und Radioaktivität, Wien und Berlin (Springer) 1928, S. 115. ff.

[71] A. Penck, Hebungen und Senkungen. „Himmel und Erde“ 25, 
[72] J. Keidel, La Geología de las Sierras de la Provincia de Buenos Aires y sus Relaciones con las Montañas de Sud Africa y los Andes. Annal. del Ministerio de Agricultura de la Nación, Sección Geología, Mineralogía y Minería, Tomo XI, Núm. 3. Buenos Aires 1916.

[73] H. Keidel, Über das Alter, die Verbreitung und die gegenseitigen Beziehungen der verschiedenen tektonischen Strukturen in den argentinischen Gebirgen. Étude faite à la XIIe Session du Congrès géologique international, reproduite du Compte-rendu, S. $671-687$ [Separat, ohne Jahreszahl].

[74] H. A. Brouwer, De alkaligesteenten van de Serra do Gericino ten Noordwesten van Rio de Janeiro en de overeenkomst der eruptiefgesteenten van Brazilië en Zuid-Afrika. Kon. Akad. van Wetensch. te Amsterdam, 1921, Deel 29, S. 1005-1020.

[75] Alex. L. du Toit, The Carboniferous Glaciation of South Africa. Transact. of the Geolog. Soc. of South Africa 24, 188-227, 1921.

[76] Lemoine, Afrique occidentale. Handb. d. regionalen Geologie VII, 6 A, 14. Heft, S. 57. Heidelberg 1913.

[77] R. Maack, Eine Forschungsreise über das Hochland von Minas Gereas zum Paranahyba. Zeitschr. d. Ges. f. Erdk. z. Berlin 1926, S. $310-323$.

[78] Alex. L. du Toit, A geological comparison of South America with South Africa. With a palaeontological contribution by F. R. Cowper Reed. Carnegie Institution of Washington Publ. Nr. 381. Washington 1927.

[79] Passarge, Die Kalahari. Berlin 1904.

[80] A. Windhausen, Ein Blick auf Schichtenfolge und Gebirgsbau im südlichen Patagonien. Geol. Rundsch. 12, 109-137, 1921.

[81] Gagel, Die mittelatlantischen Vulkaninseln. Handb. d. regionalen Geologie VII, 10, 4. Heft. Heidelberg 1910.

[82] Kossmat, Die mediterranen Kettengebirge in ihrer Beziehung zum Gleichgewichtszustande der Erdrinde. Abhandl. d. Math.Phys. Kl. d. Sächsischen Akad. d. Wiss. 38, Nr. 2. Leipzig 1921.

[83] K. Andrée, Verschiedene Beiträge zur Geologie Kanadas. Schriften d. Ges. z. Beförd. d. ges. Naturwiss. zu Marburg 13, 7, 437f. Marburg 1914.

[84] N. Tilmann, Die Struktur und tektonische Stellung der kanadischen Appalachen. Sitz.-Ber. d. naturwiss. Abt. d. Niederrhein. Ges. f. Natur- u. Heilkunde in Bonn 1916.

[85] Lauge-Koch, Stratigraphy of Northwest Greenland. Meddelelser fra Dansk geologisk Forening 5, Nr. 17, 1920, $78 \mathrm{~S}$.

[86] R. Mantovani, l'Antarctide. ,Je m'instruis“, 19. Sept. 1909, S. $595-597$.

[87] Lemoine, Madagaskar. Handb. d. regional. Geol. VII, 4, 6. Heft. Heidelberg 1911.

[88] R. von Klebelsberg, Die Pamir-Expedition des D. u. Österr. Alpen-Vereins vom geologischen Standpunkt. Zeitschr. d. D. u. Österr. A.-V. 1914 (XLV), S. 52-60.

[89] O. Wilckens, Die Geologie von Neuseeland. Die Naturwissenschaften 1920, Heft 41. Auch Geol. Rundsch. 8, 143-161, 1917.

[90] H. A. Brouwer, On the Crustal Movements in the region of the curving rows of Islands in the Eastern Part of the East-Indian? Archipelago. Kon. Ak. v. Wetensch. te Amsterdam Proceed. 22, Nr. 7 u. 8, 1916. Auch Geol. Rundsch. 8, Heft 5-8, 1917 und Nachr. d. Ges. d. Wiss. z. Göttingen 1920. 
[91] G. A. F. Molengraaff, The coral reef problem and isostasy. Kon. Akad. van Wetensch. 1916, S. 621 Anmerkung.

[92] L. van Vuuren, Het Gouvernement Celebes. Proeve eener Monographie 1, 1920 (namentlich S. 6-50).

[93] Wing Easton, Het onstaan van den maleischen Archipel, bezien in het licht van Wegener's hypothesen. Tijdschrift van het Kon. Nederlandsch Aardrijkskundig Genootschap 38, Nr. 4, Juli 1921, S. 484-512. Ferner: On some extensions of Wegener's Hypothesis and their bearing upon the meaning of the terms Geosynclines and Isostasy. Verh. van het Geolog.-Mijnbouwkundig Genootschap voor Nederland en Kolonien, Geolog. Ser., Deel V, Bl. 113-133, Juli 1921. [Hierin werden einige meines Erachtens weniger glückliche Abänderungen der Verschiebungstheorie vorgeschlagen.]

[94] G. L. Smit Sibinga, Wegener's Theorie en het ontstaan van den oostelijken O. J. Archipel. Tijdschr. van het Kon. Ned. Aardrijkskundig Genootschap, 2e Ser. dl. XLIV, 1927, Aufl. 5.

[95] B. G. Escher, Over Oorzaak en Verband der inwendige geologische Krachten. Leiden 1922.

[96] Wanner, Zur Tektonik der Molukken. Geol. Rundsch. 12, 160, 1921.

[97] G. A. F. Molengraaff, De Geologie der Zeeën van NederlandschOost-Indië(Overgedrukt uit: De Zeeën van Nederlandsch-Oost-Indië. Leiden 1921).

[98] C. Gagel, Beiträge zur Geologie von Kaiser-Wilhelmsland. Beitr. z. geol. Erforsch. d. Deutsch. Schutzgebiete, Heft 4, 55 S. Berlin 1912.

[99] K. Sapper, Zur Kenntnis Neu-Pommerns und des KaiserWilhelmslandes. Peterm. Mitt. 56, 89-193, 1910.

[100] F. Kühn, Der sogenannte „Südantillen-Bogen“ und seine Beziehungen. Zeitschr. d. Ges. f. Erdkde. z. Berlin 1920, Nr. 8/10, S. $249-262$.

[101] F. B. Taylor, Greater Asia and Isostasy. Amer. Journ. of Science XII, July 1926, S. $47-67$.

[102] H. Jeffreys, The Earth: Its Origin, History and Physical Constitution. Cambridge University Press, 1924.

[103] H. Cloos, Geologische Beobachtungen in Südafrika. IV. Granite des Tafellandes und ihre Raumbildung. Neues Jahrb. f. Min., Geol. u. Paläont., Beilage-Band XLII, S. $420-456$.

[104] B. Gutenberg, Mechanik und Thermodynamik des Erdkörpers, in Müller-Pouillet, Bd. V, 1 (Geophysik). Braunschweig 1928.

[105] C. A. Matley, The geology of the Cayman Islands (British West Indies). Quart. Journ. Geol. Soc., vol. LXXXII, part 3, 1926, p. $352-387$.

[106] F. Hermann, Paléogéographie et genèse penniques. Eclogae geclogicae Helvetiae, Vol. XIX, Nr. 3, 1925, S. 604-618.

[107] J. W. Evans, Regions of Tension. Proceed. Geolog. Soc. LXXXI, part 2, p. LXXX-CXXII. London 1925.

[108] Diener, Die Großformen der Erdoberflächen. Mitt. d. k. k. geol. Ges. Wien 58, 329-349, 1915. - Die marinen Reiche der Triasperiode. Denkschr. d. Akad. d. Wiss. Wien, math.-naturw. KI. 1915.

[109] Jaworski, Das Alter des südatlantischen Beckens. Geol. Rundsch. 1921, S. $60-74$. 
[110] A. Penck, Wegeners Hypothese der kontinentalen Verschiebungen. Zeitschr. d. Ges. f. Erdkde. z. Berlin 1921, S. 110-120.

[111] W. Penck, Zur Hypothese der Kontinentalverschiebung. Zeitschr. d. Ges. f. Erdkde. z. Berlin 1921, S. 130-143.

[112] H. A. Brouwer, On the Non-existence of Active Volcanoes between Pantar and Dammer (East Indian archipelago), in Connection with the Tectonic Movements in this Region. Kon. Ak. van Wetensch. te Amsterdam Proceed. 21, Nr. 6 u. 7, 1917.

[113] H. S. Washington, Comagmatic regions and the Wegener hypothesis. Journ. of the Washington Acad. of Sciences, Vol. 13, Sept. 1923 , p. $339-347$.

[114] F. Nölke, Physikalische Bedenken gegen A. Wegeners Hypothese der Entstehung der Kontinente und Ozeane. Peterm. Mitt. 1922 , S. 114.

[115] Stromer, Geogr. Zeitschr. 1920, S. $287 \mathrm{ff}$.

[116] F. Ökland, Einige Argumente aus der Verbreitung der nordeuropäischen Fauna mit Bezug auf Wegeners Verschiebungstheorie. Nyt Mag. f. Naturv. 65, 339-363, 1927.

[117] L. v. Ubisch, Wegeners Kontinentalverschiebungstheorie und die Tiergeographie. Verh. d. Physikal.-Med. Ges. z. Würzburg 1921.

[118] G. Colosi, La teoria della traslazione dei continenti e le dottrine biogeografiche. L'Universo 6, Nr. 3. Marzo 1925. (Hierin auch weitere biogeographische Literaturangaben.)

[119] W. R. Eckhard, Die Beziehungen der afrikanischen Tierwelt zur südasiatischen. Nat. Wochenschr. 1922, Nr. 51.

[120] H. Osterwald, Das Problem der Aalwanderungen im Lichte der Wegenerschen Verschiebungstheorie. Umschau 1928, S. 127-128.

[121] A. Wegener, Die geophysikalischen Grundlagen der Theorie der Kontinentenverschiebung. Scientia, Februar 1927.

[122] H. v. Ihering, Die Geschichte des Atlantischen Ozeans. Jena 1927.

[123] L. F. de Beaufort, De beteekenis van de theorie van Wegener voor de zoögeografie. Handelingen van het XXe Ned. Natuur-en Geneeskundig Congress, 14./16. April 1925, Groningen.

[124] H. Hergesell, Die Abkühlung der Erde und die gebirgsbildenden Kräfte. Beitr. z. Geophys. 2, 153, 1895.

[125] Semper, Das paläothermale Problem, speziell die klimatischen Verhältnisse des Eozäns in Europa und den Polargebieten. Zeitschr. Deutsch. Geol. Ges. 48, 261 f., 1896.

[126] Schröter, Artikel „Geographie der Pflanzen“ im Handwörterbuch der Naturwissenschaften.

[127] W. Köppen, Das Klima Patagoniens im Tertiär und Quartär. Gerlands Beitr. z. Geophys. 17, 3, 391-394, 1927.

[128] A. Wegener, Bemerkungen zu H. v. Iherings Kritik der Theorien der Kontinentverschiebungen und der Polwanderungen. Zeitschr. f. Geophys. 4, Heft 1, S. 46-48, 1928.

[129] R. v. Klebelsberg, Die marine Fauna der Ostrauer Schichten. Jahrb. d. k. k. Geol. Reichsanstalt 62, 461-556, 1912.

[130] J. Huus, Über die Ausbreitungshindernisse der Meerestiefen und die geographische Verbreitung der Ascidien. Nyt Mag. f. Naturv. 65, 1927.

[131] Scharff, Über die Beweisgründe für eine frühere Landbrücke zwischen Nordeuropa und Nordamerika (Proc. of the Royal Irish Ac. 28, 1, 1-28, 1909; nach dem Referat von Arldt, Naturw. Rundsch. 1910). 
[132] W. Petersen, Eupithecia fenestrata Mill, als Zeuge einer tertiären Landverbindung von Nord-Amerika mit Europa. Beitr. z. Kunde Estlands 9, 4-5, 1922.

[133] H. Hoffmann, Moderne Probleme der Tiergeographie. Die Naturwissenschaften 13,77-83, 1925.

[134] L. v. Ubisch, Stimmen die Ergebnisse der Aalforschung mit Wegeners Theorie der Kontinentalverschiebung überein? Die Naturwissenschaften 12, 345-348, 1924.

[135] T. Arldt, Südatlantische Beziehungen. Peterm. Mitt. 62, 41-46, 1916.

[136] A. Handlirsch, Beiträge zur exakten Biologie. Sitz.-Ber. d. Wiener Ak. d. Wiss., math.-naturw. Kl. 122, 1, 1913.

[137] B. Kubart, Bemerkungen zu Alfred Wegeners Verschiebungstheorie. Arb. d. phytopaläont. Lab. d. Univ. Graz II, 1926.

[138] B. Sahni, The Southern Fossil Floras: a Study in the PlantGeography of the Past. Proc. of the 13. Indian Science Congress 1926.

[139] Wallace, Die geographische Verbreitung der Tiere, deutsch von Meyer, 2 Bde. Dresden 1876.

[140] E. Bresslau, Artikel Plathelminthes im Handwörterbuch d. Naturw. 7, 993. - Auch Zs ch o kke, Zentralbl. Bakt. Paras. I, S.36, 1904.

[141] P. Marshall, New Zealand. Handb. d. regional. Geol. VII, 1, 1911.

[142] H. V. Bröndsted, Sponges from New Zealand. Papers from Dr. Th. Mortensen's Pacific Expedition 1914/16. Vidensk. Medd. fra Dansk naturh. Foren 77, 435-483; 81, 295-331.

[143] E. Meyrick, Wegeners Hypothesis and the distribution of Micro-Lepidoptera. Nature, S. 834-835. London 1925.

[144] Simroth, Über das Problem früheren Landzusammenhangs auf der südlichen Erdhälfte. Geogr. Zeitschr. 7, 665-676, 1901.

[145] Andrée, Das Problem der Permanenz der Ozeane und Kontinente. Peterm. Mitt. 63, 348, 1917.

[146] Th. Arldt, Die Frage der Permanenz der Kontinente und Ozeane. Geogr. Anzeiger 19, 2-12, 1918.

[147] A. Griesebach, Die Vegetation der Erde nach ihrer klimatischen Anordnung. Ein Abriß der vergleichenden Geographie der Pflanzen 2, 528 u. 632 . Leipzig 1872.

[148] O. Drude, Handbuch der Pflanzengeographie. S. 487. Stuttgart 1890.

[149] L. v. Ubisch, Hermann v. Iherings "Geschichte des Atlantischen Ozeans“. Peterm. Mitt. 1927, S. 206-207.

[150] E. Irmscher, Pflanzenverbreitung und Entwicklung der Kontinente. Studien zur genetischen Pflanzengeographie. Mitt. aus d. Inst. f. allgem. Botanik in Hamburg 5, 15-235, 1922.

[151] W. Köppen und A. Wegener, Die Klimate der geologischen Vorzeit. $256 \mathrm{~S}$. Berlin 1924.

[152] W. Studt, Die heutige und frühere Verbreitung der Koniferen und die Geschichte ihrer Arealgestaltung. Diss. Hamburg 1926.

[153] F. Koch, Über die rezente und fossile Verbreitung der Koniferen im Lichte neuerer geologischer Theorien. Mitt. d. Deutschen Dendrologischen Gesellschaft, Nr. 34, 1924.

[154] W. Michaelsen, Die Verbreitung der Oligochäten im Lichte der Wegenerschen Theorie der Kontinentenverschiebung und andere Fragen zur Stammesgeschichte und Verbreitung dieser 
Tiergruppe. Verh. d. naturw. Ver. zu Hamburg im Jahre 1921, 37 S. Hamburg 1922.

[155] N. Svedelius, On the discontinuous geographical Distribution of some tropical and subtropical Marine Algae. Arkiv för Botanik, utg. av K. Svenska Vetensk. Ak. 19, Nr. 3, 1924.

[156] W.Köppen, Die Klimate der Erde. Grundriß der Klimakunde. Berlin und Leipzig 1923.

[157] V. Paschinger, Die Schneegrenze in verschiedenen Klimaten. Peterm. Mitt. 1912, Erg.-Heft 173.

[158] W. Köppen, Die Lufttemperatur an der Schneegrenze. Peterm. Mitt. [Separat, ohne Jahreszahl.]

[159] Th. Arldt, Die Ursachen der Klimaschwankungen der Vorzeit, besonders der Eiszeiten. Zeitschr. f. Gletscherkunde 11, 1918.

[160] Rollin T. Chamberlin, Objections to Wegeners Theory, 1928; in [228].

[161] P. Reibisch, Ein Gestaltungsprinzip der Erde; 27. Jahresbericht d. Ver. Erdkunde zu Dresden 1901, S. 105-124. - Zweiter Teil [enthält nur unwesentliche Ergänzungen), Mitt. Ver. Erdk. Dresden 1, 39-53, 1905. - III. Die Eiszeiten. Ebenda 6, 58-75, 1907.

[162] H. Simroth, Die Pendulationstheorie. Leipzig 1907.

[163] Ch. Schuchert, The hypothesis of continental displacement, 1928 ; in [228].

[164] E. Jacobitti, Mobilità dell' Assa Terrestre, Studio Geologico. Torino 1912.

[165] G.A. F. Molengraaff, The Glacial Origin of the Dwyka Conglomerate. Trans. of the Geol. Soc. of South Africa 4, 103-115, 1898.

[166] A. du Toit, The Carboniferous Glaciation of South Africa. Ebenda 24, 188-227, 1921.

[167] Koken, Indisches Perm und die permische Eiszeit. Festband d. N. Jahrb. f. Min. 1907.

[168] R. W. Sayles, The Squantum Tillite. Bull. of the Museum of Comparative Zoölogy at Harvard College 56, Nr. 2 (Geol. Series, Vol. 10). Cambridge 1914.

[169] H. Potonié, Die Tropensumpfflachmoornatur der Moore des $x$ produktiven Karbons. Jahrb. d. Kgl. Preuß. Geol. Landesanstalt 30, Teil I, Heft 3. Berlin 1909. - Die Entstehung der Steinkohle, 5. Aufl., S. 164. Berlin 1910.

[170] Rudzki, L'âge de la terre. Scientia 13, Nr. XXVIII, 2, S. 161 $-173,1913$.

[171] E. Dacqué, Abschnitt „Paläogeographie“ in Enzyklopädie der Erdkunde, herausgeg. v. Kende, Leipzig u. Wien 1926.

[172] Danmark-Ekspeditionen til Grönlands Nordöstkyst 1906/08 under Ledelsen af L. Mylius-Erichsen 6 (Meddelelser om Grönland 46). Köbenhavn 1917.

[173] F. Burmeister, Die Verschiebung Grönlands nach den astronomischen Längenbestimmungen. Peterm. Mitt. 1921, S. 225-227.

[174] P. F. Jensen, Ekspeditionen til Vestgrönland Sommeren 1922. Meddelelser om Grönland LXIII, S. 205-283. Köbenhavn 1923.

[175] A. Wegener, Ekspeditionen til Vestgrönland Sommeren 1922 (P. F. Jensen, Medd. om Grönland LXIII, S. 205-283, Köbenhavn 1923). Die Naturwissenschaften 1923, S. 982-983.

[176] E. Stüük, Breiten- und Längenbestimmungen in Westgrönland 
[177] Galle, Entfernen sich Europa und Nordamerika voneinander? Deutsche Revue, Februar 1916.

[178] Jahresber. d. preuß. Geodät. Inst. in Vierteljahrsschr. d. Astron. Ges. 51, 139, sowie Astronomical Journal Nr. 673/674.

[179] B. Wanach, Ein Beitrag zur Frage der Kontinentalverschiebung. Zeitschr. f. Geophysik 2, 161-163, 1926.

[180] P. Poissson, L'Observatoire de Tananarive. Paris 1924. - P. E. Colin, Comptes Rendus, 5. Mars 1894, S. 512. - Ferner La Géographie 45, 354-355, 1926, wo auch die Positionen angegeben sind.

[181] Günther, Lehrb. d. Geophys. 1, 278. Stuttgart 1897.

[182] W. D. Lambert, The Latitude of Ukiah and the Motion of the Pole. Journ. of the Washington Ac. of Sc. 12, Nr. 2, 19. Jan. 1922.

[183] Neumayr - Uhlig, Erdgeschichte 1, Allgem. Geol., 2. Aufl., S. 367. Leipzig und Wien 1897.

[184] E. Kohlschütter, Über den Bau der Erdkruste in DeutschOstafrika. Nachr. d. Kgl. Ges. d. Wiss. Göttingen, Math.-Phys. Kl., 1911.

[185] J. W. Gregory, The Nature and origin of Fjords. 542 S. London 1913.

[186] F. v. Richthofen, Über Gebirgskettungen in Ostasien. Geomorphologische Studien aus Ostasien 4; Sitz.-Ber. d. Kgl. Preuß. Akad. d. Wiss. Berlin, Phys.-Math. K1. 40, 867-891, 1903.

[187] E. Wittich, Über Meeresschwankungen an der Küste von Kalifornien. Zeitschr. d. Deutschen Geol. Ges. 64, 1912, Monatsbericht Nr. 11, S. 505-512. - La Emersion moderna de la costa occidental de la Baja Californica. Mém. de la Société „Alzate“ 35, 121-144, Mexiko 1920.

[188] Tams, Die Entstehung des kalifornischen Erdbebens vom 18. April 1906. Peterm. Mitt. 64, 77, 1918.

[189] A. C. Lawson, The Mobility of the Coast Ranges of California. Univ. of California Publ. Geology 12, Nr. 7, S. 431-473, 1921.

[190] O. Meissner, Isostasie und Küstentypus. Peterm. Mitt. 64, $221,1918$.

[191] W. v. Lozinski, Vulkanismus und Zusammenschub. Geol. Rundsch. 9, 65-98, 1918.

[192] Steinmann, Die kambrische Fauna im Rahmen der organischen Gesamtentwicklung. Geol. Rundsch. 1, 69, 1910.

[193] Gothan, Neues von den ältesten Landpflanzen. Die Naturwissenschaften $\mathbf{9}, \mathbf{5 5 3}, 1921$.

[194] J. Walther, Über Entstehung und Besiedelung der Tiefseebecken. Naturwiss. Wochenschr., N. F. 3. Bd., Heft 46.

[195] S. Fujiwhara, On the Echelon Structure of Japanese Volcanic Ranges and its Significance from the Vertical Point of View. Gerlands Beitr. z. Geophys. XVI, Heft 1/2, 1927.

[196] B. Gutenberg, Die Veränderungen der Erdkruste durch Fließbewegungen der Kontinentalscholle. Gerlands Beitr. z. Geophys. 16, 239-247, 1927; 18, 225-246, 1927.

[197] A. Wegener, Der Boden des Atlantischen Ozeans. Gerlands Beitr. z. Geophys. 17, Heft 3, 1927, S. 311-321.

[198] O. Hecker, Bestimmung der Schwerkraft auf dem Indischen und Großen Ozean und an den Küsten. Zentralbureau d. Internat. Erdmess., N. F. Nr. 16. Berlin 1908.

[199] Eötvös, Verh. d. 17. Allg. Konf. d. Internat. Erdmessung, I. Teil, 1913 S. 111. 
[200] W. Köppen, Ursachen und Wirkungen der Kontinentenverschiebungen und Polwanderungen. Peterm. Mitt. 1921, S. 145-149 und 191-194. Siehe besonders S. 149. - Über Änderungen der geographischen Breiten und des Klimas in geologischer Zeit. Geografiska Annaler 1920, S. 235-299. - Zur Paläoklimatologie. Meteorol. Zeitschr. 1921, S. 97-101 (hier mit anderer Figur). - Über die Kräfte, welche die Kontinentenverschiebungen und Polwanderungen bewirken. Geol. Rundsch. 12, 314-320, 1922.

[201] P. S. Epstein, Über die Polflucht der Kontinente. Die Naturwissenschaften 9, Heft 25, S. 499-502.

[202] W. D. Lambert, Some Mechanical Curiosities connected with the Earth's Field of Force. The Amer. of Journ, of Science, Vol. II, Sept. 1921 , p. $129-158$.

[203] R. Berner, Sur la grandeur de la force qui tendrait à rapprocher un continent de l'équateur. Thèse prés. à la Faculté des sciences de l'université de Genéve. Genève 1925.

[204] R. Wavre, Sur la force qui tendrait à rapprocher un continent de l'équateur. Archives des Sciences physiques et naturelles. Août 1925.

[205] M. Möller, Kraftarten und Bewegungsformen. Braunschweig 1922.

[206] U. P. Lely, Een Proef die de Krachten demonstreert, welke de Continentendrift kan veroorzaken. „Physica“, Nederlandsch Tijdschrift voor Natuurkunde, 7e Jaargang, blz. 278-281, 1927.

[207] St. Meyer und E. Schweydler, Radioaktivität, 2. Aufl., S. $558 \mathrm{ff}$. Leipzig 1927.

[208] B. Wanach, Eine fortschreitende Lagenänderung der Erdachse. Zeitschr. f. Geophys. 3, Heft 2/3, S. 102-105.

[209] Noch nicht veröffentlicht. Briefliche Mitteilung von Oberstleutnant Jensen mit Genehmigung von Professor Nörlund.

[210] W. A. J. M. van Waterschoot van der Gracht, Remarks regarding the papers offered by the other contributors to the symposion, 1928; in [228].

[211] Schiaparelli, De la rotation de la terre sous l'influence des actions géologiques (Mém. prés. à l'observatoire de Poulkova à l'occasion de sa fête semiséculaire). $32 \mathrm{~S}$. St. Pétersbourg 1889.

[212] Sir W. Thompson, Report of Section of Mathematics and Physics, p. 11. Report of British Association 1876.

[213] G. Ferrié, L'opération des longitudes mondiales (octobre/novembre 1926). Comptes Rendus de l'académie des Eciences $\mathbf{1 8 6 .}$ Paris, 5. Mars 1928.

[214] R. Staub, Das Bewegungsproblem in der modernen Geologie. Antrittsvorlesung, Zürich 1928.

[215] R. Staub, Der Bewegungsmechanismus der Erde. Berlin 1928.

[216] M. Sluys, Les périodes glaciaires dans le Bassin Congolais. Compte Rendu du Congrés de Bordeaux 1923 de l'Association Française pour l'Avancement du Sciences, 30. Juillet 1923.

[217] A. Wegener, Two Notes concerning my Theory of Continental Drift, 1928; in [228].

[218] W. Köppen, Muß man neben der Kontinentenverschiebung noch eine Polwanderung in der Erdgeschichte annehmen? Peterm. geogr. Mitt. 1925, S. 160-162.

[219] W. Heiskanen, Die Erddimensionen nach den europäischen Gradmessungen. Veröff. d. Finn. Geodät. Inst., Nr. 6. Helsinki 1926. 
[220] R. Schumann, Über Erdschollen-Bewegung und Polhöhenschwankung. Astr. Nachr. 227, Nr. 5442, S. 289-304, 1926.

[221] W. D. Lambert, The variation of Latitude. Bull. of the National Research Council 10, Part 3, Nr. 53, p. 43-45. Washington 1925.

[222] F. Nansen, The Earth's Crust, its Surface-Forms, and Isostatic Adjustment. Avhandl. utgitt av Det Norske Videnskaps-Akademi i Oslo, I. Mat.-Naturv. Klasse 1927, Nr. 12, 121 S. Oslo 1928.

[223] P. Byerly, The Montana Earthquake of June 28, 1925, G. M. C. T. The Bull. of the Seismological Society of America 16, Nr. 4, Dec. 1926.

[224] W. Bowie, Isostasie. 275 S. New York 1927.

[225] W. A. Jaschnov, Crustacea von Nowaja Zemlja. Sonderdruck aus den Berichten des Wissenschaftlichen Meeresinstituts, Lief. 12. Moskau 1925 (russisch, mit deutscher Zusammenfassung).

[226] C. Diener, Grundzüge der Biostratigraphie. Leipzig u. Wien 1925.

[227] L. von Ubisch, Tiergeographie und Kontinentalverschiebung. Zeitschr. f. induktive Abstammungs- und Vererbungslehre 47, $159-179,1928$.

[228] Theory of Continental Drift, a symposium on the origin and movement of land masses both inter-continental and intracontinental, as proposed by Alfred Wegener, by W. A. J.M. van Waterschoot van der Gracht, Bailey Willis, Rollin T. Chamberlin, John Joly, G. A. F. Molengraaff, J. W. Gregory, Alfred Wegener, Charles Schuchert, Chester R. Longwell, Frank Bursley Taylor, William Bowie, David White, Joseph T. Singewald, Jr., and Edward W. Berry. Publ. by the American Association of Petroleum Geologists, 240 S. London 1928.

[229] E. Brennecke, Die Aufgaben und Arbeiten des Geodät. Inst. in Potsdam in der Zeit nach dem Weltkriege. Zeitschr.f.Vermess.Wesen 1927, Heft 23 u. 24 . 


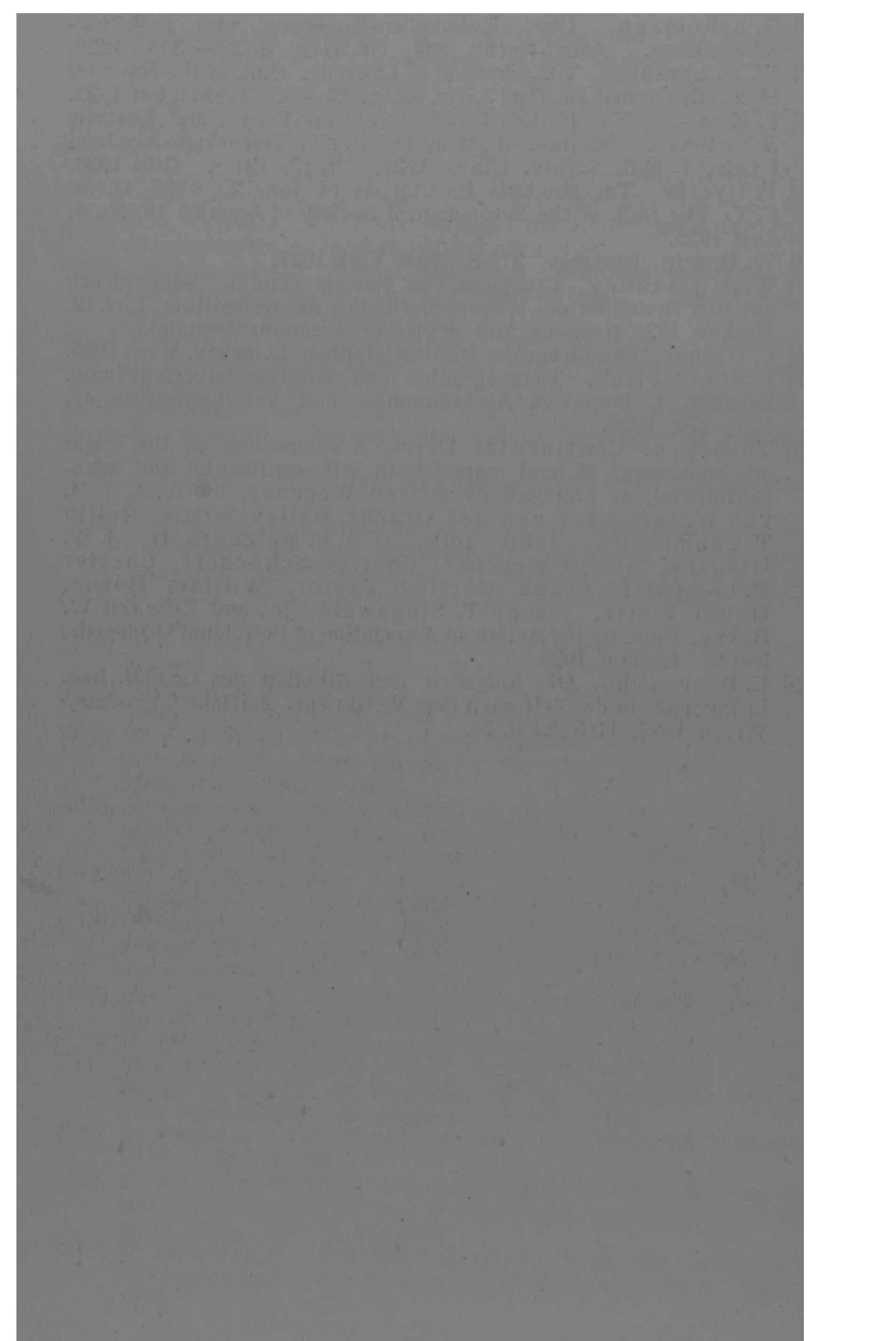


30. Mache, Prof. H., und Prof. E. v. Schweidler, Die atmosphärische Elektris zität. Methoden und Ergebnisse der modernen luftelektrischen For: schung. Mit 20 Abbildungen.

Geh. 6,50 RM

31. Eckardt, Dr, Wilh. R., Das Klimaproblem der geolog. Vergangenheit und historischen Gegenwart. Mit 18 Abbildungen und 4 Karten. Geh.6,50 RM

32. Jesionek, Prof. Dr. A., Lichtbiologie. Die experimentellen Grundlagen der modernen Lichtbehandlung.

Geh. 4,50 RM

33. Dessau, Prof. Dr. Bernh., Die physikalisch=chemischen Eigenschaften der Legierungen. Mit 82 Abbildungen.

Geh. 6,50 RM

34. Pohl, Dr. Robert, Die elektrische Fernübertragung von Bildern. Mit 25 Abbildungen.

Geh. 2,- RM, geb. 3,50 RM

35. Baedeker, Prof. Dr. K., Die elektrischen Erscheinungen in metallischen Leitern. (Leitung, Thermoelektrizität, Galvanomagnetische Effekte, Optik.) Mit 25 Abbildungen.

36. Scheel, Prof. Dr. K., Grundlagen der praktischen Metronomie. Mit 39 Abbildungen.

Geh. 5,- RM, geb. 6,50 RM

37. Günther, Prof. Dr. S., Vergleichende Mond= und Erdkunde. Mit $23 \mathrm{Ab}=$ bildungen und 4 Tafeln.

Geh. 5,- RM, geb. 6,50 RM

38. Laue, Dr. M. v., Die Relativitätstheorie. Erster B and: Das Relativitäts= prinzip der Lorentztransformation. 4, verm. Auflage. Mit 25 Abbildungen. Zweiter Band s. Bd. 68.

Geb. 12,- RM

39. Müller, Aloys, Die philosophischen Probleme der Einsteinschen Relativitätstheorie. 2. umgearbeitete und erweiterte Auflage des Buches: Das Problem des absoluten Raumes. Mit 10 Abbildungen.

Geh. 7,50 RM, geb. 9,25 RM

40. Schmidt, Ingenieur Fritz, Die Leuchtgaserzeugung und die moderne Gasbeleuchtung. Mit 63 Abbildungen. Geh. 3,- RM, geb. 4,50 RM

41. Lodge, Sir Oliver, Der Weltäther.

42. Lampa, Professor Dr. Anton, Wechselstrom $=$ Versuche. Mit 54 Abs bildungen.

43. Markau, Dr. K., Die Telephonie ohne Draht.

Geh. 6,- RM, geb. 7,50 RM

44. Bernstein, Professor Dr. Julius, elektrischen Vorgängen im Organismus auf moderner Grundlage dar= gestellt. Mit 62 Abbildungen.

Geh. 6,50 RM, geb. 8,- RM

45. Pohl, Dr. Robert, Die Physik der Röntgenstrahlen. Vergriffen.

46. Martens, Prof. Dr. F. F., Physikalische Grundlagen der Elektrotechnik. Erster Band.

Vergriffen.

47. Jacobi, Prof. Dr. Arnold, Mimikry und verwandte Erscheinungen. Mit 31 zum Teil farbigen Abbildungen. Geh. 8,50 RM, geb. 10,- RM

48. Meyer, Kirstine, Die Entwickelung des Temperaturbegriffs im Laufe der Zeiten sowie dessen Zusammenhang mit den wechselnden Vor= stellungen von der Natur der Wärme. Aus dem Dänischen übersetzt von Irmgard Kolde und mit einem Vorwort von E. Wiedemann. Mit 21 Abbildungen.

49. Konen, Prof. Dr. H., Das Leuchten der Gase und Dämpfe mit besonderer Berücksichtigung der Gesetzmäßigkeiten in Spektren. Mit $33 \mathrm{Ab}=$ bildungen im Text und einer Tafel.

Geh. 13,- RM

50. Drude, Prof. Dr. O., Die Ökologie der Pflanzen. Mit 80 eingedruckten Abbildungen.

Geh. 10,- RM, geb. 12,- RM

51. Bauer, Dr. Hu go, Der heutige Stand der Synthese von Pflanzenalkaloiden. Geh. 4,50 RM, geb. 6,- RM

52. de Haas=Lorentz, Dr. G. L., Die Brownsche Bewegung und einige ver= wandte Erscheinungen. Von der Verfasserin ins Deutsche übersetzt.

Geh. 3,50 RM

53. Rosenthal, Prof. Dr. Werner, Die tierische Immunität. Mit einer Abbildung im Text.

Geh. 8,- RM, geb. 10,- RM

54. Study, Prof. Dr. E., Die realistische Weltansicht und die Lehre vom Raume. Geometrie, Anschauung und Erfahrung. 2. umgearbeitete Auf: lage. 1. Teil: Das Problem der Aul3enwelt. Geh.3,50 RM, geb.5,- RM

55. Martens, Dr. F. F., Physikalische Grundlagen der Elektrotechnik. II. Band: Dynamomaschinen, Transformatoren und Apparate für draht= lose Telegraphie. Mit 289 Abbildungen. Geh. 15,- RM, geb. 17,25 RM 
56. Timerding, Prof. Dr. H. E., Die Analyse des Zufalls. Mit 10 Abbildungen. Geh. 5,50 RM

57. Lipschütz, Dr. Alexander, Allgemeine Physiologie des Todes. Mit 38 Abbildungen.

Geh. 6,- RM, geb. 7,50 RM

58. von Linden, Prof. Dr. Gräfin, Parasitismus im Tierreich. Mit $102 \mathrm{Ab}=$ bildungen und 7 Tafeln.

Geh. 8,- RM, geb. 9,75 RM

59. Jänecke, Prof. Dr. Ernst, Die Entstehung der deutschen Kalisalzlager. 2. veränderte Auflage. Mit 30 Abbildungen. Geh. 4,- RM, geb. 5,50 RM

60. Wegener, Prof. Dr. Alfred, Wind= und Wasserhosen in Europa. Mit 1 Titelbild und 85 Abbildungen. Geh. 10,- RM, geb. 12,- RM

61. Sapper, Prof. Dr. Karl, Geologischer Bau und Landschaftsbild. 2. Auf= lage. Mit 15 Abbildungen. Geh. 8,- RM, geb. 9,75 RM

62. Müller, Dr. Aloys, Die Referenzflächen des Himmels und der Gestirne. Mit 20 Abbildungen. Geh. 5,50 RM, geb. 7,- RM

63. Dorno, Prof. Dr. C., Physik der Sonnen= und Himmelsstrahlung. Mit 16 Abbildungen im Text und auf 3 farbigen Tafeln. Geh. 5,- RM

64. Walden, Prof. Dr. P., Optische Umkehrerscheinungen (Waldensche Um= kehrung). Mit 6 Abbildungen. Geh. 7,- RM, geb. 8,50 RM

65. Geiger, H., und W. Makower, Meßmethoden auf dem Gebiete der Radioaktivität. Mit 61 Abbildungen. Geh. 5,50 RM, geb. 7,- RM

66. Wegener, Prof. Dr. Alfred, Die Entstehung der Kontinente und Ozeane. 4. Auflage.

67. Brigl, Privatdozent P., Die chemische Erforschung der Naturfarbstoffe. Geh. 8,50 RM, geb. 10,- RM

68. Laue, Dr. M.v., Die Relativitätstheorie. $Z$ w eit er B a nd: Die allgemeine Relativitätstheorie und Einsteins Lehre von der Schwerkraft. 2. um= gearbeitete Auflage. Mit 25 Abbildungen. Geh. 9,- RM, geb. 10,75 RM Erster Band s. Bd. 38 .

69. Millikan, Prof. Robert Andrews, Das Elektron. Seine Isolierung und Messung. Bestimmung einiger seiner Eigenschaften. Ubersetzt von Prof. Dr. Karl Stöckl, Regensburg. Mit 32 Abbildungen.

Geh. 8,25 RM, geb. 10,- RM

70. Eddington, A. S., Raum, Zeit und Schwere. Ein Umriß der allgemeinen Relativitätstheorie. Ins Deutsche übertragen von W. Gordon. Mit 19 Abbildungen. $\quad$ Geh. 6,50 RM, geb. 8,- RM

71. Study, Prof. Dr. E., Einleitung in die Theorie der Invarianten linearer Transformationen auf Grund der Vektorenrechnung. I. Teil.

Geh. 8,50 RM, geb. 10,- RM

72. Reichenbach, Privatdozent Dr. H., Axiomatik der relativistischen Raum= Zeit=Lehre. Mit 15 Figuren. Geh. 6,- RM, geb. 7,50 RM

73. Giese, Privatdozent Dr. Fritz, Theorie der Psychotechnik. Grundzüge der praktischen Psychologie. I.

Geh. 7,50 RM, geb. 9,- RM

74. Theorien des Magnetismus. Aus dem Amerikanischen übersetzt von Prof. JosefW ürschmidt. Mit 67 Abbild. Geh. 16,- RM, geb. 18,-RM

75. Przibram, Hans, Tierpfropfung. Die Transplantation der Körper abschnitte, Organe und Keime. Mit 163 Abbildungen.

Geh. 17,50 RM, geb. 19,50 RM

76. Waldschmidt=Leitz, Dr. E., Die Enzyme. Wirkungen und Eigenschaften. Mit 13 Abbildungen.

Geh. 14,- RM, geb. 16,- RM

77. Lewis, Prof, Gilbert Newton, Die Valenz und der Bau der Atome und Moleküle. Mit 27 Abbildungen. Geh. 12,- RM, geb. 14,- RM

78. Geiger, Privatdozent Dr. Rudolf, Das Klima der bodennahen Luft= schicht. Mit 62 Abbildungen.

79. Lodge, Sir Oliver, Der Ather und di Wir Lodge, Sir Oliver, Der Ather und die Wirklichkeit. Eine Reihe von
Vorträgen über die zahlreichen Aufgaben, die der Raumäther zu ers 


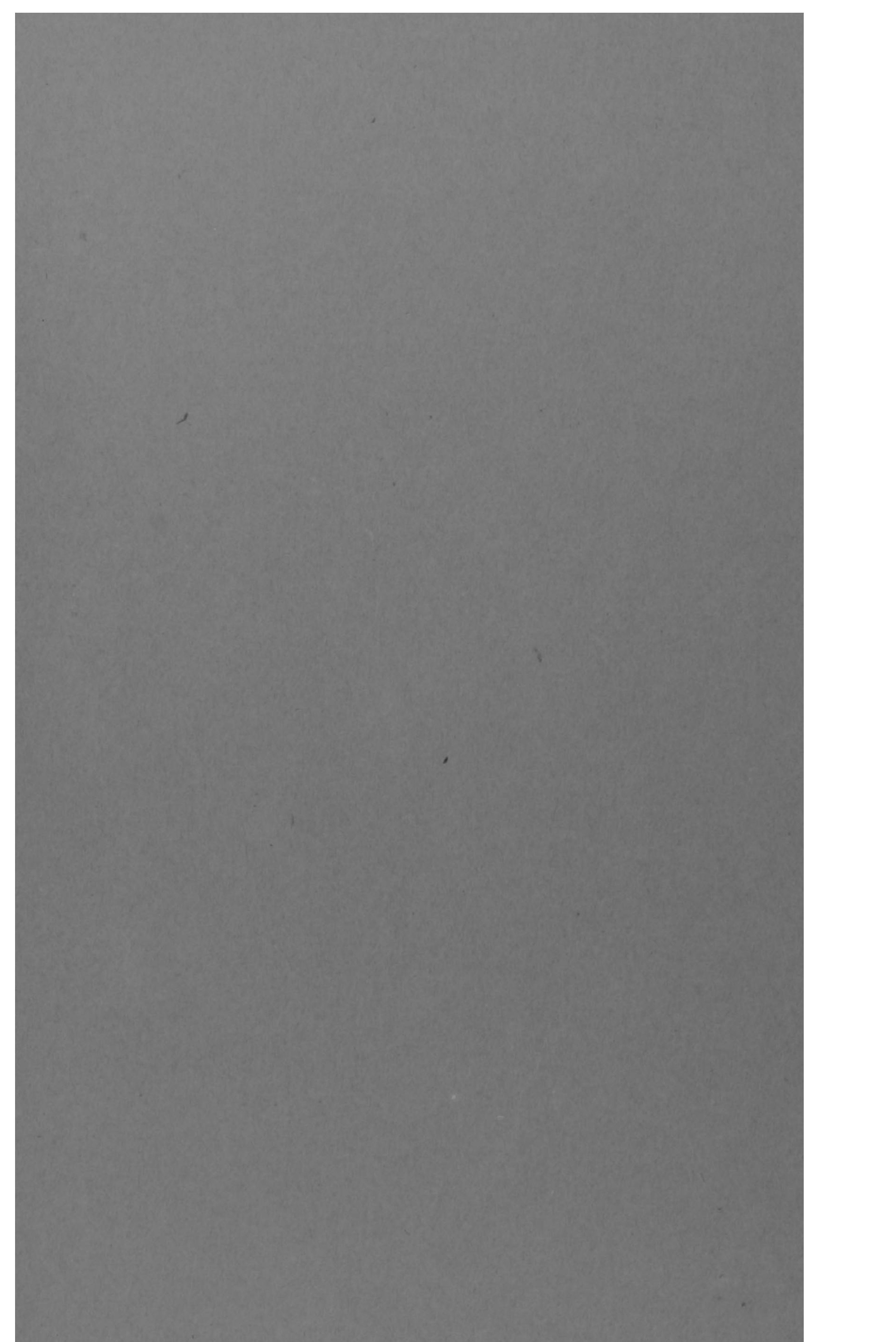


Buchbinderei H.NONN \& SOHN Moselstr:2UIr.126 


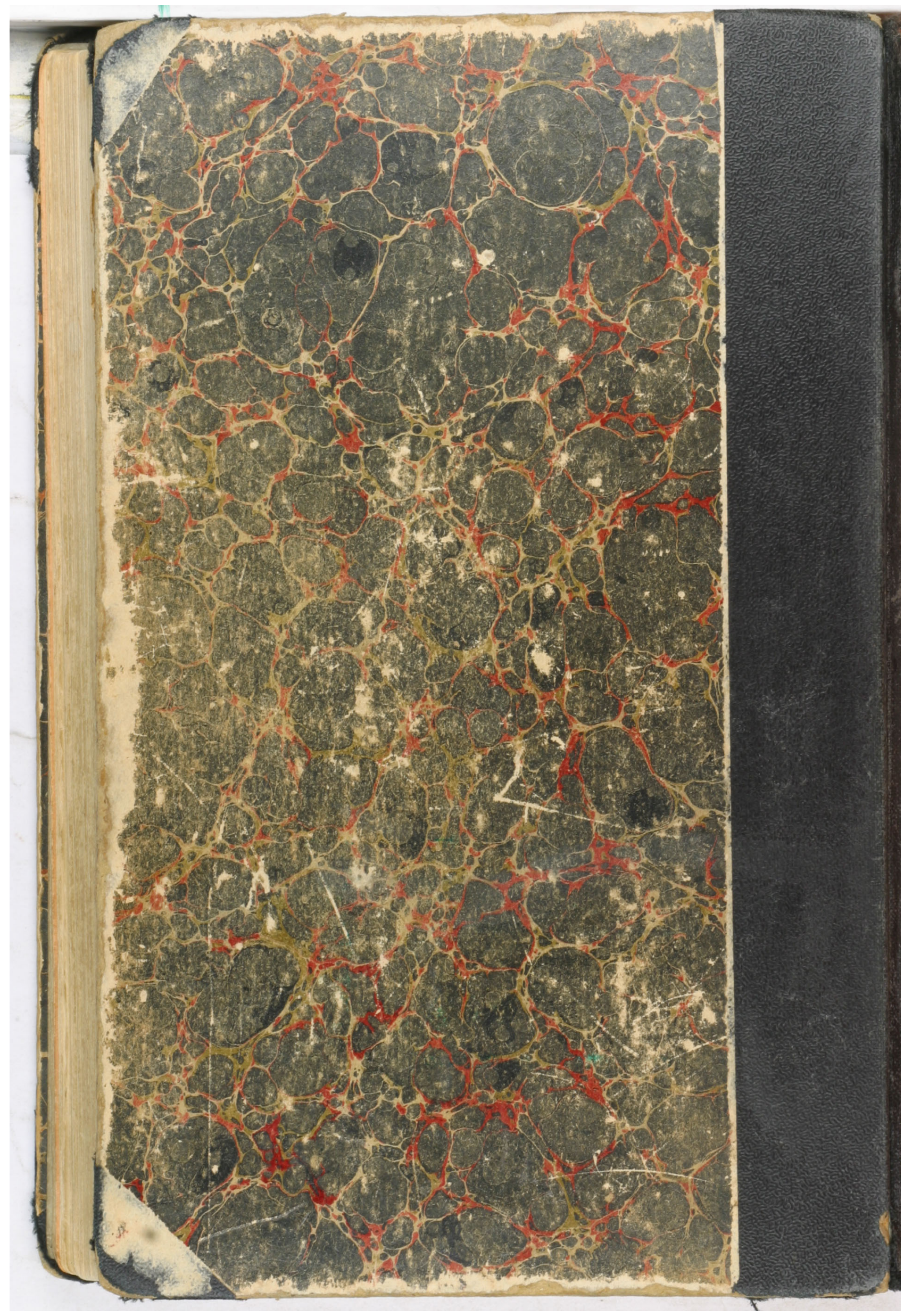

